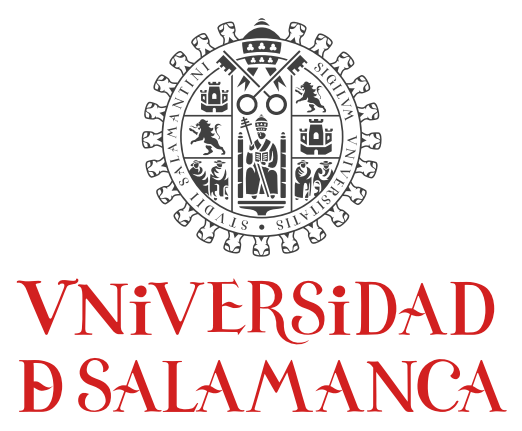

Facultad de Ciencias Químicas

Departamento de Química Física

\title{
Mecanismos de nitrosación de sustratos complejos bioactivos
}

Mario González Jiménez 

Memoria presentada por el Graduado Mario González Jiménez para optar al título de doctor.

Salamanca, seis de mayo de 2012. 

DePartamento de Química Física

Facultad de Ciencias Químicas

Plaza de los Caídos, s/n 37008 Salamanca

VNiVERSIDAD

BSALAMANCA

Tel. (34) 923294487 Fax. (34) 923294574

Julio Casado Linarejos, Catedrático de Química Física, y Emilio Calle Martín, Profesor Titular de Química Física de la Universidad de SalaMANCA

CERTIFICAN que la investigación de doctorado «Mecanismos de nitrosación de sustratos complejos bioactivos» se ha realizado bajo su dirección en este Departamento por el Graduado en Química don Mario González Jiménez.

En los términos establecidos por la normativa reguladora de los Estudios de Tercer Ciclo y Doctorado de la Universidad de Salamanca, se autoriza la presentación de este trabajo como investigación de Tesis Doctoral.

Salamanca, seis de mayo de 2012

Julio Casado Linarejos

Emilio Calle Martín 

El trabajo descrito en esta memoria se ha desarrollado dentro de los proyectos CTQ2007-63263 y CTQ2010-18999 del Ministerio de Economía y Competitividad y SA040A08 de la Junta de Castilla y León.

Mario González Jiménez también recibió una beca del Ministerio para realizar su tesis.

Se agradece sinceramente la ayuda de estos organismos. 

Entréme donde no supe y quedéme no sabiendo toda ciencia trascendiendo.

Yo no supe dónde entraba pero cuando allí me vi sin saber dónde me estaba grandes cosas entendí no diré lo que sentí que me quedé no sabiendo toda ciencia trascendiendo.

De paz y de piedad era la ciencia perfecta, en profunda soledad entendida vía recta era cosa tan secreta que me quedé balbuciendo toda ciencia trascendiendo.

Estaba tan embebido tan absorto y ajenado que se quedó mi sentido de todo sentir privado y el espíritu dotado de un entender no entendiendo toda ciencia trascendiendo.

El que allí llega de vero de sí mismo desfallece cuanto sabía primero mucho bajo le parece y su ciencia tanto crece que se queda no sabiendo, toda ciencia trascendiendo.
Cuanto más alto se sube tanto menos se entendía que es la tenebrosa nube que a la noche esclarecía por eso quien la sabía queda siempre no sabiendo, toda ciencia trascendiendo.

Este saber no sabiendo es de tan alto poder que los sabios arguyendo jamás le pueden vencer que no llega su saber a no entender entendiendo toda ciencia trascendiendo.

$Y$ es de tan alta excelencia aqueste sumo saber que no hay facultad ni ciencia que le puedan emprender quien se supiere vencer con un no saber sabiendo, toda ciencia trascendiendo.

Y si lo queréis oír consiste esta suma ciencia en un subido sentir de la divinal esencia es obra de su clemencia hacer quedar no entendiendo toda ciencia trascendiendo. Juan de Yepes Álvarez ${ }^{1}$ 

Sed es beberse a tragos las estrellas, comerse el tiempo, acelerar la prisa, asirse a un ala, atravesar la brisa, montada la ansiedad sobre centellas.

Correr a ciegas sin perder las huellas sobre el eco del llanto y de la risa, buscando el pie que inexorable pisa los días grises y las noches bellas.

Sed es beberlo todo y todavía abrir la boca contracorriente sin que logre saciarte el río entero.

La veleta que el viento desvaría. El silencio. El ruido de la fuente. La espera larga al borde del sendero.

Felipe Doyagüez Chico ${ }^{2}$ 



\section{Índice general}

Índice de figuras

Índice de esquemas

Índice de tablas

1. Introducción 33

1.1. Antecedentes históricos de las reacciones de nitrosación . . . . 33

1.2. Motivación del trabajo . . . . . . . . . . . . . . . . 39

2. Informe bibliográfico 41

2.1. Ácido nitroso y nitritos . . . . . . . . . . . . . . . . 41

2.1.1. Fuentes de exposición a los nitritos . . . . . . . . . . 45

2.1.2. Los nitritos en el cuerpo humano _ . . . . . . . . . 48

2.1.3. Análisis de nitritos en agua . . . . . . . . . . . . . 51

2.2. Agentes nitrosantes . . . . . . . . . . . . . . . . 55

2.2.1. Iones nitrosonio y nitrosacidio . . . . . . . . . . . 55

2.2.2. Trióxido de dinitrógeno . . . . . . . . . . . . . 59 


\section{4 | Índice general}

2.2.3. Sales de nitrosilo . . . . . . . . . . . . . . . . 62

2.2.4. Nitritos de alquilo . . . . . . . . . . . . . . 65

2.2.5. Agentes nitrosantes radicalarios: $\mathrm{NO}_{\mathrm{NO}_{2}} \ldots \ldots 7$

2.2.6. Otros agentes nitrosantes . . . . . . . . . . . 69

2.2.6.1. Complejos metálicos . . . . . . . . . 69

2.2.6.2. Carboxilatos de nitrosilo . . . . . . . . . . 69

2.2.6.3. Nitritos . . . . . . . . . . . 70

2.2.6.4. $N$-Nitrosaminas ............. 71

2.2.6.5. C-Nitrosocompuestos aromáticos . . . . . . 71

2.2.6.6. Líquidos iónicos . . . . . . . . . . . . 72

2.3. Reacciones de nitrosación . . . . . . . . . . . . . . . . 73

2.3.1. C-Nitrosación aromática . . . . . . . . . 73

2.3.2. Diazotación de $C$-nitrosocompuestos aromáticos . . . . . . 77

2.3.3. N-Nitrosación . . . . . . . . . . . . . . . 78

2.3.4. Reacciones de copulación . . . . . . . . . . . . . 80

2.3.5. O-Nitrosación .................. 81

2.3.6. Inhibición de la nitrosación . . . . . . . . . . . 83

2.3.7. Reordenamiento interno . . . . . . . . . . . . 89

2.3.8. S-Nitrosación . . . . . . . . . . . . . . . 90

2.3.9. Control por difusión . . . . . . . . . . . . . . 90

2.3.10. Control orbitálico . . . . . . . . . . . . . . . 92

2.4. Nitrosación, mutagenia y carcinogenia . . . . . . . . . . . . 94

2.5. Compuestos estudiados . . . . . . . . . . . . . . . 97

2.5.1. Etilbenceno .................. 97 


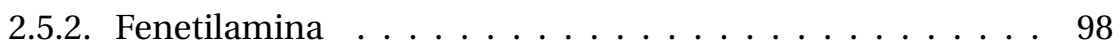

2.5.3. Tiramina . . . . . . . . . . . . . . . . . . . . 102

2.5.4. Dopamina . . . . . . . . . . . . . . . . . . 105

2.5.5. Serotonina . . . . . . . . . . . . . . . . . . . . 109

2.5.6. Minoxidilo . . . . . . . . . . . . . . . . . . . . . . . 113

$\begin{array}{ll}\text { 3. Parte experimental } & 117\end{array}$

3.1. Estudio químico . . . . . . . . . . . . . . . . . . . . 117

3.1.1. Introducción . . . . . . . . . . . . . . . . 117

3.1.1.1. Influencia de la temperatura . . . . . . . . . . 119

3.1.1.2. Influencia de la fuerza iónica . . . . . . . . . 120

3.1.1.3. Efecto isotópico cinético . . . . . . . . . . . 121

3.1.1.4. Reacciones rápidas . . . . . . . . . . . . . . . 121

3.1.2. Procedimiento experimental . . . . . . . . . . . . . 122

3.1.2.1. Consideraciones generales . . . . . . . . . . 122

3.1.2.2. Medida de las reacciones rápidas . . . . . . . . 124

3.1.2.3. Estudio de la evolución de los espectros con el pH 126

3.1.2.4. Síntesis de los nitrosocompuestos . . . . . . . . 127

3.1.2.5. Difracción de Rayos X . . . . . . . . . . . . . 129

3.1.3. Metodología y detalles computacionales . . . . . . . . 130

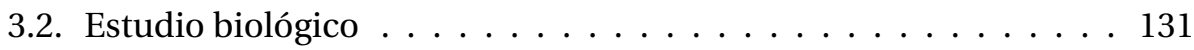

3.2.1. Mutagenia: Test de Ames _ . . . . . . . . . . . . . . . 131

3.2.1.1. Procedimiento experimental . . . . . . . . . . 134

3.2.2. Mutagenia: Test de aberraciones cromosómicas . . . . . . 137

3.2.2.1. Procedimiento experimental . . . . . . . . . . 139 


\section{6 | Índice general}

3.2.3. Citotoxicidad: Test del MTT . . . . . . . . . . . . . . . . 141

3.2.3.1. Procedimiento experimental . . . . . . . . . . 142

3.3. Equipos y reactivos utilizados . . . . . . . . . . . . . . . . . 144

3.3.1. Estudio químico . . . . . . . . . . . . . . . . . . . 144

3.3.2. Estudio biológico . . . . . . . . . . . . . . . . 146

4. Resultados experimentales $\quad 147$

4.1. Nitrosación del etilbenceno . . . . . . . . . . . . . . . . . . . . 147

4.1.1. Solubilidad y estudio espectrofotométrico . . . . . . . . 147

4.1.2. Reacción entre etilbenceno y nitrito . . . . . . . . . . . . . 148

4.2. Nitrosación de la fenetilamina . . . . . . . . . . . . . . 153

4.2.1. Solubilidad y estudio espectrofotométrico . . . . . . . . . 153

4.2.2. Reacción entre fenetilamina y nitrito . . . . . . . . . . . 155

4.2.3. Efecto de la presión en la velocidad . . . . . . . . . . . . . 156

4.2.4. Estudio espectrofotométrico del nitrito . . . . . . . . . . 158

4.2.5. Órdenes parciales de reacción . . . . . . . . . . . . . 162

4.2.6. Velocidad de descomposición del nitrito . . . . . . . . 165

4.2.7. Influencia de la acidez del medio . . . . . . . . . . . . . 166

4.2.8. Influencia de la fuerza iónica . . . . . . . . . . . . 171

4.2.9. Influencia de la temperatura . . . . . . . . . . . . . . 172

4.2.10. Determinación del producto de reacción . . . . . . . . . . 174

4.3. Nitrosación de la tiramina . . . . . . . . . . . . . . . . . . 176

4.3.1. Estudio espectrofotométrico . . . . . . . . . . 176

4.3.2. Reacción entre tiramina y nitrito . . . . . . . . . . . . . 177

4.3.3. Órdenes parciales de reacción . . . . . . . . . . . . 181 
4.3.4. Influencia de la acidez del medio . . . . . . . . . . . . . . 184

4.3.5. Influencia de la fuerza iónica . . . . . . . . . . . . . . 187

4.3.6. Efecto isotópico cinético . . . . . . . . . . . . . 188

4.3.7. Influencia de la temperatura . . . . . . . . . . . 189

4.3.8. Estructura y reactividad de la tiramina . . . . . . . . . 191

4.3.9. Determinación del producto de reacción . . . . . . . . . . . 192

4.3.10. Actividad biológica de la nitrosotiramina . . . . . . . . . 195

4.3.10.1. Test de Ames . . . . . . . . . . . . . . 195

4.3.10.2. Test de aberraciones cromosómicas . . . . . . . . 197

4.3.10.3. Test del MTT . . . . . . . . . . . . . 198

4.4. Nitrosación de la dopamina . . . . . . . . . . . . . . . . 200

4.4.1. Estudio espectrofotométrico . . . . . . . . . . 200

4.4.2. Autooxidación de la dopamina . . . . . . . . . . . . 201

4.4.3. Reacción de nitrosación de la dopamina . . . . . . . . . . . 204

4.4.4. Influencia de la concentración de iones cloruro . . . . . . . 205

4.4.5. Órdenes parciales de reacción . . . . . . . . . . . 206

4.4.6. Influencia de la acidez del medio . . . . . . . . . . . . 207

4.4.7. Influencia de la fuerza iónica . . . . . . . . . . . . . . 212

4.4.8. Efecto isotópico cinético . . . . . . . . . . . . . . . 212

4.4.9. Influencia de la temperatura . . . . . . . . . . 213

4.4.10. Estructura y reactividad de la dopamina . . . . . . . 215

4.4.11. Determinación del producto de reacción . . . . . . . . . 216

4.4.12. Actividad biológica de la nitrosodopamina . . . . . . . . 217

4.4.12.1. Test de Ames . . . . . . . . . . . . . 217 


\section{8 | Índice general}

4.4.12.2. Test de aberraciones cromosómicas . . . . . . . 221

4.4.12.3. Test del MTT . . . . . . . . . . . . . . . 222

4.5. Nitrosación de la serotonina . . . . . . . . . . . . . . 223

4.5.1. Estudio espectrofotométrico . . . . . . . . . . . 223

4.5.2. Reacción entre serotonina y nitrito . . . . . . . . . . 225

4.5.3. Tratamiento cinético de reacciones consecutivas . . . . . . 226

4.5.4. Coeficientes de absorción molar . . . . . . . . . . . . . 234

4.5.5. Influencia de la concentración de nitrito . . . . . . . . . . 235

4.5.6. Influencia de la acidez del medio . . . . . . . . . . . . . . 236

4.5.7. Influencia de la fuerza iónica . . . . . . . . . . . . . . 242

4.5.8. Efecto isotópico cinético . . . . . . . . . . . . . . . . . . 243

4.5.9. Influencia de la temperatura . . . . . . . . . . . . 245

4.5.10. Estructura y reactividad de la serotonina . . . . . . . . . . 249

4.5.11. Determinación del producto de reacción . . . . . . . . . . . 252

4.5.12. Actividad biológica de la nitrososerotonina . . . . . . . 253

4.5.12.1. Test de Ames . . . . . . . . . . . . . . 253

4.5.12.2. Test de aberraciones cromosómicas . . . . . . . . 255

4.5.12.3. Test del MTT . . . . . . . . . . . . . . 256

4.6. Nitrosación del minoxidilo . . . . . . . . . . . . . . . . 257

4.6.1. Solubilidad y estudio espectrofotométrico . . . . . . . . 257

4.6.2. Reacción entre minoxidilo y nitrito . . . . . . . . . . . 262

4.6.3. Órdenes parciales de reacción . . . . . . . . . . . 263

4.6.4. Determinación de las constantes de velocidad . . . . . . . . 264

4.6.5. Influencia de acidez del medio . . . . . . . . . . . . 267 
4.6.6. Influencia de la fuerza iónica . . . . . . . . . . . . . 270

4.6.7. Efecto isotópico cinético . . . . . . . . . . . . . 271

4.6.8. Influencia de la temperatura . . . . . . . . . . . 271

4.6.9. Determinación del producto de reacción . . . . . . . . 273

4.6.10. Actividad biológica del nitrosominoxidilo . . . . . . . 280

4.6.10.1. Test de Ames . . . . . . . . . . . . . . 280

4.6.10.2. Test del MTT . . . . . . . . . . . . . . . . . . 282

4.7. Determinación de nitrito con minoxidilo . . . . . . . . . . 284

4.7.1. Descripción del método . . . . . . . . . . . . . . . . . 284

4.7.2. Curva de calibrado . . . . . . . . . . . . . . . . . 285

4.7.3. Catálisis por el ion cloruro . . . . . . . . . . . . . 286

4.7.4. Efecto de iones metálicos . . . . . . . . . . . . . . . 287

4.7.5. Precisión del método . . . . . . . . . . . . . . . . . . . 288

4.7.6. Límites de detección y cuantificación . . . . . . . . . . 288

4.7.7. Aplicación del método . . . . . . . . . . . . . . . . . . 289

5. Discusión de los resultados 291

5.1. C-Nitrosación de compuestos aromáticos _ . . . . . . . . 291

5.2. Reacciones de N-nitrosación . . . . . . . . . . . . . . . 298

5.3. Competencia entre N-nitrosación y C-nitrosación . . . . . . . 299

5.4. Actividad biológica de los compuestos estudiados . . . . . . . 302

$\begin{array}{ll}\text { 6. Conclusiones } & 305\end{array}$

$\begin{array}{ll}\text { Bibliografía } & 309\end{array}$ 



\section{Índice de figuras}

1.1. Protagonistas de la historia de la nitrosación . . . . . . . . . . . . . 37

1.2. Número de publicaciones sobre nitrosación en el tiempo . . . . . . . . 38

1.3. Sustratos investigados en esta tesis . . . . . . . . . . . . . . . . . . 40

2.1. Estructura del ácido nitroso . . . . . . . . . . . . . . . . . . . . . . 43

2.2. Técnicas de análisis del ion nitrito y sus reactivos . . . . . . . . . . . 53

2.3. Estructura teórica del ion nitrosacidio . . . . . . . . . . . . . . . . 58

2.4. Estructura del trióxido de dinitrógeno . . . . . . . . . . . . . . . 61

2.5. Modelo de Kekule para el benceno . . . . . . . . . . . . . . . . . . . . . . 73

2.6. Modelo de la teoría de orbitales moleculares para el benceno . . . . . . . . 74

2.7. Estructura de los carboxilatos de nitrosilo . . . . . . . . . . . . . . . 83

2.8. Control por carga y control orbitálico . . . . . . . . . . . . . . . . . . 93

2.9. Sustratos investigados en esta tesis . . . . . . . . . . . . . . . . . . . 97

2.10.Catecolaminas y sustancias afines . . . . . . . . . . . . . . . . . 104

2.11.Productos del metabolismo del minoxidilo . . . . . . . . . . . . . . . . . . . 114

3.1. Perfil energético de una reacción química . . . . . . . . . . . . . . . . . . 119

3.2. Medida de una reacción por un método de flujo . . . . . . . . . . . . . . . 122 


\section{2 | Índice de figuras}

3.3. Esquema de un espectrofotómetro de flujo detenido . . . . . . . . . . . . . 124

3.4. Curva de calibrado del espectrofotómetro de flujo . . . . . . . . . . . . 125

3.5. Montaje para medir la influencia del $\mathrm{pH}$ en los espectros . . . . . . . . . 126

3.6. Montaje para sintetizar nitrosominoxidilo . . . . . . . . . . . . . . . . . 129

3.7. Relación entre dosis y número de colonias . . . . . . . . . . . . . . . . . 135

3.8. Aberraciones cromosómicas posibles . . . . . . . . . . . . . . . 138

4.1. Espectro de absorción UV-visible del etilbenceno . . . . . . . . . . . . . . 148

4.2. Banda de absorción ultravioleta del etilbenceno . . . . . . . . . . . . . . . . 149

4.3. Reacción entre etilbenceno y nitrito . . . . . . . . . . . . . . . . . . . 149

4.4. Espectro de masas y cromatograma de gases del etilbenceno . . . . . . . 150

4.5. Espectro de masas y cromatograma de gases de la mezcla etilbenceno ácido nitroso . . . . . . . . . . . . . . . . . . . . . . 151

4.6. Espectro de absorción UV-visible de la fenetilamina . . . . . . . . . . . . . 153

4.7. Coeficiente de absorción molar de la fenetilamina . . . . . . . . . . . . . . 154

4.8. Coeficiente de absorción molar a $258 \mathrm{~nm}$ de la fenetilamina . . . . . . . . . 155

4.9. Influencia del $\mathrm{pH}$ en el espectro de la fenetilamina . . . . . . . . . . . . . 156

4.10. Reacción entre fenetilamina y nitrito en medio ácido . . . . . . . . . . . . . 157

4.11.Influencia de la presión en la velocidad de reacción . . . . . . . . . . . . . . 157

4.12. Influencia del $\mathrm{pH}$ en el espectro del sistema ácido nitroso/nitrito . . . . 158

4.13. Coeficiente de absorción molar del ácido nitroso . . . . . . . . . . . . . . 160

4.14. Coeficiente de absorción molar del nitrito . . . . . . . . . . . . . . . . . 161

4.15. Nitrosación de la fenetilamina: Orden del nitrito $\ldots \ldots$. . . . . . . . 163

4.16. Nitrosación de la fenetilamina: Orden de la fenetilamina . . . . . . . . . . . 164

4.17.Influencia del pH en la descomposición del nitrito . . . . . . . . . . . 165

4.18. Nitrosación de la fenetilamina: Influencia de la acidez . . . . . . . . . . . . 167

4.19. Nitrosación de la fenetilamina: Influencia de la fuerza iónica . . . . . . . . 171 
4.20. Nitrosación de la fenetilamina: Ecuación de Arrhenius . . . . . . . . . . . 173

4.21. Nitrosación de la fenetilamina: Ecuación de Eyring . . . . . . . . . . . 173

4.22. Espectros de masas de la fenetilamina y de la mezcla de reacción . . . . 175

4.23. Espectro de absorción UV-visible de la tiramina . . . . . . . . . . . . . . 176

4.24. Influencia del pH en el espectro de la tiramina . . . . . . . . . . . . . 177

4.25. Coeficiente de absorción molar de la tiramina . . . . . . . . . . . . . . 178

4.26. Reacción entre tiramina y nitrito en medio ácido . . . . . . . . . . . . 179

4.27. Coeficiente de absorción molar de la nitrosotiramina . . . . . . . . . . . . . 180

4.28. Nitrosación de la tiramina: Orden de la tiramina . . . . . . . . . . . . . . 182

4.29. Nitrosación de la tiramina: Orden del nitrito . . . . . . . . . . . . . . . . 183

4.30. Nitrosación de la tiramina: Influencia de la acidez . . . . . . . . . . . . . . 185

4.31. Nitrosación de la tiramina: Influencia de la fuerza iónica . . . . . . . . . . 187

4.32. Nitrosación de la tiramina: Ecuación de Arrhenius . . . . . . . . . . . . 190

4.33. Nitrosación de la tiramina: Ecuación de Eyring ～. . . . . . . . . . . . . . 190

4.34. Estructura calculada de la tiramina . . . . . . . . . . . . . . . . . . 191

4.35. Mapa de densidad electrónica de la tiramina . . . . . . . . . . . . . . . . 192

4.36. Energía comparada de los complejos $\sigma$ de la nitrosotiramina . . . . . . . 193

4.37. Espectro de masas de la tiramina nitrosada . . . . . . . . . . . . . . . . . 194

4.38. Nitrosotiramina: Resultados del test de Ames con la cepa TA98 . . . . . . . 196

4.39. Nitrosotiramina: Resultados del test de Ames con la cepa TA100 . . . . . 196

4.40. Test del MTT aplicado a la nitrosotiramina . . . . . . . . . . . . . . . . . 199

4.41.Espectro UV-visible de la dopamina . . . . . . . . . . . . . . . 200

4.42. Coeficiente de absorción molar de la dopamina . . . . . . . . . . . . . . 201

4.43. Espectro UV-visible de la dopamina oxidada . . . . . . . . . . . . . . . . 202

4.44. Estudio espectroscópico de la oxidación de la dopamina . . . . . . . . . . 203

4.45. Acidez de las disoluciones de hidrocloruro de dopamina . . . . . . . . . . 203 


\section{4 | Índice de figuras}

4.46. Reacción entre dopamina y nitrito en medio ácido . . . . . . . . . . . . 204

4.47. Coeficiente de absorción molar de la nitrosodopamina . . . . . . . . . . . . 205

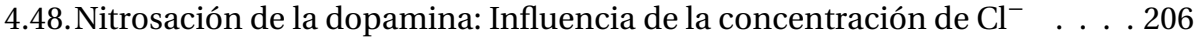

4.49. Nitrosación de la dopamina: Orden de la dopamina . . . . . . . . . . . 208

4.50. Nitrosación de la dopamina: Orden del nitrito . . . . . . . . . . . . . . . 209

4.51. Nitrosación de la dopamina: Influencia de la acidez . . . . . . . . . . . . 210

4.52. Nitrosación de la dopamina: Influencia de la fuerza iónica . . . . . . . . . 212

4.53. Nitrosación de la dopamina: Ecuaciones de Arrhenius y de Eyring . . . . . 214

4.54. Estructura calculada de la dopamina . . . . . . . . . . . . . . . 215

4.55. Mapa de densidad electrónica de la dopamina . . . . . . . . . . . . . . 216

4.56. Energía comparada de los complejos $\sigma$ de la nitrosodopamina . . . . . . . 217

4.57.Espectro de masas de la dopamina nitrosada . . . . . . . . . . . . . . . 218

4.58. Nitrosotiramina: Resultados del test de Ames con la cepa TA98 . . . . . . 219

4.59. Nitrosotiramina: Resultados del test de Ames con la cepa TA100 . . . . . 219

4.60. Nitrosotiramina: Test de Ames (TA98) con dosis entre 20 y $80 \mu \mathrm{g} \ldots \ldots . .220$

4.61. Test del MTT aplicado a la nitrosodopamina . . . . . . . . . . . . . . . . 222

4.62. Espectro de absorción UV-visible de la serotonina . . . . . . . . . . . . . . 223

4.63. Coeficiente de absorción molar de la serotonina . . . . . . . . . . . . . . . 224

4.64. Influencia del $\mathrm{pH}$ en el espectro de la serotonina . . . . . . . . . . . . . 225

4.65. Reacción entre serotonina y nitrito en medio ácido . . . . . . . . . . . . 226

4.66. Estudio cinético de la reacción entre serotonina y nitrito . . . . . . . . . . 227

4.67.Ajuste de las cinéticas al mecanismo de reacciones consecutivas . . . . . 231

4.68. Ajuste de las cinéticas al mecanismo de reacciones consecutivas . . . . . . 232

4.69. Ajuste de las cinéticas al mecanismo de reacciones consecutivas . . . . . . 233

4.70. Coeficientes de absorción molar de la nitrososerotonina . . . . . . . . . . . 234

4.71. Nitrosación de la serotonina: Orden del nitrito . . . . . . . . . . . . . . 236 
4.72. Nitrosación de la serotonina: Influencia de la acidez $\left(k_{\mathrm{obs}, 1}\right) \ldots \ldots 238$

4.73. Nitrosación de la serotonina: Influencia de la acidez $\left(k_{\mathrm{obs}, 2}\right) \ldots \ldots$. . . . 239

4.74. Nitrosación de la serotonina: Influencia de la fuerza iónica . . . . . . . . 243

4.75. Influencia de la temperatura en los perfiles de reacción . . . . . . . . 245

4.76. Nitrosación de la serotonina: Ecuación de Arrhenius $\left(k_{\mathrm{obs}, 1}\right) \quad \ldots \ldots$. . . 247

4.77. Nitrosación de la serotonina: Ecuación de Eyring $\left(k_{\mathrm{obs}, 1}\right) \ldots \ldots$. . . . . . 247

4.78. Nitrosación de la serotonina: Ecuación de Arrhenius $\left(k_{\mathrm{obs}, 2}\right) \quad \ldots \ldots$. . . 248

4.79. Nitrosación de la serotonina: Ecuación de Eyring $\left(k_{\mathrm{obs}, 2}\right) \ldots \ldots$. . . . . . 248

4.80. Estructura calculada de la serotonina . . . . . . . . . . . . . . 250

4.81. Mapa de densidad electrónica de la serotonina . . . . . . . . . . . . . 250

4.82. Energía comparada de los complejos $\sigma$ de la nitrososerotonina . . . . . . 251

4.83. Espectro de masas de la serotonina nitrosada . . . . . . . . . . . 252

4.84. Nitrososerotonina: Resultados del test de Ames con la cepa TA98 . . . . . . 254

4.85. Nitrososerotonina: Resultados del test de Ames con la cepa TA100 . . . . . 254

4.86. Test del MTT aplicado a la nitrososerotonina . . . . . . . . . . . . . . 256

4.87.Espectro UV-visible del minoxidilo . . . . . . . . . . . . . . . . 257

4.88. Coeficiente de absorción molar del minoxidilo . . . . . . . . . . . . . . . 258

4.89. Influencia del pH en el espectro del minoxidilo . . . . . . . . . . . . 259

4.90. Coeficiente de absorción molar del minoxidilo a $\mathrm{pH}=3,1 \ldots 260$

4.91. Coeficiente extinción molar del minoxidilo a $\mathrm{pH}=4,1 \ldots 261$

4.92. Reacción entre minoxidilo y nitrito en medio ácido . . . . . . . . . . . . 262

4.93. Coeficientes de absorción molar del nitrosominoxidilo . . . . . . . . . 263

4.94. Nitrosación del minoxidilo: Orden del minoxidilo . . . . . . . . . . . . . 265

4.95. Nitrosación del minoxidilo: Orden del nitrito . . . . . . . . . . . . . . . 266

4.96. Ajuste de los resultados al método integral . . . . . . . . . . . . . 267

4.97. Nitrosación del minoxidilo: Influencia de la acidez . . . . . . . . . . . . 269 


\section{6 | Índice de figuras}

4.98. Nitrosación del minoxidilo: Influencia de la fuerza iónica . . . . . . . . 270

4.99. Nitrosación del minoxidilo: Ecuación de Arrhenius . . . . . . . . . . . . . . 272

4.100.Nitrosación del minoxidilo: Ecuación de Eyring . . . . . . . . . . . . 272

4.101.Espectro de masas del nitrosominoxidilo _ . . . . . . . . . . . . . . . 274

4.102.Imagen del nitrosominoxidilo por difracción de RX . . . . . . . . . 275

4.103.RMN ${ }^{1} \mathrm{H}$ del minoxidilo disuelto en DMSO deuterado . . . . . . . . . . . . 276

4.104.RMN ${ }^{1} \mathrm{H}$ del nitrosominoxidilo disuelto en $\mathrm{CD}_{3} \mathrm{OD} \ldots \ldots$. . . . . . . 277

4.105.RMN ${ }^{13} \mathrm{C}$ del minoxidilo disuelto en DMSO deuterado . . . . . . . . . . 278

4.106. RMN ${ }^{13} \mathrm{C}$ del nitrosominoxidilo disuelto en $\mathrm{CD}_{3} \mathrm{OD} \ldots \ldots$. . . . . . . . 279

4.107.Geometría de la celda unidad de un cristal de nitrosominoxidilo . . . . 280

4.108.Nitrosominoxidilo: Resultados del test de Ames con la cepa TA98 . . . . 281

4.109.Nitrosominoxidilo: Resultados del test de Ames con la cepa TA100 . . . 281

4.110.Test del MTT aplicado al nitrosominoxidilo . . . . . . . . . . . . . . . 283

4.111.Perfiles cinéticos de la nitrosación de minoxidilo . . . . . . . . . . . . . . . 285

4.112.Curva de calibrado del método propuesto . . . . . . . . . . . . . . . 286

4.113.Efecto de los iones $\mathrm{Cl}^{-}$en el tiempo de medida . . . . . . . . . . . . . . . 287

5.1. Compuestos estudiados por González Mancebo et al. . . . . . . . . . . . 292

5.2. Relación isocinética entre los compuestos estudiados . . . . . . . . . . . 293

5.3. Representación de Palm-Vizgert . . . . . . . . . . . . . . . . . . . . . . . . . 294

5.4. Competencia entre N-nitrosación y C-nitrosación en la tiramina y la do-

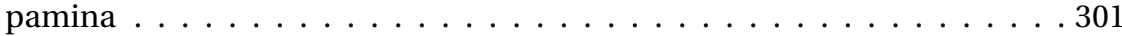

5.5. Competencia entre N-nitrosación y C-nitrosación en la serotonina . . . 302 


\section{Índice de esquemas}

1.1. Reacción de Piria . . . . . . . . . . . . . . . . . . . . . . . . 34

1.2. Obtención del primer diazocompuesto por Griess . . . . . . . . . . . . . . 34

1.3. Reordenamiento de Fischer-Hepp . . . . . . . . . . . . . . . 35

1.4. Reordenamiento de Demjanov . . . . . . . . . . . . . 36

2.1. Transformaciones químicas de la mioglobina. . . . . . . . . . . . . . . 47

2.2. Ciclo de los nitritos y nitratos en el cuerpo humano. . . . . . . . . . . . 49

2.3. Reacción de nitrosación radicalaria con óxido nítrico . . . . . . . . . . . 68

2.4. Mecanismo de nitrosación por nitritos . . . . . . . . . . . 70

2.5. Método de Liebermann para la detección de nitrosaminas . . . . . . . 71

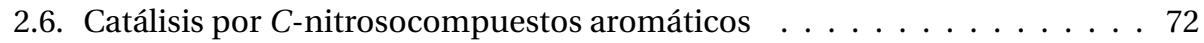

2.7. Síntesis de sales de diazonio con líquidos iónicos . . . . . . . . . . . 72

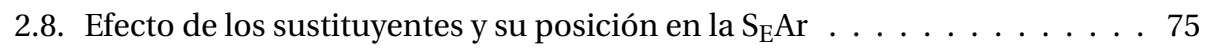

2.9. $\mathrm{S}_{\mathrm{E}} \mathrm{Ar}$ en un anillo heteroatómico: piridina $\ldots \ldots \ldots$. . . . . . 76

2.10. Mecanismo de diazotación de un $C$-nitrosocompuesto . . . . . . . . . . 77

2.11. Mecanismos de nitrosación y desaminación de aminas primarias . . . . 78

2.12. Mecanismo de transposición de una $N$-nitrosamina secundaria . . . . . 79

2.13. Mecanismo de descomposición de una $N$-nitrosamina terciaria . . . . . 80 


\section{8 | Índice de esquemas}

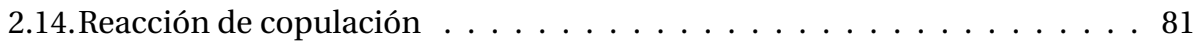

2.15. Mecanismo del reordenamiento de Fischer-Hepp . . . . . . . . . . . . 82

2.16. Mecanismo de reducción del ion nitrosacidio por el ácido ascórbico . . . . 84

2.17. Reordenamiento de Tiffeneau-Demjanov . . . . . . . . . . . . . . . . . . . 89

2.18. Reacción de ciclación de aminoácidos . . . . . . . . . . . . . . . . 90

2.19.Activación metabólica de $N$-nitrosocompuestos . . . . . . . . . . . . 96

2.20. Ruta biosintética de catecolaminas . . . . . . . . . . . . . . 100

2.21. Equilibrio ácido-base de la tiramina . . . . . . . . . . . . . . . . . 105

2.22. Metabolización de la dopamina . . . . . . . . . . . . . . 108

2.23. Oxidación de la dopamina . . . . . . . . . . . . . . . . . . 108

2.24. Biosíntesis de serotonina . . . . . . . . . . . . . . . . . . . . 112

2.25. Productos del metabolismo del minoxidilo . . . . . . . . . . . . . . . . . . 114

3.1. Ruta de la síntesis de nitrosotiramina . . . . . . . . . . . . . . . . . . 127

3.2. Reducción metabólica de MTT . . . . . . . . . . . . . . . . . . . . . . . . . 142

4.1. Mecanismo de nitrosación de la fenetilamina . . . . . . . . . . . . . 168

4.2. Mecanismo de nitrosación de la tiramina . . . . . . . . . . . . . . 186

4.3. Reacción de complejación de la nitrosotiramina. . . . . . . . . . . . . . . . 194

4.4. Mecanismo de nitrosación de la dopamina . . . . . . . . . . . . . . . 211

4.5. Mecanismo de la primera nitrosación de la serotonina . . . . . . . . . . . 237

4.6. Mecanismo de la segunda nitrosación de la serotonina . . . . . . . . . . . . 241

4.7. Reacción de complejación de la nitrososerotonina . . . . . . . . . . . 253

4.8. Mecanismo de nitrosación del minoxidilo f . . . . . . . . . . . . . . 268 


\section{Índice de tablas}

2.1. Constantes de acidez del ácido nitroso . . . . . . . . . . . . . . . . . . 44

2.2. Solubilidad y estabilidad térmica de diferentes nitritos . . . . . . . . . . 46

2.3. Límites de detección de los métodos de determinación de nitrito . . . . 54

2.4. Magnitudes termodinámicas de la descomposición del $\mathrm{N}_{2} \mathrm{O}_{3} \ldots \ldots$. . . . 60

2.5. Propiedades físicas de algunas sales de nitrosilo . . . . . . . . . . . . . 63

2.6. Constantes de equilibrio de formación de sales de nitrosilo . . . . . . . . . 64

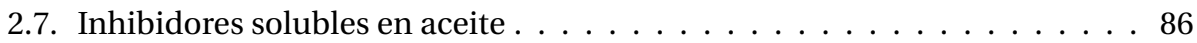

2.8. Inhibidores solubles en agua (I) $\ldots \ldots \ldots$. . . . . . . . . . 87

2.9. Inhibidores solubles en agua (II) $\ldots \ldots \ldots \ldots$

2.10. Inhibidor soluble en aceite y en agua $\ldots \ldots \ldots 8$

2.11. Constantes de velocidad de nitrosaciones controladas por difusión . . . . 92

2.12.Propiedades del etilbenceno . . . . . . . . . . . . . . . . . 99

2.13. Propiedades de la fenetilamina . . . . . . . . . . . . . . 101

2.14. Propiedades de la tiramina $\ldots \ldots \ldots$. . . . . . . . . . 103

2.15. Propiedades de la dopamina . . . . . . . . . . . . . . . . . . 107

2.16. Propiedades de la serotonina . . . . . . . . . . . . 111

2.17.Propiedades del minoxidilo . . . . . . . . . . . . . . . . . . . . 115 


\section{0 | Índice de tablas}

3.1. Curva de calibrado del espectrofotómetro de flujo . . . . . . . . . . . . 125

3.2. Genotipos de las cepas bacterianas empleadas en el test de Ames . . . . 132

3.3. Origen de los equipos y reactivos químicos empleados (Parte I) . . . . . . . 144

3.4. Origen de los reactivos químicos empleados (Parte II) . . . . . . . . . . 145

3.5. Origen del material empleado en el estudio biológico . . . . . . . . . . . 146

4.1. Etilbenceno: Condiciones experimentales de la CG - EM . . . . . . . . . . . 152

4.2. Coeficiente de absorción molar de la fenetilamina . . . . . . . . . . . . 155

4.3. Coeficiente de absorción molar del ácido nitroso . . . . . . . . . . . 160

4.4. Coeficiente de absorción molar del nitrito f . . . . . . . . . . . . 161

4.5. Nitrosación de la fenetilamina: Orden del nitrito . . . . . . . . . . . . . 163

4.6. Nitrosación de la fenetilamina: Orden de la fenetilamina . . . . . . . . . . . 164

4.7. Nitrosación de la fenetilamina: Influencia de la acidez . . . . . . . . . . 167

4.8. Nitrosación de la fenetilamina: Influencia de la fuerza iónica . . . . . . . . 171

4.9. Nitrosación de la fenetilamina: Influencia de la temperatura . . . . . . . 172

4.10. Coeficiente de absorción molar de la tiramina . . . . . . . . . . . . . . . . 178

4.11. Coeficiente de absorción molar de la nitrosotiramina . . . . . . . . . . . . . 180

4.12. Nitrosación de la tiramina: Orden de la tiramina . . . . . . . . . . . . . . . 182

4.13. Nitrosación de la tiramina: Orden del nitrito . . . . . . . . . . . . . . 183

4.14. Nitrosación de la tiramina: Influencia de la acidez . . . . . . . . . . . . . . . 185

4.15. Nitrosación de la tiramina: Influencia de la fuerza iónica . . . . . . . . . . . 187

4.16. Nitrosación de la tiramina: Influencia de la temperatura . . . . . . . . . 189

4.17.Parámetros de activación de la reacción de nitrosación de la tiramina . . 189

4.18. Resultados del test de Ames aplicado a la nitrosotiramina . . . . . . . . . 195

4.19. Test de aberraciones cromosómicas aplicado a la nitrosotiramina . . . . . 197

4.20. Test del MTT aplicado a la nitrosotiramina . . . . . . . . . . . . . . . . 199

4.21. Coeficiente de absorción molar de la dopamina . . . . . . . . . . . . . 201 
4.22. Coeficiente de absorción molar de la nitrosodopamina . . . . . . . . . . 205 4.23. Nitrosación de la dopamina: Orden de la dopamina . . . . . . . . . . . 208 4.24. Nitrosación de la dopamina: Orden del nitrito . . . . . . . . . . . . . . . 209 4.25. Nitrosación de la dopamina: Influencia de la acidez . . . . . . . . . . . 210 4.26. Nitrosación de la dopamina: Influencia de la fuerza iónica . . . . . . . . . . 212 4.27. Nitrosación de la dopamina: Influencia de la temperatura . . . . . . . . . 213 4.28. Parámetros de activación de la reacción de nitrosación de la dopamina 215 4.29. Test de Ames aplicado a la nitrosodopamina . . . . . . . . . . . . . 218 4.30. Nitrosotiramina: Test de Ames (TA98) con dosis entre 20 y $80 \mu \mathrm{g} \ldots \ldots . .220$ 4.31. Test de aberraciones cromosómicas aplicado a la nitrosodopamina . . . . 221 4.32. Test del MTT aplicado a la nitrosodopamina . . . . . . . . . . . . . . 222 4.33. Coeficiente de absorción molar de la serotonina . . . . . . . . . . . . . . 224 4.34. Coeficientes de absorción molar de la nitrososerotonina . . . . . . . . . . . 234 4.35. Nitrosación de la serotonina: Orden del nitrito . . . . . . . . . . . . . . . . 236 4.36. Nitrosación de la serotonina: Influencia de la acidez $\left(k_{\mathrm{obs}, 1}\right) \ldots \ldots 238$ 4.37. Nitrosación de la serotonina: Influencia de la acidez $\left(k_{\mathrm{obs}, 2}\right) \ldots \ldots$. . . . 239 4.38. Nitrosación de la serotonina: Influencia de la fuerza iónica . . . . . . . . 243 4.39. Efectos isotópicos observados en la nitrosación de la serotonina . . . . . . 244 4.40. Nitrosación de la serotonina: Influencia de la temperatura $\left(k_{\mathrm{obs}, 1}\right) \ldots 246$ 4.41. Nitrosación de la serotonina: Influencia de la temperatura $\left(k_{\mathrm{obs}, 2}\right) \ldots \ldots 246$ 4.42.Parámetros termodinámicos de las nitrosaciones de la serotonina . . . . . 249 4.43. Test de Ames aplicado a la nitrososerotonina . . . . . . . . . . . . . 253 4.44. Test de aberraciones cromosómicas aplicado a la nitrososerotonina . . . 255 4.45. Test del MTT aplicado a la nitrososerotonina . . . . . . . . . . . . . 256 4.46. Coeficiente de absorción molar del minoxidilo . . . . . . . . . . . . . 258 4.47. Coeficiente de absorción molar del minoxidilo a $\mathrm{pH}=3,1 \ldots 260$ 


\section{2 | Índice de tablas}

4.48. Coeficiente extinción molar del minoxidilo a $\mathrm{pH}=4,1 \ldots \ldots$. . . . . 261

4.49. Coeficientes de absorción molar del nitrosominoxidilo . . . . . . . . . . 263

4.50. Nitrosación del minoxidilo: Orden del minoxidilo . . . . . . . . . . . . . 265

4.51. Nitrosación del minoxidilo: Orden del nitrito . . . . . . . . . . . . . . . 266

4.52. Ajuste de los resultados al método integral . . . . . . . . . . . . . 267

4.53. Nitrosación del minoxidilo: Influencia de la acidez . . . . . . . . . . . . 269

4.54. Nitrosación del minoxidilo: Influencia de la temperatura . . . . . . . . . 271

4.55. Parámetros de activación de la reacción de nitrosación del minoxidilo . 273

4.56. Propiedades de la celda y del difractograma . . . . . . . . . . . . . . 275

4.57. Resultados del test de Ames aplicado al nitrosominoxidilo . . . . . . . . . . 282

4.58. Test del MTT aplicado al nitrosominoxidilo . . . . . . . . . . . . . . . 283

4.59. Curva de calibrado del método propuesto _ . . . . . . . . . . . . 286

4.60. Determinación de la precisión del método propuesto $\ldots \ldots$. . . . . 288

5.1. Relación isocinética entre los compuestos estudiados . . . . . . . . . 293

5.2. Representación de Palm-Vizgert . . . . . . . . . . . . . . . . . . . 294

5.3. Constantes de C-nitrosación aromática de diversos sustratos . . . . . . . 296

5.4. Índices de reactividad de sustratos aromáticos C-nitrosados . . . . . . . 297 


\section{Capítulo 1}

\section{Introducción}

\subsection{Antecedentes históricos de las reacciones de nitrosa- ción}

El origen de las reacciones de nitrosación está ligado al de la propia química. Durante el siglo XVIII, en el albor de la nueva ciencia, una de las primeras reacciones que se estudió sistemáticamente fue el ataque de los poderosos ácidos minerales a los alcoholes aislados de los alimentos. Así, de la condensación de alcoholes y ácido nitroso se obtuvieron los primeros nitrosocompuestos: los ésteres de nitrito. ${ }^{4}$ Estos compuestos aún no tenían aplicación alguna y se descomponían fácilmente, por lo que merecieron escaso interés.

Mucho más atractivos fueron los siguientes nitrosocompuestos descubiertos: las nitrosaminas. En 1846, el político y químico calabrés Raffaele Piria trabajaba en la Universidad de Pisa aislando y caracterizando productos de descomposición de proteínas vegetales. En un experimento, a partir de unos kilos de almortas obtuvo unos pocos gramos de unos cristales que, tras múltiples ensayos, identificó como ácido aspártico. ${ }^{5}$ Haciendo pruebas con los cristales, trató una disolución de los mismos con ácido nitroso y observó que se transformaban en ácido málico (esquema 1.1).

Asombrado, publicó el descubrimiento de la reacción de desaminación en una pequeña revista italiana llamada Il Cimento. Esta publicación apenas tenía difu- 


\section{4 | Antecedentes históricos de las reacciones de nitrosación}<smiles>NC(CC(=O)O)C(=O)ONC(=O)CC(O)C(=O)O</smiles>

Esquema 1.1: Reacción de Piria.

sión, pero su artículo circuló por toda Europa. Dos años más tarde su trabajo se tradujo al alemán, idioma en el que alcanzó una gran repercusión. ${ }^{5,6}$ Uno de los químicos más importantes de la época, August Wilhelm von Hofmann, aplicó enseguida la reacción a una gran variedad de aminas alifáticas y aromáticas, entre ellas la anilina, que consiguió transformar en fenol. ${ }^{7}$ Uno de sus alumnos, William Henry Perkin, con tan sólo dieciocho años, descubrió por casualidad mientras experimentaba con la anilina el primer colorante sintético de la historia al que denominó púrpura de anilina. ${ }^{8}$ Hasta ese momento los colorantes se obtenían mediante costosos procesos a partir de plantas, insectos, moluscos o minerales, por lo que el inmenso potencial económico que tenían los nuevos colorantes artificiales espoleó la investigación sobre el tema.

En 1858 - mientras Perkin inauguraba su primera fábrica de púrpura de anilina ${ }^{9}$ - el alemán Johann Peter Griess aisló el primer diazocompuesto en un paso intermedio de la reacción de Piria aplicada al ácido picrámico (esquema 1.2). ${ }^{10} \mathrm{Al}$ cabo de un tiempo también consiguió aislar las primeras sales de diazonio aromáticas ${ }^{11}$ y descubrió que se podían acoplar a otros compuestos aromáticos para obtener pigmentos cuyo color dependía de las moléculas de partida. ${ }^{12}$ Sin embargo, a pesar de la gran cantidad de dinero que podía haber<smiles>Nc1cc([N+](=O)[O-])cc([N+](=O)[O-])c1[N+](=O)[O-]</smiles>

Esquema 1.2: Primer diazocompuesto aislado. 


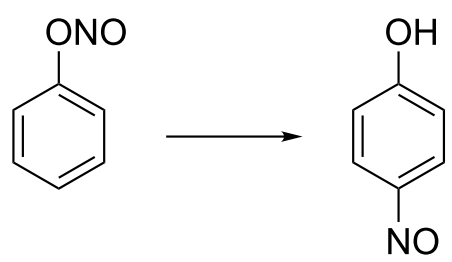

Esquema 1.3: Reordenamiento de Fischer-Hepp.

ganado con los resultados de su investigación, Peter Griess nunca quiso sacar provecho económico de su trabajo. Cedió libremente todas sus recetas a la industria de los colorantes y apenas registró patentes. Sus descubrimientos le habían dado toda la satisfacción que necesitaba.

En los años siguientes se produjeron un gran número de avances en el área de la nitrosación. En 1863, utilizando la reacción de Piria, se aislaron las primeras nitrosaminas a partir de aminas secundarias ${ }^{13}$ y, en 1874, Viktor Meyer describió por primera vez la nitrosación de un carbono de una molécula aromática. ${ }^{14-16}$ Pronto se fueron caracterizando nuevos nitrosocompuestos procedentes de las reacciones entre el ácido nitroso y otros grupos funcionales de moléculas orgánicas.

En aquella época, elucidar la estructura de los nuevos compuestos no era nada fácil. ${ }^{17} \mathrm{~A}$ la ausencia de técnicas se sumaban las peculiares propiedades de las moléculas estudiadas. Los nitrosocompuestos presentaban colores muy variados que incluso cambiaban al preparar disoluciones y los diazocompuestos mostraban una reactividad muy diferente a la de las sales de diazonio, pese a tener ambos la misma fórmula empírica, $\mathrm{ArN}_{2} \mathrm{X}$. Por consiguiente, la determinación de los mecanismos de reacción se hacía más compleja todavía, especialmente tras encontrarse nuevas reacciones de reordenamiento que afectaban a moléculas nitrosadas. ${ }^{18}$ En 1886, Otto Fischer y Eduard Hepp descubrieron que el grupo nitroso en $O$-nitrosocompuestos aromáticos podía cambiar su posición de un oxígeno a un carbono de la misma molécula (esquema 1.3) ${ }^{19}$ y en 1903 Nikolai Demjanov observó que los ciclos con radicales que poseen una amina primaria, al tratarlos con ácido nitroso, se expandían (esquema 1.4). ${ }^{20,21}$

Con el tiempo, la obtención de nuevos colorantes dejó de ser un incentivo 


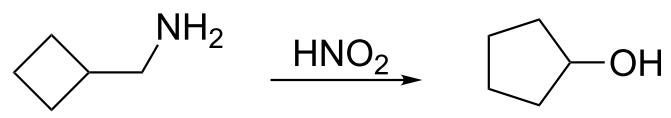

Esquema 1.4: Reordenamiento de Demjanov.

para investigar sobre las nitrosaciones y, dadas las escasas aplicaciones que tenían en otras industrias y su poca utilidad en síntesis orgánica, estas reacciones perdieron interés, como demuestra el número de publicaciones sobre la materia en la primera mitad del siglo XX (figura 1.2).

En los años 50 un descubrimiento volvió a atraer la atención de la comunidad científica hacia las reacciones de nitrosación. Dos toxicólogos británicos, John Barnes y Peter Magee, descubrieron que la dimetilnitrosamina, un nitrosocompuesto utilizado como disolvente, provoca cáncer. Unos años antes habían estudiado su toxicidad tras conocer que, después haber estado expuestos durante unas semanas a dimetilnitrosamina, los empleados de un laboratorio inglés habían contraído graves enfermedades hepáticas, llegando a fallecer uno de ellos. ${ }^{22}$ La forma en que el compuesto dañaba el hígado, con necrosis y hemorragias internas, les recordó los casos de envenenamiento con "Hierba de Santiago", una planta temida por los ganaderos de toda Europa. ${ }^{23}$ Casualmente, unas semanas después de su estudio, apareció un artículo que demostraba que animales a los que se les había suministrado durante un largo periodo de tiempo una pequeña cantidad no tóxica de extractos de Hierba de Santiago habían desarrollado cáncer. ${ }^{24}$ Magee y Barnes repitieron el mismo experimento con dimetilnitrosamina, obteniendo idéntico resultado: las ratas a las que habían administrado pequeñas dosis de dimetilnitrosamina durante semanas enfermaron con tumores cancerosos en el hígado. ${ }^{25} \mathrm{El}$ impacto de su trabajo hizo que científicos de todo el mundo comenzasen a estudiar las propiedades biológicas de otros nitrosocompuestos, descubriéndose casi siempre que eran igualmente peligrosos.

En 1964 se encontró una nueva fuente de nitrosocompuestos tras la muerte por cáncer hepático de varias ovejas en Noruega. El análisis de su pienso a base de harina de arenque demostró que el nitrito sódico utilizado como conservante había reaccionado con elementos del pescado formando nitrosaminas. ${ }^{26-28}$ 

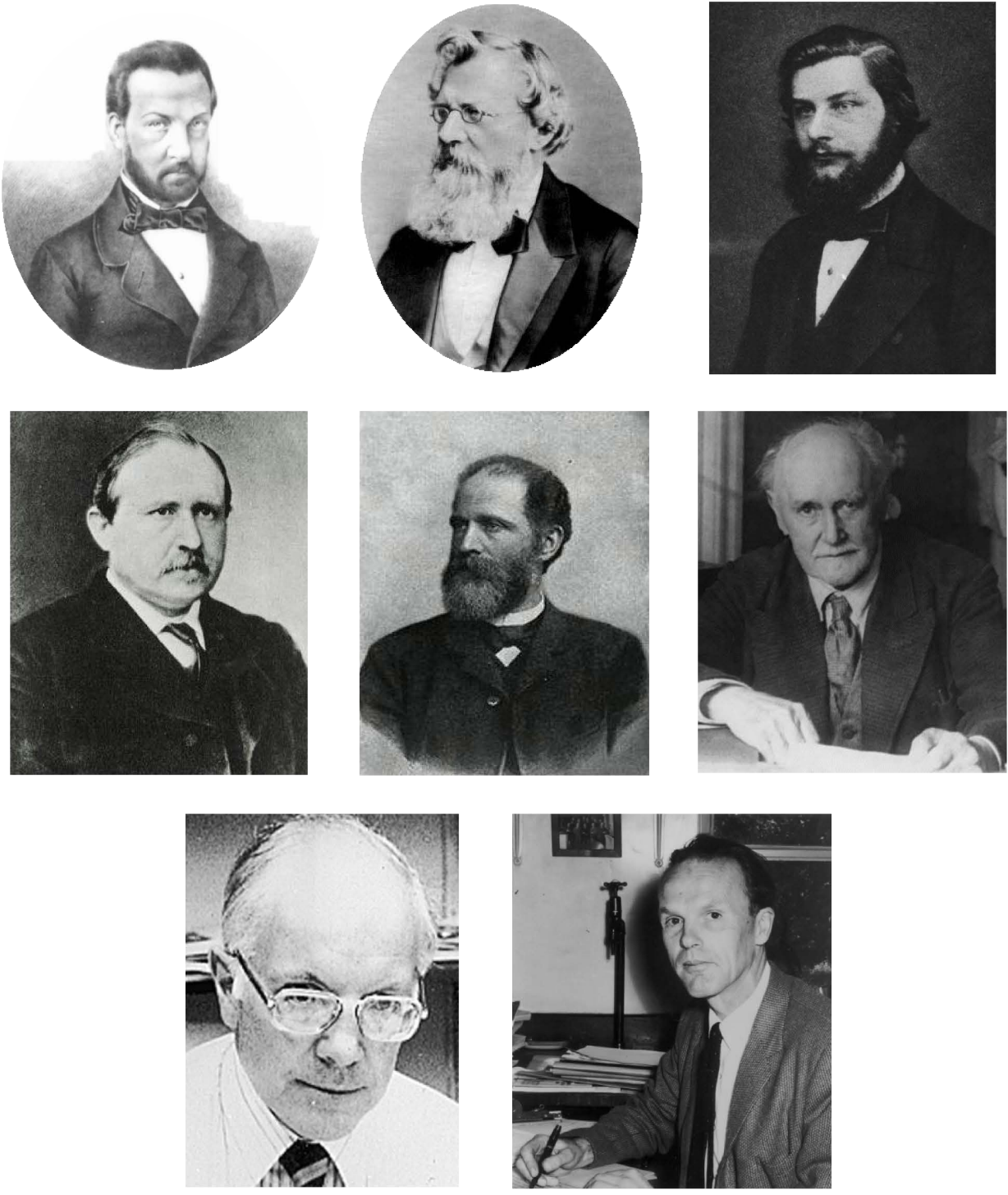

Figura 1.1: De izquierda a derecha y de arriba a abajo: Rafaelle Piria (1814-1865), August Wilhelm von Hoffman (1818-1892), William Henry Perkin (1838-1907); Johann Peter Griess (1829-1888), Viktor Meyer (1848-1897), Nikolai Yakovlevich Demjanov (18611938); Peter Noel Magee (1921-2000) y John Morrison Barnes (1913-1975). 


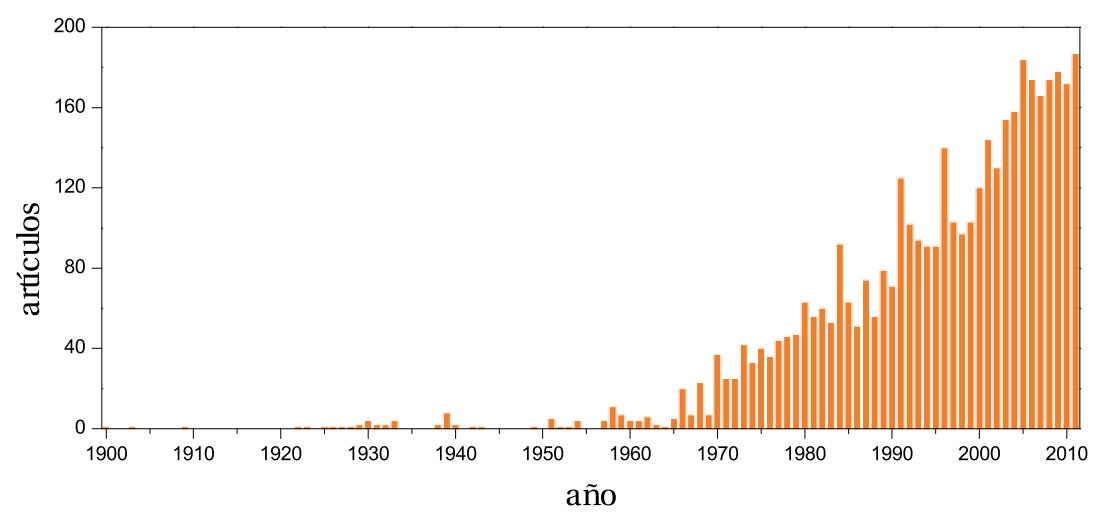

Figura 1.2: Número de publicaciones por año con el tema "nitrosación" según la página ISI web of knowledge. ${ }^{29}$

Como el uso del nitrito sódico estaba muy extendido en la industria alimentaria - como colorante, potenciador del sabor e inhibidor del crecimiento de la Clostridium botulinum, bacteria anaerobia responsable del botulismo- aumentó la preocupación por la exposición humana a los nitrosocompuestos y, en 1968, la Organización Mundial de la Salud organizó en Jamaica un congreso sobre el tema. En él se apremió a desarrollar un nuevo método de análisis puesto que los que había entonces, basados en el análisis colorimétrico de los nitrosocompuestos separados por cromatografía, no tenían la sensibilidad suficiente para determinar las pequeñas cantidades presentes en los alimentos. ${ }^{30} \mathrm{Al}$ poco tiempo, una empresa norteamericana, Thermo-Electron Corporation, presentó un dispositivo que sometía a pirólisis a los nitrosocompuestos que había separado por cromatografía. De esta forma, se descomponían emitiendo óxido de nitrógeno, que cuantificaba por medio de espectroscopía de infrarrojos. El aparato, denominado "Analizador de energía térmica" (TEA), era tan eficaz que inmediatamente se convirtió en un instrumento estándar. ${ }^{31}$

Tras el trabajo de Magee y Barnes fueron apareciendo nuevas fuentes de exposición humana a nitrosocompuestos. En 1965 se encontraron en el tabaco, ${ }^{32}$ en 1973 en el caucho de tetinas y chupetes, ${ }^{33}$ en 1977 en $\operatorname{cosméticos}^{34,35}$ y en 
1979 en la cerveza. ${ }^{36,37}$ También se demostró que el hecho de consumir nitrito sódico en la dieta podía hacer que los nitrosocompuestos se formasen en el propio aparato digestivo ${ }^{38}$ (condiciones ideales de $\mathrm{pH}$ y temperatura del estómago o catálisis por enzimas de los flujos digestivos ${ }^{39}$ ). Por ello, las agencias y organismos reguladores en el ámbito de la Ciencia y Tecnología alimentaria fueron elaborando normas ad hoc para reducir sus niveles. Así aparecieron reglas para limitar las cantidades permitidas de nitrito sódico en alimentos o para modificar el proceso de secado del tabaco y de tostado de la malta en la fabricación de cervezas. El grupo de Sidney Mirvish, ${ }^{40}$ en Estados Unidos, demostró que el ácido ascórbico dificulta el mecanismo de nitrosación por inhibición in vivo de nitrosocompuestos ${ }^{41}$ o por conversión de los agentes nitrosantes en el inocuo óxido nítrico. ${ }^{42}$ Pronto se demostró que el consumo de ácido ascórbico inhibía también la formación de nitrosocompuestos in vivo, reduciendo el cáncer en estudios epidemiológicos. Por ello, se estableció que a todo alimento que incluyese nitrito sódico como aditivo se le debería incorporar también una pequeña cantidad de ácido ascórbico u otro inhibidor (véase página 87).

En la actualidad el estudio de las reacciones y mecanismos de nitrosación ocupa diversas áreas científicas: los biólogos examinan los mecanismos de actuación de los nitrosocompuestos, ${ }^{43}$ los médicos hacen estudios epidemiológicos sobre personas y áreas de exposición ${ }^{44}$ y los químicos estudian los mecanismos de nitrosación y la forma de inhibirlos o bloquearlos. ${ }^{45}$

\subsection{Motivación del trabajo}

En todos esos años de historia, la química de la N-nitrosación (página 78) ha sido un área fructífera para la química física orgánica y la cinética química. Actualmente se entienden perfectamente muchas reacciones y, en muchos casos, se ha establecido la naturaleza de las especies nitrosantes efectivas, a menudo por procedimientos cinéticos.

En contraste, las reacciones de C-nitrosación (página 73) son mucho menos conocidas, debido en parte a la debilidad de los agentes nitrosantes como electrófilos y a la baja solubilidad de los sustratos, que dificultan mucho el 
<smiles>CCc1ccccc1</smiles><smiles>NCCc1ccccc1</smiles><smiles>NCCc1ccc(O)cc1</smiles><smiles>NCCc1c[nH]c2cc(O)ccc12</smiles><smiles>Nc1cc(N2CCCCC2)nc(N)[n+]1[O-]</smiles>

Figura 1.3: Sustratos cuya nitrosación se ha estudiado. De izquierda a derecha: etilbenceno, fenetilamina, tiramina, dopamina, serotonina y minoxidilo.

seguimiento de las cinéticas y el establecimiento de un mecanismo.

En la bibliografía apenas se encuentran trabajos donde se haya abordado la nitrosación de moléculas complejas que puedan ser objeto de C-y N-nitrosación simultánea. ${ }^{46} \mathrm{Y}$ eso a pesar de que el hombre está muy frecuentemente en contacto con sustratos con varios grupos nitrosables que pueden conducir a la formación de nitrosocompuestos potencialmente peligrosos. Dentro de esa categoría se encuentran algunos aminoácidos, lípidos y medicamentos.

Por esas razones se ha abordado el trabajo descrito en esa Memoria. Como objeto de estudio se ha elegido una serie de moléculas bioactivas con varios sitios nitrosables: etilbenceno, fenetilamina, tiramina, serotonina y minoxidilo (figura 1.3).

Las cinco primeras moléculas constituyen el grupo de las catecolaminas y compuestos relacionados. Ejercen importantes funciones en el organismo donde actúan como neurotransmisores, siendo frecuentes en numerosos alimentos. Por su parte, el minoxidilo es un fármaco antihipertensivo cuyo uso se ha popularizado en los últimos años para combatir la alopecia.

Además del problema que entraña la ingestión de estos compuestos por su posible interacción con agentes nitrosantes en el aparato digestivo, existe el riesgo de que alguna de estas moléculas neurotransmisoras (dopamina y serotonina, principalmente) puedan reaccionar con los nitratos/nitritos presentes en el fluido cerebroespinal, especialmente en el caso de alguna enfermedad neurológica, cuando la concentración de nitrito aumenta y el pH del medio puede facilitar mecanismos de nitrosación. ${ }^{47}$ 


\section{Capítulo 2}

\section{Informe bibliográfico}

\section{1. Ácido nitroso y nitritos}

El ácido nitroso, $\mathrm{HNO}_{2}$, es un ácido inorgánico monoprótico conocido desde la Edad Media. Fue descrito por primera vez en el siglo XIII por el falso Geber, un famoso alquimista anónimo probablemente de origen español en su libro De inventione veritatis. ${ }^{48}$ A partir de vitriolo de Chipre $\left(\mathrm{CuSO}_{4}\right)$, salitre y agua obtenía ácido nitroso según las siguientes reacciones: ${ }^{49}$

$$
\begin{gathered}
2 \mathrm{CuSO}_{4} \rightarrow 2 \mathrm{CuO}+2 \mathrm{SO}_{2}+\mathrm{O}_{2} \\
\mathrm{KNO}_{3}+\mathrm{SO}_{2} \rightarrow \mathrm{KO}_{3} \mathrm{SONO} \\
2 \mathrm{KO}_{3} \mathrm{SONO}_{2} \rightarrow \mathrm{N}_{2} \mathrm{O}_{3}+\mathrm{K}_{2} \mathrm{SO}_{4}+\mathrm{SO}_{3} \\
\mathrm{~N}_{2} \mathrm{O}_{3}+\mathrm{H}_{2} \mathrm{O} \rightarrow 2 \mathrm{HNO}_{2}
\end{gathered}
$$

El ácido nitroso es un compuesto que no puede ser aislado como compuesto puro, ${ }^{50}$ ya que se descompone en ácido nítrico, agua y óxido nítrico: ${ }^{51}$

$$
3 \mathrm{HNO}_{2} \rightleftharpoons \mathrm{HNO}_{3}+\mathrm{H}_{2} \mathrm{O}+2 \mathrm{NO}
$$

La constante de este equilibrio fue determinada por Gilbert Lewis hace más de un siglo: ${ }^{52}$

$$
K=\frac{\left[\mathrm{H}^{+}\right]\left[\mathrm{NO}_{3}^{-}\right] p_{\mathrm{NO}}^{2}}{\left[\mathrm{HNO}_{2}\right]^{3}}=29 \mathrm{~atm}^{2} \mathrm{M}^{-1}\left(25^{\circ} \mathrm{C}\right)
$$




\section{2 | Ácido nitroso y nitritos}

También se determinó el mecanismo de descomposición, que consiste en la formación del anhídrido nitroso y su posterior transformación, seguida de hidrólisis: $^{51}$

$$
\begin{array}{rll}
4 \mathrm{HNO}_{2} & \rightleftharpoons 2 \mathrm{~N}_{2} \mathrm{O}_{3}+2 \mathrm{H}_{2} \mathrm{O} \\
2 \mathrm{~N}_{2} \mathrm{O}_{3} & \rightleftharpoons & \mathrm{N}_{2} \mathrm{O}_{4}+2 \mathrm{NO} \\
\mathrm{N}_{2} \mathrm{O}_{4}+\mathrm{H}_{2} \mathrm{O} & \stackrel{k_{\mathrm{d}}}{\rightleftharpoons} & 2 \mathrm{HNO}_{3}
\end{array}
$$

Si la hidrólisis es la etapa limitante, se puede deducir la ecuación teórica de velocidad a partir del mecanismo anterior:

$$
v=k_{d} \frac{\left[\mathrm{HNO}_{2}\right]^{4}}{P_{\mathrm{NO}}^{2}}-k_{f}\left[\mathrm{HNO}_{3}\right]\left[\mathrm{H}^{+}\right]\left[\mathrm{NO}_{3}^{-}\right]
$$

Esta ecuación explica por qué en procesos industriales, para evitar la descomposición del ácido nitroso, se trabaja en una atmósfera de óxido nítrico. Una presión parcial de 1 atm garantiza la supresión del proceso.

También el hecho de que el producto de reacción sea un gas con baja solubilidad en agua $\left(1,93 \cdot 10^{-3} \mathrm{M} \mathrm{atm}^{-1}, 23\right.$ veces menor que el oxígeno molecular) hace que la velocidad de descomposición dependa de la agitación del medio. ${ }^{53}$ Otro factor caracterizado es la influencia de la temperatura en la velocidad:

$$
\log _{10} k_{d}=22,65-\frac{6250}{T} \mathrm{~atm}^{2} \mathrm{M}^{-3} \mathrm{~min}^{-1}
$$

En condiciones ácidas, la descomposición del ácido nitroso a lo largo del tiempo aumenta de complejidad, ya sea por reacciones de protonación de los compuestos implicados:

$$
\begin{gathered}
\mathrm{HNO}_{2}+\mathrm{H}^{+} \rightleftharpoons \mathrm{H}_{2} \mathrm{NO}_{2}^{+} \\
\mathrm{N}_{2} \mathrm{O}_{3}+2 \mathrm{H}^{+} \rightarrow 2 \mathrm{NO}^{+}+\mathrm{H}_{2} \mathrm{O}
\end{gathered}
$$

o por reacciones de los productos gaseosos de la descomposición:

$$
\begin{gathered}
\mathrm{N}_{2} \mathrm{O}_{3} \rightarrow \mathrm{NO}+\mathrm{NO}_{2} \\
2 \mathrm{NO}+\mathrm{O}_{2} \rightarrow 2 \mathrm{NO}_{2} \\
2 \mathrm{NO}_{2}+\mathrm{H}_{2} \mathrm{O} \rightleftharpoons \mathrm{HNO}_{2}+\mathrm{HNO}_{3}
\end{gathered}
$$




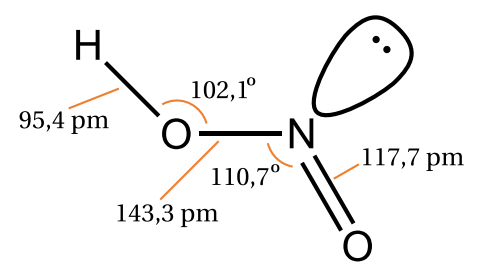

Figura 2.1: Estructura del ácido nitroso.

Debido a su descomposición, el ácido nitroso no se puede adquirir de forma comercial, pero se prepara fácilmente in situ por acidificación de cualquier nitrito con un ácido mineral: ${ }^{54}$

$$
\mathrm{NaNO}_{2}+\mathrm{HCl} \stackrel{a q}{\longrightarrow} \mathrm{HNO}_{2}+\mathrm{NaCl}
$$

Se pueden preparar disoluciones libres de otros iones escogiendo combinaciones de reactivos cuyas sales sean insolubles:

$$
\begin{gathered}
\mathrm{Ba}\left(\mathrm{NO}_{2}\right)_{2}+\mathrm{H}_{2} \mathrm{SO}_{4} \stackrel{a q}{\longrightarrow} 2 \mathrm{HNO}_{2}+\mathrm{BaSO}_{4} \downarrow \\
\mathrm{AgNO}_{2}+\mathrm{HCl} \stackrel{a q}{\longrightarrow} \mathrm{HNO}_{2}+\mathrm{AgCl} \downarrow
\end{gathered}
$$

El ácido nitroso gaseoso se puede preparar mezclando agua, óxido nítrico y dióxido de nitrógeno en la misma proporción:

$$
2 \mathrm{HNO}_{2}(\mathrm{~g}) \rightleftharpoons \mathrm{H}_{2} \mathrm{O}(\mathrm{g})+\mathrm{NO}(\mathrm{g})+\mathrm{NO}_{2}(\mathrm{~g})
$$

Como $K_{p}=8,0 \cdot 10^{5} \mathrm{~N} \mathrm{~m}^{-2}$, a temperatura ambiente y 7,9 atm, una presión parcial $p_{x}=2,63$ atm de reactivos permite obtener tan sólo $p_{\mathrm{HNO}_{2}}=0,0047 \mathrm{~atm}$ de ácido nitroso.

La figura 2.1 muestra la estructura de la molécula gaseosa de ácido nitroso determinada mediante espectroscopía de microondas. Corresponde a la forma trans del compuesto. Existe también la forma cis, que al igual que la trans es plana, pero más inestable. Medidas realizadas con infrarrojos sugieren que la forma trans es $2,3 \mathrm{~kJ} \mathrm{~mol}^{-1}$ más estable que la forma cis a temperatura ambiente. 


\section{4 | Ácido nitroso y nitritos}

\begin{tabular}{cc}
\hline$T /{ }^{\circ} \mathrm{C}$ & $\mathrm{pK}_{\mathrm{a}}$ \\
\hline 15 & 3,224 \\
20 & 3,177 \\
25 & 3,138 \\
35 & 3,100 \\
\hline
\end{tabular}

Tabla 2.1: Constantes de acidez del ácido nitroso en función de la temperatura. ${ }^{55}$

A pesar del enlace simple central, la energía de activación del cambio es relativamente alta, $45,2 \mathrm{~kJ} \mathrm{~mol}^{-1}$, por lo que la forma trans es más abundante en condiciones normales.

El ácido nitroso es bastante débil. Su $\mathrm{pK}_{\mathrm{a}}$ (tabla 2.1) se encuentra entre los del ácido acético $(4,75)$ y cloroacético $(2,85)$ y es similar a los del ácido fórmico $(3,75)$ y sulfanílico $(3,23)$. Ello implica, que a pHs superiores a 5 , todo el ácido nitroso está desprotonado.

Los nitritos se suelen preparar por reducción suave de nitratos, utilizando carbono, hierro o plomo. El potencial estándar de reducción para la reacción:

$$
\mathrm{NO}_{3}^{-}+2 \mathrm{H}^{+}+2 \mathrm{e}^{-} \rightleftharpoons \mathrm{NO}_{2}^{-}+\mathrm{H}_{2} \mathrm{O}
$$

es $E^{\circ}=0,835 \mathrm{~V}$. A escala industrial, el nitrito sódico se prepara por reacción entre una mezcla de óxidos de nitrógeno y una disolución de carbonato sódico o hidróxido sódico. ${ }^{56}$ La fracción molar de dióxido de nitrógeno se denomina grado de oxidación $(\mathrm{OD})$ :

$$
\frac{\left[\mathrm{NO}_{2}\right]}{[\mathrm{NO}]+\left[\mathrm{NO}_{2}\right]} \times 100=\mathrm{OD}
$$

Cuando el grado de oxidación es menor del $50 \%$, la reacción que ocurre es la siguiente:

$$
2 \mathrm{NaOH}+\mathrm{NO}_{2}+\mathrm{NO} \rightarrow 2 \mathrm{NaNO}_{2}+\mathrm{H}_{2} \mathrm{O}
$$


El exceso de monóxido de nitrógeno no reacciona pero el oxígeno ambiental lo oxida a dióxido de nitrógeno. A OD $>50 \%$ y una presión parcial del oxígeno alta, las siguientes reacciones, más lentas, también tienen lugar:

$$
\begin{gathered}
2 \mathrm{NaOH}+2 \mathrm{NO}_{2} \rightarrow \mathrm{NaNO}_{3}+\mathrm{NaNO}_{2}+\mathrm{H}_{2} \mathrm{O} \\
2 \mathrm{NaOH}+3 \mathrm{NO}_{2} \rightarrow 2 \mathrm{NaNO}_{3}+\mathrm{NO}+\mathrm{H}_{2} \mathrm{O}
\end{gathered}
$$

Con carbonato sódico, la reacción transcurre de la misma manera. En la práctica, la formación de nitrato no puede ser completamente bloqueada incluso en OD inferiores al $50 \%$. La forma de evitar al máximo la aparición de nitrato sódico consiste en mantener un grado de oxidación menor al $50 \%$ y un $\mathrm{pH}$ superior a 8 , para impedir la descomposición del ácido nitroso. De esta forma se consigue un nitrito sódico de pureza superior al $99 \%$ y con un contenido de nitrato sódico de tan solo un $0,6 \%$.

Los demás nitritos se preparan de la misma forma, excepto aquellos cuyos hidróxidos son caros, como el nitrito potásico, que se prepara por reducción.

El ángulo $\widehat{\mathrm{ONO}}$ de las moléculas de nitritos de numerosos metales ( $\mathrm{Li}, \mathrm{Na}$, $\mathrm{K}, \mathrm{Cs}, \mathrm{Ag}, \mathrm{Tl}, \mathrm{Ba}$ ) varía entre 116 y $132^{\circ}$, con longitudes del enlace $\mathrm{N}-\mathrm{O}$ comprendidas entre 113 y $123 \mathrm{pm} .{ }^{50}$ Los nitritos de metales menos básico como $\mathrm{Co}(\mathrm{II}), \mathrm{Ni}(\mathrm{II})$ y Hg(II) tienen colores intensos; en ellos el enlace entre el metal y el resto de la molécula probablemente sea de tipo covalente. La solubilidad de los nitritos en agua varía considerablemente con el catión, así como su estabilidad térmica (tabla 2.2).

\subsubsection{Fuentes de exposición a los nitritos}

La principal vía de exposición humana a los nitritos es oral. Otras vías de exposición son excepcionales dado que los nitritos no pueden ser absorbidos por la piel y que la inhalación involuntaria es muy complicada. ${ }^{57}$ Dos son las fuentes principales de exposición a los nitritos: su generación por bacterias y su empleo como aditivos alimentarios.

Existen dos tipos de bacterias generadoras de nitritos. Unas son las bacterias nitrificantes, de los géneros nitrosomonas y nitrosococcus, que forman parte del 


\section{6 |Ácido nitroso y nitritos}

\begin{tabular}{|c|c|c|}
\hline Nitrito & $\begin{array}{c}\text { Solubilidad } \\
\text { / g/100 ml }\end{array}$ & $\begin{array}{l}\text { Estabilidad térmica } \\
\qquad /{ }^{\circ} \mathrm{C}\end{array}$ \\
\hline $\mathrm{NaNO}_{2}$ & $85,5^{a}$ & 284 (p.f.) $^{c}$ \\
\hline $\mathrm{KNO}_{2}$ & $314^{b}$ & 441 (p.f.) $^{c}$ \\
\hline $\mathrm{AgNO}_{2}$ & 0,41 & 140 \\
\hline $\mathrm{Ba}\left(\mathrm{NO}_{2}\right)_{2}$ & 72,8 & 220 \\
\hline $\mathrm{Hg}\left(\mathrm{NO}_{2}\right)_{2}$ & & 75 \\
\hline $\mathrm{NH}_{4} \mathrm{NO}_{2}$ & & $60^{d}$ \\
\hline \multicolumn{3}{|c|}{${ }^{a}$ Higroscópico } \\
\hline \multicolumn{3}{|c|}{${ }^{b}$ Delicuescente } \\
\hline \multicolumn{3}{|c|}{${ }^{c}$ Funden sin descomposición } \\
\hline
\end{tabular}

Tabla 2.2: Solubilidad en agua a $25^{\circ} \mathrm{C}$ y estabilidad térmica de diferentes nitritos.

ciclo del nitrógeno convirtiendo las sales de amonio del suelo y las aguas en nitrito, siendo la principal fuente de nitritos en el agua, especialmente si procede de zonas agrícolas con gran uso de fertilizantes ricos en nitratos de amonio. ${ }^{58}$ Otras son las bacterias desnitrificantes (Actinomyces naeslundii, Veillonella atypica, Clostridium ramosum, entre otras) presentes en la boca y en el intestino, donde reducen los nitratos procedentes de los alimentos y el agua a nitritos. ${ }^{59,60}$ El agua de zonas agrícolas y productos como las verduras o los tubérculos son ricos en nitratos, por lo que su consumo aumenta la cantidad de nitritos de forma natural.

El uso del nitrito sódico como aditivo se remonta siglos atrás, ya que en carnes y otros alimentos actúa como colorante, potenciador del sabor, antioxidante y antimicrobiano.

Su utilidad como colorante se debe a que reacciona con la mioglobina de las fibras musculares. Esta proteína contiene un átomo de hierro dentro de un grupo hemo, que proporciona a la carne su característico color rojo. En condiciones normales, la proteína capta una molécula de oxígeno, adquiriendo un color rojo 


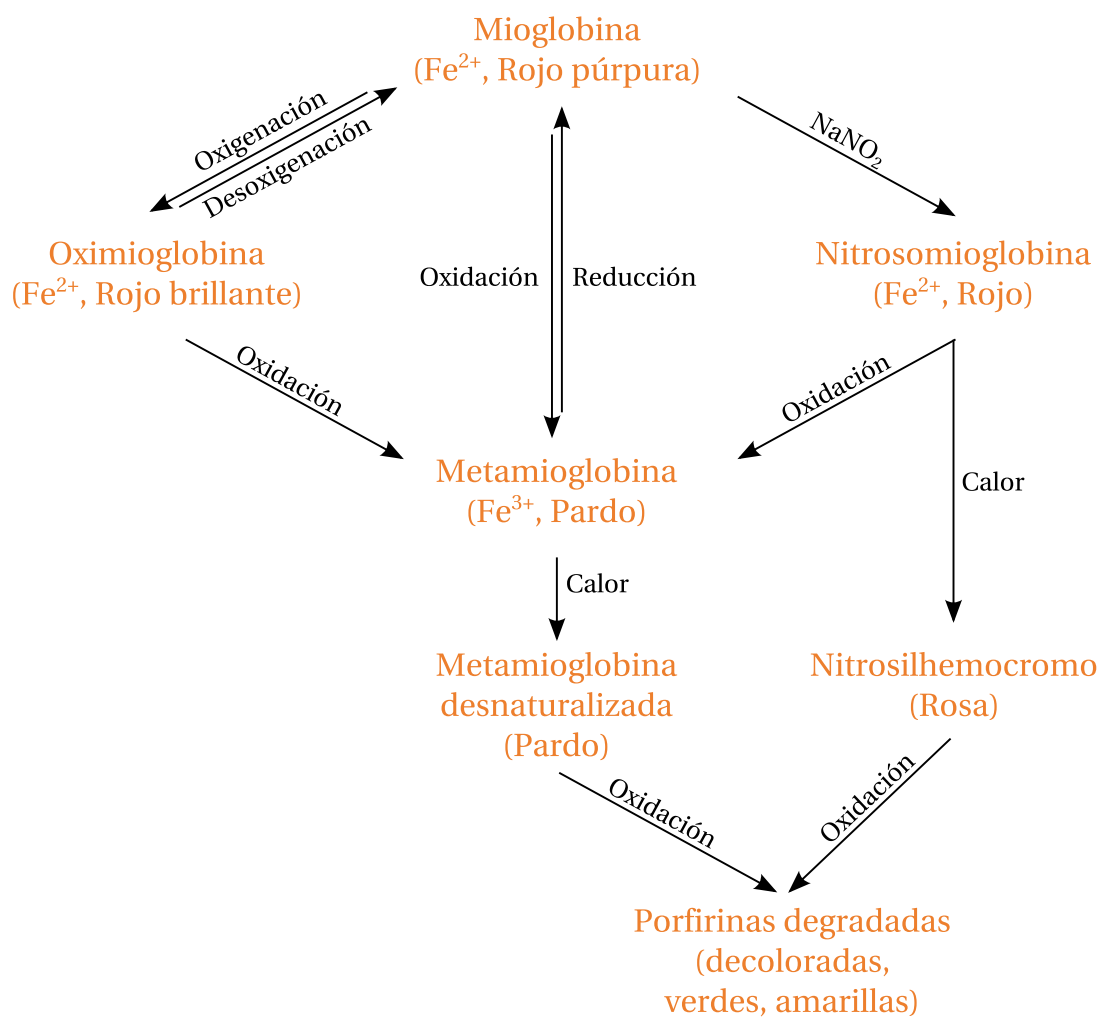

Esquema 2.1: Transformaciones químicas de la mioglobina.

brillante (oximioglobina) y la transporta dentro del músculo. ${ }^{61} \mathrm{Al}$ cortar la carne, la mioglobina queda expuesta al oxígeno del aire que oxida su átomo de hierro (esquema 2.1) cambiando su color a un antiestético color pardo (metamioglobina), que el consumidor asocia a carne en malas condiciones. Para evitarlo se puede envasar la carne en una atmósfera rica en oxígeno que favorece la formación de oximioglobina, utilizar un antioxidante o añadir nitrito sódico que, al descomponerse en óxido nítrico, se une al hierro del grupo hemo haciendo que la proteína, nitrosomioglobina, adquiera un color rojo duradero. ${ }^{62}$ Cuando se calienta la carne por encima de $60{ }^{\circ} \mathrm{C}$, este pigmento se desnaturaliza y se convierte en el nitrosilhemocromo que da como resultado el color rosado típico 


\section{8 | Ácido nitroso y nitritos}

de las salchichas cocidas. Tanto el nitrosilhemocromo como la metamioglobina pueden seguir oxidándose con el tiempo y generar colorantes que van del amarillo al verde.

La principal aplicación de los nitritos en la industria alimentaria es como conservantes ya que inhiben el desarrollo de bacterias a partir de sus esporas. De esta forma los nitritos eliminan el peligro de contaminación con Clostridium botulinum, bacteria esporogénica que provoca el botulismo. ${ }^{63}$ Este organismo segrega una toxina que está considerada uno de los compuestos más venenosos, dado que $1 \mathrm{mg}$ puede matar a más de un millón de conejillos de indias. Al ser anaerobia, era frecuente su aparición en embutidos, conservas y alimentos envasados al vacío. El uso de nitrito y otras técnicas de esterilización han hecho que esta bacteria actualmente sólo aparezca en algunas ocasiones en conservas domésticas. En medicina estética, su toxina se conoce como Botox.

La exposición a nitritos y nitratos está muy regulada. Actualmente se permite 0,5 mg/l de nitritos y $50 \mathrm{mg} / \mathrm{l}$ de nitratos en el agua potable (Directiva 98/83/CE y Real Decreto 140/2003). ${ }^{64,65}$ Como aditivo (el nitrito potásico recibe el código E249 y el sódico E250) se autorizan $50 \mathrm{mg} / \mathrm{kg}$ en productos cárnicos no tratados por calor, curados o desecados, $100 \mathrm{mg} / \mathrm{kg}$ en productos cárnicos enlatados y foie gras y $175 \mathrm{mg} / \mathrm{kg}$ en productos curados (Directiva 95/2/CE). ${ }^{66}$ Según la OMS, la ingestión diaria admisible de nitritos y nitratos en $\mathrm{mg}$ por $\mathrm{kg}$ de peso corporal es de 0,07 y 3,7 respectivamente. ${ }^{67}$

\subsubsection{Los nitritos en el cuerpo humano}

Hasta hace una década se pensaba que los nitritos y nitratos, ya sea ingeridos en la dieta o como residuos del metabolismo del óxido nítrico, carecían de utilidad alguna para el organismo. Sin embargo en los últimos años se ha demostrado que el cuerpo humano los utiliza para generar óxido nítrico de forma alternativa a la NO sintasa. ${ }^{68}$

En 1998, los estadounidenses Robert Furchgott, Louis Ignarro y Ferid Murad recibieron el premio Nóbel por demostrar que el óxido nítrico es una de las pocas moléculas gaseosas que el cuerpo humano utiliza como molécula señalizadora. El NO actúa como neurotransmisor en el cerebro, regulador del sistema cardio- 


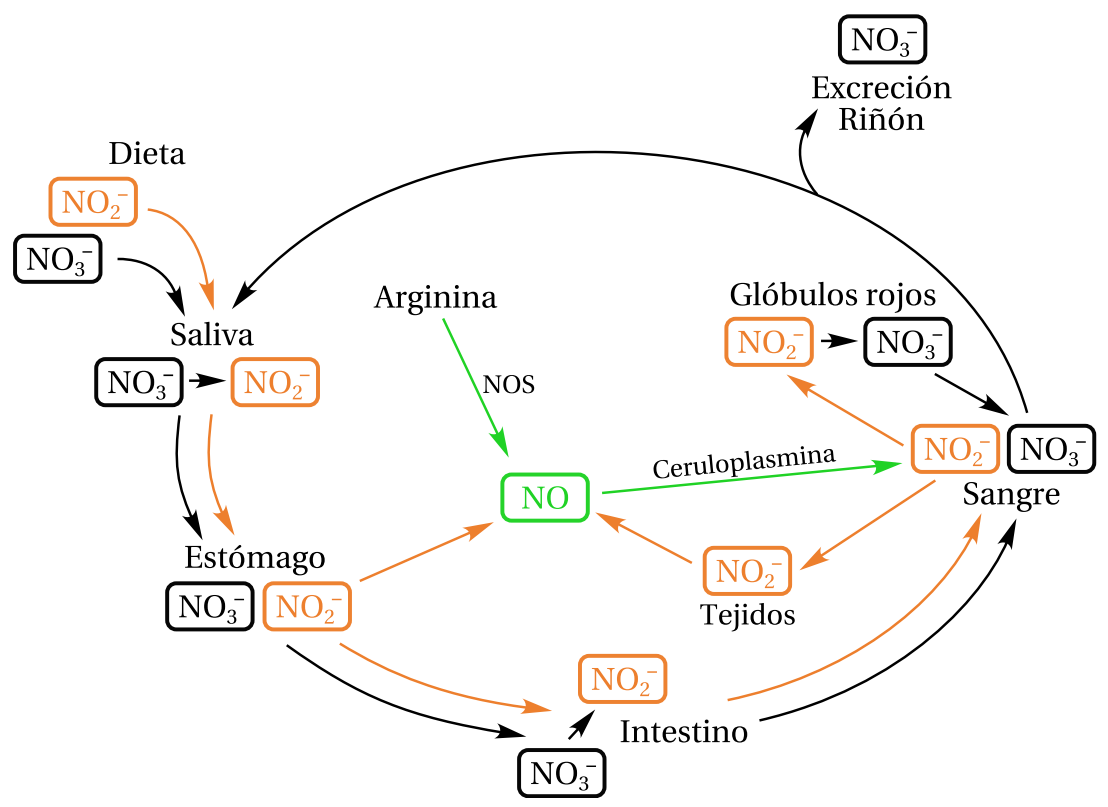

Esquema 2.2: Ciclo de los nitritos y nitratos en el cuerpo humano. Las flechas de color negro representan la circulación del nitrato en el organismo, las flechas de color naranja, la del nitrito y las flechas de color verde, la del óxido nítrico.

vascular $^{69}$ y en las defensas, que lo emplean para destruir microorganismos utilizando el NO para atacar ADN, proteínas y componentes de la pared celular. ${ }^{70}$ Por eso se emplean habitualmente en medicina compuestos que liberan óxido nítrico, como la nitroglicerina o el nitrito de amilo (página 65), o bien favorecen su liberación, como el sildenafilo o el taladafilo.

Generalmente el cuerpo humano genera NO con ayuda de la óxido nítrico sintasa (NOS) que transforma la arginina en óxido nitroso y citrulina. De forma análoga a la respiración y fermentación celular, cuando la célula no tiene suficiente oxígeno para poder sintetizar óxido nítrico mediante la enzima NOS, utiliza la ruta alternativa del nitrato/nitrito (esquema 2.2). ${ }^{71}$ Esta ruta aprovecha el nitrito que se encuentra almacenado en la sangre procedente de la dieta y de la reducción del nitrato por las bacterias presentes en la saliva y lo reduce de 


\section{0 | Ácido nitroso y nitritos}

varias formas a óxido nítrico:

- Por medio de la mioglobina muscular:

$$
\mathrm{NO}_{2}^{-}+\mathrm{Fe}^{2+}+\mathrm{H}^{+} \rightarrow \mathrm{NO}+\mathrm{Fe}^{3+}+\mathrm{OH}^{-}
$$

- Con la enzima xantina oxidorreductasa:

$$
\mathrm{NO}_{2}^{-}+\mathrm{Mo}^{4+}+\mathrm{H}^{+} \rightarrow \mathrm{NO}+\mathrm{Mo}^{5+}+\mathrm{OH}^{-}
$$

- Por reacciones entre el nitrito y compuestos reductores presentes en la sangre, como ácido ascórbico (Asc) o polifenoles (Ph-OH):

$$
\begin{gathered}
\mathrm{H}^{+}+\mathrm{NO}_{2}^{-} \rightleftharpoons \mathrm{HNO}_{2} \\
2 \mathrm{HNO}_{2}+\mathrm{Asc} \rightarrow 2 \mathrm{NO}+\text { dehidroAsc }+2 \mathrm{H}_{2} \mathrm{O} \\
\mathrm{Ph}-\mathrm{OH}+\mathrm{HNO}_{2} \rightarrow \mathrm{Ph}-\mathrm{O}^{-}+\mathrm{NO}+\mathrm{H}_{2} \mathrm{O}
\end{gathered}
$$

De igual forma, el NO no utilizado se convierte otra vez en nitrito con ayuda de la enzima ceruloplasmina, presente en la sangre y en los tejidos.

$$
\begin{gathered}
\mathrm{NO}+\mathrm{Cu}^{2+} \rightarrow \mathrm{NO}^{+}+\mathrm{Cu}^{+} \\
\mathrm{NO}^{+}+\mathrm{H}_{2} \mathrm{O} \rightarrow \mathrm{HNO}_{2}+\mathrm{H}^{+} \\
\mathrm{HNO}_{2} \rightleftharpoons \mathrm{H}^{+}+\mathrm{NO}_{2}^{-}
\end{gathered}
$$

Este nitrito se acumula para convertirse de nuevo en NO cuando sea necesario. Si hay demasiado nitrito en sangre, los glóbulos rojos lo oxidan a nitrato mediante su hemoglobina $(\mathrm{Hb})$ para que pueda ser excretado en el riñón:

$$
4 \mathrm{NO}_{2}^{-}+4 \mathrm{HbO}_{2}^{2+}+4 \mathrm{H}^{+} \rightarrow 4 \mathrm{NO}_{3}^{-}+4 \mathrm{Met}-\mathrm{Hb}^{3+}+2 \mathrm{H}_{2} \mathrm{O}+\mathrm{O}_{2}
$$

Así, los niveles de nitrito en el plasma sanguíneo se mantienen constantes en el rango de 20 - $40 \mu \mathrm{M}$. Los niveles de nitrato son menores: 50 - $300 \mathrm{nM}$. Las personas que hacen ejercicio a menudo tienen mayor actividad de la enzima NOS y a la vez mayores niveles de nitrito y nitrato en sangre. 


\subsubsection{Análisis de nitritos en agua}

Debido al potencial peligro de los nitritos, su frecuencia e importancia económica y biológica, se han desarrollado multitud de métodos para el análisis cualitativo y cuantitativo de muestras.

Al principio, la cantidad de nitrito que había en una muestra se conocía añadiéndole hidroxilamina o yoduro. De esta forma, el nitrito se reducía a nitrógeno que se recogía y se medía. ${ }^{72}$ En 1879, Peter Griess, consciente de la poca precisión y sensibilidad del método gasométrico, propuso utilizar las reacciones de diazotación que había descubierto (página 34) para la cuantificación de nitritos. ${ }^{73}$ La mezcla que sugirió, ácido sulfanílico y 1-naftilamina en presencia de ácido sulfúrico, se denominó reactivo de Griess. En 1889, Lajos Ilosvay, profesor de química en la Universidad de Budapest, perfeccionó el reactivo sustituyendo el ácido sulfúrico por ácido acético, que reducía la descomposición del nitrito a la vez que aceleraba la velocidad de reacción. ${ }^{74}$ Su mezcla, llamada posteriormente reactivo de Griess-Ilosvay, se hizo muy popular y actualmente se sigue utilizado rutinariamente en multitud de áreas. ${ }^{75}$ Un ejemplo es el procedimiento oficial de la AOAC (Association of Official Analytical Chemists) para determinar nitritos en la carne. Consiste en homogeneizar y extraer el nitrito de la muestra, diluir 100 veces, calentar durante una hora para eliminar interferencias y tras neutralizar, aplicar el reactivo de Griess-Ilosvay. ${ }^{76} \mathrm{El}$ reactivo incluso se utiliza en el análisis cuantitativo de nitratos, previa reducción a nitritos mediante zinc. Una crítica habitual al método de Griess es que para poder medir el nitrito requiere de cuatro reacciones en las que participan compuestos muy inestables. En primer lugar, a partir de nitrito se forma un agente nitrosante que nitrosa la 1-naftilamina. A continuación, ésta se reordena en un diazocompuesto y, por último, se produce la reacción de copulación entre el diazocompuesto y el ácido sulfanílico (página 80). Esto puede producir una reducción de la exactitud que ha promovido la búsqueda de nuevos reactivos para la reacción u otros métodos de análisis basados en nuevos sistemas.

Existen técnicas que miden el nitrito directamente por conductimetría o electrocatálisis. Son métodos incómodos que requieren una separación previa del nitrito por cromatografía. Esta condición excluye la mayor parte de muestras 


\section{$52 \mid$ Ácido nitroso y nitritos}

de origen biológico, que tienden a precipitar en la columna, a no ser que se sometan a otra purificación previa. También se puede analizar el nitrito directamente por espectroscopía ultravioleta o por infrarroja. Sin embargo, además de la alta pureza que requieren, debido a su baja absortividad molar, no se pueden medir concentraciones diluidas por debajo de $1 \mathrm{mM}$.

La alternativa más sencilla a la reacción de Griess es cuantificar el nitrito por medio de una reacción de nitrosación. Presenta la ventaja de que existen un gran número de sustratos nitrosables, cada uno con propiedades diferentes que permiten utilizar multitud de técnicas para la medida. Así, se puede utilizar difenilamina para medir mediante polarografía de pulso diferencial; 2,4,6-triaminopirimidina, mepazina, 2-mercaptoetanol o ácido cromotrópico, entre otros, para el uso de colorimetría; diaminonaftaleno para fluorometría, o los compuestos volátiles 1-hidrazinoftalazina o $p$-bromoanilina para la determinación mediante cromatografía de gases. Esta variedad de técnicas permite esquivar interferencias, problemas de purificación y descomposiciones. Sin embargo, el principal inconveniente de estas reacciones es que requieren medios ácidos que favorecen la descomposición del nitrito en óxido nitroso (página 41), aunque cada técnica tiene fijadas unas condiciones de trabajo que lentifican dicho proceso.

Una forma de evitar los inconvenientes de la descomposición es nitrosar compuestos reductores como el ion yoduro o el ácido ascórbico que convierten todo el nitrito en óxido nitroso, que se puede medir luego por quimioluminiscencia. Son técnicas de tres pasos, puesto que después de la nitrosación del reductor existe una reacción de transferencia electrónica interna que forma óxido nítrico. Otro reductor empleado es la hidroquinona, que permite cuantificar el óxido nítrico por neumatoamperometría.

Existen otros métodos para el análisis cuantitativo del nitrito, pero son poco frecuentes y tienen menos aplicaciones. Algunos están basados en la capacidad del nitrito de catalizar algunas reacciones, otros utilizan enzimas biológicas, como la nitritorreductasa para obtener amoniaco y cuantificarlo o, incluso, se ha desarrollado un método de cinco pasos, basado en el de Griess que, tras la copulación, emplea sulfato de amonio y cobre (II) para formar un triazol fluorescente. Aunque se puede escoger entre infinidad de métodos en función del 


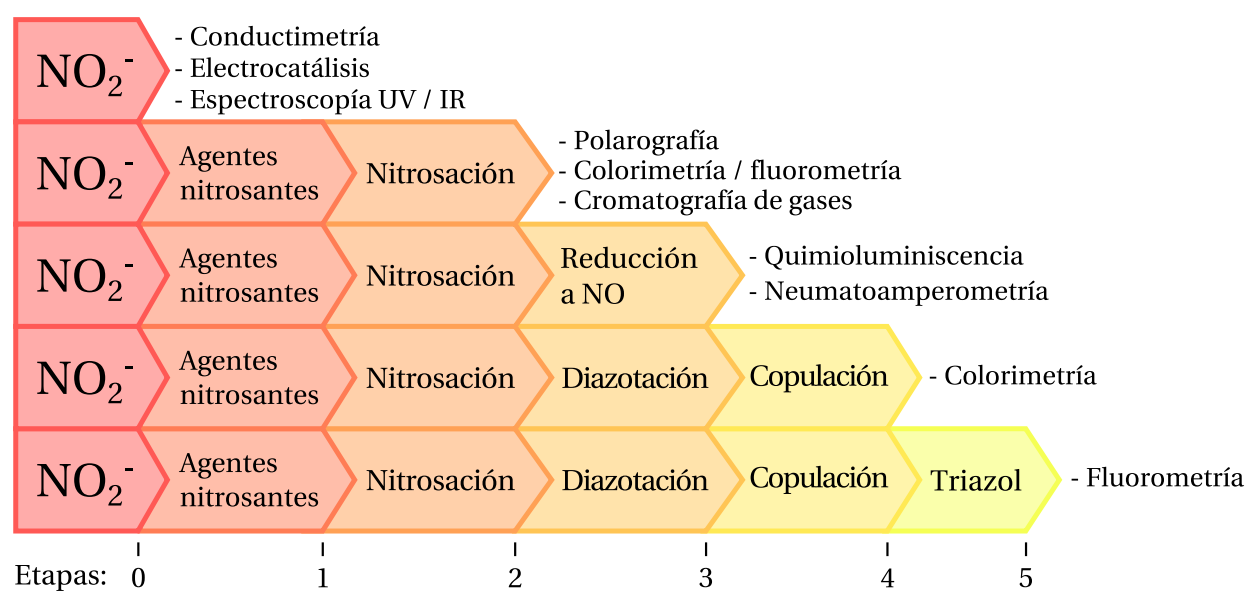

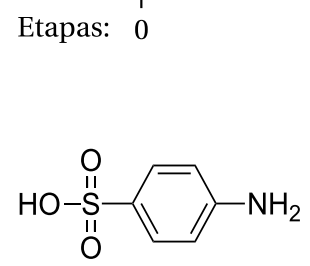

ác. sulfanílico<smiles>Nc1cccc2ccccc12</smiles>

1-naftilamina<smiles>Nc1cc(N)nc(N)n1</smiles>

triaminopirimidina<smiles>NNc1nncc2ccccc12</smiles>

1-hidrazinoftalazina<smiles>CN1CCCCC1CCN1c2ccccc2Sc2ccccc21</smiles><smiles>Nc1cccc2cccc(N)c12</smiles><smiles>O=S(=O)(O)c1cc(O)c2c(O)cc(S(=O)(=O)O)cc2c1</smiles>

ác. cromotrópico

difenilamina<smiles>Nc1ccc(Br)cc1</smiles>

Figura 2.2: Técnicas de análisis del ion nitrito según el número de etapas y reactivos empleados. 
54 | Ácido nitroso y nitritos

\begin{tabular}{lrlr}
\hline \multicolumn{1}{c}{ Método } & \multicolumn{1}{c}{$\mathrm{LD}$} & \multicolumn{1}{c}{ Método } & $\mathrm{LD}$ \\
\hline Absorción óptica directa & $1,0 \mathrm{mM}$ & Catálisis de reacciones & $0,4 \mu \mathrm{M}$ \\
Cromatografía en papel & $0,2 \mathrm{mM}$ & Conductimetría & $0,2 \mu \mathrm{M}$ \\
Enzimas biológicas & $0,1 \mathrm{mM}$ & Cromatografía indirecta & $0,2 \mu \mathrm{M}$ \\
Formación de complejos & $40,0 \mu \mathrm{M}$ & Captura de electrones & $0,1 \mu \mathrm{M}$ \\
Electrocatálisis & $10,0 \mu \mathrm{M}$ & Quimioluminiscencia & $0,1 \mu \mathrm{M}$ \\
Absorción óptica de NOX & $4,0 \mu \mathrm{M}$ & Resonancia Raman & $0,1 \mu \mathrm{M}$ \\
Neumatoamperometría & $4,0 \mu \mathrm{M}$ & Extracción del disolvente & $40,0 \mathrm{nM}$ \\
Electrodos & $1,0 \mu \mathrm{M}$ & Fluorescencia & $20,0 \mathrm{nM}$ \\
Método de Griess & $1,0 \mu \mathrm{M}$ & Crom. gas-líquido & $20,0 \mathrm{nM}$ \\
Desactivación de fluoresc. & $1,0 \mu \mathrm{M}$ & Polarografía & $6,0 \mathrm{nM}$ \\
Valoración & $1,0 \mu \mathrm{M}$ & Absorción de colorantes & $0,02 \mathrm{nM}$ \\
\hline
\end{tabular}

Tabla 2.3: Límites de detección (LD) de los diferentes métodos de determinación de nitrito.

origen de las muestras, del precio o del tiempo, material y precisión necesarios (tabla 2.3), el método de Griess sigue siendo hoy el más utilizado a pesar de su antigüedad.

En cuanto al análisis cualitativo, la forma tradicional de caracterizar nitritos en una muestra consiste en añadir ácido sulfúrico o acético concentrados y sulfato ferroso. Si hay nitritos aparece un color pardo oscuro que corresponde al complejo nitrosilhierro. ${ }^{77}$ Existe otra forma, que pasa por descomponer el nitrito añadiendo ácido sulfúrico concentrado e hirviendo. A continuación se hacen pasar los gases desprendidos por un filtro húmedo con yoduro y almidón. Si hay nitrito, el $\mathrm{NO}_{2}$ desprendido oxida el yoduro haciendo que el yodo creado de lugar a un color azul con el almidón. 


\subsection{Agentes nitrosantes}

Por sí mismo, el ácido nitroso no es un buen agente nitrosante. Se puede valorar como un hidróxido de nitrosilo, $\mathrm{NO}^{+} \mathrm{OH}^{-}$, donde la elevada basicidad del hidroxilo hace que el nitrosonio pierda su capacidad electrófila. Al estar en medio ácido, el ácido nitroso se descompone en compuestos mucho más activos que nitrosan mucho más rápido, por lo que no se puede considerar un agente nitrosante efectivo y no se tiene en cuenta.

\subsubsection{Iones nitrosonio y nitrosacidio}

El ion nitrosonio, $\mathrm{NO}^{+}$, es un compuesto isoelectrónico con el CO y el $\mathrm{N}_{2}$. Debido a la existencia del triple enlace entre el nitrógeno y el oxígeno, el espacio entre los núcleos de estos dos átomos es de $106 \mathrm{pm}$. Se trata de un compuesto muy utilizado en química orgánica e inorgánica dado su carácter de oxidante monoelectrónico: ${ }^{78}$

$$
\mathrm{NO}^{+}+\mathrm{e}^{-} \rightleftharpoons \mathrm{NO}
$$

El potencial estándar de reducción para esta reacción se encuentra comprendido entre $E^{\circ}=1,28 \mathrm{~V}$ y $E^{\circ}=1,02 \mathrm{~V}$, en función de la polaridad del disolvente que estabilice su carga eléctrica. ${ }^{79}$

Existen ciertas sales de nitrosilo (página 62) que son estables e incluso comerciales, con purezas superiores al 95\%: $\mathrm{NOBF}_{4}, \mathrm{NOClO}_{4}, \mathrm{NOPF}_{6} \ldots$ El tetrafluoroborato de nitrosilo también se puede preparar en el laboratorio por reacción entre nitrito de amilo y anhídrido propiónico en presencia de una disolución acuosa de $\mathrm{HBF}_{4} \cdot{ }^{80}$ Las sales de nitrosilo son sensibles a la humedad y se suelen almacenar en botellas de plástico y atmósfera inerte, puesto que los productos de descomposición expuestos al aire reaccionan con el vidrio. Son solubles y estables en $\mathrm{MeCN}, \mathrm{MeNO}_{2}$ o $\mathrm{SO}_{2}$ líquido, pero reaccionan con dietil éter, acetona o tetrahidrofurano. Son insolubles en $\mathrm{CH}_{2} \mathrm{Cl}_{2}$ y otros disolventes clorados. También se pueden disolver en metanol, aunque forman un equilibrio con él.

$$
\mathrm{NO}^{+}+\mathrm{MeOH} \rightleftharpoons \mathrm{MeONO}+\mathrm{H}^{+}
$$




\section{6 | Agentes nitrosantes}

El ion nitrosonio se forma por la acidificación del ácido nitroso:

$$
\mathrm{HNO}_{2}+\mathrm{H}^{+} \rightleftharpoons \mathrm{NO}^{+}+\mathrm{H}_{2} \mathrm{O}
$$

La constante de este equilibrio viene dada por la ecuación:

$$
K=\frac{\left[\mathrm{NO}^{+}\right] a_{w}}{\left[\mathrm{HNO}_{2}\right] a_{\mathrm{H}^{+}}}
$$

La constante de este equilibrio, a $20^{\circ} \mathrm{C}$, vale $2 \cdot 10^{-7} \cdot{ }^{81} \mathrm{Su}$ valor implica que la formación de ion nitrosonio está favorecida a alta acidez y baja actividad acuosa, como ocurre con los ácidos concentrados. Siguiendo los picos característicos del ion nitrosonio en $260 \mathrm{~nm}$ en espectroscopía ultravioleta y en $2.300 \mathrm{~cm}^{-1}$ en Raman, se ha demostrado que el ácido nitroso en ácido perclórico al $60 \%$ o en ácido sulfúrico al $60 \%$ está totalmente convertido en $\mathrm{NO}^{+} .{ }^{82}$

Sin embargo, en condiciones de moderada acidez, existen pruebas de que el ion nitrosacidio $\left(\mathrm{H}_{2} \mathrm{NO}_{2}^{+}\right)$es un constituyente importante de la disolución, ya que en los espectros no todo el ácido nitroso que desaparece se presenta como ion nitrosonio. ${ }^{83}$ El ion nitrosacidio se forma en un equilibrio intermedio:

$$
\mathrm{HNO}_{2}+\mathrm{H}^{+} \rightleftharpoons \mathrm{H}_{2} \mathrm{NO}_{2}^{+} \rightleftharpoons \mathrm{NO}^{+}+\mathrm{H}_{2} \mathrm{O}
$$

Por su estructura, donde una molécula neutra como el agua se encuentra asociada al ion nitrosonio, $\mathrm{NO}^{+} \mathrm{H}_{2} \mathrm{O}$, es de esperar que sea casi tan nitrosante como el propio ion nitrosonio. Como la mayor parte de las nitrosaciones suelen transcurrir en medios acuosos levemente ácidos, existe controversia sobre cual de los dos iones es el nitrosante efectivo en estas condiciones. A través de la cinética química no es posible resolver la polémica, ya que ambos reactivos proporcionan la misma ecuación de velocidad:

$$
v=k[\mathrm{~S}]\left[\mathrm{HNO}_{2}\right]\left[\mathrm{H}^{+}\right]
$$

Existen algunos argumentos que sugieren que en disolución acuosa, el agente nitrosante es el ion nitrosacidio. Uno de los más importantes es el resultado de la nitrosación del ácido hidrazoico en agua enriquecida en oxígeno-18, que sirve 
como trazador. ${ }^{84}$ El producto de la reacción, azida de nitrosonio, es inestable y se descompone rápidamente en nitrógeno y óxido nitroso, cuya proporción en ${ }^{18} \mathrm{O}$ se puede analizar fácilmente por espectroscopía de masas. Estas reacciones son:

$$
\mathrm{HNO}_{2}+\mathrm{HN}_{3} \rightarrow \mathrm{N}_{3} \mathrm{NO}+\mathrm{H}_{2} \mathrm{O} \rightarrow \mathrm{N}_{2} \mathrm{O}+\mathrm{N}_{2}
$$

El estudio cinético de esta reacción obtuvo una ecuación experimental de velocidad como la 2.6:

$$
v=k\left[\mathrm{~N}_{3}^{-}\right]\left[\mathrm{HNO}_{2}\right]\left[\mathrm{H}^{+}\right]
$$

lo que quiere decir que tanto el ion nitrosonio como el ion nitrosacidio pueden ser los agentes nitrosantes. En caso de que fuese el ion nitrosacidio, el mecanismo de reacción sería:

$$
\mathrm{H}_{2} \mathrm{NO}_{2}^{+} \underset{\text { lenta }}{\stackrel{\mathrm{N}_{3}^{-}}{\longrightarrow}} \mathrm{N}_{3} \mathrm{NO}+\mathrm{H}_{2} \mathrm{O} \underset{\text { rápida }}{\longrightarrow} \mathrm{N}_{2} \mathrm{O}+\mathrm{N}_{2}
$$

donde la etapa limitante de la velocidad sería el ataque nucleófilo de la azida al ion nitrosacidio. Si el agente nitrosante fuese el ion nitrosonio, la etapa limitante de la velocidad (la reacción entre el ion nitrosonio y el ion azida) vendría precedida por la ruptura y formación continua del ion nitrosacidio.

$$
\mathrm{H}_{2} \mathrm{NO}_{2}^{+} \underset{\text { rápida }}{\underset{\text { renta }}{\rightleftharpoons}} \mathrm{NO}^{+}+\mathrm{H}_{2} \mathrm{O} \underset{\text { len }}{\stackrel{\mathrm{N}_{3}^{-}}{\longrightarrow}} \mathrm{N}_{3} \mathrm{NO} \underset{\text { rápida }}{\longrightarrow} \mathrm{N}_{2} \mathrm{O}+\mathrm{N}_{2}
$$

Dado que este equilibrio es el responsable del intercambio de oxígeno entre el agua y el ácido nitroso, si es más rápido que la reacción de nitrosación, el óxido nitroso resultante tendría en el experimento la misma proporción de ${ }^{18} \mathrm{O}$ que el agua utilizada. Sin embargo, la relación entre $\mathrm{N}_{2}^{16} \mathrm{O}$ y $\mathrm{N}_{2}^{18} \mathrm{O}$ es mucho menor que la del agua de los experimentos, lo que invalida el segundo mecanismo y apunta al ion nitrosacidio como responsable de la nitrosación.

Otros experimentos han aportado pruebas de la capacidad del ion nitrosacidio como agente nitrosante efectivo. Un trabajo sobre resonancia magnética de ${ }^{15} \mathrm{~N}$ del ácido nitroso y sus derivados encontró pruebas de un equilibrio entre 


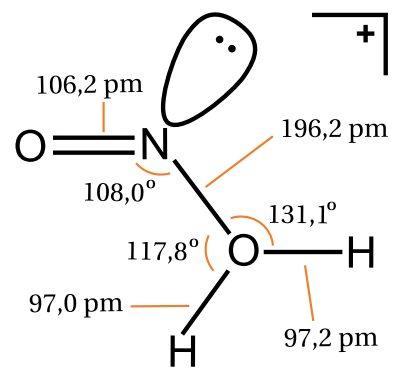

Figura 2.3: Estructura teórica del ion nitrosacidio.

el ácido nitroso y el ion nitrosacidio, que lentamente se descomponía en ion nitrosonio. ${ }^{85} \mathrm{El}$ desplazamiento del equilibrio hacia el nitrosacidio aumentaba con la acidez. Estudios teóricos han calculado la estructura del ion nitrosacidio (figura 2.3), en el que aparece un enlace $\mathrm{O}-\mathrm{N}$ tan largo que la molécula se tiene que interpretar como un complejo $\left[\mathrm{NO}^{+} \cdots \mathrm{H}_{2} \mathrm{O}\right] .{ }^{86}$ La energía de disociación de esta molécula para dar $\mathrm{NO}^{+}$ha sido calculada en $18,2 \mathrm{kcal} \mathrm{mol}^{-1}$. Aun así, a falta de una prueba física definitiva, la duda subsiste, ya que también hay experimentos que demuestran nitrosación por ion nitrosonio, como la nitrosación del peróxido de hidrógeno, donde la ecuación de velocidad tiene un orden 0 respecto al sustrato:

$$
v=k\left[\mathrm{HNO}_{2}\right]\left[\mathrm{H}^{+}\right]
$$

lo que implica que la etapa limitante de velocidad es la formación del ion nitrosonio

$$
\mathrm{HNO}_{2}+\mathrm{H}^{+} \rightleftharpoons \mathrm{H}_{2} \mathrm{NO}_{2}^{+} \underset{\text { lenta }}{\longrightarrow} \mathrm{NO}^{+}+\mathrm{H}_{2} \mathrm{O} \stackrel{\mathrm{H}_{2} \mathrm{O}_{2}}{\longrightarrow} \mathrm{HNO}_{3}
$$

coherentemente con el valor teórico calculado.

Algunos autores han propuesto que la estructura del electrófilo debería considerarse como participación de dos formas resonantes, el ion nitrosacidio y el ion nitrosonio junto a una molécula de agua, donde el coeficiente de participación del ion nitrosacidio disminuye al aumentar la acidez: 


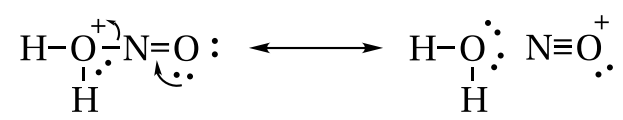

Esta teoría podría explicar la influencia del efecto del medio en algunas nitrosaciones, en las que una gran concentración de sales neutras acelera la velocidad de reacción. ${ }^{87}$

\subsubsection{Trióxido de dinitrógeno}

El trióxido de dinitrógeno, $\mathrm{N}_{2} \mathrm{O}_{3}$, es uno de los óxidos binarios del nitrógeno más inestables. Se trata de la forma anhidra del ácido nitroso:

$$
2 \mathrm{HNO}_{2} \rightleftharpoons \mathrm{N}_{2} \mathrm{O}_{3}+\mathrm{H}_{2} \mathrm{O}
$$

A finales de los años 60 y principio de los 70 la bibliografía sobre mecanismos de formación de $\mathrm{N}$-nitrosocompuestos mostraba resultados contrapuestos sobre la influencia de los diferentes sustratos nitrosables en la constante de velocidad, $k$, de la reacción de ataque del trióxido de dinitrógeno sobre la amina libre. Así, mientras Challis, ${ }^{88}$ Mirvish ${ }^{89}$ y Moss ${ }^{90}$ encontraban para la nitrosación de aminas de pKs elevados una constancia de los valores de $k$ difícil de explicar, ${ }^{18}$ Schmid encontró que, en la diazotación de anilininas de $\mathrm{pK}<5$, el valor de $k$ varía, mostrando correlación entre $k$ y el pK del sustrato. ${ }^{91}$ Casado et al. llegaron a conclusiones coherentes con los resultados de Schmid. ${ }^{92}$

En 1981, Markovits et al. determinaron el valor de la constante de equilibrio de formación de $\mathrm{N}_{2} \mathrm{O}_{3}:{ }^{93}$

$$
K=\frac{\left[\mathrm{N}_{2} \mathrm{O}_{3}\right] a_{w}}{\left[\mathrm{HNO}_{2}\right]^{2}}
$$

Markovits encontró el valor $K=(3,03 \pm 0,23) \cdot 10^{-3} \mathrm{M}^{-1}$ ostensiblemente distinto del encontrado con anterioridad por Turney ${ }^{94,95}\left(K=0,20 \mathrm{M}^{-1}\right)$.

Con el valor de Markovits, Casado et al investigaron las reacciones de nitrosación de una larga serie de aminas, recalculando los valores obtenidos por otros autores. ${ }^{96}$ Los valores de $k$ encontrados y los de las correspondientes entalpía de activación evidenciaron que las reacciones de nitrosación de aminas 


\begin{tabular}{cc}
\hline Propiedad & Valor \\
\hline$K_{d}$ & $1,91 \mathrm{~atm}$ \\
$\Delta H$ & $40,5 \mathrm{~kJ} \mathrm{~mol}^{-1}$ \\
$\Delta S$ & $139 \mathrm{~J} \mathrm{~K}^{-1} \mathrm{~mol}^{-1}$ \\
$\Delta G$ & $-1,59 \mathrm{~kJ} \mathrm{~mol}^{-1}$ \\
\hline
\end{tabular}

Tabla 2.4: Magnitudes termodinámicas de la descomposición del $\mathrm{N}_{2} \mathrm{O}_{3}$ a $25^{\circ} \mathrm{C}$.

secundarias transcurren mediante control por difusión, no dependiendo de la especificidad de los sustratos.

El trióxido de dinitrógeno sólo se puede aislar a bajas temperaturas debido a que, por encima de su punto de fusión $\left(-100,1^{\circ} \mathrm{C}\right)$ se descompone:

$$
\begin{gathered}
\mathrm{N}_{2} \mathrm{O}_{3} \stackrel{K_{d}}{\rightleftharpoons} \mathrm{NO}+\mathrm{NO}_{2} \\
2 \mathrm{NO}_{2} \rightleftharpoons \mathrm{N}_{2} \mathrm{O}_{4}
\end{gathered}
$$

En estado sólido, el $\mathrm{N}_{2} \mathrm{O}_{3}$ es de color azul pálido; líquido tiene un azul intenso a bajas temperaturas, pero su color se desvanece y se vuelve verdoso debido a la presencia de $\mathrm{NO}_{2}$ a temperaturas más altas. El espectro visible del $\mathrm{N}_{2} \mathrm{O}_{3}$ tiene un máximo de absorción en $\lambda=630 \mathrm{~nm}\left(\varepsilon=29,3 \mathrm{M}^{-1} \mathrm{~cm}^{-1}\right) .{ }^{97}$ La disociación también limita la precisión con la que las propiedades físicas del compuesto pueden ser determinadas. A $25^{\circ} \mathrm{C}$, el equilibrio disociativo en la fase gaseosa se caracteriza por las magnitudes termodinámicas recogidas en la tabla $2.4 .{ }^{50}$

En el laboratorio, el trióxido de dinitrógeno se prepara condensando cantidades equimoleculares de $\mathrm{NO}$ y $\mathrm{NO}_{2}$ :

$$
\mathrm{NO}+\mathrm{NO}_{2} \stackrel{260 \mathrm{~K}}{\longrightarrow} \mathrm{N}_{2} \mathrm{O}_{3}
$$

o por adición de la proporción exacta de $\mathrm{O}_{2}$ al NO:

$$
\mathrm{O}_{2}+4 \mathrm{NO} \rightleftharpoons 2 \mathrm{~N}_{2} \mathrm{O}_{3}
$$


También se puede preparar de forma alternativa por reducción de ácido nítrico con $\mathrm{As}_{2} \mathrm{O}_{3}$ a $70{ }^{\circ} \mathrm{C}$, o por reducción de ácido nítrico fumante con dióxido de azufre, seguida de hidrólisis:

$$
\begin{gathered}
2 \mathrm{HNO}_{3}+2 \mathrm{H}_{2} \mathrm{O}+\mathrm{As}_{2} \mathrm{O}_{3} \rightarrow \mathrm{N}_{2} \mathrm{O}_{3}+2 \mathrm{H}_{3} \mathrm{AsO}_{4} \\
2 \mathrm{HNO}_{3}+2 \mathrm{SO}_{2} \rightarrow 2 \mathrm{NOHSO}_{4} \stackrel{2 \mathrm{H}_{2} \mathrm{O}}{\longrightarrow} \mathrm{N}_{2} \mathrm{O}_{3}+2 \mathrm{H}_{2} \mathrm{SO}_{4}
\end{gathered}
$$

Sin embargo, con estos métodos no se puede conseguir un producto totalmente anhidro.

Mediante espectroscopía de microondas se determinó la estructura del compuesto (figura 2.4) ${ }^{98}$ Destaca por tener la misma estructura plana que el ion nitrosacidio y, también como él, un enlace central muy largo entre los dos nitrógenos.

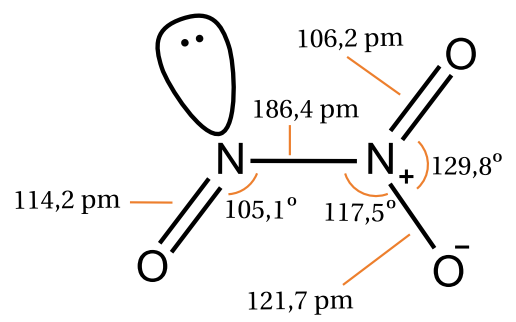

Figura 2.4: Estructura del trióxido de dinitrógeno.

El estudio de la reactividad química del trióxido de dinitrógeno se ha visto muy limitado por su disociación en los reactivos $\mathrm{NO}_{\text {y }} \mathrm{NO}_{2}$. Sin embargo, se ha comprobado que se comporta como el anhídrido del ácido nitroso que es. Así, en medio acuoso se hidroliza:

$$
\mathrm{N}_{2} \mathrm{O}_{3} \stackrel{a q}{\longrightarrow} 2 \mathrm{HNO}_{2}
$$

y en medio alcalino se convierte en nitrito:

$$
\mathrm{N}_{2} \mathrm{O}_{3}+\mathrm{NaOH} \rightarrow 2 \mathrm{NaNO}_{2}
$$




\section{2 | Agentes nitrosantes}

La reacción del $\mathrm{N}_{2} \mathrm{O}_{3}$ con ácidos concentrados forma sales de nitrosilo:

$$
\mathrm{N}_{2} \mathrm{O}_{3}+3 \mathrm{H}_{2} \mathrm{SO}_{4} \rightarrow 2 \mathrm{NO}^{+}+\mathrm{H}_{3} \mathrm{O}^{+}+3 \mathrm{HSO}_{4}^{-}
$$

Esta reacción se utiliza como otra vía de obtención de sales como $\mathrm{NOClO}_{4}$ o $\mathrm{NOBF}_{4}$.

El trióxido de dinitrógeno puede actuar como agente nitrosante en fase gaseosa o en disolución acuosa. Se trata de un importante electrófilo en disolución acuosa, habiéndose encontrado que es la especie activa en múltiples reacciones orgánicas e inorgánicas en las que participa el ácido nitroso, generalmente a pHs bajos. Las reacciones de nitrosación en las que participa este agente se caracterizan por presentar un orden parcial dos respecto a la concentración de ácido nitroso: ${ }^{99}$

$$
v=k[\mathrm{~S}]\left[\mathrm{HNO}_{2}\right]^{2}
$$

De igual forma que con el ion nitrosonio, pueden aparecer reacciones que presenten un orden parcial cero respecto a la concentración de sustrato cuando la reacción entre el $\mathrm{N}_{2} \mathrm{O}_{3}$ y el sustrato sea más rápida que la formación del propio $\mathrm{N}_{2} \mathrm{O}_{3}$ :

$$
v=k\left[\mathrm{HNO}_{2}\right]^{2}
$$

\subsubsection{Sales de nitrosilo}

Dentro del grupo de sales de nitrosilo entran todas las combinaciones del ion nitrosonio con otros aniones $\left(\mathrm{X}^{-}\right)$como $\mathrm{Cl}^{-}, \mathrm{HSO}_{4}^{-}$ó $\mathrm{BF}_{4}^{-}$. Debido a la electronegatividad de los átomos de nitrógeno y oxígeno, estos aportan muy poca electrofilia al enlace, por lo que dependiendo del anión, los enlaces pueden tener muy poco carácter iónico. ${ }^{81}$ Prueba de ello son las distancias de enlace entre los iones, menores a las que se esperarían para una unión iónica o que algunas sales de nitrosilo sean gaseosas (tabla 2.5).

La mejor representación de estas sales es la combinación de dos estructuras resonantes:

$$
\mathrm{X}^{-} \mathrm{N}=\mathrm{O}_{.}^{\mathrm{O}:} \longleftrightarrow \ddot{\mathrm{X}}^{-} \mathrm{N} \equiv \mathrm{O}^{+}
$$




\begin{tabular}{lccccc}
\hline \multicolumn{1}{c}{ NOX } & P. F. $/{ }^{\circ} \mathrm{C}$ & P. E. $/{ }^{\circ} \mathrm{C}$ & $\mathrm{d}_{\mathrm{N}-\mathrm{O}} / \mathrm{pm}$ & $\mathrm{d}_{\mathrm{N}-\mathrm{X}} / \mathrm{pm}$ & $\widetilde{\mathrm{O}-\mathrm{N}-\mathrm{X}}$ \\
\hline $\mathrm{NOF}$ & $-132,5$ & $-59,9$ & 113 & 152 & $110^{\circ}$ \\
$\mathrm{NOCl}$ & $-59,6$ & $-6,4$ & 114 & 198 & $113^{\circ}$ \\
$\mathrm{NOBr}$ & $-56,0$ & descomp. & 115 & 214 & $117^{\circ}$ \\
$\mathrm{NOHSO}_{4}$ & 73,5 & descomp. & & & \\
$\mathrm{NOBF}_{4}$ & 250 & 250 & & & \\
\hline
\end{tabular}

Tabla 2.5: Propiedades físicas de algunas sales de nitrosilo. ${ }^{50}$

Las sales de nitrosilo puras se preparan de forma diferente en función de su estabilidad. Los haluros de nitrosilo, más inestables, se preparan por reacción directa entre el óxido nítrico y el halógeno: ${ }^{82}$

$$
2 \mathrm{NO}+\mathrm{X}_{2} \rightleftharpoons 2 \mathrm{NOX}
$$

excepto el fluoruro de nitrosilo que se suele preparar por fluoración con $\mathrm{AgF}_{2}:{ }^{50}$

$$
\mathrm{NO}+\mathrm{AgF}_{2} \rightarrow \mathrm{NOF}+\mathrm{AgF}
$$

Las sales de nitrosilo más estables, como las ya mencionadas $\mathrm{NOClO}_{4}, \mathrm{NOBF}_{4}$ ó $\mathrm{NOPF}_{6}$, se preparan haciendo reaccionar trióxido de dinitrógeno (página 62) o cloruro de nitrosilo con una fuente del anión en acetonitrilo o nitrometano. Muchas de estas sales están disponibles comercialmente (página 55).

La reactividad de las sales de nitrosilo es muy alta. En medio acuoso se hidrolizan rápidamente:

$$
\mathrm{NOX}+\mathrm{H}_{2} \mathrm{O} \rightarrow \mathrm{HNO}_{2}+\mathrm{HX}
$$

Debido a las condiciones ácidas del medio, el ácido nitroso se oxida a ácido nítrico haciendo que estas disoluciones acuosas tengan la propiedad de disolver metales. De esta forma, en poco tiempo, la disolución acuosa concentrada de $\mathrm{NOCl}$ se transforma en agua regia. ${ }^{100}$ 


\begin{tabular}{lclc}
\hline \multicolumn{1}{c}{ NOX } & $K_{\text {NOX }} / \mathrm{M}^{-1}$ & \multicolumn{1}{c}{ NOX } & $K_{\text {NOX }} / \mathrm{M}^{-1}$ \\
\hline $\mathrm{NOHSO}_{4}$ & $3 \cdot 10^{-5}$ & NOSCN & 30 \\
$\mathrm{NONO}_{3}$ & $3 \cdot 10^{-3}$ & NOSC $\left(\mathrm{NH}_{2}\right)_{2}$ & 5.000 \\
$\mathrm{NOCl}$ & $1,1 \cdot 10^{-3}$ & $\mathrm{NOS}_{2} \mathrm{O}_{3}^{-}$ & $1,7 \cdot 10^{7}$ \\
$\mathrm{NOBr}$ & $5,1 \cdot 10^{-2}$ & & \\
\hline
\end{tabular}

Tabla 2.6: Valores de $K_{\text {NOX }}$ a $25^{\circ} \mathrm{C}$.

Las sales de nitrosilo se emplean para nitrosar compuestos muy poco reactivos, como amidas o sulfonamidas, o compuestos inestables en medio ácido, aunque se suelen evitar en la medida de lo posible, ya que son muy peligrosas. ${ }^{101}$ Para evitar su hidrólisis, las síntesis siempre se realizan en medio anhidro.

Como consecuencia de su alta reactividad, la presencia de algunos aniones en el medio de una reacción de nitrosación puede hacer que aumente su velocidad, debido a que se forman sales de nitrosilo mediante el equilibrio:

$$
\begin{gathered}
\mathrm{HNO}_{2}+\mathrm{H}^{+}+\mathrm{X}^{-} \rightleftharpoons \mathrm{NOX}+\mathrm{H}_{2} \mathrm{O} \\
K_{\mathrm{NOX}}=\frac{[\mathrm{NOX}] a_{w}}{\left[\mathrm{HNO}_{2}\right]\left[\mathrm{X}^{-}\right] a_{\mathrm{H}^{+}}}
\end{gathered}
$$

La tabla 2.6 recoge valores experimentales de $K_{\mathrm{NOX}}$ de varias sales de nitrosilo. Existe una correlación entre la magnitud de $K_{\text {NOX }}$ y la nucleofilia de $\mathrm{X}^{-}$. La presencia de los aniones y la formación de NOX modifica la ecuación de velocidad de la reacción de nitrosación:

$$
v=K_{\mathrm{NOX}} k_{\mathrm{NOX}}\left[\mathrm{HNO}_{2}\right]\left[\mathrm{X}^{-}\right]\left[\mathrm{H}^{+}\right][\mathrm{S}]
$$

donde [S] es la concentración de sustrato y $k_{\mathrm{NOX}}$ la constante de velocidad de orden dos de la reacción entre NOX y el sustrato.

Para evitar el efecto catalítico de las sales de nitrosilo, en estudios cinéticos o en otras situaciones se pueden utilizar aniones que no forman NOX, como los iones perclorato o $p$-toluensulfonato. ${ }^{87,102}$ 


\subsubsection{Nitritos de alquilo}

Los nitritos de alquilo o ésteres de nitrito son compuestos de fórmula general RONO donde R es un grupo alquilo. Como todos los ésteres inorgánicos procedentes de la condensación de un alcohol y un oxoácido inorgánico, los nitritos de alquilo se conocen desde las primeras investigaciones químicas en el siglo XVIII. Así, el éster de nitrito más famoso, el nitrito de amilo, fue descubierto en 1844 por el químico francés Antoine-Jérôme Balard, dos años antes de que Piria describiese su reacción de nitrosación (página 33). ${ }^{4}$

Los nitritos de alquilo se preparan haciendo reaccionar alcoholes con ácido nitroso en presencia de un catalizador ácido: ${ }^{82}$

$$
\mathrm{ROH}+\mathrm{HNO}_{2} \rightleftharpoons \mathrm{RONO}+\mathrm{H}_{2} \mathrm{O}
$$

Después se pueden separar de la mezcla de reacción por destilación, puesto que, al no poder formar puentes de hidrógeno, tienen un punto de ebullición menor que el del alcohol del que proceden. Una forma alternativa para preparar ésteres de nitrito es empleando trióxido de dinitrógeno, con el que generalmente se consiguen mejores rendimientos.

$$
\mathrm{ROH}+\mathrm{N}_{2} \mathrm{O}_{3} \rightleftharpoons \mathrm{RONO}+\mathrm{HNO}_{2}
$$

La mayor parte de los nitritos de alquilo proceden de alcoholes alifáticos y suelen ser líquidos volátiles incoloros o amarillentos. Tienen la ventaja de que pueden ser agentes nitrosantes en medio básico, por lo que se usan frecuentemente para nitrosar, tanto en disoluciones acuosas como orgánicas, compuestos que se descomponen en medio ácido. Por su estabilidad en medio básico, en nuestro grupo se abordó el estudio de reacciones de nitrosación en medios alcalinos (no infrecuentes en órganos humanos como el intestino y el páncreas y en algunos fluidos humanos como la saliva y la orina). Las reacciones de nitrosación transcurren en dos pasos, una reacción electrófila en la que el nitrito de alquilo reacciona con el sustrato y una ruptura posterior: ${ }^{103,104}$

$$
\begin{gathered}
\mathrm{RONO}+\mathrm{SH}+\mathrm{OH}^{-} \rightleftharpoons \mathrm{RONO}-\mathrm{S}+\mathrm{H}_{2} \mathrm{O} \\
\mathrm{RONO}-\mathrm{S} \rightleftharpoons \mathrm{RO}^{-}+\mathrm{NO}-\mathrm{S}
\end{gathered}
$$




\section{6 | Agentes nitrosantes}

La ecuación de velocidad de esta reacción es: ${ }^{105,106}$

$$
v=k[\mathrm{~S}][\mathrm{RONO}]
$$

Se ha demostrado que en la velocidad de nitrosación influye la ramificación del radical alquilo, siendo más rápidas las nitrosaciones con nitritos de alquilo primarios que las que emplean secundarios. ${ }^{107} \mathrm{~A}$ su vez, los nitritos de alquilo secundarios son más rápidos que los terciarios.

En medio ácido, los nitritos de alquilo también pueden nitrosar, porque aunque se hidrolicen rápidamente: ${ }^{108}$

$$
\mathrm{RONO}+\mathrm{HA} \rightarrow \mathrm{ROH}+\mathrm{A}^{-}+\mathrm{NO}^{+}
$$

el producto de su descomposición es un agente nitrosante. Sin embargo, no se utilizan porque existen alternativas mucho más prácticas para nitrosar en medio acuoso ácido. La ecuación de velocidad para la descomposición es de orden dos:

$$
v=k[\mathrm{RONO}]\left[\mathrm{H}^{+}\right]
$$

La hidrólisis también ocurre en medio básico, sin embargo es mucho más lenta que la ácida, lo que permite utilizarla en síntesis. A diferencia del medio ácido, esta descomposición tiene como producto un compuesto no nitrosante, el ion nitrito:

$$
\mathrm{RONO}+2 \mathrm{OH}^{-} \rightarrow \mathrm{RO}^{-}+\mathrm{NO}_{2}^{-}+\mathrm{H}_{2} \mathrm{O}
$$

La ecuación de velocidad de esta reacción es de orden tres: ${ }^{109}$

$$
v=k[\mathrm{RONO}]\left[\mathrm{OH}^{-}\right]^{2}
$$

La principal aplicación de los nitritos de alquilo se encuentra en medicina. Debido a que desprenden óxido nítrico al ser metabolizados son eficaces vasodilatadores (página 48). El nitrito de alquilo más empleado es el nitrito de amilo. Ya su descubridor, Balard, indicó que le producía dolores de cabeza, pero no fue hasta 1867 cuando el médico escocés Thomas Lauder Brunton empezó a 
utilizarlo como tratamiento contra la angina de pecho. ${ }^{110}$ Fue un medicamento muy popular en la época victoriana y aparece incluso en una novela de Sherlock Holmes, The Adventure of the Resident Patient, donde se le administra a uno de los personajes para tratarlo de un ataque de catalepsia. ${ }^{111}$ Actualmente, el nitrito de amilo ha cedido su protagonismo a la nitroglicerina y sólo se usa en casos de emergencia. Debido a sus propiedades psicoactivas, es empleado, junto con otros nitritos de alquilo, como estupefaciente.

\subsubsection{Agentes nitrosantes radicalarios: $\mathrm{NO}$ y $\mathrm{NO}_{2}$}

El interés sobre el poder nitrosante del óxido nítrico, NO, ha aumentado desde el descubrimiento de sus efectos fisiológicos (página 48). Sin embargo, por sí mismo, el óxido nítrico no es un compuesto nitrosante ya que, pese a su similitud con el ion nitrosonio, ${ }^{82}$ sus diferencias son significativas. ${ }^{112} \mathrm{La}$ configuración electrónica del óxido nitroso

$$
(\sigma 2 s)^{2}\left(\sigma 2 s^{*}\right)^{2}\left(\sigma 2 p_{z}\right)^{2}(\pi 2 p)^{4}\left(\pi 2 p^{*}\right)^{1}
$$

con un electrón $\pi$ antienlazante desapareado que da lugar a un orden de enlace 2,5 , mientras que el $\mathrm{NO}^{+}$, con su configuración electrónica igual a la del $\mathrm{N}_{2}$ y el CO, tiene un orden de enlace 3. Esto se refleja en la longitud de enlace (frecuencias de vibración $1.840 \mathrm{~cm}^{-1}$ para el NO y $2.300 \mathrm{~cm}^{-1}$ para el NO${ }^{+}$). Para poder ejercer como agente nitrosante, es necesario que el óxido nítrico pierda ese electrón desapareado. Dado que el potencial estándar de reducción para la reacción:

$$
\mathrm{NO}^{+}+\mathrm{e}^{-} \rightarrow \mathrm{NO}
$$

es de 1,21 V, es muy fácil para muchos compuestos retirar el electrón. Dos reacciones son de interés para la nitrosación debido a que forman potentes sales de nitrosilo. Una es la oxidación del óxido nítrico por halógenos:

$$
2 \mathrm{NO}+\mathrm{X}_{2} \rightarrow 2 \mathrm{NOX}
$$


que produce haluros de nitrosilo y la otra es la reacción del óxido nítrico con el oxígeno de la atmósfera para producir dióxido de nitrógeno:

$$
2 \mathrm{NO}+\mathrm{O}_{2} \rightarrow 2 \mathrm{NO}_{2}
$$

El dióxido de nitrógeno es otro radical libre que por si mismo tampoco es nitrosante. Sin embargo, dimeriza rápidamente a tetraóxido de dinitrógeno, sal de nitrosilo que, como se ha visto en la tabla 2.6 (página 64), tiene una estabilidad similar a la de los haluros de nitrosilo.

Además, la mezcla de óxido nítrico y dióxido de nitrógeno en un mismo recipiente conduce, mediante el siguiente equilibrio

$$
\mathrm{NO}+\mathrm{NO}_{2} \rightleftharpoons \mathrm{N}_{2} \mathrm{O}_{3}
$$

a la formación de trióxido de dinitrógeno. Esta es una de las múltiples razones por las que los óxidos de nitrógeno $\left(\mathrm{NO}_{\mathrm{x}}\right)$, procedentes del tráfico, son un problema de salud pública, especialmente en las grandes ciudades. En zonas costeras, donde la atmósfera tiene cloro, el peligro aumenta.

Tanto el óxido nítrico como el dióxido de nitrógeno, como radicales libres que son, pueden unirse a otras moléculas orgánicas con un electrón desapareado para formar un nitrosocompuesto. Existen técnicas que primero preparan los radicales libres mediante metales como litio, iones monocargados como $\mathrm{Ag}^{+}$ o con radiación visible o ultravioleta y luego los nitrosan burbujeando óxido nítrico. ${ }^{113}$ Dos ejemplos encontrados en la bibliografía, uno de C-nitrosación y otro de N-nitrosación, se muestran en el esquema $2.3^{114,115}$.

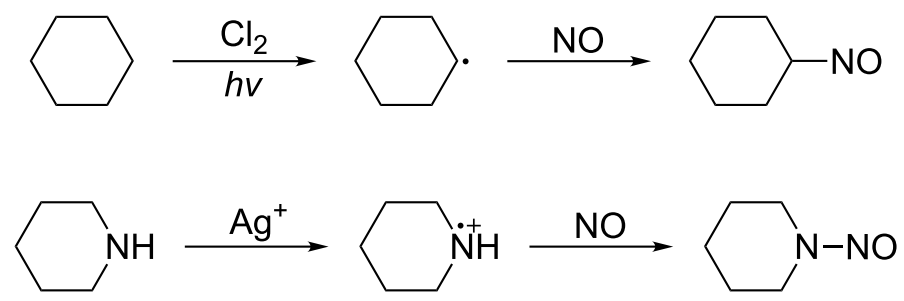

Esquema 2.3: Reacción de nitrosación radicalaria con óxido nítrico. 
En algunos artículos antiguos, especialmente en el área biológica, se afirmaba que el óxido nítrico es un agente nitrosante. Sin embargo se ha demostrado que se trataba de un error producido por contaminaciones con oxígeno. ${ }^{116}$

\subsubsection{Otros agentes nitrosantes}

\section{Complejos metálicos}

Los complejos del óxido nítrico se conocen desde hace siglos; en ellos el grupo NO está en forma de ion nitrosonio. ${ }^{117}$ Algunos complejos de nitrosilo son las sales de Roussin, roja $\mathrm{Na}_{2}\left[\mathrm{Fe}_{2}(\mathrm{NO})_{4} \mathrm{~S}_{2}\right]$ o negra $\mathrm{Na}\left[\mathrm{Fe}_{4}(\mathrm{NO})_{7} \mathrm{~S}_{3}\right]$, o el ion nitroprusiato $\left[\mathrm{Fe}(\mathrm{CN})_{5} \mathrm{NO}\right]^{2-}$. Dada su condición de portadores de óxido nítrico se han empleado históricamente como vasodilatadores, siendo el nitroprusiato sódico (se comercializa bajo la marca Nitropress) uno de los más potentes. En estos compuestos el átomo de nitrógeno tiene hibridación $s p$ por lo que en la unión con el metal, el ligando tiene configuración lineal.

En cuanto su comportamiento como agentes nitrosantes un estudio en el que se utilizó nitroprusiato sódico revela una curiosa ecuación de velocidad en la que el orden de reacción respecto a la concentración de sustrato es dos: ${ }^{118}$

$$
v=k\left[\mathrm{Na}_{2}\left[\mathrm{Fe}(\mathrm{CN})_{5} \mathrm{NO}\right]\right][S]^{2}
$$

lo que se ha explicado mediante un mecanismo en el que, en primer lugar, existe una reacción rápida entre el sustrato y el nitroprusiato, seguida de una segunda reacción en la que ese complejo reacciona con otra molécula de sustrato, liberando el compuesto nitrosado.

\section{Carboxilatos de nitrosilo}

Los carboxilatos de nitrosilo se forman en el equilibrio que se produce al disolver nitrito sódico en ácido carboxílico ${ }^{82}$ :

$$
\mathrm{RCOOH}+\mathrm{NaNO}_{2} \rightleftharpoons \mathrm{RCOONO}+\mathrm{H}_{2} \mathrm{O}
$$


Son agentes nitrosantes muy efectivos, lo que hace que, como con las sales de nitrosilo, la presencia de carboxilatos en el medio de reacción aumenta la velocidad de la misma. ${ }^{119-121}$ Este efecto fue utilizado por Lajos Ilosvay para perfeccionar el método de Griess para análisis de nitritos (página 51). Por la misma razón, se debe evitar el uso de tampones acetato en estudios cinéticos de nitrosación.

En síntesis, se emplea nitrito sódico disuelto en ácido trifluoroacético para nitrosar amidas insolubles en agua o anilinas altamente desactivadas como perfluoroanilina o 2,6-difluoroanilina.

\section{Nitritos}

Ya se ha indicado que los nitritos, por si solos, no son agentes nitrosantes efectivos. Sin embargo, es posible emplearlos como agentes N-nitrosantes si se transforma la amina en un ion iminio haciéndola reaccionar con un aldehido, que actúa como catalizador. De esta forma, la carga positiva del ion atrae al nitrito, que efectúa un ataque nucleófilo (esquema 2.4). ${ }^{122,123}$

Además, esta reacción presenta la ventaja de no requerir medio ácido. En síntesis, los aldehidos más utilizados son benzaldehido, formaldehido, piridoxal o cloral.
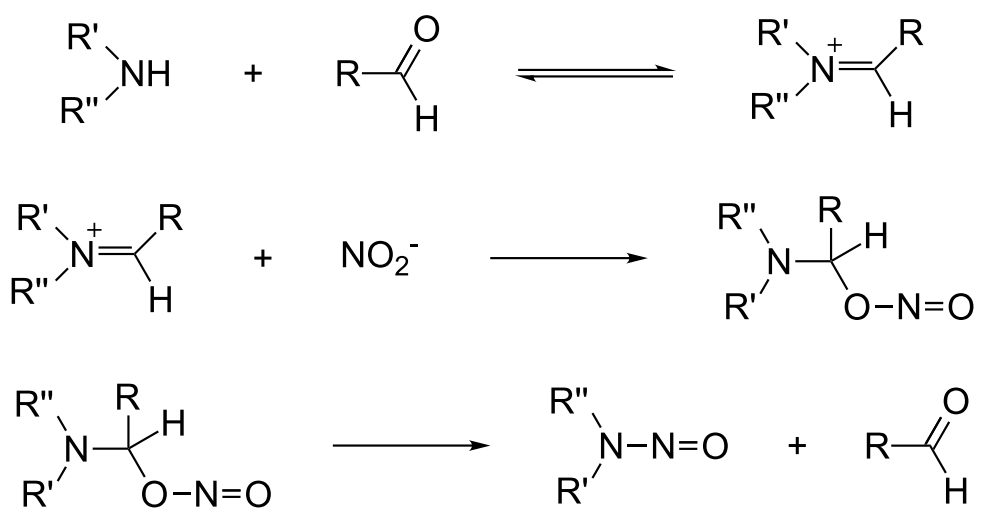

Esquema 2.4: Mecanismo de nitrosación por nitritos. 


\section{N-Nitrosaminas}

Las $N$-nitrosaminas no son buenos nitrosantes debido a la fuerza del enlace entre sus dos nitrógenos. Para que se produzca una transferencia directa del grupo nitroso es necesario que exista en el medio algún compuesto que catalice la ruptura de ese enlace, como los iones haluro o tiocianato.

Mucho más comunes son las nitrosaciones debidas a la hidrólisis de las nitrosaminas. Éstas se descomponen fácilmente en medios acuosos y ácidos para liberar ácido nitroso: ${ }^{82}$

$$
\mathrm{R}_{2} \mathrm{~N}-\mathrm{NO}+\mathrm{H}_{2} \mathrm{O} \rightarrow \mathrm{R}_{2} \mathrm{~N}-\mathrm{H}+\mathrm{HNO}_{2}
$$

El método de Liebermann aprovecha esta propiedad para determinar nitrosaminas cualitativamente (esquema 2.5) haciendo reaccionar el ácido nitroso que se libera con exceso de fenol, que rápidamente da un compuesto de color rojo. ${ }^{124}$ Una prueba adicional consiste en comprobar que la mezcla se torna azul al añadir una disolución de hidróxido sódico al $10 \%$. Este método también se emplea para confirmar la presencia de fenol en una muestra añadiendo nitrito sódico en medio ácido.

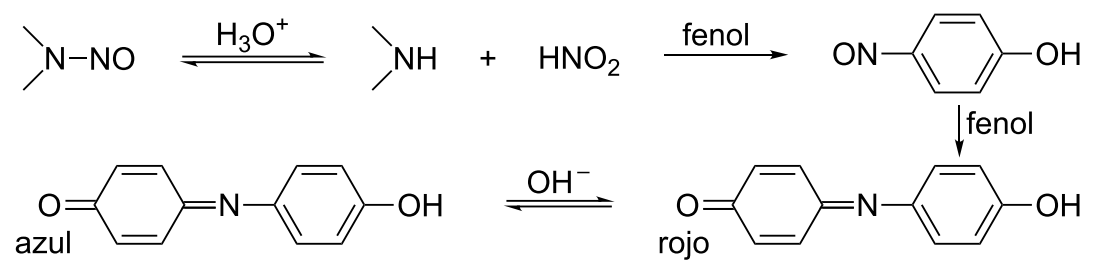

Esquema 2.5: Método de Liebermann para la detección de nitrosaminas.

\section{C-Nitrosocompuestos aromáticos}

De igual modo que las $N$-nitrosaminas, los $C$-nitrosocompuestos pueden actuar como agentes nitrosantes cuando se rompe el enlace que une el grupo nitroso al carbono y lo liberan al medio. Sin embargo, el efecto más interesante que poseen es la capacidad de catalizar reacciones de nitrosación cuando se 


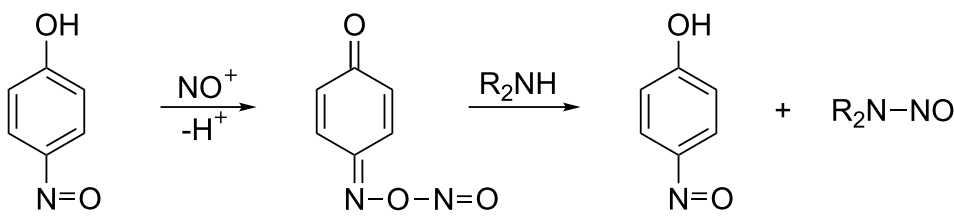

Esquema 2.6: Catálisis por $C$-nitrosocompuestos aromáticos.

encuentran presentes. ${ }^{125} \mathrm{El}$ mecanismo propuesto para explicar este efecto se muestra en el esquema 2.6.

El grupo nitroso unido al anillo aromático actúa como un nucleófilo que se asocia al ion nitrosacidio atrayendo su carga eléctrica y aumentando su electrofilia. Así, el ion nitrosacidio activado es más efectivo y por lo tanto la reacción se acelera. Se ha demostrado que incluso a un pH de 5, donde apenas hay ácido nitroso puede haber reacción de nitrosación a una velocidad significativa en presencia de $C$-nitrosocompuestos aromáticos.

\section{Líquidos iónicos}

Un líquido iónico es un fluido constituido exclusivamente por iones. Se considera que están dentro de esta categoría todas las sales cuyo punto de fusión es inferior al punto de ebullición del agua. La composición química de estos compuestos generalmente consiste en un catión orgánico y un anión inorgánico. Se han sintetizado líquidos iónicos cuyo catión es un nitrosocompuesto que actúa como portador del ion nitrosonio, siendo muy eficiente en la nitrosación de otros compuestos. Dada su naturaleza iónica, es un método especialmente útil en la síntesis de sales de diazonio, que son muy estables en su seno. ${ }^{126}$

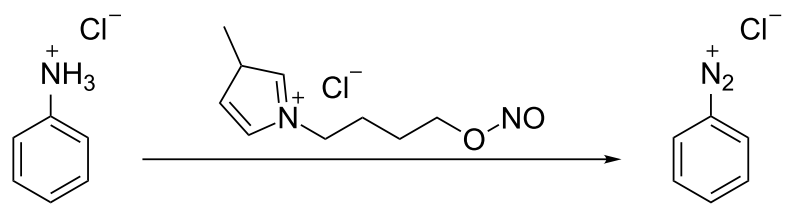

Esquema 2.7: Síntesis de sales de diazonio con líquidos iónicos. 


\subsection{Reacciones de nitrosación}

Pese al gran número de agentes nitrosantes que existen y a la variedad de sustratos susceptibles de ser nitrosados, los mecanismos de las reacciones de nitrosación se pueden agrupar en unas pocas categorías en función del camino que siguen para alcanzar los productos y del átomo del sustrato que reaccione. El conocimiento de estos mecanismos permite proponer compuestos que catalicen o inhiban las reacciones según interese.

\subsubsection{C-Nitrosación aromática}

Cuando en 1825 Michael Faraday descubrió el benceno, dos de sus características asombraron a los químicos de su época. ${ }^{127}$ La primera era la fórmula empírica que se desprendía de su análisis elemental, $\mathrm{CH}$, una inusual proporción carbono-hidrógeno. La segunda era su estabilidad. August von Kekule en 1866 propuso una estructura cíclica con tres dobles enlaces que explicaba la primera propiedad (figura 2.5).<smiles>c1ccccc1</smiles>

Figura 2.5: Modelo de Kekule.

Para comprender la segunda tuvieron que pasar más de seis décadas hasta el desarrollo de la teoría de orbitales moleculares. Esta teoría describía la molécula de benceno como seis átomos de carbono con hibridación $s p^{2}$ que utilizaban sus tres orbitales híbridos para unirse entre sí y con el hidrógeno en un anillo. Los seis orbitales $p$ restantes se solapan para formar el sistema $\pi$ del benceno (figura 2.6). Este sistema consta de seis orbitales moleculares de los que sólo están ocupados por electrones los tres que son enlazantes, lo que explica la 


\section{4 | Reacciones de nitrosación}

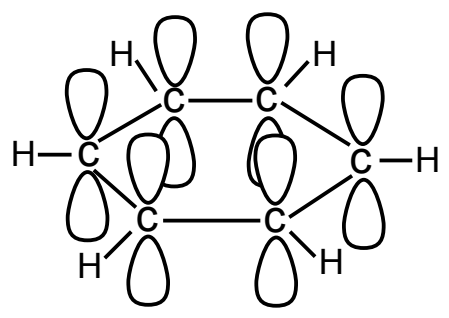

Figura 2.6: Modelo de la Teoría de Orbitales Moleculares.

estabilidad inusual del benceno. Los compuestos que presentan esta estabilidad adicional se denominan compuestos aromáticos.

Sin embargo, aunque los electrones se encuentran estabilizados formando el sistema aromático, algunos electrófilos fuertes pueden tomarlos para formar un carbocatión.

Este carbocatión, denominado complejo sigma o complejo de Wheland, ya no es aromático, pero se encuentra estabilizado por resonancia y regresa a la aromaticidad o bien expulsando al grupo electrófilo atacante o bien deshaciéndose del protón.

Si la pérdida del protón está más favorecida que la del grupo electrófilo, la reacción global se denomina sustitución electrofílica aromática $\left(\mathrm{S}_{\mathrm{E}} \mathrm{Ar}\right)$.

Debido a la electronegatividad de sus átomos, los electrófilos de las reacciones de nitrosación son débiles y requieren que el anillo aromático esté fuertemente activado para poder reaccionar con él. ${ }^{128}$ Por ejemplo, el ion nitrosonio, $\mathrm{NO}^{+}$, es $10^{14}$ veces más lento reaccionando con el benceno que el ion nitronio, $\mathrm{NO}_{2}^{+} \cdot 129$

Se dice que un anillo aromático está activado cuando su estructura presenta un sustituyente en una posición determinada que hace que aumente la velocidad de reacción. Que un sustituyente sea más o menos activante depende de su capacidad de estabilizar el complejo $\sigma$ bien sea por inducción, es decir, cediendo densidad electrónica a través del enlace $\sigma$ (alquilos, arilos), o por resonancia, es decir, cediendo densidad electrónica a través de un enlace $\pi$ en una de las estructuras de resonancia (aminas, amidas, alcoholes, éteres). Estas estabilizaciones sólo son posibles cuando el sustituyente se encuentra en las posiciones 


\section{Grupos activantes}

- Estabilizado por inducción<smiles></smiles><smiles>[R]C1=CC=CC([1H])C1</smiles><smiles>[R]c1ccc(C)cc1CC</smiles>

- Estabilizado por resonancia<smiles>[R][Y]=C1C=CC=CC1[Hg]F</smiles><smiles></smiles><smiles>[R][Y]=C1C=CC(C)(C)C=C1</smiles>

\section{Grupos desactivantes}

- orto-, para- orientadores<smiles>[X]C1=CC=CCC1=[Y4]</smiles><smiles>[X]C1=CC=CC([1H])C1</smiles><smiles>CC1=CC(=[W])C=CC1C</smiles>

- meta-orientadores

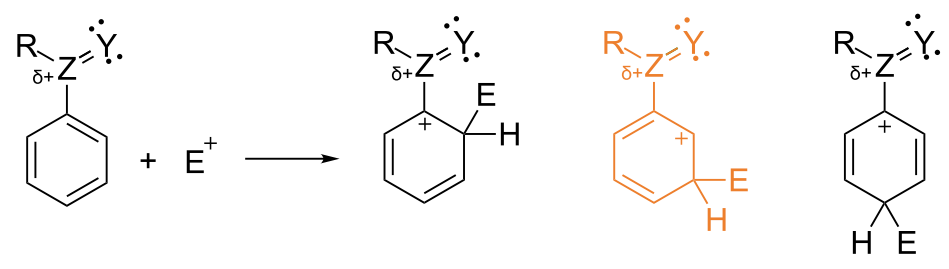

Esquema 2.8: Resumen de los complejos $\sigma$ obtenidos por ataque electrófilo en función del sustituyente y su posición. Las estructuras estables responsables de la orientación en la sustitución se muestran de color naranja. 


\section{6 | Reacciones de nitrosación}

orto o para respecto al electrófilo entrante.

Los grupos deficientes en electrones (ésteres, carboxilos, carbonilos, nitrilos, nitratos) retrasan la sustitución electrofílica. Su gran efecto desactivante en las posiciones orto y para hace que el ataque electrofílico ocurra principalmente en la posición meta, ya que esta posición está menos desactivada.

Los halógenos y los óxidos de amina se comportan como un tercer tipo de sustituyente. Son compuestos desactivantes, ya que su gran electronegatividad hace disminuir la densidad electrónica a través del enlace $\sigma$, efecto denominado sustracción inductiva. Sin embargo, se comportan como orto-, para- orientadores, debido a que sus pares electrónicos libres estabilizan por resonancia el complejo $\sigma$ de la misma forma que los activantes. Un resumen de la influencia que tienen los sustituyentes y su posición se muestra en el esquema 2.8 .

En los anillos heteroaromáticos la posición del heteroátomo influye en el lugar en que se produce la sustitución. Anillos de cinco miembros como furano, pirrol o tiofeno ceden su par de electrones $\pi$ al anillo favoreciendo la reacción de sustitución en la posición menos impedida. Anillos de seis miembros como la piridina atraen con su electronegatividad los electrones del anillo aromático, desactivando la reacción. Como los sustituyentes desactivantes, la presencia de un heteroátomo desactiva la sustitución en cualquier posición, aunque está menos desactivada la posición meta (esquema 2.9).
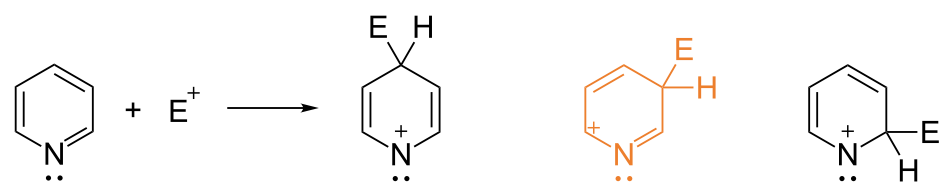

Esquema 2.9: $\mathrm{S}_{\mathrm{E}} \mathrm{Ar}$ en un anillo heteroatómico: piridina. La estructura estable responsable de la orientación en la sustitución se muestra de color naranja.

Si el sustrato aromático es policíclico, el mayor número de opciones de resonancia aumenta la estabilidad de los intermedios de reacción, lo que los hace más reactivos que el benceno. Si no tienen sustituyentes, los anillos policíclicos reaccionarán en los puntos en los que se forme el carbocatión más estable, esto es, en la posición 1 para el naftaleno y en los carbonos libres del anillo central 
para el fenantreno y el antraceno.

El efecto de los grupos sustituyentes depende de la reactividad del electrófilo. Cuanto más fuerte es, menos energía requiere para llegar al estado de transición, formando el complejo de Wheland sin ceder casi carga positiva durante la mayor parte del proceso, haciendo que el grupo sustituyente apenas influya en la posición de sustitución.

A los electrófilos débiles, como el $\mathrm{NO}^{+} / \mathrm{H}_{2} \mathrm{NO}_{2}^{+}$, la baja reactividad hace que su estado de transición sea muy próximo al complejo de Wheland, apareciendo una carga positiva importante en el anillo, haciendo que los sustituyentes sean muy influyentes.

\subsubsection{Diazotación de $C$-nitrosocompuestos aromáticos}

Cuando la C-nitrosación de un compuesto aromático se lleva a cabo en condiciones de acidez suave y con exceso de ácido nitroso, el $C$-nitrosocompuesto formado puede volver a nitrosarse para formar una sal de diazonio ${ }^{130}$. El mecanismo por el que se cree que esta reacción transcurre se representa en el esquema 2.10. El compuesto nitrosado es atacado por el trióxido de dinitrógeno u otro agente nitrosante. La estequiometría de la reacción ha demostrado que el producto de la nitrosación en su transformación a sal de diazonio oxida dos iones nitrito a iones nitrato. Bajo una acidez más fuerte la reacción también se produce, pero el mecanismo es más complicado. En ambas situaciones, si se añade un ion metálico que actúe de quelante, como el ion cúprico, $\mathrm{Cu}^{2+}$, no transcurre la reacción. Esta reacción es una alternativa a la ruta habitual de diazotación de anillos aromáticos que consiste en nitrar el anillo, reducir el grupo nitro a una amina y nitrosar la amina para obtener la sal de diazonio.

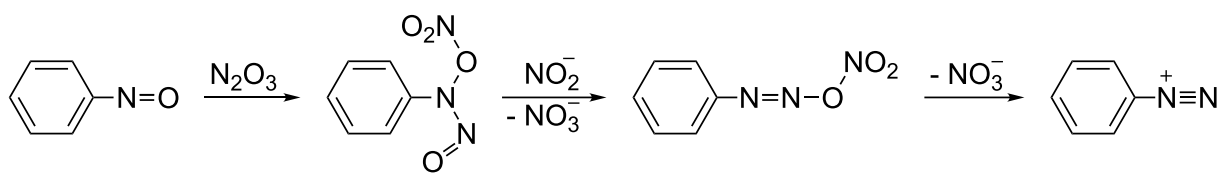

Esquema 2.10: Mecanismo de diazotación de un $C$-nitrosocompuesto. 


\section{8 | Reacciones de nitrosación}

\subsubsection{N-Nitrosación}

El curso de las reacciones de nitrosación de aminas depende de la sustitución a la que están sometidas y de si son aromáticas o alifáticas. Sin embargo todas tienen en común que el primer paso consiste en el ataque nucleófilo de la amina sobre el agente nitrosante. Si la reacción se produce con el ácido nitroso, la mayor parte de los estudios indican que la especie implicada es el trióxido de dinitrógeno, $\mathrm{N}_{2} \mathrm{O}_{3}$. El comportamiento del producto de reacción depende de la naturaleza de la amina. ${ }^{131}$

Las aminas primarias al nitrosarse se convierten en $N$-nitrosaminas, que rápidamente se transforman, vía hidroxilazocompuesto, en una sal de diazonio (esquema 2.11). Si la sal de diazonio está unida a un radical alifático, se descompondrá inmediatamente, empujada por la estabilidad del nitrógeno resultante. En el caso de que el radical sea aromático, las estructuras resonantes que forma estabilizan la sal de diazonio, permitiendo preparar sales y conservarlas en disolución o incluso aisladas.

La descomposición de la sal de diazonio puede producirse mediante un proceso $S_{N} 1$ o un proceso $S_{N} 2$. Los productos de la descomposición, también denominados productos de desaminación, dependen de los nucleófilos presentes. Algunos compuestos derivados de la descomposición de sales de diazonio son éteres, lactonas (esquema 2.18, página 90) ${ }^{132}$ o productos de eliminación, si el

$\mathrm{R}-\mathrm{NH}_{2} \stackrel{\mathrm{HNO}_{2}}{\longrightarrow} \mathrm{R}-\mathrm{NH}-\mathrm{N}=\mathrm{O} \stackrel{+\mathrm{H}^{+}}{\rightleftharpoons} \mathrm{R}-\mathrm{NH}-\mathrm{N}=\stackrel{+}{\mathrm{O}} \mathrm{H} \stackrel{-\mathrm{H}^{+}}{\rightleftharpoons} \mathrm{R}-\mathrm{N}=\mathrm{N}-\mathrm{OH}$

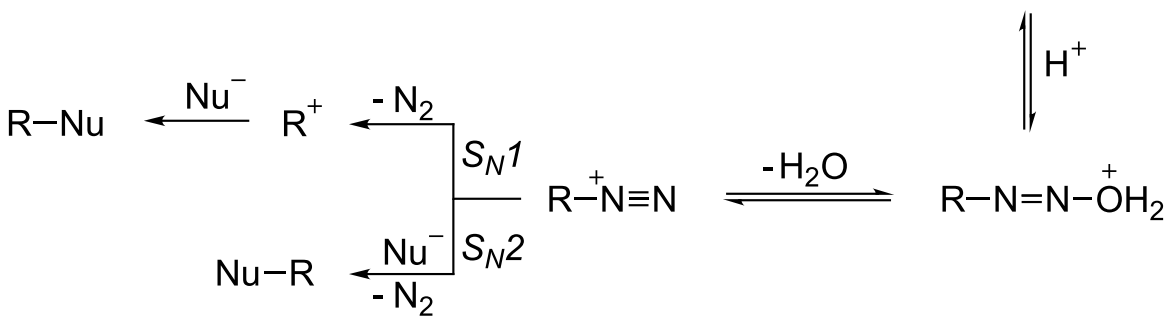

Esquema 2.11: Mecanismos de nitrosación y desaminación de aminas primarias. 
nucleófilo es un alcohol, el ácido carboxílico de un aminoácido o una base fuerte, respectivamente. La reacción de Piria de la que se habló en la introducción (página 34) es el conjunto de la reacción entre una amina primaria y el ácido nitroso en disolución acuosa formando alcohol como producto de desaminación. Estas reacciones pueden tener utilidad en síntesis si se evita la mezcla de productos. La formación de nitrógeno, un grupo saliente excelente, es aprovechado en multitud de procedimientos para obtener diversos compuestos a partir de aminas aromáticas. Algunos ejemplos son la desaminación directa por reducción con ácido fosfórico, la reacción de Schiemann para sustituir la amina por flúor, las reacciones de Sandmeyer y de Gatterman, para sustituirla por cloro o bromo, la reacción de Gomberg-Bachmann, para unir dos anillos aromáticos o la arilación de Meerwein, para sustituir el hidrógeno de un doble enlace pobre en electrones por un anillo aromático. ${ }^{133}$

La nitrosación de aminas secundarias conduce a una $N$-nitrosamina, independientemente de que la amina sea aromática o alifática. Este producto, al contrario que la amina de la que procede, no tiene carácter básico al tratarse de la amida de un ácido nitroso. Las $N$-nitrosaminas secundarias son muy estables y pueden aislarse. Generalmente, los $N$-nitrosoderivados de las aminas secundarias tienen aspecto oleoso y son de color amarillo.

Las $\mathrm{N}$-nitrosaminas secundarias aromáticas, ante catalizadores nucleófilos en medio ácido se transponen para dar $C$-nitrosocompuestos. Esta transposición es en realidad una reacción intermolecular entre la nitrosamina y el nucleófilo, que actúa como transportador del ion nitrosonio (esquema 2.12). Cuanto mayor es la acidez, más favorecida está la formación del compuesto termodinámicamente

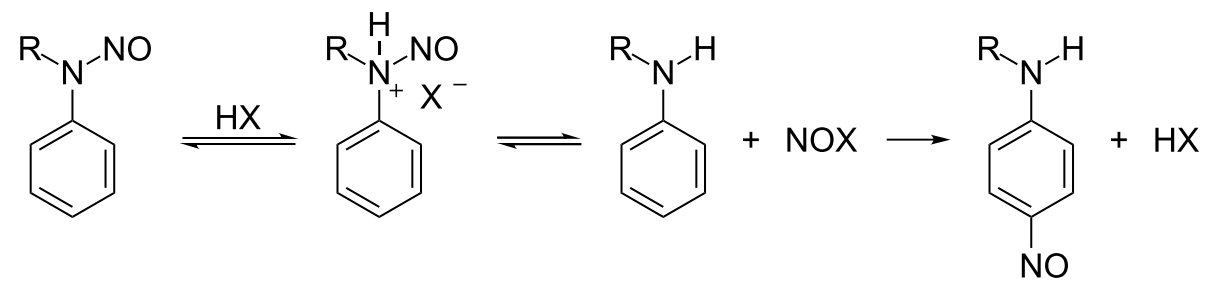

Esquema 2.12: Mecanismo de transposición de una $N$-nitrosamina secundaria aromática. 


\section{0 | Reacciones de nitrosación}

más estable que es el producto de C-nitrosación.

Las aminas terciarias también reaccionan formando $N$-nitrosocompuestos, sin embargo, esta reacción es reversible y el producto está poco favorecido, aunque se han sintetizado algunas sales de nitrosaminas terciarias con tetrafluoroborato y otros contraiones. ${ }^{134}$ Estos compuestos son muy inestables y se descomponen en un carbonilo, una nitrosamina secundaria y óxido nitroso, según el mecanismo que recoge el esquema 2.13. ${ }^{135}$ Esta es la principal fuente de errores en la determinación de su toxicología. Si uno de los radicales de la amina es un grupo aromático, la reacción de C-nitrosación estará más favorecida siempre que las posiciones orto o para estén libres. Existe la posibilidad de que esta reacción se produzca por transposición del grupo nitroso desde la amina a través de una primera etapa de nitrosación en meso.

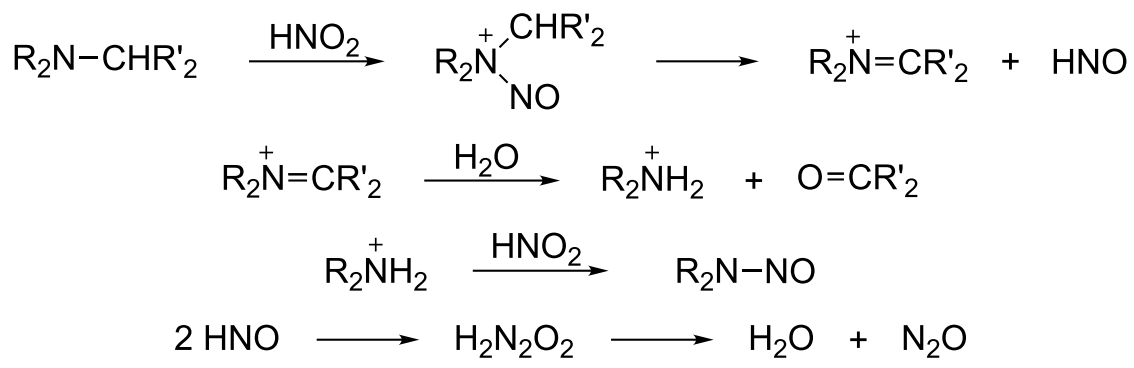

Esquema 2.13: Mecanismo de descomposición de una $N$-nitrosamina terciaria.

Existen reacciones de nitrosación de sales de amonio cuaternario y de óxidos de amina a altas temperaturas. Sin embargo, apenas se conocen los mecanismos por los que transcurren. ${ }^{136}$

\subsubsection{Reacciones de copulación}

Los iones diazonio aromáticos son electrófilos débiles capaces de realizar sustituciones en compuestos ricos en electrones, como los anillos aromáticos activados. Esta reacción se conoce como reacción de copulación (esquema 2.14). ${ }^{131}$ Los sustituyentes del ion diazonio y del anillo aromático con el que 


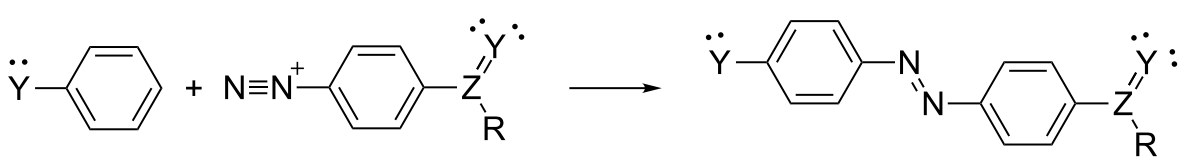

Esquema 2.14: Reacción de copulación.

copula son fundamentales para fomentar la reacción. Como se ha visto en la sección 2.3.1 con la C-nitrosación (página 73), favorecerá la reacción que el anillo aromático esté unido a grupos que cedan sus electrones y aumenten su densidad electrónica, como alcoholes o éteres. Del mismo modo, sustituyentes deficientes en electrones, como nitratos o ésteres, aumentan el carácter electrófilo del ion diazonio y facilitan la reacción.

El pH es también un factor importante en la copulación. Si es demasiado bajo, se puede protonar el grupo que cede electrones al anillo aromático y sustraerlos. Si el pH es demasiado alto, la mayor parte del ion diazonio se encuentra en forma de $\mathrm{Ar}-\mathrm{N}=\mathrm{N}-\mathrm{OH}$ ó $\mathrm{Ar}-\mathrm{N}=\mathrm{N}-\mathrm{O}^{-}$, por lo que la concentración de diazonio efectiva es muy baja.

Los productos de la reacción de copulación son los azocompuestos. Generalmente se utilizan como colorantes debido a que tienen un color muy intenso provocado por la deslocalización electrónica que proporciona el puente azo. Además, el gran número de combinaciones diferentes que se pueden preparar mediante las reacciones de copulación permite obtener casi cualquier color. Otro uso de los azocompuestos es como antibióticos. Esta propiedad se descubrió cuando se intentaron teñir bacterias con un colorante formado por un azocompuesto con el grupo sulfanilamida. Investigaciones posteriores han demostrado que su efectividad se debe a que el producto de su reducción en el cuerpo humano es antibacteriano.

\subsubsection{O-Nitrosación}

Ya se ha visto en la sección 2.2.4 (página 65) que la reacción electrófila entre un agente nitrosante y un alcohol conduce a la formación del correspondiente nitrito de alquilo mediante el siguiente equilibrio: 


$$
\begin{gathered}
\mathrm{ROH}+\mathrm{HNO}_{2} \rightleftharpoons \mathrm{RONO}+\mathrm{H}_{2} \mathrm{O} \\
K=\frac{[\mathrm{RONO}] a_{w}}{\left[\mathrm{HNO}_{2}\right][\mathrm{ROH}]}
\end{gathered}
$$

Por lo general la constante de equilibrio, $K$, no depende mucho de la estructura del alcohol, aunque respeta la lógica sucesión primario $>$ secundario $>$ terciario. ${ }^{105}$ Esto se tiene que tener en cuenta a la hora de entender la efectividad de estos compuestos como agentes nitrosantes. Cuanto más ramificados, más efectivos son, aunque también más lentos.

Los alcoholes aromáticos nitrosados, del mismo modo que las nitrosaminas, también sufren la transposición de su grupo nitroso en lo que se conoce como reordenamiento de Fischer-Hepp, que parece tener un reordenamiento intramolecular, en el que el anillo se protona, formando un intermedio con forma de bote que permite la transposición del grupo nitroso (esquema 2.15).

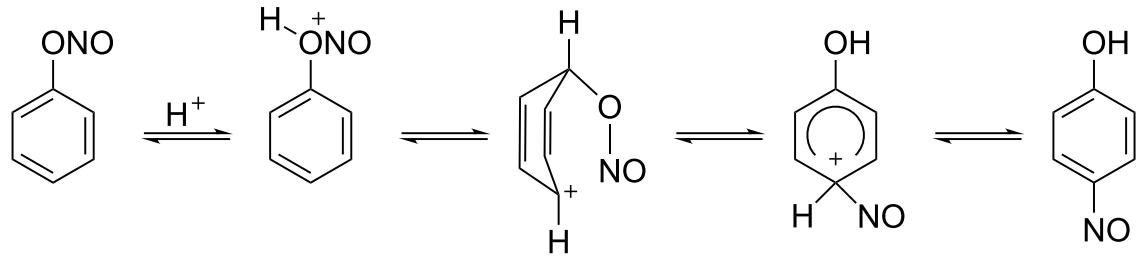

Esquema 2.15: Mecanismo del reordenamiento de Fischer-Hepp.

Otro tipo de reacciones entre un agente nitrosante y el oxígeno son las nitrosaciones de ácidos carboxílicos para obtener carboxilatos de nitrosilo. Estos compuestos tienen características similares a las de las sales de nitrosilo y también pueden ser empleados como agentes nitrosantes. Se forman siguiendo el siguiente equilibrio:

$$
\mathrm{RCOOH}+\mathrm{HNO}_{2} \rightleftharpoons \mathrm{RCOONO}+\mathrm{H}_{2} \mathrm{O}
$$

Para sintetizar carboxilatos de nitrosilo se desplaza el equilibrio de la reacción hacia el lado del carboxilato añadiendo gran exceso de ácido nitroso.

La estructura de estos compuestos no se ha determinado experimentalmente, 
pero estudios teóricos apuntan a que el grupo nitroso se encuentra situado en una posición trans (figura 2.7). ${ }^{137}$

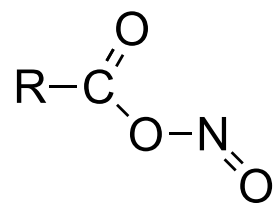

Figura 2.7: Estructura de los carboxilatos de nitrosilo.

\subsubsection{Inhibición de la nitrosación}

Se han investigado mecanismos de inhibición de las reacciones de nitrosación para reducir la exposición de la población a nitrosocompuestos. Todas las estrategias pasan por convertir los agentes nitrosantes en compuestos no reactivos, generalmente haciendo competir a los sustratos con compuestos que reduzcan u oxiden el ion nitrosonio, la mayor parte de las veces a través de una primera etapa de O-nitrosación.

El primer compuesto que mostró inhibición de las reacciones de nitrosación fue el ácido ascórbico. ${ }^{89,138}$ Su estructura con tres sitios O-nitrosables aumenta su efectividad. Además es una molécula lo suficientemente fuerte para vencer el potencial de reducción del ion nitrosonio (página 67) y reducirlo en dos reacciones consecutivas (esquema 2.16).

En relación con la inhibición de las reacciones de nitrosación por ácido ascórbico, es necesaria cierta cautela en su empleo en ciencia y tecnología de los alimentos donde, con frecuencia, se manejan conjuntamente sorbato y nitrito. ${ }^{139}$ En efecto, se sabe que en mezclas sorbato-nitrito se forman especies químicas con actividad mutágena sobre el ADN. ${ }^{140-145}$ Una de esas especies es el ácido etilnitrólico (AEN), ${ }^{140}$ molécula de baja actividad en el test de Ames, pero altamente activa en ensayos rec. ${ }^{142}$

La molécula AEN es, como mínimo, cuarenta veces más activa que la de ácido sórbico y, como mínimo, también treinta veces más activa que el nitrito de sodio en los ensayos rec con bacterias; ${ }^{140}$ donde ejerce acción mutágena sobre la 


\section{4 | Reacciones de nitrosación}<smiles>CC(C)C(=O)ON=[N+]=[N-]</smiles>

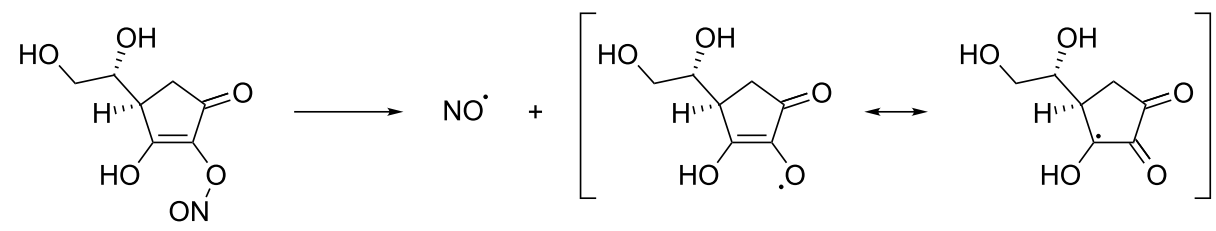<smiles>CC(C)C[C@H](O)[C@@H]1CC(=O)C(=O)C1ON=O</smiles><smiles>CC(C)C(=O)ON=O</smiles>

Esquema 2.16: Mecanismo de reducción de dos moléculas de ion nitrosacidio por ácido ascórbico.

Salmonella. ${ }^{146}$

Como en nuestro grupo de trabajo se ha encontrado correlación entre potencial alquilante y carcinogenia de especies alquilantes fuertes (lactonas) y débiles (sorbatos), se ha abordado el estudio de la posible capacidad alquilante del AEN. ${ }^{147-152}$ Como sustrato de alquilación se ha utilizado el nucleófilo 4(p-nitrobencil)piridina (NBP), trampa de agentes alquilantes y de nucleofilia semejante a las bases del ADN. ${ }^{153}$ Como resultado de ese estudio cinético se ha encontrado que la especie activa, alquilante, formada en las mezclas sorbatonitrito, es el óxido de acetonitrilo. ${ }^{154}$

Se han estudiado compuestos de estructura similar a la del ácido ascórbico, 
como fenoles (ácido gálico, hidroquinonas) o polifenoles (taninos, ácido clorogénico) que han demostrado ser igual de efectivos eliminando los agentes nitrosantes tanto in vitro como in vivo. ${ }^{155}$ Además son compuestos habituales en la alimentación (zumos, vinos, café, tés...). Sin embargo, existen especies fenólicas, como el propio fenol u otros fenoles simples que pueden sufrir Cnitrosación convirtiéndose en agentes nitrosantes, por lo que su uso como inhibidores es restringido.

Otro inhibidor presente en medios biológicos pero peligroso es el peróxido de hidrógeno, que oxida el ion nitrosonio a nitrato. ${ }^{156}$ La reacción transcurre a través de la $\mathrm{O}$-nitrosación del agua oxigenada para formar ácido peroxinitroso que se isomeriza a ion nitrato: ${ }^{157}$

$$
\begin{gathered}
\mathrm{H}_{2} \mathrm{O}_{2}+\mathrm{NO}^{+} \rightarrow \mathrm{HOONO}+\mathrm{H}^{+} \\
\mathrm{HOONO}+\mathrm{H}_{2} \mathrm{O} \rightarrow \mathrm{NO}_{3}^{-}+\mathrm{H}_{3} \mathrm{O}^{+}
\end{gathered}
$$

De la cinética de esta nitrosación ya se ha hablado en la sección 2.2.1 (página 58). El ácido peroxinitroso es muy venenoso y su toxicidad está relacionada el daño biológico que causa el óxido nítrico. ${ }^{158}$

Algunos compuestos de azufre también inhiben las reacciones de nitrosación. El ion bisulfito se oxida a sulfato mientras reduce el ion nitrosonio a óxido nítrico y óxido de dinitrógeno. El ácido sulfámico y sus sales reducen los agentes nitrosantes a $\mathrm{N}_{2}$. Los tioles, como la cisteina o el glutatión, también inhiben las nitrosaciones porque son ellos quienes se nitrosan formando tionitritos. Sin embargo, bajo ciertas condiciones, particularmente a un $\mathrm{pH}$ superior a 5 , pueden actuar como agentes nitrosantes.

La legislación vigente obliga a añadir en la formulación de productos de riesgo como cosméticos o alimentos tratados con nitrito (embutidos, pescados) agentes antioxidantes $\mathrm{u}$ otros compuestos inhibidores para aumentar la seguridad. Los compuestos que se pueden emplear se clasifican según sean o no solubles en agua. Las tablas 2.7, 2.8, 2.9 y 2.10 recogen los inhibidores permitidos para uso humano. ${ }^{159}$ 


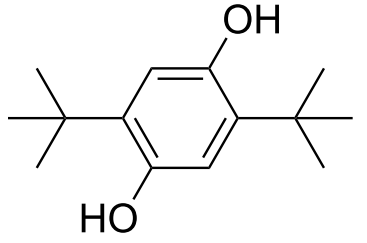

di- $t$-butil hidroquinona<smiles>CCCCCCCOC(=O)c1cc(O)c(O)c(O)c1</smiles>

Galato de octilo

(E311)

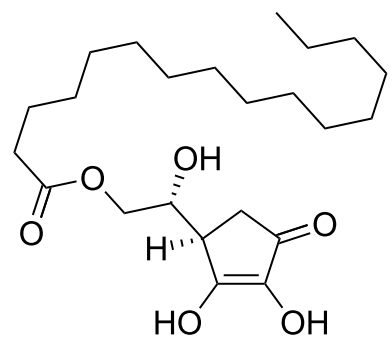

Palmitato de ascorbilo (E304)<smiles>CCOc1ccc2c(c1)C(C)=CC(C)(C)N2</smiles>

Etoxiquina<smiles>CCCOC(=O)c1cc(O)c(O)c(O)c1</smiles>

Galato de propilo<smiles>Cc1cc(O)c(C)c2c1O[C@]1(C)CCC[C@H](C)CCCC[C@H](C)CC(C)CC[C@@]21C</smiles>

Tocoferol (E307)

Tabla 2.7: Inhibidores permitidos para uso humano solubles en aceite. 
<smiles>O=C1C[C@H]([C@H](O)CO)C(O)=C1O</smiles>

Ácido ascórbico

(E300)<smiles>NS(=O)(=O)O</smiles>

Ácido sulfámico<smiles></smiles>

Bisulfito sódico (E223)

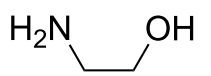

Etanolamina<smiles>O=C1C[C@H](C(O)CO)C(O)=C1O</smiles>

Ácido eritórbico

(E315)<smiles></smiles>

Adipato sódico

(E356)<smiles>N[C@@H](CS)C(=O)O</smiles>

Cisteina

(E920)<smiles>[NH3+][OH+]C1=C(O)C(=O)C[C@H]1[C@H](O)CO</smiles>

Eritorbato sódico<smiles>O=C(O)c1cc(O)ccc1O</smiles>

Ácido gentísico<smiles>[NH3+][OH+]C1=C(O)C(=O)C[C@H]1[C@H](O)CO</smiles>

Ascorbato sódico

(E301)<smiles>[NH3+][18O]C(=O)CC(O)(CC(=O)O)C(=O)O</smiles>

Citrato sódico (E331)<smiles>NC(=O)CC(=O)N[C@@H](CS)C(=O)NCC(=O)O</smiles>

Glutatión

(E316)

Tabla 2.8: Inhibidores permitidos para uso humano solubles en agua (I). 


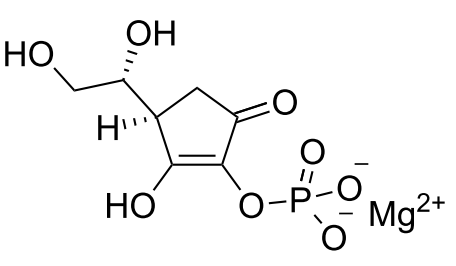

Fosfato de ascorbilo y magnesio

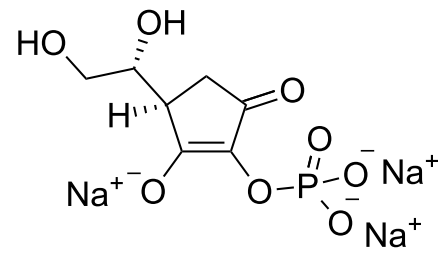

Fosfato de ascorbilo y sodio<smiles></smiles>

Sorbato potásico (E202)<smiles>[NH3+]OC(=O)[C@@H](O)[C@@H](O)C(=O)[OH2+]</smiles>

Tartrato sódico

(E335)<smiles>Oc1ccc(O)cc1</smiles>

Hidroquinona

Tabla 2.9: Inhibidores permitidos para uso humano solubles en agua (II).

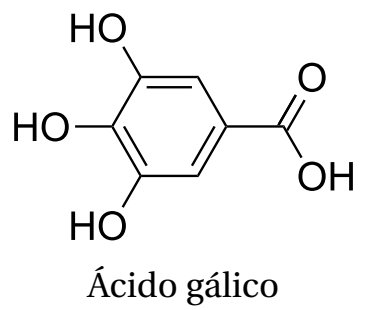

Tabla 2.10: Inhibidor permitido para uso humano soluble en aceite y en agua. 


\subsubsection{Reordenamiento interno}

Muchas reacciones de nitrosación conllevan reordenamientos posteriores que pueden ser de dos clases. La primera son las reacciones tipo Fischer-Hepp, en las que el grupo nitroso sufre una transposición hacia una ubicación más estable. El cambio puede ser intermolecular, como ocurre con las aminas aromáticas (página 79) o intramolecular, como en el caso de los fenoles (página 82) o los ácidos carboxílicos nitrosados. ${ }^{160}$ La eficiencia de estas reacciones se puede explicar en términos estereoquímicos.

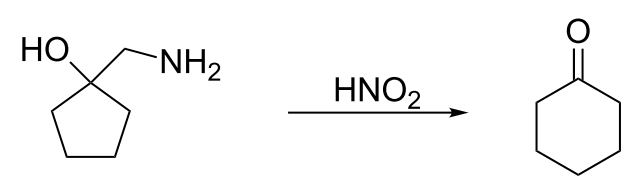

Esquema 2.17: Reordenamiento de Tiffeneau-Demjanov.

La segunda clase de reacciones de reordenamiento interno son las producidas por descomposición de las sales de diazonio en las nitrosaciones de aminas primarias. Promovidas termodinámicamente por la estabilidad del nitrógeno desprendido, estas reacciones son muy variadas.

El reordenamiento de Demjanov (esquema 1.4, página 36) es una reacción en la que, a través de la nitrosación de una amina primaria en posición $\beta$ respecto a un anillo de cuatro, cinco o seis carbonos, se expande el tamaño del anillo.

Una variante de esta reacción es el reordenamiento de Tiffeneau-Demjanov (esquema 2.17), en la que existe un alcohol en el carbono en el que se unen anillo y cadena. Este alcohol cataliza la expansión del anillo transformándose posteriormente a una ciclocetona. ${ }^{161}$ En este caso se pueden ampliar anillos desde el ciclopropano hasta el ciclooctano con algún grado de éxito. ${ }^{162}$ Otra reacción de interés es la ciclación de aminoácidos para formar lactonas. ${ }^{132}$ La amina primaria se nitrosa, convirtiéndose en una sal de diazonio que sufre un ataque nucleófilo por parte del ácido carboxílico (esquema 2.18). 


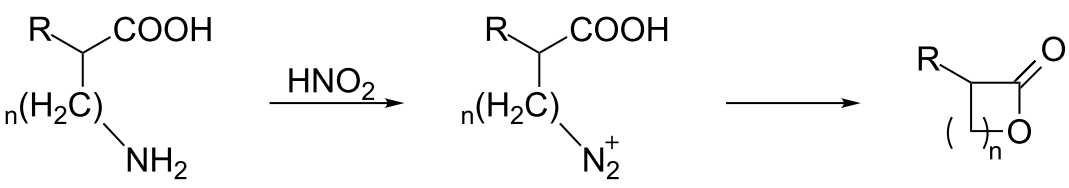

Esquema 2.18: Reacción de ciclación de aminoácidos.

\subsubsection{S-Nitrosación}

Debido a que las propiedades químicas del azufre son similares a las del oxígeno, los compuestos con átomos de dicha especie sufren reacciones con agentes nitrosantes análogas a las de la O-nitrosación. ${ }^{82}$ Tioles, tiocarbonilos, tioéteres o ácidos sulfanílicos pueden convertirse en $S$-nitrosocompuestos. ${ }^{163,164}$

Generalmente, los productos de S-nitrosación son inestables y se descomponen desprendiendo óxido nítrico. ${ }^{165}$ Esta reacción está relacionada con la síntesis metabólica de NO en el organismo.

\subsubsection{Control por difusión}

Una reacción controlada por difusión es aquella en la que los participantes reaccionan tan rápidamente que su velocidad se ve limitada por la velocidad de los procesos físicos que hacen que se encuentren los reactivos. ${ }^{166,167}$ Para dos moléculas solvatadas en un medio, A y B, este proceso se puede representar de la siguiente manera: ${ }^{168}$

$$
\mathrm{A}(s o l v)+\mathrm{B}(s o l v) \stackrel{k_{c}}{\longrightarrow} \mathrm{AB}(s o l v) \stackrel{k_{t}}{\longrightarrow}[\mathrm{ET}]^{\ddagger}(s o l v)
$$

Los modelos que describen el estado líquido representan las moléculas de los reactivos rodeadas de moléculas de disolvente. Los reactivos se van moviendo por los huecos que dejan las moléculas de disolvente hasta que se encuentran adyacentes, formando el complejo de colisión. La velocidad de este proceso está caracterizada por $k_{c}$. El complejo de colisión, función de factores como la temperatura o la orientación de los reactivos, puede conducir a la reacción, 


\section{Informe bibliográfico $\mid 91$}

formando el estado de transición, $[\mathrm{ET}]^{\ddagger}$, solvatado a una velocidad regida por $k_{t}$.

En las reacciones controladas por difusión, la energía de activación de la reacción, $\mathrm{E}_{a}$, es menor que la energía para el flujo viscoso del disolvente y $k_{t}$ es mucho mayor que $k_{c}$.

A partir de las Leyes de Flick es posible estimar la constante de velocidad de una reacción controlada por difusión en función de la distancia crítica entre las dos moléculas, $d_{\mathrm{AB}}$, y los coeficiente de difusión de los reactivos, $D_{\mathrm{A}}$ y $D_{\mathrm{B}}$ :

$$
k=4 \pi N_{A}\left(D_{\mathrm{A}}+D_{\mathrm{B}}\right) d_{\mathrm{AB}}
$$

Los coeficientes de difusión dependen de la viscosidad del disolvente y $\eta$, la temperatura, $T$ :

$$
D=\frac{k_{\mathrm{B}} T}{6 \pi \eta r}
$$

$k_{\mathrm{B}}$ es la constante de Boltzmann y $r$ es el radio efectivo de la molécula. Si la reacción transcurre entre especies iónicas, es necesario multiplicar la ecuación 2.19 por un coeficiente denominado factor electrostático $f$ :

$$
f=\frac{y}{\mathrm{e}^{y}-1}
$$

donde $y$ es una constante que engloba las cargas de los dos iones con su signo, $z_{\mathrm{A}}$ y $z_{\mathrm{B}}$, la distancia crítica, $d$, la permitividad eléctrica del disolvente, $\varepsilon$, la carga de un electrón, $e$, y la temperatura, $T$ :

$$
y=\frac{z_{\mathrm{A}} z_{\mathrm{B}} e^{2}}{4 \pi \varepsilon d k_{\mathrm{B}} T}
$$

El factor electrostático es mayor de la unidad si los reactivos tienen cargas opuestas y menor si los reactivos tienen el mismo signo, lo que corrige la atracción o la repulsión electrostática en la ecuación de velocidad.

Muchas reacciones de nitrosación, en especial las que tienen al $\mathrm{N}_{2} \mathrm{O}_{3}$ como agente nitrosante, están controladas por difusión. Se llegó a esta conclusión tras el estudio de las constantes de velocidad de la reacción de nitrosación de 
92 | Reacciones de nitrosación

\begin{tabular}{|c|c|c|c|}
\hline Sustrato & $k / 10^{8} \mathrm{M}^{-1} \mathrm{~s}^{-1}$ & Sustrato & $k / 10^{8} \mathrm{M}^{-1} \mathrm{~s}^{-1}$ \\
\hline morfolina & 2,2 & metilbencilamina & 1,8 \\
\hline$o$-cloroanilina & 0,14 & etilbencilamina & 3,1 \\
\hline$m$-cloroanilina & 0,96 & $N$-metilglicina & 1,5 \\
\hline$p$-cloroanilina & 2,8 & 2-butilamina & 1,6 \\
\hline$o$-toluidina & 4,2 & propilamina & 0,94 \\
\hline anilina & 7,5 & diisobutilamina & 1,3 \\
\hline$m$-toluidina & 8,2 & dimetilamina & 1,2 \\
\hline$N$-metilanilina & 4,0 & dietilamina & 1,1 \\
\hline$p$-toluidina & 19,0 & dipropilamina & 1,2 \\
\hline$p$-metoxianilina ${ }^{a}$ & 1,8 & metilciclohexilamina & 2,2 \\
\hline piperacina & 1,3 & diisopropilamina & 1,3 \\
\hline hidroxilamina & 2,0 & piperidina & 1,3 \\
\hline nitrosopiperacina & 0,75 & dibutilamina & 1,8 \\
\hline
\end{tabular}

${ }^{a}$ Constante medida a $0{ }^{\circ} \mathrm{C}$.

Tabla 2.11: Constantes de velocidad a $25{ }^{\circ} \mathrm{C}$ de nitrosaciones controladas por difusión en agua. ${ }^{96}$

decenas de aminas. Pese a la gran variedad de estructuras analizadas, todas las constantes tenían un valor del orden de $10^{8} \mathrm{M}^{-1} \mathrm{~s}^{-1}$ (tabla 2.11). ${ }^{96}$ El hecho de que todas las reacciones tuviesen una energía de activación baja apoyó la teoría.

\subsubsection{Control orbitálico}

Las reacciones con control orbitálico son aquellas en las que su velocidad se ve influenciada por la energía del último nivel ocupado (HOMO) del nucleófilo.

Generalmente, la formación de un enlace entre un electrófilo y un nucleófilo está regida por las diferencias de carga eléctrica entre los reactivos. ${ }^{169} \mathrm{El} \mathrm{nu-}$ cleófilo, rico en electrones, se ve atraído por el electrófilo, comenzando la unión 


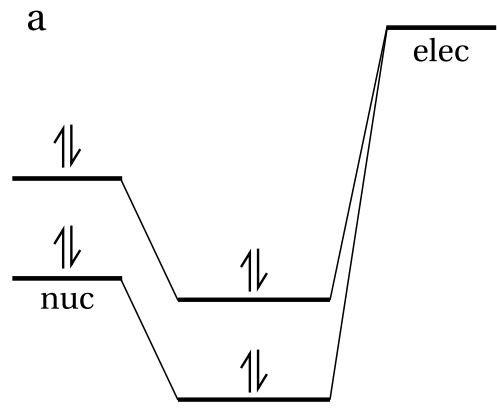

b

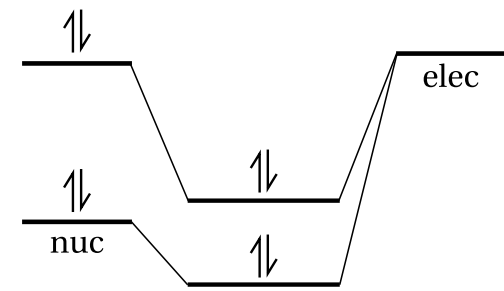

Figura 2.8: Diagramas de orbitales moleculares para una reacción con control por carga (a) y con control orbitálico (b).

sin apenas ceder los electrones. Según la teoría de orbitales moleculares, estas uniones, denominadas reacciones controladas por carga, se deben a la gran diferencia de energía que existe entre el orbital ocupado más alto del nucleófilo y el orbital vacío más bajo del electrófilo (figura 2.8).

En ocasiones, la diferencia de energías entre los dos orbitales es muy pequeña y la formación del enlace se ve dirigida por la interacción de los electrones del nucleófilo con el orbital vacío del electrófilo. En este caso, la velocidad de reacción depende del nivel de energía del último orbital ocupado del nucleófilo y se dice que la reacción tiene control orbitálico. En estas reacciones existe una correlación entre el valor de la constante de velocidad y el potencial de ionización vertical del nucleófilo.

En las nitrosaciones las reacciones de control orbitálico son comunes debido a la electronegatividad de los átomos de nitrógeno y oxígeno, que hacen al grupo nitroso poco electrófilo. El ejemplo más documentado son las aminolisis de los nitritos de alquilo. ${ }^{105}$ Como las aminas son nucleófilos débiles, la diferencia de energías entre sus orbitales y los de los nitritos de alquilo son pequeñas y se ven regidas por el control orbitálico, lo que explica la diferencia de velocidad con las reacciones equivalentes de las aminolisis de los ésteres de alquilo. ${ }^{170} \mathrm{La}$ correlación entre los potenciales de ionización de las aminas con las constantes de velocidad demuestran el control orbitálico. 


\subsection{Nitrosación, mutagenia y carcinogenia}

La relación entre nitrosocompuestos y cáncer aún hoy, medio siglo después del trabajo pionero de Magee y Barnes, es motivo de polémica. Pese a que se ha demostrado que producen una amplia variedad de tumores en más de 40 especies animales, incluidos primates superiores, aún no existen pruebas epidemiológicas concluyentes de que los nitrosocompuestos sean carcinogénicos para el hombre. ${ }^{171,172}$

Varias nitrosaminas, como la nitrosodietilamina, nitrosodimetilamina o nitrosonornicotina están clasificadas por la Agencia Internacional para la Investigación en Cáncer (IARC) como compuestos probablemente carcinogénicos para los humanos (Grupo 2A). ${ }^{173,174}$ Existen estudios que relacionan el consumo de nitritos y nitrosaminas con el cáncer de estómago y con el riesgo de desarrollar cáncer de esófago. De igual modo, se ha encontrado una asociación positiva y significativa entre el consumo de alimentos tratados con nitrito y el cáncer nasofaríngeo. ${ }^{175} \mathrm{Al}$ interpretar estos estudios se debe tener en cuenta que, por lo general, las carnes y los pescados tratados con nitrito suelen contener también importantes cantidades de sal. La sal induce procesos inflamatorios que reducen la mucosa protectora del estómago e incrementan el riesgo de cáncer de estómago. La infección con Helicobacter pylori puede estar relacionada con el consumo de sal y de nitrosocompuestos, aumentando la carcinogenia tras dañar el epitelio.

Pese a las sospechas derivadas de los ensayos con animales, no se ha encontrado una relación clara entre el consumo de nitrosocompuestos y el desarrollo de cánceres de páncreas, colon o cerebro. ${ }^{176}$ Sí que se ha encontrado una relación entre la exposición durante el embarazo a $N$-nitrosocompuestos, principalmente $N$-nitrosamidas, y el riesgo de tumor cerebral infantil. ${ }^{177}$

Los mecanismos químicos por los que los nitrosocompuestos provocan mutaciones en el código genético pasan por la formación de un carbocatión que alquile las bases del ADN. Este carbocatión se forma por nitrosación y posterior desaminación de una amina primaria por un agente nitrosante (página 78) o mediante la activación metabólica de una $N$-nitrosamina secundaria. Otros nitrosocompuestos no pueden ser agentes alquilantes por lo que su actividad 
mutágena depende de su capacidad para nitrosar alguna amina del medio. ${ }^{172}$

Las bases del ADN son sustratos ricos en electrones adecuados para la reacción con un carbocatión. Casi todos sus heteroátomos son susceptibles de ser alquilados, aunque el sitio preferido depende de la naturaleza del agente alquilante. ${ }^{178}$ La posición N-7 de la guanosina es el punto más nucleófilo de las bases del ADN y es donde suelen reaccionar casi todos los agentes alquilantes sin impedimento estérico. Las reacciones en otros lugares dependen de la estructura del electrófilo. Los agentes alquilantes fuertes (de pequeño tamaño, carga positiva y baja polarizabilidad) como los iones diazonio reaccionan mejor con los oxígenos de los nucleófilos del ADN, mientras que los agentes alquilantes débiles tienden a reaccionar con los nitrógenos de las bases. Los productos de las reacciones de alquilación son estables para la mayor parte de las posiciones.

El proceso por el cual una $N$-nitrosamina secundaria se convierte en un agente alquilante se muestra en el esquema 2.19. La nitrosamina secundaria es estable en condiciones fisiológicas y llega sin dificultad a la célula. Ésta la procesa por medio del citocromo $\mathrm{P} 450$, un tipo de proteinas situado en la membranas interiores de la mitocondria o del retículo endoplasmático que metaboliza los compuestos exógenos de la célula a través de una reacción de monooxidación:

$$
\mathrm{RH}+\mathrm{O}_{2}+\mathrm{NADPH}+\mathrm{H}^{+} \rightarrow \mathrm{ROH}+\mathrm{H}_{2} \mathrm{O}+\mathrm{NADP}^{+}
$$

Al metabolizar la nitrosamina secundaria, el citocromo P450 la transforma en una $\alpha$-hidroxilnitrosamina, que espontáneamente se divide en un aldehído y un alquildiazohidróxido. Como ocurría en los procesos de desaminación de nitrosaminas primarias, el alquildiazohidróxido se transforma en una sal de diazonio a través de la pérdida de una molécula de agua tras su protonación. La sal de diazonio obtenida es capaz de alquilar cualquier posición nucleófila de los constituyentes celulares, ya sean ácidos nucleicos o proteínas. De esta forma, los nitrosocompuestos pueden interferir y alterar los procesos celulares, considerándose, además de mutágenos y carcinógenos, compuestos citotóxicos.

Todos los organismos tienen sistemas de reparación para el daño que provoca la alquilación de su ADN. ${ }^{179}$ En total, el ADN de un ser humano sufre más de 20.000 lesiones endógenas por día y por célula, siendo las principales fuentes 


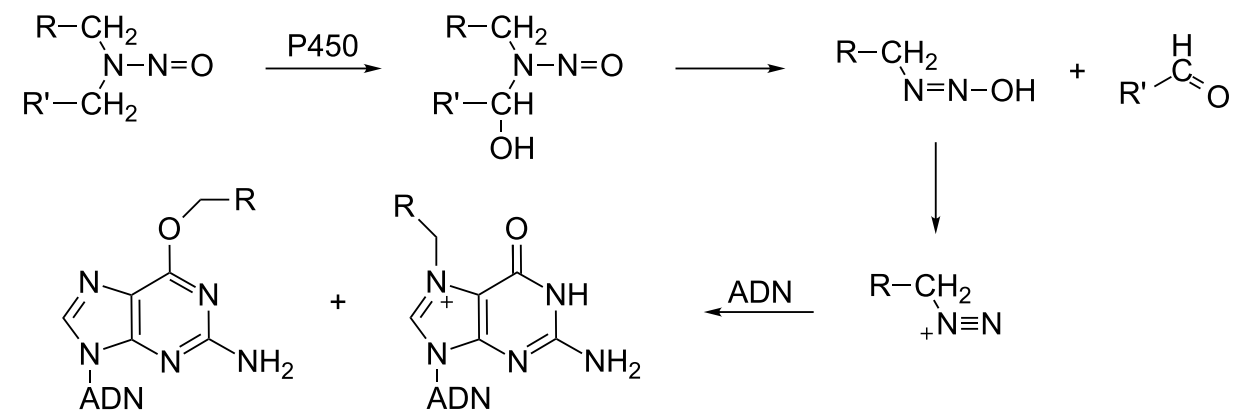

Esquema 2.19: Activación metabólica de $N$-nitrosocompuestos.

la despurinización y la desaminación espontáneas de las bases y la oxidación natural. La contribución relativa del daño por alquilación no se conoce con exactitud; sin embargo, la mera existencia de varios sistemas de reparación para las lesiones por alquilación indica que la exposición endógena y medioambiental debe ser significativa. De hecho, todos los mecanismos principales de reparación del ADN (reparación sobre la marcha, reparación directa, reparación por escisión de base, reparación por escisión de nucleótido, reparación de malapareamiento) están involucrados en el procesado de productos de alquilación primarios (metilaciones, cloroetilaciones) y en la corrección de los daños secundarios provocados por esos productos (rupturas de la hebra, enlace cruzado entre bases de hebras opuestas, pérdida de la basicidad). ${ }^{180}$

Debido a estos sistemas de reparación y a que no todas las modificaciones en las bases son biológicamente importantes, no siempre es posible establecer una correlación entre estructura química y carcinogenia o entre las condiciones de exposición al agente alquilante y carcinogenia. ${ }^{181}$ 


\subsection{Compuestos estudiados}

En el presente trabajo, se han elegido seis compuestos aromáticos de complejidad creciente para el estudio cinético-mecanístico de su nitrosación (figura 2.9). A continuación se describirá cada compuesto haciendo hincapié en algunas características de interés.<smiles>CCc1ccccc1</smiles><smiles>NCCc1ccccc1</smiles><smiles>NCCc1ccc(O)cc1</smiles><smiles>NCCc1ccc(O)c(O)c1</smiles><smiles>NCCc1c[nH]c2cc(O)ccc12</smiles><smiles>Nc1cc(N2CCCCC2)nc(N)[n+]1[O-]</smiles>

Figura 2.9: Sustratos cuya nitrosación se ha estudiado. De izquierda a derecha: etilbenceno, fenetilamina, tiramina, dopamina, serotonina y minoxidilo.

\subsubsection{Etilbenceno}

El etilbenceno (tabla 2.12) es un líquido incoloro, inflamable y de olor similar al de la gasolina. Se encuentra de forma natural en el petróleo y en el carbón, aunque se obtiene principalmente de la reacción entre etileno y benceno: ${ }^{182}$

$$
\mathrm{C}_{6} \mathrm{H}_{6}+\mathrm{C}_{2} \mathrm{H}_{4} \rightarrow \mathrm{C}_{6} \mathrm{H}_{5} \mathrm{CH}_{2} \mathrm{CH}_{3}
$$

El 99\% del etilbenceno producido en el mundo (28 millones de toneladas anuales en 2002) se dedica a la preparación del monómero estireno, una de las materias primas más importantes en la fabricación de plásticos. ${ }^{183}$ El estireno se obtiene por la deshidrogenación de la cadena lateral del etilbenceno en una reacción catalizada por ácidos de Lewis:

$$
\mathrm{C}_{6} \mathrm{H}_{5} \mathrm{CH}_{2} \mathrm{CH}_{3} \stackrel{\mathrm{AlCl}_{3}}{\longrightarrow} \mathrm{C}_{6} \mathrm{H}_{5} \mathrm{CH}=\mathrm{CH}_{2}+\mathrm{H}_{2}
$$


El $1 \%$ restante principalmente se emplea como disolvente en pinturas, lacas, tintas de impresora e insecticidas. Otro uso, mucho más minoritario, es como compuesto de partida para la síntesis industrial de acetofenona y dietilbenceno.

La reactividad del etilbenceno es baja, sin embargo puede llevar a cabo reacciones típicas de compuestos alquilaromáticos, como desalquilaciones térmicas, sustituciones electrófilas aromáticas con electrófilos fuertes u oxidación de su cadena lateral para formar acetonas y ácidos carboxílicos aromáticos.

Desde el punto de vista biológico, el etilbenceno está clasificado por la Agencia Internacional para la Investigación en Cáncer como un posible carcinógeno (Grupo 2B). ${ }^{184}$ Ratones expuestos a una atmósfera enriquecida con el compuesto desarrollaron cáncer de riñón. Sin embargo, los datos que se desprenden de los test habituales de genotoxicidad in vivo e in vitro no pudieron demostrar las propiedades cancerígenas del compuesto.

El etilbenceno es metabolizado por el organismo a través de la $\alpha$-hidroxilación a 1-feniletanol, que se excreta por la orina. También puede sufrir otras modificaciones metabólicas como la oxidación del carbono $\omega$ para dar 2-feniletanol, la oxidación del anillo aromático produciéndose 4-etilfenol u oxidaciones posteriores de los productos de metabolización. Todos los productos también son separados en el riñón y eliminados en la orina.

\subsubsection{Fenetilamina}

La fenetilamina (tabla 2.13) es un alcaloide natural monoamínico que actúa como neurotransmisor en el sistema nervioso central. Su estructura, efectos farmacológicos y efectos en el comportamiento se parecen a los de la anfetamina (figura 2.10), por lo que varios investigadores han sugerido un papel significativo de la fenetilamina en la esquizofrenia y otros desórdenes psicológicos como el enamoramiento o la depresión. ${ }^{185}$

La fenetilamina se encuentra en multitud de alimentos, como legumbres, frutos secos o marisco, aunque el alimento que más fenetilamina contiene es el chocolate. Para proteger al sistema nervioso, la fenetilamina consumida via oral jamás alcanza el resto del organismo puesto que, tras ser absorbida en el sistema 


\begin{tabular}{ll}
\hline & Etilbenzol \\
Otros nombres: & Feniletano \\
Número CAS: & $100-41-4$ \\
Apariencia: & Líquido incoloro \\
Punto de fusión: & $-95{ }^{\circ} \mathrm{C}$ \\
Punto de ebullición: & $136{ }^{\circ} \mathrm{C}$ \\
Peso molecular: & 106,17 g/mol \\
Densidad: & $0,8665 \mathrm{~kg} / \mathrm{m}^{3}$ a $20{ }^{\circ} \mathrm{C}$ \\
Solubilidad: & 0,015 g/ 100 ml agua $\left(20{ }^{\circ} \mathrm{C}\right)$ \\
Índice de refracción: & Soluble en benceno \\
Precauciones: & $\mathrm{R}-11$ : Fácilmente inflamable \\
& $\mathrm{R}-20: \mathrm{Nocivo}$ por inhalación \\
& $\mathrm{S}-16:$ Conservar alejado de toda llama o fuente de chispas \\
& $-\mathrm{No}$ fumar \\
& $\mathrm{S}-24 / 25:$ Evítese el contacto con los ojos y la piel \\
& $\mathrm{S}-29: \mathrm{No}$ tirar los residuos por el desagüe \\
\hline
\end{tabular}

Tabla 2.12: Propiedades del etilbenceno. ${ }^{186}$ 
<smiles>NC(Cc1ccccc1)C(=O)O</smiles>

\section{L-fenilalanina}<smiles>CC(C)C(=O)O</smiles><smiles>NCCc1ccccc1</smiles>

fenetilamina<smiles>N[C@@H](Cc1ccc(O)cc1)C(=O)O</smiles>

L-tirosina<smiles>CC(Cl)C(=O)O</smiles><smiles>NCCc1ccc(O)cc1</smiles>

tiramina<smiles>N[C@@H](Cc1ccc(O)c(O)c1)C(=O)O</smiles>

L-DOPA<smiles>CC(C)C(=O)O</smiles><smiles>NCCc1ccc(O)c(O)c1</smiles>

dopamina

Esquema 2.20: Biosíntesis de fenetilamina, tiramina y dopamina a partir de fenilalanina. a, fenilalanina hidroxilasa, b, tirosina hidroxilasa, c, fenilalanina descarboxilasa, d, tirosina descarboxilasa, e, L-DOPA descarboxilasa.

digestivo, es transportada por la vena porta al hígado, donde la mayor parte es inactivada rápidamente a través de su transformación en ácido fenilacético por las enzimas monoamina oxidasa (MAO). ${ }^{187}$ Además de la hidroxilación por las enzimas MAO, la fenetilamina puede ser metabolizada por otras enzimas, como la aldehido deshidrogenasa o la dopamina $\beta$-hidroxilasa para dar productos que se eliminan por la orina. ${ }^{188}$ La cantidad habitual de fenetilamina en sangre para un adulto sano es de $1,2 \mathrm{ng} / \mathrm{ml}{ }^{189}$

La fenetilamina es una molécula liposoluble que atraviesa sin problemas la barrera hematoencefálica. De forma pura es un líquido corrosivo de color amarillento y un intenso olor a flores podridas causado por su grupo aromático 


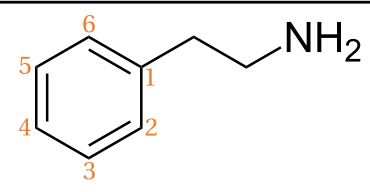

Fenetilamina (PHE)

\begin{tabular}{|c|c|}
\hline Otros nombres: & $\beta$-feniletilamina \\
\hline & 2-feniletilamina \\
\hline Abreviatura: & PEA (en neurociencias) \\
\hline Número CAS: & 64-04-0 \\
\hline Apariencia: & Líquido incoloro \\
\hline Punto de fusión: & $-60^{\circ} \mathrm{C}$ \\
\hline Punto de ebullición: & $198,5^{\circ} \mathrm{C}$ \\
\hline Peso molecular: & $121,18 \mathrm{~g} / \mathrm{mol}$ \\
\hline Densidad: & $0,962 \mathrm{~kg} / \mathrm{m}^{3}$ a $20^{\circ} \mathrm{C}$ \\
\hline Solubilidad: & $2,9 \mathrm{~g} / 100 \mathrm{ml}$ agua $\left(20^{\circ} \mathrm{C}\right)$ \\
\hline Índice de refracción: & 1,533 \\
\hline Precauciones: & R-22: Nocivo por ingestión \\
\hline & R-34: Provoca quemaduras \\
\hline & $\begin{array}{l}\text { S-26: En caso de contacto con los ojos, lávese abundante- } \\
\text { mente con agua y acuda a un médico }\end{array}$ \\
\hline & $\begin{array}{l}\text { S-36/37/39: Úsese indumentaria y guantes adecuados y } \\
\text { protección para los ojos/la cara }\end{array}$ \\
\hline & $\begin{array}{l}\text { S-45: En caso de accidente o malestar, acúdase inmedia- } \\
\text { tamente al médico }\end{array}$ \\
\hline Constante de acidez ( & \\
\hline
\end{tabular}

Tabla 2.13: Propiedades de la fenetilamina. ${ }^{190}$ 


\section{2 | Compuestos estudiados}

y su amina primaria. Es un molécula muy básica que forma sales estables con diversos ácidos. Con el ácido clorhídrico forma una sal que tiene un punto de fusión de $217^{\circ} \mathrm{C}$ y con el dióxido de carbono del aire reacciona formando carbonato de fenetilamonio.

La fenetilamina es sintetizada en el cuerpo humano en la ruta de las catecolaminas a partir de la descarboxilación de la fenilalanina (esquema 2.20). Las catecolaminas son un grupo de sustancias con actividad neuronal que en principio contienen una amina y el grupo catecol (o-dihidroxifenilo), aunque dentro del grupo se incluyen sustancias afines de estructura similar (figura 2.10). La mayor parte de estos compuestos se produce en las glándulas suprarrenales, si tienen una función hormonal, o en las neuronas catecolaminérgicas, si se emplean como neurotransmisores. Disfunciones en el metabolismo de las catecolaminas son causa de enfermedades mentales como la esquizofrenia o trastornos bipolares o enfermedades neurológicas como el Párkinson o la migraña. Muchos medicamentos y sustancias estupefacientes tienen estructuras parecidas para actuar en el sistema nervioso.

Los productos de nitrosación de la fenetilamina no han demostrado ser ni mutágenos ni genotóxicos en dos ensayos biológicos in vitro realizados con el test de Ames (sección 3.2.1) y el Cromotest SOS, respectivamente. ${ }^{191}$

\subsubsection{Tiramina}

La tiramina (tabla 2.14) es una sustancia monoamínica aromática con actividad biológica. Casi todos los seres vivos son capaces de sintetizarla a través de la descarboxilación del aminoácido tirosina (esquema 2.20) y por eso aparece de forma natural en multitud de alimentos, como legumbres, frutas, frutos secos, chocolate, carnes, mariscos y pescado. En cualquier caso, los alimentos con mayor concentración de tiramina son los que su preparación favorece la descomposición de la tiramina, como son los productos fermentados (yogures, quesos, salsas de soja o bebidas alcohólicas) o envejecidos (conservas, embutidos o productos ahumados) ${ }^{192}$.

Dados los alimentos en los que se distribuye, la tiramina es un compuesto que frecuentemente aparece acompañado de nitritos, por lo que el riesgo de que se 


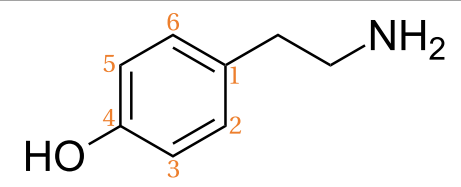

Tiramina (TYR)

\begin{tabular}{|c|c|}
\hline \multirow[t]{3}{*}{ Otros nombres: } & 4-(2-aminoetil)fenol \\
\hline & 4-hidroxifenetilamina \\
\hline & 2-(4-hidroxifenil)etilamina \\
\hline Abreviatura: & TY (en neurociencias) \\
\hline Número CAS: & $51-67-2$ \\
\hline Apariencia: & Polvo beige \\
\hline Punto de fusión: & $160^{\circ} \mathrm{C}$ \\
\hline Peso molecular: & $137,18 \mathrm{~g} / \mathrm{mol}$ \\
\hline \multirow[t]{2}{*}{ Solubilidad: } & Soluble en agua \\
\hline & Soluble en alcohol \\
\hline \multirow[t]{3}{*}{ Precauciones: } & R-36/37/38: Irrita los ojos, la piel y las vías respiratorias \\
\hline & $\begin{array}{l}\text { S-26: En caso de contacto con los ojos, lávese abundante- } \\
\text { mente con agua y acuda a un médico }\end{array}$ \\
\hline & S-36: Úsese indumentaria protectora adecuada) \\
\hline \multicolumn{2}{|c|}{ Constantes de acidez $\left(\mathbf{p K} \mathbf{K}_{\mathbf{a}}\right)$ : } \\
\hline
\end{tabular}

Tabla 2.14: Propiedades de la tiramina. ${ }^{193}$ 
<smiles>NCC(O)c1ccc(O)c(O)c1</smiles>

Noradrenalina<smiles>CC(N)C(O)c1ccccc1</smiles>

Norefedrina<smiles>CC(N)Cc1ccccc1</smiles>

Anfetamina<smiles>CNCC(O)c1ccc(O)c(O)c1</smiles>

Adrenalina<smiles>CNC(C)C(O)c1ccccc1</smiles>

Efedrina<smiles>CNC(C)Cc1ccccc1</smiles>

Metilanfetamina<smiles>CNCC(O)c1ccc(O)cc1</smiles>

Sinefrina<smiles>COC(=O)C(c1ccccc1)C1CCCCN1</smiles>

Metilfenidato<smiles>CNC(C)Cc1ccc(O)c(OC)c1</smiles>

HMMA<smiles>COc1cc(CCN)cc(OC)c1OC</smiles>

Mescalina<smiles>NCCc1ccc2c(c1)OCO2</smiles>

Éxtasis<smiles>O=Cc1ccc2c(c1)OCO2</smiles>

Heliotropina

Figura 2.10: Otras catecolaminas de interés biológico.

transforme en nitrosocompuestos potencialmente peligrosos es alto. Existen varios estudios sobre la mutagenia de alimentos ricos en tiramina tratados con nitrito sódico ${ }^{191,194,195}$ y de la propia tiramina nitrosada. ${ }^{191,196}$ Todos ellos coinciden en que la tiramina nitrosada es un importante agente mutágeno. Estudios realizados in vivo han demostrado que la tiramina nitrosada induce la formación de cáncer en la cavidad oral que es precisamente uno de los cánceres más 
comunes en zonas donde el consumo de soja fermentada es más frecuente. ${ }^{197}$

La tiramina es metabolizada por las enzimas monoamina oxidasa que la oxidan a ácido 4-hidroxifenilacético. A diferencia de la fenetilamina y la mayor parte de los aminoácidos, la tiramina no puede atravesar la barrera hematoencefálica, por lo que no es tan peligrosa. Sin embargo se ha demostrado que la tiramina, en el cuerpo humano, provoca la liberación de otras monoaminas almacenadas, como la dopamina o la epinefrina, lo que provoca hipertensión arterial y dolores de cabeza. Las personas que toman medicamentos antidepresivos deben evitar el consumo de alimentos ricos en tiramina, ya que inhiben las enzimas MAO, haciendo que la concentración de tiramina en el organismo aumente. Bajo estos medicamentos, el consumo de tan sólo 6 mg de tiramina provoca hipertensión y $25 \mathrm{mg}$ se puede considerar una dosis letal para algunas personas. ${ }^{198}$

La tiramina es un compuesto básico cuya constante de acidez es cuatro veces mayor que la de la fenetilamina. Esta diferencia se debe a que la amina también puede protonarse en la forma neutra de la molécula al formar un equilibrio con el alcohol aromático para dar su forma zwitteriónica (esquema 2.21). ${ }^{190}$ Dada su basicidad, la tiramina forma sales estables con múltiples compuestos, tanto orgánicos como inorgánicos. ${ }^{199}$<smiles>NCCc1ccc(Oc2ccc(CC[NH3+])cc2)cc1</smiles>

Esquema 2.21: Protonación de la amina a la forma zwitteriónica de la tiramina.

\subsubsection{Dopamina}

La dopamina (tabla 2.15) es un compuesto orgánico de la familia de las catecolaminas. Hasta los años 50 se pensaba que la única función que tenía la dopamina en el organismo era la de actuar como intermedio en la biosíntesis de otras catecolaminas como norepinefrina y epinefrina (figura 2.10). Esta concepción cambió con los trabajos de Kathleen Montagu, que encontró cantidades significativas de dopamina en el cerebro, ${ }^{200}$ y de Arvid Carlsson (premio Nóbel 


\section{6 | Compuestos estudiados}

de fisiología y medicina en el año 2000), quien demostró su actividad como neurotransmisor. ${ }^{201}$

Principalmente, la dopamina es sintetizada por neuronas y células de las glándulas suprarrenales en la ruta de las catecolaminas (véase esquema 2.20). ${ }^{202}$ La dopamina se sintetiza utilizando como base la tirosina acumulada en la célula, que se oxida a fenilalanina y posteriormente a 3,4-dihidroxifenilalanina (de cuyo acrónimo, DOPA, toma el nombre la dopamina). La descarboxilación de este compuesto genera la dopamina. La etapa limitante de la velocidad en este mecanismo es la generación de L-DOPA, que debido a que se descarboxila inmediatamente, su concentración en el cerebro es generalmente baja.

La dopamina tiene diversas funciones en el organismo. En el cerebro, existen un tipo de neuronas, denominadas dopaminérgicas, cuyo neurotransmisor principal es la dopamina. Se encuentran en la parte compacta de la sustancia negra, el área tegmental ventral y el hipotálamo y sus axones se proyectan a varias áreas del cerebro. Se cree que este sistema participa en actividades como el aprendizaje, el sueño, la memoria, la consciencia o la gratificación sexual. ${ }^{203}$ La muerte de las células dopaminérgicas en la sustancia negra y, por consiguiente, la biosíntesis insuficiente de dopamina son el origen de la enfermedad de Parkinson. Fuera del cerebro, la dopamina participa en la regulación del funcionamiento de los riñones, el sistema inmunitario y el aparato circulatorio. Como medicamento, la dopamina en forma de hidrocloruro se emplea para aumentar la tensión sanguínea y restaurar los valores hemodinámicos por vía intravenosa tras un infarto de miocardio, una septicemia o cirugía a corazón abierto.

La degradación de la dopamina en el cuerpo humano se produce por dos vías (esquema 2.22). La primera es, como con los compuestos anteriores, con la ruta de las enzimas monoamina oxidasa, que transforman la dopamina en 3,4-dihidroxifenilacetaldehido. Casi inmediatamente, este compuesto es transformado en ácido 3,4-dihidroxifenilacético (DOPAC) por la enzima aldehido deshidrogenasa (ALDH). La segunda es una ruta exclusiva de las catecolaminas en las que la enzima catecol-O-metiltransferasa (COMT), metila el alcohol en la posición 3 del anillo aromático para formar 3-metoxitiramina (3-MT). Los productos de ambas vías se transforman en un producto común, denominado 


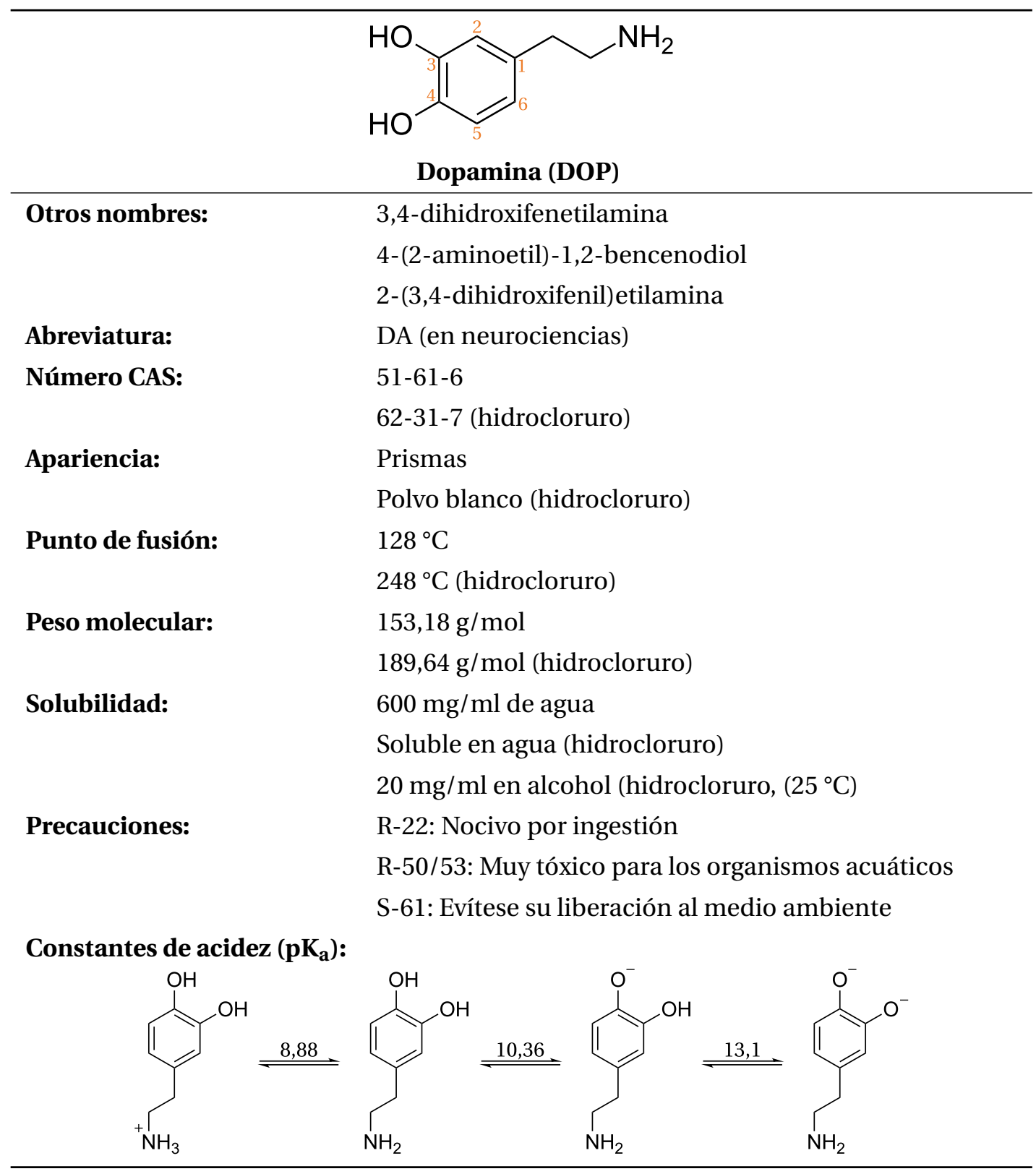

Tabla 2.15: Propiedades de la dopamina. ${ }^{190,204}$ 
<smiles>COc1cc(CCN)ccc1O</smiles>

Esquema 2.22: Metabolización de la dopamina.

ácido homovanílico (HVA), que es el metabolito principal de descomposición de la dopamina en los seres humanos.

Desde el punto del vista químico, la dopamina es una base fuerte. De igual modo que en la tiramina, su constante de acidez es inusualmente alta (8 veces superior a la de la fenetilamina) debido al equilibrio que se crea entre la forma neutra de la molécula y su estructura zwitteriónica, en este caso estabilizada por un puente de hidrógeno con el segundo alcohol del anillo. ${ }^{190}$ La dopamina forma sales con multitud de ácidos, siendo el hidrocloruro de dopamina la forma más habitual de comercializar el compuesto. La dopamina pura se oxida con el oxígeno ambiental, ${ }^{205}$ en una reacción radicalaria. ${ }^{206}$ En disolución acuosa esta reacción se encuentra catalizada por el medio básico, con el anion superóxido como intermedio ${ }^{207}$ y que terminaba con la ciclación de la cadena lateral como muestra el esquema 2.23. ${ }^{208}$

El mecanismo de la oxidación radicalaria es el siguiente, donde la dopamina es la dihidroquinona $\left(\mathrm{QH}_{2}\right)$ y también aparece la semiquinona $(\cdot \mathrm{QH})$ y la quinona resultante $(\mathrm{Q}):^{206}$<smiles>CC(C)CC1=CC(=O)C(=O)C=C1CCN</smiles>

Esquema 2.23: Oxidación de la dopamina a través de su quinona a leucoaminocromo. 


$$
\begin{array}{cc}
\text { Iniciación: } & \mathrm{QH}_{2}+\mathrm{OH}^{-} \rightleftharpoons \mathrm{QH}^{-}+\mathrm{H}_{2} \mathrm{O} \\
& \mathrm{QH}^{-}+\mathrm{O}_{2} \rightarrow \mathrm{QH}+\mathrm{O}_{2}^{--} \\
\text {Propagación: } & \mathrm{QH}^{-}+\mathrm{O}_{2}+2 \mathrm{H}^{+} \rightleftharpoons \cdot \mathrm{QH}+\mathrm{H}_{2} \mathrm{O}_{2} \\
& \mathrm{QH}+\mathrm{O}_{2} \rightleftharpoons \mathrm{Q}+\mathrm{O}_{2}^{--}+\mathrm{H}^{+} \\
\text {Terminación: } & \mathrm{QH}+\mathrm{QH}^{-} \rightarrow \mathrm{Q}+\mathrm{QH}_{2} \\
& \mathrm{O}_{2}^{--}+\mathrm{O}_{2}^{--}+2 \mathrm{H}^{+} \rightarrow \mathrm{O}_{2}+\mathrm{H}_{2} \mathrm{O}_{2}
\end{array}
$$

La velocidad de autooxidación de la dopamina es importante en medios alcalinos, aunque a pHs intermedios (6-8) también se puede producir, especialmente si hay metales que catalicen la reacción radicalaria en el medio. ${ }^{209} \mathrm{La}$ mayor parte de los productos de ciclación de las catecolaminas son fluorescentes. Sin embargo, no es el caso de la dopamina.

El leucoaminocromo obtenido por la oxidación de la dopamina continua oxidándose a dopaminacromo, que rápidamente polimeriza entre sí para formar un pigmento oscuro de estructura similar a la melanina. ${ }^{210}$ Este pigmento se ha detectado en melanosomas y en células turmorales y tiene un gran poder citotóxico.

Existe un estudio en bacterias in vitro con el test de Ames (página 131) que ha llegado a la conclusión de que la dopamina, tras ser tratada con ácido nitroso, es mutágena, aunque no identifica cual es el producto de nitrosación que provoca la respuesta positiva en el experimento. ${ }^{211}$

\subsubsection{Serotonina}

La serotonina (tabla 2.16) es un compuesto orgánico bicíclico conjugado que actúa como neurotransmisor en el cuerpo humano. Desde mediados del siglo XIX se sabía que había una sustancia en la sangre que provocaba la contracción de los músculos lisos, aunque no fue aislada hasta un siglo más tarde, en 1951, por investigadores de la Clínica Cleveland en Estados Unidos. Unos años antes, en 1938, el científico italiano Vittorio Erspamer, de la Universidad de Pavia, había aislado de las células enterocromafines del intestino una sustancia a la que denominó enteramina, que también provocaba la contracción de los músculos lisos. La purificación y la cristalización posterior de la serotonina y la enteramina 


\section{0 | Compuestos estudiados}

demostraron que ambos compuestos en realidad eran la misma molécula, la 5-hidroxitriptamina. La primera compañía que sintetizó esta molécula fue la farmacéutica americana Upjohn, que la comercializó para investigación bajo el nombre de serotonina, por lo que la molécula se quedó con ese nombre en lugar del original italiano. ${ }^{212}$

La serotonina tiene múltiples funciones en el cuerpo humano. Está relacionada con la alimentación, puesto que la liberación de serotonina aumenta el apetito. La presencia de comida en el lumen hace que las células enterocromafines del intestino, que contienen aproximadamente el $90 \%$ de la serotonina total del cuerpo, liberen serotonina para provocar la contracción de los músculos del intestino entorno al quilo. Ante un compuesto irritante, como la capsicina, estas células aumentan la cantidad de serotonina para que los músculos se muevan más deprisa.

La serotonina también tiene un importante papel en el metabolismo de los huesos, controlando su masa, y en el sistema circulatorio, donde, ante un daño, actúa como vasoconstrictor y como factor de crecimiento para los fibrocitos. Por eso, las plaquetas son el principal almacén de la serotonina en la sangre. Como la serotonina es un indicador de sangrado, un gran aumento repentino en una zona localizada causa dolor. Como el veneno de muchos insectos (avispas y escorpiones) contiene gran cantidad de serotonina, su picadura es muy dolorosa. La mayor parte de la serotonina en el sistema nervioso central se encuentra concentrada en la glándula pineal, que aunque se encuentra junto al cerebro, está fuera de la barrera hematoencefálica, que la serotonina no puede cruzar. La serotonina en este órgano está relacionada con el metabolismo de la melatonina y la luz o la oscuridad para el control del cuerpo ante el sueño y el despertar. ${ }^{202}$ En el cerebro, la mayor parte de la serotonina es secretada por las neuronas de los núcleos del rafé, cuyos axones terminan en el cerebelo y en la médula espinal. La serotonina en este caso está relacionada con los estados de ánimo, la memoria o la consciencia.

La serotonina se obtiene a partir del aminoácido esencial triptófano en la ruta representada en el esquema 2.24. La enzima triptófano hidroxilasa oxida el triptófano que casi inmediatamente se descarboxila bajo la acción de la 5hidroxitriptófano descarboxilasa. La serotonina se metaboliza de forma similar 


\begin{tabular}{|c|c|}
\hline \multicolumn{2}{|r|}{ Serotonina (SER) } \\
\hline \multirow[t]{2}{*}{ Otros nombres: } & 3-(2-aminoetil)-5-hidroxiindol \\
\hline & 5-hidroxitriptamina \\
\hline Abreviatura: & 5-HT (en neurociencias) \\
\hline \multirow[t]{2}{*}{ Número CAS: } & $50-67-9$ \\
\hline & 153-98-0 (hidrocloruro) \\
\hline \multirow[t]{2}{*}{ Apariencia: } & Polvo blanco \\
\hline & Polvo ligeramente gris (hidrocloruro) \\
\hline \multirow[t]{2}{*}{ Punto de fusión: } & $121^{\circ} \mathrm{C}$ \\
\hline & $149-154^{\circ} \mathrm{C}$ (hidrocloruro) \\
\hline Punto de ebullición: & $416^{\circ} \mathrm{C}$ \\
\hline \multirow[t]{2}{*}{ Peso molecular: } & $176,215 \mathrm{~g} / \mathrm{mol}$ \\
\hline & 212,68 g/mol (hidrocloruro) \\
\hline \multirow[t]{3}{*}{ Solubilidad: } & Algo soluble en agua \\
\hline & Soluble en agua (hidrocloruro) \\
\hline & Soluble en DMSO (hidrocloruro) \\
\hline \multirow[t]{4}{*}{ Precauciones: } & $\begin{array}{l}\mathrm{R}-20 / 21 / 22 \text { : Nocivo por inhalación, contacto con la piel e } \\
\text { ingestión }\end{array}$ \\
\hline & R-36/37/38: Irrita los ojos, la piel y las vías respiratorias \\
\hline & S-22: No respirar el polvo \\
\hline & S-36: Úsese indumentaria protectora adecuada \\
\hline \multicolumn{2}{|c|}{ Constantes de acidez $\left(\mathbf{p K}_{\mathbf{a}}\right)$ : } \\
\hline & $\mathrm{NH}_{2}{ }_{10,73} \mathrm{O}^{-}$ \\
\hline
\end{tabular}

Tabla 2.16: Propiedades de la serotonina. ${ }^{213}$ 


\section{2 | Compuestos estudiados}

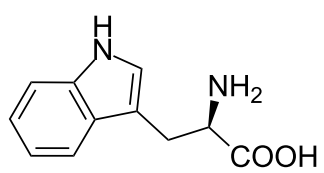

L-triptófano

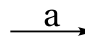

5-hidroxi-L-triptófano

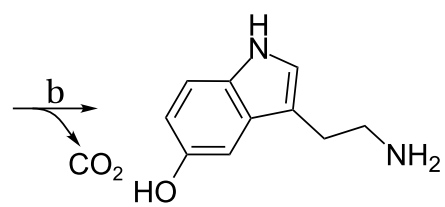

Serotonina

Esquema 2.24: Biosíntesis de serotonina a partir de triptófano. a, triptófano hidroxilasa, b, 5-hidroxitriptófano descarboxilasa.

a la de los neurotransmisores que hemos visto anteriormente. La monoamina oxidasa junto con la aldehido deshidrogenasa eliminan la amina de su cadena lateral dejando el carbono terminal oxidado en forma de ácido carboxílico. El compuesto formado, ácido 5-hidroxiindolacético, es excretado en la orina.

La serotonina es un compuesto básico por la amina que está en su cadena lateral, que pese a estar unida a la misma distancia del anillo aromático que la tiramina y la dopamina, no sufre el mismo efecto que estos compuestos y su constante de acidez es similar a la de la fenetilamina. La amina del indol que la compone no es básica, dado que tiene su par electrónico compartido en el sistema aromático y es necesario emplear ácidos fuertes muy concentrados para protonarla. Se estima que su $\mathrm{pK}_{\mathrm{a}}$ es $-3,6$. El segundo $\mathrm{pK}_{\mathrm{a}}$ de esta amina es muy alto, alrededor de 21, por lo que sólo es posible sustraer el protón con bases muy fuertes como hidruro sódico o butillitio en condiciones anhidras y protegiendo la amina de la cadena lateral y el alcohol. La sal creada reacciona con cualquier electrófilo aunque sea débil, que se une al nitrógeno del indol.

Sin necesidad de transformarla en una sal, la serotonina sufre con facilidad sustituciones electrófilas, debido a que, como ya se ha visto en la sección 2.3.1 (página 76), los anillos conjugados estabilizan el complejo de Wheland.

Se ha realizado el test de Ames a una mezcla de serotonina, nitrito sódico y ácido acético. El resultado de este experimento indica que el producto de la nitrosación de la serotonina en estas condiciones es mutagénico. ${ }^{214}$ 


\subsubsection{Minoxidilo}

El minoxidilo (tabla 2.17) es un compuesto formado por la unión de un óxido de diaminopirimidina y un anillo de piperidina. Fue desarrollado como antihipertensivo en los años 50, 60 y 70 por la Upjohn Company, la misma empresa que comercializó por primera vez la serotonina. Durante los ensayos clínicos previos a su aprobación como medicamento se administró varias dosis de minoxidilo a once pacientes con hipertensión, cuya presión arterial se redujo de forma efectiva en sólo seis días. ${ }^{215}$ Dado el éxito del experimento, se le permitió a su director, el médico americano Charles Chidsey, realizar una nueva prueba aplicando durante más tiempo el compuesto a un grupo mayor de personas. Al pasar de las dos semanas de tratamiento, varios pacientes desarrollaron hipertricosis, es decir, crecimiento en exceso de pelo por todo el cuerpo. Al ver esta propiedad del medicamento, se hizo una prueba aplicando el minoxidilo de forma tópica en el brazo a varios voluntarios, a los que les creció pelo en la zona tratada. El éxito de este experimento permitía evitar los efectos secundarios del consumo oral, por lo que tras muchas más pruebas para estudiar la dosis adecuada y la toxicidad, en 1979 se aprobó su uso como medicamento contra la alopecia. ${ }^{216}$ Actualmente es uno de los medicamentos más populares del mundo con un mercado de más de 100 millones de dólares por año tan solo en los Estados Unidos. ${ }^{217}$

La actividad hipertensiva del minoxidilo se debe a que uno de sus metabolitos, el sulfato de minoxidilo, relaja rápidamente el músculo liso vascular, lo que en la piel se traduce en un mayor riego sanguíneo en los folículos del pelo, lo que aumenta el tamaño del cabello y reduce la caída. ${ }^{218,219}$

Además de su sulfuración, el minoxidilo es metabolizado por el organismo por oxidación del anillo piperidínico, aunque la principal vía de metabolización es en el hígado mediante su unión al ácido glucurónico con la enzima glucuronosil transferasa (figura 2.11). De cualquiera de estas formas el minoxidilo es expulsado por la orina.

El minoxidilo es una base débil gracias al óxido de amina de su estructura. Sus dos aminas son bases aún más débiles debido a que su par de electrones libre está cedido al anillo aromático. El óxido de amina puede reducirse en 


\section{4 | Compuestos estudiados}<smiles></smiles><smiles></smiles><smiles>N=c1cc(N2CCCCC2)nc(N)n1OS(=O)(=O)O</smiles><smiles>N=c1cc(N2CCCCC2)nc(N)n1OC1OC(C(=O)O)C2C(O)OC1C2O</smiles>

Figura 2.1 1: Productos del metabolismo del minoxidilo. En la primera fila, los productos de oxidación. En la segunda fila, sulfato de minoxidilo y ácido minoxidil-O-glucurónico.

medio ácido según la ecuación que muestra el esquema 2.25.

No existe en la bibliografía ningún valor de su potencial estándar de reducción debido a que depende mucho de las condiciones experimentales, especialmente del pH. Precisamente, aprovechando esta propiedad se ha determinado de forma experimental por polarografía el $\mathrm{pK}_{\mathrm{a}}$ del óxido de amina. ${ }^{220}$<smiles>Nc1cc(N2CCCCC2)nc(N)[n+]1O</smiles><smiles>Nc1cc(N2CCCCC2)nc(N)n1</smiles>

Esquema 2.25: Reacción de reducción del minoxidilo en medio ácido. 


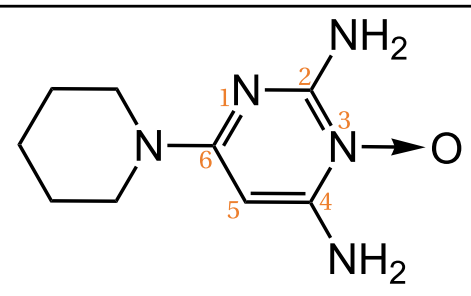

Minoxidilo (MIN)

\section{Otros nombres:}

Número CAS:

Apariencia:

Punto de fusión:

Peso molecular:

Solubilidad:

Precauciones: 3-óxido de 2,4-diamino-6-(piperin-1'-il)pirimidina

3-óxido de 2,4-diamino-6-piperidinopirimidina 38304-91-5

Polvo cristalino blanco

$128^{\circ} \mathrm{C}$

$248^{\circ} \mathrm{C}$ (hidrocloruro)

$209,25 \mathrm{~g} / \mathrm{mol}$

$0,27 \mathrm{~g} / 100 \mathrm{ml}$ agua $\left(25^{\circ} \mathrm{C}\right)$

$2,17 \mathrm{~g} / 100 \mathrm{ml}$ etanol $\left(25^{\circ} \mathrm{C}\right)$

$5,37 \mathrm{~g} / 100 \mathrm{ml}$ metanol $\left(25^{\circ} \mathrm{C}\right)$

R-22: Nocivo por ingestión

R-36/37/38: Irrita los ojos, la piel y las vías respiratorias

S-26: En caso de contacto con los ojos, lávese abundantemente con agua y acuda a un médico

S-36: Úsese indumentaria protectora adecuada

Constantes de acidez $\left(\mathrm{pK}_{\mathrm{a}}\right)$ :<smiles>Nc1cc(N2CCCCC2)nc(N)c1N1CCCCC1</smiles>

Tabla 2.17: Propiedades del minoxidilo. ${ }^{221,222}$ 



\section{Capítulo 3}

\section{Parte experimental}

\subsection{Estudio químico}

\subsubsection{Introducción}

La cinética es la parte de la química que estudia la velocidad de las reacciones químicas y los factores que en ella influyen, con objeto de determinar sus mecanismos de reacción. ${ }^{168}$

La velocidad de una reacción se define como la variación en el tiempo de su grado de avance. Para la reacción:

$$
a \mathrm{~A}+b \mathrm{~B} \rightarrow c \mathrm{C}+d \mathrm{D}
$$

el grado de avance, $\xi(t)$, es el cambio en el número $n$ de moles de un reactivo en un determinado tiempo $t$ dividido por su coeficiente estequiométrico:

$$
\xi(t)=\frac{n_{\mathrm{A}}^{o}-n_{\mathrm{A}}}{a}=\frac{n_{\mathrm{B}}^{o}-n_{\mathrm{B}}}{b}=\frac{n_{\mathrm{C}}}{c}=\frac{n_{\mathrm{D}}}{d}
$$

Así, la velocidad se define de forma general como:

$$
v=\frac{d \xi(t)}{d t}= \pm \frac{1}{i} \frac{d n_{I}}{d t}
$$




\section{8 | Estudio químico}

El signo es positivo si el compuesto I es un producto y negativo si se trata de un reactivo. En las reacciones en disolución el volumen de reacción generalmente es constante, por lo que su velocidad se puede expresar a través de la variación de concentración del reactivo:

$$
v=\frac{1}{V} \frac{d \xi(t)}{d t}= \pm \frac{1}{i} \frac{d[\mathrm{I}]}{d t}
$$

Se denomina ecuación de velocidad de una reacción química a la relación explícita entre la velocidad de reacción y las concentraciones de las especies activas que participan en la reacción. Para la reacción anterior sería:

$$
v=k[\mathrm{~A}]^{\alpha}[\mathrm{B}]^{\beta}
$$

donde $k$ es un coeficiente de proporcionalidad denominado constante de velocidad y $\alpha$ y $\beta$ son parámetros exponenciales que se denominan órdenes parciales de reacción y su suma, $t=\alpha+\beta$, se denomina orden total de la reacción. Los órdenes, en principio, no pueden ser calculados a priori y, como la constante de velocidad, deben ser obtenidos experimentalmente.

Existen varios métodos para determinar los parámetros cinéticos de una reacción. El método integral consiste en la integración directa de la ecuación de velocidad planteada y compararla con los datos experimentales concentracióntiempo.

El método diferencial mide directamente la velocidad de reacción cuando sólo hay un reactivo mediante la pendiente de la curva concentración-tiempo y lo compara con la concentración de reactivo. ${ }^{223}$ Así, tomando logaritmos la ecuación de velocidad queda linealizada:

$$
\ln v=\ln k+\alpha \ln [\mathrm{A}]
$$

Cuando hay varios reactivos se puede hacer una aproximación poniendo todos los reactivos menos uno en franco exceso. De esta forma se puede considerar que la concentración de estos compuestos se mantiene constante a lo largo de la reacción, permitiendo calcular el orden parcial del que queda en defecto. Esta técnica se llama método de aislamiento de Ostwald.

Como la velocidad cambia según avanza la reacción, habitualmente se mide 
la pendiente en el tramo inicial, donde ésta es máxima y así se reduce la incertidumbre de la medida. Para determinar con precisión los parámetros de la reacción se pueden medir varias reacciones, manteniendo todas las condiciones constantes excepto la concentración inicial de un reactivo, y así representar una recta de concentraciones iniciales frente a velocidades iniciales. Éste es el método de las velocidades iniciales.

\section{Influencia de la temperatura}

La temperatura es uno de los factores más influyentes en la velocidad de una reacción química. La ecuación de Arrhenius relaciona la constante de velocidad de una reacción con la temperatura $T$ a la que transcurre:

$$
k=A e^{-E_{a} / R T}
$$

En esta ecuación aparecen dos constantes con significado cinético: el factor preexponencial, $A$, función de las características de los reactivos, y la energía de activación, $E_{a}$ (figura 3.1).

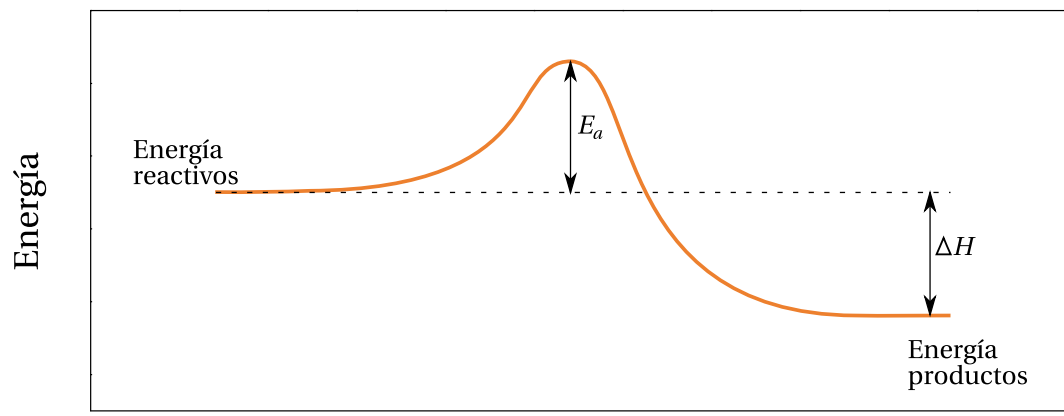

Coordenada de reacción

Figura 3.1: Perfil energético de una reacción química. La magnitud de la barrera de energía se denomina energía de activación, $E_{\mathrm{a}}$ y la diferencia entre las energías de los reactivos y los productos es la entalpía de la reacción, $\Delta H$. 


\section{0 | Estudio químico}

La teoría del estado de transición explica la velocidad de las reacciones químicas admitiendo que los reactivos, para dar lugar a los productos, tienen que pasar por una estructura intermedia inestable, denominada estado de transición o complejo activo. Como se admite que tanto los reactivos como los productos se encuentran en equilibrio con el estado de transición, a través de la energía de Gibbs para los estados de equilibrio:

$$
\Delta G=-R T \ln K_{e}
$$

se pueden calcular las propiedades termodinámicas del estado de transición:

$$
k=\frac{k_{\mathrm{B}} T}{h} e^{-\Delta G^{\ddagger} / R T}
$$

donde $k_{\mathrm{B}}$ es la constante de Boltzmann y $h$ es la constante de Plank. Separando la energía de Gibbs en los dos términos de los que se compone $\left(\Delta G^{\ddagger}=\Delta H^{\ddagger}-\Delta S^{\ddagger} T\right)$ se obtiene la ecuación de Eyring-Wynne-Jones:

$$
k=\frac{k_{\mathrm{B}} T}{h} e^{\Delta S^{\ddagger} / R} e^{-\Delta H^{\ddagger} / R T}
$$

que relaciona la constante de velocidad de una reacción y su temperatura, con la entropía y la entalpía de activación.

\section{Influencia de la fuerza iónica}

La fuerza iónica es una medida de la concentración de electrolitos en una disolución y se define como:

$$
I=\frac{1}{2} \sum m_{i} z_{i}^{2}
$$

donde $m$ es la concentración molal y $z$ es la carga del ion $i$.

De la teoría de Debye-Hückel se deduce la ecuación de Brønsted-Debye-Hückel, que relaciona la constante de velocidad de una reacción con la fuerza iónica del medio:

$$
\log _{10} k=\log _{10} \frac{k_{\mathrm{B}} T K^{\ddagger}}{h}+1,018 z_{A} z_{B} \sqrt{I}
$$


Mediante esta ecuación es posible conocer las cargas eléctricas que participan en una reacción química. Al representar varias cinéticas medidas en diferentes condiciones de fuerza iónica según la ecuación 3.11 se obtiene una recta cuya pendiente depende de los signos de carga eléctrica $z_{A}$ y $z_{B}$. Si tienen el mismo signo, la pendiente será positiva, si es diferente, la pendiente será negativa y si alguno de los dos no tiene carga, la recta no tendrá pendiente.

\section{Efecto isotópico cinético}

Moléculas químicamente idénticas pero con diferentes isótopos en su composición reaccionan con diferentes velocidades. Por ejemplo, es la diferencia de las velocidades de electrolisis la que permite separar el $\mathrm{D}_{2} \mathrm{O}$ del agua, a pesar de que la abundancia relativa D:H es 1:6.000. Este hecho se conoce como efecto isotópico cinético (KIE, Kinetic Isotope Effect). En una reacción química se produce efecto isotópico primario cuando se rompe un enlace con implicación de isótopos diferentes. Cuanto mayor sea la diferencia de masa de los isótopos, tanto más claro es el KIE. Por eso este efecto es muy útil en el estudio de mecanismos de ruptura de complejos de Wheland (véase sección 2.3.1).

\section{Reacciones rápidas}

Las reacciones rápidas son aquellas en las que el tiempo de mezcla de los reactivos o el tiempo de análisis son significativos respecto al tiempo de reacción y requieren técnicas experimentales especiales.

Algunos métodos están basados en reducir el tiempo de mezcla y otros provocan la reacción o modifican un sistema en equilibrio mediante una perturbación instantánea de la temperatura, la presión o por radiación electromagnética.

En esta tesis se ha empleado una técnica de flujo detenido. En las técnicas de flujo, los reactivos se colocan en recipientes aislados provistos de émbolos. Al accionar el sistema, los émbolos empujan las disoluciones hacia una cámara de mezclado, donde la reacción comienza, y las desplaza por un tubo en el que se mide la concentración a través del espacio (figura 3.2). Conociendo el caudal es posible determinar el tiempo de reacción. 


\section{2 | Estudio químico}

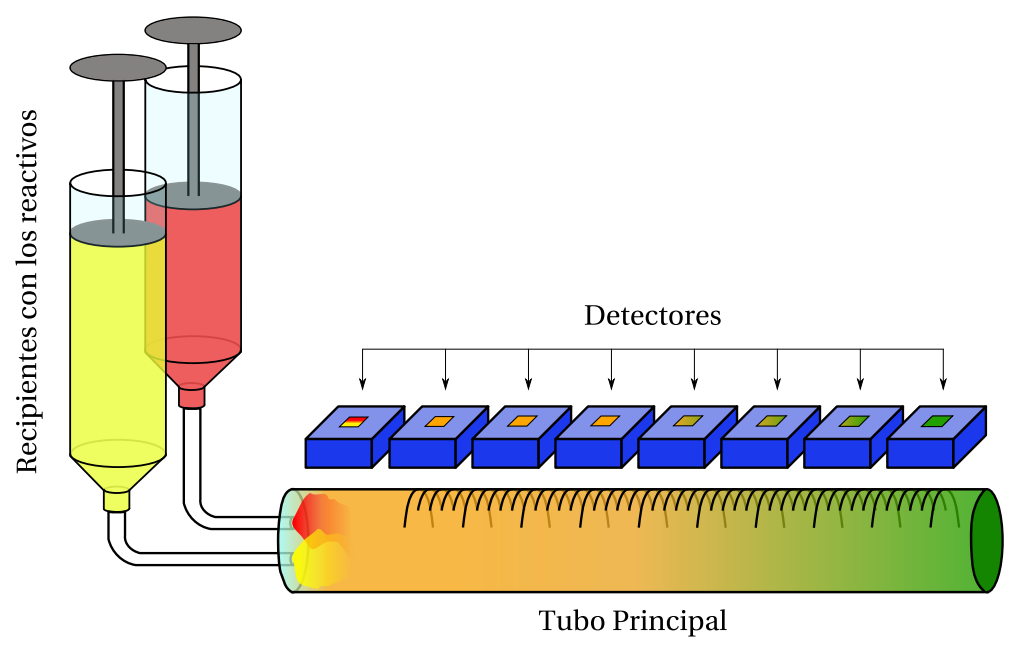

Figura 3.2: Medida de una reacción por un método de flujo.

Para evitar el consumo excesivo de reactivos se ha desarrollado el método de flujo detenido o stopped-flow, en el que aparece un tercer recipiente con émbolo que actúa de receptor de la disolución mezcla. Según se va llenando, el émbolo se desplaza hasta un punto en el que acciona un contacto eléctrico que detiene el avance de los dos émbolos con los reactivos y pone en marcha el detector del instrumento para el seguimiento de la reacción, que habitualmente consta de un espectrofotómetro como detector y un sistema de termostatado para el control de la temperatura. De esta forma se pueden seguir reacciones de hasta $10^{-3}$ segundos de vida media.

\subsubsection{Procedimiento experimental}

\section{Consideraciones generales}

Las técnicas experimentales para el seguimiento cinético de las reacciones estudiadas en esta tesis se han diseñado en función de factores como solubilidad, coeficiente de extinción molar de los reactivos, así como de otros factores como 
la reducción de errores estadísticos, duración del experimento y minimización de desechos. Cada uno de los métodos empleados se detalla en el siguiente capítulo junto al estudio de la nitrosación de cada compuesto.

Todas las nitrosaciones se han efectuado empleando como reactivo de partida nitrito sódico en medio ácido. De esta forma el nitrito se transforma inmediatamente en diferentes especies $\left(\mathrm{NO}_{2}^{-}, \mathrm{HNO}_{2}, \mathrm{H}_{2} \mathrm{NO}_{2}^{+}, \mathrm{N}_{2} \mathrm{O}_{3} \ldots\right)$ según los equilibrios que se han mostrado en el informe bibliográfico (secciones 2.1, 2.2.1 y 2.2.2). Por ello se hablará generalmente de la suma de todas las especies reunidas bajo el término genérico nitrito y la abreviatura NIT:

$$
[\mathrm{NIT}]=\left[\mathrm{NO}_{2}^{-}\right]+\left[\mathrm{HNO}_{2}\right]+\left[\mathrm{H}_{2} \mathrm{NO}_{2}^{+}\right]+\left[\mathrm{N}_{2} \mathrm{O}_{3}\right]+\cdots
$$

En las condiciones de acidez en las que se ha trabajado, casi todo el nitrito se encuentra como $\mathrm{NO}_{2}^{-}$y $\mathrm{HNO}_{2}$, por lo que la relación se simplifica:

$$
[\mathrm{NIT}]=\left[\mathrm{NO}_{2}^{-}\right]+\left[\mathrm{HNO}_{2}\right]
$$

En todos los experimentos la fuerza iónica se ha controlado añadiendo al medio de reacción una disolución concentrada de perclorato sódico monohidratado. Se ha empleado esta sal debido a que, como se vio en la sección 2.2.3 (página 64), el perclorato es uno de los pocos aniones que no cataliza las reacciones de nitrosación.

Por la misma razón, en todos los estudios cinéticos se ha empleado ácido perclórico para aportar el medio ácido necesario. El pH en en que se ha trabajado siempre ha sido inferior a 5, porque por encima de este $\mathrm{pH}$ la concentración del ácido nitroso (página 44) es insignificante.

El medio en que se han preparado las disoluciones y en que se han seguido las reacciones ha sido siempre agua ultrapura tipo I (resistividad $>18 \mathrm{M} \Omega \cdot \mathrm{cm}$ ).

Las disoluciones se prepararon por pesada directa de los reactivos salvo los compuestos líquidos que se han medido con instrumentos volumétricos con la precisión adecuada.

En las reacciones de corta duración, la temperatura se ha controlado por medio del portacubetas termostatado del espectrofotómetro que funcionaba 


\section{4 | Estudio químico}

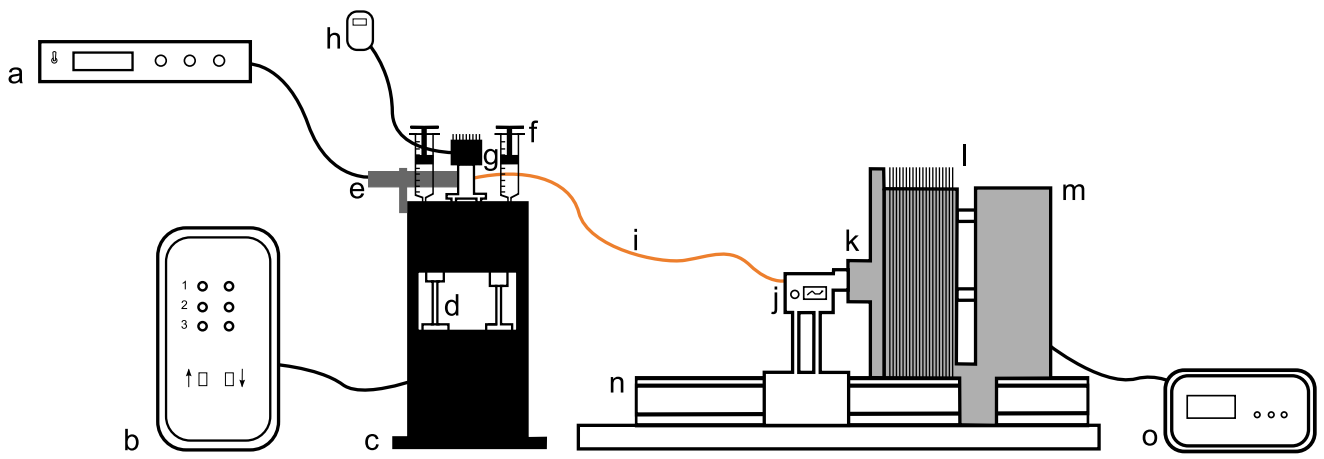

Figura 3.3: Esquema de un espectrofotómetro de flujo detenido. Donde: a, voltímetro del fotomultiplicador; b, controlador de los émbolos; c, soporte de los émbolos; d, émbolos; e, fotomultiplicador; f, jeringas; g, cámara de mezclado; h, termómetro; i, fibra óptica; j, monocromador; k, lámpara de arco; l, intercambiador de calor; m, ánodo de la lámpara; n, carro del monocromador y o, fuente de la lámpara.

mediante un sistema Peltier $\left( \pm 0,1^{\circ} \mathrm{C}\right)$. En las reacciones cuya duración es superior a 24 horas se han empleado termostatos de tanque de agua de 10 litros con unidad de refrigeración y bomba de presión para recirculación de agua termostatada. El termostato tiene un margen de error máximo de $0,1{ }^{\circ} \mathrm{C}$.

El pH de cada muestra se calculaba con antelación y luego se medía con un $\mathrm{pH}$-metro con electrodo de $\mathrm{Ag} / \mathrm{AgCl}$ y sensor de temperatura que tenía una precisión de $\pm 0,01$.

Por último, la concentración de reactivos se ha seguido por espectroscopía UV-visible con un espectrofotómetro de doble haz y cubetas de cuarzo de $1 \mathrm{~cm}$ de paso óptico.

\section{Medida de las reacciones rápidas}

Para el seguimiento de las reacciones rápidas se ha utilizado un espectrofotómetro de flujo detenido de tres émbolos como el que muestra el esquema de la figura 3.3. El equipo tiene una lámpara de arco cuya luz llega a la cámara de mezclado a través de un monocromador y una fibra óptica. 
Para detectar la disminución de luminiscencia emplea un fotomultiplicador cuyas lecturas de voltaje son convertidas mediante un ordenador a medidas de absorbancia en unidades arbitrarias. Para convertir estas unidades arbitrarias en unidades de absorbancia se ha llevado a cabo un calibrado para la longitud de onda de seguimiento de la nitrososerotonina ( $\lambda=371 \mathrm{~nm}$, página 226$) \mathrm{em}$ pleando seis disoluciones de nitrososerotonina de absorbancia conocida y se han medido con el equipo de flujo detenido durante dos minutos. Relacionando la media de esta medida con la absorbancia del compuesto se obtiene la curva de calibrado del equipo (figura 3.4).

\begin{tabular}{cccc}
\hline$A$ & $A /$ U. A. & $A$ & $A /$ U. A. \\
\hline 0,444 & 0,4446 & 1,115 & 1,1310 \\
0,624 & 0,6249 & 1,269 & 1,2965 \\
0,940 & 0,9354 & 1,450 & 1,4039 \\
\hline
\end{tabular}

$$
y=0,296-0,196 x+1,469 x^{2}-0,554 x^{3}
$$

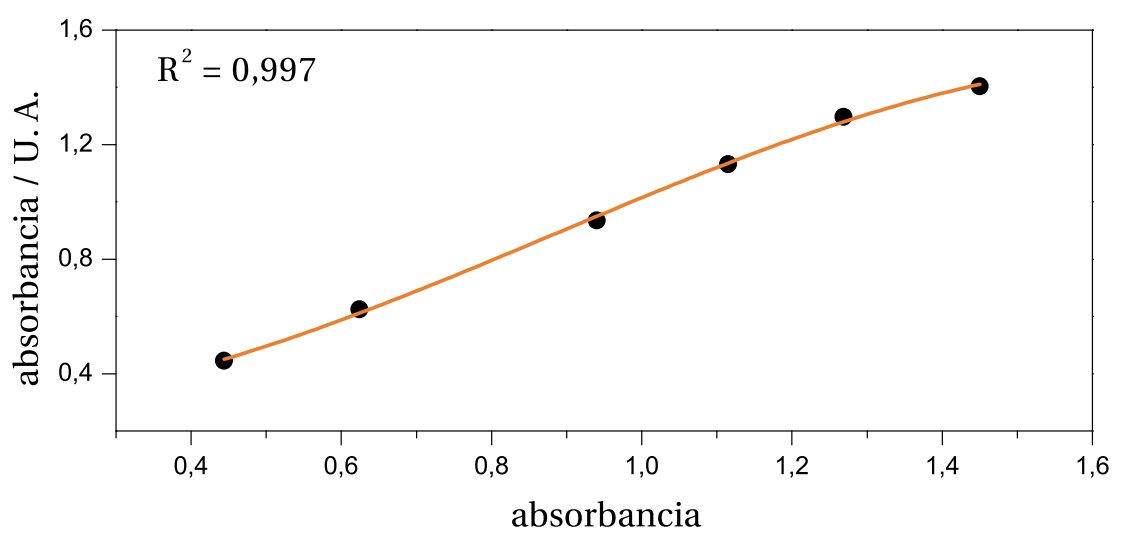

Tabla 3.1 y Figura 3.4: Curva de calibrado del espectrofotómetro de flujo detenido. $T=$ $25^{\circ} \mathrm{C}$.

Todas las medidas efectuadas con este equipo se han transformado a unida- 


\section{6 | Estudio químico}

des de absorbancia empleando la ecuación 3.14.

Estudio de la evolución de los espectros con el pH

Para medir los cambios que se producen en el espectro de absorción de un compuesto en función del $\mathrm{pH}$ del medio se prepara una disolución ácida $(\mathrm{pH}$ = 1) del compuesto de mucho volumen (superior a $500 \mathrm{ml}$ ), para hacer que la adición de pequeñas disoluciones alcalinas puedan despreciarse en el volumen total y así no varíe la concentración de sustrato. Se toma una alicuota y se mide el espectro de absorción para el medio más ácido.

A continuación se va modificando el $\mathrm{pH}$ añadiendo pequeñas cantidades de disoluciones de hidróxido sódico (1 M, 0,1 M y 0,01 M) mientras se agita la mezcla con un agitador magnético y se mide continuamente la acidez con una instalación como la que muestra el esquema de la figura 3.5. Cuando se alcanza el pH adecuado se toma una alicuota y se recoge su espectro de absorción. Todas las alicuotas se devuelven de nuevo al vaso para mantener la concentración de reactivo.

En el caso de que en algún paso se alcance un pH demasiado básico se puede volver hacia atrás añadiendo una disolución de ácido clorhídrico.

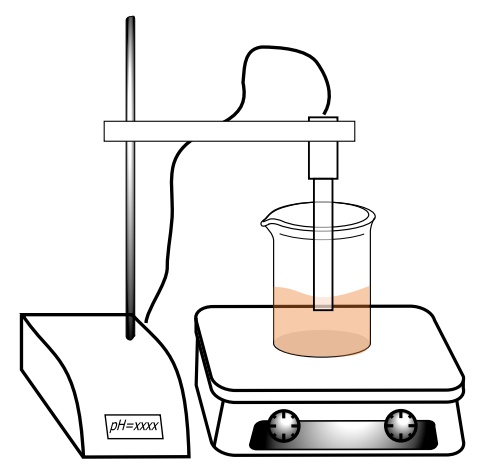

Figura 3.5: Esquema del montaje para medir la influencia del pH en los espectros. 
Síntesis de los nitrosocompuestos<smiles>CC(=O)NCCc1ccc(ONc2cc(CCNC(C)=O)ccc2OC(C)=O)cc1</smiles>

Esquema 3.1: Ruta de la síntesis de nitrosotiramina nitrosominoxidilo.

Síntesis de nitrosotiramina La síntesis de nitrosotiramina se ha realizado en tres pasos para evitar la diazotación del grupo amino (esquema 3.1). En primer lugar se protege ese grupo por medio de una acetilación. Para ello, se han disuelto $2 \mathrm{~g}$ de tiramina en $3 \mathrm{ml}$ de piridina y $3 \mathrm{ml}$ de anhídrido acético (2,2 equivalentes). También se ha añadido una pequeña cantidad de 4-(dimetilamino)piridina que actúa de catalizador. Esta mezcla se ha mantenido un día reaccionando en un balón cerrado, puesto que es una reacción sensible a la humedad. Después de este tiempo se ha aislado la tiramina protegida de la siguiente manera: Primero se ha transferido el medio de reacción a un embudo de decantación, se ha añadido acetato de etilo y se ha lavado tres veces con una disolución de ácido clorhídrico $1 \mathrm{M}$. De esta forma, la piridina y el acetato producido en la reacción se eliminan al retirar la fase acuosa. La fase orgánica se ha lavado con una disolución de hidrogenocarbonato sódico al 5\% para neutralizar la acidez y retirar las sales que pudiesen quedar. Por último, la fase orgánica se ha lavado con una disolución saturada de cloruro sódico para retirar el agua que quedaba en ella y se ha traspasado a un erlenmeyer donde, con sulfato sódico anhidro, se ha secado completamente. Se ha filtrado la disolución para eliminar la sal y se ha evaporado el acetato de etilo en el rotavapor para obtener la tiramina protegida.

El siguiente paso fue la nitrosación de la tiramina protegida. En un balón de vidrio, se disolvió el producto en $20 \mathrm{ml}$ de agua y se añadió $1 \mathrm{ml}$ de ácido clorhídrico $37 \%$. A continuación se ha incorporado, disuelta en menos de $10 \mathrm{ml}$ 


\section{8 | Estudio químico}

de agua, una cantidad equimolar de nitrito sódico. La adición se ha realizado gota a gota para evitar la descomposición del nitrito con el ácido del medio. Se ha dejado reaccionar durante dos días y se ha extraido el nitrosocompuesto producido en un embudo de decantación con acetato de etilo. La fase orgánica con el compuesto nitrosado se ha secado con sulfato sódico anhidro y se ha filtrado, para aislar el producto evaporando el disolvente en el rotavapor.

Por último se han eliminado los grupos acetato unidos al alcohol y a la amina de la nitrosotiramina. El nitrosocompuesto se ha disuelto en $10 \mathrm{ml}$ de etanol y se ha añadido $1 \mathrm{~g}$ de $\mathrm{NaOH}$ disuelto en $4 \mathrm{ml}$ de agua. Se ha calentado a reflujo durante 10 minutos en un baño de agua y, tras enfriar la mezcla, se ha añadido una disolución de $\mathrm{HCl} 1 \mathrm{M}$ hasta $\mathrm{pH}$ ácido y se han transferido a un embudo de decantación, donde se ha añadido acetato de etilo para eliminar el acetato liberado. El disolvente de la fase acuosa con el compuesto nitrosado se ha evaporado y el precipitado obtenido se ha disuelto en etanol, donde el cloruro sódico formado no es soluble. Se ha separado la disolución alcohólica preparada por filtración y se ha evaporado el disolvente para obtener la nitrosotiramina deseada. Ésta se ha purificado por cristalización en etanol.

Síntesis de nitrosodopamina La nitrosodopamina se ha sintetizado siguiendo los mismos pasos que en la síntesis de la nitrosotiramina, salvo que, en el primer paso, al tener un alcohol adicional en su estructura, es necesario emplear 3,2 equivalentes de anhídrido acético (3,2 ml).

Síntesis de nitrososerotonina La síntesis de nitrososerotonina se ha realizado de la misma forma que la nitrosotiramina. Ha sido necesario tener cuidado con el proceso de separación de la serotonina protegida debido a que su estructura se parecía a la de la piridina.

Síntesis de nitrosominoxidilo El nitrosominoxidilo se ha sintetizado por reacción directa entre minoxidilo y ácido nitroso. Se han disuelto en un balón pequeño 4,9 g de minoxidilo ( $23 \mathrm{mmol}$ ) en $17 \mathrm{ml}$ de tetrahidrofurano y $3 \mathrm{ml}$ de ácido tetrafluorobórico $\left(\mathrm{HBF}_{4}, 48 \%\right)$ y se ha puesto a enfriar en un baño de hielo con agua y sal. A continuación se ha añadido lentamente una disolución acuosa 
de 1,6 g (24 mmol en $7 \mathrm{ml}$ ) de nitrito sódico. Tras 24 horas de reacción se ha evaporado el tetrahidrofurano y el agua con la ayuda de un rotavapor. La masa restante se ha disuelto en acetonitrilo donde al poco tiempo precipitan unos cristales verdosos, que se han filtrado al vacío y se han lavado con acetonitrilo y éter.

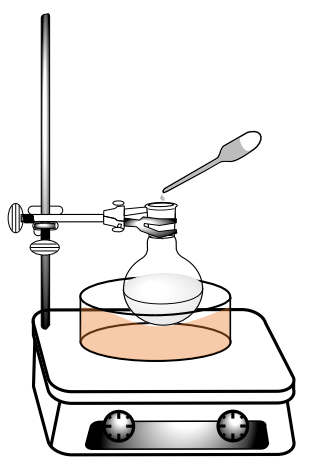

Figura 3.6: Esquema del montaje para sintetizar nitrosominoxidilo.

\section{Difracción de Rayos X}

Para recoger todos los datos sobre la estructura con un difractómetro se colocó un cristal de compuesto sobre una fibra de vidrio. Se trabajó a $0{ }^{\circ} \mathrm{C}$ utilizando radiación $\mathrm{Cu} \mathrm{K}_{\alpha}(\lambda=0,154178 \mathrm{~nm})$ y la técnica de escaneo $\omega$. A continuación se corrigieron los efectos de polarización y de Lorenz. Tanto la resolución de la estructura como el refinado y la salida de datos se llevaron a cabo con SHELXTL. Las estructuras se resolvieron por métodos directos combinados con síntesis de Fourier diferencial y refinados por procedimientos de mínimos cuadrados de matriz completa, con parámetros térmicos anisotrópicos en los últimos ciclos de refinado para todo los átomos que fuesen hidrógeno, que fueron colocados en posiciones calculadas. 


\section{0 | Estudio químico}

\subsubsection{Metodología y detalles computacionales}

Los cálculos de las geometrías y energías de los compuestos del presente trabajo se han realizado con una estación de trabajo Mountain equipada con un procesador Intel Core i7-980X de 3,33 GHz y una memoria RAM de 24,0 GB.

Todas las moléculas se han computado siguiendo el mismo procedimiento: En primer lugar se preparaba con el programa de software libre Avogadro la matriz Z con las coordenadas de todos los átomos de la molécula.

A continuación y con la misma aplicación, se realizaba una optimización previa de la geometría de la molécula para acortar los tiempos de cómputo y evitar la obtención de resultados erróneos.

Empleando como punto de partida la matriz Z perfeccionada se calculaba con el programa Gaussian W03 la configuración molecular de menor energía, correspondiente a la estructura óptima. ${ }^{224}$ Los cálculos se realizaban empleando el modelo B3LYP de la teoría del funcional de la densidad y la base $6-31+G(d, p)$. Esta combinación de modelo y base se escogió por su exactitud y su potencia. ${ }^{225,226}$

Por último, antes de registrar la energía de la estructura molecular calculada se comprobaba que la optimización se había realizado de forma correcta, calculando las frecuencias de vibración de la molécula y verificando que ninguna fuese imaginaria. ${ }^{227}$

Los cálculos se han realizado para moléculas en estado gaseoso, dado que las conclusiones a las que se llegan con moléculas solvatadas en las sustituciones electrófilas aromáticas son comparables. ${ }^{228,229}$

Los resultados obtenidos no se han corregido posteriormente puesto que el factor de escalado empírico de la combinación B3LYP 6-31+G (d,p) es esencialmente la unidad. ${ }^{230}$ 


\subsection{Estudio biológico}

\subsubsection{Mutagenia: Test de Ames}

El test de Ames es uno de los ensayos biológicos más utilizados para el estudio de la mutagenia de un compuesto químico. Es una prueba sencilla, barata y rápida que tiene un gran valor predictivo en la identificación de compuestos cancerígenos en roedores ${ }^{231}$. Fue desarrollado en los años 60 y 70 por el profesor de la Universidad de Berkeley Bruce Ames, ${ }^{232}$ basándose en un test diseñado por el polaco Wacław Szybalski que emplea bacterias de Escherichia coli. ${ }^{233}$ Ames había investigado los mecanismos biológicos por los que la Salmonella typhimurium sintetizaba histidina, por lo que desarrolló un método como el de Szybalski con estas bacterias. ${ }^{234}$ Con el tiempo tanto Ames ${ }^{235,236}$ como otros autores ${ }^{237}$ han perfeccionado la técnica probando su efectividad con múltiples compuestos carcinógenos. ${ }^{238,239}$

La base del test de Ames es un cultivo de Salmonella modificado genéticamente para que no pueda sintetizar el aminoácido histidina a partir de nitrógeno inorgánico. Estas bacterias, mientras se encuentran en un medio de cultivo con dicho compuesto, se desarrollan con normalidad. En el caso de que la histidina del medio se agote, las bacterias de Salmonella fallecen al depender del aporte externo (bacterias His auxotróficas). Puede ocurrir que, espontáneamente o por el efecto de un agente mutágeno, alguna bacteria del cultivo revierta el error que la impedía sintetizar histidina a través de una mutación y cree una nueva colonia de bacterias que sobrevive incluso cuando se acaba el aminoácido (bacterias His prototróficas).

El test de Ames consiste en preparar un cultivo de estas bacterias en una placa con una cantidad muy limitada de histidina y una concentración determinada del compuesto sujeto del estudio. Si éste es mutágeno, provocará mutaciones en el código genético de las bacterias de forma aleatoria, haciendo que algunas de ellas reviertan el error que les impedía sintetizar histidina y comenzar una nueva colonia. El número de colonias que se forman en un determinado periodo de tiempo está relacionado con la efectividad como mutágeno del compuesto estudiado y de su concentración en la placa. 


\section{2 | Estudio biológico}

\begin{tabular}{cccc}
\hline Cepa & Mutación His & Plásmidos & Otras mutaciones \\
\hline TA90 & hisD6610 & & $\Delta u v r B, r f a$ \\
TA92 & hisG46 & pKM101 & \\
TA94 & hisD3052 & pKM101 & \\
TA97 & hisD6610 & pKM101 & $\Delta u v r B, r f a$ \\
TA98 & hisD3052 & pKM101 & $\Delta u v r B, r f a$ \\
TA100 & hisG46 & pKM101 & $\Delta u v r B, r f a$ \\
TA102 & hisG428 & pKM101 & $r f a$ \\
& & pAQ1 & \\
TA110 & hisD6610 & pKM101 & \\
TA1534 & hisD3052 & & $\Delta u v r B$ \\
TA1535 & $h i s G 46$ & & $\Delta u v r B, r f a$ \\
TA1538 & hisD3052 & & $\Delta u v r B, r f a$ \\
TA1950 & hisG46 & & $\Delta u v r B$ \\
\hline
\end{tabular}

Tabla 3.2: Genotipos de las cepas bacterianas empleadas en el test de Ames.

Existen diversas cepas de Salmonella para el test de Ames (tabla 3.2). ${ }^{236}$ Cada cepa contiene un tipo diferente de mutación en el operón de la histidina que la hace sensible a un tipo específico de mutágenos. Además, a cada cepa se le ha añadido otras mutaciones en otros puntos del código genético para aumentar su habilidad para detectar mutágenos. Las dos mutaciones secundarias más comunes son dos: La primera se denomina rfa y causa la pérdida parcial de la barrera de lipopolisacáridos que envuelve la superficie de la bacteria, aumentando la permeabilidad de su pared a moléculas de gran tamaño que de otro modo no podrían haber cruzado a través de la pared normal. La segunda mutación se denomina $\Delta u v r B$ ( $\Delta$ de deleción) y consiste en la deleción del gen que codifica una proteína del sistema de reparación por escisión del ADN, lo que obviamente hace que las mutaciones no se reparen correctamente, aumentando significativamente la sensibilidad del test. Por motivos técnicos, la supresión 
del gen $u v r B$ se extiende al gen bio y en consecuencia, las bacterias afectadas también dependen de un aporte externo de biotina para crecer.

Además, casi todas las cepas contienen plásmidos añadidos, es decir, moléculas de ADN extracromosómico que modifican el comportamiento de la bacteria. El plásmido más común es el pKM101, que aumenta la mutagénesis química y espontánea al fomentar el sistema de reparación del ADN de síntesis por translesión, que ante un error en la cadena, para evitar la ruptura del cromosoma, continua copiando el ADN, pese al error. Este plásmido también hace que la bacteria se haga resistente al antibiótico ampicilina, lo que es muy útil en el trabajo experimental. Otro plásmido es el pAQ1, que tiene otro gen para sintetizar histidina con una mutación, la hisG428. Su adición aumenta las posibilidades de que la bacteria pueda volver a sintetizar histidina.

En función del tipo de mutación las cepas son más sensibles a algunos tipos de mutágenos que a otros. La mutación hisG46 se encuentra en el gen que codifica la primera enzima de la biosíntesis de histidina. Sustituye en el código genético la secuencia-CCC- (que corresponde a prolina) por-CTC- (leucina). De esta forma las cepas que contienen esta mutación son sensibles a los mutágenos que causan sustituciones de pares de bases, como los agentes alquilantes. La mutación hisD3052 se produce en el gen hisD que codifica la enzima histinol deshidrogenasa. Es una mutación por inserción de una base extra en un punto repetitivo del código de la enzima (-CGCGCGCG-). Por eso los mutágenos que provocan desplazamiento del marco de lectura hacen que el gen regrese otra vez al código original, revirtiendo la mutación.

Muy similar es la mutación hisD6610 que añade una citosina adicional a una cadena de seis citosinas -CCCCCC- y que también detecta mutaciones por desplazamiento del marco de lectura. Estas mutaciones son provocadas por compuestos que forman aductos con el ADN y mutágenos intercalantes.

La mutación hisG428 inserta el codón de parada-ATT- en mitad del gen, provocando que la bacteria no termine de sintetizar sus enzimas. De esta forma se pueden detectar agentes mutágenos oxidativos e intercalantes, a los que las otras mutaciones son insensibles.

Un inconveniente de que el test de Ames esté basado en una bacteria es que al ser un organismo procariota apenas tiene mecanismos para metabolizar 


\section{4 | Estudio biológico}

compuestos químicos. Como ya se vio que ocurría con las nitrosaminas (página 94), muchas sustancias inocuas se tornan peligrosos mutágenos al ser metabolizados por el organismo. Para poder imitar este proceso, al test de Ames se le puede añadir un preparado de tejido hepático de rata u otro mamífero que contiene todas las enzimas necesarias para la bioactivación de los mutágenos potenciales. El extracto más habitual es el denominado S9, que consiste en un homogenado obtenido por centrifugación de tejido hepático múrido y contiene todas las enzimas del citosol y los microsomas de sus células, como el citocromo P450 y diversas transferasas. Para aumentar la concentración de enzimas, las ratas son tratadas con bifenilos policlorados días antes de su sacrificio.

Durante el experimento algunas bacterias mutan espontáneamente y recuperan la capacidad de sintetizar histidina, formando un número de colonias característico de cada cepa (reversión). Se considera que el test de Ames ha dado un resultado positivo cuando el número de colonias que se ha formado durante el experimento es reproducible, depende linealmente de la dosis de mutágeno y la respuesta es, al menos, el doble de intensa que la de la reversión espontánea. Para que un compuesto se considere mutágeno es necesario que al menos con una cepa el test sea positivo. Sin embargo, para afirmar que un compuesto no es mutágeno, el test de Ames tiene que ser negativo al menos en cuatro cepas diferentes. Cuando la dosis del compuesto que se está probando es demasiado alta, puede ser tóxica para las bacterias de la placa, por lo que la relación dosis-número de colonias deja de ser lineal y, si se sigue aumentando la dosis, puede provocar la muerte de todas las bacterias del medio, obteniéndose la curva dosis-colonias que muestra la figura 3.7.

\section{Procedimiento experimental}

Para realizar el test de Ames por incorporación en placa en primer lugar se han tenido que preparar los medios del experimento:

Se han inoculado las bacterias de las cepas TA98 y TA100. En un tubo estéril para cada cepa, se han añadido $5 \mathrm{ml}$ de un preparado denominado NB (nutrient broth) que es un medio de cultivo con tampones, iones inorgánicos, extractos de levadura y péptidos, $5 \mu \mathrm{l}$ de una disolución del antibiótico ampicilina de 


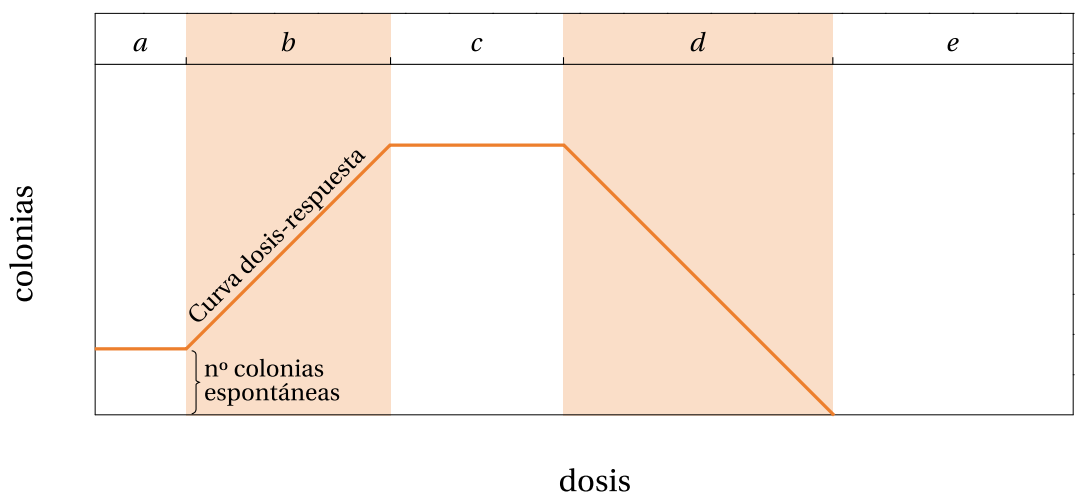

Figura 3.7: Curva dosis-colonias. En $a$ no existe respuesta. En $b$ se alcanzan dosis mutagénicas. A partir de $c$ la dosis es tóxica para las bacterias y en $d$ la toxicidad es superior a la mutagénesis. En $e$ la dosis es mortal para todas las bacterias.

concentración $50 \mathrm{mg} / \mathrm{ml}$ ( $50 \%$ agua, $50 \%$ etanol) y $20 \mu \mathrm{l}$ de las reservas de las bacterias que estaban congeladas en glicerol a $-70{ }^{\circ} \mathrm{C}$. Se ha mezclado en un vórtex y se ha incubado a $37^{\circ} \mathrm{C}$ bajo agitación durante 16 horas tras los cuales las bacterias están en estado estacionario.

Se preparan las placas VB que son placas petri de poliestireno de $90 \mathrm{~mm}$ de diámetro con $30 \mathrm{ml}$ de agar VB (Vogel-Bonner). El agar VB se preparó mezclando $465 \mathrm{ml}$ de agua desionizada con 7,5 g de agar nutritivo, se autoclavó para esterilizar y se añadió $25 \mathrm{ml}$ de glucosa al $40 \%$ y $10 \mathrm{ml}$ de medio VB. Esta mezcla se añadió a las placas mientras estaba caliente. El medio VB es una mezcla esterilizada de $5 \mathrm{~g}$ de sulfato de magnesio heptahidratado, $50 \mathrm{~g}$ de ácido cítrico monohidratado, $87,5 \mathrm{~g}$ de fosfato de disodio y amonio y $250 \mathrm{~g}$ de hidrógeno fosfato potásico en $500 \mathrm{ml}$ de agua. Tras esto se espera que solidifique y se almacena en frío.

También se prepararon los tubos con agar de superficie histidina-biotina (Top-agar His/Bio), que se prepararon poniendo 1,5 g de agar nutritivo, 1,25 g de cloruro sódico en $225 \mathrm{ml}$ de agua desionizada y se autoclava. A continuación se añaden $25 \mathrm{ml}$ de una disolución estéril de histidina y biotina de concentración 


\section{6 | Estudio biológico}

$5 \cdot 10^{-4} \mathrm{M}$ para cada nutriente. De la mezcla, y antes de que solidificara, se ponen $2 \mathrm{ml}$ en cada tubo, que se cierra y se almacena en frío.

También se prepara la mezcla del extracto S9 al 10\%, que se tiene que realizar en el mismo día. Consiste en una mezcla de 3,35 $\mathrm{ml}$ de agua, $5 \mathrm{ml}$ de tampón de Ames (mezcla de hidrogenofosfato sódico y dihidrogenofosfato sódico $0,2 \mathrm{M}$, el $\mathrm{pH}$ es 7,4), $50 \mu \mathrm{l}$ de glucosa-6-fosfato $1 \mathrm{M}, 400 \mu \mathrm{l}$ de $\mathrm{NADP}^{+}$0,1 M (nicotinamida adenina dinucleótido fosfato), $200 \mu \mathrm{l}$ de una disolución de sales $\mathrm{MgCl}_{2}$ 0,4 $\mathrm{M}$ y $\mathrm{KCl}$ 1,65 M y $1 \mathrm{ml}$ del extracto S9. El extracto S9 es comercial, el resto es esterilizado en autoclave excepto la glucosa-6-fosfato y el $\mathrm{NADP}^{+}$que para esterilizarlos basta con filtrarlos a través de un filtro de 220 pm de tamaño de poro.

El procedimiento consiste en fundir el agar de los tubos de agar de superficie al baño María a $100{ }^{\circ} \mathrm{C}$ y posteriormente almacenarlos en un baño seco a $45^{\circ} \mathrm{C}$. Cuando el agar ha alcanzado esa temperatura se toma un tubo y se vierte en él $10 \mu \mathrm{l}$ del compuesto a probar, $100 \mu \mathrm{l}$ del preparado con las bacterias cultivadas durante toda la noche (previa agitación en vórtex) y si es el caso, $500 \mu \mathrm{l}$ de la mezcla S9. El tubo inmediatamente se homogeniza y se vierte sobre una placa VB. Cuando solidifica el agar de superficie, se tapa la placa, se invierte y se incuba durante 48 horas. Pasado el tiempo de incubación, se cuenta el número de colonias. Si el número es grande se puede utilizar un software para contabilizar las colonias a través de una foto (Labworks Software, versión 4.6, de la compañía UVP, Upland, California, EE.UU.). En este caso, la foto se toma por triplicado en tres posiciones de la placa diferentes.

El test de Ames se realizó tomando varias dosis de compuesto disueltas en dimetilsulfóxido (DMSO). También se hizo un control negativo sin compuesto y un control positivo con un mutágeno probado (10 $\mu \mathrm{g}$ de 4 -nitro- $o$-fenilendiamina (NPD) para la cepa TA98, 0,3 $\mu$ g de $N$-óxido de 4-nitroquinolina (4NQO) para la cepa TA100 y $0,2 \mu \mathrm{g}$ y $2 \mu \mathrm{g}$ de 2 -aminoantraceno (2AA) para las cepas TA98 y TA100, respectivamente, en presencia del sistema de activación S9). También se incluye un control de esterilidad del extracto S9 en ausencia de bacterias. Todos los experimentos son realizados por duplicado y, tras comprobar que los duplicados concordaban se realizó la media y la desviación estándar del conteo. 


\subsubsection{Mutagenia: Test de aberraciones cromosómicas}

El objetivo del test de aberraciones cromosómicas es la detección de agentes mutágenos que pueden causar anomalías en los cromosomas en cultivos de células de mamíferos. Pese a que es un test muy laborioso, tiene la ventaja de que es un método que permite conocer el efecto preciso de un mutágeno en el cromosoma y es efectivo para predecir el riesgo de cáncer del compuesto estudiado. ${ }^{240,241}$

La anomalía en el cromosoma es inducida por un mutágeno que produzca la rotura de la cadena de ADN. Esta ruptura puede ser reparada por dos mecanismos de la célula: la unión de extremos no homólogos por la ADN ligasa IV, que busca en los extremos de cada porción secuencias parecidas y, cuando las encuentra, realiza la unión en ese lugar y la reparación recombinante que busca en otra molécula de ADN una secuencia idéntica o casi idéntica a la porción que se ha roto y la utiliza como plantilla para crear una cadena que luego duplica. Estos mecanismos de reparación pueden devolver el cromosoma a su estado original, unir dos extremos de forma incorrecta o no unirlos en absoluto. La célula que ha sufrido estos daños puede continuar viviendo, lo que, en ocasiones, puede tener consecuencias perjudiciales para el organismo.

El test de aberraciones cromosómicas consiste en exponer las células a un agente mutágeno durante un tiempo determinado para, a continuación, detener la reproducción de la célula en la metafase y observar en el microscopio el estado de los cromosomas. Estos pueden estar bien o presentar dos clases de aberraciones, las aberraciones simétricas, que afectan al cromosoma entero y que se deben a rupturas antes de la replicación de la célula, y las aberraciones asimétricas, que sólo afectan a una cromátida del cromosoma y que se producen durante o después de la replicación. Generalmente, las radiaciones ionizantes producen aberraciones simétricas, mientras que los mutágenos químicos producen aberraciones asimétricas.

La figura 3.8 representa los tipos de aberraciones estructurales que se pueden encontrar para un cromosoma. Estas pueden ser huecos, en las que una pequeña ruptura no afecta a la forma del cromosoma (d, e); rupturas, en las que una parte del cromosoma o la cromátida se separa del resto, aunque se man- 
a

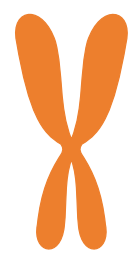

$\mathrm{b}$

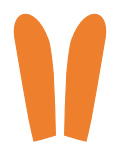

C

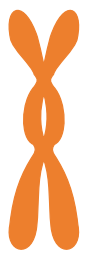

d

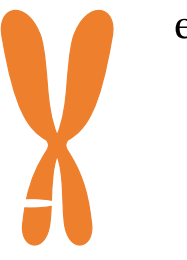

$\mathrm{h}$

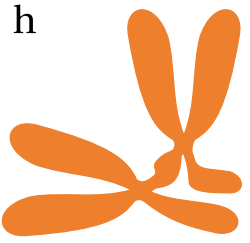

e

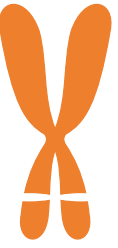

f

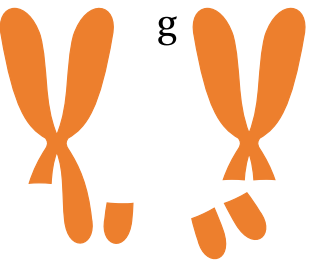

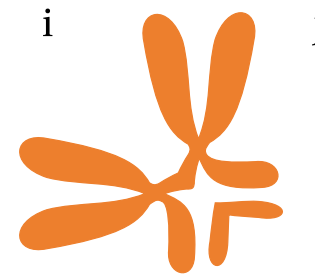

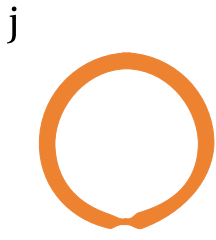

Figura 3.8: Aberraciones cromosómicas posibles. a. Cromosoma intacto, b. Fragmento acéntrico, c. Cromosoma dicéntrico, d. Hueco en la cromátida, e. Hueco en el cromosoma, f. Ruptura en la cromátida, g. Ruptura en el cromosoma, h. Cromosoma trirradial, i. Cromosoma tetrarradial, $\mathbf{j}$. Cromosoma anular.

tiene unida por las proteínas que estabilizan el cromosoma (f, g); cromosomas acéntricos, cuando se ha perdido una parte del cromosoma con el centrómero (b); y los frutos de uniones de cromosomas rotos como son los cromosomas dicéntricos, cuando el sistema de reparación une dos cromosomas rotos con sus centrómeros por los extremos rotos (c); los cromosomas trirradiales, unión de dos cromosomas con ruptura en la cromátida (h); cromosomas tetrarradiales, unión de dos cromosomas con huecos en una de sus cromátidas (i) o el cromosoma anular, cuando se unen los dos extremos rotos de un mismo cromosoma (j). 
Para cada compuesto y concentración se prepara una lámina con un número determinado de células. ${ }^{242,243}$ Los criterios para considerar un test como positivo son que el número de células con aberraciones cromosómicas aumente con la concentración de mutágeno y que este aumento sea reproducible.

\section{Procedimiento experimental}

Aunque para este test se puede utilizar cualquier célula de mamífero, hemos utilizado células V-79 debido a su excelente capacidad para fijarse y su corto periodo de reproducción (12 - 14 horas). La línea de células V-79 fue desarrollada por Denys Ford y George Yerganian en 1958 a partir de tejido pulmonar de hámster chino joven y macho (Cricetulus griseus). ${ }^{244}$ Se designó originalmente como cepa V, pero Mortimer Elkind la renombró como cepa V-79 en 1959. ${ }^{245}$

Se ha tomado un tubo eppendorf con $3 \mathrm{ml}$ de reservas de células V-79 que estaba congelado a $-70{ }^{\circ} \mathrm{C}$ en un medio con DMSO como crioprotector y tras descongelarlo en un baño a $37^{\circ} \mathrm{C}$ se ha añadido a un tubo con $8 \mathrm{ml}$ de medio $\mathrm{V}$-79. El medio V-79 es una mezcla de $8 \mathrm{ml}$ de suero fetal bovino y $72 \mathrm{ml}$ de medio de Ham con mezcla de nutrientes f-10 con un $1 \%$ de antibiótico estreptomicina. El medio de Ham f-10 es una mezcla de 10 sales inorgánicas, 19 aminoácidos, 10 vitaminas, buffers, rojo de fenol y otros compuestos esenciales para las células como glucosa y nucleósidos. Para eliminar la mayor parte de DMSO se ha centrifugado el tubo durante 5 minutos a 1.500 revoluciones por minuto, de tal forma que las células precipitan al fondo del tubo. A continuación se elimina todo el sobrenadante excepto una pequeña cantidad en la que se ponen las células en suspensión con la pipeta. Estas células se añaden a un frasco de cultivo de $75 \mathrm{~cm}^{2}$ de superficie con $10 \mathrm{ml}$ de medio V-79 y se añade filtrado aire enriquecido en $\mathrm{CO}_{2}$ (Composición: $\mathrm{CO}_{2} 5 \%, \mathrm{O}_{2} 21 \%, \mathrm{~N}_{2} 74 \%$ ) para formar un buffer con la disolución y evitar que se vuelva alcalina.

Cuando las células se fijan al frasco tras 24 horas en incubación a $37^{\circ} \mathrm{C}$ se sustituye el medio de cultivo retirando el antiguo y añadiendo $10 \mathrm{ml}$ de medio de Ham f- 10 calentado a $37^{\circ} \mathrm{C}$ y añadiendo de nuevo gas enriquecido en $\mathrm{CO}_{2}$. Estas células continúan reproduciéndose hasta que llenan toda la superficie del frasco, lo que se denomina confluencia del cultivo. Para que pueda continuar la 
reproducción es necesario proporcionar más espacio a las células. Mediante un proceso denominado tripsinización, las células se despegan de la superficie del frasco, y, si se desea aumentar el número de células, se trasladan a un frasco más grande o a un mayor número de frascos. Si, por el contrario, se desea mantener línea reproduciéndose en una superficie igual a la usada hasta entonces, se descartan parte de las células.

La tripsinización se realiza con ayuda de una enzima peptidasa denominada tripsina, que rompe mediante hidrólisis las proteínas con las que las células se unen al frasco. La tripsina es inhibida por el suero fetal bovino, por lo que antes de añadirla se retira el medio V-79 y se añaden $4 \mathrm{ml}$ de verseno. El verseno es una disolución de ácido etilendiaminotetraacético (EDTA) de concentración $200 \mathrm{mg} / \mathrm{L}$ que, debido a sus propiedades quelantes, se utiliza para favorecer el proceso en el que las células se ponen en suspensión. Antes de comenzar es necesario alcalinizar el verseno con unas gotas de disolución concentrada de hidrogenocarbonato sódico para que funcione correctamente. Se puede utilizar el verseno para lavar el frasco y eliminar los últimos restos de medio V-79. A continuación se añade $1 \mathrm{ml}$ de disolución de tripsina a $5 \mathrm{ml}$ de verseno todo ello a $37{ }^{\circ} \mathrm{C}$ y se añaden al frasco. Se controla en el microscopio el momento en el que todas las células pierden su adherencia al frasco y entonces se añaden $10 \mathrm{ml}$ de medio V-79 para evitar que la tripsina continúe atacando las células. Con la pipeta, se ponen las células en suspensión y se transfieren $10 \mathrm{ml}$ de disolución a un tubo que se centrifuga durante 5 minutos a 1.500 revoluciones por minuto. Se elimina el sobrenadante y se deja aproximadamente $1 \mathrm{ml}$ de disolución, donde se ponen en suspensión las células que han quedado en el fondo del tubo. Después se añade una gota de la suspensión en un nuevo frasco con $10 \mathrm{ml}$ de medio V-79 y se regula su pH llenando el frasco con aire enriquecido en $\mathrm{CO}_{2}$.

Para preparar el test de aberraciones cromosómicas se prepara un cultivo de células V-79 en un frasco grande de $175 \mathrm{~cm}^{2}$ de superficie. Cuando el frasco está lleno de células se tripsiniza su contenido y las células en suspensión se dividen en 16 frascos de $25 \mathrm{~cm}^{2}$ con $5 \mathrm{ml}$ de medio. Se incuba durante 24 horas y, a continuación, se añade a cada frasco $50 \mu \mathrm{l}$ del compuesto a probar. También se prepara un control negativo sin compuesto y un control positivo con $7,5 \mu \mathrm{l}$ de MMC (mitomicina C) de concentración $1 \mathrm{mg} / \mathrm{ml}$. Se incuban los frascos durante 
otras 18 horas y se añade $10 \mu \mathrm{l}$ de colchicina de concentración $300 \mu \mathrm{g} / \mathrm{ml}$, que detiene la división celular en la metafase. Tres horas más tarde, se tripsiniza el contenido de cada frasco y se transfiere a un tubo, que se centrifuga a 1.500 r.p.m. durante 5 minutos. Se elimina el líquido sobrenadante y se añaden $8 \mathrm{ml}$ de una disolución acuosa de $\mathrm{KCl}$ 0,56\% para que, con la presión osmótica, las células se hinchen, aunque sin llegar a romperse y se calientan en un baño a $37^{\circ} \mathrm{C}$ durante 2 minutos. Posteriormente, se centrifuga de nuevo, se retira el sobrenadante y se añaden $5 \mathrm{ml}$ de una mezcla de 1 parte de ácido acético glaciar y 3 partes de etanol $98 \%$ que estaba a $-20^{\circ} \mathrm{C}$ para favorecer la fijación de las células. Inmediatamente se centrifuga y, aprovechando que las células quedan fijadas en el fondo del tubo, se retira el líquido. Después, se vuelven a añadir a cada tubo $0,5 \mathrm{ml}$ de la mezcla ácido acético/etanol, donde se ponen en suspensión las células agitando con un vórtex y, mediante una pipeta, se distribuye la solución con las células sobre una lámina de vidrio para microscopía. Al día siguiente, cuando se ha secado el disolvente, se tiñen las células con violeta de metilo y se cubren con láminas cubreobjetos. Por último, con la ayuda de un microscopio, se estudian 50 células que se encuentran en la metafase y se contabiliza el número de aberraciones cromosómicas que presentan según el tipo de aberración. Cada concentración de compuesto se estudia por triplicado mediante la preparación de tres láminas de vidrio diferentes.

\subsubsection{Citotoxicidad: Test del MTT}

El test del MTT es un ensayo colorimétrico cuantitativo para el estudio de la proliferación y supervivencia de células eucariotas. Está basado en su capacidad para detectar la proporción de células que están vivas en el medio. Fue desarrollado por el científico británico Tim Mosmann en 1983 para evitar los complicados métodos que existían hasta la fecha, que requerían de isótopos radiactivos y de complicados procesos experimentales. ${ }^{246}$

El fundamento del ensayo es que sólo las células metabólicamente activas son capaces de reducir a formazano el grupo tretrazolio del compuesto químico MTT (bromuro de 3-(4,5-dimetiltiazol-2-il)-2,5-difeniltetrazolio). La reducción provoca que la molécula cambie de color de amarillo a violeta (esquema 3.2), 


\section{2 | Estudio biológico}
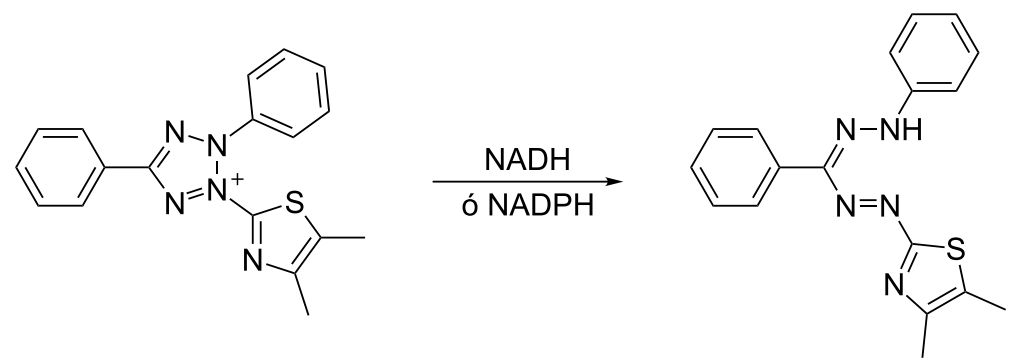

Esquema 3.2: Reducción metabólica de MTT.

por lo que la cantidad de producto, proporcional al número de células vivas, se puede cuantificar fácilmente con un espectrofotómetro. La mayor parte de la reducción es llevada a cabo por las enzimas deshidrogenasa de la superficie de las mitocondrias de la célula, aunque también pueden participar otras enzimas reductoras del citosol u otros orgánulos. ${ }^{247}$

Este ensayo se puede emplear para conocer la citotoxicidad de un determinado compuesto químico, aplicando diferentes concentraciones a un número determinado de células y midiendo la cantidad de ellas que sobreviven a cada concentración. Es un método muy utilizado en la investigación de medicamentos contra el cáncer, ya que permite cuantificar la efectividad del medicamento sobre las células cancerosas y también estudiar la toxicidad sobre las células normales. También es posible medir con este test la actividad biológica de un conjunto de células, puesto que reducirán más MTT cuanto más activas se encuentren.

Con el tiempo han aparecido mejoras del método y compuestos alternativos al MTT, más solubles en agua o con un coeficiente de extinción molar mayor. ${ }^{248}$

\section{Procedimiento experimental}

En este experimento también se han utilizado células V-79 por las mismas ventajas que presentaban para el test de aberraciones cromosómicas.

En cada pocillo de una placa de 96 pruebas se colocan $200 \mu$ l de medio V-79 
y $2 \cdot 10^{4}$ células V-79, excepto una columna de 8 pocillos que se deja sin células para actuar de control positivo. Las células, procedentes de la tripsinización de un cultivo previo, se contabilizan mediante una cámara de Neubauer, que indica el número de células por volumen de suspensión. A continuación, se incuba la placa durante 24 horas a $37^{\circ} \mathrm{C}$ en una atmósfera con $5 \%$ de $\mathrm{CO}_{2}$. Después de este tiempo se añaden las diferentes concentraciones de compuestos a estudiar de tal forma que haya al menos cuatro pocillos por compuesto y concentración. También se deja una columna con 8 pocillos sin añadir ningún compuesto como control negativo. Se añade el gas enriquecido en $\mathrm{CO}_{2}$ y se vuelve a incubar durante 24 horas, tras las cuales se comprueba que no ha habido contaminación y se vacían los pozos para rellenarlos de nuevo con $200 \mu \mathrm{l}$ de medio V-79 y 0,010 g de MTT por pozo. Se incuba la placa durante tres horas a $37^{\circ} \mathrm{C}$ y se retira la mezcla con MTT, quedando un poso cristalino de color violeta que es el MTT que las células han reducido.

Para medir la cantidad de MTT reducido, se lava cada pozo con $100 \mu \mathrm{l}$ de PBS (solución tampón fosfato $0,1 \mathrm{M}$ ) y se añaden $200 \mu \mathrm{l}$ de DMSO que actúa como disolvente del colorante. Se homogeneiza la disolución y con un espectrofotómetro se mide la absorbancia de cada pozo a $595 \mathrm{~nm}$. 


\subsection{Equipos y reactivos utilizados}

\subsubsection{Estudio químico}

\begin{tabular}{ll}
\hline \multicolumn{2}{c}{ Equipos empleados } \\
\hline Purificador de agua & Wasserlab Ultramatic \\
Medidor de pH & Hanna Instruments pH-211 \\
Espectrofotómetro UV-visible & Shimadzu UV-2401-PC \\
Portacubetas & Shimadzu CSP-240-A \\
Cubetas de cuarzo & Hellma 110QS \\
Termostato & Lauda Ecoline Re 120 \\
Stopped-flow & Biologic SFM 300 \\
Espectrómetro de masas & Waters ZQ4000 \\
Espectrómetro de RMN & Bruker Avance 400 MHz \\
Espectrómetro GCMS & Shimadzu QP5000 \\
Báscula & Precisa XT120A \\
Difractómetro RX & Seifert XRD 3003 SC \\
\hline \multicolumn{2}{c}{ Reactivos para cinéticas } \\
\hline Nitrito sódico, ultrapuro & Panreac \\
Perclorato sódico, para análisis & Merck \\
Ácido perclórico 60\% & Panreac \\
Óxido de deuterio 99\% & Aldrich \\
Ácido clorhídrico 37\% & Panreac \\
Hidrogenoftalato potásico & Merck \\
Cloruro sódico & Panreac \\
Éter etílico & Panreac \\
\hline
\end{tabular}

Tabla 3.3: Origen de los equipos y reactivos químicos empleados (Parte I). 


\begin{tabular}{ll}
\hline \multicolumn{2}{c}{ Sustratos de investigación } \\
\hline Etilbenceno & Fluka \\
Fenetilamina & Fluka \\
Tiramina & SAFC \\
Hidrocloruro de dopamina & Sigma \\
Hidrocloruro de serotonina & Alfa Aesar \\
Minoxidilo & Fragon Ibérica \\
\hline \multicolumn{2}{c}{ Reactivos para síntesis } \\
\hline Ácido tetrafluorobórico 48\% & Sigma-Aldrich \\
Metanol & Panreac \\
Etanol & Panreac \\
Tetrahidrofurano & Panreac \\
Piridina & Alfa Aesar \\
4-(dimetilamino)piridina & Alfa Aesar \\
Anhídrido acético & Alfa Aesar \\
Acetato de etilo & Panreac \\
Acetonitrilo & Panreac \\
Hidrogenocarbonato sódico & Panreac \\
\hline \multicolumn{2}{c}{ Sales para el método analítico } \\
\hline Cloruro de aluminio hexahidratado & Panreac \\
Cloruro de níquel hexahidratado & Panreac \\
Cloruro de calcio & Merck \\
Sulfato de cobre (II) pentahidratado & Panreac \\
Sulfato de hierro (II) heptahidratado & Panreac \\
Sulfato de hierro (III) hexahidratado & Merck \\
Sulfato de zinc heptahidratado & Panreac \\
Sulfato de cromo (III) & Merck \\
\hline & \\
\hline
\end{tabular}

Tabla 3.4: Origen de los reactivos químicos empleados (Parte II). 


\subsubsection{Estudio biológico}

\begin{tabular}{lc}
\hline & Equipos empleados \\
\hline Espectrofotómetro & Biochrom Anthos Zenyth 3100 \\
Báscula & Sartorius TE64 \\
Cámara de Neubauer & Optic Labor 0,100 mm \\
Microscopio & Leitz Dialux 70 \\
Centrifugadora & Tehtnica Centric 322A \\
\hline & Células y bacterias \\
\hline Salmonella typhimurium & Suministradas por el Prof. B. N. Ames \\
& Universidad de Berkeley, EE.UU. \\
Células V79 & Suministradas por el Prof. H. R. Glatt \\
& Instituto alemán de nutrición humana \\
\hline & Reactivos \\
\hline Agar nutritivo & BD Bacto-Agar \\
Aroclor 1254 induced S9 & Molecular Toxicology, Inc. \\
Nutrient broth (NB) & Oxoid \\
4NQO & Sigma \\
2-aminoantraceno & Sigma \\
NPD & Sigma \\
NADP & Sigma \\
Glucosa-6-fosfato & Sigma \\
MTT 97,5\% Ham f-10 & Sigma \\
\hline
\end{tabular}

Tabla 3.5: Origen del material empleado en el estudio biológico. 


\section{Capítulo 4}

\section{Resultados experimentales}

\subsection{Nitrosación del etilbenceno}

\subsubsection{Solubilidad y estudio espectrofotométrico}

Aunque la solubilidad del etilbenceno en agua es baja (página 99), la concentración máxima que se puede alcanzar a $20^{\circ} \mathrm{C}, 1,4 \cdot 10^{-3} \mathrm{M}$, es suficiente para realizar el estudio cinético de su reacción de nitrosación.

En la práctica, empleando ultrasonidos para disolver el etilbenceno, se han conseguido mezclar $0,016 \mathrm{ml}$ del compuesto en $100 \mathrm{ml}$ de agua a $20^{\circ} \mathrm{C}$, lo que equivale a una concentración de $1,3 \cdot 10^{-3} \mathrm{M}$. El etilbenceno es un compuesto volátil y menos denso que el agua, por lo que se tuvo precaución de que no se evaporase al tratar de disolverlo a temperaturas superiores.

Se ha obtenido el espectro de absorción UV-visible de la disolución anterior entre 190 y $700 \mathrm{~nm}$ (figura 4.1). El etilbenceno en disolución acuosa sólo muestra dos bandas de absorción en la zona ultravioleta del espectro. Una muy intensa entre 190 y $225 \mathrm{~nm}$, que corresponde a una transición permitida $\pi \rightarrow \pi^{*}$, y otra débil entre 230 y $275 \mathrm{~nm}$, característica de los compuestos bencénicos alquilmonosustituidos, que se debe a una transición $\pi \rightarrow \pi^{*}$ prohibida (figura 4.2). ${ }^{249}$

Ninguna de estas dos bandas resulta de interés para el seguimiento de la reacción 


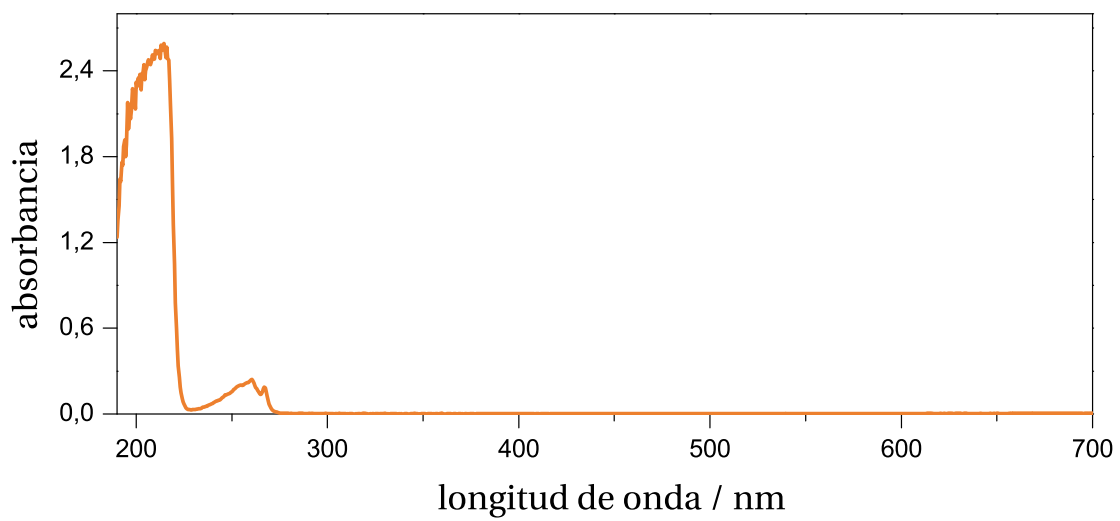

Figura 4.1: Espectro de absorción UV-visible del etilbenceno. $[\mathrm{ETH}]=1,3 \cdot 10^{-3} \mathrm{M}$, $\mathrm{pH}=7,0, T=20,0^{\circ} \mathrm{C}$.

de nitrosación.

\subsubsection{Reacción entre etilbenceno y nitrito}

Debido a la escasa activación del anillo aromático del etilbenceno, se ha estudiado su posible reacción con el ácido nitroso en las condiciones experimentales más favorables para la nitrosación. Esto es: concentración en amplio exceso de nitrito (20 veces superior) y $\mathrm{pH}=3,0 .{ }^{132,250}$

Desde el punto de vista espectroscópico, incluso en las condiciones descritas, no se puede afirmar que haya reacción química entre el ácido nitroso y el etilbenceno. La figura 4.3 muestra la evolución temporal del espectro de absorción de una mezcla de ambos reactivos. No aparece ninguna nueva banda de absorción y tan sólo se observa la descomposición normal del ácido nitroso (banda 300-400 nm).

La ausencia de reacción para un tiempo significativo se ha confirmado mediante cromatografía de gases - espectrometría de masas. Una mezcla de reacción como la de la figura 4.3 se ha mantenido a temperatura constante de $T=30,0^{\circ} \mathrm{C}$ durante 48 horas. A continuación se ha realizado una extracción 


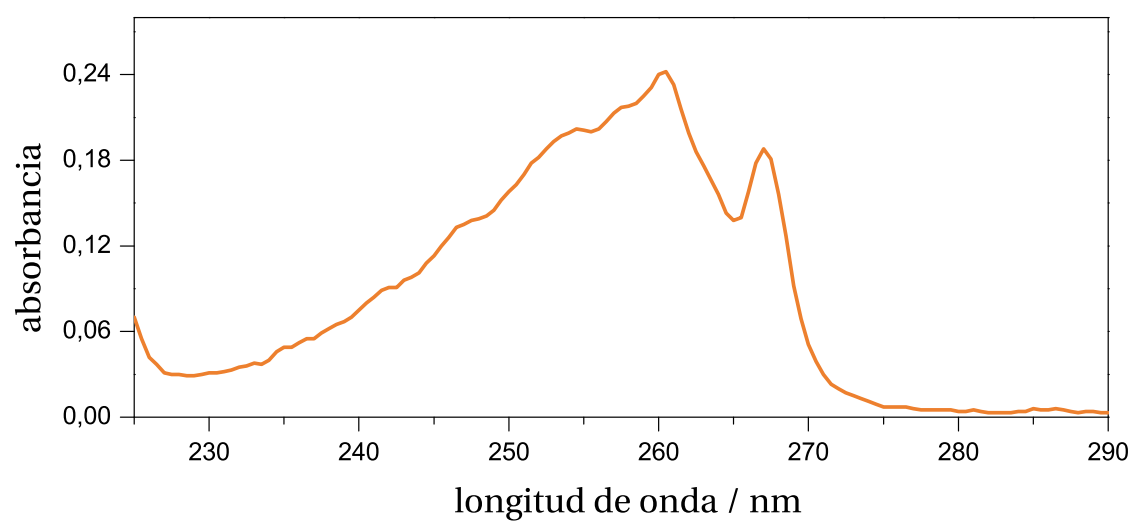

Figura 4.2: Banda de absorción ultravioleta del etilbenceno. $[\mathrm{ETH}]=1,3 \cdot 10^{-3} \mathrm{M}, \mathrm{pH}=7,0$, $T=20,0^{\circ} \mathrm{C}$.

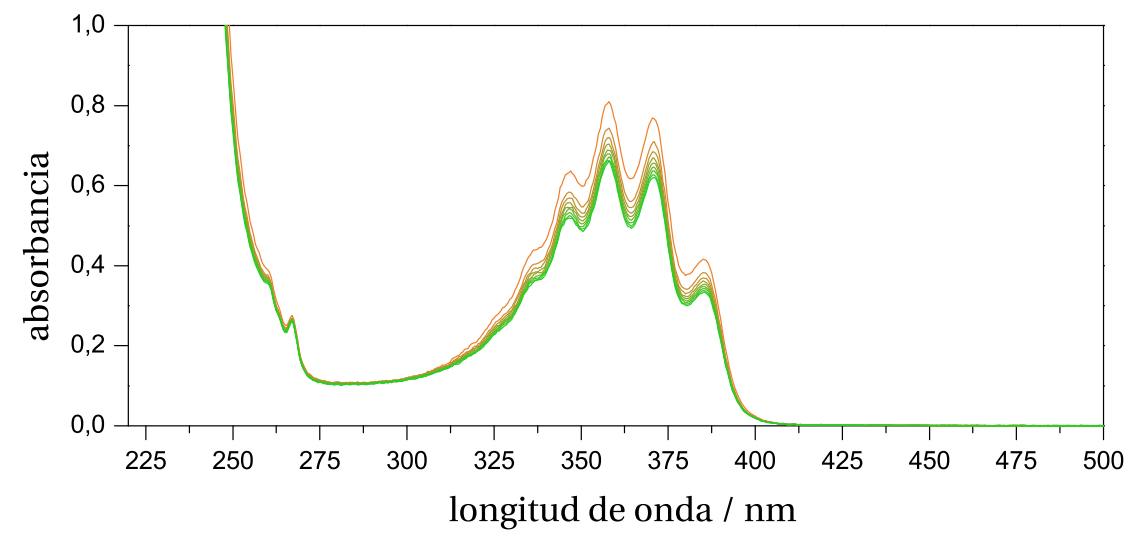

Figura 4.3: Variación del espectro de absorción de la mezcla etilbenceno - ácido nitroso con el tiempo. Espectros tomados cada 6 horas desde $t=0$ (naranja) hasta $t=54$ horas (verde). $[\mathrm{ETH}]_{\circ}=1,04 \cdot 10^{-3} \mathrm{M},[\mathrm{NIT}]_{\circ}=2,09 \cdot 10^{-2} \mathrm{M}, \mathrm{pH}=3,07, T=25,0{ }^{\circ} \mathrm{C}$. 
150 | Nitrosación del etilbenceno
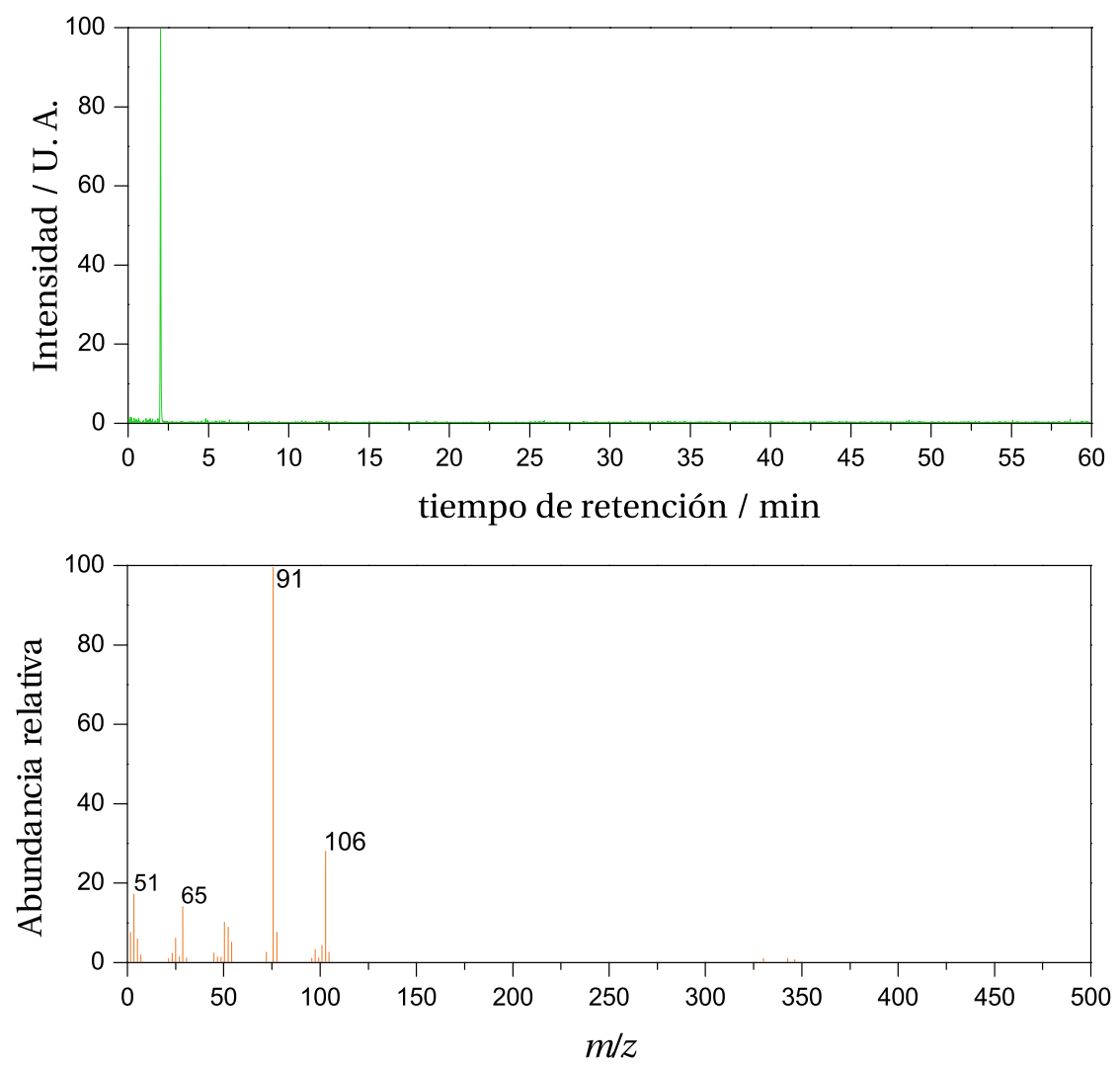

Figura 4.4: Cromatograma de gases y espectro de masas por impacto electrónico positivo del etilbenceno realizados bajo las condiciones de la tabla 4.1. 

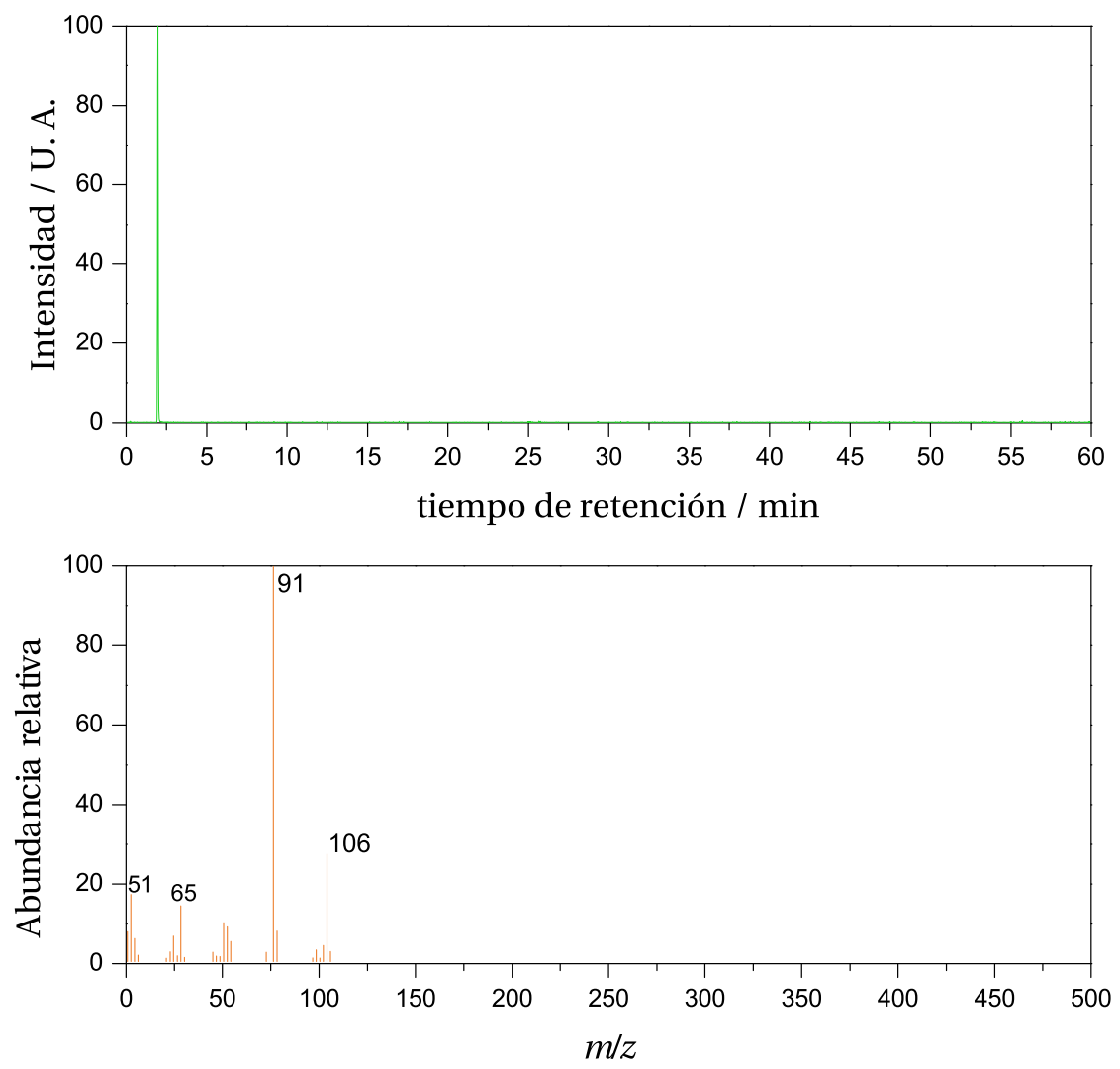

Figura 4.5: Cromatograma de gases y espectro de masas por impacto electrónico positivo de la mezcla de etilbenceno y ácido nitroso realizados bajo las condiciones de la tabla 4.1 . 


\section{2 | Nitrosación del etilbenceno}

líquido-líquido de $20 \mathrm{ml}$ de disolución mezcla con $10 \mathrm{ml}$ de éter etílico. La fase orgánica se ha cromatografiado y ha aparecido un pico a un tiempo de retención de 2 minutos. El cromatograma y el espectro de masas de esta experiencia se muestra en la figura 4.5. Estas gráficas se han comparado con el resultado de analizar en las mismas condiciones una disolución de etilbenceno $1,04 \cdot 10^{-3} \mathrm{M}$ (figura 4.4). Ambas presentan sólo un pico en el mismo tiempo de retención y espectros de masas idénticos, lo que confirma la ausencia de reacción entre el ácido nitroso y el etilbenceno en un periodo de 48 horas, a pesar de las condiciones de temperatura, acidez y exceso de nitrito favorables a la nitrosación.

Las características experimentales de los cromatogramas - espectros de masas de las figuras 4.4 y 4.5 se encuentran recogidas en la tabla 4.1.

\begin{tabular}{ll}
\hline \multicolumn{1}{c}{ Propiedad } & \multicolumn{1}{c}{ Valor } \\
\hline$T$ inyector & $270^{\circ} \mathrm{C}$ \\
$T$ interfase & $270{ }^{\circ} \mathrm{C}$ \\
$T$ horno inicial & $50^{\circ} \mathrm{C}$ (durante 5 min.) \\
Gradiente temperatura & $7^{\circ} \mathrm{C} / \mathrm{min}$ \\
$T$ horno final & $270^{\circ} \mathrm{C}$ (durante $\left.22 \mathrm{~min}.\right)$ \\
Gas portador & $\mathrm{Helio}$ \\
Caudal & $1,2 \mathrm{ml} / \mathrm{min}$ \\
Relación Split & $8 / 1$ \\
Espectrómetro de masas & $\mathrm{Cuadrupolo}$ \\
Rango de masas & $50-400$ \\
\hline
\end{tabular}

Tabla 4.1: Condiciones experimentales de los cromatogramas - espectros de masas. 


\subsection{Nitrosación de la fenetilamina}

\subsubsection{Solubilidad y estudio espectrofotométrico}

La solubilidad de la fenetilamina (PHE) en agua es relativamente buena (página 101). En medios ácidos y neutros la amina se encuentra protonada confiriendo a la fenetilamina carácter iónico. Sin embargo, a $20^{\circ} \mathrm{C}$ y concentraciones superiores a $1 \mathrm{ml} / 100 \mathrm{~g}$ de agua $\left(8 \cdot 10^{-2} \mathrm{M}\right)$, la fenetilamina tiende a formar micelas en el seno del medio. Estos agregados son fáciles de romper por tratamiento con ultrasonidos.

El espectro de absorción UV-visible de la fenetilamina se muestra en la siguiente figura:

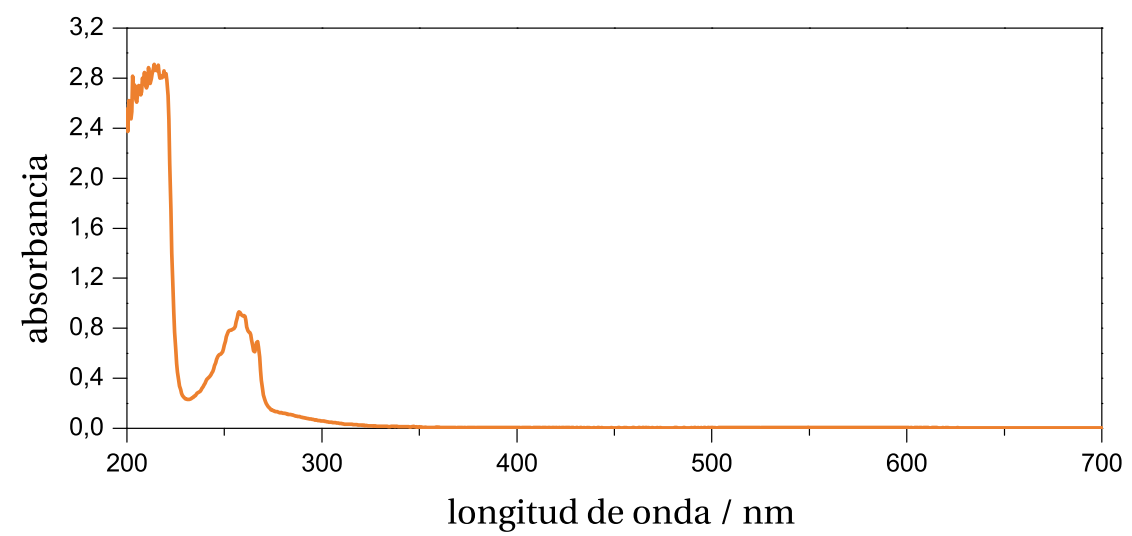

Figura 4.6: Espectro de absorción UV-visible de la fenetilamina. $[\mathrm{PHE}]=4 \cdot 10^{-3} \mathrm{M}$, $\mathrm{pH}=10,6, T=20,0^{\circ} \mathrm{C}$.

Las bandas de absorción de la fenetilamina son más intensas que las del etilbenceno. La primera se encuentra entre 190 y $235 \mathrm{~nm}$ y la segunda entre 235 y $275 \mathrm{~nm}$. Se ha estudiado el coeficiente de absorción molar de esta última banda midiendo los espectros de absorción de la fenetilamina para diferentes concentraciones de la misma (figura 4.7). De acuerdo con la ley de Lambert-Beer, 


\section{4 | Nitrosación de la fenetilamina}

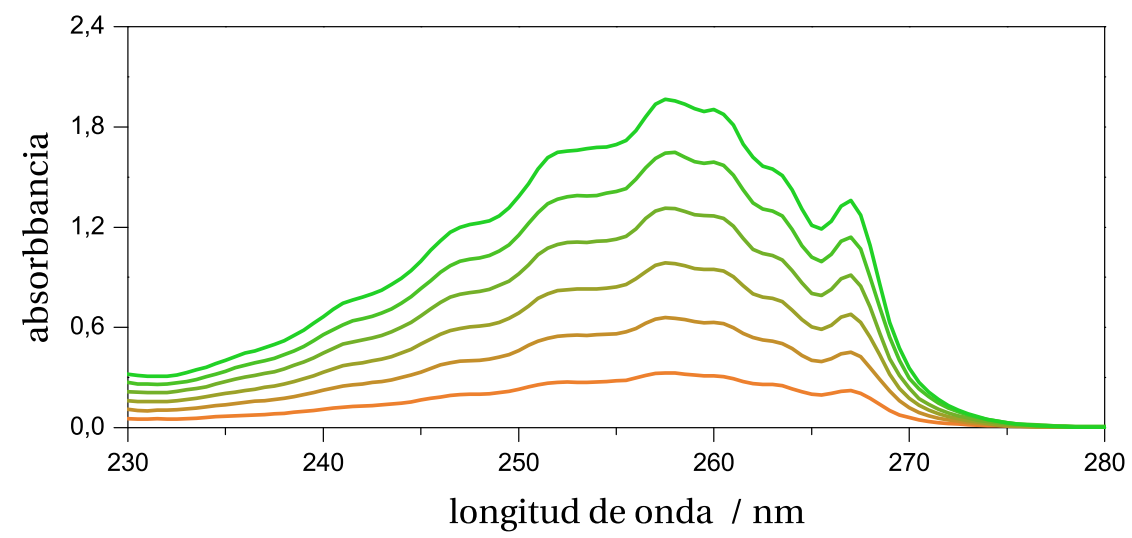

Figura 4.7: Espectros de absorción de seis disoluciones de fenetilamina con distintas concentraciones. $[\mathrm{PHE}]=1,59 \cdot 10^{-3}-9,53 \cdot 10^{-3} \mathrm{M}, \mathrm{pH}=10,6, T=20,0{ }^{\circ} \mathrm{C}$.

la absorbancia $A$ es directamente proporcional al a concentración $c$ (ecuación 4.1 , donde $l$ es el paso óptico de la cubeta de muestra y $\varepsilon$ el coeficiente de absorción molar).

$$
A=\varepsilon l c
$$

La figura 4.8 muestra los valores de absorbancia del máximo de la banda $(258 \mathrm{~nm})$ para cada concentración de fenetilamina y el ajuste de estos datos a la ecuación de Lambert-Beer. Como se ha utilizado una cubeta de $1 \mathrm{~cm}$ de paso óptico, el coeficiente de absorción molar para la fenetilamina en estas condiciones, a $258 \mathrm{~nm}$, es:

$$
\varepsilon_{\mathrm{PHE}, 258 \mathrm{~nm}}=206 \pm 1 \mathrm{M}^{-1} \mathrm{~cm}^{-1}
$$

La figura 4.9 muestra la variación del espectro de absorción de la fenetilamina con el pH, dibujado según se ha descrito en la sección 3.1.2.3. Como el grupo $-\mathrm{NH}_{2}$ se encuentra separado del anillo aromático por dos carbonos alifáticos, el espectro apenas se modifica. Llama la atención el pico en $268 \mathrm{~nm}$ que, de ser el más definido en medio básico, casi desaparece en medio ácido. 


\begin{tabular}{cccc}
\hline$[\mathrm{PHE}] / \mathrm{M}$ & $A_{258}$ & {$[\mathrm{PHE}] / \mathrm{M}$} & $A_{258}$ \\
\hline $1,59 \cdot 10^{-3}$ & 0,326 & $6,35 \cdot 10^{-3}$ & 1,311 \\
$3,18 \cdot 10^{-3}$ & 0,655 & $7,94 \cdot 10^{-3}$ & 1,647 \\
$4,76 \cdot 10^{-3}$ & 0,982 & $9,53 \cdot 10^{-3}$ & 1,956 \\
\hline
\end{tabular}

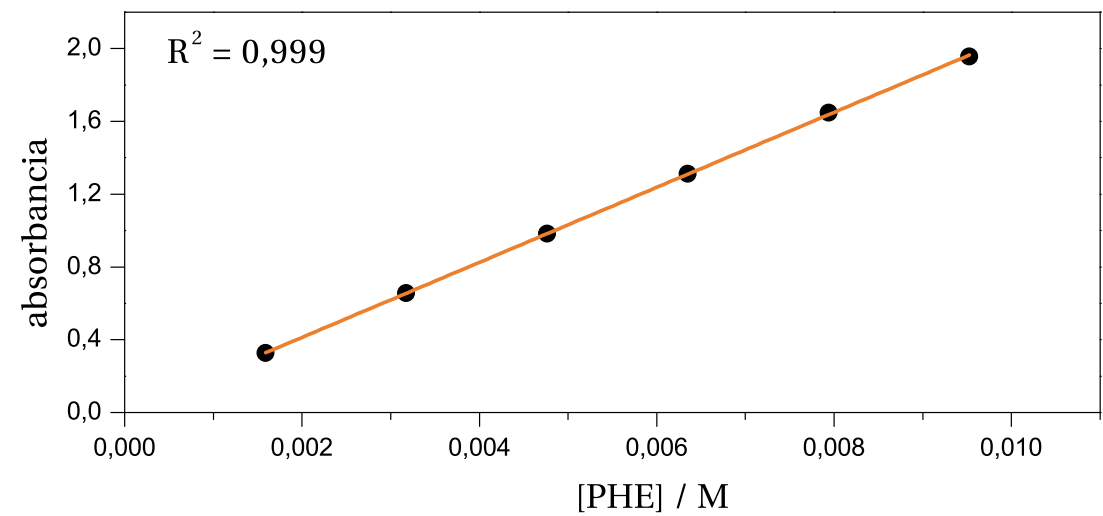

Tabla 4.2 y Figura 4.8: Cumplimiento de la ley de Lambert-Beer por la fenetilamina. $\lambda=$ $258 \mathrm{~nm}, \mathrm{pH}=10,6, T=20,0^{\circ} \mathrm{C}$.

\subsubsection{Reacción entre fenetilamina y nitrito}

Conocido el comportamiento espectroscópico de la fenetilamina, se han estudiado los cambios que se producen al hacerla reaccionar con nitrito sódico en medio acuoso y ácido (figura 4.10).

La banda de absorción del sistema nitrito/ácido nitroso (310 - $400 \mathrm{~nm})$ desciende con el tiempo, mientras que sobre los picos de la fenetilamina, que apenas cambian de forma aparece una nueva banda de absorción. El descenso de la absorbancia del nitrito no se puede explicar exclusivamente por la descomposición del ácido nitroso (sección 4.2.6), lo que muestra que el nitrito reacciona 


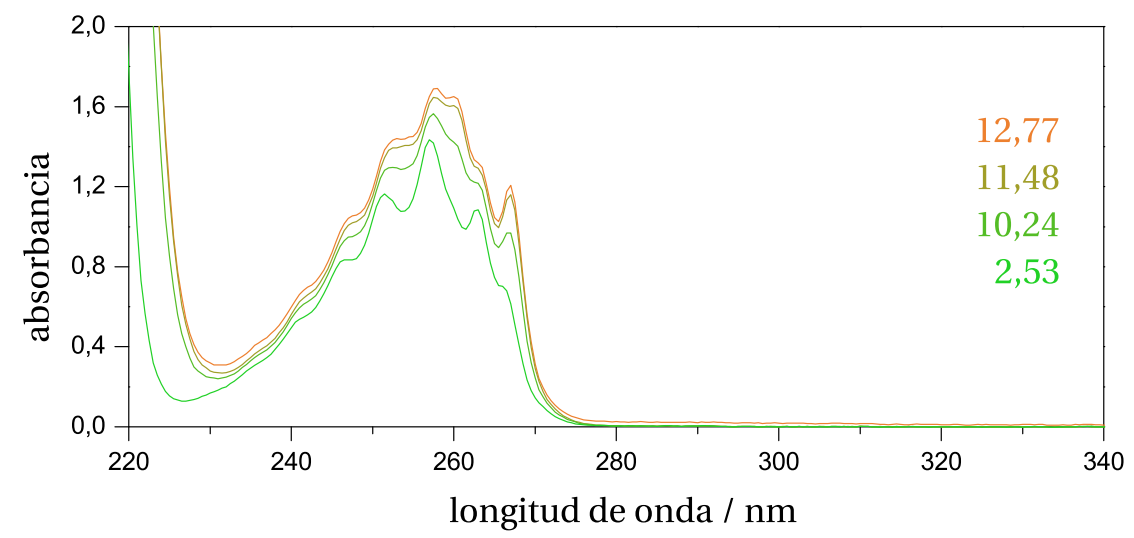

Figura 4.9: Variación del espectro de absorción UV-visible de la fenetilamina con el pH. $[\mathrm{PHE}]=8 \cdot 10^{-3} \mathrm{M}, T=20,0^{\circ} \mathrm{C}$.

con el sustrato.

Como el pico de la fenetilamina no cambia de forma sensiblemente y en las longitudes de onda inferiores a $250 \mathrm{~nm}$ absorben muchas disoluciones reguladoras y los productos de descomposición del ácido nitroso, se siguió la reacción a través de la banda de absorción del nitrito/ácido nitroso.

\subsubsection{Efecto de la presión en la velocidad}

Tanto en las reacciones de N-nitrosación (sección 2.3.3), como en la descomposición del ácido nitroso (sección 2.1), alguno de los productos es gaseoso. Por ello, la presión es un factor más a tener en cuenta en este tipo de reacciones. La reacción de la figura 4.10 se estudió a presión constante, sin tapar ni el matraz de reacción ni la cubeta de muestra durante el ensayo. Se ha repetido el mismo experimento cerrando los recipientes de reacción de tal forma que la presión aumenta con el tiempo según se acumulan los gases en el espacio libre del recipiente. El resultado se muestra en la figura 4.11.

La comparación de esta figura con la del experimento a presión constante demuestra que la presión inhibe tanto la reacción de nitrosación de la fenetilamina 


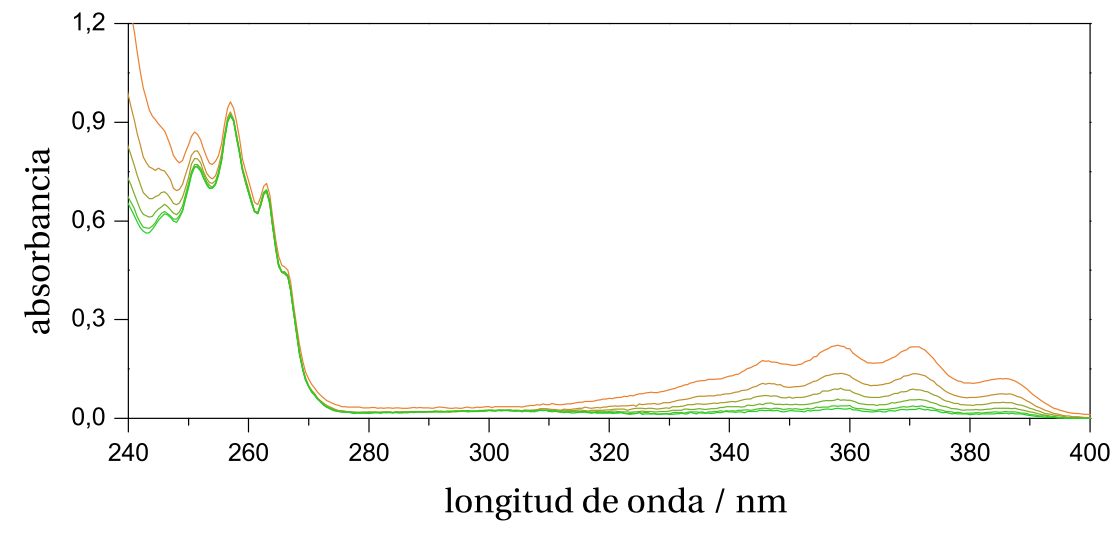

Figura 4.10: Variación con el tiempo del espectro de absorción de la fenetilamina durante su nitrosación. Espectros tomados cada 10 horas desde el naranja al verde. $[\mathrm{PHE}]_{\circ}=4,21 \cdot 10^{-3} \mathrm{M},[\mathrm{NIT}]_{\circ}=5,31 \cdot 10^{-3}, \mathrm{pH}=3,01, T=25,0{ }^{\circ} \mathrm{C}$.

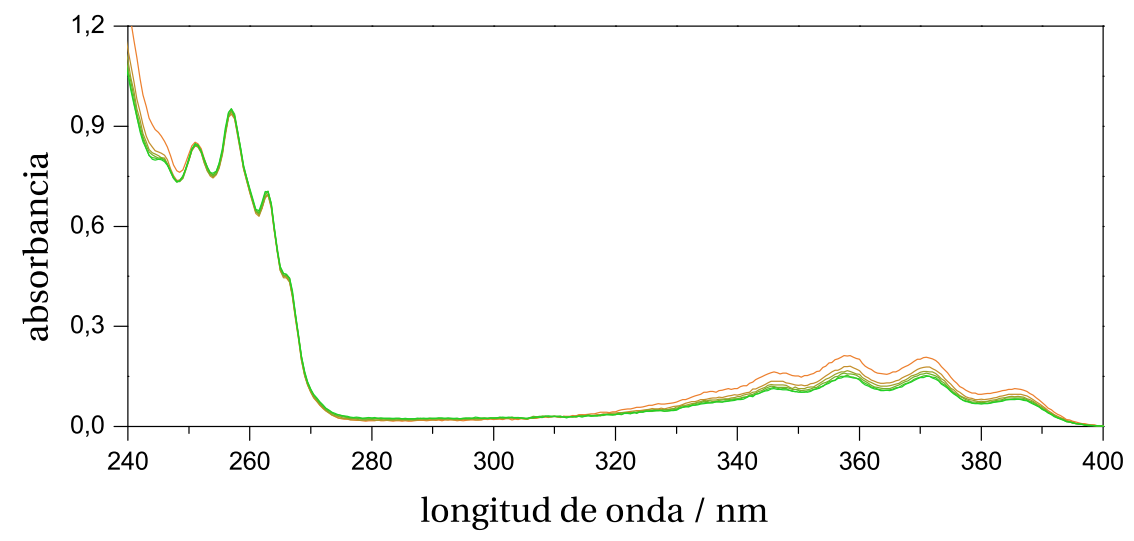

Figura 4.11: Influencia de la presión en la velocidad de reacción. Espectros tomados cada 10 horas desde el naranja al verde. $[\mathrm{PHE}]_{\circ}=4,21 \cdot 10^{-3} \mathrm{M},[\mathrm{NIT}]_{\circ}=5,31 \cdot 10^{-3}, \mathrm{pH}=3,01$, $T=25,0^{\circ} \mathrm{C}$. 


\section{8 | Nitrosación de la fenetilamina}

como la descomposición del ácido nitroso. Por ello, como no se puede controlar de forma exacta la presión de los gases desprendidos, se decidió realizar todos los experimentos de este trabajo a presión constante.

\subsubsection{Estudio espectrofotométrico del nitrito}

El inconveniente de seguir una reacción a través de la disminución en la absorbancia del sistema nitrito - ácido nitroso es que sus bandas de absorción varían mucho con la acidez. La figura 4.12 muestra cómo cambian los espectros de absorción de una disolución de nitrito sódico en función del pH.

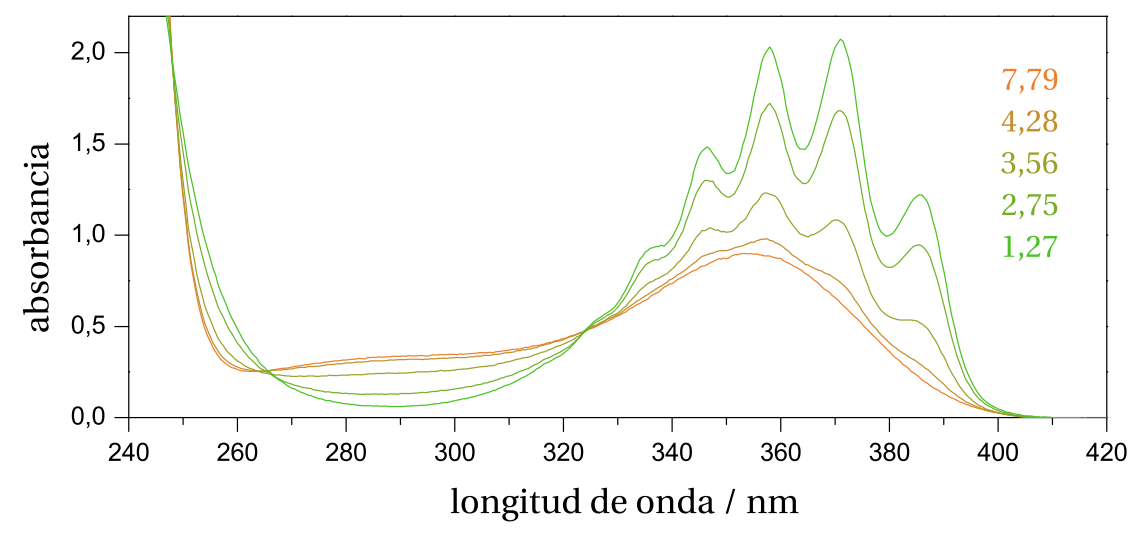

Figura 4.12: Variación del espectro de absorción UV-visible del nitrito con el pH. El color de los espectros varía según el pH desde el más básico (naranja) al más ácido (verde). [NIT] $=3,94 \cdot 10^{-2} \mathrm{M}, T=25,0^{\circ} \mathrm{C}$.

Se observan dos bandas características del grupo -NO. La primera centrada en $\lambda \simeq 355 \mathrm{~nm}$ corresponde a una transición $\mathrm{n} \rightarrow \pi^{*}$, la segunda, mucho más intensa, corresponde a una transición $\pi \rightarrow \pi^{*}$ centrada en en $\lambda \simeq 220 \mathrm{~nm}$. El sistema tiene tres puntos isosbésticos en 249, 265 y $323 \mathrm{~nm}$.

Para seguir la reacción de nitrosación se ha elegido el máximo de absorción de la banda en la zona visible del ácido nitroso $(\lambda=371 \mathrm{~nm})$ en lugar de los 
puntos isosbésticos, para evitar interferencias con la fenetilamina y por su mayor absorbancia. Para calcular el coeficiente de absorción molar en esta longitud de onda hay que tener en cuenta que la absorbancia total $A_{T}$ se debe a la suma de la absorbancia de las dos especies mezcladas, el ácido nitroso y el nitrito:

$$
A_{T}=A_{\mathrm{HNO}_{2}}+A_{\mathrm{NO}_{2}^{-}}
$$

De modo que la ley de Lambert-Beer (ecuación 4.1, página 154) se escribir así:

$$
A_{T}=\varepsilon_{\mathrm{HNO}_{2}} l\left[\mathrm{HNO}_{2}\right]+\varepsilon_{\mathrm{NO}_{2}^{-}} l\left[\mathrm{NO}_{2}^{-}\right]
$$

La proporción de nitrito y ácido nitroso en función del pH se conoce a través de la constante del equilibrio ácido-base entre las dos especies:

$$
K_{a}=\frac{\left[\mathrm{H}^{+}\right]\left[\mathrm{NO}_{2}^{-}\right]}{\left[\mathrm{HNO}_{2}\right]}
$$

Combinando las ecuaciones 4.4 y 4.7 se obtiene:

$$
A_{T}=\varepsilon_{\mathrm{HNO}_{2}} l \frac{\left[\mathrm{H}^{+}\right]\left[\mathrm{NO}_{2}^{-}\right]}{K_{a}}+\varepsilon_{\mathrm{NO}_{2}^{-}} l\left[\mathrm{NO}_{2}^{-}\right]
$$

Simplificando la ecuación anterior obtenemos la expresión:

$$
A_{T}=\frac{\varepsilon_{\mathrm{NO}_{2}^{-}} K_{a}+\varepsilon_{\mathrm{HNO}_{2}}\left[\mathrm{H}^{+}\right]}{\left[\mathrm{H}^{+}\right]+K_{a}} l[\mathrm{NIT}]
$$

donde [NIT] es la suma de las concentraciones de las dos especies. Así, para el pico responsable de estas dos especies podemos definir un coeficiente de extinción molar global, $\varepsilon_{\mathrm{NIT}}$ :

$$
\varepsilon_{\mathrm{NIT}}=\frac{\varepsilon_{\mathrm{NO}_{2}^{-}} K_{a}+\varepsilon_{\mathrm{HNO}_{2}}\left[\mathrm{H}^{+}\right]}{\left[\mathrm{H}^{+}\right]+K_{a}}
$$

Los coeficientes de extinción molar del ácido nitroso (figura 4.13) y del nitrito (figura 4.14) se han determinado experimentalmente. Para ello se han preparado distintas concentraciones de estas especies a $\mathrm{pH}=1,5$, donde la proporción ácido nitroso/nitrito es de 35:1 y a pH = 6, donde la proporción de nitrito/ácido nitroso es de 850:1, obteniéndose el valor de $\varepsilon_{\mathrm{NIT}}$ :

$$
\varepsilon_{\mathrm{NIT}}=\frac{(16,37 \pm 0,06) \mathrm{M}^{-1} \mathrm{~cm}^{-1} K_{a}+(52,3 \pm 0,5) \mathrm{M}^{-1} \mathrm{~cm}^{-1}\left[\mathrm{H}^{+}\right]}{\left[\mathrm{H}^{+}\right]+K_{a}}
$$


160 | Nitrosación de la fenetilamina

\begin{tabular}{cccc}
\hline$\left[\mathrm{HNO}_{2}\right] / \mathrm{M}$ & $A_{\mathrm{HNO}_{2}}$ & {$\left[\mathrm{HNO}_{2}\right] / \mathrm{M}$} & $A_{\mathrm{HNO}_{2}}$ \\
\hline $3,77 \cdot 10^{-3}$ & 0,227 & $2,261 \cdot 10^{-2}$ & 1,197 \\
$7,54 \cdot 10^{-3}$ & 0,446 & $2,638 \cdot 10^{-2}$ & 1,401 \\
$1,130 \cdot 10^{-2}$ & 0,610 & $3,015 \cdot 10^{-2}$ & 1,626 \\
$1,507 \cdot 10^{-2}$ & 0,840 & $3,768 \cdot 10^{-2}$ & 2,014 \\
$1,884 \cdot 10^{-2}$ & 1,018 & & \\
\hline
\end{tabular}

$$
y=(0,03 \pm 0,01)+(52,3 \pm 0,5) x
$$

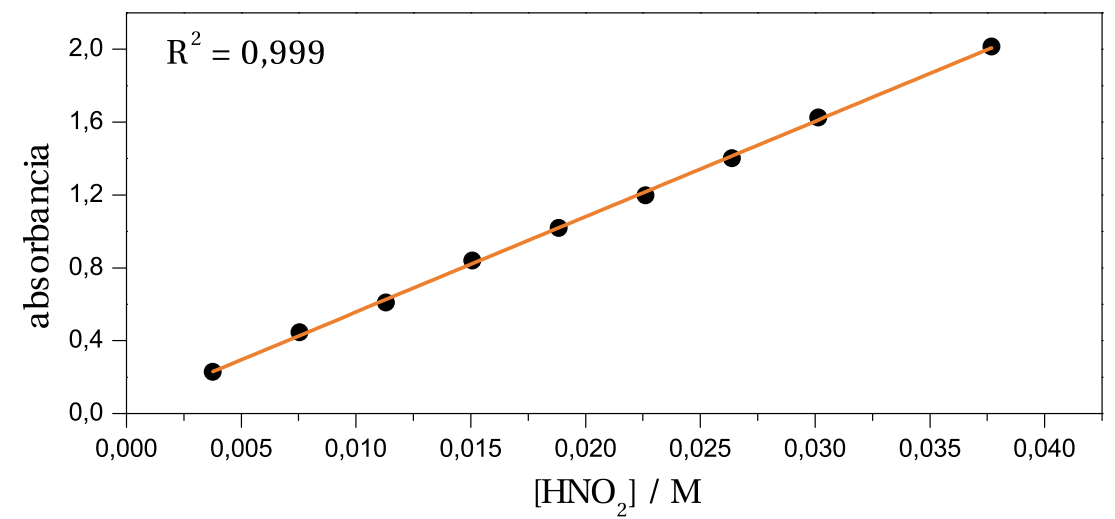

Tabla 4.3 y Figura 4.13: Cumplimiento de la ley de Lambert-Beer por el ácido nitroso. $\lambda=371 \mathrm{~nm}, \mathrm{pH}=1,49, T=25,0^{\circ} \mathrm{C}$. 


\begin{tabular}{cccc}
\hline$\left[\mathrm{NO}_{2}^{-}\right] / \mathrm{M}$ & $A_{\mathrm{NO}_{2}^{-}}$ & {$\left[\mathrm{NO}_{2}^{-}\right] / \mathrm{M}$} & $A_{\mathrm{NO}_{2}^{-}}$ \\
\hline $9,39 \cdot 10^{-3}$ & 0,164 & $5,633 \cdot 10^{-2}$ & 0,923 \\
$1,878 \cdot 10^{-2}$ & 0,309 & $6,572 \cdot 10^{-2}$ & 1,084 \\
$2,817 \cdot 10^{-2}$ & 0,464 & $7,511 \cdot 10^{-2}$ & 1,241 \\
$3,756 \cdot 10^{-2}$ & 0,624 & $9,388 \cdot 10^{-2}$ & 1,540 \\
$4,694 \cdot 10^{-2}$ & 0,775 & & \\
\hline
\end{tabular}

$$
y=(0,006 \pm 0,003)+(16,37 \pm 0,06) x
$$

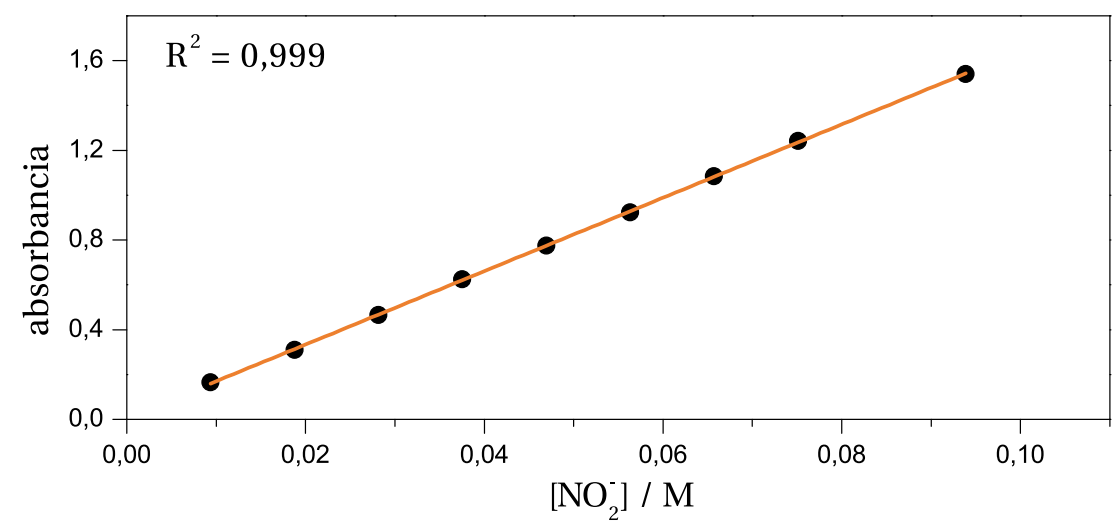

Tabla 4.4 y Figura 4.14: Cumplimiento de la ley de Lambert-Beer por el nitrito. $\lambda=371$ $\mathrm{nm}, \mathrm{pH}=6,05, T=25,0{ }^{\circ} \mathrm{C}$. 


\section{2 | Nitrosación de la fenetilamina}

\subsection{5. Órdenes parciales de reacción}

El método cinético para la determinación de los órdenes parciales de reacción se eligió cuidadosamente en función de varios factores. En primer lugar se eligió el método de velocidades iniciales para soslayar en la medida de lo posible la descomposición del ácido nitroso. Por la misma razón se han llevado a cabo lo experimentos a $\mathrm{pH}=3,8$. Además, esta acidez tiene la ventaja de que la absorbancia del sistema ácido nitroso - nitrito es suficiente para que las medidas tengan poca incertidumbre. Uno de los reactivos tiene que estar en exceso para calcular el orden parcial del otro compuesto. El nitrito no puede ser el reactivo en exceso porque su absorbancia no debe ser superior a 2, que es hasta donde el espectrofotómetro empleado puede medir sin error significativo. Por lo que tiene que ser la fenetilamina la que esté en exceso, aunque debido a su solubilidad $\mathrm{y}$, para mantener las condiciones adecuadas para el método de aislamiento, la concentración de nitrito debe ser baja, lo que ha provocado que la absorbancia sea pequeña y la reacción lenta. Por ello, para reducir la incertidumbre, se han repetido los experimentos por triplicado.

De esta forma, la ecuación de velocidad depende exclusivamente del nitrito y de la pseudoconstante de velocidad $q$ :

$$
\begin{gathered}
v=k_{\mathrm{obs}}[\mathrm{PHE}]^{m}[\mathrm{NIT}]_{\circ}^{n} \\
q=k_{\mathrm{obs}}[\mathrm{PHE}]^{m} \\
v=q[\mathrm{NIT}]_{\circ}^{n}
\end{gathered}
$$

La figura 4.15 muestra cómo, variando la concentración de nitrito inicial y midiendo la velocidad, se obtiene el orden parcial $n$ según la ecuación linealizada:

$$
\ln v_{\circ}=\ln q+n \ln [\mathrm{NIT}]_{\circ}
$$

De la pendiente de la recta obtenida se obtiene un orden dos respecto a la concentración de nitrito.

Repitiendo los experimentos mientras se varía la concentración de fenetilamina en exceso (figura 4.16) se determina el orden del reactivo a partir de la pseudoconstante $q$ :

$$
\ln q=\ln k_{\mathrm{obs}}+m \ln [\mathrm{PHE}]
$$




\begin{tabular}{lccc}
\hline$[\mathrm{NIT}]_{\circ} / \mathrm{M}$ & $v_{\circ} / \mathrm{M} \mathrm{s}^{-1}$ & {$[\mathrm{NIT}]_{\circ} / \mathrm{M}$} & $v_{\circ} / \mathrm{M} \mathrm{s}^{-1}$ \\
\hline $3,442 \cdot 10^{-2}$ & $1,747 \cdot 10^{-6}$ & $3,029 \cdot 10^{-2}$ & $1,375 \cdot 10^{-6}$ \\
$3,304 \cdot 10^{-2}$ & $1,592 \cdot 10^{-6}$ & $2,891 \cdot 10^{-2}$ & $1,214 \cdot 10^{-6}$ \\
$3,167 \cdot 10^{-2}$ & $1,536 \cdot 10^{-6}$ & & \\
\hline
\end{tabular}

$$
y=-(6,5 \pm 0,6)+(2,0 \pm 0,2) x
$$

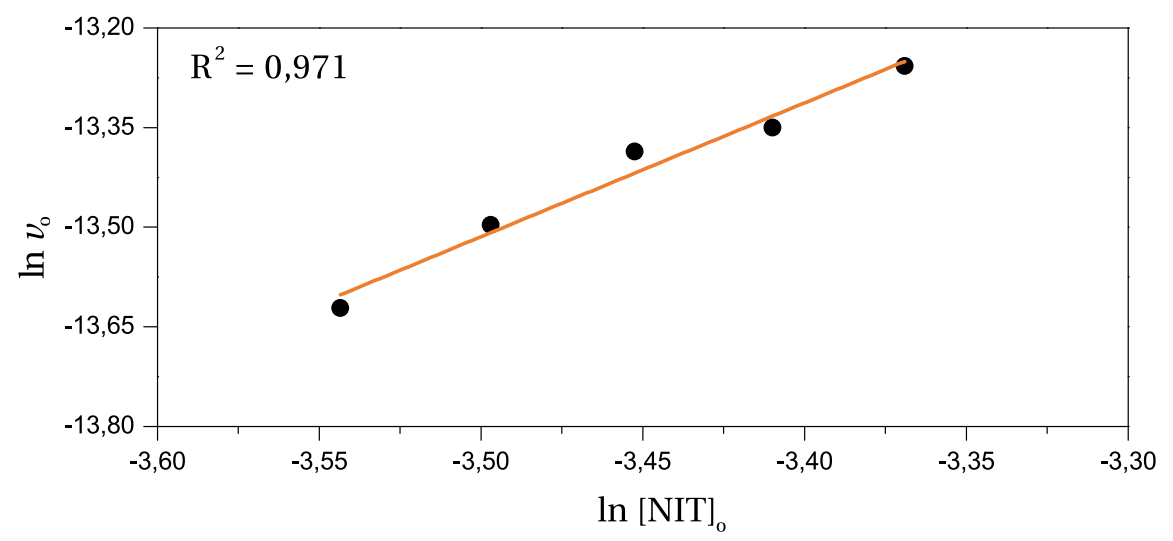

Tabla 4.5 y Figura 4.15: Influencia de la concentración de nitrito en la velocidad inicial de nitrosación. $[\mathrm{PHE}]=0,168 \mathrm{M}, \mathrm{pH}=3,81, T=20,0{ }^{\circ} \mathrm{C}$. 
164 | Nitrosación de la fenetilamina

\begin{tabular}{cccc}
\hline$[\mathrm{PHE}] / \mathrm{M}$ & $q / \mathrm{M}^{-1} \mathrm{~s}^{-1}$ & {$[\mathrm{PHE}] / \mathrm{M}$} & $q / \mathrm{M}^{-1} \mathrm{~s}^{-1}$ \\
\hline 0,180 & $1,653 \cdot 10^{-3}$ & 0,156 & $1,466 \cdot 10^{-3}$ \\
0,168 & $1,564 \cdot 10^{-3}$ & 0,147 & $1,362 \cdot 10^{-3}$ \\
0,163 & $1,477 \cdot 10^{-3}$ & 0,138 & $1,258 \cdot 10^{-3}$ \\
\hline
\end{tabular}

$$
y=-(4,6 \pm 0,2)+(1,01 \pm 0,08) x
$$

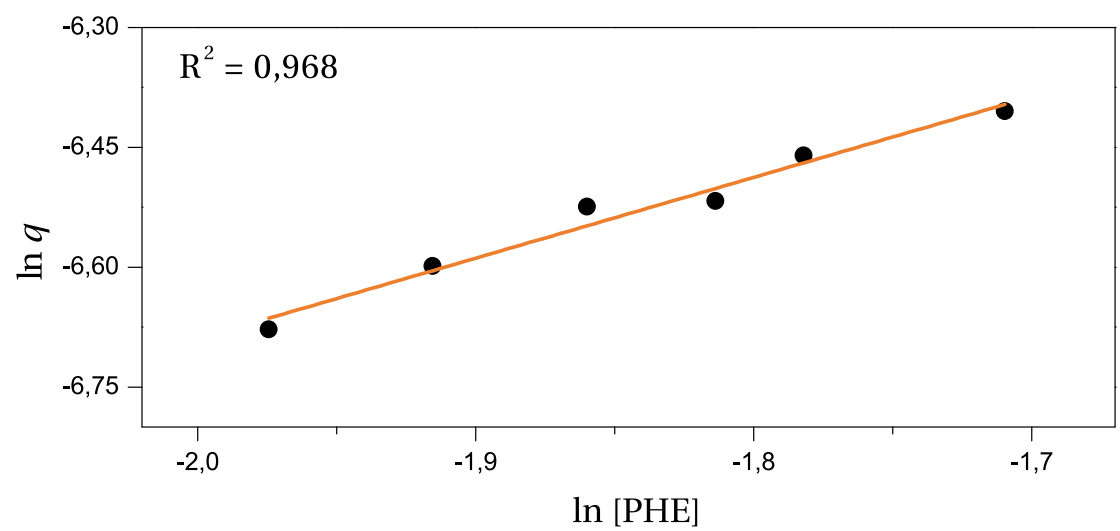

Tabla 4.6 y Figura 4.16: Influencia de la concentración de fenetilamina en el parámetro $q$. $[\mathrm{NIT}]_{\circ}=3,44 \cdot 10^{-2}-2,891 \cdot 10^{-2} \mathrm{M}, \mathrm{pH}=3,81, T=20,0^{\circ} \mathrm{C}$. 
El orden parcial respecto a la concentración del sustrato fenetilamina es uno.

\subsubsection{Velocidad de descomposición del nitrito}

Una consecuencia de seguir la reacción de nitrosación a través de la desaparición de la banda de absorción del nitrito es que la velocidad experimental medida es en realidad la suma de la velocidad de desaparición del nitrito por la nitrosación, $v_{n}$, y la velocidad de descomposición del nitrito, $v_{d}$.

$$
v_{\text {exp }}=v_{n}+v_{d}
$$

Como se vio en la sección 2.1, la velocidad de la reacción de descomposición del ácido nitroso es proporcional a la cuarta potencia de la concentración de esta especie.

Se hizo un experimento en el que se determinó $v_{d}$ en diferentes condiciones de acidez (figura 4.17). Para ello se empleó la misma concentración de nitrito

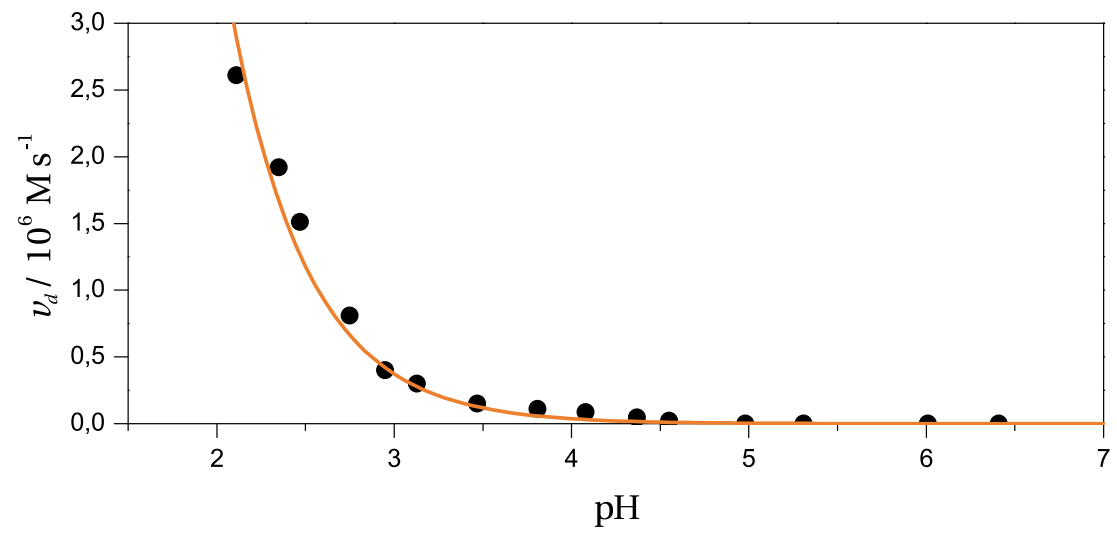

Figura 4.17: Influencia del $\mathrm{pH}$ en velocidad de descomposición del nitrito. $[\mathrm{NIT}]_{\circ}=4,95 \cdot 10^{-2} \mathrm{M},[\mathrm{FTA}]=5,00 \cdot 10^{-2} \mathrm{M}, I=0,31 \mathrm{M}, T=20,0^{\circ} \mathrm{C}$. De color naranja se muestra la curva de la concentración de ácido nitroso según el pH para una concentración de nitrito + ácido nitroso fija. 


\section{6 | Nitrosación de la fenetilamina}

que en las experiencias para medir la constante de velocidad. Se observa que la curva $v_{d} / \mathrm{pH}$ tiene la misma forma que la curva $\left[\mathrm{HNO}_{2}\right] / \mathrm{pH}$.

\subsubsection{Influencia de la acidez del medio}

Conocidos los órdenes parciales de reacción, la ecuación 4.12 permite calcular inmediatamente el valor de $k_{\text {obs }}$. Se ha medido ésta constante de velocidad en varios experimentos en los que se ha variado la concentración de protones, manteniendo constante la de los demás reactivos, así como la temperatura y la fuerza iónica. La figura 4.18 recoge los resultados. Se observa que al aumentar la acidez del medio lo hace la velocidad de nitrosación hasta llegar a un máximo en $\mathrm{pH}=3$, a partir del cual la velocidad comienza a descender.

El perfil de esta curva es característico de las reacciones de N-nitrosación de aminas primarias, en las que según aumenta la acidez, la velocidad de reacción aumenta debido a la mayor concentración de ácido nitroso. Sin embargo, también al aumentar la acidez, la amina se protona, perdiendo su carga negativa que permite la reacción de nitrosación. El esquema 4.1 muestra el mecanismo de nitrosación propuesto, basado en el que se ha aplicado en múltiples trabajos de nuestro grupo. ${ }^{132,251}$ El agente nitrosante se ha considerado que es el trióxido de dinitrógeno, debido al orden parcial dos respecto a la concentración de nitrito.

A partir del mecanismo planteado, se puede deducir la ecuación de velocidad teórica a la que se deben de ajustar los datos. Considera que la etapa limitante de la velocidad es la nitrosación de la fenetilamina con la amina desprotonada, luego la ecuación de velocidad de este paso es:

$$
v=k_{a}\left[\mathrm{~N}_{2} \mathrm{O}_{3}\right][\mathrm{PHEN}]
$$

La concentración de trióxido de dinitrógeno se puede conocer aplicando los sucesivos equilibrios químicos que llevan a su formación desde el nitrito y que dependen de la concentración de protones. En primer lugar su formación a partir del ion nitrosacidio:

$$
K_{3}=\frac{\left[\mathrm{N}_{2} \mathrm{O}_{3}\right]}{\left[\mathrm{H}_{2} \mathrm{NO}_{2}^{+}\right]\left[\mathrm{NO}_{2}^{-}\right]}
$$




\begin{tabular}{cccc}
\hline $\mathrm{pH}$ & $k_{\mathrm{obs}} / \mathrm{M}^{-2} s^{-1}$ & $\mathrm{pH}$ & $k_{\mathrm{obs}} / \mathrm{M}^{-2} s^{-1}$ \\
\hline 2,5 & $1,561 \cdot 10^{-2}$ & 3,7 & $1,013 \cdot 10^{-2}$ \\
2,8 & $1,740 \cdot 10^{-2}$ & 4,0 & $5,80 \cdot 10^{-3}$ \\
2,9 & $2,012 \cdot 10^{-2}$ & 4,4 & $1,92 \cdot 10^{-3}$ \\
3,15 & $1,932 \cdot 10^{-2}$ & 5,6 & 0 \\
3,5 & $1,360 \cdot 10^{-2}$ & & \\
\hline
\end{tabular}

$$
y=(8,6 \pm 0,4) \cdot 10^{-5} \frac{10^{-x}}{\left((1,09 \pm 0,05) \cdot 10^{-3}+10^{-x}\right)^{2}}
$$

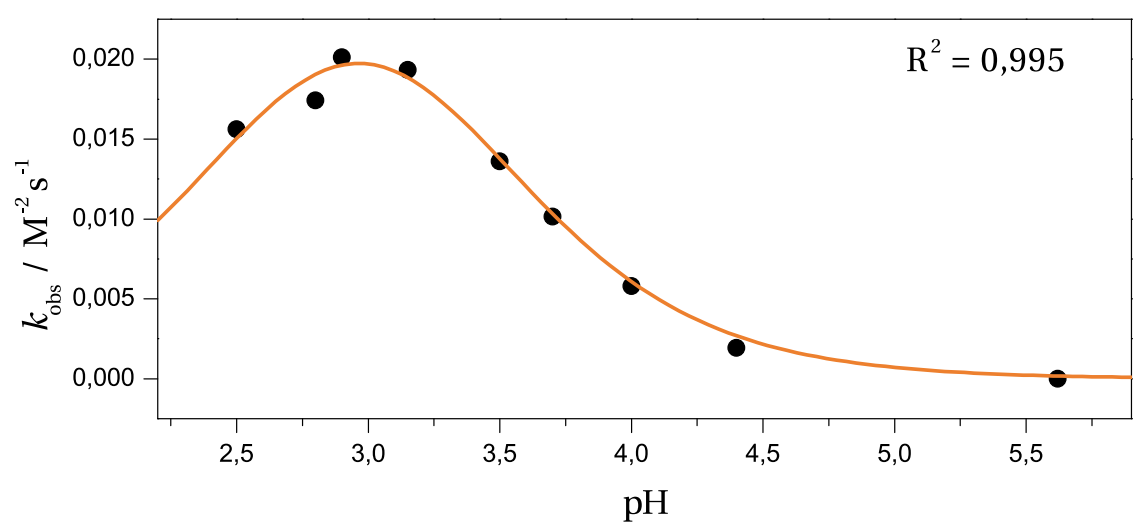

Tabla 4.7 y Figura 4.18: Influencia de la acidez del medio en la constante de velocidad. $[\mathrm{PHE}]_{\circ}=6,311 \cdot 10^{-2} \mathrm{M},[\mathrm{NIT}]_{\circ}=2,7 \cdot 10^{-2}-5,5 \cdot 10^{-2} \mathrm{M},[\mathrm{FTA}]=5,00 \cdot 10^{-2} \mathrm{M}, I=0,34 \mathrm{M}$, $T=20,0^{\circ} \mathrm{C}$. 
<smiles>NCCc1ccccc1</smiles>

$\mathrm{HNO}_{2}$

$$
\mathrm{HNO}_{2}+\mathrm{H}^{+}
$$$$
\mathrm{H}_{2} \mathrm{NO}_{2}{ }^{+}+\mathrm{NO}_{2}^{-}
$$<smiles>NCCc1ccccc1</smiles>

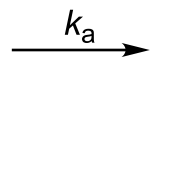

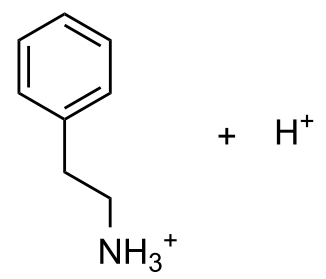

$\mathrm{NO}_{2}^{-}+\mathrm{H}^{+}$

$\mathrm{H}_{2} \mathrm{NO}_{2}{ }^{+} / \mathrm{NO}^{+}+\mathrm{H}_{2} \mathrm{O}$

$\mathrm{N}_{2} \mathrm{O}_{3}+\mathrm{H}_{2} \mathrm{O}$

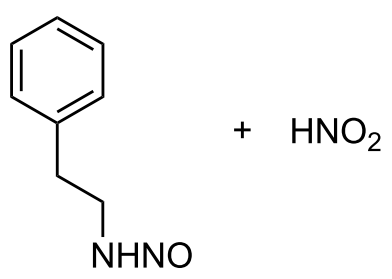

Esquema 4.1: Mecanismo propuesto para la nitrosación de la fenetilamina.

$$
v=k_{a} K_{3}\left[\mathrm{H}_{2} \mathrm{NO}_{2}^{+}\right]\left[\mathrm{NO}_{2}^{-}\right][\mathrm{PHEN}]
$$

A continuación se deduce la concentración de ion nitrosacidio a partir de su equilibrio con el ácido nitroso:

$$
\begin{gathered}
K_{2}=\frac{\left[\mathrm{H}_{2} \mathrm{NO}_{2}^{+}\right]}{\left[\mathrm{HNO}_{2}\right]\left[\mathrm{H}^{+}\right]} \\
v=k_{a} K_{3} K_{2}\left[\mathrm{HNO}_{2}\right]\left[\mathrm{H}^{+}\right]\left[\mathrm{NO}_{2}^{-}\right][\mathrm{PHEN}]
\end{gathered}
$$

Y por último, se simplifica la ecuación a través del equilibrio ácido - base entre 
el ácido nitroso y el nitrito:

$$
\begin{gathered}
K_{1}=\frac{\left[\mathrm{NO}_{2}^{-}\right]\left[\mathrm{H}^{+}\right]}{\left[\mathrm{HNO}_{2}\right]} \\
v=k_{a} K_{3} K_{2} K_{1}\left[\mathrm{HNO}_{2}\right]^{2}[\mathrm{PHEN}]
\end{gathered}
$$

Como se indicó en la página 122, por [NIT] se entiende la suma de las concentraciones de nitrito y ácido nitroso:

$$
\begin{gathered}
{[\mathrm{NIT}]=\left[\mathrm{HNO}_{2}\right]+\left[\mathrm{NO}_{2}^{-}\right]} \\
{\left[\mathrm{HNO}_{2}\right]=\frac{[\mathrm{NIT}]\left[\mathrm{H}^{+}\right]}{\left[\mathrm{H}^{+}\right]+K_{1}}}
\end{gathered}
$$

Llevando la ecuación 4.29 a la 4.27:

$$
v=k_{a} K_{3} K_{2} K_{1} \frac{[\mathrm{NIT}]^{2}\left[\mathrm{H}^{+}\right]^{2}[\mathrm{PHEN}]}{\left(\left[\mathrm{H}^{+}\right]+K_{1}\right)^{2}}
$$

De igual modo ocurre con la fenetilamina, [PHE], que en el medio de reacción puede estar como base, [PHEN], o como su ácido conjugado, [PHENH]:

$$
\begin{gathered}
{[\mathrm{PHE}]=[\mathrm{PHENH}]+[\mathrm{PHEN}]} \\
K_{\mathrm{I}}=\frac{[\mathrm{PHEN}]\left[\mathrm{H}^{+}\right]}{[\mathrm{PHENH}]} \\
{[\mathrm{PHEN}]=\frac{K_{\mathrm{I}}[\mathrm{PHE}]}{\left[\mathrm{H}^{+}\right]+K_{\mathrm{I}}}}
\end{gathered}
$$

Llevando la ecuación 4.33 a la 4.30 se obtiene la ecuación teórica de velocidad de nitrosación de la fenetilamina:

$$
v=k_{a} K_{3} K_{2} K_{1} K_{\mathrm{I}} \frac{[\mathrm{NIT}]^{2}\left[\mathrm{H}^{+}\right]^{2}[\mathrm{PHE}]}{\left(\left[\mathrm{H}^{+}\right]+K_{\mathrm{I}}\right)\left(\left[\mathrm{H}^{+}\right]+K_{1}\right)^{2}}
$$

que, comparada con la ecuación experimental:

$$
v=k_{\mathrm{obs}}[\mathrm{NIT}]^{2}[\mathrm{PHE}]
$$




\section{0 | Nitrosación de la fenetilamina}

conduce a la relación entre la constante de velocidad observada, $k_{\text {obs }}$ y la concentración de protones.

$$
k_{\mathrm{obs}}=k_{a} K_{3} K_{2} K_{1} K_{\mathrm{I}} \frac{\left[\mathrm{H}^{+}\right]^{2}}{\left(\left[\mathrm{H}^{+}\right]+K_{\mathrm{I}}\right)\left(\left[\mathrm{H}^{+}\right]+K_{1}\right)^{2}}
$$

Como $K_{\mathrm{I}}=1,65 \cdot 10^{-10} \mathrm{M}$ y la concentración de protones es superior a $10^{-5}$ $\mathrm{M}$ (figura 4.18), los resultados experimentales se han ajustado a la siguiente ecuación:

$$
k_{\mathrm{obs}}=\alpha \frac{\left[\mathrm{H}^{+}\right]}{\left(\left[\mathrm{H}^{+}\right]+\beta\right)^{2}}
$$

La figura 4.18 muestra el buen ajuste de los datos experimentales a la ecuación 4.36 con los parámetros:

$$
\begin{gathered}
\alpha=(8,6 \pm 0,4) \cdot 10^{-5} \mathrm{M}^{-1} \mathrm{~s}^{-1} \\
\beta=(1,09 \pm 0,05) \cdot 10^{-3} \mathrm{M}
\end{gathered}
$$

El valor de $\beta$ sirve como comprobación de que el ajuste es correcto desde el punto de vista químico, ya que se trata de la constante de equilibrio $K_{1}$. El valor negativo de su logaritmo conduce a un $\mathrm{pK}_{\mathrm{a}}$ de 2,98 $\pm 0,05$, cercano al bibliográfico $(3,17$, tabla 2.1$)$.

Con el parámetro $\alpha$ se calcula la constante de velocidad de la reacción de nitrosación $k_{a}$ :

$$
k_{a}=\frac{\alpha}{K_{3} K_{2} K_{1} K_{\mathrm{I}}}
$$

El valor del producto $K_{1} K_{2} K_{3}=(3,03 \pm 0,23) \cdot 10^{-3} \mathrm{M}^{-1}$ es conocido (sección 2.2.2). ${ }^{93}$ Como la constante de acidez de la fenetilamina también es conocida $\left(K_{\mathrm{I}}=1,65 \cdot 10^{-10} \mathrm{M}\right)$ :

$$
k_{a}=(1,72 \pm 0,08) \cdot 10^{8} \mathrm{M}^{-1} \mathrm{~s}^{-1}
$$

La magnitud de $k_{a}$ es propia de una reacción controlada por difusión (tabla 2.11, página 92 ). 


\subsubsection{Influencia de la fuerza iónica}

Se midió la velocidad de nitrosación de la fenetilamina con diferentes concentraciones de perclorato sódico y manteniendo constante el resto de variables. La figura 4.19 recoge el resultado de aplicar la ecuación de Brønsted (ecuación 3.11, página 120) a estos experimentos:

\begin{tabular}{cccc}
\hline$I / \mathrm{M}$ & $k_{\mathrm{obs}} / \mathrm{M}^{-2} s^{-1}$ & $I / \mathrm{M}$ & $k_{\mathrm{obs}} / \mathrm{M}^{-2} s^{-1}$ \\
\hline 0,15 & $6,96 \cdot 10^{-3}$ & 0,34 & $5,80 \cdot 10^{-3}$ \\
0,21 & $6,60 \cdot 10^{-3}$ & 0,40 & $7,02 \cdot 10^{-3}$ \\
0,28 & $7,73 \cdot 10^{-3}$ & 0,45 & $7,20 \cdot 10^{-3}$ \\
\hline
\end{tabular}

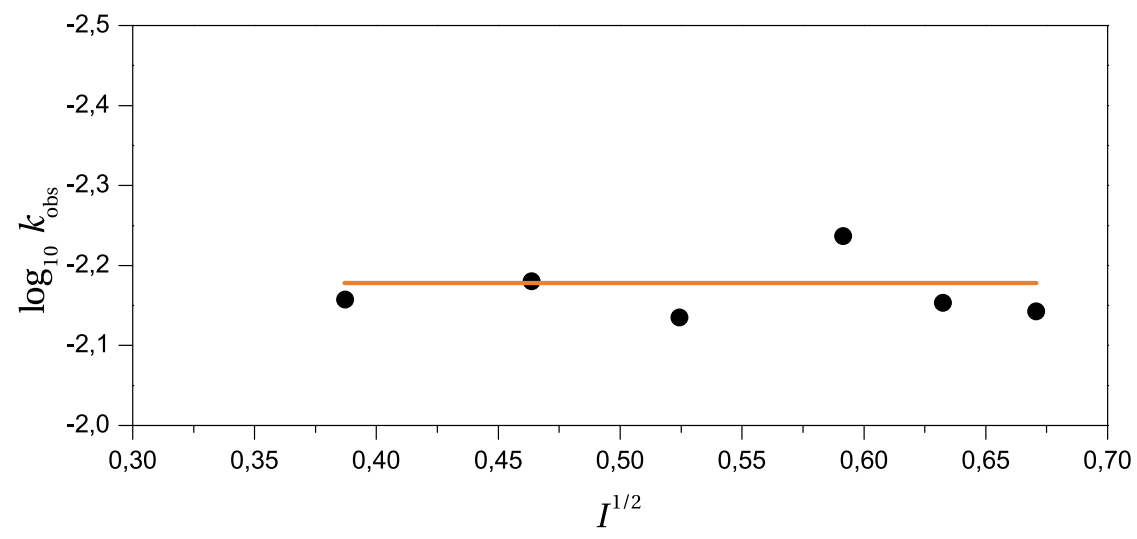

Tabla 4.8 y Figura 4.19: Influencia de la fuerza iónica en la constante de velocidad. $[\mathrm{PHE}]_{\circ}=6,311 \cdot 10^{-2} \mathrm{M},[\mathrm{NIT}]_{\circ}=2,7 \cdot 10^{-2}-5,5 \cdot 10^{-2} \mathrm{M},[\mathrm{FTA}]=5,00 \cdot 10^{-2} \mathrm{M}, \mathrm{pH}=4,0, T=$ $20,0^{\circ} \mathrm{C}$.

Como era de esperar, la variación en la fuerza iónica del medio no influye en la velocidad de reacción, lo que apoya el mecanismo propuesto en el que ninguno de los dos reactivos de la etapa limitante de velocidad es iónico. 


\subsubsection{Influencia de la temperatura}

Se ha analizado cómo cambia la velocidad de nitrosación de la fenetilamina con la temperatura, haciendo variar ésta entre 20,0 y $37,5^{\circ} \mathrm{C}$. Los resultados se muestran en la siguiente tabla:

\begin{tabular}{cccc}
\hline$T /{ }^{\circ} \mathrm{C}$ & $k_{\text {obs }} / \mathrm{M}^{-2} s^{-1}$ & $T /{ }^{\circ} \mathrm{C}$ & $k_{\text {obs }} / \mathrm{M}^{-2} s^{-1}$ \\
\hline 20,0 & $7,21 \cdot 10^{-3}$ & 32,5 & $1,910 \cdot 10^{-2}$ \\
22,5 & $8,67 \cdot 10^{-3}$ & 35,0 & $2,302 \cdot 10^{-2}$ \\
25,0 & $1,029 \cdot 10^{-2}$ & 37,5 & $2,658 \cdot 10^{-2}$ \\
30,0 & $1,398 \cdot 10^{-2}$ & & \\
\hline
\end{tabular}

Tabla 4.9: Influencia de la temperatura en la constante de velocidad. $[\mathrm{PHE}]_{\circ}=6,31 \cdot 10^{-2} \mathrm{M},[\mathrm{NIT}]_{\circ}=2,7 \cdot 10^{-2}-5,5 \cdot 10^{-2} \mathrm{M},[\mathrm{FTA}]=5,00 \cdot 10^{-2} \mathrm{M}, \mathrm{pH}=$ $3,80, I=0,34 \mathrm{M}$

A partir de estos datos y utilizando la forma linealizada de la ecuación de Arrhenius (ecuación 3.6, página 119):

$$
\ln k_{\mathrm{obs}}=\ln A-\frac{E_{a}}{R T}
$$

se ha determinado la energía de activación, $E_{a}=58 \pm 5 \mathrm{~kJ} \mathrm{~mol}^{-1}$. La figura 4.20 muestra el resultado del ajuste.

Con la ecuación de Eyring (ecuación 3.9, página 120) se han determinado los parámetros de activación. Ajustando los datos de la tabla 4.9 a la forma lineal de dicha ecuación:

$$
\ln \frac{k_{\mathrm{obs}}}{T}=\ln \frac{k_{\mathrm{B}}}{h}+\frac{\Delta S^{\ddagger}}{R}-\frac{\Delta H^{\ddagger}}{R T}
$$

se obtienen los valores $\Delta H^{\ddagger}=56 \pm 4 \mathrm{~kJ} \mathrm{~mol}^{-1} \mathrm{y} \Delta S^{\ddagger}=-104 \pm 16 \mathrm{~J} \mathrm{~K}^{-1} \mathrm{~mol}^{-1}$. La figura 4.21 muestra el resultado del ajuste.

El valor de la entalpía de activación $\Delta H^{\ddagger}$ está asociado a la constante $\alpha$ de la ecuación 4.38. Para conocer el valor de la entalpía asociada a la constante $k_{a}$ es necesario sustraer el calor a presión constante de los dos procesos que 


$$
y=(18 \pm 2)+(58 \pm 5) \cdot 10^{3} x
$$

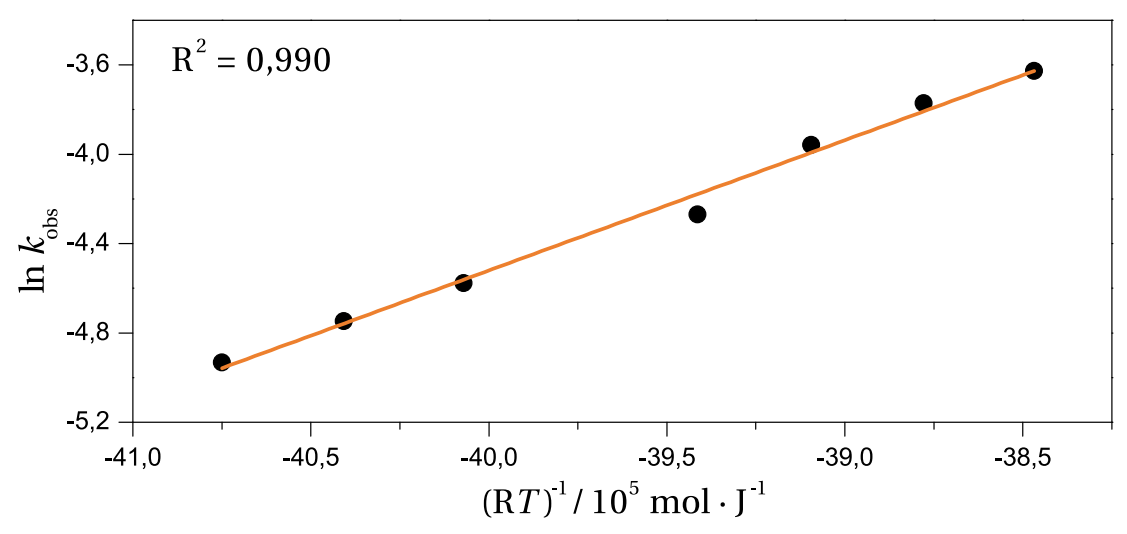

Figura 4.20: Cumplimiento de la ecuación de Arrhenius por los resultados de la tabla 4.9 .

$$
y=(12 \pm 2)+(56 \pm 4) \cdot 10^{3} x
$$

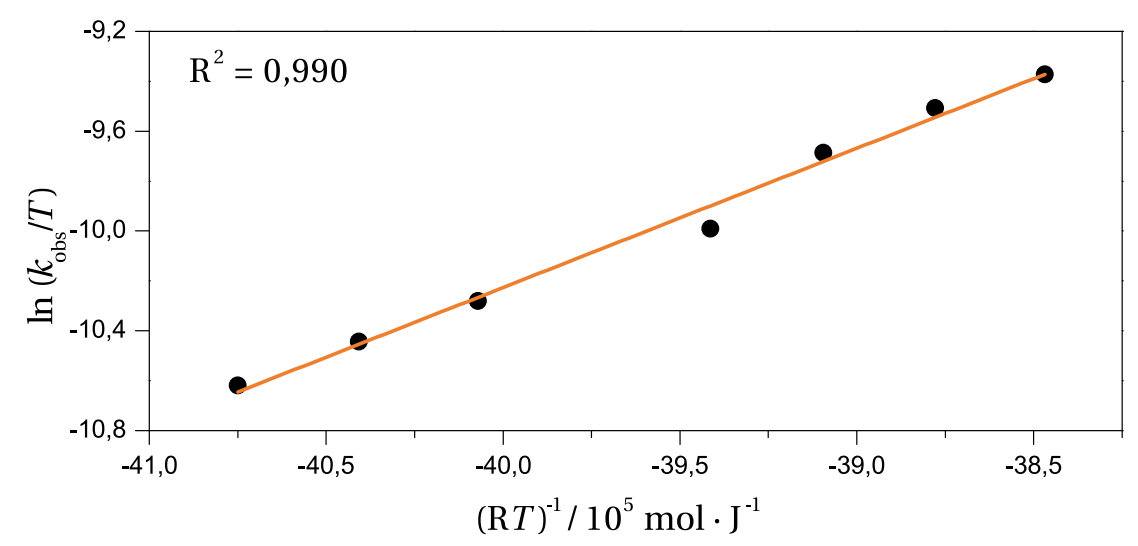

Figura 4.21: Cumplimiento de la ecuación de Eyring por los resultados de la tabla 4.9. 


\section{4 | Nitrosación de la fenetilamina}

también intervienen: la entalpía de formación de $\mathrm{N}_{2} \mathrm{O}_{3}, \Delta H_{m}$, y la entalpía de protonación de la amina, $\Delta H_{p}$ :

$$
\Delta H_{k}^{\ddagger}=\Delta H^{\ddagger}-\Delta H_{m}-\Delta H_{p}
$$

El valor $\Delta H_{m}=6,8 \pm 0,6 \mathrm{~kJ} \mathrm{~mol}^{-1}$ ha sido determinado por nuestro grupo. ${ }^{96} \mathrm{Co}-$ mo el valor exacto de la entalpía de protonación de la amina no se conoce, se ha manejado el de una molécula análoga, L-fenilalanina, $\Delta H_{p}=42,0 \mathrm{~kJ} \mathrm{~mol}^{-1}{ }^{252}$ Así ha encontrado el valor $\Delta H_{k}^{\ddagger} \approx 7 \mathrm{~kJ} \mathrm{~mol}^{-1}$ para la entalpía del paso limitante de velocidad, que está dentro del margen de valores asociados a procesos controlados por difusión, lo que apoya el mecanismo propuesto. ${ }^{82}$

\subsubsection{Determinación del producto de reacción}

El mecanismo propuesto para la nitrosación de la fenetilamina concuerda con el desprendimiento de burbujas observado durante la reacción. Para confirmar el producto de nitrosación se ha dibujado el espectro de masas de la fenetilamina, comparándolo con el de una muestra tomada al final de la reacción de nitrosación.

La gráfica superior de la figura 4.22 muestra el espectro de masas de una disolución acuosa de fenetilamina. Se observa el pico de su masa molecular en 121,9 y un fragmento de su estructura en 105,9, producido por la electroionización del compuesto, en la que se ha producido la fisión del enlace alquílico del carbono unido al nitrógeno de la amina para formar el carbocatión $\mathrm{C}_{6} \mathrm{H}_{5}\left(\mathrm{CH}_{2}\right)_{2}^{+}$.

El espectro de masas inferior corresponde a la fenetilamina tras la reacción de nitrosación. Existe el inconveniente de que el producto de nitrosación corresponde a la sustitución de la amina por un alcohol (reacción de Piria, página 34) que, al perder su protón, tiene igual masa que aquella. A pesar de ello, el descenso en la intensidad de ese pico y el cambio de la proporción con el pico de 122,7 respecto al $10 \%$ de la fenetilamina sugiere la presencia de un oxígeno. Aparece también un pico en $\mathrm{m} / z=144,7$ debido al aducto formado entre el anión del feniletanol con el sodio del nitrito. Por último, no aparece ningún pico relacionado con una C-nitrosación, que debería aparecer en 135 o 151. 
Todo ello confirma que el tipo de nitrosación que se produce en la molécula de fenetilamina es N-nitrosación.
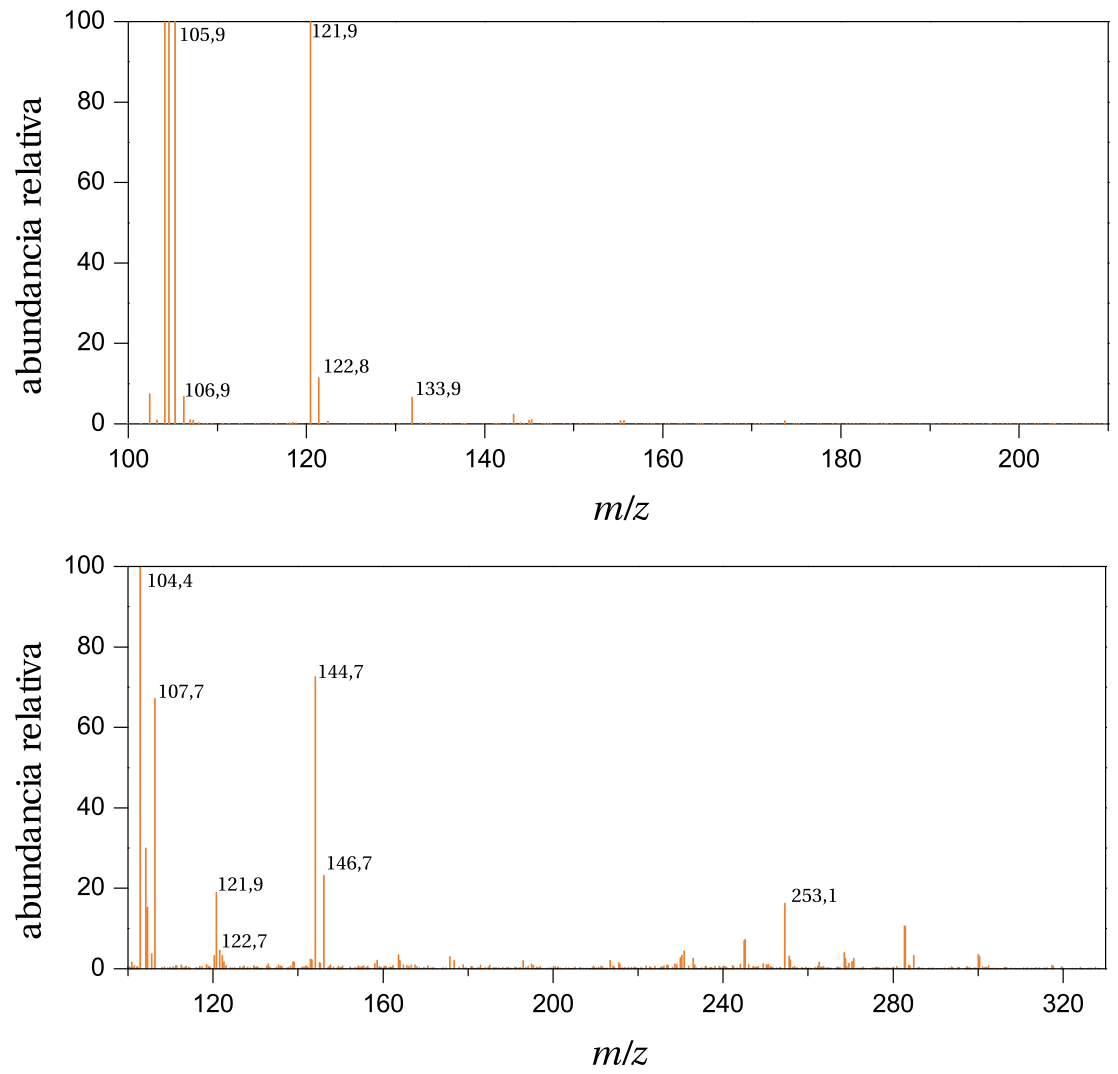

Figura 4.22: Espectros de masas por impacto electrónico positivo de la fenetilamina (gráfica superior) y de la mezcla de fenetilamina y ácido nitroso. 


\subsection{Nitrosación de la tiramina}

\subsubsection{Estudio espectrofotométrico}

El espectro UV-visible de varias disoluciones con diferentes concentraciones de tiramina (TYR) se muestra en la figura 4.23. Se pueden ver dos bandas de absorción diferenciadas. Una de gran intensidad, entre 190 y $260 \mathrm{~nm}$, con tres picos, que se debe a la transición $\pi \rightarrow \pi^{*}$ permitida de los electrones de su estructura aromática y otra banda comprendida entre 260 y $320 \mathrm{~nm}$ que se debe a la transición $\pi \rightarrow \pi^{*}$ prohibida, por lo que es más débil. ${ }^{249}$

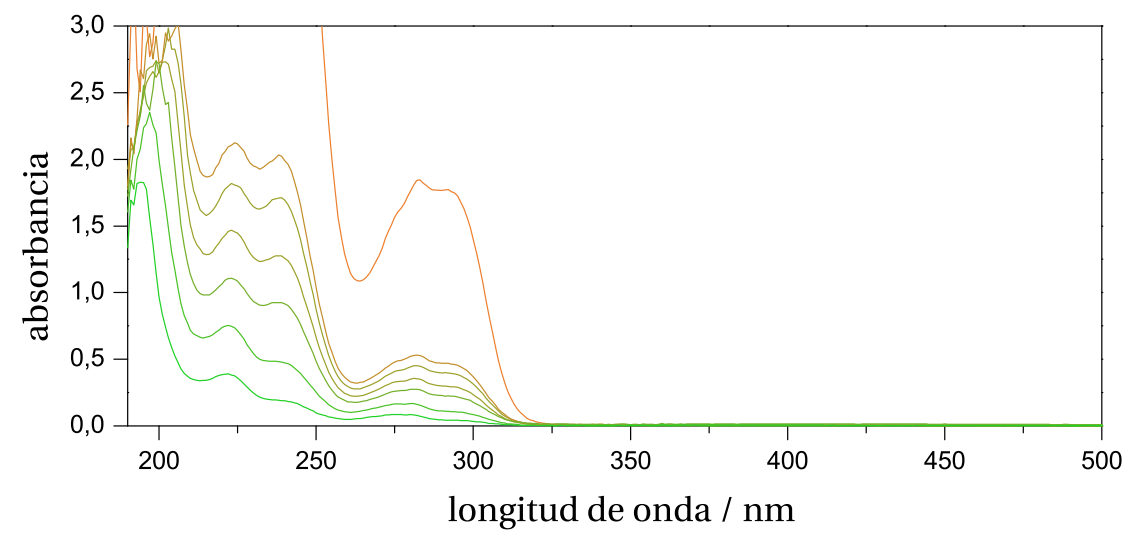

Figura 4.23: Espectros de absorción de varias disoluciones de tiramina. $[$ TYR $]=7,42 \cdot 10^{-3}-1,48 \cdot 10^{-4} \mathrm{M}, \mathrm{pH}=10,15, T=20,0^{\circ} \mathrm{C}$.

Se ha estudiado la forma en la que cambia el espectro de absorción de la tiramina según el pH del medio (figura 4.24). Los fenoles al perder el protón se quedan con una carga negativa que se deslocaliza en el anillo aromático y que provoca un incremento de la longitud de onda y del coeficiente de absorción del compuesto, tanto en la banda que corresponde a la transición $\pi \rightarrow \pi^{*}$ permitida como a la prohibida. La tiramina, con sus $\mathrm{pK}_{\mathrm{a}} \mathrm{s}$ de 9,3 y 10,4 (página 103), cambia la forma de su espectro en la zona de $\mathrm{pH}$ comprendida entre 7,33 y 11,50, que 


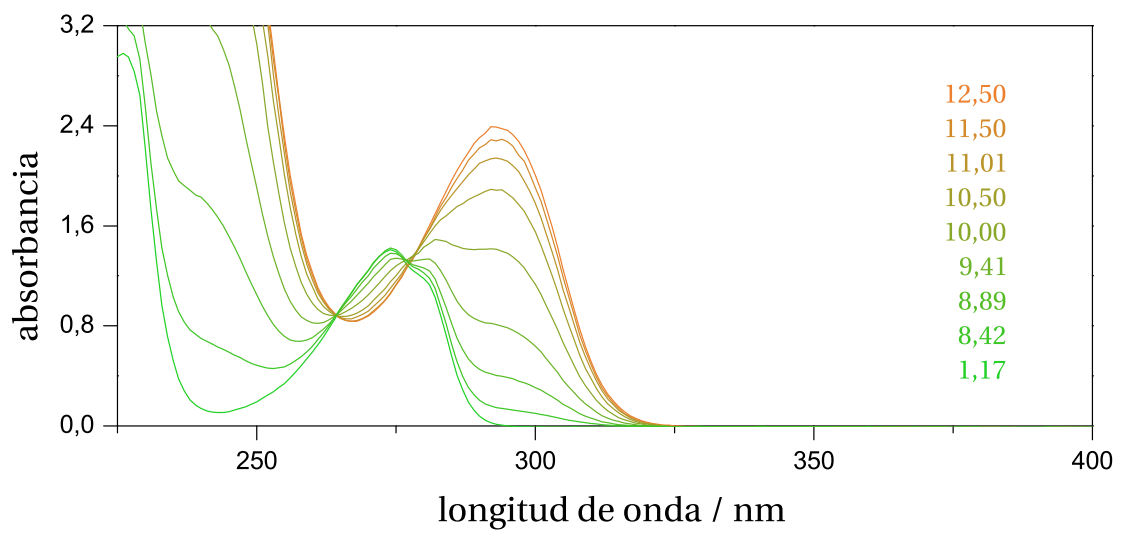

Figura 4.24: Variación del espectro de absorción de la tiramina con el pH. [TYR] = $1,0 \cdot 10^{-3} \mathrm{M}, T=20,0{ }^{\circ} \mathrm{C}$.

queda muy alejada de la zona donde se estudian las reacciones de nitrosación.

Según varía el pH aparecen dos puntos isosbésticos en 264 y $277 \mathrm{~nm}$. Con los datos de la figura 4.23 se han calculado sus coeficientes de extinción molar, ya que el segundo punto tenía una absorbancia muy cercana al máximo de absorción en medio ácido. La figura 4.25 muestra el ajuste de los datos a la ecuación de Lambert-Beer (página 154). Los coeficientes de absorción de la tiramina son:

$$
\begin{aligned}
& \varepsilon_{\mathrm{TYR}, 264 \mathrm{~nm}}=360 \pm 10 \mathrm{M}^{-1} \mathrm{~cm}^{-1} \\
& \varepsilon_{\mathrm{TYR}, 277 \mathrm{~nm}}=550 \pm 10 \mathrm{M}^{-1} \mathrm{~cm}^{-1}
\end{aligned}
$$

\subsubsection{Reacción entre tiramina y nitrito}

Después de conocer el comportamiento espectroscópico de la tiramina se ha investigado cómo se puede seguir la reacción de nitrosación de la misma mediante espectroscopía UV-visible. Se ha preparado una disolución acuosa y ácida de tiramina y nitrito sódico y se ha seguido la evolución temporal del espectro (figura 4.26). 
178 | Nitrosación de la tiramina

\begin{tabular}{cccccc}
\hline$[\mathrm{TYR}] / \mathrm{M}$ & $A_{277}$ & $A_{264}$ & {$[\mathrm{TYR}] / \mathrm{M}$} & $A_{277}$ & $A_{264}$ \\
\hline $8,90 \cdot 10^{-4}$ & 0,492 & 0,326 & $4,45 \cdot 10^{-4}$ & 0,265 & 0,181 \\
$7,42 \cdot 10^{-4}$ & 0,419 & 0,279 & $2,96 \cdot 10^{-4}$ & 0,164 & 0,111 \\
$5,93 \cdot 10^{-4}$ & 0,335 & 0,225 & $1,48 \cdot 10^{-4}$ & 0,084 & 0,056 \\
\hline
\end{tabular}

$$
\begin{aligned}
& y=(0,005 \pm 0,007)+(550 \pm 10) x \\
& y=(0,006 \pm 0,007)+(360 \pm 10) x
\end{aligned}
$$

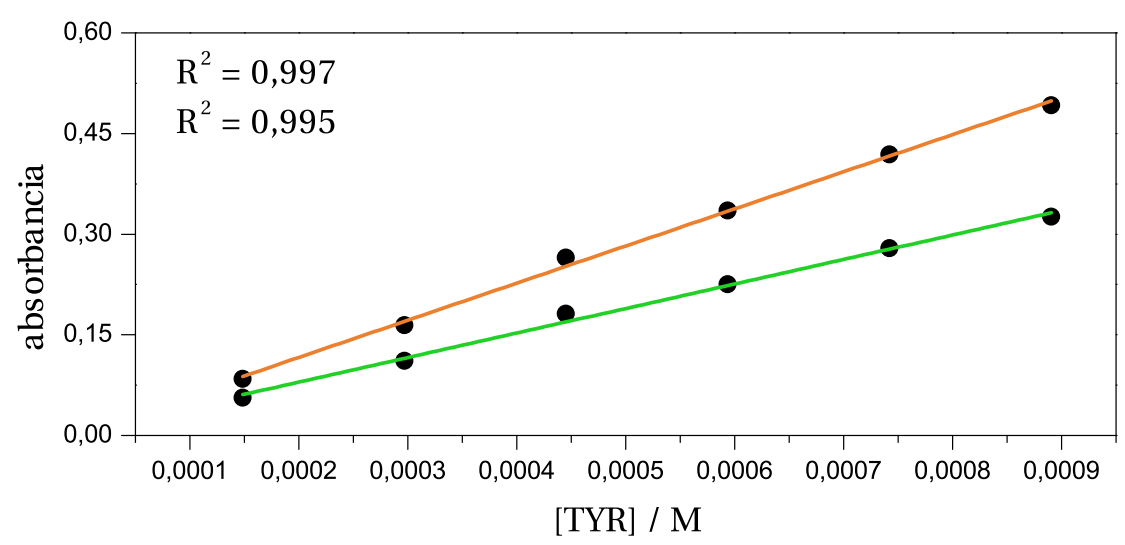

Tabla 4.10 y Figura 4.25: Cumplimiento de la ley de Lambert-Beer por la tiramina en sus puntos isosbésticos. $\lambda=264 \mathrm{~nm}$ (verde), $\lambda=277 \mathrm{~nm}$ (naranja), $\mathrm{pH}=10,15, T=20,0$ ${ }^{\circ} \mathrm{C}$. 


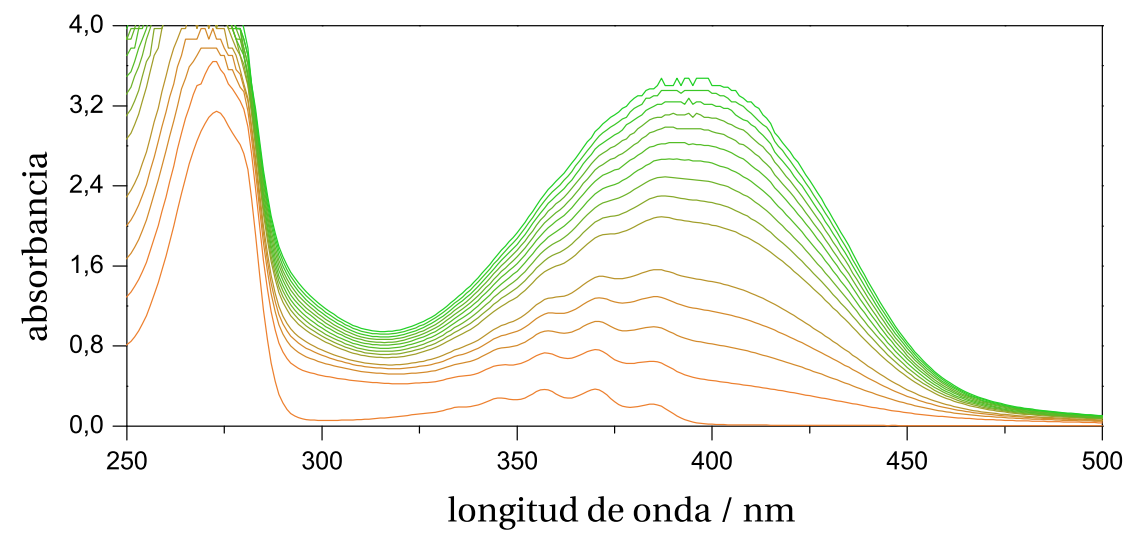

Figura 4.26: Variación del espectro de absorción de la mezcla de tiramina y ácido nitroso durante la nitrosación. Espectros tomados cada 2 horas y media. Entre 12,5 y 17,5 h falta un espectro. $[\mathrm{TYR}]=2,45 \cdot 10^{-3} \mathrm{M}$, $[\mathrm{NIT}]=7,03 \cdot 10^{-3} \mathrm{M}, \mathrm{pH}=2,45, T=20,0{ }^{\circ} \mathrm{C}$.

En esta figura se puede ver cómo la banda de absorción del sistema nitrito - ácido nitroso desaparece con el tiempo mientras aparece una banda intensa de absorción entre 325 y $475 \mathrm{~nm}$ con el máximo en $398 \mathrm{~nm}$. La reacción de nitrosación también modifica la absorbancia en la zona de mayor energía del espectro. El pico de absorción entre 260 y $320 \mathrm{~nm}$ incrementa su intensidad y su anchura.

Teniendo en cuenta las características espectroscópicas de reactivos y productos se seleccionó la longitud de onda $\lambda=405 \mathrm{~nm}$ para seguir la reacción de nitrosación. Esta longitud de onda se ha elegido debido a la gran variación en su absorbancia, dada su cercanía al máximo de la banda y a que el nitrito presenta una absorbancia prácticamente nula en esa zona del espectro (figura 4.12, página 158).

El coeficiente de absorción molar del producto de reacción, nitrosotiramina, se determinó preparando disoluciones acuosas ácidas de diferentes concentraciones de tiramina y añadiendo gran exceso de nitrito sódico. Cuando la reacción alcanzaba la meseta - toda la tiramina se había convertido en nitrosotiraminase registraba la absorbancia para ajustarla a la ley de Lambert-Beer (figura 4.27). 
180 | Nitrosación de la tiramina

\begin{tabular}{cccc}
\hline$[\mathrm{NTYR}] / \mathrm{M}$ & $A_{405}$ & {$[\mathrm{NTYR}] / \mathrm{M}$} & $A_{405}$ \\
\hline $2,009 \cdot 10^{-4}$ & 0,110 & $4,018 \cdot 10^{-4}$ & 0,382 \\
$3,014 \cdot 10^{-4}$ & 0,259 & $5,022 \cdot 10^{-4}$ & 0,461 \\
$3,014 \cdot 10^{-4}$ & 0,252 & $6,027 \cdot 10^{-4}$ & 0,605 \\
\hline
\end{tabular}

$y=-(0,10 \pm 0,02)+(1.180 \pm 50) x$

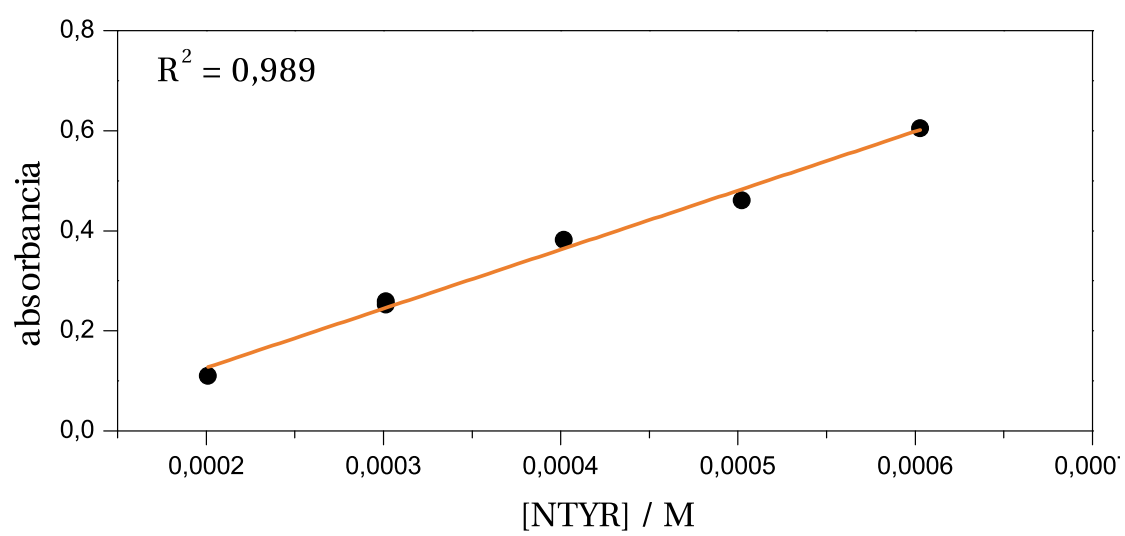

Tabla 4.11 y Figura 4.27: Cumplimiento de la ley de Lambert-Beer por la nitrosotiramina. $\lambda=405 \mathrm{~nm},[\mathrm{NIT}]=4,6 \cdot 10^{-2} \mathrm{M}, \mathrm{pH}=4,08, T=20,0^{\circ} \mathrm{C}$. 
A partir del ajuste de los datos experimentales se encontró que

$$
\varepsilon_{\mathrm{NTYR}, 405 \mathrm{~nm}}=1.180 \pm 50 \mathrm{M}^{-1} \mathrm{~cm}^{-1}
$$

\subsection{3. Órdenes parciales de reacción}

Los órdenes parciales de reacción se han obtenido utilizando el método de velocidades iniciales junto al método de aislamiento. Se ha escogido un $\mathrm{pH}=3,4$ para que la reacción fuese más rápida. El nitrito ha sido el reactivo en exceso. De esta forma, la ecuación de velocidad

$$
v=k_{\mathrm{obs}}[\mathrm{TYR}]^{m}[\mathrm{NIT}]^{n}
$$

se simplifica al introducir la pseudoconstante $p$

$$
p=k_{\mathrm{obs}}[\mathrm{NIT}]^{n}
$$

de modo que:

$$
v=p[\mathrm{TYR}]^{m}
$$

que en forma linealizada, y teniendo en cuenta el método de velocidades iniciales, resulta:

$$
\ln v_{\circ}=\ln p+m \ln [\mathrm{TYR}] \text { 。 }
$$

La figura 4.28 muestra el ajuste de los datos experimentales a la ecuación 4.50. Su pendiente tiene un valor de $1,004 \pm 0,008$, revelando que el orden parcial respecto a la concentración de tiramina es uno.

A continuación, modificando los excesos de nitrito se ha calculado el orden parcial respecto a la concentración de esta especie, a través de la forma lineal de la ecuación 4.48:

$$
\ln p=\ln k_{\mathrm{obs}}+n \ln [\mathrm{NIT}]
$$

que se encuentra representada en la figura 4.29. El orden parcial respecto a la concentración de nitrito es uno. 
182 | Nitrosación de la tiramina

\begin{tabular}{cccc}
\hline$[\mathrm{TYR}]_{\circ} / \mathrm{M}$ & $v_{\circ} / \mathrm{M} \mathrm{s}^{-1}$ & {$[\mathrm{TYR}]_{\diamond} / \mathrm{M}$} & $v_{\circ} / \mathrm{M} \mathrm{s}^{-1}$ \\
\hline $0,45 \cdot 10^{-3}$ & $3,076 \cdot 10^{-8}$ & $1,50 \cdot 10^{-3}$ & $1,025 \cdot 10^{-7}$ \\
$0,60 \cdot 10^{-3}$ & $4,102 \cdot 10^{-8}$ & $1,80 \cdot 10^{-3}$ & $1,230 \cdot 10^{-7}$ \\
$0,90 \cdot 10^{-3}$ & $6,153 \cdot 10^{-8}$ & $2,40 \cdot 10^{-3}$ & $1,641 \cdot 10^{-7}$ \\
$1,20 \cdot 10^{-3}$ & $8,205 \cdot 10^{-8}$ & $3,00 \cdot 10^{-3}$ & $2,051 \cdot 10^{-7}$ \\
\hline
\end{tabular}

$$
y=-(9,56 \pm 0,05)+(1,004 \pm 0,008) x
$$

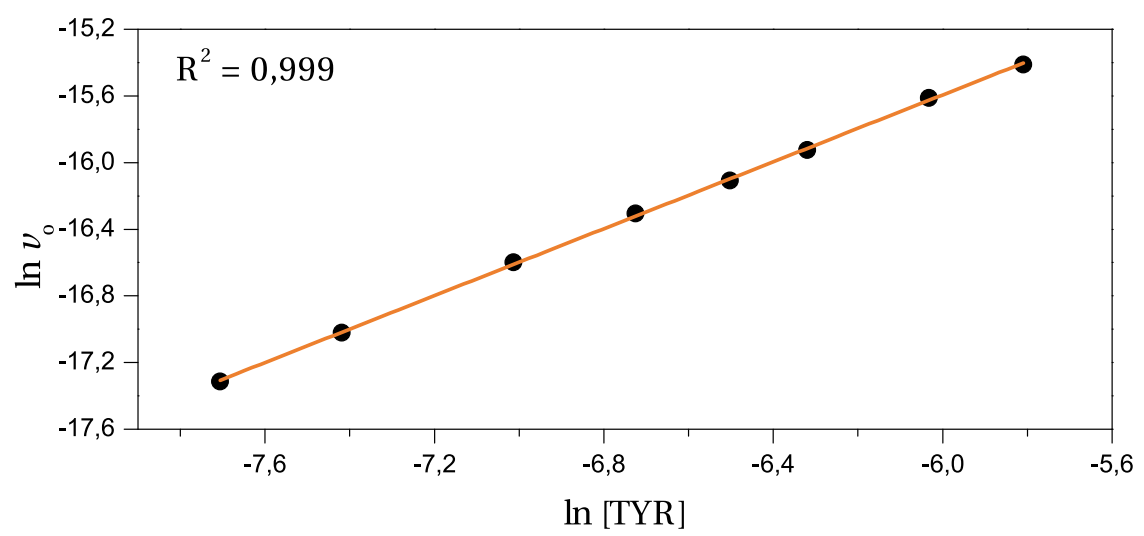

Tabla 4.12 y Figura 4.28: Influencia de la concentración de tiramina en la velocidad inicial de reacción. [NIT] $=0,04 \mathrm{M}, \mathrm{pH}=3,4, I=0,2 \mathrm{M}, T=20,0{ }^{\circ} \mathrm{C}$. 


\begin{tabular}{cccc}
\hline$[\mathrm{NIT}] / \mathrm{M}$ & $p / \mathrm{s}^{-1}$ & {$[\mathrm{NIT}] / \mathrm{M}$} & $p / \mathrm{s}^{-1}$ \\
\hline 0,03 & $4,75 \cdot 10^{-5}$ & 0,07 & $1,095 \cdot 10^{-4}$ \\
0,04 & $7,01 \cdot 10^{-5}$ & 0,09 & $1,496 \cdot 10^{-4}$ \\
0,05 & $7,75 \cdot 10^{-5}$ & & \\
\hline
\end{tabular}

$$
y=-(6,4 \pm 0,2)+(0,99 \pm 0,06) x
$$

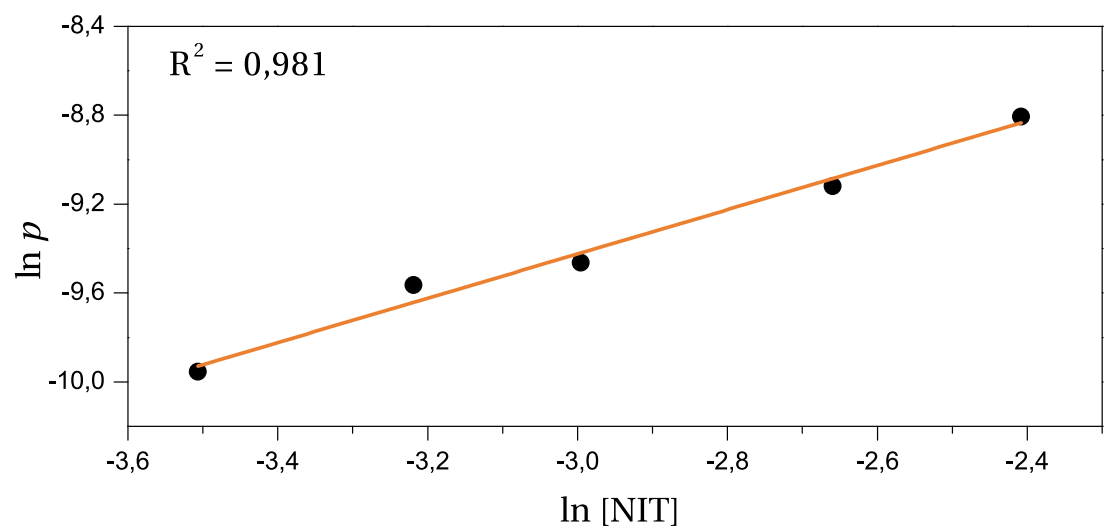

Tabla 4.13 y Figura 4.29: Influencia de la concentración de nitrito en el parámetro $p$. $[\mathrm{TYR}]_{\circ}=0,45 \cdot 10^{-3}-3,00 \cdot 10^{-3} \mathrm{M}, \mathrm{pH}=3,4, I=0,2 \mathrm{M}, T=20,0{ }^{\circ} \mathrm{C}$. 


\section{4 | Nitrosación de la tiramina}

\subsubsection{Influencia de la acidez del medio}

Se ha medido la constante de velocidad en varios experimentos en los que se ha variado la concentración de protones, manteniendo constantes las de los demás reactivos, así como la temperatura y la fuerza iónica. La figura 4.30 recoge los resultados. Se observa un aumento progresivo de la velocidad de nitrosación según aumenta la acidez del medio en una curva sigmoidea.

El perfil de esta curva es semejante a los de mecanismos de C-nitrosación en los que la etapa limitante de velocidad es la ruptura del complejo de Wheland (sección 2.3.1), ${ }^{253,254}$ observados con anterioridad en nuestro grupo de trabajo. ${ }^{250,255,256}$

Del mecanismo propuesto (esquema 4.2), acorde con los órdenes parciales unitarios respecto a las concentraciones de cada reactivo, se deduce fácilmente la siguiente ecuación de velocidad:

$$
v=\frac{k_{a} K_{2}[\mathrm{TYR}][\mathrm{NIT}]\left[\mathrm{H}^{+}\right]^{2}}{\left(\left[\mathrm{H}^{+}\right]+K_{1}\right)\left(1+\frac{k_{-a}}{K_{b} k_{c}}\left[\mathrm{H}^{+}\right]\right)}
$$

Al comparar las ecuaciones teórica (4.55) y experimental:

$$
v=k_{\text {obs }}[\mathrm{TYR}][\mathrm{NIT}]
$$

se desprende inmediatamente que:

$$
k_{\mathrm{obs}}=\frac{k_{a} K_{2}\left[\mathrm{H}^{+}\right]^{2}}{\left(\left[\mathrm{H}^{+}\right]+K_{1}\right)\left(1+\frac{k_{-a}}{K_{b} k_{c}}\left[\mathrm{H}^{+}\right]\right)}
$$

La ecuación 4.57 se ha ajustado en la forma:

$$
k_{\text {obs }}=\frac{\alpha\left[\mathrm{H}^{+}\right]^{2}}{\left(\left[\mathrm{H}^{+}\right]+K_{1}\right)\left(1+\beta\left[\mathrm{H}^{+}\right]\right)}
$$

obteniéndose los siguientes valores de $\alpha$ y $\beta$ :

$$
\begin{gathered}
\alpha=47 \pm 9 \mathrm{M}^{-2} \mathrm{~s}^{-1} \\
\beta=7.800 \pm 700 \mathrm{M}^{-1}
\end{gathered}
$$




\begin{tabular}{cccc}
\hline $\mathrm{pH}$ & $k_{\text {obs }} / \mathrm{M}^{-1} \mathrm{~s}^{-1}$ & $\mathrm{pH}$ & $k_{\text {obs }} / \mathrm{M}^{-1} \mathrm{~s}^{-1}$ \\
\hline 2,7 & $4,264 \cdot 10^{-3}$ & 3,4 & $1,618 \cdot 10^{-3}$ \\
2,8 & $4,106 \cdot 10^{-3}$ & 3,5 & $1,361 \cdot 10^{-3}$ \\
3,0 & $3,193 \cdot 10^{-3}$ & 3,8 & $7,44 \cdot 10^{-4}$ \\
3,1 & $2,740 \cdot 10^{-3}$ & 3,8 & $7,73 \cdot 10^{-4}$ \\
3,3 & $2,017 \cdot 10^{-3}$ & 4,2 & $3,92 \cdot 10^{-4}$ \\
\hline
\end{tabular}

$y=\frac{(47 \pm 9)\left(10^{-x}\right)^{2}}{\left(10^{-x}+6,65 \cdot 10^{-4}\right)\left(1+(7.800 \pm 700) 10^{-x}\right)}$

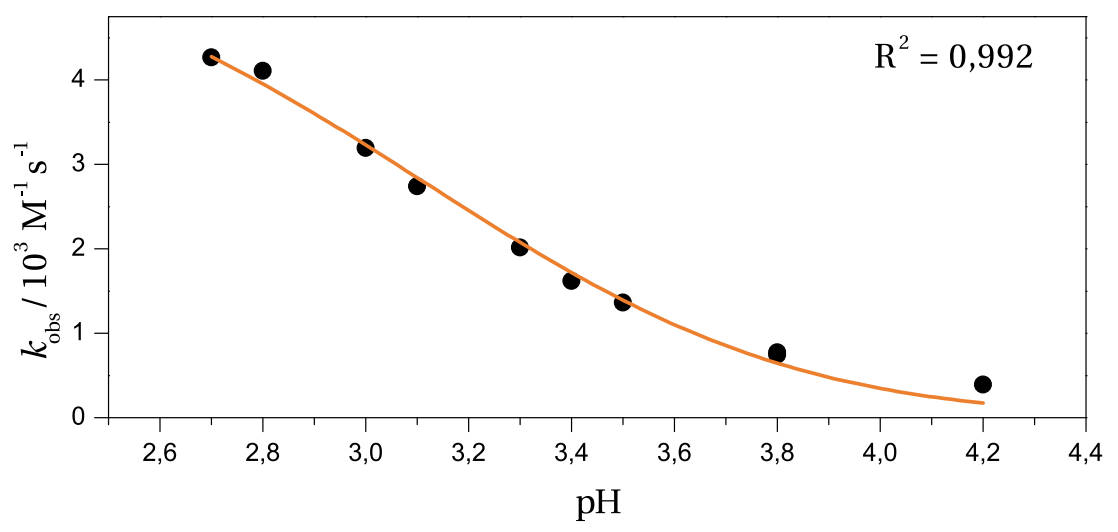

Tabla 4.14 y Figura 4.30: Influencia de la acidez del medio en la constante de velocidad. $[\mathrm{TYR}]_{\circ}=3 \cdot 10^{-4}-3,0 \cdot 10^{-3} \mathrm{M},[\mathrm{NIT}]_{\circ}=3 \cdot 10^{-3}-3,0 \cdot 10^{-2} \mathrm{M}, I=0,2 \mathrm{M}, T=20,0{ }^{\circ} \mathrm{C}$. 
186 | Nitrosación de la tiramina

$$
\begin{aligned}
& \mathrm{HNO}_{2} \stackrel{K_{1}}{\rightleftharpoons} \mathrm{NO}_{2}^{-}+\mathrm{H}^{+} \\
& \mathrm{HNO}_{2}+\mathrm{H}^{+} \stackrel{K_{2}}{\rightleftharpoons} \mathrm{H}_{2} \mathrm{NO}_{2}^{+} / \mathrm{NO}^{+}+\mathrm{H}_{2} \mathrm{O}
\end{aligned}
$$<smiles>NCCC1=CC([O])C(=[OH+])C=C1</smiles><smiles></smiles>

\section{$\frac{\mathrm{H}_{2} \mathrm{O}}{k_{\mathrm{c}}, \text { lenta }}$}<smiles>NCCC1=CC(=NO)C(=O)C=C1</smiles><smiles>NCCc1ccc(O)c(N=O)c1</smiles>

Esquema 4.2: Mecanismo propuesto para la nitrosación de la tiramina.

$\beta$ corresponde al cociente $k_{-a} / K_{b} k_{c}$. Como el valor de $K_{2}$ se conoce $\left(K_{2}=3 \cdot 10^{-7}\right.$ $\left.\mathrm{M}^{-1}\right),{ }^{81}$ con el valor de $\alpha$ se ha calculado el de $k_{a}$ :

$$
k_{a}=(1,6 \pm 0,3) \cdot 10^{8} \mathrm{M}^{-1} \mathrm{~s}^{-1}
$$

Estos valores son del mismo orden que los obtenidos con otras moléculas que reaccionan con este mismo mecanismo (sección 5.1). 


\subsubsection{Influencia de la fuerza iónica}

Se ha medido la velocidad de nitrosación de la tiramina con diferentes concentraciones de perclorato sódico, manteniendo constante el resto de variables para determinar la influencia de la fuerza iónica. La figura 4.31 recoge el resultado de aplicar la ecuación de Brønsted-Debye-Hückel (ecuación 3.11, página 120) a estos experimentos.

\begin{tabular}{cccc}
\hline$I / \mathrm{M}$ & $k_{\mathrm{obs}} / \mathrm{M}^{-1} \mathrm{~s}^{-1}$ & $I / \mathrm{M}$ & $k_{\mathrm{obs}} / \mathrm{M}^{-1} \mathrm{~s}^{-1}$ \\
\hline 0,0234 & $1,188 \cdot 10^{-3}$ & 0,1834 & $1,170 \cdot 10^{-3}$ \\
0,1059 & $1,055 \cdot 10^{-3}$ & 0,2634 & $1,162 \cdot 10^{-3}$ \\
0,1434 & $1,111 \cdot 10^{-3}$ & & \\
\hline
\end{tabular}

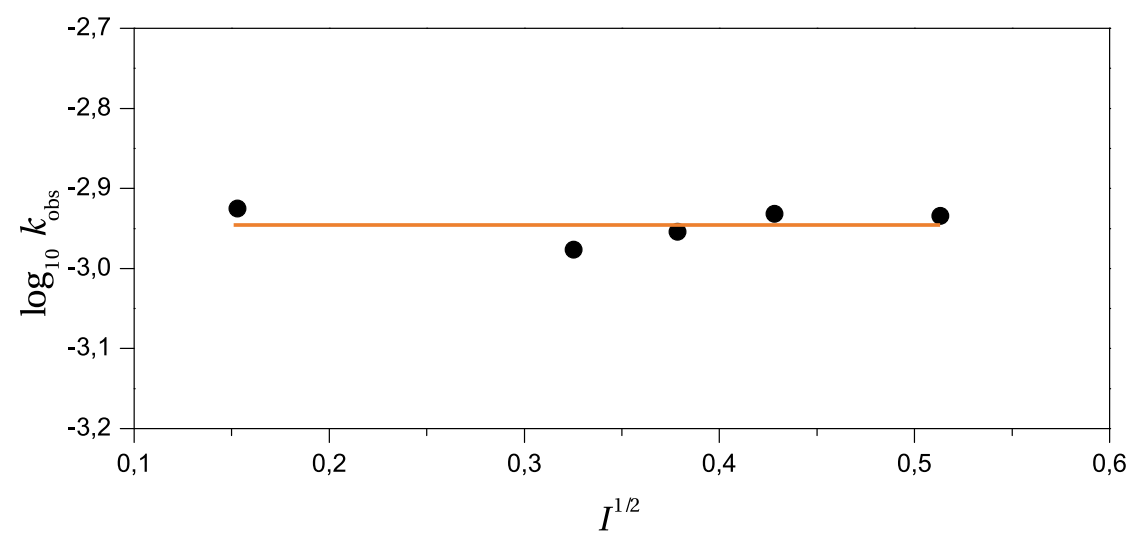

Tabla 4.15 y Figura 4.31: Influencia de la fuerza iónica en la constante de velocidad. $[\text { TYR }]_{\circ}=3 \cdot 10^{-4}-3,0 \cdot 10^{-3} \mathrm{M},[\mathrm{NIT}]_{\circ}=3 \cdot 10^{-3}-3,0 \cdot 10^{-2} \mathrm{M}, \mathrm{pH}=3,4, T=20,0{ }^{\circ} \mathrm{C}$.

Se puede ver cómo la fuerza iónica no influye en la constante de velocidad de esta reacción. Esto concuerda con el mecanismo propuesto, en el que la etapa limitante es la ruptura del complejo $\sigma$ o de Wheland. 


\section{8 | Nitrosación de la tiramina}

\subsubsection{Efecto isotópico cinético}

Una consecuencia del mecanismo propuesto es que debido a que, la etapa limitante de la velocidad depende de la pérdida de un protón por parte del complejo de Wheland, la reacción debe mostrar un efecto isotópico cinético (sección 3.1.1.3, página 121). Para comprobar si este efecto se produce en la nitrosación de la tiramina se han preparado dos cinéticas a $\mathrm{pH}=2,1$, una realizada utilizando como disolvente agua y otra empleando agua pesada. A este $\mathrm{pH}$ ocurre que $\left(k_{a} / K_{b} k_{c}\right)\left[\mathrm{H}^{+}\right] \gg 1 \mathrm{y}\left[\mathrm{H}^{+}\right] \gg K_{1}$, y así la ecuación 4.57 se simplifica de la siguiente manera:

$$
k_{\mathrm{obs}}^{\mathrm{H}_{2} \mathrm{O}}=\frac{k_{a}^{\mathrm{H}_{2} \mathrm{O}} K_{2}^{\mathrm{H}_{2} \mathrm{O}} K_{b}^{\mathrm{H}_{2} \mathrm{O}} k_{c}^{\mathrm{H}_{2} \mathrm{O}}}{k_{-a}^{\mathrm{H}_{2} \mathrm{O}}}
$$

El superíndice $\mathrm{H}_{2} \mathrm{O}$ indica que esta ecuación está realizada en agua normal. Si utilizamos agua pesada, los deuterones del medio inmediatamente sustituirán a los protones de las moléculas que intervienen en la reacción, transformándose la ecuación anterior en:

$$
k_{\text {obs }}^{\mathrm{D}_{2} \mathrm{O}}=\frac{k_{a}^{\mathrm{D}_{2} \mathrm{O}} K_{2}^{\mathrm{D}_{2} \mathrm{O}} K_{b}^{\mathrm{D}_{2} \mathrm{O}} k_{c}^{\mathrm{D}_{2} \mathrm{O}}}{k_{-a}^{\mathrm{D}_{2} \mathrm{O}}}
$$

El cociente entre ambas ecuaciones nos permite calcular el efecto isotópico asociado a la reacción:

$$
\frac{k_{\text {obs }}^{\mathrm{H}_{2} \mathrm{O}}}{k_{\text {obs }}^{\mathrm{D}_{2} \mathrm{O}}}=\frac{K_{2}^{\mathrm{H}_{2} \mathrm{O}}}{K_{2}^{\mathrm{D}_{2} \mathrm{O}}} \frac{k_{\mathrm{c}}^{\mathrm{H}_{2} \mathrm{O}}}{k_{\mathrm{c}}^{\mathrm{D}_{2} \mathrm{O}}}
$$

Algunos términos de la ecuación han desaparecido debido a que el efecto isotópico no afecta a las constantes de equilibrio sin participación de hidrógeno, luego $k_{a}^{\mathrm{H}_{2} \mathrm{O}} / k_{-a}^{\mathrm{H}_{2} \mathrm{O}}=k_{a}^{\mathrm{D}_{2} \mathrm{O}} / k_{-a}^{\mathrm{D}_{2} \mathrm{O}} \mathrm{y} K_{b}^{\mathrm{H}_{2} \mathrm{O}}=K_{b}^{\mathrm{D}_{2} \mathrm{O}}$.

Se ha llevado a cabo la cinética al $\mathrm{pH}$ indicado en $\mathrm{H}_{2} \mathrm{O}$ y se ha obtenido una $k_{\text {obs }}$ de $0,551 \mathrm{M}^{-1} \mathrm{~s}^{-1}$. A continuación se ha repetido el experimento en $\mathrm{D}_{2} \mathrm{O}$, donde la constante de velocidad ha sido $0,515 \mathrm{M}^{-1} \mathrm{~s}^{-1}$. Sabiendo que $K_{2}^{\mathrm{D}_{2} \mathrm{O}} / K_{2}^{\mathrm{H}_{2} \mathrm{O}}$ es 2,7 se obtiene un efecto isotópico de: ${ }^{257}$

$$
\frac{k_{\mathrm{c}}^{\mathrm{H}_{2} \mathrm{O}}}{k_{\mathrm{c}}^{\mathrm{D}_{2} \mathrm{O}}}=2,91
$$


Este efecto isotópico es análogo al observado en la nitrosación de otros fenoles (sección 5.1, página 291).

\subsubsection{Influencia de la temperatura}

Midiendo la constante de velocidad a diferentes temperaturas se han calculado los parámetros de activación de la reacción de nitrosación de la tiramina. La tabla 4.16 muestra los resultados de los diferentes experimentos entre $20 \mathrm{y}$ $40{ }^{\circ} \mathrm{C}$.

\begin{tabular}{cccc}
\hline$T /{ }^{\circ} \mathrm{C}$ & $k_{\text {obs }} / \mathrm{M}^{-1} \mathrm{~s}^{-1}$ & $T /{ }^{\circ} \mathrm{C}$ & $k_{\text {obs }} / \mathrm{M}^{-1} \mathrm{~s}^{-1}$ \\
\hline 20,0 & $2,945 \cdot 10^{-3}$ & 30,0 & $7,230 \cdot 10^{-3}$ \\
22,5 & $3,449 \cdot 10^{-3}$ & 32,5 & $8,994 \cdot 10^{-3}$ \\
25,0 & $4,836 \cdot 10^{-3}$ & 35,0 & $1,261 \cdot 10^{-2}$ \\
27,5 & $5,878 \cdot 10^{-3}$ & 40,0 & $1,894 \cdot 10^{-2}$ \\
\hline
\end{tabular}

Tabla 4.16: Influencia de la temperatura en la constante de velocidad. [TYR $]_{\circ}=3 \cdot 10^{-4}$ $3,0 \cdot 10^{-3} \mathrm{M},[\mathrm{NIT}]_{\circ}=3 \cdot 10^{-3}-3,0 \cdot 10^{-2} \mathrm{M}, \mathrm{pH}=3,1$.

Las figuras 4.32 y 4.33 muestran el buen ajuste de los datos experimentales a las ecuaciones de Arrhenius y Eyring. A partir de ellas, se obtuvieron los siguientes valores para los parámetros de activación:

\begin{tabular}{ccc}
\hline$E_{a} / \mathrm{kJ} \mathrm{mol}^{-1}$ & $\Delta H^{\ddagger} / \mathrm{kJ} \mathrm{mol}^{-1}$ & $\Delta S^{\ddagger} / \mathrm{J} \mathrm{K}^{-1} \mathrm{~mol}^{-1}$ \\
\hline $73 \pm 2$ & $70 \pm 2$ & $-54 \pm 8$ \\
\hline
\end{tabular}

Tabla 4.17: Parámetros de activación de la reacción de nitrosación de la tiramina a partir de los datos de la tabla 4.16. 
190 | Nitrosación de la tiramina

$$
y=(23,9 \pm 0,8)+(70 \pm 2) \cdot 10^{3} x
$$

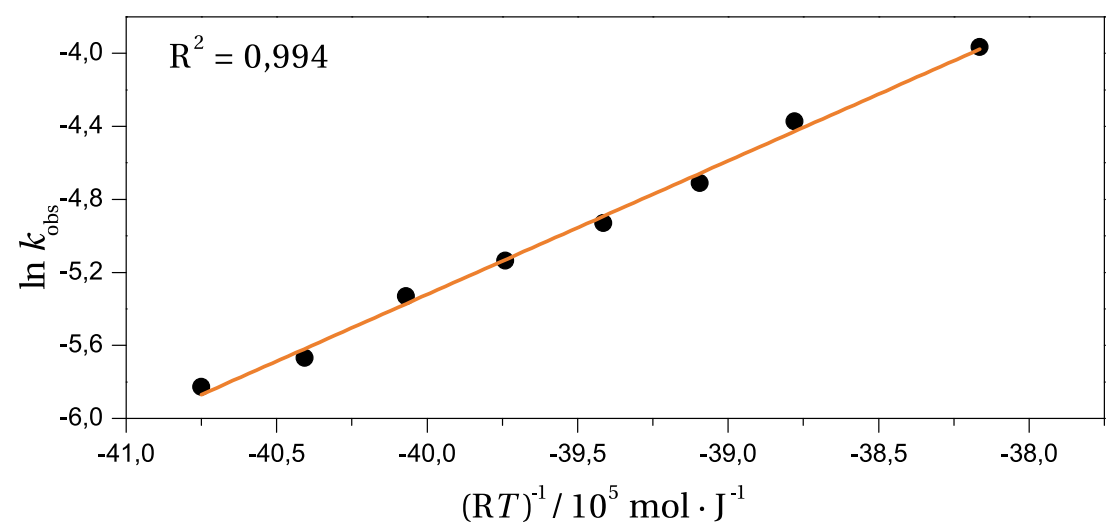

Figura 4.32: Cumplimiento de la ecuación de Arrhenius por los resultados de la tabla 4.16 .

$$
y=(17 \pm 1)+(71 \pm 2) \cdot 10^{3} x
$$

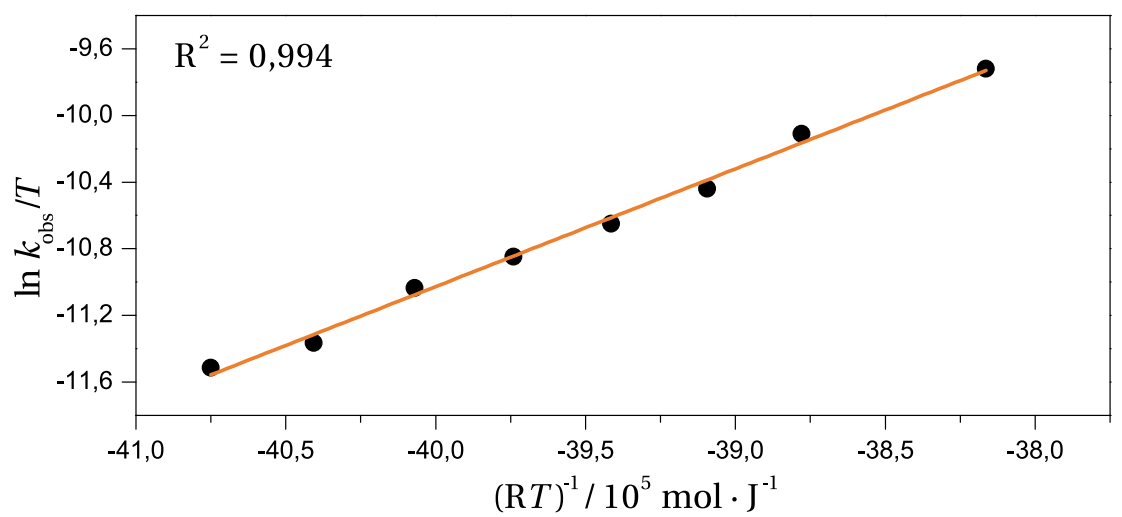

Figura 4.33: Cumplimiento de la ecuación de Eyring por los resultados de la tabla 4.16. 


\subsubsection{Estructura y reactividad de la tiramina}

La figura 4.34 muestra la estructura optimizada mediante un calculo $a b$ initio (DFT-B3LYP 6-31+G (d,p)) de la tiramina. Para predecir la orientación preferida de la nitrosación se ha calculado, empleando el mismo método y la misma base, la superficie de densidad electrónica de la tiramina y la energía de los dos posibles complejos $\sigma$ o de Wheland que pueden aparecer en la reacción entre el ácido nitroso y la tiramina.

La superficie de densidad electrónica (figura 4.35) muestra que la zona de mayor potencial negativo de la estructura es el alcohol (coloreado en rojo). Sin embargo, a la hora de ajustar los datos experimentales a un mecanismo, no se ha observado ninguna participación de este grupo funcional en la reacción de nitrosación, quizás porque la posición en para al alcohol está ocupada para sufrir una reacción de Fisher-Hepp (página 82). Las otras dos zonas con más densidad de carga negativa de la molécula y, por tanto, más nucleófilas son los átomos de carbono del anillo aromático y la amina. Se puede ver, que pese a la cercanía del hidrógeno altamente polarizado del alcohol, los átomos de carbono en orto muestran mayor densidad electrónica que los que se encuentran en la
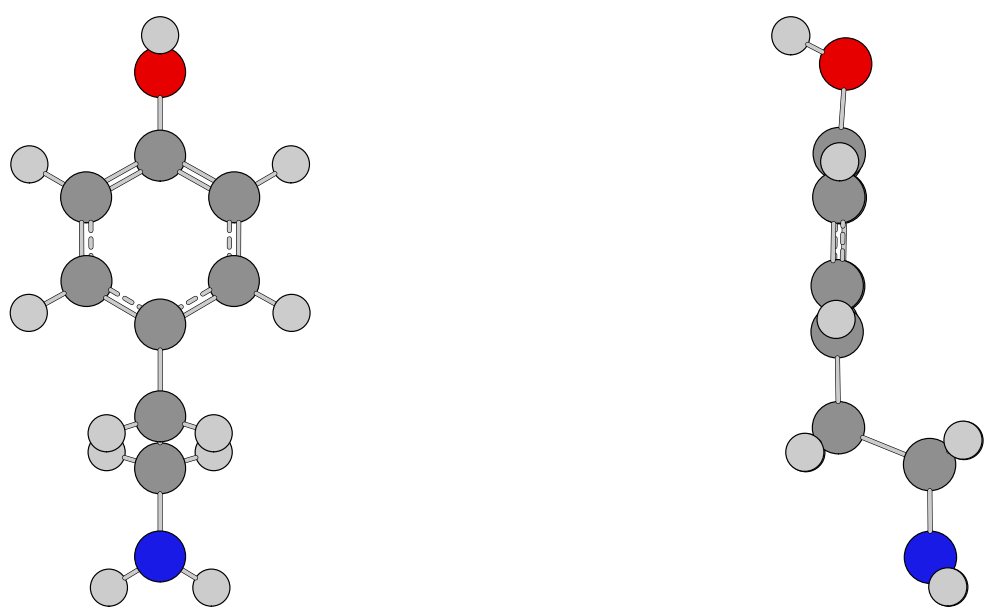

Figura 4.34: Estructura calculada de la tiramina. DFT-B3LYP 6-31+G (d,p). 

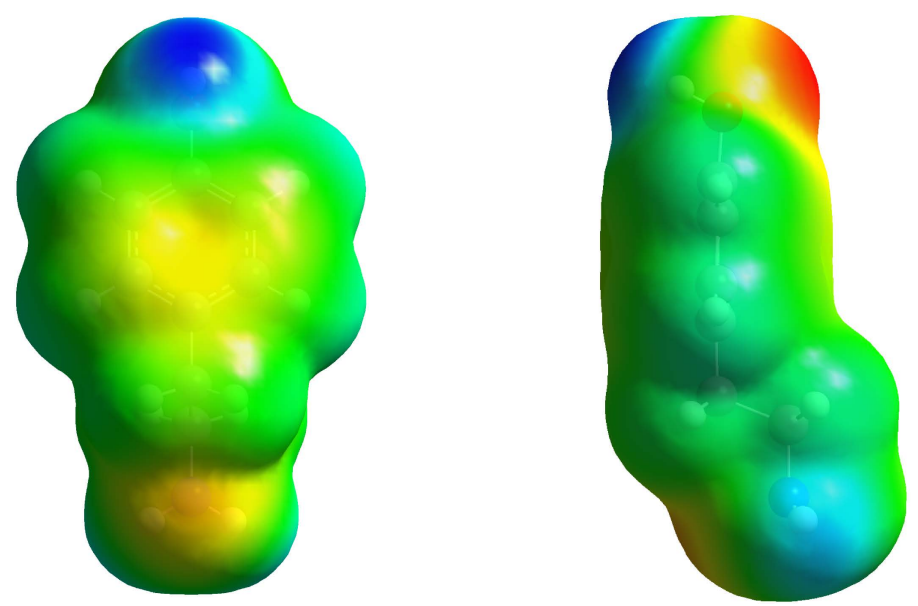

Figura 4.35: Mapa de densidad electrónica de la tiramina. DFT-B3LYP 6-31+G (d,p).

posición en meta.

La tiramina puede C-nitrosarse en dos posiciones diferentes debido a su simetría: en orto y en meta. Por medio de los cálculos descritos se ha estimado la estabilidad de los dos posibles complejos de Wheland sustituidos. La figura 4.36 muestra las diferencias de energía de cada uno de los compuestos, tomando como referencia la energía del sistema tiramina + ion nitrosonio. Se puede ver que el complejo de Wheland en orto es más estable que la tiramina nitrosada en la posición meta, por lo que, junto a la evidencia que se desprende del mapa de densidad electrónica, se puede afirmar que la nitrosación de la tiramina ocurrirá preferentemente en la posición orto, especialmente sabiendo que la etapa limitante de la velocidad es la ruptura del complejo.

\subsubsection{Determinación del producto de reacción}

Para caracterizar el producto de nitrosación de la tiramina se ha realizado un espectro de masas de una disolución acuosa y ácida de tiramina y nitrito tras un día de reacción. 


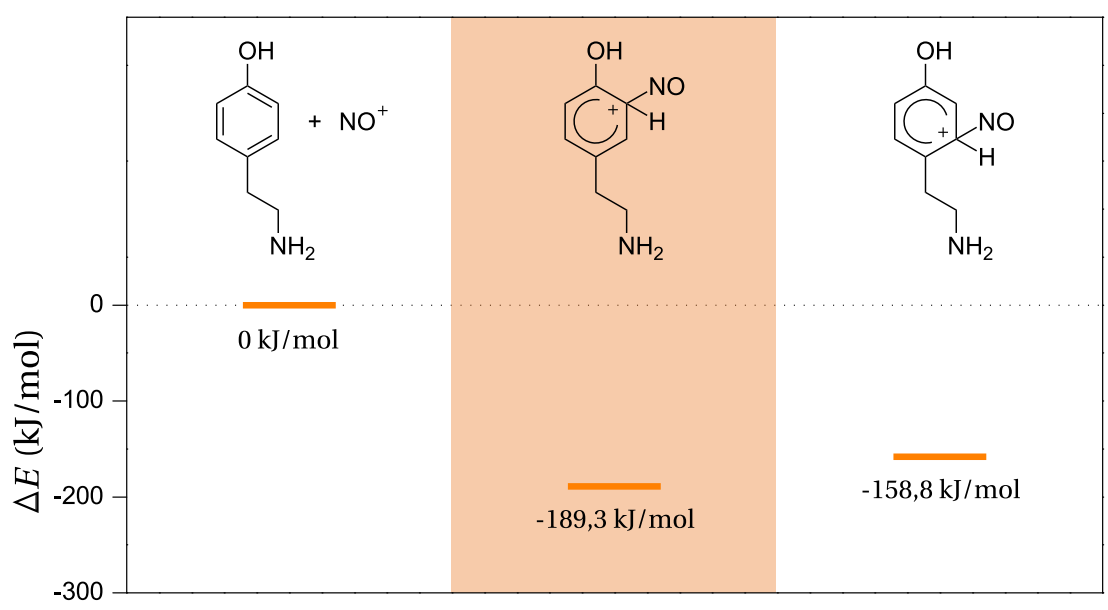

Figura 4.36: Diferencias de energía calculadas para los posibles complejos $\sigma$ de la nitrosación de la tiramina. DFT-B3LYP 6-31+G (d,p).

El espectro obtenido (figura 4.37) muestra dos picos de gran intensidad. El primero, en $\mathrm{m} / z=138$ corresponde a la tirosina que aún no ha reaccionado. El segundo pico en 165,9 , de abundancia relativa $100 \%$, coincide con la tiramina nitrosada. Este espectro indica que la nitrosación se está produciendo principalmente en el anillo aromático de la estructura, puesto que las nitrosaminas primarias, aunque tienen la misma masa que el C-nitrosocompuesto, son inestables y no pueden aparecer en un pico tan intenso como el que muestra la figura 4.37 .

Para estudiar el producto de nitrosación se añadió una disolución de sulfato de cobre (II) a la mezcla de reacción de nitrito y tiramina cuando la reacción de nitrosación había acabado, de tal forma que el cobre estuviese en exceso. El cambio de color producido en esta mezcla, tras dos días a temperatura ambiente, confirmó la presencia de tiramina nitrosada en orto, por la formación de un compuesto de coordinación con el cobre que no se produce con la tiramina sin nitrosar (esquema 4.3). 
194 | Nitrosación de la tiramina

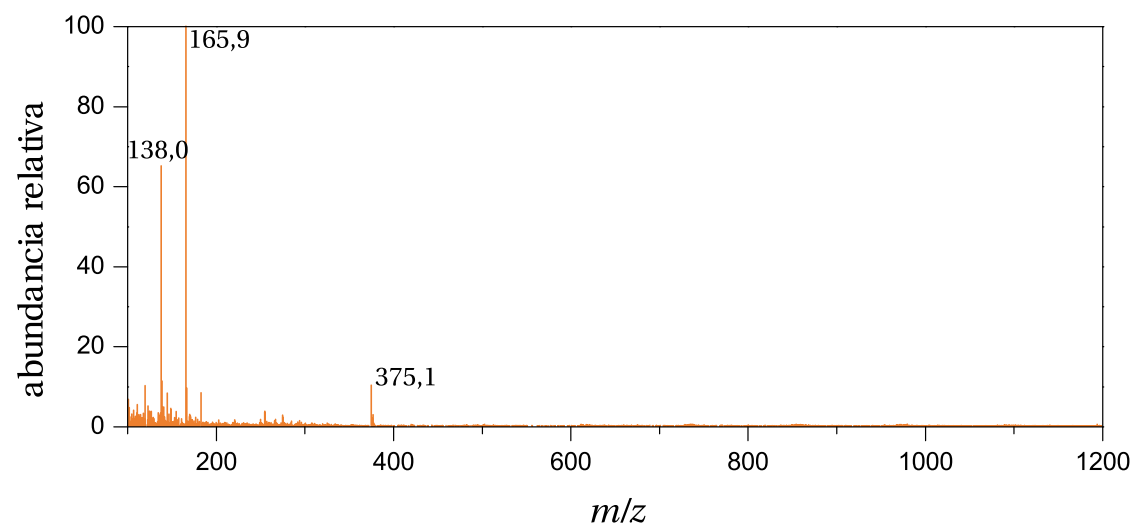

Figura 4.37: Espectro de masas por impacto electrónico positivo de la tiramina nitrosada.<smiles>NCCc1ccc(O)c([N+](=O)[O-])c1</smiles><smiles>NCCc1ccc(O[Cl+][Cl+])c(N)c1</smiles>

Esquema 4.3: Reacción de complejación de la nitrosotiramina. 


\subsubsection{Actividad biológica de la nitrosotiramina}

\section{Test de Ames}

La mutagenia de la nitrosotiramina se ha estudiado mediante el test de Ames en las cepas TA98 y TA100, en ausencia y presencia de complejo de activación metabólica S9 según se ha descrito antes (página 134). Las cantidades empleadas se han escogido de forma que aumenten logarítmicamente hasta la solubilidad máxima del nitrosocompuesto en DMSO. Los resultados obtenidos se encuentran en la tabla 4.18 y se muestran representados en las figuras 4.38 para las bacterias TA98 y 4.39 para las bacterias TA100.

\begin{tabular}{ccccc}
\hline$\mu \mathrm{g}$ NTYR / placa & TA98 & TA98 + S9 & TA100 & TA100 + S9 \\
\hline control negativo & $14 \pm 2$ & $25 \pm 1$ & 203 & 81,5 \\
6,8 & $13 \pm 1$ & $24 \pm 2$ & $203 \pm 6$ & $84 \pm 2$ \\
17 & $14 \pm 1$ & 21 & $210 \pm 20$ & $94 \pm 6$ \\
68 & $17 \pm 1$ & 25 & 396 & 141 \\
170 & $17 \pm 1$ & $28 \pm 1$ & 438 & 240,5 \\
680 & $42 \pm 2$ & $39 \pm 4$ & $620 \pm 90$ & $400 \pm 10$ \\
control positivo & $340 \pm 10$ & 426 & $1.900 \pm 200$ & $740 \pm 10$ \\
\hline
\end{tabular}

Tabla 4.18: Test de Ames aplicado a la nitrosotiramina. Controles positivos: TA98: $10 \mu \mathrm{g}$ NPD, TA98 + S9: $2 \mu \mathrm{g}$ 2AA, TA100: 0,6 $\mu \mathrm{g}$ 4NQO y TA100 + S9 $2 \mu \mathrm{g} 2 \mathrm{AA}$.

En ambas cepas se observa que, al aumentar la dosis de nitrosotiramina, el número de colonias en cada placa se incrementa, indicando que existe una respuesta positiva en el test. Se aprecia que las bacterias de la cepa TA100 son más sensibles a la nitrosotiramina, puesto que muestran, a partir de dosis más bajas de compuesto, un aumento mayor de revertientes que en la cepa TA98. Esto es señal de que la nitrosotiramina actúa como un leve mutágeno que produce la sustitución de pares de bases en el código genético. El complejo S9 no ejerce una influencia significativa sobre las muestras. 
196 | Nitrosación de la tiramina

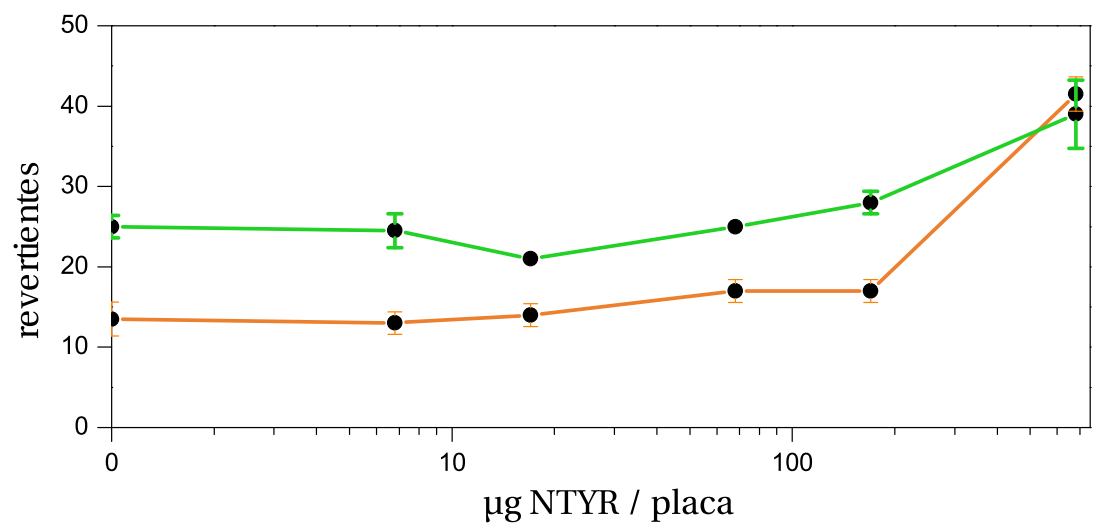

Figura 4.38: Resultados del Test de Ames con la cepa TA98 aplicado a la nitrosotiramina. Los resultados sin extracto S9 se muestran de color naranja y los resultados con extracto S9, de color verde.

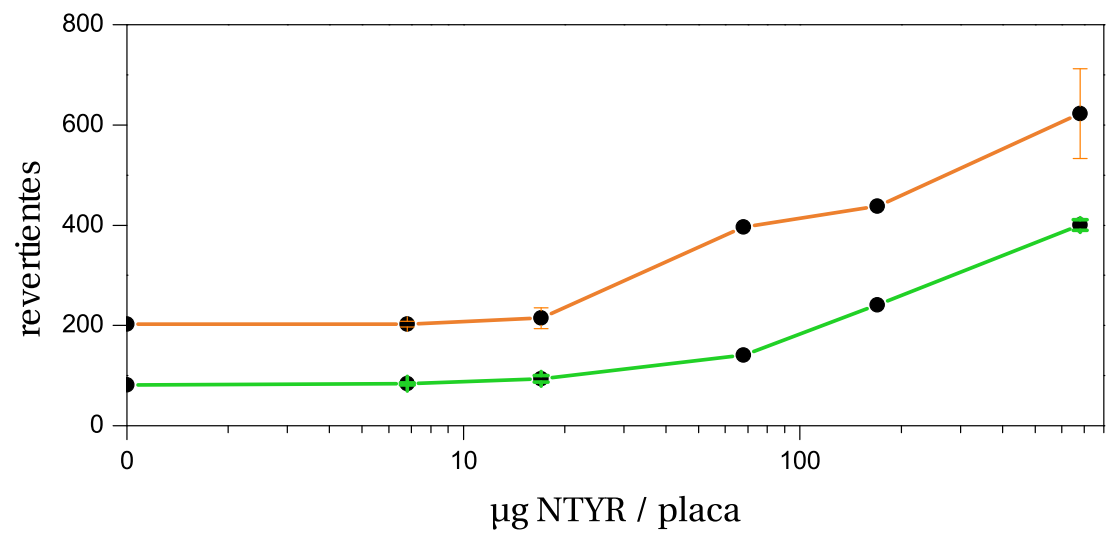

Figura 4.39: Resultados del Test de Ames con la cepa TA100 aplicado a la nitrosotiramina. Los resultados sin extracto $\mathrm{S} 9$ se muestran de color naranja y los resultados con extracto S9, de color verde. 
Test de aberraciones cromosómicas

Para estudiar si la nitrosotiramina es un agente mutágeno que causa anormalías en los cromosomas de células eucariotas, se ha realizado el test de aberraciones cromosómicas según el procedimiento descrito en la página 139. La tabla 4.19 muestra el número de células con aberraciones cromosómicas según el tipo de aberración entre las $180(60 \times 3)$ células estudiadas para cada concentración.

\begin{tabular}{ccccccc}
\hline$[\mathrm{NTYR}] / \mu \mathrm{M}$ & CTG & CSG & CTB & CSB & ACENT & DIC \\
\hline control negativo & 0 & 0 & 0 & 0 & 0 & 0 \\
4,1 & 0 & 0 & 0 & 0 & 0 & 0 \\
41 & 1 & 0 & 0 & 0 & 0 & 1 \\
410 & 1 & 0 & 0 & 0 & 0 & 0 \\
4.100 & \multicolumn{7}{c}{ Concentración tóxica para las células } \\
control positivo & 8 & 4 & 28 & 14 & 0 & 0 \\
\hline [NTYR] / $\mu \mathrm{M}$ & TRI & TET & OTRO & RING & MA & $\%$ AC \\
\hline control negativo & 0 & 0 & 0 & 0 & 0 & 0 \\
4,1 & 0 & 0 & 0 & 0 & 0 & 0 \\
41 & 0 & 0 & 0 & 0 & 0 & 1 \\
410 & 0 & 0 & 0 & 0 & 0 & 0 \\
4.100 & \multicolumn{7}{c}{ Concentración tóxica para las células } \\
control positivo & 16 & 2 & 0 & 4 & 0 & 42 \\
\hline
\end{tabular}

Tabla 4.19: Aberraciones cromosómicas inducidas por la nitrosotiramina en células eucariotas V-79. Las abreviaturas son: CTG, hueco en la cromátida; CSG, hueco en el cromosoma; CTB, ruptura en la cromátida; CSB, ruptura en el cromosoma; ACENT, fragmento acéntrico; DIC, cromosoma dicéntrico; TRI, cromosoma trirradial; TETRA, cromosoma tetrarradial, OTRO, otra aberración; RING, cromosoma anular; MA, metafase multiaberrante; \% AC, \% de células aberrantes, excluyendo CTG y CSG. Control positivo: MMC 1,5 $\mu \mathrm{M}$. 


\section{8 | Nitrosación de la tiramina}

Se puede ver que la nitrosotiramina muestra una pequeña respuesta en el test que, sin embargo, no se puede considerar significativa para calificar la molécula de genotóxica. La concentración más alta de nitrosocompuesto ha resultado ser tóxica para las células, por lo que no se ha podido comprobar la mutagenia de la nitrosotiramina en esa concentración.

\section{Test del MTT}

Se ha estudiado la citotoxicidad de la nitrosotiramina mediante el ensayo de proliferación celular MTT. Tras exponer durante 24 horas las células V-79 a distintas concentraciones del compuesto se ha medido la supervivencia de las células mediante el procedimiento descrito en la página 142. La figura 4.40 muestra el resultado de la experiencia.

Se puede comprobar que para las dosis empleadas de nitrosotiramina, la supervivencia celular ha sido alta. Sólo en las células expuestas a la disolución más concentrada de nitrosocompuesto, $2 \cdot 10^{-3} \mathrm{M}$, la citotoxicidad ha sido significativa, donde 1 de cada 5 células había muerto. Estos resultados concuerdan con los del test de aberraciones cromosómicas, donde la concentración más alta empleada $\left(4,1 \cdot 10^{-3} \mathrm{M}\right)$ había provocado que muchas células de la lámina muriesen y no se pudiesen observar el suficiente número de células en la metafase para realizar el conteo de aberraciones. 


\begin{tabular}{ccc}
\hline & {$[$ NTYR $] / \mu \mathrm{M}$} & Supervivencia \\
\hline $\mathrm{a}$ & 62 & $(104 \pm 6) \%$ \\
$\mathrm{~b}$ & 200 & $(95 \pm 11) \%$ \\
$\mathrm{c}$ & 615 & $(90 \pm 11) \%$ \\
$\mathrm{~d}$ & 2.000 & $(83 \pm 9) \%$ \\
\hline
\end{tabular}

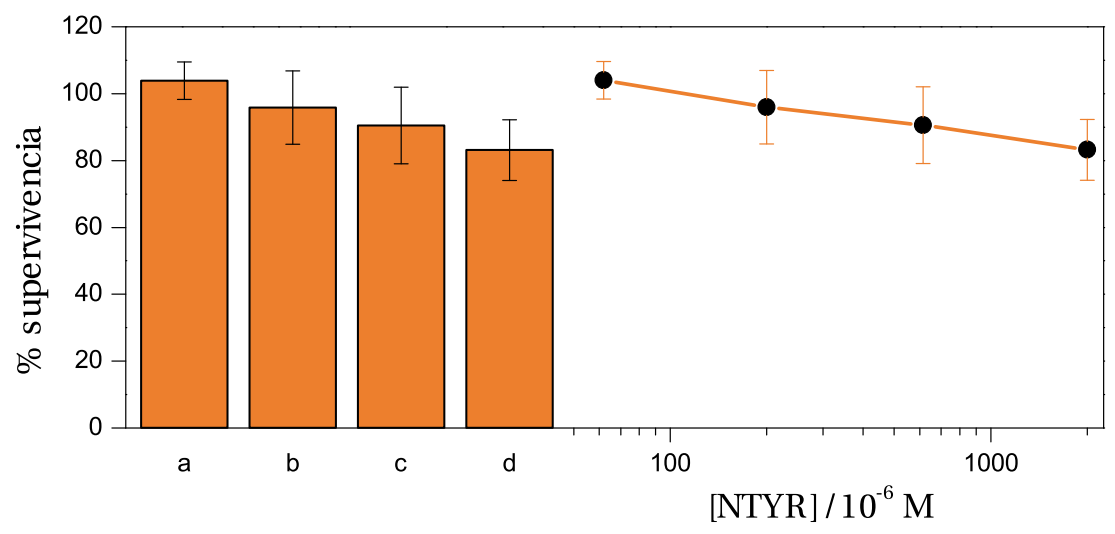

Tabla 4.20 y Figura 4.40: Supervivencia celular de V-79 en función de la concentración de nitrosotiramina. 


\subsection{Nitrosación de la dopamina}

\subsubsection{Estudio espectrofotométrico}

Para el estudio cinético de la nitrosación de la dopamina (DOP) se ha empleado como reactivo hidrocloruro de dopamina que es muy soluble en agua. Su espectro de absorción se muestra en la figura 4.41. La dopamina, al tener dos grupos que aportan densidad electrónica al anillo aromático, tiene las bandas de absorción menos energéticas de toda la serie de moléculas investigadas. Su banda de la transición $\pi \rightarrow \pi^{*}$ permitida aparece entre 180 y $245 \mathrm{~nm}$ y $\pi \rightarrow \pi^{*}$ prohibida entre 255 y $300 \mathrm{~nm}$. Esta última tiene un máximo en $279 \mathrm{~nm}$ donde se ha determinado el coeficiente de absorción molar (figura 4.42).

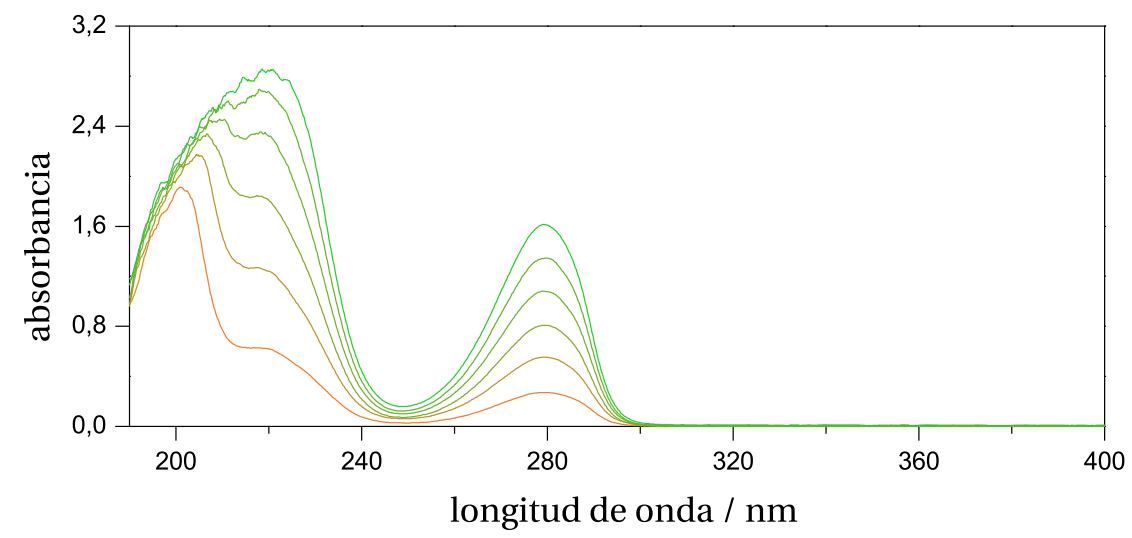

Figura 4.41: Espectro de absorción UV-visible de la dopamina. [DOP] $=1,0 \cdot 10^{-3} \mathrm{M}$ $6,0 \cdot 10^{-3} \mathrm{M}, \mathrm{pH}=3,15, T=20,0^{\circ} \mathrm{C}$.

La magnitud de su coeficiente de absorción molar

$$
\varepsilon_{\text {DOP, } 279 \mathrm{~nm}}=266 \pm 2 \mathrm{M}^{-1} \mathrm{~cm}^{-1}
$$

está en el intervalo de valores de las transiciones $\pi \rightarrow \pi^{*}$ prohibidas. ${ }^{249}$ 


\begin{tabular}{cccc}
\hline$[\mathrm{DOP}] / \mathrm{M}$ & $A_{279}$ & {$[\mathrm{DOP}] / \mathrm{M}$} & $A_{279}$ \\
\hline $1,0 \cdot 10^{-3}$ & 0,2702 & $4,0 \cdot 10^{-3}$ & 1,0802 \\
$2,0 \cdot 10^{-3}$ & 0,5532 & $5,0 \cdot 10^{-3}$ & 1,3421 \\
$3,0 \cdot 10^{-3}$ & 0,8067 & $6,0 \cdot 10^{-3}$ & 1,6133 \\
\hline
\end{tabular}

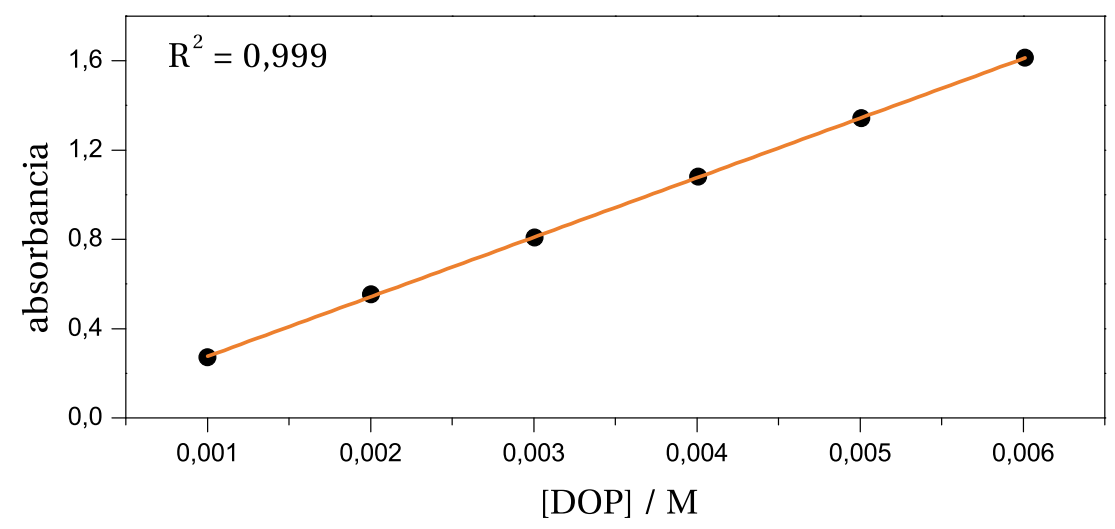

Tabla 4.21 y Figura 4.42: Cumplimiento de la ley de Lambert-Beer por la dopamina. $\lambda$ $=279 \mathrm{~nm}, \mathrm{pH}=3,15, T=25,0^{\circ} \mathrm{C}$.

No se ha podido estudiar la influencia del pH en el espectro de absorción de la dopamina porque este compuesto se degrada en medios básicos rápidamente.

\subsubsection{Autooxidación de la dopamina}

La dopamina se oxida rápidamente en disolución acuosa alcalina con el oxígeno de la atmósfera (figura 2.23, página 108). El polímero que se forma en esta reacción hace que el color de la disolución torne a un intenso color negro con destellos rojizos. La figura 4.43 muestra el espectro de absorción de una disolución de dopamina oxidada. Se puede ver cómo la banda de absorción es 


\section{2 | Nitrosación de la dopamina}

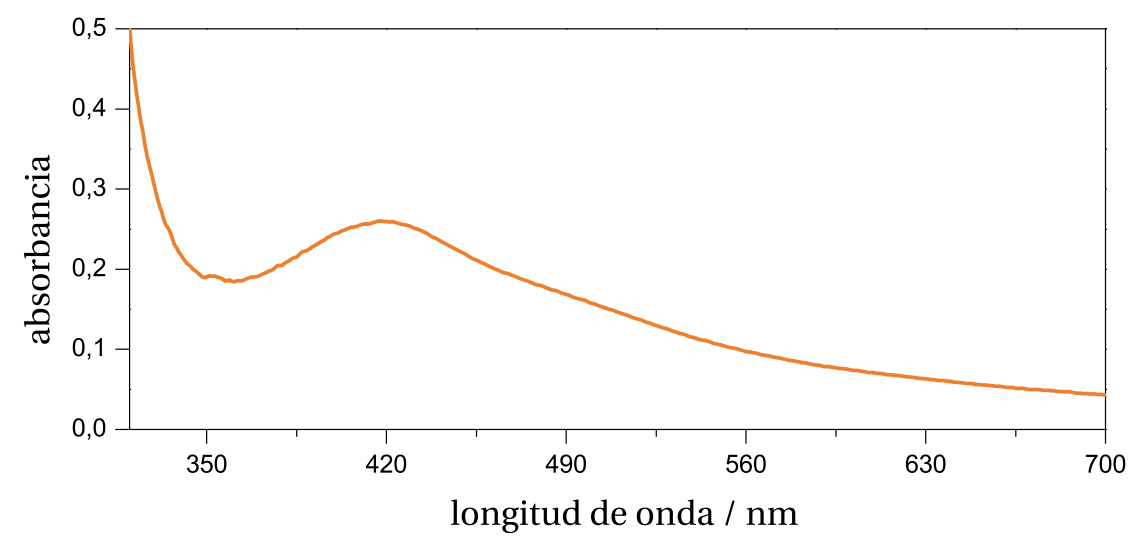

Figura 4.43: Espectro de absorción UV-visible de una disolución de dopamina 10 minutos después de su preparación. [DOP] $=1,52 \cdot 10^{-2} \mathrm{M}, \mathrm{pH}=9,37, T=20,0{ }^{\circ} \mathrm{C}$.

muy ancha, cubriendo todo el espectro visible, con un máximo sobre $420 \mathrm{~nm}$, que con el tiempo se desplaza hasta $490 \mathrm{~nm}$ (figura 4.44), lo que justifica los colores descritos.

Se ha cuantificado la velocidad de autooxidación de la dopamina para ver hasta que punto podría afectar al seguimiento de la cinética de su nitrosación. Para ello se prepararon varias disoluciones de dopamina a pHs ácidos cercanos a la neutralidad. Se comprobó que sólo a partir de un $\mathrm{pH}>7,5$ la velocidad de autooxidación puede ser un inconveniente para el estudio cinético.

Las disoluciones de dopamina son ácidas debido a que se trabajó con su hidrocloruro. Se hicieron ensayos con disoluciones de varias concentraciones a fin de seleccionar las de $\mathrm{pH}$ más idóneos para evitar la autooxidación de la dopamina. La figura 4.45 muestra que, a concentraciones superiores a 0,5 M, las disoluciones no requieren adición de ácido para su estabilización. 


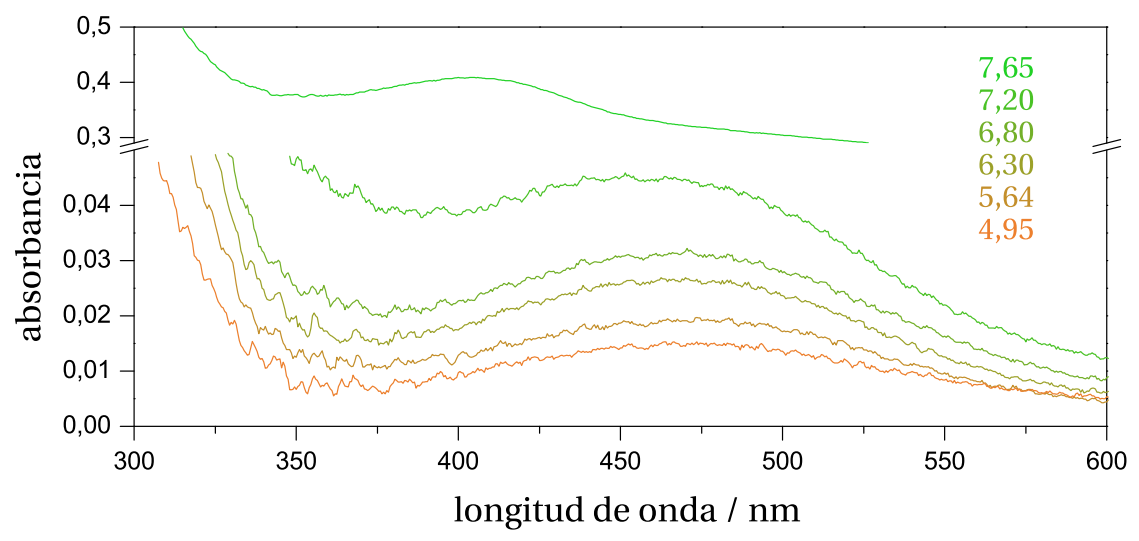

Figura 4.44: Espectros de absorción de la dopamina a diferentes pHs, 96 horas después de su preparación. El espectro a $\mathrm{pH}=7,65$ se midió 16 horas después de la preparación. $[D O P]=5,5 \cdot 10^{-3} \mathrm{M}, T=20,0^{\circ} \mathrm{C}$.

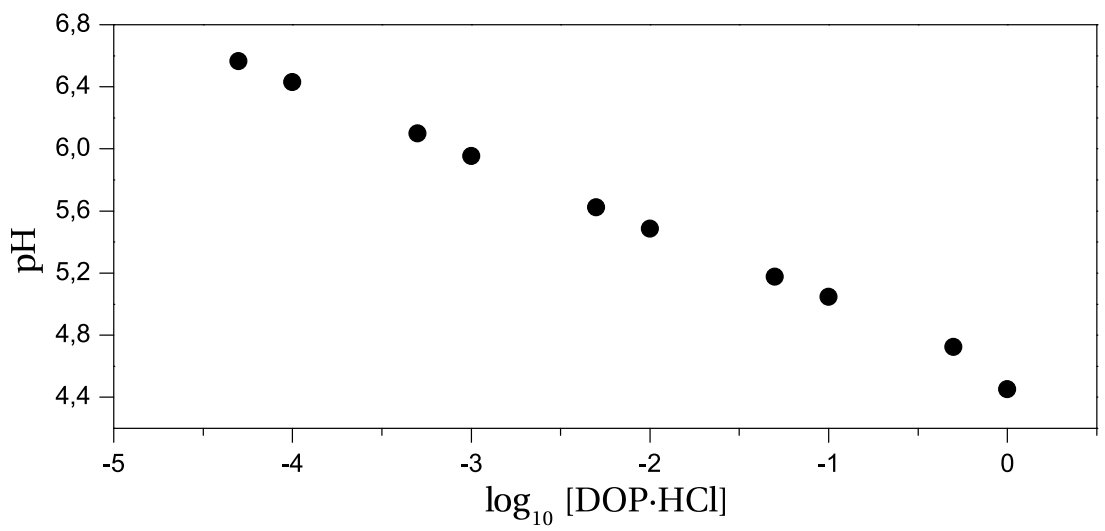

Figura 4.45: $\mathrm{pH}$ de diferentes disoluciones de hidrocloruro de dopamina en función de su concentración. $T=23,0^{\circ} \mathrm{C}$. 


\subsubsection{Reacción de nitrosación de la dopamina}

Después de estudiar el espectro de la dopamina se preparó una disolución ácida de nitrito sódico para comprobar que, al mezclarla con la dopamina, existe reacción de nitrosación y medir la absorción del producto resultante.

La figura 4.46 muestra cómo varían en el tiempo los espectros de absorción de la disolución mezcla. Se observa la aparición de una amplia banda con un máximo en $347 \mathrm{~nm}$ y de un pico mucho más estrecho en la zona de los $250 \mathrm{~nm}$. Los picos de la dopamina apenas cambian de forma y tamaño.

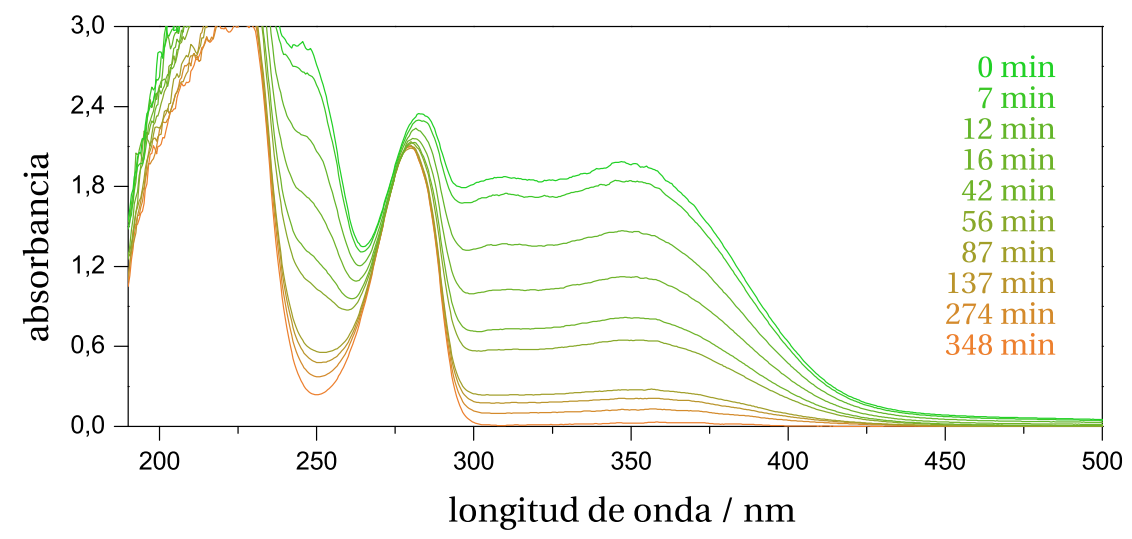

Figura 4.46: Variación con el tiempo del espectro de absorción de la dopamina durante su nitrosación. $[\mathrm{DOP}]=[\mathrm{NIT}]=8 \cdot 10^{-3} \mathrm{M}, \mathrm{pH}=4,08, T=25,0^{\circ} \mathrm{C}$.

El máximo de la banda de absorción del producto de nitrosación en $\lambda=347$ nm es idóneo para el seguimiento cinético de la reacción de nitrosación (la diferencia de absorbancia con el nitrito, cuyas bandas aparecen en esa zona, es grande).

Para medir el coeficiente de absorción molar de la nitrosodopamina en esa longitud de onda, se hizo reaccionar disoluciones de dopamina de diferentes concentraciones con un exceso de nitrito. Una vez alcanzada la meseta de saturación (toda la dopamina se ha convertido en nitrosodopamina) en cada 


\begin{tabular}{cccc}
\hline$[\mathrm{NDOP}] / \mathrm{M}$ & $A_{347}$ & {$[\mathrm{NDOP}] / \mathrm{M}$} & $A_{347}$ \\
\hline $3,51 \cdot 10^{-5}$ & 0,2179 & $1,401 \cdot 10^{-4}$ & 0,7524 \\
$7,03 \cdot 10^{-5}$ & 0,4288 & $1,757 \cdot 10^{-4}$ & 0,9655 \\
$1,054 \cdot 10^{-4}$ & 0,5912 & $2,109 \cdot 10^{-4}$ & 1,1600 \\
\hline
\end{tabular}

$$
y=(0,04 \pm 0,01)+(5.200 \pm 100) x
$$

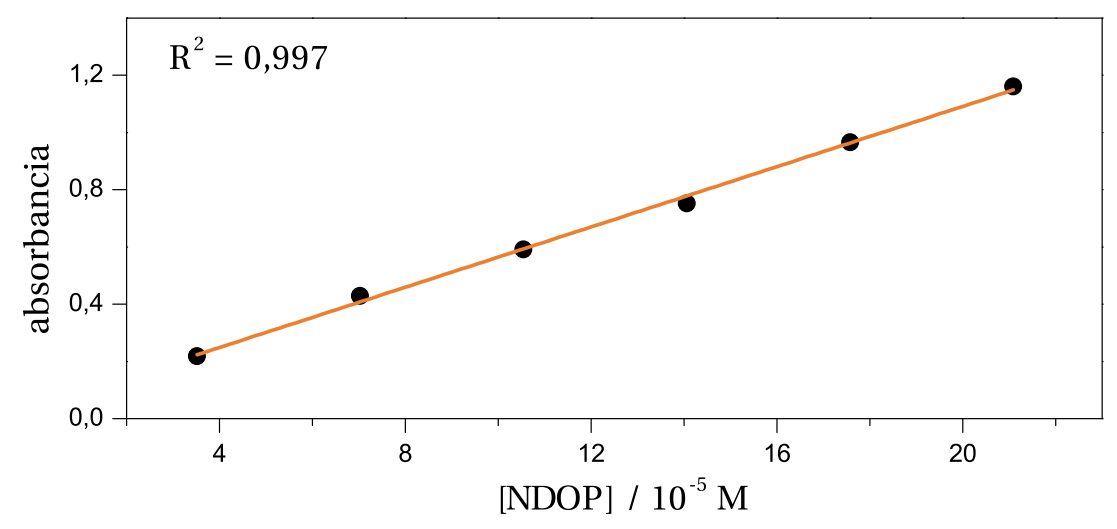

Tabla 4.22 y Figura 4.47: Cumplimiento de la ley de Lambert-Beer por la nitrosodopamina. $\lambda=347 \mathrm{~nm}$, [NIT] $=5,2 \cdot 10^{-2} \mathrm{M}, \mathrm{pH}=4,16, T=25,0^{\circ} \mathrm{C}$.

uno de esos casos, los valores de las absorbancias se representaban frente a las respectivas concentraciones (figura 4.47), encontrándose así que:

$$
\varepsilon_{\mathrm{NDOP}, 347 \mathrm{~nm}}=5.200 \pm 100 \mathrm{M}^{-1} \mathrm{~cm}^{-1}
$$

\subsubsection{Influencia de la concentración de iones cloruro}

Como se indicó en la sección 2.2.3, los iones cloruro catalizan la reacción de nitrosación a través de la formación de cloruro de nitrosilo. Hasta ahora se ha evitado la presencia de este ion o cualquier otro agente catalizador en los 


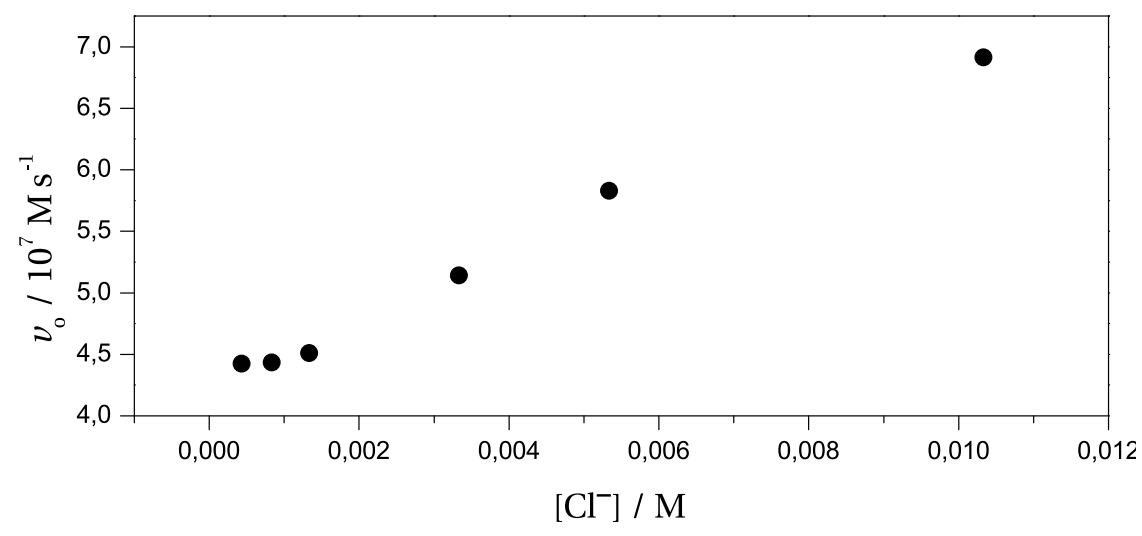

Figura 4.48: Influencia de la concentración de iones cloruro en la velocidad inicial de reacción. $[\mathrm{DOP}]_{\circ}=3,33 \cdot 10^{-4} \mathrm{M}$, $[\mathrm{NIT}]_{\circ}=6,03 \cdot 10^{-4} \mathrm{M}, \mathrm{pH}=4,08, T=20,0{ }^{\circ} \mathrm{C}$.

estudios cinéticos pero, debido al uso de dopamina en forma de hidrocloruro, en esta cinética de nitrosación puede que exista catálisis.

Para estudiar la influencia del ion cloruro en la reacción, se hicieron varias cinéticas con diferentes concentraciones de cloruro añadido en forma de cloruro sódico.

La figura 4.48 muestra el resultado de este experimento. Se puede ver que el aumento de velocidad sólo es significativo en concentraciones de cloruro superiores a $2 \cdot 10^{-3} \mathrm{M}$. Como la concentración de dopamina y, por ende, de cloruro en las cinéticas de este trabajo se encuentran por debajo de esta cantidad, se ha despreciado el efecto que puede tener este en los estudios cinéticos.

\subsection{5. Órdenes parciales de reacción}

Para averiguar los órdenes de reacción parciales se utilizó el método de velocidades iniciales. Se trabajó siempre en las mismas condiciones de $\mathrm{pH}$ y de fuerza iónica. Para determinar el orden parcial respecto a la concentración de dopamina, se prepararon seis disoluciones de concentraciones diferentes, mantenida constante la concentración de nitrito. La figura 4.49 muestra el buen 
ajuste de los resultados a la ecuación:

$$
\ln v_{\circ}=\ln p+m \ln [\mathrm{DOP}]_{\circ}
$$

el valor de cuya pendiente $m=1,02 \pm 0,04$, indica orden uno de reacción.

De igual forma, variando las concentraciones de nitrito y mantenida constante la concentración de dopamina se calculó el orden parcial respecto a la concentración de nitrito, obteniéndose la siguiente ecuación:

$$
\ln v_{\circ}=\ln q+n \ln [\mathrm{NIT}]_{\circ}
$$

La figura 4.50 muestra la aplicación de esta ecuación a los resultados experimentales. La pendiente de esta recta, que corresponde al orden parcial del nitrito, $n$, es uno.

\subsubsection{Influencia de la acidez del medio}

Se midió la constante de velocidad en varios experimentos en los que se mantuvieron constantes todos los parámetros cinéticos, excepto el $\mathrm{pH}$. La figura 4.51 muestra las constantes de velocidad según la acidez del medio. La forma de curva sigmoidea hace pensar que la dopamina sigue el mismo mecanismo que la tiramina, lo que sugiere un mecanismo equivalente (esquema 4.4).

La ecuación teórica de velocidad que se deduce de dicho mecanismo es:

$$
v=\frac{K_{2} k_{\mathrm{a}}\left[\mathrm{H}^{+}\right]^{2}[\mathrm{NIT}][\mathrm{DOP}]}{\left(\left[\mathrm{H}^{+}\right]+K_{1}\right)\left(1+\frac{k_{-\mathrm{a}}}{K_{\mathrm{b}} k_{\mathrm{c}}}\left[\mathrm{H}^{+}\right]\right)}
$$

Este mecanismo concuerda con los órdenes parciales y el orden total de reacción que determinados con anterioridad. Al comparar la ecuación de velocidad teórica (4.72) con la experimental:

$$
v=k_{\mathrm{obs}}[\mathrm{NIT}][\mathrm{DOP}]
$$

se obtiene que:

$$
k_{\mathrm{obs}}=\frac{K_{2} k_{\mathrm{a}}\left[\mathrm{H}^{+}\right]^{2}}{\left(\left[\mathrm{H}^{+}\right]+K_{1}\right)\left(1+\frac{k_{-\mathrm{a}}}{K_{\mathrm{b}} k_{\mathrm{c}}}\left[\mathrm{H}^{+}\right]\right)}
$$


208 | Nitrosación de la dopamina

\begin{tabular}{cccc}
\hline$[\mathrm{DOP}]_{\circ} / \mathrm{M}$ & $v_{\circ} / \mathrm{M} \mathrm{s}^{-1}$ & {$[\mathrm{DOP}]_{\circ} / \mathrm{M}$} & $v_{\circ} / \mathrm{M} \mathrm{s}^{-1}$ \\
\hline $5,98 \cdot 10^{-5}$ & $9,37 \cdot 10^{-9}$ & $1,20 \cdot 10^{-4}$ & $1,76 \cdot 10^{-8}$ \\
$7,98 \cdot 10^{-5}$ & $1,24 \cdot 10^{-8}$ & $1,59 \cdot 10^{-4}$ & $2,57 \cdot 10^{-8}$ \\
$9,97 \cdot 10^{-5}$ & $1,60 \cdot 10^{-8}$ & $1,99 \cdot 10^{-4}$ & $3,19 \cdot 10^{-8}$ \\
\hline
\end{tabular}

$$
y=-(8,5 \pm 0,3)+(1,02 \pm 0,04) x
$$

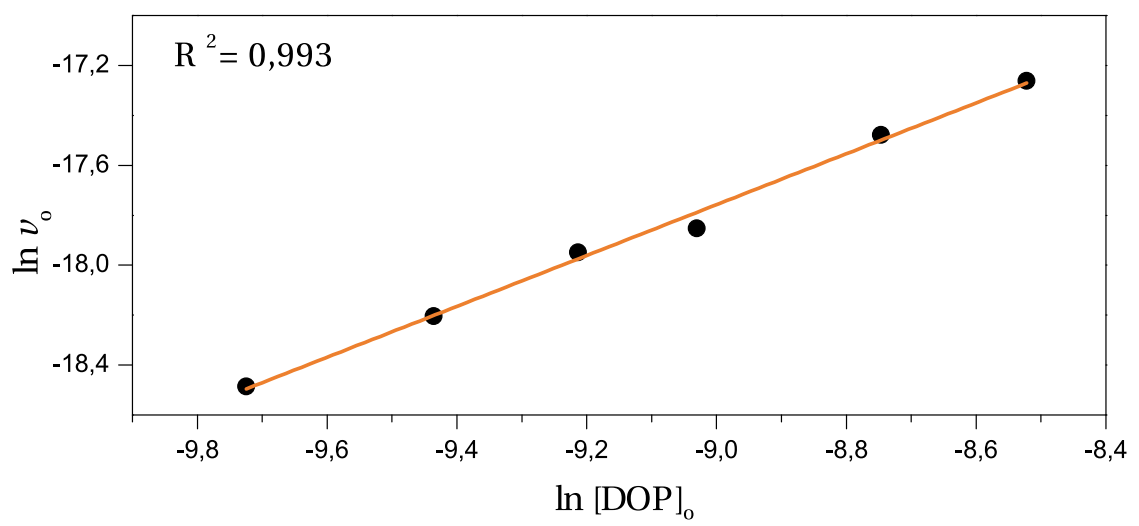

Tabla 4.23 y Figura 4.49: Influencia de la concentración de dopamina en la velocidad inicial de nitrosación. [NIT] $]_{\circ}=1,20 \cdot 10^{-3} \mathrm{M}, \mathrm{pH}=4,01, I=0,2 \mathrm{M}, T=20,0{ }^{\circ} \mathrm{C}$. 


\begin{tabular}{cccc}
\hline$[\mathrm{NIT}]_{\diamond} / \mathrm{M}$ & $v_{\circ} / \mathrm{M} \mathrm{s}^{-1}$ & {$[\mathrm{NIT}]_{\diamond} / \mathrm{M}$} & $v_{\circ} / \mathrm{M} \mathrm{s}^{-1}$ \\
\hline $1,66 \cdot 10^{-4}$ & $3,37 \cdot 10^{-8}$ & $3,31 \cdot 10^{-4}$ & $7,05 \cdot 10^{-8}$ \\
$2,08 \cdot 10^{-4}$ & $4,18 \cdot 10^{-8}$ & $4,15 \cdot 10^{-4}$ & $8,22 \cdot 10^{-8}$ \\
$2,49 \cdot 10^{-4}$ & $5,13 \cdot 10^{-8}$ & & \\
\hline
\end{tabular}

$$
y=-(8,4 \pm 0,3)+(1,00 \pm 0,04) x
$$

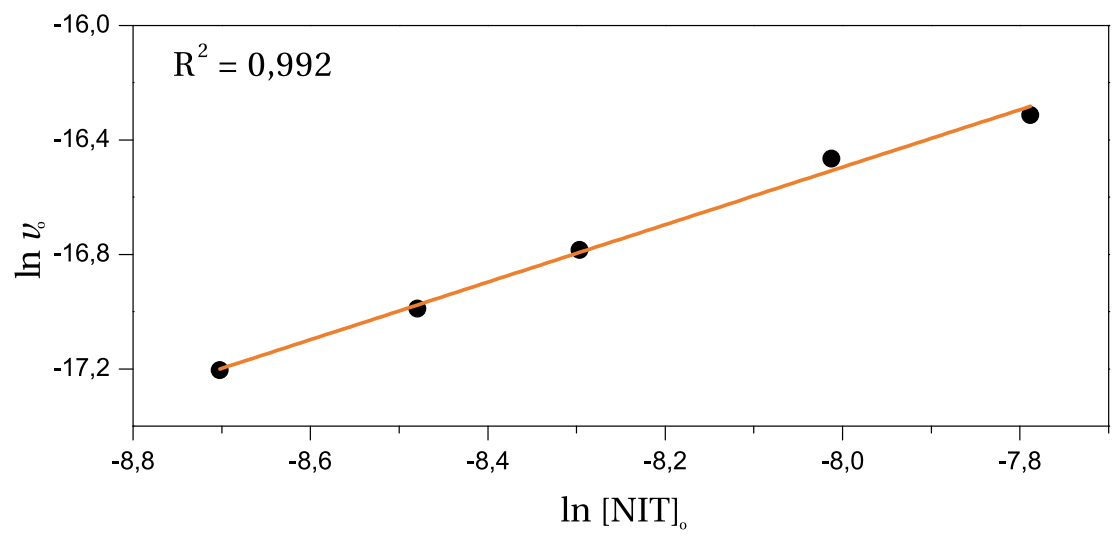

Tabla 4.24 y Figura 4.50: Influencia de la concentración de nitrito en la velocidad inicial de reacción. $[\mathrm{DOP}]_{\circ}=1,32 \cdot 10^{-3} \mathrm{M}, \mathrm{pH}=3,98, I=0,2 \mathrm{M}, T=20,0^{\circ} \mathrm{C}$. 
210 | Nitrosación de la dopamina

\begin{tabular}{cccc}
\hline $\mathrm{pH}$ & $k_{\mathrm{obs}} / \mathrm{M}^{-1} \mathrm{~s}^{-1}$ & $\mathrm{pH}$ & $k_{\mathrm{obs}} / \mathrm{M}^{-1} \mathrm{~s}^{-1}$ \\
\hline 2,6 & 0,3218 & 3,5 & 0,0869 \\
2,8 & 0,2625 & 3,7 & 0,0328 \\
3,0 & 0,1998 & 3,9 & 0,0115 \\
3,1 & 0,1677 & 4,0 & 0,0046 \\
3,3 & 0,0991 & 4,1 & 0,0017 \\
\hline
\end{tabular}

$$
y=\frac{(1.100 \pm 100)\left(10^{-x}\right)^{2}}{\left(10^{-x}+6,65 \cdot 10^{-4}\right)\left(1+(2.400 \pm 400) 10^{-x}\right)}
$$

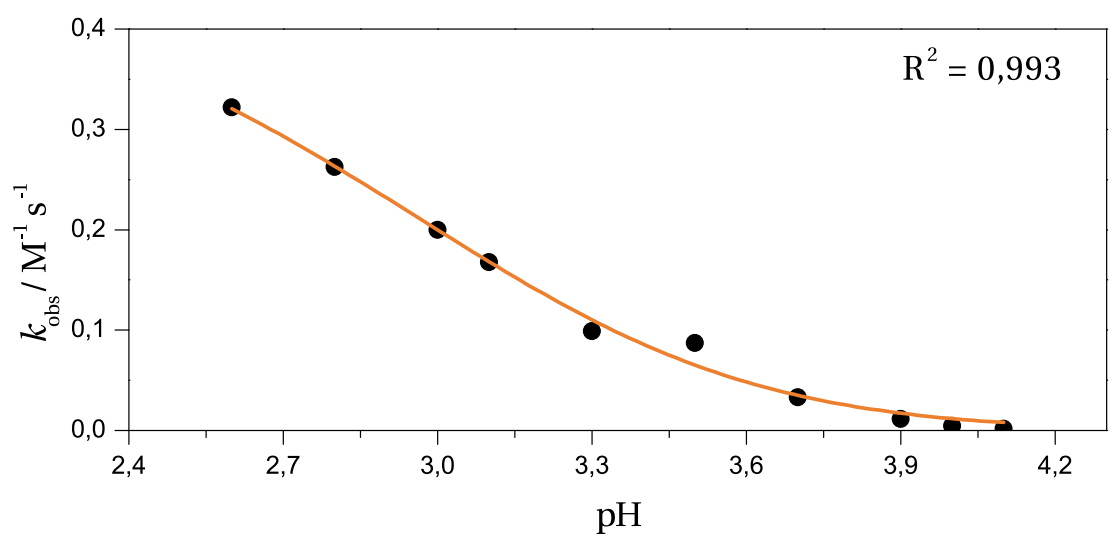

Tabla 4.25 y Figura 4.51: Influencia de la acidez del medio en la constante de velocidad. $[\mathrm{DOP}]_{\circ}=[\mathrm{NIT}]_{\circ}=6,0 \cdot 10^{-4}-2,02 \cdot 10^{-3} \mathrm{M}, I=0,2 \mathrm{M}, T=20,0{ }^{\circ} \mathrm{C}$.

La figura 4.51 muestra el ajuste de esta ecuación a los datos experimentales. Como con la tiramina, con él se han determinado los parámetros $\alpha$ y $\beta$ :

$$
k_{\mathrm{obs}}=\frac{\alpha\left[\mathrm{H}^{+}\right]^{2}}{\left(\left[\mathrm{H}^{+}\right]+K_{1}\right)\left(1+\beta\left[\mathrm{H}^{+}\right]\right)}
$$

Por mínimos cuadrados se ha calculado que:

$$
\alpha=1.100 \pm 100 \mathrm{M}^{-2} \mathrm{~s}^{-1}
$$




$$
\begin{aligned}
& \mathrm{HNO}_{2} \stackrel{K_{1}}{\rightleftharpoons} \mathrm{NO}_{2}^{-}+\mathrm{H}^{+} \\
& \mathrm{HNO}_{2}+\mathrm{H}^{+} \stackrel{K_{2}}{\rightleftharpoons} \mathrm{H}_{2} \mathrm{NO}_{2}^{+} / \mathrm{NO}^{+}+\mathrm{H}_{2} \mathrm{O}
\end{aligned}
$$<smiles>NCCc1ccc(O)c(O)c1</smiles><smiles>[Y20][C@H](C)O[C@H]1C=C(O)C(=O)C=C1CCN</smiles>

Esquema 4.4: Mecanismo propuesto para la nitrosación de la dopamina.

$$
\beta=2.400 \pm 400 \mathrm{M}^{-1}
$$

Se observa un valor de $\beta$ inferior al de la tiramina y dos órdenes de magnitud mayor para $\alpha$. Como $K_{2}=3 \cdot 10^{-7} \mathrm{M}^{-1}$, resulta que: ${ }^{81}$

$$
k_{a}=(3,66 \pm 0,03) \cdot 10^{9} \mathrm{M}^{-1} \mathrm{~s}^{-1}
$$

Este valor es coherente con un ataque del ion nitrosonio/nitrosacidio a la dopamina controlado por difusión. En la sección 5.1 se discuten estos resultados. 


\subsubsection{Influencia de la fuerza iónica}

La figura 4.52 muestra los resultados de experimentos cinéticos con la fuerza iónica como variable. La no influencia de la misma, sugiere que en la etapa determinante de velocidad no intervienen especies con carga.

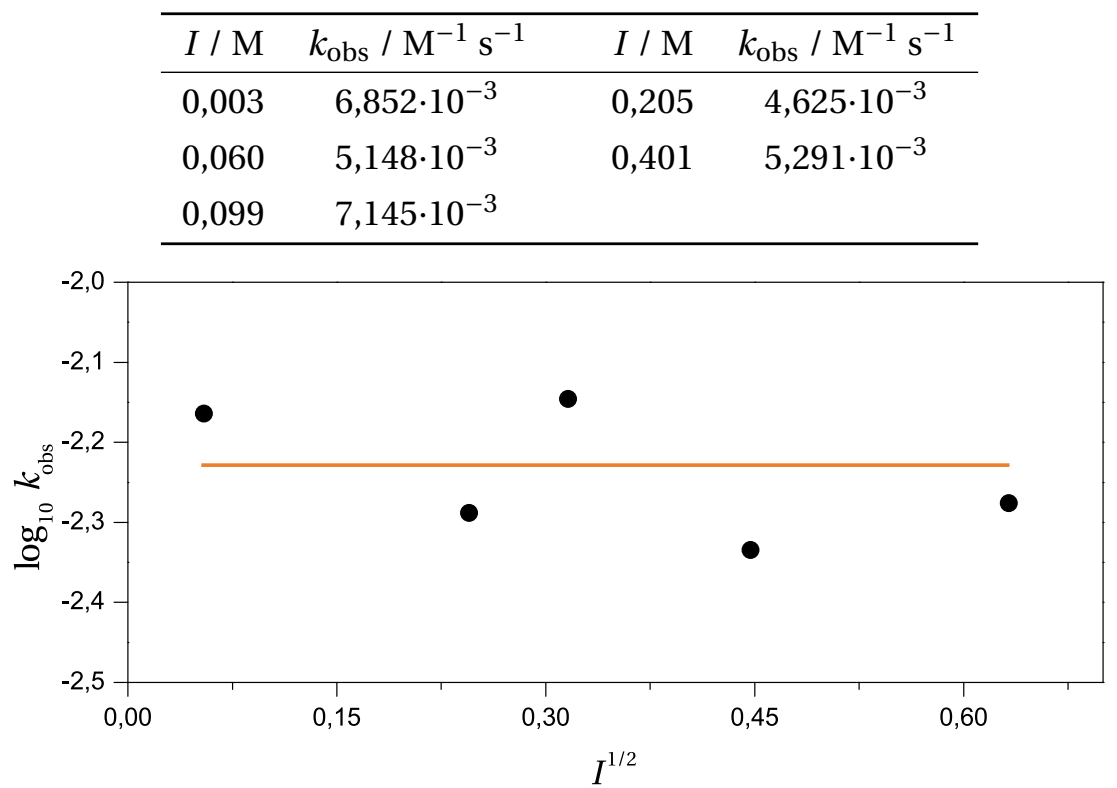

Tabla 4.26 y Figura 4.52: Influencia de la fuerza iónica en la constante de velocidad. $[\mathrm{DOP}]_{\circ}=[\mathrm{NIT}]_{\circ}=6,0 \cdot 10^{-4}-2,02 \cdot 10^{-3} \mathrm{M}, \mathrm{pH}=4,1, T=20,0{ }^{\circ} \mathrm{C}$.

\subsubsection{Efecto isotópico cinético}

Con objeto de verificar el mecanismo propuesto (figura 4.4), que incluye como etapa limitante una transferencia protónica con ruptura del complejo sigma, se programaron experimentos cinéticos paralelos en $\mathrm{H}_{2} \mathrm{O}$ y $\mathrm{D}_{2} \mathrm{O}$ para comprobar la existencia de un efecto cinético isotópico.

Se trabajó a pH muy ácido, de modo que $\left(k_{a} / K_{b} k_{c}\right)\left[\mathrm{H}^{+}\right] \gg 1$ y $\left[\mathrm{H}^{+}\right] \gg K_{1}$, lo 
que implica que la ecuación 4.74 se simplifica en la forma:

$$
\frac{k_{\text {obs }}^{\mathrm{H}_{2} \mathrm{O}}}{k_{\text {obs }}^{\mathrm{D}_{2} \mathrm{O}}}=\frac{K_{2}^{\mathrm{H}_{2} \mathrm{O}}}{K_{2}^{\mathrm{D}_{2} \mathrm{O}}} \frac{k_{\mathrm{c}}^{\mathrm{H}_{2} \mathrm{O}}}{k_{\mathrm{c}}^{\mathrm{D}_{2} \mathrm{O}}}
$$

A pH $=2,1$, los valores de la constante de velocidad $k_{c}^{\mathrm{H}_{2} \mathrm{O}}=0,4202 \mathrm{M}^{-1} \mathrm{~s}^{-1} \mathrm{y}$ $k_{c}^{\mathrm{D}_{2} \mathrm{O}}=0,3264 \mathrm{M}^{-1} \mathrm{~s}^{-1}$. Como $K_{2}^{\mathrm{D}_{2} \mathrm{O}} / K_{2}^{\mathrm{H}_{2} \mathrm{O}}$ se conoce (página 188), resulta que:

$$
\frac{k_{\mathrm{c}}^{\mathrm{H}_{2} \mathrm{O}}}{k_{\mathrm{c}}^{\mathrm{D}_{2} \mathrm{O}}}=3,47
$$

lo que apoya el mecanismo propuesto.

\subsubsection{Influencia de la temperatura}

Como en el caso de la fenetilamina (sección 4.2.9) y tiramina (sección 4.3.7) se estudió la influencia de la temperatura sobre la constante de velocidad $k_{\text {obs }}$. Se trabajó en el intervalo $T=22,5$ y $35,0^{\circ} \mathrm{C}$ en las condiciones que se indican en la tabla 4.27 .

\begin{tabular}{cccc}
\hline$T /{ }^{\circ} \mathrm{C}$ & $k_{\text {obs }} / \mathrm{M}^{-1} \mathrm{~s}^{-1}$ & $T /{ }^{\circ} \mathrm{C}$ & $k_{\text {obs }} / \mathrm{M}^{-1} \mathrm{~s}^{-1}$ \\
\hline 22,5 & $1,812 \cdot 10^{-2}$ & 32,5 & $5,149 \cdot 10^{-2}$ \\
25,0 & $2,523 \cdot 10^{-2}$ & 35,0 & $6,811 \cdot 10^{-2}$ \\
30,0 & $4,048 \cdot 10^{-2}$ & & \\
\hline
\end{tabular}

Tabla 4.27: Influencia de la temperatura en la constante de velocidad. [DOP $]_{\circ}=[\mathrm{NIT}]_{\circ}$ $=6,0 \cdot 10^{-4}-2,01 \cdot 10^{-3} \mathrm{M}, \mathrm{pH}=3,76, I=0,2 \mathrm{M}$

Como muestra la figura 4.53, los resultados se ajustan bien a las ecuaciones de Arrhenius y Eyring. Se obtuvieron los siguientes valores para los parámetros de activación. 
214 | Nitrosación de la dopamina

$$
y=(27 \pm 1)+(79 \pm 2) \cdot 10^{3} x
$$

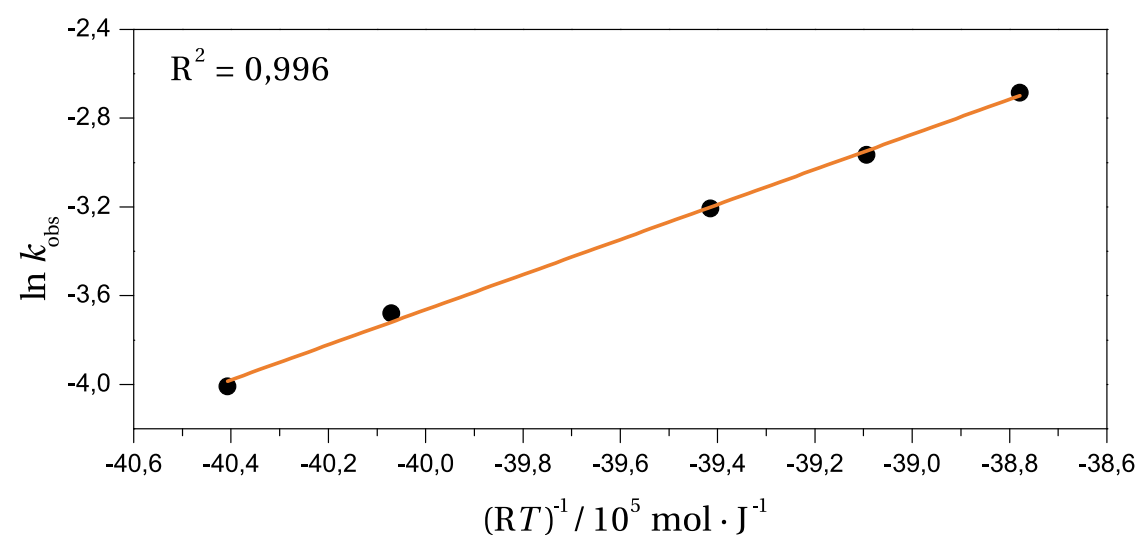

$$
y=(21 \pm 1)+(76 \pm 2) \cdot 10^{3} x
$$

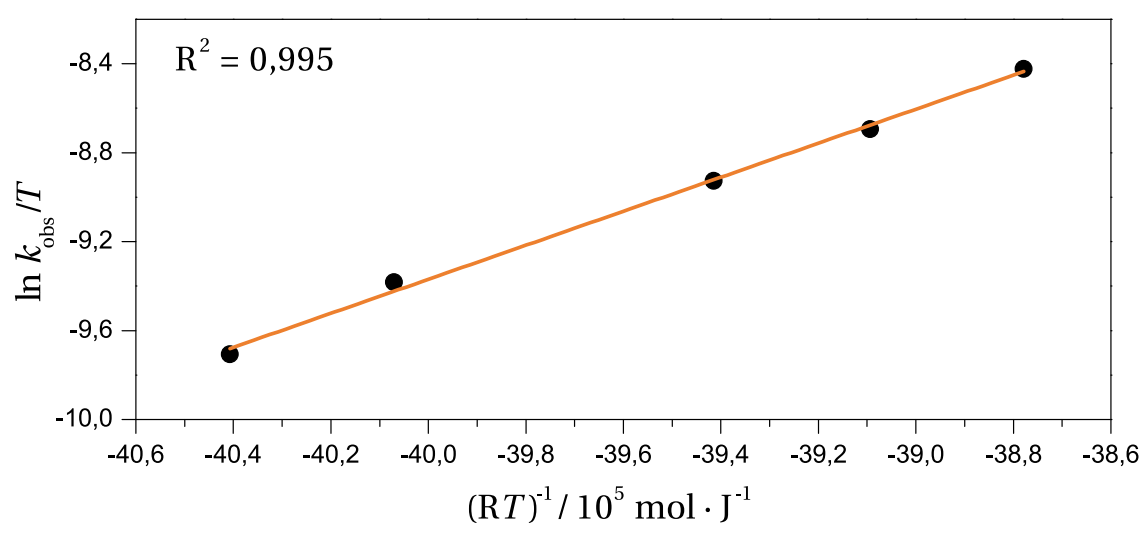

Figura 4.53: Cumplimiento de las ecuaciones de Arrhenius (gráfica superior) y Eyring por los resultados de la tabla 4.27. 


\begin{tabular}{ccc}
\hline$E_{a} / \mathrm{kJ} \mathrm{mol}^{-1}$ & $\Delta H^{\ddagger} / \mathrm{kJ} \mathrm{mol}^{-1}$ & $\Delta S^{\ddagger} / \mathrm{J} \mathrm{K}^{-1} \mathrm{~mol}^{-1}$ \\
\hline $79 \pm 2$ & $76 \pm 2$ & $-20 \pm 8$ \\
\hline
\end{tabular}

Tabla 4.28: Parámetros de activación de la reacción de nitrosación de la dopamina a partir de los datos de la tabla 4.16

\subsubsection{Estructura y reactividad de la dopamina}

De igual modo que con la tiramina (página 191), se ha optimizado mediante cálculos ab initio (DFT-B3LYP 6-31+G (d,p)) la estructura de la dopamina (figura 4.54) para determinar a continuación el mapa de densidad electrónica de la molécula (figura 4.55) con el fin de estimar la posición más favorable para la nitrosación.

Como puede observarse en la figura 4.55, de las tres posiciones en las que se puede nitrosar la dopamina, la que tiene mayor densidad electrónica es el carbono 5 del anillo aromático, situado en posición orto respecto a la cadena lateral del aminoetilo, posición para respecto al alcohol del carbono 2 y posición meta con el alcohol del carbono 1.
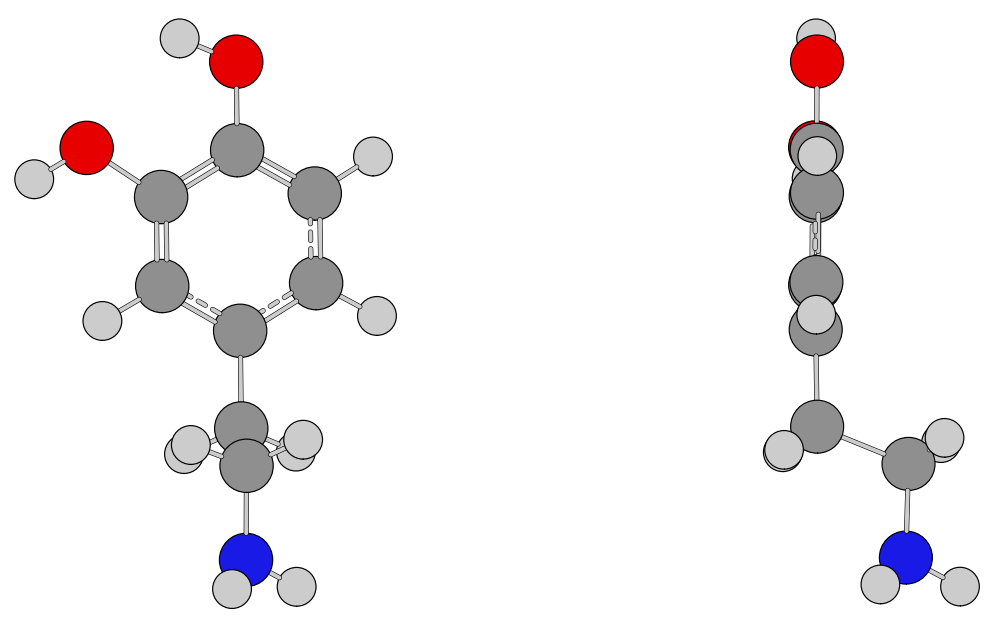

Figura 4.54: Estructura calculada de la dopamina. DFT-B3LYP 6-31+G (d,p). 

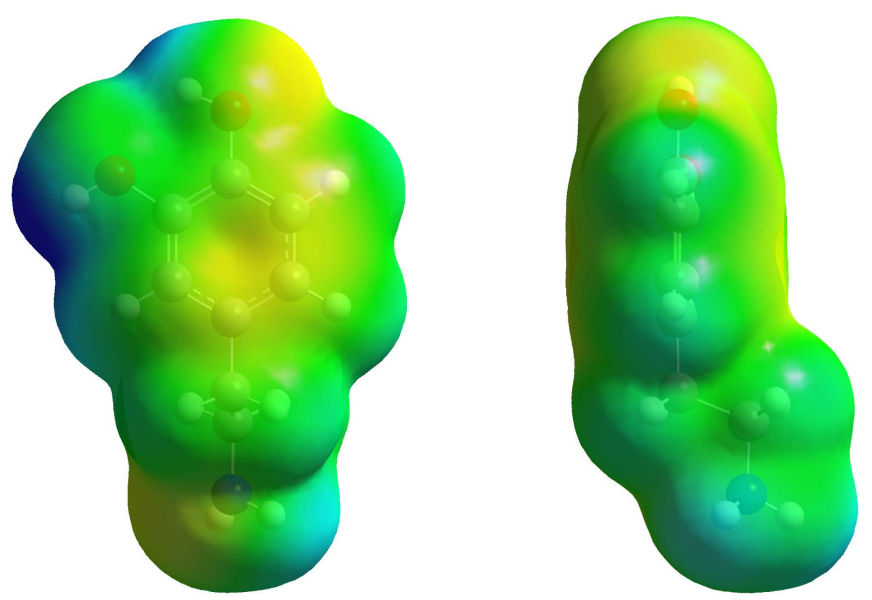

Figura 4.55: Mapa de densidad electrónica de la dopamina. DFT-B3LYP 6-31+G (d,p).

También se calculó qué complejo de Wheland de los tres posibles es el más estable, tomando como referencia la energía de las moléculas de dopamina y del ion nitrosonio. La figura 4.56 muestra que también la posición 5 es la más favorecida, ya que su complejo $\sigma$ es el de menor energía, por lo que es de esperar que la nitrosación de la dopamina se produzca mayoritariamente en esta posición.

\subsubsection{Determinación del producto de reacción}

Mediante espectrometría de masas se ha determinado el producto de la reacción de nitrosación de la dopamina. La figura 4.57 muestra el espectro de masas realizado a una mezcla de dopamina y nitrito sódico tras 24 horas de reacción. Se puede ver cómo el producto mayoritario de la reacción coincide con el peso de la dopamina nitrosada $(\mathrm{m} / \mathrm{z}=182,1)$. Los picos restantes se deben a impurezas puesto que no se pueden asociar a la masa de ningún reactivo ni producto, ni a ningún fragmento de los mismos. No aparece el pico de masa-carga asociado a la masa de la dopamina, 153,08 g/mol, de lo que se deducen dos cosas: en primer lugar, que toda la dopamina ha reaccionado; y en segundo lugar, que la 


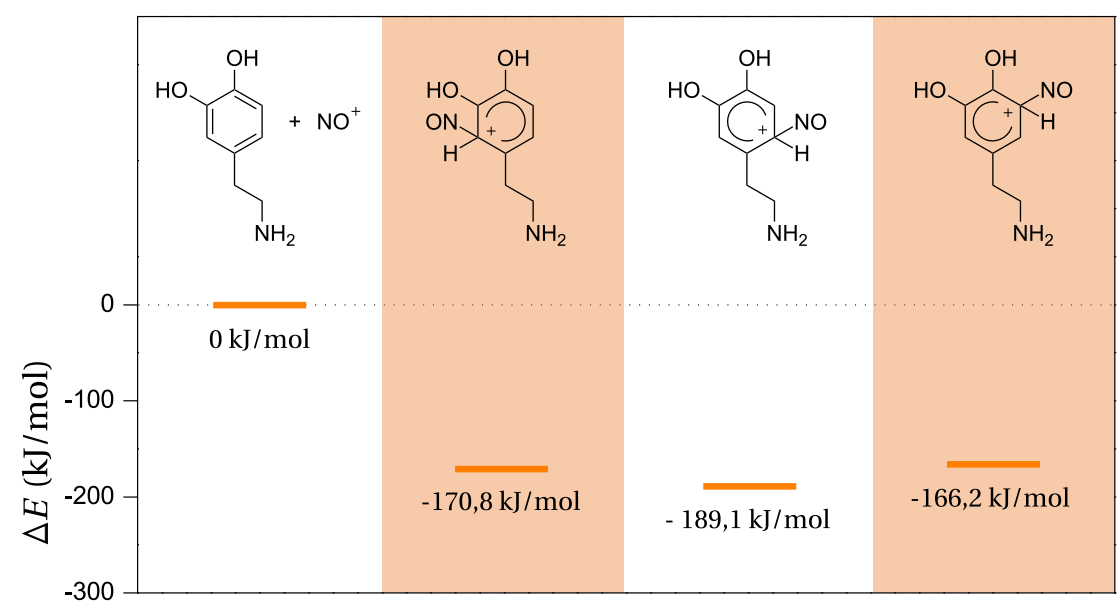

Figura 4.56: Diferencias de energía calculadas para los posibles complejos $\sigma$ de la nitrosación de la dopamina. DFT-B3LYP 6-31+G (d,p).

reacción de N-nitrosación es despreciable puesto que en esa misma relación masa/carga se encontraría el alcohol producido en esta clase de nitrosaciones.

\subsubsection{Actividad biológica de la nitrosodopamina}

\section{Test de Ames}

Mediante el test de Ames se ha estudiado si la nitrosodopamina sintetizada es un compuesto mutágeno. Se han utilizado las cepas TA98 y TA100, en ausencia y presencia de complejo de activación metabólica S9 según se ha descrito en la página 134. Los resultados que se muestran en la tabla 4.29 y representados en las figuras 4.58 y 4.59 apuntan a que la nitrosodopamina no tiene propiedades mutagénicas. En la figura 4.58 se puede ver cómo en el test de Ames para TA98 sin activación aparece un punto sobre $30 \mu \mathrm{g}$ de nitrosodopamina por placa que puede ser significativo y representar una dosis mutagénica. Se ha repetido el test de Ames en las mismas condiciones y con unas dosis cercanas a las de ese 


\section{8 | Nitrosación de la dopamina}

punto para refutar esta suposición. El resultado de este experimento se muestra en la tabla 4.30 y la figura 4.60 , donde se puede ver que la nitrosodopamina, en ese intervalo de dosis, no tiene una respuesta significativa para el test de Ames.

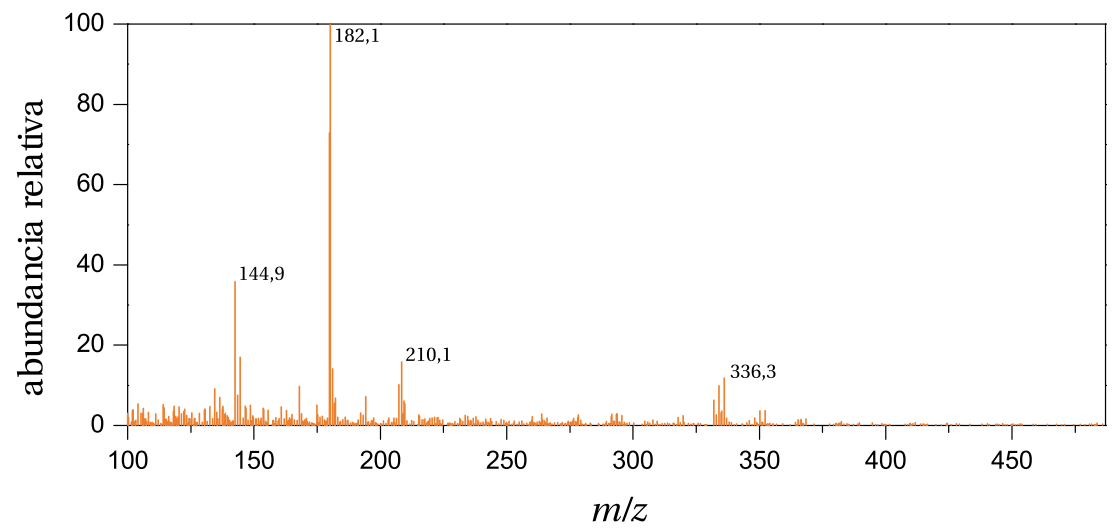

Figura 4.57: Espectro de masas por impacto electrónico positivo de la dopamina nitrosada.

\begin{tabular}{ccccc}
\hline$\mu \mathrm{g}$ NDOP / placa & TA98 & TA98 + S9 & TA100 & TA100 + S9 \\
\hline control negativo & $12 \pm 2$ & $28 \pm 2$ & $194 \pm 9$ & $80 \pm 10$ \\
10 & 17 & $29 \pm 0$ & $197 \pm 16$ & $79 \pm 2$ \\
30 & 24 & $28 \pm 2$ & $200 \pm 27$ & $80 \pm 4$ \\
100 & 18 & 29 & 175 & 75 \\
300 & $18 \pm 4$ & $28 \pm 2$ & 203 & 82 \\
1000 & $19 \pm 0$ & $31 \pm 4$ & $170 \pm 5$ & $79 \pm 6$ \\
control positivo & $404 \pm 2$ & 426 & 1.209 & $740 \pm 10$ \\
\hline
\end{tabular}

Tabla 4.29: Resultados del test de Ames aplicado a la nitrosodopamina. Controles positivos: TA98: $10 \mu \mathrm{g}$ NPD, TA98 + S9: $2 \mu \mathrm{g}$ 2AA, TA100: 0,3 $\mu \mathrm{g}$ 4NQO y TA100 + S9 $2 \mu \mathrm{g}$ 2AA. 


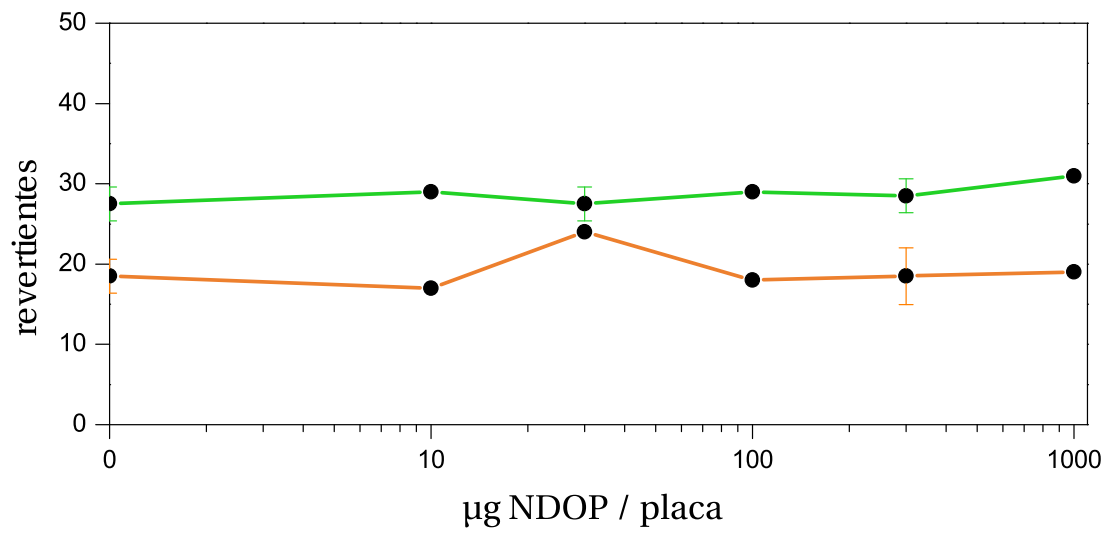

Figura 4.58: Test de Ames de la nitrosodopamina TA98. Los resultados sin extracto S9 se muestran de color naranja y los resultados con extracto $\$ 9$, de color verde.

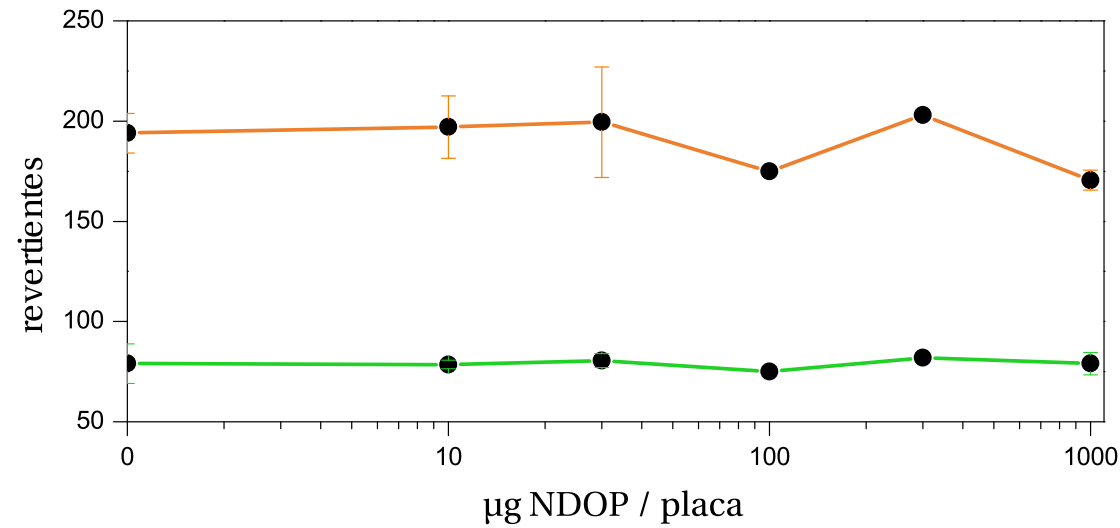

Figura 4.59: Test de Ames de la nitrosodopamina TA100. Los resultados sin extracto S9 se muestran de color naranja y los resultados con extracto \$9, de color verde. 


\begin{tabular}{cc}
\hline$\mu \mathrm{g}$ NDOP / placa & TA98 \\
\hline control negativo & $17,5 \pm 0,7$ \\
20 & 17 \\
40 & 20 \\
60 & 19 \\
80 & $18 \pm 1$ \\
control positivo & 365 \\
\hline
\end{tabular}

Tabla 4.30: Test de Ames de la nitrosodopamina. Control positivo: TA98: $10 \mu \mathrm{g}$ NPD.

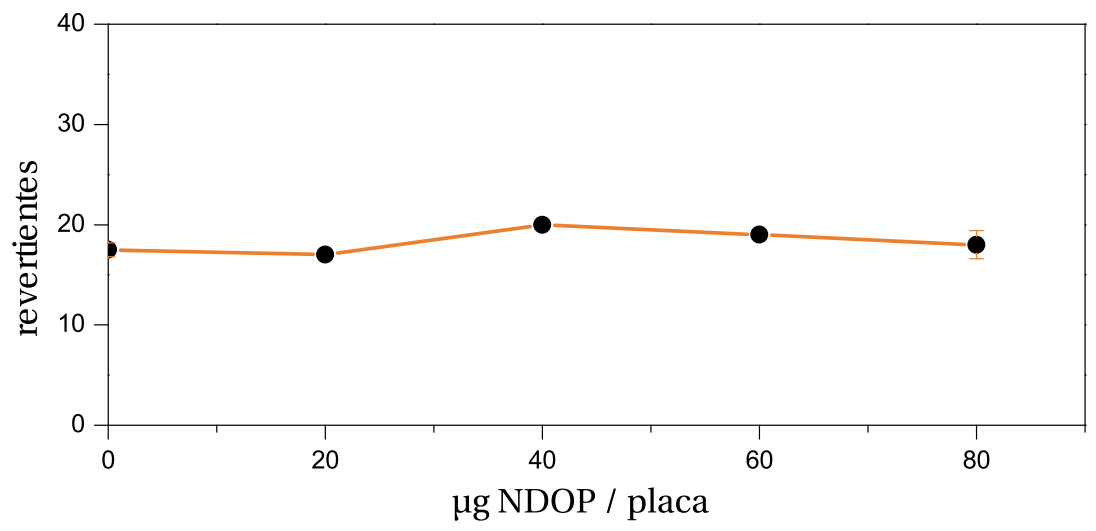

Figura 4.60: Test de Ames de la nitrosodopamina TA98. 
Test de aberraciones cromosómicas

En la tabla 4.31 se puede ver cómo la nitrosodopamina ha sido incapaz de crear alguna aberración cromosómica en las células V-79 tras seguir el procedimiento descrito en la página 139. Esto quiere decir que la nitrosodopamina no es un compuesto genotóxico, al menos hasta la concentración que la solubilidad del compuesto en DMSO ha permitido medir $\left(5,5 \cdot 10^{-3} \mathrm{M}\right)$.

\begin{tabular}{ccccccc}
\hline [NDOP] / $\mu \mathrm{M}$ & CTG & CSG & CTB & CSB & ACENT & DIC \\
\hline control negativo & 0 & 0 & 0 & 0 & 0 & 0 \\
5,5 & 0 & 0 & 0 & 0 & 0 & 0 \\
55 & 0 & 0 & 0 & 0 & 0 & 0 \\
550 & 0 & 0 & 0 & 0 & 0 & 0 \\
5.500 & \multicolumn{7}{c}{ Concentración tóxica para las células } \\
control positivo & 8 & 4 & 28 & 14 & 0 & 0 \\
\hline [NDOP] / $\mu \mathrm{M}$ & TRI & TET & OTRO & RING & MA & $\%$ AC \\
\hline control negativo & 0 & 0 & 0 & 0 & 0 & 0 \\
5,5 & 0 & 0 & 0 & 0 & 0 & 0 \\
55 & 0 & 0 & 0 & 0 & 0 & 0 \\
550 & 0 & 0 & 0 & 0 & 0 & 0 \\
5.500 & \multicolumn{7}{c}{ Concentración tóxica para las células } \\
control positivo & 16 & 2 & 0 & 4 & 0 & 42 \\
\hline
\end{tabular}

Tabla 4.31: Aberraciones cromosómicas inducidas por la nitrosodopamina en células eucariotas V-79. Las abreviaturas son: CTG, hueco en la cromátida; CSG, hueco en el cromosoma; CTB, ruptura en la cromátida; CSB, ruptura en el cromosoma; ACENT, fragmento acéntrico; DIC, cromosoma dicéntrico; TRI, cromosoma trirradial; TETRA, cromosoma tetrarradial, OTRO, otra aberración; RING, cromosoma anular; MA, metafase multiaberrante; \% AC, \% de células aberrantes, excluyendo CTG y CSG. Control positivo: MMC 1,5 $\mu \mathrm{M}$. 


\section{Test del MTT}

La figura 4.61 muestra la supervivencia de las células V-79 tras 24 horas de exposición a diferentes concentraciones de nitrosocompuesto. Se puede ver que este compuesto es más citotóxico que la nitrosotiramina, ya que a concentraciones similares de compuesto, la nitrosodopamina puede provocar la muerte en el $40 \%$ de las células del frasco. Gracias a los datos obtenidos ha sido posible calcular extrapolando la concentración que mataría a la mitad de las células del experimento, denominada concentración inhibitoria media $\left(\mathrm{IC}_{50}\right)$. Para la nitrosodopamina, en estas condiciones, el valor aproximado de $\mathrm{IC}_{50}$ es $3,4 \cdot 10^{-3} \mathrm{M}$.

\begin{tabular}{ccc}
\hline & {$[$ NDOP] $/ \mu \mathrm{M}$} & Supervivencia \\
\hline $\mathrm{a}$ & 82,5 & $(102 \pm 4) \%$ \\
$\mathrm{~b}$ & 275 & $(97 \pm 6) \%$ \\
$\mathrm{c}$ & 825 & $(85 \pm 8) \%$ \\
$\mathrm{~d}$ & 2.800 & $(60 \pm 5) \%$ \\
\hline
\end{tabular}

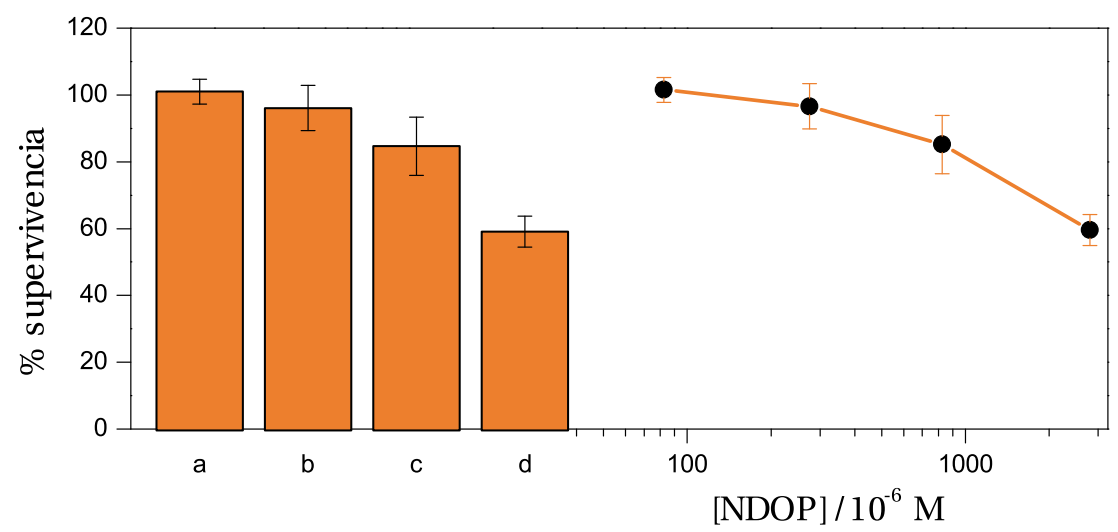

Tabla 4.32 y Figura 4.61: Supervivencia celular de V-79 en función de la concentración de nitrosodopamina. 


\subsection{Nitrosación de la serotonina}

\subsubsection{Estudio espectrofotométrico}

El hidrocloruro de serotonina es la forma comercial de este neurotransmisor. Se ha comprobado que su solubilidad es muy adecuada para un estudio cinético de nitrosación. La figura 4.62 muestra los espectros de absorción de diferentes concentraciones de este compuesto.

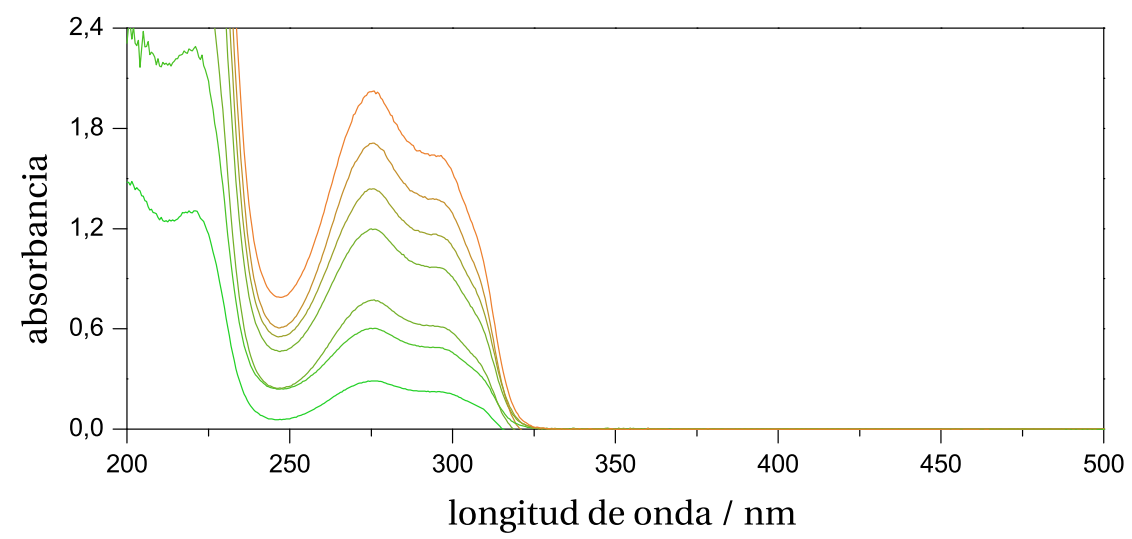

Figura 4.62: Espectro de absorción de la serotonina. $[\mathrm{SER}]=6,43 \cdot 10^{-5}-3,64 \cdot 10^{-4} \mathrm{M}, \mathrm{pH}$ $=3,2, T=20,0^{\circ} \mathrm{C}$.

Las dos bandas de absorción que presenta la disolución de serotonina (SER) entre 250 y $325 \mathrm{~nm}$ una, y otra, más energética, con una banda que llega hasta $245 \mathrm{~nm}$, son características de los indoles, aunque la presencia de un alcohol en su estructura desplaza las bandas hacia posiciones menos energéticas. A pH ácido la segunda banda muestra dos picos diferenciados y solapados con máximos en $275 \mathrm{~nm}$, el más intenso y en $296 \mathrm{~nm}$ el más débil. Los coeficientes de extinción molar de estos picos se han calculado mediante la ecuación de Lambert-Beer (página 154) según muestra la figura 4.63.

$$
\varepsilon_{\mathrm{SER}, 275 \mathrm{~nm}}=5.600 \pm 200 \mathrm{M}^{-1} \mathrm{~cm}^{-1}
$$


224 | Nitrosación de la serotonina

\begin{tabular}{cccccc}
\hline$[\mathrm{SER}] / \mathrm{M}$ & $A_{275}$ & $A_{296}$ & {$[\mathrm{SER}] / \mathrm{M}$} & $A_{275}$ & $A_{296}$ \\
\hline $6,43 \cdot 10^{-5}$ & 0,287 & 0,225 & $2,57 \cdot 10^{-4}$ & 1,435 & 1,158 \\
$1,07 \cdot 10^{-4}$ & 0,603 & 0,489 & $3,21 \cdot 10^{-4}$ & 1,709 & 1,369 \\
$1,50 \cdot 10^{-4}$ & 0,771 & 0,614 & $3,64 \cdot 10^{-4}$ & 2,020 & 1,633 \\
$2,14 \cdot 10^{-4}$ & 1,198 & 0,968 & & & \\
\hline
\end{tabular}

$$
\begin{aligned}
& y=-(0,04 \pm 0,03)+(5.600 \pm 200) x \\
& y=-(0,03 \pm 0,03)+(4.500 \pm 100) x
\end{aligned}
$$

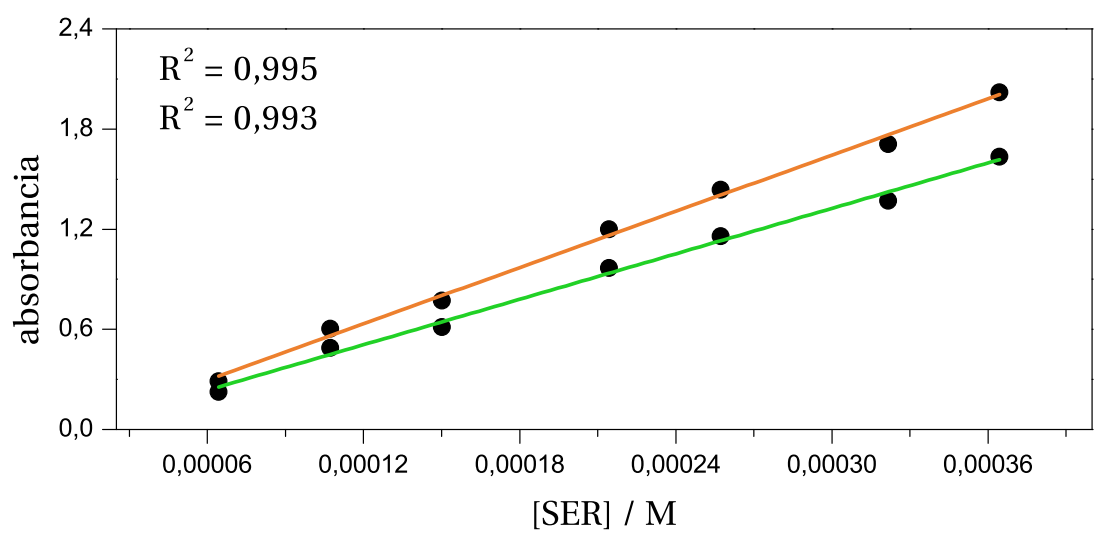

Tabla 4.33 y Figura 4.63: Cumplimiento de la ley de Lambert-Beer por la serotonina. $\lambda$ $=296 \mathrm{~nm}$ (verde), $\lambda=275 \mathrm{~nm}$ (naranja), $\mathrm{pH}=3,2, T=20,0^{\circ} \mathrm{C}$.

$$
\varepsilon_{\mathrm{SER}, 296 \mathrm{~nm}}=4.500 \pm 100 \mathrm{M}^{-1} \mathrm{~cm}^{-1}
$$

El alcohol de la serotonina, unido a un grupo aromático, tiene un $\mathrm{pK}_{\mathrm{a}}=$ 10,73. Al aumentar la basicidad del medio, su protón se pierde, haciendo que la carga negativa del grupo alcoxi se distribuya por el indol desplazando sus bandas de absorción, debidas a las transiciones $\pi \rightarrow \pi^{*}$, hacia posiciones menos energéticas. Como la amina se encuentra alejada del anillo aromático por dos carbonos alifáticos, apenas tiene influencia en la forma en la que la molécula 


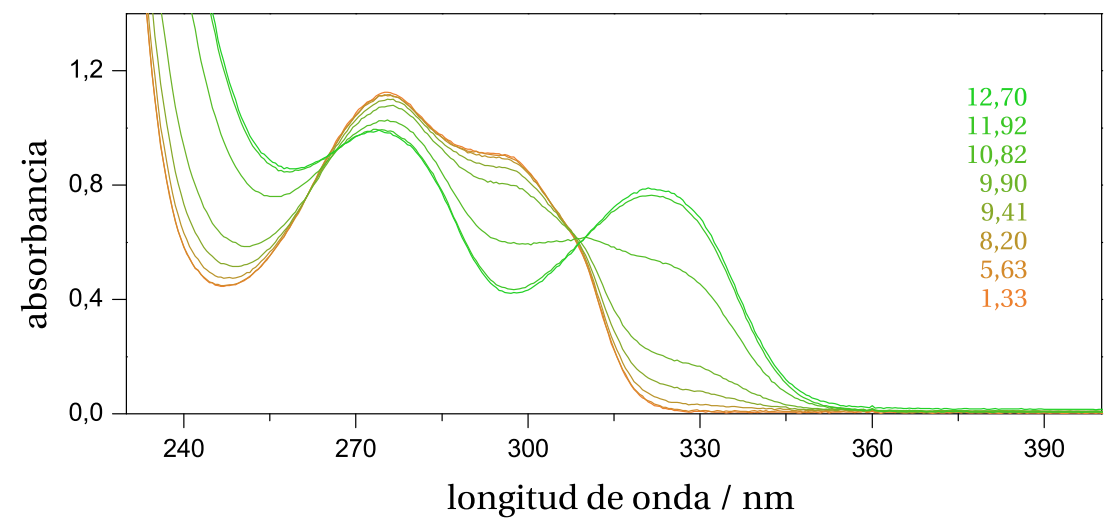

Figura 4.64: Variación del espectro de absorción de la serotonina según el pH. $[\mathrm{SER}]=2,14 \cdot 10^{-4} \mathrm{M}, T=20,0^{\circ} \mathrm{C}$.

absorbe.

Mediante el procedimiento descrito en la sección 3.1.2.3, se estudió la variación en el espectro de la serotonina con el pH (figura 4.64). Al aumentar el pH, el pico con el máximo en $275 \mathrm{~nm}$ no cambia, el pico en $296 \mathrm{~nm}$ desaparece y aparece un nuevo pico centrado en $322 \mathrm{~nm}$. También se desplaza hacia posiciones menos energéticas la banda ultravioleta del espectro. El espectro de absorción tiene dos puntos isosbésticos en $265 \mathrm{~nm}$ y $308 \mathrm{~nm}$, que no son interesantes desde el punto de vista cinético, puesto que no existe un cambio en el espectro hasta un $\mathrm{pH}$ superior a 8 .

\subsubsection{Reacción entre serotonina y nitrito}

El seguimiento de los espectros de absorción de una mezcla serotoninanitrito sódico en medio ácido muestra que la reacción que se produce entre ambos es muy rápida. La figura 4.65 ilustra los cambios de esos espectros a lo largo del tiempo de reacción (a los 60 minutos ya ha transcurrido el $80 \%$ de la misma).

La reacción se ha seguido cinéticamente (figura 4.66) en $\lambda=371 \mathrm{~nm}$, que 


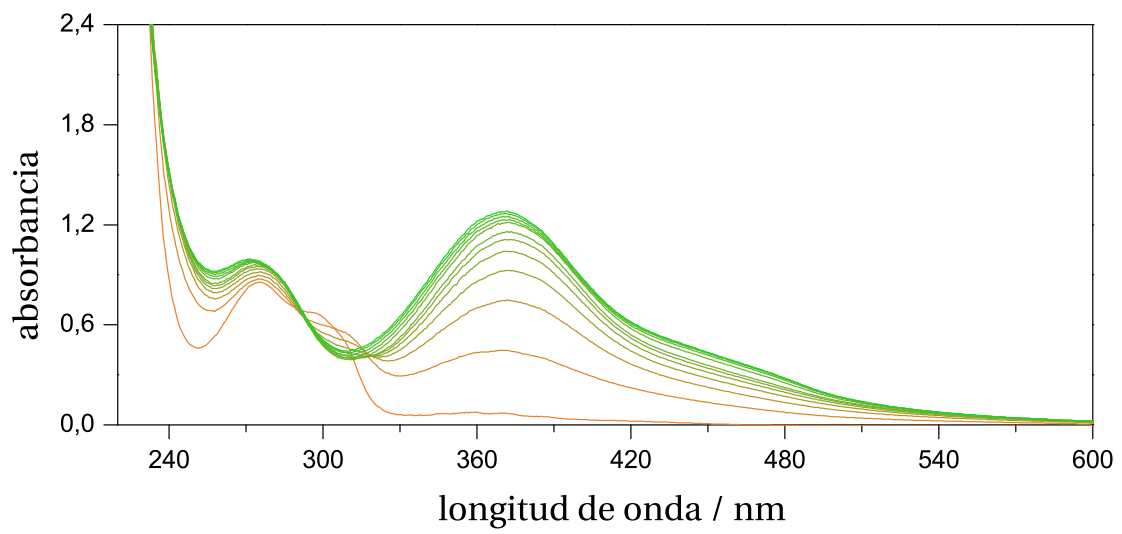

Figura 4.65: Variación con el tiempo del espectro de absorción de la fenetilamina durante su nitrosación. Los primeros seis espectros han sido tomados cada 10 minutos. El resto cada 40 minutos. $[\mathrm{SER}]=3,03 \cdot 10^{-4} \mathrm{M}$, [NIT] $=3,01 \cdot 10^{-3}, \mathrm{pH}=3,90, T=20,0^{\circ} \mathrm{C}$.

corresponde al máximo de absorción del producto de nitrosación, por su gran intensidad y porque coincide con la longitud de onda del sistema ácido nitroso/nitrito, estudiado con anterioridad (sección 4.2.4).

Para determinar el coeficiente de absorción molar de la nitrososerotonina (figura 4.66) se trabajó con disoluciones de seis concentraciones de serotonina. Se observa que, aunque la absorbancia crece rápidamente, no se alcanza una meseta sino que continúa creciendo, aunque lentamente. Como este comportamiento sugiere un mecanismo de reacciones consecutivas, ello se ha interpretado a través de una segunda nitrosación (véase sección 4.5.11):

$$
\text { SER } \left.\underset{\left(k_{\mathrm{obs}, 1}\right)}{\stackrel{\mathrm{HNO}_{2}}{\longrightarrow}} \text { SER-NO } \underset{\left(k_{\mathrm{obs}, 2}\right)}{\stackrel{\mathrm{HNO}_{2}}{\longrightarrow}} \text { SER-(NO) }\right)_{2}
$$

\subsubsection{Tratamiento cinético de reacciones consecutivas}

El tratamiento cinético de reacciones consecutivas es de cierta complejidad desde el punto de vista matemático, especialmente en reacciones de orden dos o tres, como son las de nitrosación en las que el agente nitrosante es el ion 


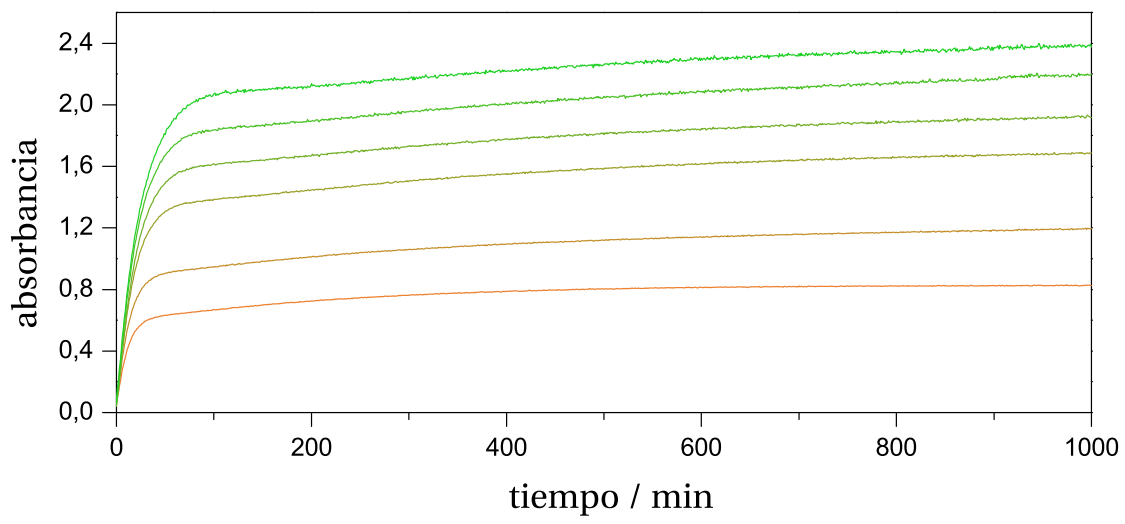

Figura 4.66: Variación de la absorbancia con el tiempo durante la nitrosación de la serotonina. $\lambda=371 \mathrm{~nm}$, $[\mathrm{SER}]=3,78 \cdot 10^{-5}-1,28 \cdot 10^{-4} \mathrm{M}$, $[\mathrm{NIT}]=3,01 \cdot 10^{-3}, \mathrm{pH}=3,92$, $T=20,0^{\circ} \mathrm{C}$.

nitrosonio/nitrosacidio o el trióxido de dinitrógeno (páginas 55 y 59).

La forma más común de solventar este problema consiste en aumentar la concentración de uno de los reactivos para, mediante el método de aislamiento, crear una sucesión de reacciones de pseudoorden uno. ${ }^{258}$ En el caso de la serotonina, el nitrito ha sido el reactivo que se ha puesto en exceso, ya que al comienzo del estudio cinético no se conocía su orden parcial. Con esta simplificación, el tratamiento matemático de dos reacciones consecutivas de orden uno es asequible. Por simplicidad, se muestra la secuencia de la ecuación 4.82 de la siguiente forma:

$$
\mathrm{A} \stackrel{k_{1}}{\longrightarrow} \mathrm{B} \stackrel{k_{2}}{\longrightarrow} \mathrm{C}
$$

Para calcular los parámetros cinéticos de estas reacciones, en primer lugar hay que conocer las velocidades de formación y desaparición de cada uno de los compuestos que en ellas participan.

La velocidad de desaparición de la serotonina, A, está regida por la constante de velocidad $k_{1}$ :

$$
-\frac{d[\mathrm{~A}]}{d t}=k_{1}[\mathrm{~A}]
$$




\section{8 | Nitrosación de la serotonina}

La serotonina mononitrosada, B, después de formarse, puede volver a nitrosarse y desaparecer:

$$
\frac{d[\mathrm{~B}]}{d t}=k_{1}[\mathrm{~A}]-k_{2}[\mathrm{~B}]
$$

En esta ecuación, $k_{1}[\mathrm{~A}]$ representa la formación de $\mathrm{B}$ a partir de $\mathrm{A}$ y el término $k_{2}[\mathrm{~B}]$ representa la transformación de B en C. La velocidad de formación de la dinitrososerotonina, C, se calcula mediante la ecuación:

$$
-\frac{d[\mathrm{C}]}{d t}=k_{2}[\mathrm{~B}]
$$

La ecuación 4.83 representa un proceso de primer orden. Reordenando la ecuación e integrando

$$
\int-\frac{d[\mathrm{~A}]}{[\mathrm{A}]}=\int k_{1} d t
$$

se obtiene cómo varía la concentración de serotonina en el tiempo:

$$
[\mathrm{A}]=[\mathrm{A}]_{\circ} e^{-k_{1} t}
$$

donde $[\mathrm{A}]_{\text {。 }}$ es la concentración inicial de serotonina, que se convertirá en los distintos compuestos:

$$
[\mathrm{A}]_{\circ}=[\mathrm{A}]+[\mathrm{B}]+[\mathrm{C}]
$$

Para conocer la concentración de B se puede utilizar la solución de la ecuación 4.83:

$$
\frac{d[\mathrm{~B}]}{d t}=k_{1}[\mathrm{~A}]_{\circ} e^{-k_{1} t}-k_{2}[\mathrm{~B}]
$$

Reordenando los términos de esta ecuación se observa que se trata de una ecuación diferencial lineal de primer orden:

$$
\frac{d[\mathrm{~B}]}{d t}+k_{2}[\mathrm{~B}]=k_{1}[\mathrm{~A}]_{\circ} e^{-k_{1} t}
$$

Para resolverla se puede multiplicar en ambos lados de la ecuación por el factor integrador $e^{k_{2} t}$

$$
\left(\frac{d[\mathrm{~B}]}{d t}+k_{2}[\mathrm{~B}]\right) e^{k_{2} t}=k_{1}[\mathrm{~A}]_{\circ} e^{-k_{1} t} e^{k_{2} t}
$$


y simplificar:

$$
\frac{d[\mathrm{~B}]}{d t} e^{k_{2} t}+k_{2}[\mathrm{~B}] e^{k_{2} t}=k_{1}[\mathrm{~A}]_{\circ} e^{\left(k_{2}-k_{1}\right) t}
$$

La parte izquierda de la ecuación es igual a:

$$
\frac{d[\mathrm{~B}]}{d t} e^{k_{2} t}+k_{2}[\mathrm{~B}] e^{k_{2} t}=\frac{d\left([\mathrm{~B}] e^{k_{2} t}\right)}{d t}
$$

Así que sustituyendo en la ecuación 4.92:

$$
\frac{d\left([\mathrm{~B}] e^{k_{2} t}\right)}{d t}=k_{1}[\mathrm{~A}]_{\circ} e^{\left(k_{2}-k_{1}\right) t}
$$

e integrando:

$$
\int \frac{d\left([\mathrm{~B}] e^{k_{2} t}\right)}{d t} d t=\int k_{1}[\mathrm{~A}]_{\circ} e^{\left(k_{2}-k_{1}\right) t} d t
$$

se obtiene la solución de la ecuación:

$$
[\mathrm{B}] e^{k_{2} t}=\frac{k_{1}}{k_{2}-k_{1}}[\mathrm{~A}]_{\odot} e^{\left(k_{2}-k_{1}\right) t}+D
$$

Donde $D$ es una constante de integración. Para calcular su valor, tras despejar la concentración de B,

$$
[\mathrm{B}]=\frac{k_{1}}{k_{2}-k_{1}} e^{-k_{1} t}[\mathrm{~A}]_{\circ}+D e^{-k_{2} t}
$$

se calcula la concentración inicial de B a tiempo cero. De esta forma, la ecuación anterior queda de la siguiente manera:

$$
[\mathrm{B}]_{\circ}=\frac{k_{1}[\mathrm{~A}]_{\circ}}{k_{2}-k_{1}}+D
$$

Despejando D y sustituyendo en 4.97:

$$
[\mathrm{B}]=\frac{k_{1}}{k_{2}-k_{1}}[\mathrm{~A}]_{\circ}\left(e^{-k_{1} t}-e^{-k_{2} t}\right)+[\mathrm{B}]_{\circ} e^{-k_{2} t}
$$

En esta ecuación, el primer término del lado derecho representa la mononitrososerotonina que hay en el medio tras su formación a través de la nitrosación de 


\section{0 | Nitrosación de la serotonina}

la serotonina y la posterior desaparición por otra nitrosación, mientras que el segundo término describe la mononitrososerotonina que está presente inicialmente. Como esta cantidad es cero, la expresión anterior se puede simplificar:

$$
[\mathrm{B}]=\frac{k_{1}[\mathrm{~A}]_{\circ}}{k_{2}-k_{1}}\left(e^{-k_{1} t}-e^{-k_{2} t}\right)
$$

Para la segunda reacción, la formación de dinitrososerotonina (C) a partir de mononitrososerotonina, la ecuación vuelve a ser la de un proceso de primer orden, por lo que su solución es inmediata:

$$
[\mathrm{C}]=[\mathrm{A}]_{\circ}\left(1-\frac{1}{k_{2}-k_{1}}\left(k_{2} e^{-k_{1} t}-k_{1} e^{-k_{2} t}\right)\right)
$$

Calculadas las concentraciones de cada uno de los compuestos de las reacciones consecutivas se procedió a ajustar estas ecuaciones a los resultados experimentales. En $\lambda 371 \mathrm{~nm}$, sólo absorben los compuestos B y C. Como:

$$
\begin{aligned}
& A_{\mathrm{B}}=\varepsilon_{\mathrm{B}} l[\mathrm{~B}] \\
& A_{\mathrm{C}}=\varepsilon_{\mathrm{C}} l[\mathrm{C}]
\end{aligned}
$$

se puede deducir la absorbancia a lo largo del tiempo de la reacción:

$$
A=\varepsilon_{\mathrm{B}} l \frac{k_{1}[\mathrm{~A}]_{\circ}}{k_{2}-k_{1}}\left(e^{-k_{1} t}-e^{-k_{2} t}\right)+\varepsilon_{\mathrm{C}}[\mathrm{A}]_{\circ}\left(1-\frac{1}{k_{2}-k_{1}}\left(k_{2} e^{-k_{1} t}-k_{1} e^{-k_{2} t}\right)\right)
$$

Para comprobar que el mecanismo de reacciones consecutivas propuesto encaja con las curvas cinéticas medidas en la nitrosación de la serotonina, se realizaron varios experimentos a diferentes pHs, ajustándolos a la ecuación 4.104. Las figuras 4.67, 4.68 y 4.69 muestran el ajuste de los datos experimentales y la absorbancia de los compuestos $\mathrm{B}$ y $\mathrm{C}$ a lo largo del tiempo. Como el ajuste es excelente, se decidió seguir las reacciones de nitrosación por este método de trabajo. 

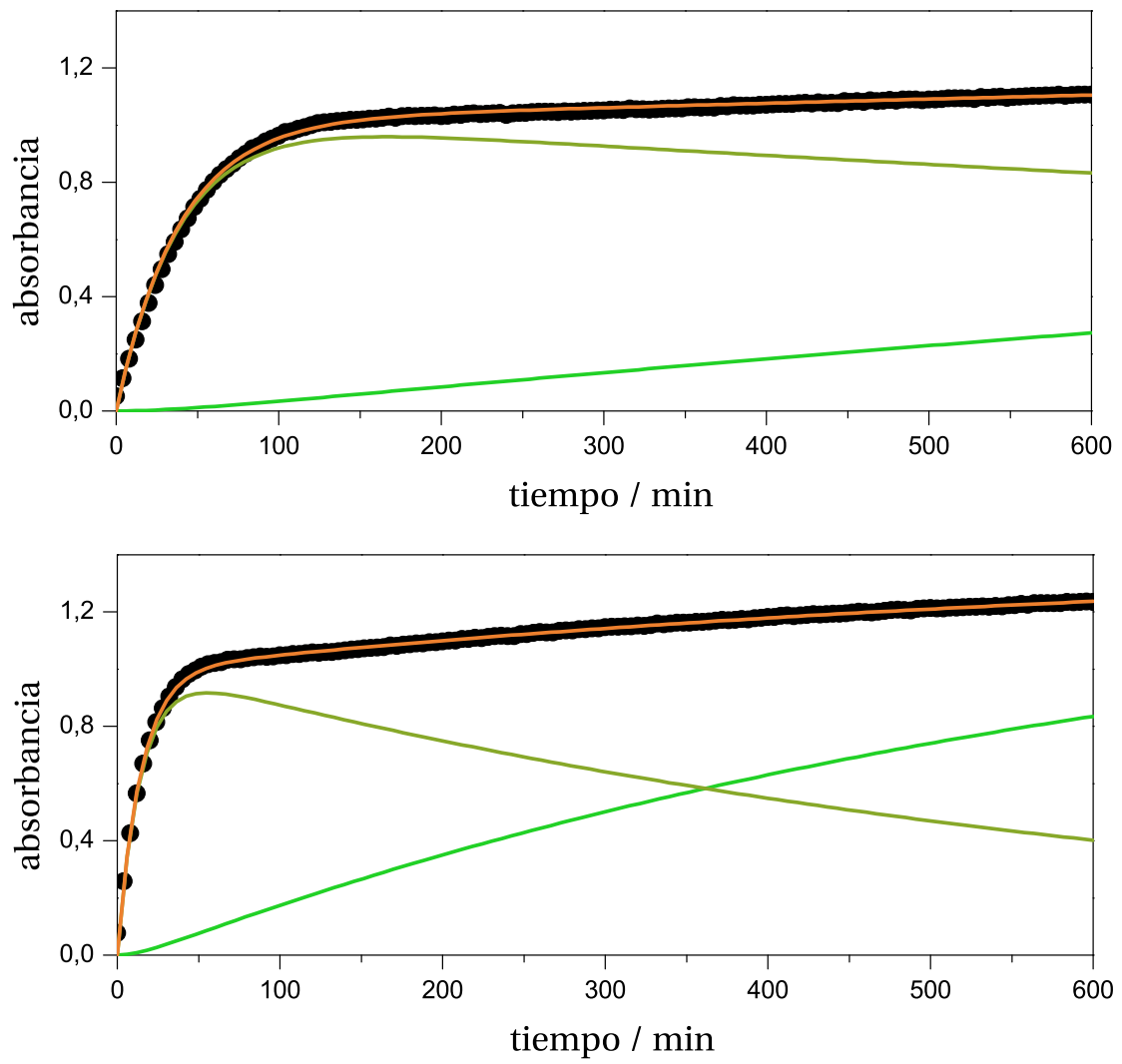

Figura 4.67: Ajuste de las cinéticas a la ecuación 4.104. La absorbancia total, $A$, se muestra de color naranja, $\mathrm{A}_{\mathrm{B}}$ de color pardo y $\mathrm{A}_{\mathrm{C}}$ de color verde. $\mathrm{pH}=4,05$ (gráfica superior) y 3,77 (gráfica inferior), $[\mathrm{SER}]=1,31 \cdot 10^{-4} \mathrm{M},[\mathrm{NIT}]=3,02 \cdot 10^{-3}, T=20,0^{\circ} \mathrm{C}$. 

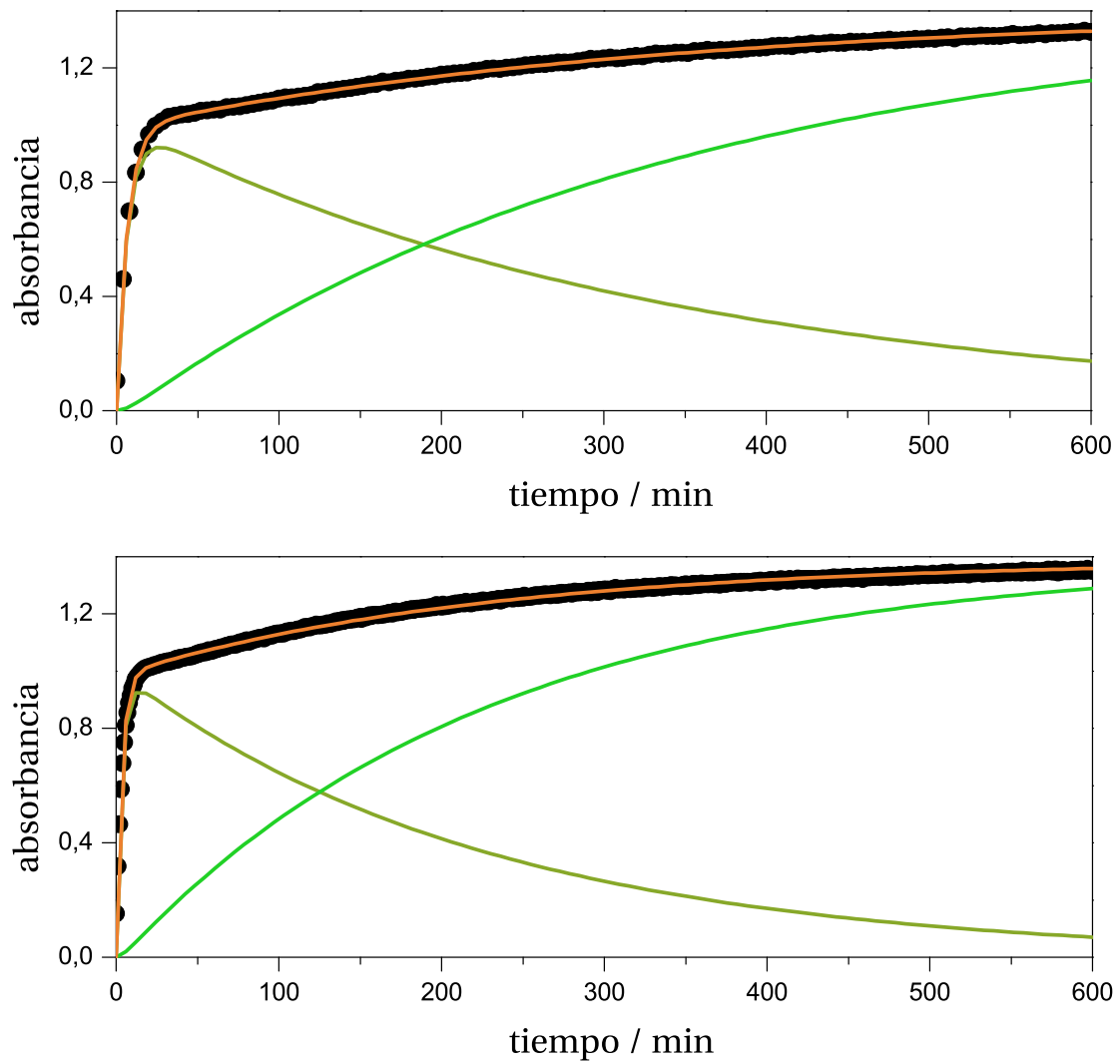

Figura 4.68: Ajuste de las cinéticas a la ecuación 4.104. La absorbancia total, $A$, se muestra de color naranja, $A_{B}$ de color pardo y $A_{C}$ de color verde. $\mathrm{pH}=3,54$ (gráfica superior) y 3,32 (gráfica inferior), $[\mathrm{SER}]=1,31 \cdot 10^{-4} \mathrm{M}$, $[\mathrm{NIT}]=3,02 \cdot 10^{-3}, T=20,0^{\circ} \mathrm{C}$. 

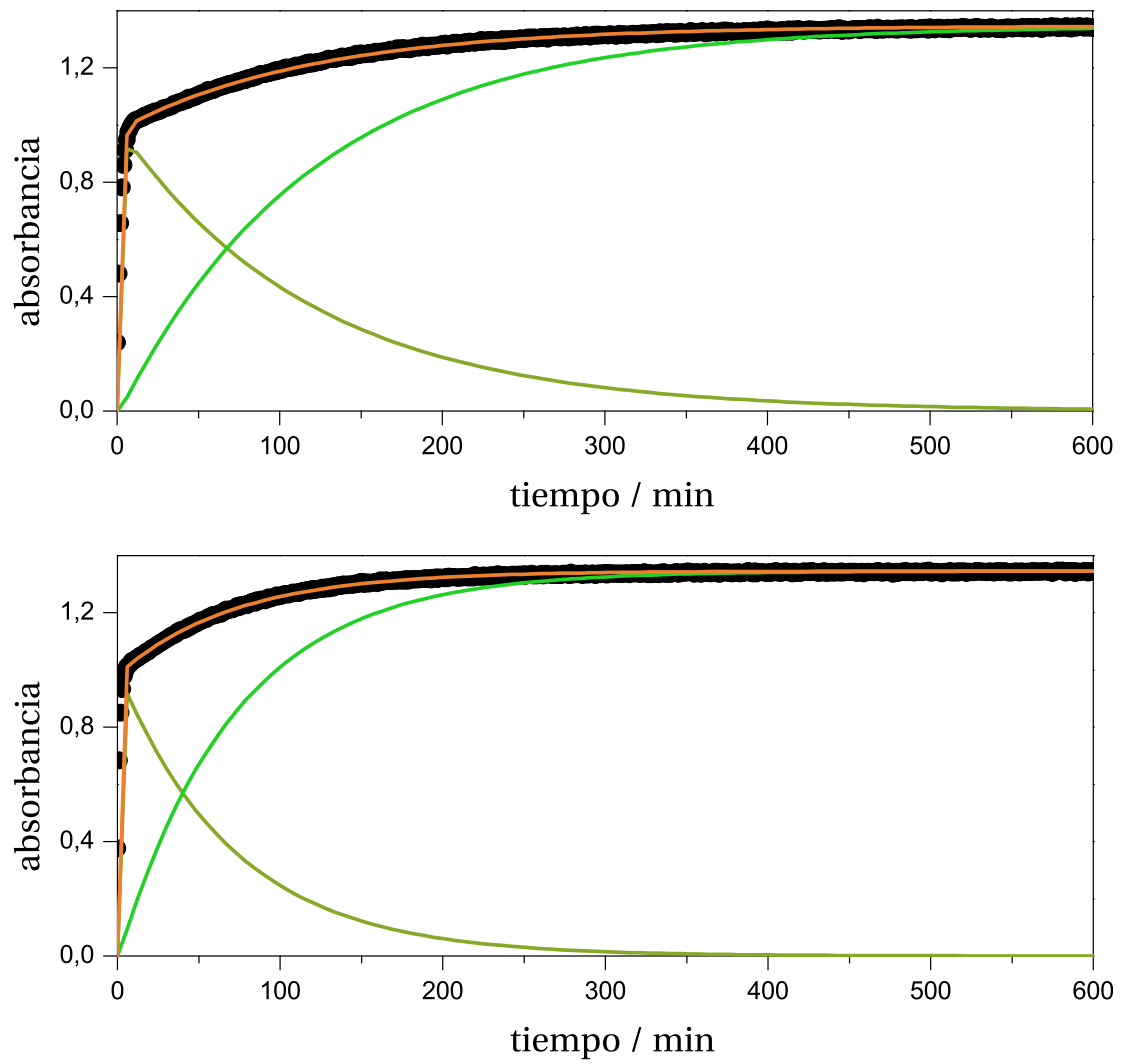

Figura 4.69: Ajuste de las cinéticas a la ecuación 4.104. La absorbancia total, $A$, se muestra de color naranja, $\mathrm{A}_{\mathrm{B}}$ de color pardo y $\mathrm{A}_{\mathrm{C}}$ de color verde. $\mathrm{pH}=3,12$ (gráfica superior) y 2,88 (gráfica inferior), $[\mathrm{SER}]=1,31 \cdot 10^{-4} \mathrm{M}$, $[\mathrm{NIT}]=3,02 \cdot 10^{-3}, T=20,0^{\circ} \mathrm{C}$. 


\subsubsection{Coeficientes de absorción molar}

La ecuación 4.104 tiene cuatro variables: $\varepsilon_{\mathrm{B}}, \varepsilon_{\mathrm{C}}, k_{1}\left(k_{\mathrm{obs}, 1}\right)$ y $k_{2}\left(k_{\mathrm{obs}, 2}\right)$. Los ajustes matemáticos permiten calcular con una incertidumbre moderada sus valores. Para simplificar los cálculos y reducir el número de variables y el error de los ajustes posteriores, se han determinado los coeficientes de extinción molar preparando seis experimentos en los que se modificaron las concentración de serotonina mientras se mantenían constantes la concentración de nitrito y el resto de los parámetros termodinámicos como $\mathrm{pH}$, fuerza iónica y temperatura.

\begin{tabular}{cccccc}
\hline$[\mathrm{SER}] / \mathrm{M}$ & $A_{B}$ & $A_{C}$ & {$[\mathrm{SER}] / \mathrm{M}$} & $A_{B}$ & $A_{C}$ \\
\hline $9,02 \cdot 10^{-5}$ & 0,6545 & 0,9384 & $1,805 \cdot 10^{-4}$ & 1,3478 & 1,8479 \\
$1,203 \cdot 10^{-4}$ & 0,8830 & 1,2515 & $2,106 \cdot 10^{-4}$ & 1,5567 & 2,1435 \\
$1,504 \cdot 10^{-4}$ & 1,0951 & 1,5328 & $2,407 \cdot 10^{-4}$ & 1,7790 & 2,4795 \\
\hline
\end{tabular}

$$
\begin{aligned}
& y=-(0,02 \pm 0,01)+(7.500 \pm 80) x \\
& y=(0,02 \pm 0,02)+(10.100 \pm 100) x
\end{aligned}
$$

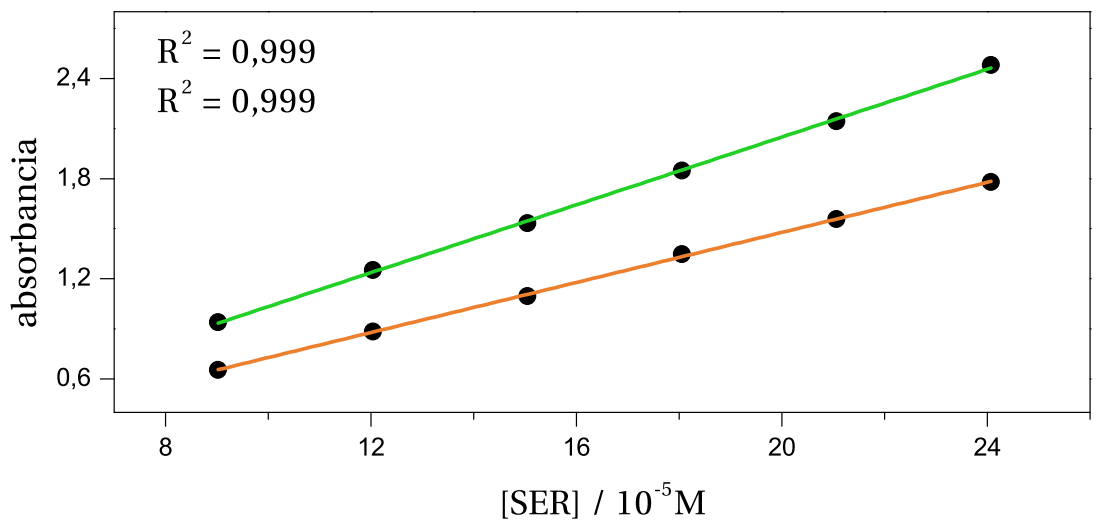

Tabla 4.34 y Figura 4.70: Cumplimiento de la ley de Lambert-Beer por los compuestos $\mathrm{B}$ (naranja) y C (verde). [NIT] $=6,028 \cdot 10^{-3} \mathrm{M}, \mathrm{pH}=4,02, T=20,0^{\circ} \mathrm{C}$. 
De esta forma, ajustando los datos experimentales al mecanismo de reacciones consecutivas, se ha determinado la absorbancia que correspondería a cada producto, para, a continuación, mediante la ley de Lambert-Beer determinar los coeficientes de absorción representando estas absorbancias frente a la concentración inicial de serotonina. Los resultados de esta experiencia, representados en la figura 4.70, muestran que los coeficientes de absorción molar de la mononitrososerotonina y la dinitrososerotonina son:

$$
\begin{gathered}
\varepsilon_{\mathrm{B}, 371 \mathrm{~nm}}=7.500 \pm 80 \mathrm{M}^{-1} \mathrm{~cm}^{-1} \\
\varepsilon_{\mathrm{C}, 371 \mathrm{~nm}}=10.100 \pm 100 \mathrm{M}^{-1} \mathrm{~cm}^{-1}
\end{gathered}
$$

\subsubsection{Influencia de la concentración de nitrito}

Para conocer los órdenes parciales respecto a la concentración de nitrito se diseñaron varios experimentos en los que se modificó la concentración de nitrito en exceso en cada caso. Como las constantes determinadas son pseudoconstantes de orden uno, la verdadera constante de velocidad de reacción se encuentra multiplicada por la concentración de nitrito elevada a su orden parcial:

$$
k_{\mathrm{obs}}=k[\mathrm{NIT}]^{n}
$$

Tomando logaritmos se obtiene la ecuación de una recta a la que se ajustaron los datos experimentales (figura 4.71)

$$
\ln k_{\text {obs }}=\ln k+n \ln [\mathrm{NIT}]
$$

A partir de las pendientes de las rectas ajustadas de las ecuaciones 4.111 y 4.112 se encontraron órdenes parciales dos y uno respecto a la primera y segunda reacciones de nitrosación, respectivamente, lo que sugiere distintos mecanismos:

$$
\begin{array}{r}
v_{1}=k_{\mathrm{obs}, 1}[\mathrm{NIT}]^{2}[\mathrm{SER}] \\
v_{2}=k_{\mathrm{obs}, 2}[\mathrm{NIT}][\mathrm{SER}]
\end{array}
$$




\begin{tabular}{cccccc}
\hline$[\mathrm{NIT}] / \mathrm{M}$ & $k_{\mathrm{obs}, 1} / \mathrm{s}^{-1}$ & $k_{\mathrm{obs}, 2} / \mathrm{s}^{-1}$ & {$[\mathrm{NIT}] / \mathrm{M}$} & $k_{\mathrm{obs}, 1} / \mathrm{s}^{-1}$ & $k_{\mathrm{obs}, 2} / \mathrm{s}^{-1}$ \\
\hline $3,014 \cdot 10^{-3}$ & $1,755 \cdot 10^{-3}$ & $7,025 \cdot 10^{-5}$ & $5,727 \cdot 10^{-3}$ & $6,798 \cdot 10^{-3}$ & $1,329 \cdot 10^{-4}$ \\
$3,919 \cdot 10^{-3}$ & $3,097 \cdot 10^{-3}$ & $9,812 \cdot 10^{-5}$ & $6,632 \cdot 10^{-3}$ & $8,276 \cdot 10^{-3}$ & $1,673 \cdot 10^{-4}$ \\
$4,823 \cdot 10^{-3}$ & $4,316 \cdot 10^{-3}$ & $1,163 \cdot 10^{-4}$ & $7,536 \cdot 10^{-3}$ & $1,162 \cdot 10^{-2}$ & $1,828 \cdot 10^{-4}$ \\
\hline
\end{tabular}

$$
\begin{gathered}
y=(5,4 \pm 0,4)+(2,02 \pm 0,06) x \\
y=-(3,6 \pm 0,3)+(1,03 \pm 0,04) x
\end{gathered}
$$

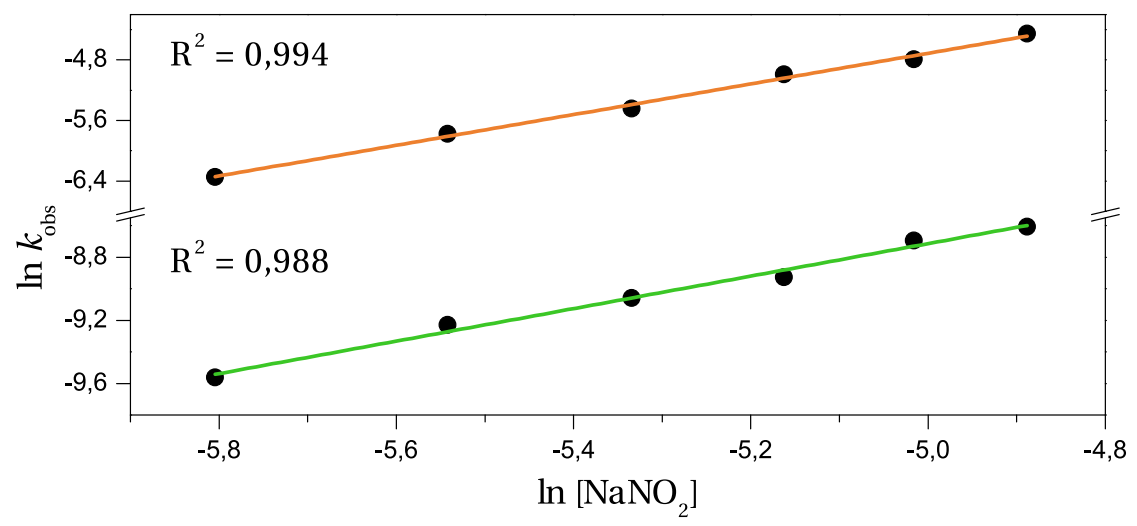

Tabla 4.35 y Figura 4.71: Influencia de la concentración de nitrito en las constantes de velocidad $k_{\mathrm{obs}, 1}$ (naranja) y $k_{\mathrm{obs}, 2}$ (verde). [SER]。 $=1,53 \cdot 10^{-4} \mathrm{M}, \mathrm{pH}=4,00, I=0,24 \mathrm{M}$, $T=20,0{ }^{\circ} \mathrm{C}$.

\subsubsection{Influencia de la acidez del medio}

Para investigar las dos etapas del mecanismo de nitrosación de la serotonina, el primer objetivo fue determinar las correspondientes constantes de velocidad. Se utilizó para ello el ajuste a la ecuación 4.104 de los resultados de varios experimentos cinéticos a distintos pHs, mantenidos constantes los demás parámetros. Las figuras 4.72 y 4.73 muestran los resultados obtenidos.

Para la primera nitrosación se ha propuesto un mecanismo basado en las 
reacciones de N-nitrosación, como el de la nitrosación de fenetilamina (sección 4.2.7). En él, la etapa limitante de velocidad es el ataque del trióxido de dinitrógeno sobre el nitrógeno del anillo indólico (esquema 4.5).

$$
\begin{array}{rll}
\mathrm{HNO}_{2} & \stackrel{K_{1}}{\rightleftharpoons} \mathrm{NO}_{2}^{-}+\mathrm{H}^{+} \\
\mathrm{HNO}_{2}+\mathrm{H}^{+} \stackrel{K_{2}}{\rightleftharpoons} \mathrm{H}_{2} \mathrm{NO}_{2}^{+} / \mathrm{NO}^{+}+\mathrm{H}_{2} \mathrm{O} \\
\mathrm{H}_{2} \mathrm{NO}_{2}^{+}+\mathrm{NO}_{2}^{-} \stackrel{K_{3}}{\rightleftharpoons} \mathrm{N}_{2} \mathrm{O}_{3}+\mathrm{H}_{2} \mathrm{O}
\end{array}
$$

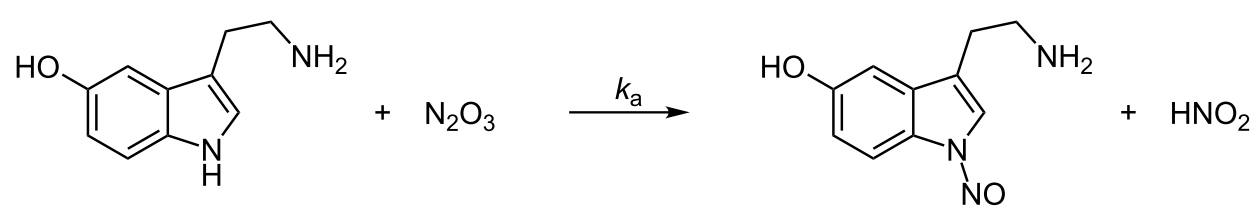

Esquema 4.5: Mecanismo propuesto para la primera nitrosación de la serotonina.

Del mecanismo propuesto se deduce la ecuación de velocidad 4.113, similar a la encontrada con la fenetilamina (ecuación 4.34, página 169).

$$
v_{1}=k_{a} K_{3} K_{2} K_{1} \frac{[\mathrm{NIT}]^{2}\left[\mathrm{H}^{+}\right]^{2}[\mathrm{SER}]}{\left(\left[\mathrm{H}^{+}\right]+K_{1}\right)^{2}}
$$

Sin embargo, dada su condición de heteroátomo aromático, el nitrógeno indólico sólo se protona en condiciones de extrema acidez, por lo que hay que descartar su paso a nitrógeno cuaternario que inhibiría la reacción de nitrosación. ${ }^{259}$ Con ello, la ecuación de velocidad se simplifica, no dependiendo de la constante de acidez de la amina (en la ecuación 4.34, $K_{I}>>\left[\mathrm{H}^{+}\right]$).

De la comparación de las ecuaciones de velocidad experimental y teórica se desprende inmediatamente que:

$$
k_{\mathrm{obs}, 1}=k_{a} K_{3} K_{2} K_{1} \frac{\left[\mathrm{H}^{+}\right]^{2}}{\left(\left[\mathrm{H}^{+}\right]+K_{1}\right)^{2}}
$$


238 | Nitrosación de la serotonina

\begin{tabular}{cccc}
\hline $\mathrm{pH}$ & $k_{\mathrm{obs}, 1} / \mathrm{M}^{-2} \mathrm{~s}^{-1}$ & $\mathrm{pH}$ & $k_{\mathrm{obs}, 1} / \mathrm{M}^{-2} \mathrm{~s}^{-1}$ \\
\hline 2,81 & 910,8 & 3,71 & 161,3 \\
3,12 & 590,3 & 3,77 & 129,2 \\
3,32 & 417,3 & 3,98 & 65,7 \\
3,54 & 260,4 & 4,05 & 47,5 \\
3,55 & 233,1 & 4,53 & 10,7 \\
\hline
\end{tabular}

$$
y=\frac{(1.430 \pm 30)\left(10^{-x}\right)^{2}}{\left((40 \pm 1) \cdot 10^{-5}+10^{-x}\right)^{2}}
$$

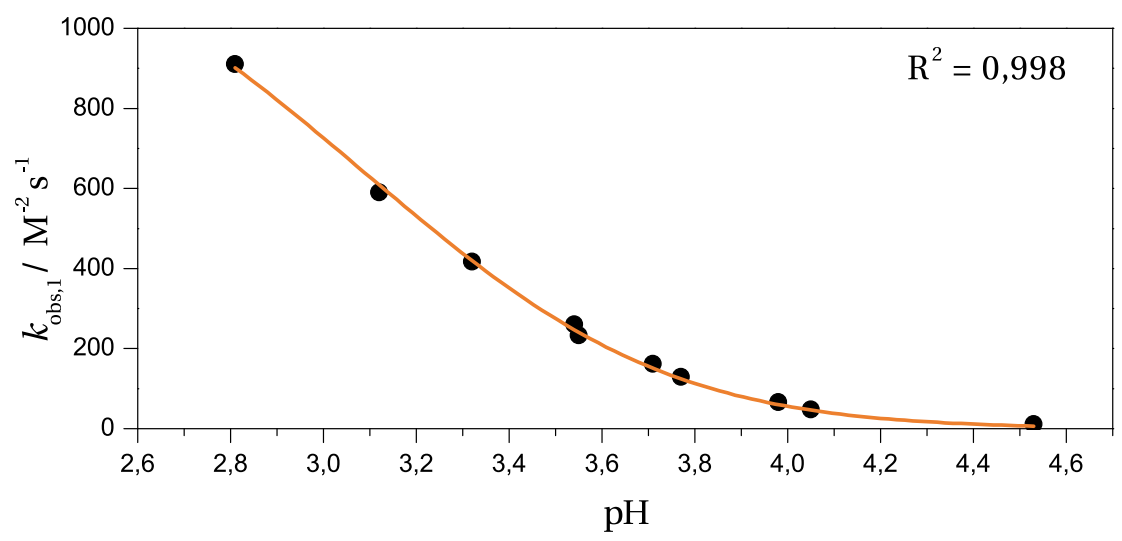

Tabla 4.36 y Figura 4.72: Influencia de la acidez del medio en la constante de velocidad $k_{\mathrm{obs}, 1}$. [SER] $]_{\circ}=1,31 \cdot 10^{-4} \mathrm{M},[\mathrm{NIT}]=3,02 \cdot 10^{-3}, I=0,24 \mathrm{M}, T=20,0^{\circ} \mathrm{C}$. 


\begin{tabular}{cccc}
\hline $\mathrm{pH}$ & $k_{\mathrm{obs}, 2} / \mathrm{M}^{-1} \mathrm{~s}^{-1}$ & $\mathrm{pH}$ & $k_{\mathrm{obs}, 2} / \mathrm{M}^{-1} \mathrm{~s}^{-1}$ \\
\hline 2,81 & $4,685 \cdot 10^{-2}$ & 3,71 & $1,267 \cdot 10^{-2}$ \\
3,12 & $3,308 \cdot 10^{-2}$ & 3,77 & $9,95 \cdot 10^{-3}$ \\
3,32 & $2,703 \cdot 10^{-2}$ & 3,98 & $5,96 \cdot 10^{-3}$ \\
3,54 & $1,911 \cdot 10^{-2}$ & 4,05 & $3,56 \cdot 10^{-3}$ \\
3,55 & $1,768 \cdot 10^{-2}$ & 4,53 & $1,5 \cdot 10^{-4}$ \\
\hline
\end{tabular}

$$
y=\frac{(1.300 \pm 200)\left(10^{-x}\right)^{2}}{\left(10^{-x}+6,65 \cdot 10^{-4}\right)\left(1+(18.000 \pm 3.000) 10^{-x}\right)}
$$

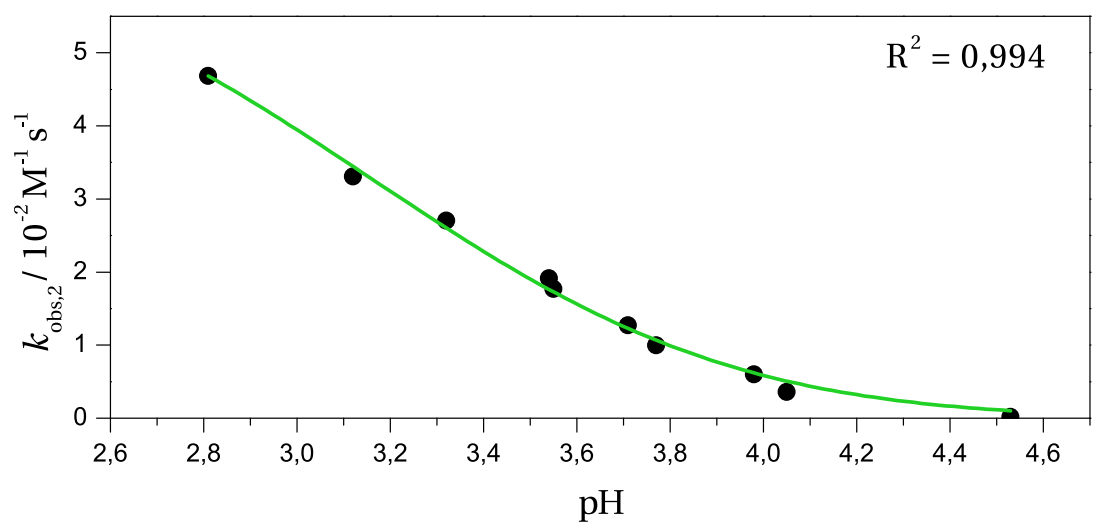

Tabla 4.37 y Figura 4.73: Influencia de la acidez del medio en la constante de velocidad $k_{\text {obs }, 2} \cdot[\mathrm{SER}]_{\circ}=1,31 \cdot 10^{-4} \mathrm{M},[\mathrm{NIT}]=3,02 \cdot 10^{-3}, I=0,24 \mathrm{M}, T=20,0{ }^{\circ} \mathrm{C}$. 


\section{0 | Nitrosación de la serotonina}

La ecuación 4.114 se ha ajustado a los datos experimentales para determinar los parámetros $\alpha$ y $\beta$ de la relación:

$$
k_{\mathrm{obs}, 1}=\alpha \frac{\left[\mathrm{H}^{+}\right]^{2}}{\left(\left[\mathrm{H}^{+}\right]+\beta\right)^{2}}
$$

Los valores de estos parámetros, según los ajustes que se muestran en la figura 4.72, son:

$$
\begin{gathered}
\alpha=1.430 \pm 30 \mathrm{M}^{-2} \mathrm{~s}^{-1} \\
\beta=(40 \pm 1) \cdot 10^{-5} \mathrm{M}
\end{gathered}
$$

De nuevo, el valor del parámetro $\beta$ sirve como comprobación de que el ajuste es correcto desde el punto de vista químico, ya que se trata de la constante de equilibrio $K_{1}$. El valor de su logaritmo negativo proporciona un $\mathrm{pK}_{\mathrm{a}}$ de $3,3 \pm 0,2$, que es consecuente con el valor real 3,17 (tabla 2.1).

Con el parámetro $\alpha$ se calcula la constante de velocidad de la reacción de nitrosación $k_{a}$ :

$$
k_{a}=\frac{\alpha}{K_{3} K_{2} K_{1}}
$$

Como el valor de $K_{1} K_{2} K_{3}$ es, precisamente, la constante de Markovits (sección 2.2.2) cuyo valor se conoce: ${ }^{93} K_{M}=3,03 \cdot 10^{-3} \mathrm{M}^{-1}$, el valor de $k_{a}$ es inmediato:

$$
k_{a}=(4,8 \pm 0,1) \cdot 10^{5} \mathrm{M}^{-1} \mathrm{~s}^{-1}
$$

El valor de la constante $k_{a}$ es muy alto, pero es dos órdenes de magnitud más pequeño que el límite para que la reacción se considere controlada por difusión. ${ }^{260}$

Para la segunda reacción de nitrosación se ha comprobado que el mecanismo de C-nitrosación que se ha utilizado para la tiramina y la dopamina se ajusta bien a los datos experimentales de la figura 4.73. El esquema 4.6 muestra el mecanismo propuesto.

A partir de este mecanismo se deduce la ecuación de velocidad:

$$
v_{2}=\frac{k_{a} K_{2}[\mathrm{SER}][\mathrm{NIT}]\left[\mathrm{H}^{+}\right]^{2}}{\left(\left[\mathrm{H}^{+}\right]+K_{1}\right)\left(1+\frac{k_{-a}}{K_{b} k_{c}}\left[\mathrm{H}^{+}\right]\right)}
$$




$$
\begin{gathered}
\mathrm{HNO}_{2} \stackrel{\mathrm{K}_{1}}{\rightleftharpoons} \mathrm{NO}_{2}^{-}+\mathrm{H}^{+} \\
\mathrm{HNO}_{2}+\mathrm{H}^{+} \stackrel{K_{2}}{\rightleftharpoons} \mathrm{H}_{2} \mathrm{NO}_{2}^{+} / \mathrm{NO}^{+}+\mathrm{H}_{2} \mathrm{O}
\end{gathered}
$$<smiles>NCCc1cn([N+](=O)[O-])c2ccc(O)cc12</smiles>

$+\mathrm{H}_{2} \mathrm{NO}_{2}{ }^{+} / \mathrm{NO}^{+} \frac{k_{\mathrm{a}}}{\underset{k_{-a}}{\rightleftharpoons}}$<smiles>NCCc1cn(N=O)c2cc([N+](=O)[O-])c(O)cc12</smiles><smiles>NCCc1cn([N+](=O)[O-])c2cc([NH+]=O)c([OH+])cc12</smiles><smiles>[Y]C(O)[C@@H](C)[C@@H](C)O</smiles>

Esquema 4.6: Mecanismo propuesto para la segunda nitrosación de la serotonina.

que concuerda con los resultados experimentales de orden uno para cada uno de los reactivos. Para ajustar los datos experimentales con la ecuación de velocidad teórica se compara la ecuación experimental (página 235) con la ecuación 4.119, 


\section{2 | Nitrosación de la serotonina}

de la que se deduce el valor teórico de la constante de velocidad observada:

$$
k_{\mathrm{obs}, 2}=\frac{k_{a} K_{2}\left[\mathrm{H}^{+}\right]^{2}}{\left(\left[\mathrm{H}^{+}\right]+K_{1}\right)\left(1+\frac{k_{-a}}{K_{b} k_{c}}\left[\mathrm{H}^{+}\right]\right)}
$$

El ajuste de esta ecuación a los datos experimentales también se muestra en la figura 4.73. Con este ajuste se han determinado los parámetros $\alpha$ y $\beta$ :

$$
k_{\mathrm{obs}, 2}=\frac{\alpha\left[\mathrm{H}^{+}\right]^{2}}{\left(\left[\mathrm{H}^{+}\right]+K_{1}\right)\left(1+\beta\left[\mathrm{H}^{+}\right]\right)}
$$

donde:

$$
\begin{gathered}
\alpha=1.300 \pm 200 \mathrm{M}^{-2} \mathrm{~s}^{-1} \\
\beta=18.000 \pm 3.000 \mathrm{M}^{-1}
\end{gathered}
$$

A partir de $\alpha$ se puede conocer $k_{a}$, puesto que $K_{2}$ es un valor conocido $\left(K_{2}=\right.$ $\left.3 \cdot 10^{-7} \mathrm{M}^{-1}\right){ }^{81}$

$$
k_{a}=(4,3 \pm 0,3) \cdot 10^{9} \mathrm{M}^{-1} \mathrm{~s}^{-1}
$$

Este valor de $k_{a}$ es del mismo orden de magnitud que las constantes de nitrosación de otros compuestos C-nitrosados (sección 5.1).

\subsubsection{Influencia de la fuerza iónica}

Como en el caso de los demás sustratos, se ha investigado la nitrosación de serotonina en medios de fuerza iónica variable. Para ello se programaron experimentos cinéticos en los que, mantenidos constantes los demás parámetros, se añadían diferentes concentraciones de perclorato sódico. La figura 4.74 ilustra el resultado de aplicar la ecuación de Brønsted-Debye-Hückel (página 120) a las velocidades específicas de reacción encontradas en cada caso.

La no influencia de la fuerza iónica es coherente con el mecanismo propuesto en el sentido de que en ninguna de las reacciones limitantes implicadas en el mecanismo propuesto participan reactivos iónicos. 


\begin{tabular}{cccccc}
\hline$I$ & $k_{\mathrm{obs}, 1}$ & $k_{\mathrm{obs}, 2}$ & $I$ & $k_{\mathrm{obs}, 1}$ & $k_{\mathrm{obs}, 2}$ \\
$/ \mathrm{M}$ & $/ \mathrm{M}^{-2} \mathrm{~s}^{-1}$ & $/ \mathrm{M}^{-1} \mathrm{~s}^{-1}$ & $/ \mathrm{M}$ & $/ \mathrm{M}^{-2} \mathrm{~s}^{-1}$ & $/ \mathrm{M}^{-1} \mathrm{~s}^{-1}$ \\
\hline 0,0863 & 247,93 & 0,0309 & 0,3263 & 252,50 & 0,0223 \\
0,1663 & 244,10 & 0,0293 & 0,4064 & 262,12 & 0,0200 \\
0,2464 & 241,36 & 0,0217 & 0,4864 & 271,80 & 0,0210 \\
\hline
\end{tabular}

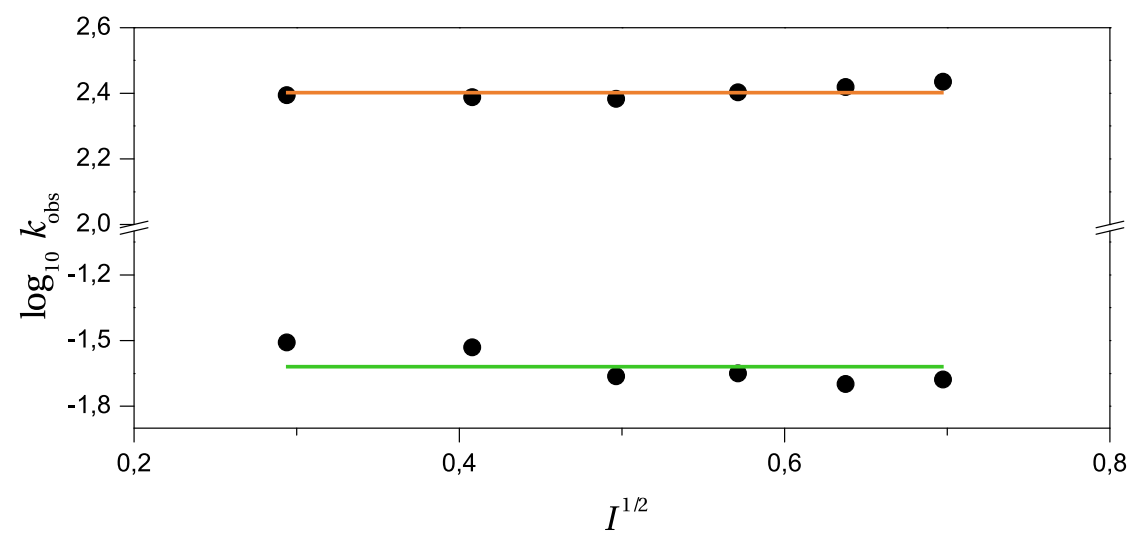

Tabla 4.38 y Figura 4.74: Influencia de la fuerza iónica en las constantes de velocidad $k_{1}$ (naranja) y $k_{2}$ (verde). $[\mathrm{SER}]_{\circ}=1,53 \cdot 10^{-4} \mathrm{M}$, [NIT] $=6,028 \cdot 10^{-3} \mathrm{M}, \mathrm{pH}=3,50, T=20,0^{\circ} \mathrm{C}$.

\subsubsection{Efecto isotópico cinético}

En esta fase de nuestra investigación se trabajó a pH = 2,2, donde la ecuación 4.114 (página 237) se transforma en:

$$
k_{\mathrm{obs}, 1}=k_{a} K_{3} K_{2} K_{1}
$$

A su vez, la ecuación 4.120 (página 188) se reduce a:

$$
k_{\mathrm{obs}, 2}=\frac{k_{a} K_{2} K_{b} k_{c}}{k_{-a}}
$$

Como en el pH de trabajo la reacción es muy rápida, el seguimiento cinético de la nitrosación se hizo mediante técnica de flujo detenido (Stopped-Flow; ver 


\section{4 | Nitrosación de la serotonina}

apartado 3.1.1.4).

La comparación de los valores de $k_{\text {obs }}$ en agua y agua deuterada (97\%) conduce, para la primera nitrosación, a la ecuación 4.124:

$$
\frac{k_{\text {obs, } 1}^{\mathrm{H}_{2} \mathrm{O}}}{k_{\mathrm{obs}, 1}^{\mathrm{D}_{2} \mathrm{O}}}=\frac{k_{a}^{\mathrm{H}_{2} \mathrm{O}} K_{2}^{\mathrm{H}_{2} \mathrm{O}} K_{1}^{\mathrm{H}_{2} \mathrm{O}}}{k_{a}^{\mathrm{D}_{2} \mathrm{O}} K_{2}^{\mathrm{D}_{2} \mathrm{O}} K_{1}^{\mathrm{D}_{2} \mathrm{O}}}
$$

y, para la segunda, a la ecuación 4.125:

$$
\frac{k_{\text {obs, } 2}^{\mathrm{H}_{2} \mathrm{O}}}{k_{\mathrm{obs}, 2}^{\mathrm{D}_{2} \mathrm{O}}}=\frac{K_{2}^{\mathrm{H}_{2} \mathrm{O}}}{K_{2}^{\mathrm{D}_{2} \mathrm{O}}} \frac{k_{\mathrm{c}}^{\mathrm{H}_{2} \mathrm{O}}}{k_{\mathrm{c}}^{\mathrm{D}_{2} \mathrm{O}}}
$$

Los valores de las constantes de velocidad experimentales, medidas por triplicado, se muestran en la tabla 4.39.

\begin{tabular}{ccc}
\hline & $k_{\text {obs, } 1} / \mathrm{M}^{-2} \mathrm{~s}^{-1}$ & $k_{\text {obs, } 2} / \mathrm{M}^{-1} \mathrm{~s}^{-1}$ \\
\hline $\mathrm{H}_{2} \mathrm{O}$ & $1.232,4$ & $5,485 \cdot 10^{-2}$ \\
$\mathrm{D}_{2} \mathrm{O}$ & $1.516,1$ & $6,314 \cdot 10^{-2}$ \\
\hline
\end{tabular}

Tabla 4.39: Constantes de velocidad de la nitrosación de la serotonina según el disolvente empleado.

Como $K_{1}^{\mathrm{D}_{2} \mathrm{O}} / K_{1}^{\mathrm{H}_{2} \mathrm{O}}=0,647$ y que $K_{2}^{\mathrm{D}_{2} \mathrm{O}} / K_{2}^{\mathrm{H}_{2} \mathrm{O}}=2,7$, para la primera nitrosación se encuentra que: 257,261

$$
\frac{k_{a}^{\mathrm{H}_{2} \mathrm{O}}}{k_{a}^{\mathrm{D}_{2} \mathrm{O}}}=1,42
$$

Este valor, pequeño para corresponder a la desprotonación del complejo de Wheland, es próximo al que, en procesos controlado por difusión, corresponde a la relación de viscosidades entre el agua y el agua deuterada, que es 1,25 aproximadamente, a $25^{\circ} \mathrm{C} .{ }^{262}$ 
Para la segunda reacción de nitrosación, el efecto isotópico derivado de la ruptura del complejo $\sigma$ es:

$$
\frac{k_{\mathrm{c}}^{\mathrm{H}_{2} \mathrm{O}}}{k_{\mathrm{c}}^{\mathrm{D}_{2} \mathrm{O}}}=2,35
$$

El valor obtenido es consistente con el mecanismo propuesto.

\subsubsection{Influencia de la temperatura}

Como en el caso del efecto isotópico cinético, para la determinación de los parámetros cinéticos se utilizó la técnica de flujo detenido que ofrece la ventaja adicional de que, al estar termostatadas las jeringas de inyección, la mezcla transcurre a la temperatura prefijada (figura 3.3, d). En el caso de la segunda nitrosación, las medidas cinéticas se hicieron por partida doble: flujo detenido y espectrografía UV-visible convencional, debido a que el stopped-flow no permite seguir tiempos muy largos de reacción.

La figura 4.75 muestra los perfiles cinéticos de las reacciones de nitrosación

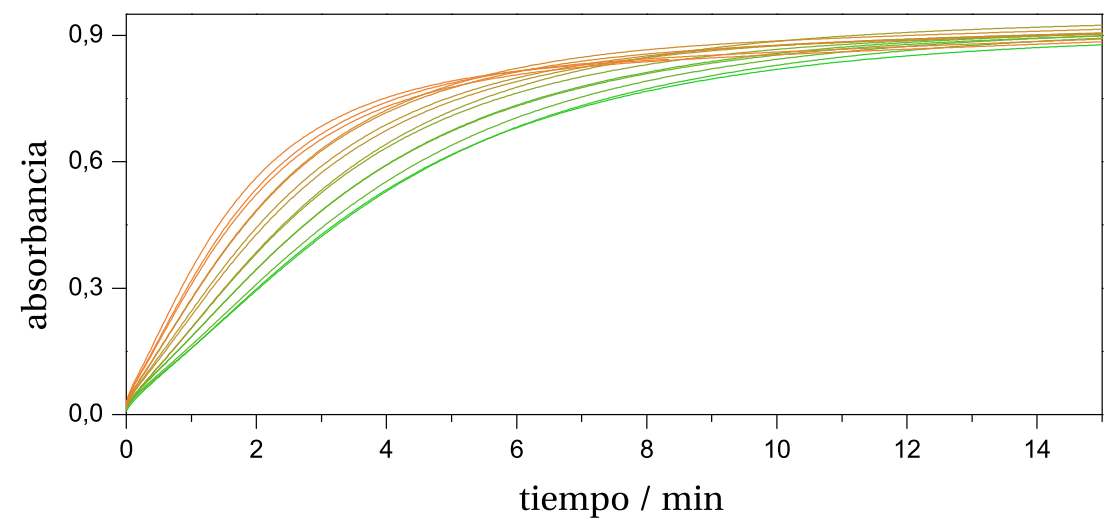

Figura 4.75: Variación de la absorbancia con el tiempo durante la nitrosación de la serotonina a diferentes temperaturas. $\lambda=371 \mathrm{~nm}$, [SER $]_{\circ}=3,78 \cdot 10^{-5}-1,28 \cdot 10^{-4} \mathrm{M}$, $[\mathrm{NIT}]=3,00 \cdot 10^{-3}, \mathrm{pH}=3,65, T=20,32$ (verde) $-33,87$ (naranja) ${ }^{\circ} \mathrm{C}$. 


\section{6 | Nitrosación de la serotonina}

de la serotonina a diferentes temperaturas. Se observa cómo, al subir la temperatura, aumenta más rápidamente la pendiente del tramo inicial, asociado a $k_{\mathrm{obs}, 1}$, que la del tramo final, relacionada con $k_{\mathrm{obs}, 2}$.

Los datos experimentales obtenidos a cada temperatura se han ajustado a la ecuación 4.104 que permite conocer las constantes de velocidad. Las tablas 4.40 y 4.41 muestran los valores de $k_{\mathrm{obs}, 1}$ y $k_{\mathrm{obs}, 2}$, respectivamente.

\begin{tabular}{cccc}
\hline$T /{ }^{\circ} \mathrm{C}$ & $k_{\mathrm{obs}, 1} / \mathrm{M}^{-2} \mathrm{~s}^{-1}$ & $T /{ }^{\circ} \mathrm{C}$ & $k_{\mathrm{obs}, 1} / \mathrm{M}^{-2} \mathrm{~s}^{-1}$ \\
\hline 20,32 & 392,85 & 27,09 & 583,91 \\
20,32 & 395,51 & 27,11 & 561,37 \\
20,32 & 421,38 & 29,33 & 649,55 \\
22,55 & 458,24 & 29,33 & 629,24 \\
22,55 & 453,08 & 29,33 & 629,25 \\
24,95 & 505,46 & 31,86 & 699,74 \\
24,95 & 531,70 & 33,87 & 758,50 \\
\hline
\end{tabular}

Tabla 4.40: Influencia de la temperatura en la constante de velocidad $k_{\mathrm{obs}, 1}$. $[\mathrm{SER}]_{\circ}=3,78 \cdot 10^{-5}-1,28 \cdot 10^{-4} \mathrm{M},[\mathrm{NIT}]=3,00 \cdot 10^{-3} \mathrm{M}, \mathrm{pH}=3,65$.

\begin{tabular}{cccc}
\hline$T /{ }^{\circ} \mathrm{C}$ & $k_{\mathrm{obs}, 2} / \mathrm{M}^{-1} \mathrm{~s}^{-1}$ & $T /{ }^{\circ} \mathrm{C}$ & $k_{\mathrm{obs}, 2} / \mathrm{M}^{-1} \mathrm{~s}^{-1}$ \\
\hline 22,55 & 0,0458 & 27,11 & 0,0676 \\
23,03 & 0,0484 & 28,38 & 0,0710 \\
24,95 & 0,0573 & 29,33 & 0,0782 \\
24,97 & 0,0556 & 30,93 & 0,0865 \\
27,09 & 0,0675 & 31,86 & 0,0903 \\
\hline
\end{tabular}

Tabla 4.41: Influencia de la temperatura en la constante de velocidad $k_{\mathrm{obs}, 2}$. $[\mathrm{SER}]_{\circ}=3,78 \cdot 10^{-5}-1,28 \cdot 10^{-4} \mathrm{M},[\mathrm{NIT}]=3,00 \cdot 10^{-3} \mathrm{M}, \mathrm{pH}=3,65$.

Las figuras 4.76 y 4.77 , para $k_{\mathrm{obs}, 1}$, y 4.78 y 4.79 , para $k_{\mathrm{obs}, 2}$, muestran el buen ajuste a las ecuaciones de Arrhenius y Eyring-Wynne-Jonnes. 


$$
y=(20,7 \pm 0,5)+(36 \pm 1) \cdot 10^{3} x
$$

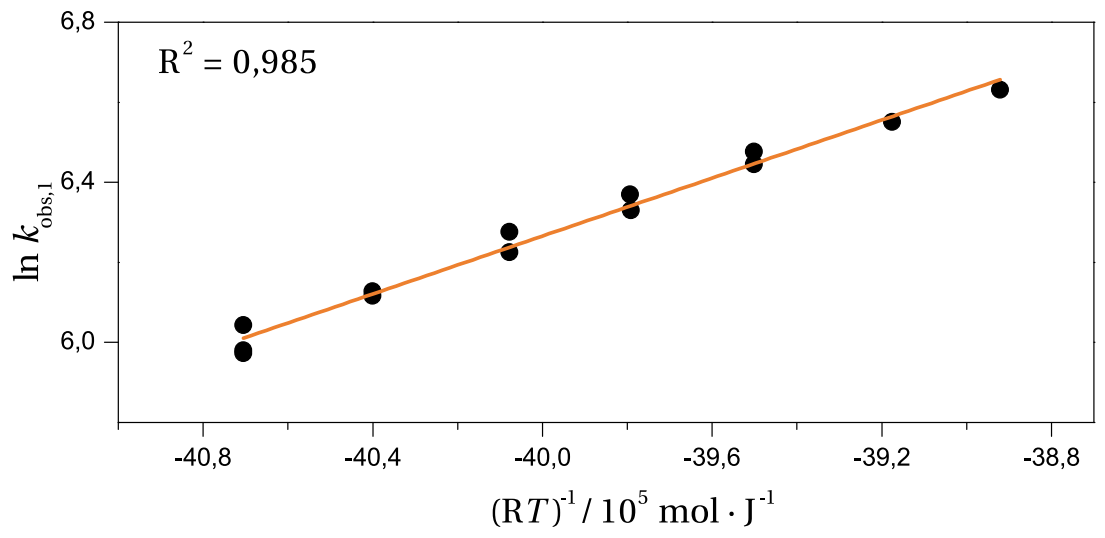

Figura 4.76: Cumplimiento de la ecuación de Arrhenius por los resultados de la tabla 4.40 .

$$
y=(14,0 \pm 0,5)+(33 \pm 1) \cdot 10^{3} x
$$

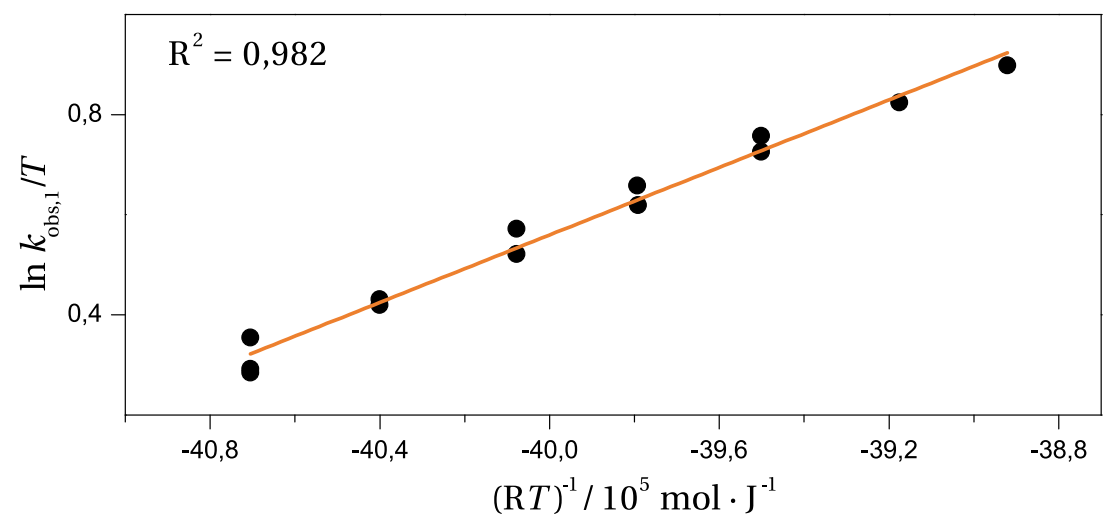

Figura 4.77: Cumplimiento de la ecuación de Eyring por los resultados de la tabla 4.40. 


$$
y=(19,3 \pm 0,6)+(55 \pm 2) \cdot 10^{3} x
$$

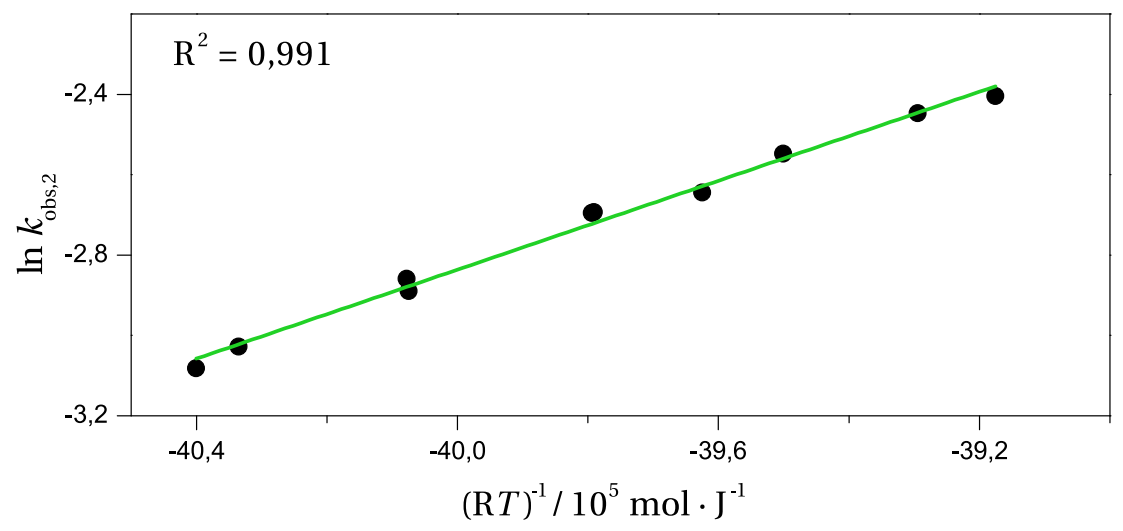

Figura 4.78: Cumplimiento de la ecuación de Arrhenius por los resultados de la tabla 4.41 .

$$
y=(12,6 \pm 0,7)+(53 \pm 2) \cdot 10^{3} x
$$

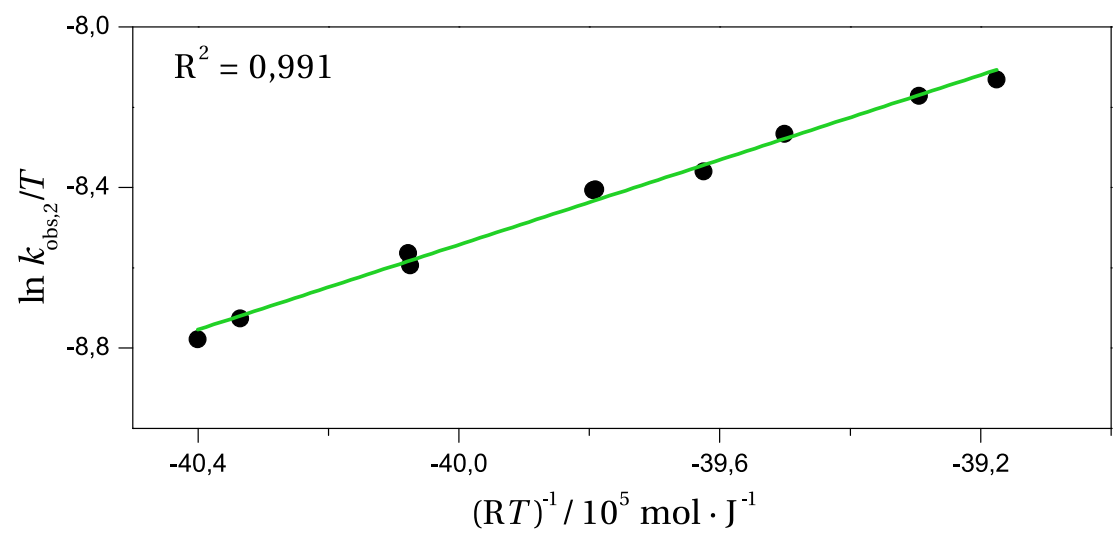

Figura 4.79: Cumplimiento de la ecuación de Eyring por los resultados de la tabla 4.41. 
La siguiente tabla resume los parámetros cinéticos encontrados:

\begin{tabular}{lccc}
\hline & $E_{a} / \mathrm{kJ} \mathrm{mol}^{-1}$ & $\Delta H^{\ddagger} / \mathrm{kJ} \mathrm{mol}^{-1}$ & $\Delta S^{\ddagger} / \mathrm{J} \mathrm{K}^{-1} \mathrm{~mol}^{-1}$ \\
\hline$k_{\mathrm{obs}, 1}$ & $36 \pm 2$ & $33 \pm 2$ & $-81 \pm 3$ \\
$k_{\mathrm{obs}, 2}$ & $55 \pm 2$ & $53 \pm 2$ & $-92 \pm 5$ \\
\hline
\end{tabular}

Tabla 4.42: Parámetros termodinámicos calculados para las reacciones de nitrosación de la serotonina.

Para tratar de profundizar en el mecanismo de la primera nitrosación se calculó el valor de la entalpía de activación asociada a la constante $k_{a}$ como diferencia entre la entalpía de activación $\Delta H^{\ddagger}$ y la entalpía de formación $\Delta H_{m}$ del trióxido de dinitrógeno:

$$
\Delta H_{k}^{\ddagger}=\Delta H^{\ddagger}-\Delta H_{m}
$$

Cómo $\Delta H_{m}=6,8 \pm 0,6 \mathrm{~kJ} \mathrm{~mol}^{-1}$, resulta que $\Delta H_{k}^{\ddagger}=26 \pm 2 \mathrm{~kJ} \mathrm{~mol}^{-1} \cdot{ }^{96}$ De nuevo se obtiene un valor cercano al límite de una reacción controlada por difusión $\left(20 \mathrm{~kJ} \mathrm{~mol}^{-1}\right){ }^{260}$

\subsubsection{Estructura y reactividad de la serotonina}

De todas las moléculas estudiadas en este trabajo, la serotonina es la que tiene más sitios potencialmente nitrosables, puesto que su estructura indólica tiene cinco posiciones libres para reaccionar, todas ellas lo suficientemente activadas por el nitrógeno del anillo y el grupo alcohólico de la posición 5 .

Por ello se ha estimado, por medio de cálculos computacionales, cuál es la posición más favorecida para ser nitrosada. En primer lugar, se ha optimizado la estructura de la molécula (figura 4.80) para, a continuación, calcular la distribución de carga en su estructura. La reacción de sustitución es electrófila, por lo que es más probable que se produzca en las posiciones con mayor densidad de carga negativa (de color rojo). La figura 4.81 muestra el mapa de distribución de cargas. Se observa que el oxígeno es el átomo con mayor carga negativa. Sin embargo, como ocurrió con la tiramina, los datos experimentales no se ajustaban a 

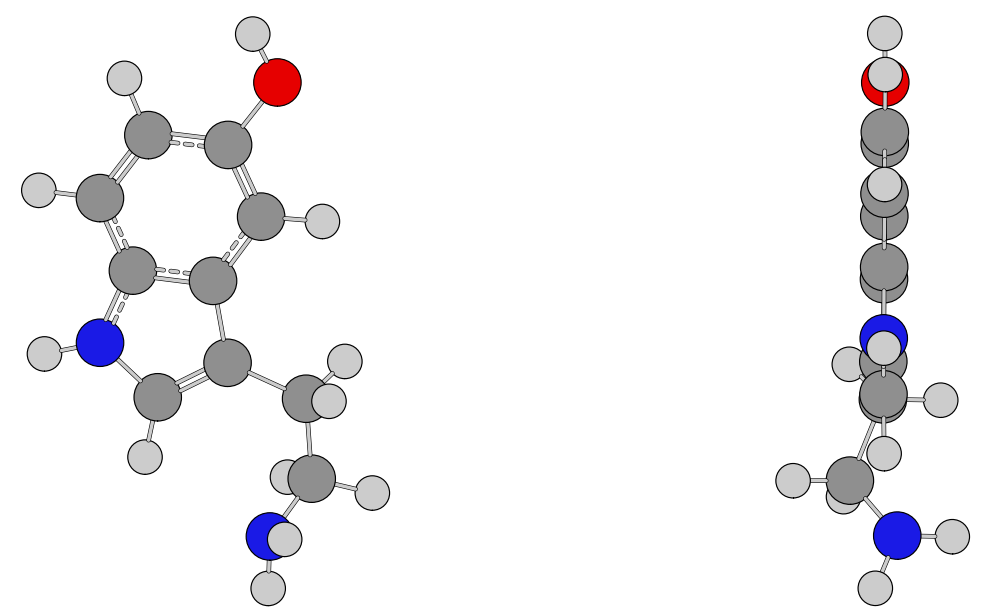

Figura 4.80: Estructura calculada de la serotonina. DFT-B3LYP 6-31+G (d,p).
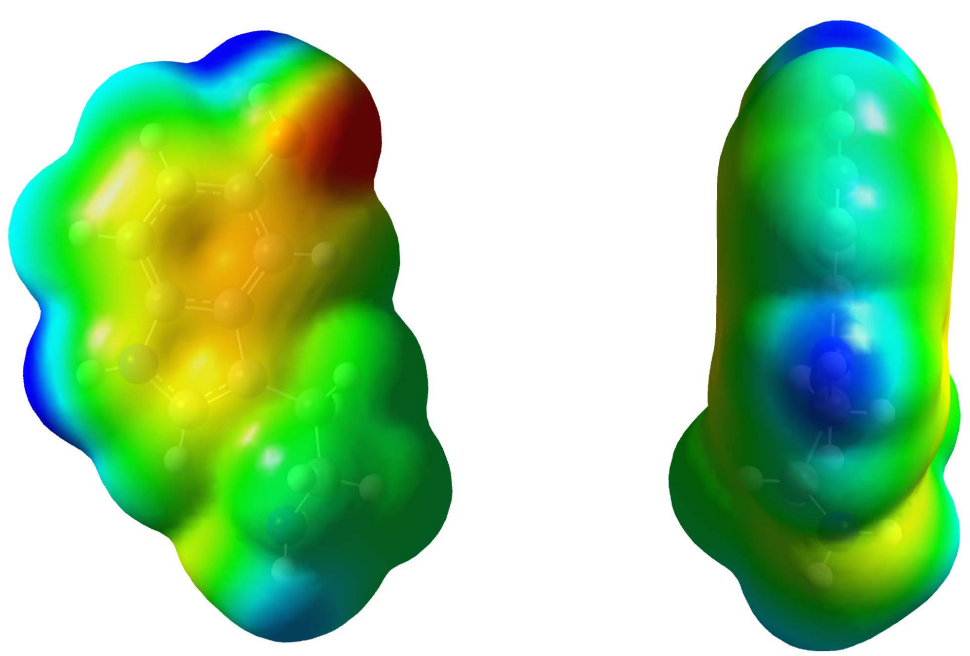

Figura 4.81: Mapa de densidad electrónica de la serotonina. DFT-B3LYP 6-31+G (d,p). 


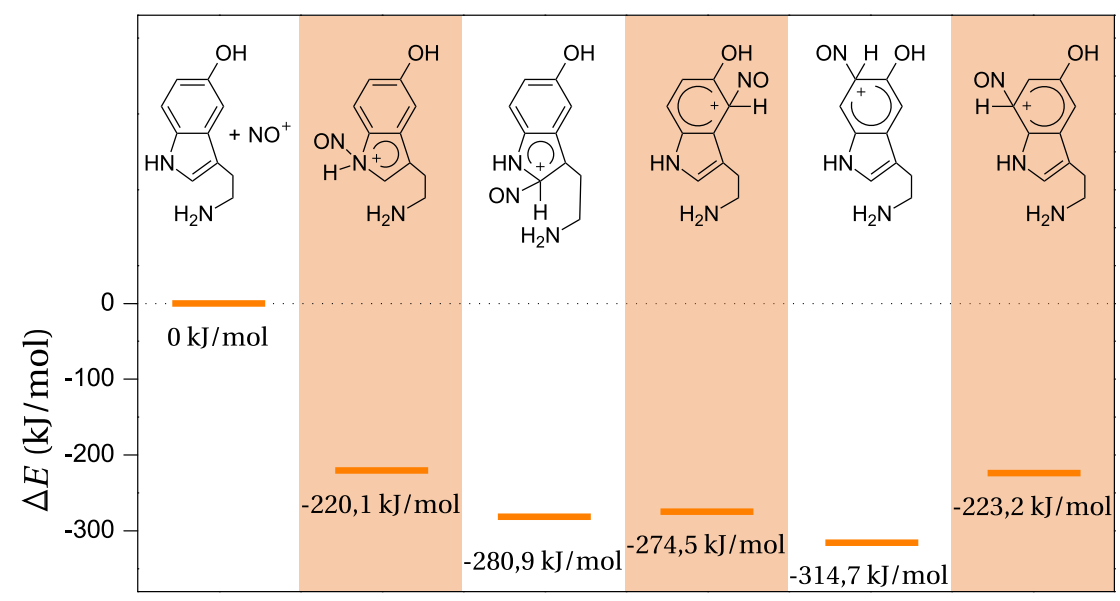

Figura 4.82: Diferencias de energía calculadas para los posibles complejos $\sigma$ de la nitrosación de la serotonina. DFT-B3LYP 6-31+G (d,p).

un posible mecanismo de catálisis por la reacción de Fischer-Hepp. También se puede ver que la densidad electrónica en el anillo de seis miembros de la serotonina es mayor que la densidad en el otro anillo, por lo que es de esperar que la reacción esté favorecida en esos lugares.

Se ha calculado las energías de los cinco posibles complejos de Wheland que puede formar la serotonina al nitrosarse respecto a la energía de la serotonina y el ion nitrosonio por separado. La figura 4.82 muestra que el compuesto más estable con mucha diferencia es el complejo $\sigma$ nitrosado en el carbono 6 . El siguiente compuesto más estable, el nitrosado en el carbono 2, es poco probable debido al impedimento estérico de la cadena lateral adyacente. Se observa que el complejo de Wheland en la posición meta respecto al alcohol se encuentra desfavorecido y que la nitrosación en el heteroátomo de nitrógeno también está desfavorecida. Este resultado no está en contraposición con el mecanismo propuesto para la primera reacción de nitrosación de la serotonina, en el que el agente nitrosante es el trióxido de dinitrógeno, mucho más electrófilo que el ion nitrosonio empleado en este experimento in silico. 


\subsubsection{Determinación del producto de reacción}

Hora y media después de preparar una disolución ácida y acuosa de serotonina y nitrito sódico se hizo un espectro de masas. El espectro obtenido, que se muestra en la figura 4.83, corrobora el mecanismo de doble nitrosación propuesto en este trabajo. Se observa cómo el pico que corresponde a la masa de la serotonina muestra una abundancia relativa baja, mientras que el compuesto más abundante tiene una masa/carga 205,0, correspondiente a la de la serotonina nitrosada, consecuente con la rápida nitrosación que se produce nada más mezclar la serotonina con el ácido nitroso. Además, aparece un pico en $m / z=234,1$ con una abundancia relativa del $23 \%$ acorde con la masa de la serotonina doblemente nitrosada.

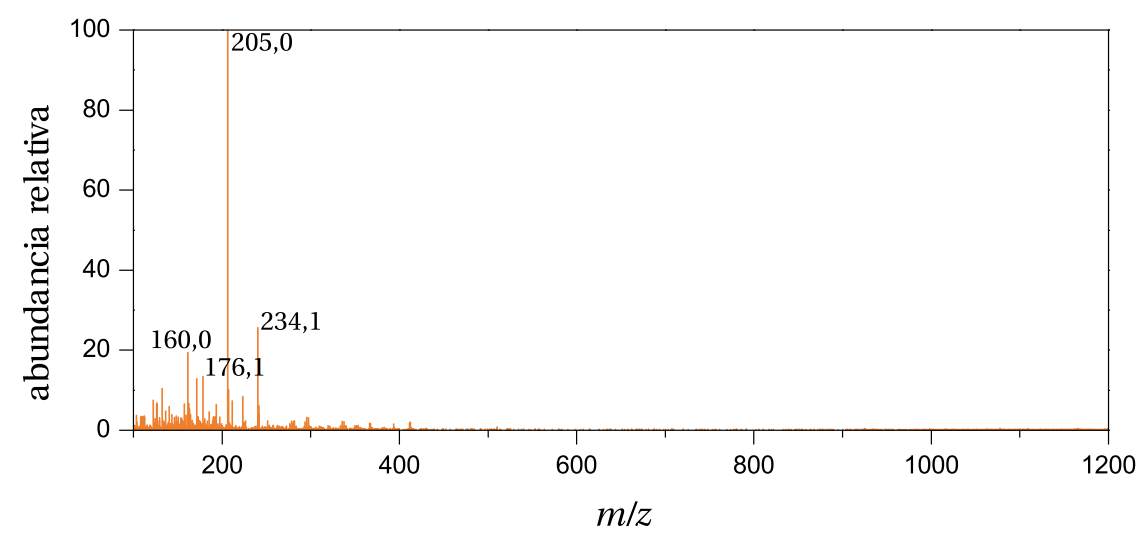

Figura 4.83: Espectro de masas por impacto electrónico positivo de la serotonina nitrosada.

Según los cálculos computacionales, las posiciones más favorecidas para la nitrosación de la serotonina son las de los carbonos adyacentes al grupo alcohólico de su estructura. De igual modo que se hizo con la tiramina, se ha comprobado la presencia de los compuestos nitrosados en esas posiciones mediante la formación de un compuesto de coordinación con cobre (II). A una disolución acuosa y ácida con serotonina y nitrito, al acabar la reacción 
entre estos dos compuestos, se añadió una cantidad en exceso de sulfato de cobre (II). Tras dos días, la mezcla creada había cambiado de color, confirmando la presencia de los compuestos de nitrososerotonina calculados (esquema 4.7).

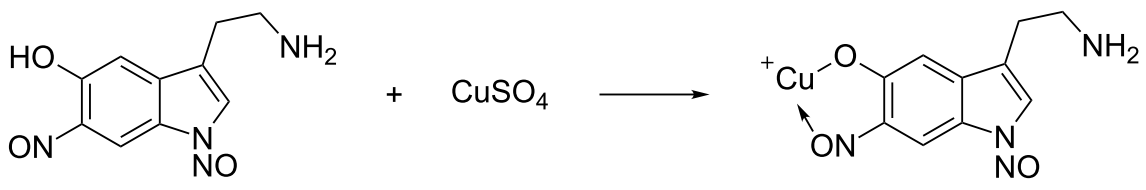

Esquema 4.7: Reacción de complejación de la nitrososerotonina.

\subsubsection{Actividad biológica de la nitrososerotonina}

Test de Ames

El test de Ames sugiere que la nitrososerotonina no es mutágena. Tras realizar el test según el procedimiento descrito en la página 134, en bacterias de las cepas TA98 y TA100, con y sin complejo de activación metabólica S9, ninguna de las dosis de nitrososerotonina empleadas induce la aparición de un número

\begin{tabular}{ccccc}
\hline$\mu$ g NSER / placa & TA98 & TA98 + S9 & TA100 & TA100 + S9 \\
\hline control negativo & $19 \pm 1$ & $28 \pm 2$ & $180 \pm 10$ & $80 \pm 10$ \\
7 & 16 & $24 \pm 2$ & $150 \pm 3$ & $84 \pm 4$ \\
23 & 17 & $26 \pm 2$ & 158 & 83 \\
70 & 16 & 28 & 194 & 77 \\
230 & $18 \pm 4$ & $30 \pm 2$ & $160 \pm 10$ & 82 \\
700 & $22 \pm 5$ & $26 \pm 1$ & $154 \pm 2$ & $82 \pm 2$ \\
control positivo & $390 \pm 10$ & 426 & $1.080 \pm 80$ & $740 \pm 10$ \\
\hline
\end{tabular}

Tabla 4.43: Resultados del test de Ames aplicado a la nitrososerotonina. Controles positivos: TA98: $10 \mu \mathrm{g}$ NPD, TA98 + S9: $2 \mu \mathrm{g}$ 2AA, TA100: 0,3 $\mu \mathrm{g}$ 4NQO y TA100 + S9 $2 \mu \mathrm{g}$ 2AA 


\section{4 | Nitrosación de la serotonina}

de revertientes significativamente mayor que el que se produce de forma espontánea en el control negativo. La tabla 4.43 y las figuras 4.84 y 4.85 recogen los resultados del ensayo.

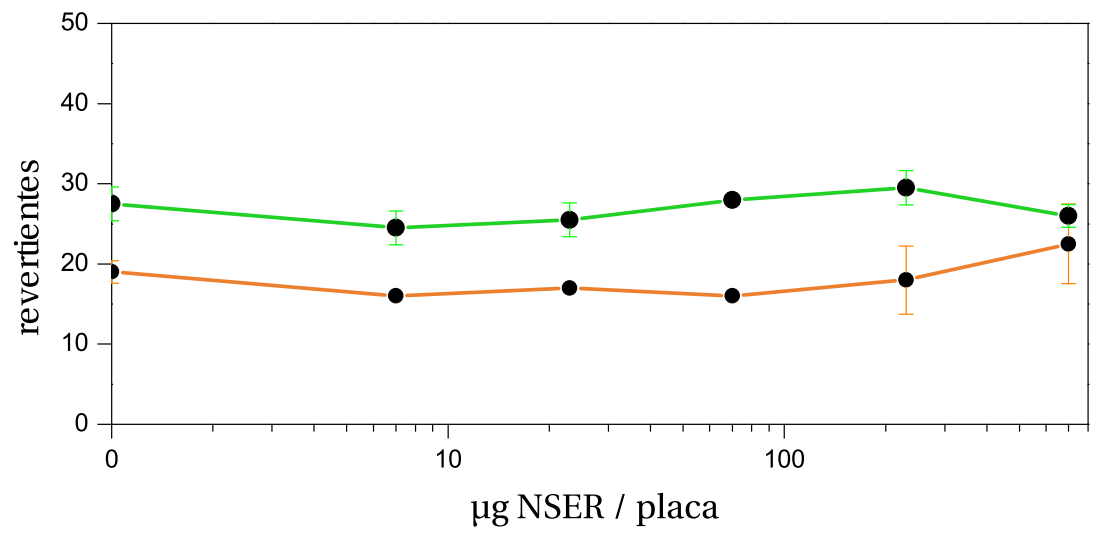

Figura 4.84: Test de Ames de la nitrososerotonina TA98. Los resultados sin extracto S9 se muestran de color naranja y los resultados con extracto S9, de color verde.

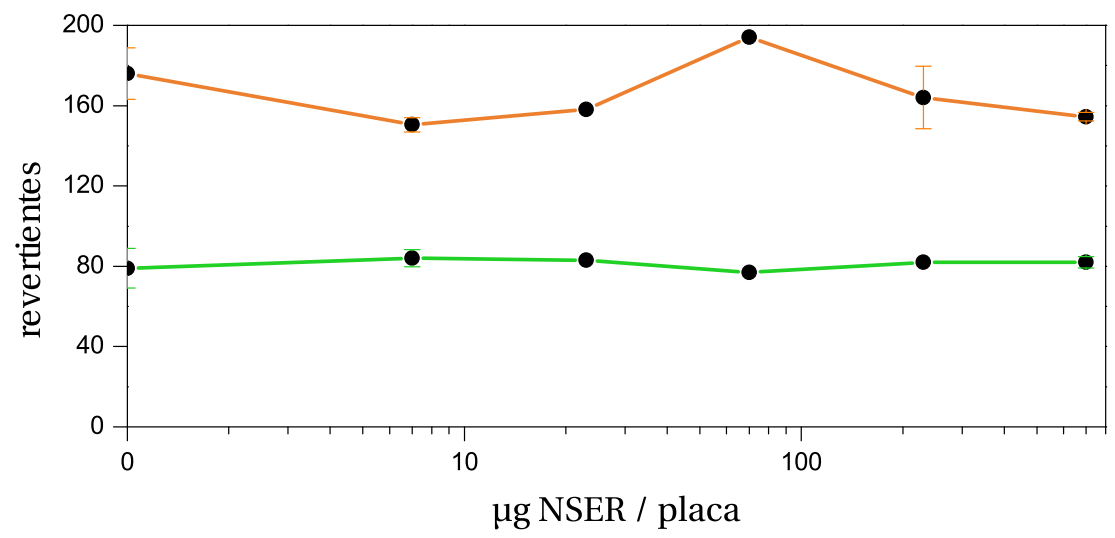

Figura 4.85: Test de Ames de la nitrososerotonina TA100. Los resultados sin extracto S9 se muestran de color naranja y los resultados con extracto S9, de color verde. 
Test de aberraciones cromosómicas

El test de aberraciones cromosómicas ha demostrado que, en concordancia con los resultados del test de Ames, la nitrososerotonina tampoco es un compuesto que provoque anormalidades en los cromosomas de las células V-79. La tabla 4.44 muestra los resultados del experimento realizado según el procedimiento descrito en la página 139. En una de las placas de las células expuestas durante 24 horas a una concentración 3,4 $\mu \mathrm{M}$ de nitrososerotonina se observó una célula con un hueco en una de sus dos cromátidas. Sin embargo esta aberración no es significativa.

\begin{tabular}{ccccccc}
\hline [NSER] / $\mu \mathrm{M}$ & CTG & CSG & CTB & CSB & ACENT & DIC \\
\hline control negativo & 0 & 0 & 0 & 0 & 0 & 0 \\
3,4 & 1 & 0 & 0 & 0 & 0 & 0 \\
34 & 0 & 0 & 0 & 0 & 0 & 0 \\
340 & 0 & 0 & 0 & 0 & 0 & 0 \\
3.400 & \multicolumn{7}{c}{ Concentración tóxica para las células } \\
control positivo & 8 & 4 & 28 & 14 & 0 & 0 \\
\hline [NSER] / $\mu \mathrm{M}$ & TRI & TET & OTRO & RING & MA & $\%$ AC \\
\hline control negativo & 0 & 0 & 0 & 0 & 0 & 0 \\
3,4 & 0 & 0 & 0 & 0 & 0 & 0 \\
34 & 0 & 0 & 0 & 0 & 0 & 0 \\
340 & 0 & 0 & 0 & 0 & 0 & 0 \\
3.400 & \multicolumn{7}{c}{ Concentración tóxica para las células } \\
control positivo & 16 & 2 & 0 & 4 & 0 & 42 \\
\hline
\end{tabular}

Tabla 4.44: Aberraciones cromosómicas inducidas por la nitrososerotonina en células eucariotas V-79. Control positivo: MMC 1,5 $\mu \mathrm{M}$. 


\section{6 | Nitrosación de la serotonina}

\section{Test del MTT}

La serotonina, pese a que parece no ser mutágena, ha demostrado ser muy citotóxica en el test del MTT. Mediante el procedimiento descrito en la página 142 se midió la supervivencia de las células V-79 a diferentes concentraciones de nitrososerotonina tras una exposición de 24 horas al nitrosocompuesto. La figura 4.86 muestra el resultado de la experiencia.

Se puede ver cómo, incluso en la dosis más baja de compuesto, se produce una mortalidad del $10 \%$ entre las células V-79. Con una concentración 10 veces superior a la dosis más baja mueren todas las células del medio de cultivo. En función de los datos obtenidos, se ha calculado la concentración inhibitoria media $\left(\mathrm{IC}_{50}\right.$ ) de nitrososerotonina en estas condiciones: $\mathrm{IC}_{50}=3,7 \cdot 10^{-4} \mathrm{M}$.

\begin{tabular}{ccc}
\hline & {$[$ NSER] $/ \mu \mathrm{M}$} & Supervivencia \\
\hline $\mathrm{a}$ & 51 & $(90 \pm 9) \%$ \\
$\mathrm{~b}$ & 170 & $(76 \pm 7) \%$ \\
$\mathrm{c}$ & 510 & $(0,0 \pm 0,2) \%$ \\
$\mathrm{~d}$ & 1.700 & $(0,7 \pm 0,3) \%$ \\
\hline
\end{tabular}

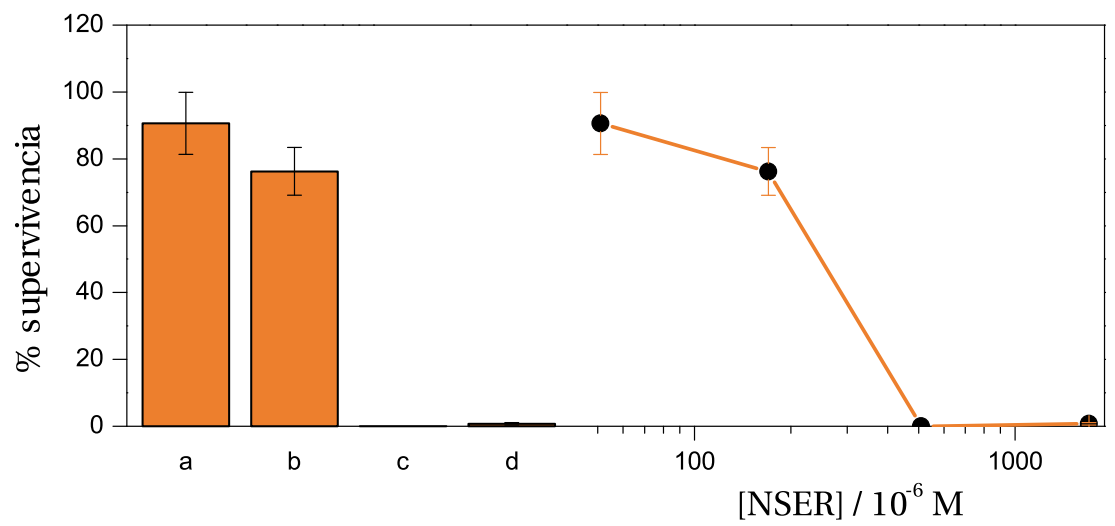

Tabla 4.45 y Figura 4.86: Supervivencia celular de V-79 en función de la concentración de nitrososerotonina. 


\subsection{Nitrosación del minoxidilo}

\subsubsection{Solubilidad y estudio espectrofotométrico}

El resto piperidinil unido al anillo aromático de la pirimidina hace que el minoxidilo (MIN) se disuelva con dificultad en agua, pese a la polaridad que le confieren sus grupos funcionales (página 115).

En medio neutro, a $20,0^{\circ} \mathrm{C}$, se ha conseguido disolver $0,1540 \mathrm{~g}$ de minoxidilo en $100 \mathrm{ml}$ de agua. En medios ácidos, donde el óxido de amina se encuentra protonado, la solubilidad de este compuesto iónico aumenta significativamente.

El espectro de absorción del minoxidilo tiene tres bandas de gran intensidad con máximos en 230, 262 y $288 \mathrm{~nm}$ (figura 4.87).

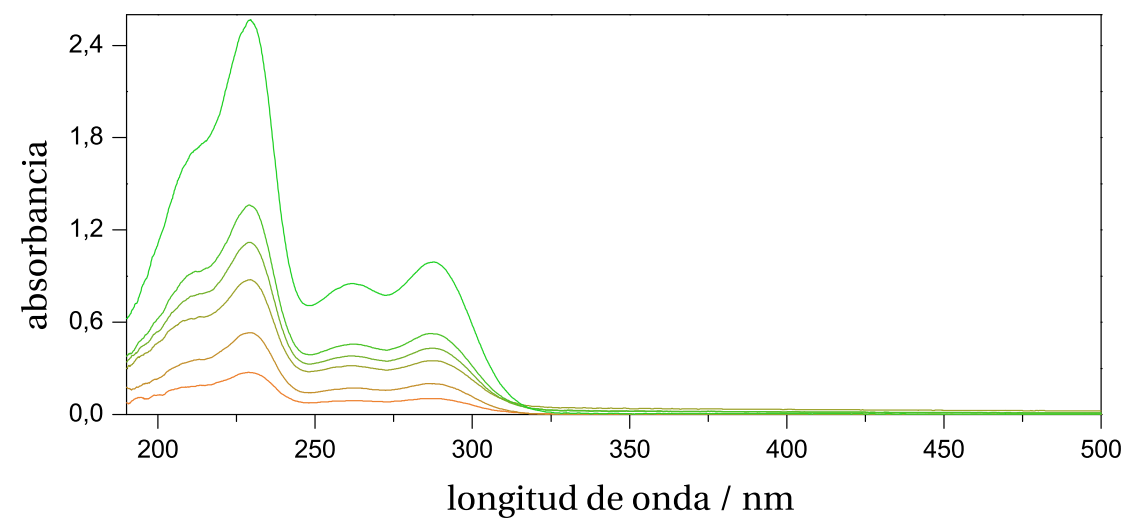

Figura 4.87: Espectro de absorción UV-visible del minoxidilo. $[\mathrm{MIN}]=7,99 \cdot 10^{-6}$ $7,99 \cdot 10^{-5} \mathrm{M}, \mathrm{pH}=6,8, T=20,0^{\circ} \mathrm{C}$.

Por su interés cinético, se han determinado los coeficientes de absorción molar de las dos bandas más intensas (figura 4.88):

$$
\begin{aligned}
& \varepsilon_{\mathrm{MIN}, 230 \mathrm{~nm}}=34.300 \pm 900 \mathrm{M}^{-1} \mathrm{~cm}^{-1} \\
& \varepsilon_{\mathrm{MIN}, 288 \mathrm{~nm}}=13.400 \pm 400 \mathrm{M}^{-1} \mathrm{~cm}^{-1}
\end{aligned}
$$




\section{8 | Nitrosación del minoxidilo}

\begin{tabular}{cccccc}
\hline$[\mathrm{MIN}] / \mathrm{M}$ & $A_{230}$ & $A_{288}$ & {$[\mathrm{MIN}] / \mathrm{M}$} & $A_{230}$ & $A_{288}$ \\
\hline $7,99 \cdot 10^{-6}$ & 0,1042 & 0,2714 & $3,19 \cdot 10^{-5}$ & 0,4299 & 1,1134 \\
$1,59 \cdot 10^{-5}$ & 0,1997 & 0,5319 & $3,99 \cdot 10^{-5}$ & 0,5242 & 1,3537 \\
$2,39 \cdot 10^{-5}$ & 0,3252 & 0,8494 & & & \\
\hline
\end{tabular}

$$
\begin{aligned}
& y=(0,00 \pm 0,02)+(34.300 \pm 900) x \\
& y=(0,00 \pm 0,01)+(13.400 \pm 400) x
\end{aligned}
$$

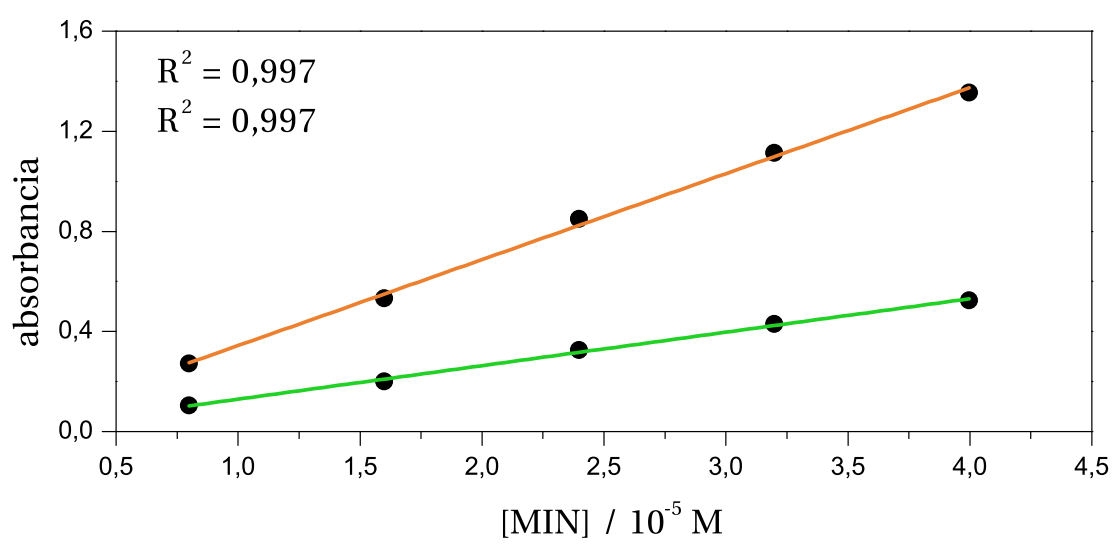

Tabla 4.46 y Figura 4.88: Cumplimiento de la ley de Lambert-Beer por el minoxidilo. $\lambda$ $=288 \mathrm{~nm}$ (verde), $\lambda=230 \mathrm{~nm}$ (naranja), $\mathrm{pH}=6,8, T=20,0^{\circ} \mathrm{C}$.

Se observa cómo los átomos que aportan electrones a la estructura aromática del minoxidilo hacen que sus bandas de absorción tengan coeficientes muy altos.

Debido al $\mathrm{pK}_{\mathrm{a}}$ de la reacción de protonación del óxido de amina, el espectro de absorción del minoxidilo cambia cuando el pH es cercano a 4,6. Se ha determinado cómo la variación de $\mathrm{pH}$ modifica la forma de los espectros, ya que puede ser significativo en el seguimiento cinético de la reacción de nitrosación del compuesto. La figura 4.89 muestra el resultado del experimento realizado según se indica en la sección 3.1.2.3. 


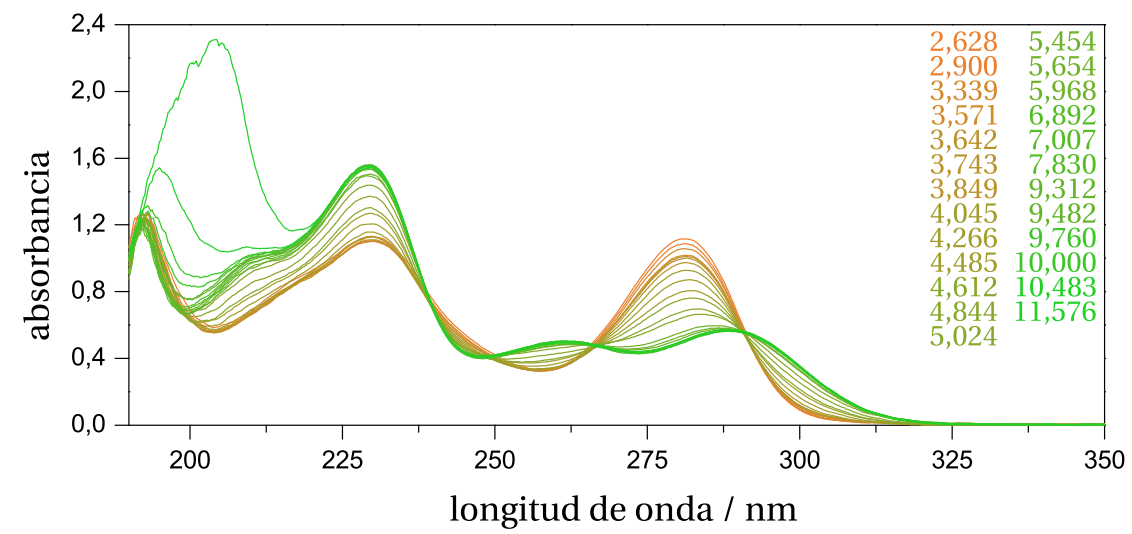

Figura 4.89: Variación del espectro de absorción del minoxidilo según el pH. [MIN] = $5,01 \cdot 10^{-5} \mathrm{M}, T=20,0^{\circ} \mathrm{C}$.

Al aumentar la acidez del medio, el oxígeno con carga negativa del óxido de amina se protona, rompiendo el enlace dativo por el que cedía su carga negativa al anillo aromático. Este efecto se aprecia en el espectro de absorción del compuesto, en el que según se reduce el $\mathrm{pH}$, la banda con máximo en $288 \mathrm{~nm}$ se desplaza hacia una posición más energética centrada en $\lambda=280 \mathrm{~nm}$. La figura 4.89 muestra que el equilibrio ácido-base del minoxidilo tiene cuatro puntos isosbésticos en $\lambda=198,239,265$ y $290 \mathrm{~nm}$.

También se ha determinado el coeficiente de extinción molar de la banda menos energética del minoxidilo a $\mathrm{pH}=3,1 \mathrm{y} \mathrm{pH}=4,1$ (figuras 4.90 y 4.91 , respectivamente):

$$
\begin{aligned}
& \varepsilon_{\mathrm{MIN}, 282 \mathrm{~nm}, \mathrm{pH}=3,1}=22.400 \pm 100 \mathrm{M}^{-1} \mathrm{~cm}^{-1} \\
& \varepsilon_{\mathrm{MIN}, 282 \mathrm{~nm}, \mathrm{pH}=4,1}=19.800 \pm 400 \mathrm{M}^{-1} \mathrm{~cm}^{-1}
\end{aligned}
$$

Como era de esperar, su intensidad se incrementa al aumentar la acidez. 


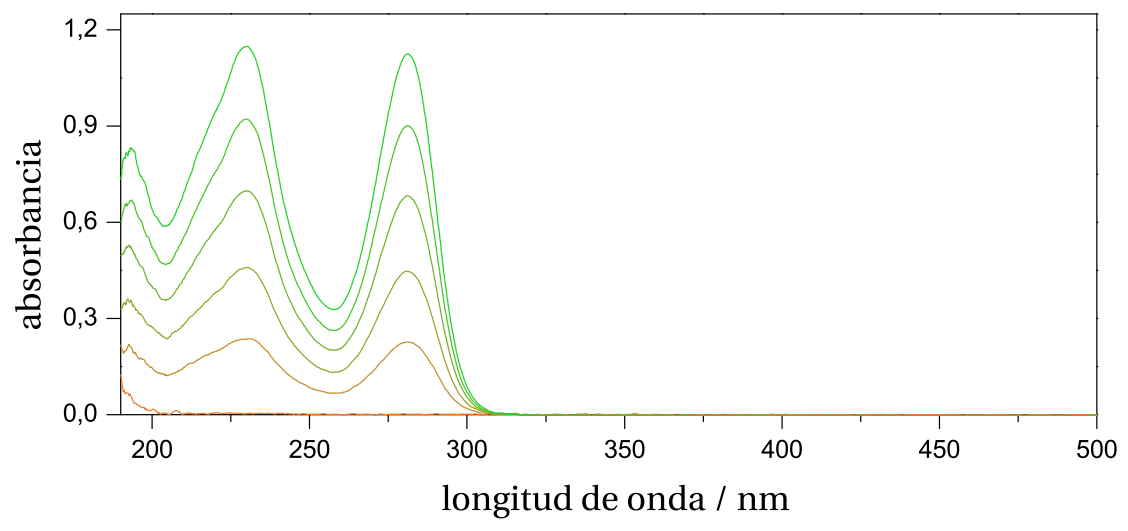

\begin{tabular}{cccc}
\hline$[\mathrm{MIN}] / \mathrm{M}$ & $A_{282}$ & {$[\mathrm{MIN}] / \mathrm{M}$} & $A_{282}$ \\
\hline $1,0 \cdot 10^{-5}$ & 0,2253 & $4,0 \cdot 10^{-5}$ & 0,8971 \\
$2,0 \cdot 10^{-5}$ & 0,4445 & $5,0 \cdot 10^{-5}$ & 1,1203 \\
$3,0 \cdot 10^{-5}$ & 0,6785 & & \\
\hline
\end{tabular}

$$
y=(0,000 \pm 0,004)+(22.400 \pm 100) x
$$

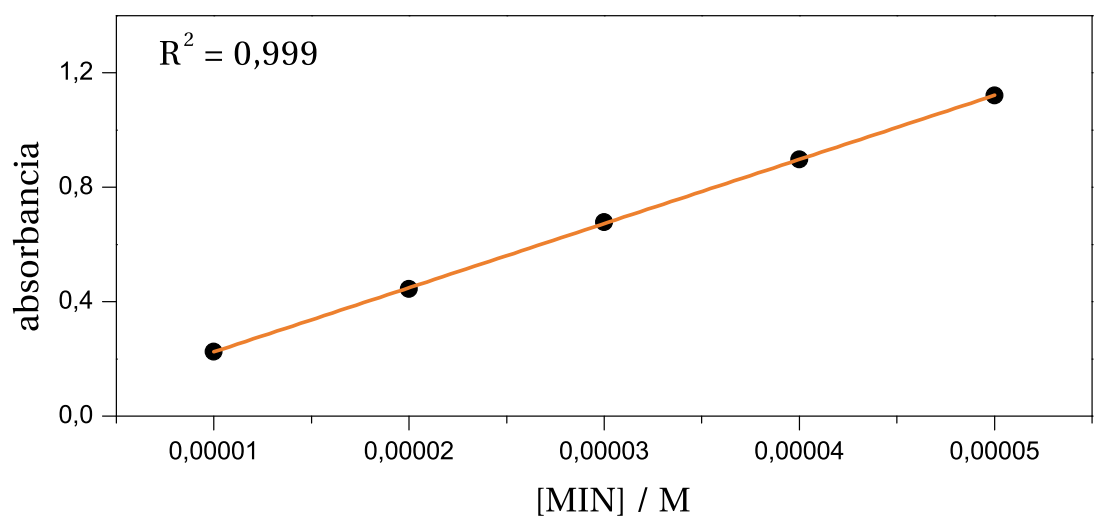

Tabla 4.47 y Figura 4.90: Coeficiente de absorción molar del minoxidilo a $\mathrm{pH}=3,1$. $\lambda=282 \mathrm{~nm}, T=20,0{ }^{\circ} \mathrm{C}$. 


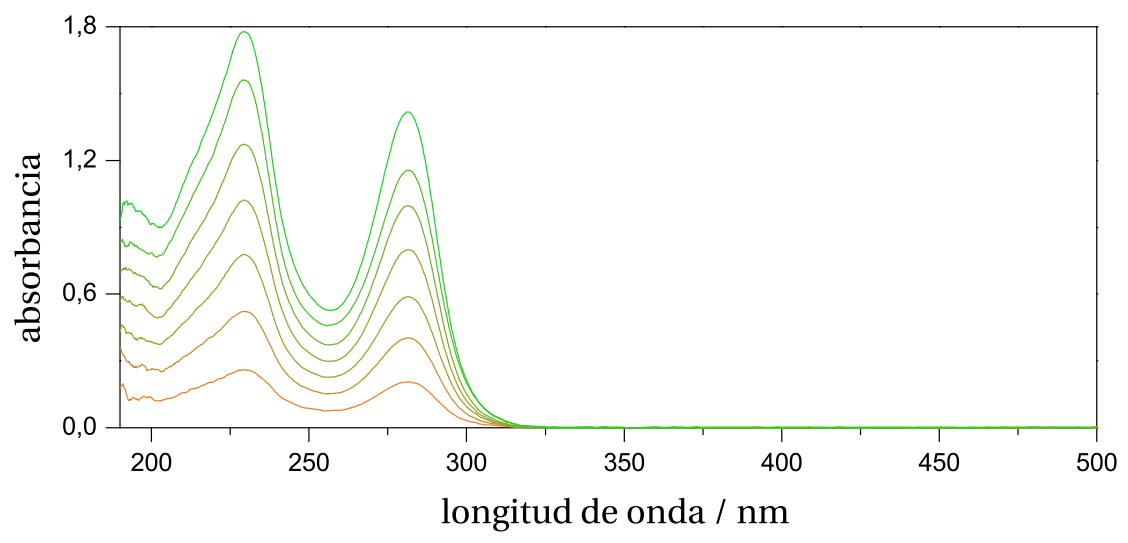

\begin{tabular}{cccc}
\hline$[\mathrm{MIN}] / \mathrm{M}$ & $A_{282}$ & {$[\mathrm{MIN}] / \mathrm{M}$} & $A_{282}$ \\
\hline $1,0 \cdot 10^{-5}$ & 0,2058 & $5,0 \cdot 10^{-5}$ & 0,9952 \\
$2,0 \cdot 10^{-5}$ & 0,4024 & $6,0 \cdot 10^{-5}$ & 1,1549 \\
$3,0 \cdot 10^{-5}$ & 0,5868 & $7,0 \cdot 10^{-5}$ & 1,4150 \\
$4,0 \cdot 10^{-5}$ & 0,7980 & & \\
\hline
\end{tabular}

$$
y=(0,00 \pm 0,02)+(19.800 \pm 400) x
$$

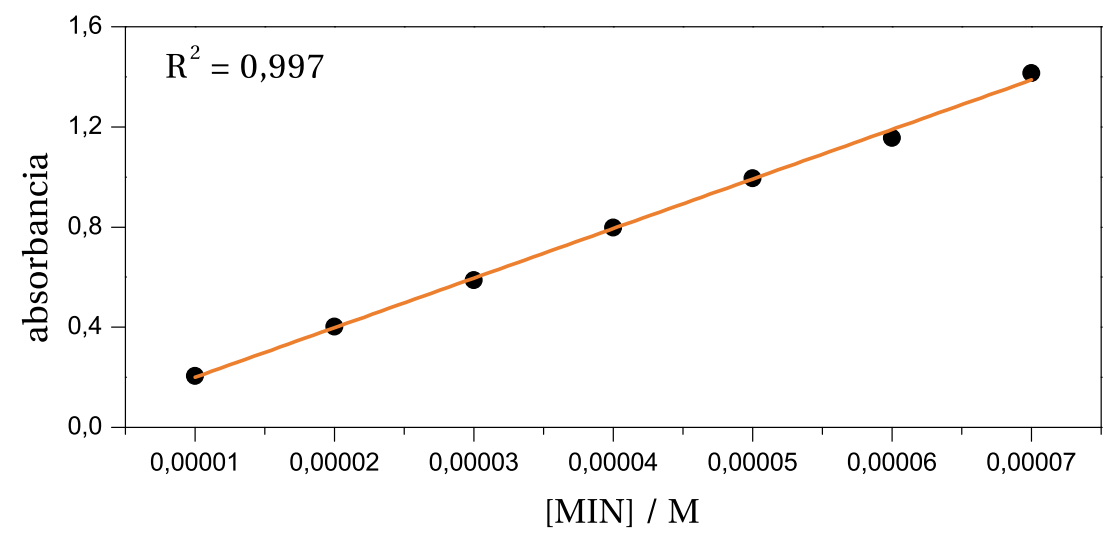

Tabla 4.48 y Figura 4.91: Coeficiente de absorción molar del minoxidilo a $\mathrm{pH}=4,1$. $\lambda=282 \mathrm{~nm}, T=20,0^{\circ} \mathrm{C}$. 


\subsubsection{Reacción entre minoxidilo y nitrito}

Para averiguar la mejor forma de seguir cinéticamente la reacción de nitrosación del minoxidilo, se preparó una disolución de ambos reactivos en medio ácido y se obtuvieron sus espectros de absorción a lo largo del tiempo. La figura 4.92 muestra los resultados.

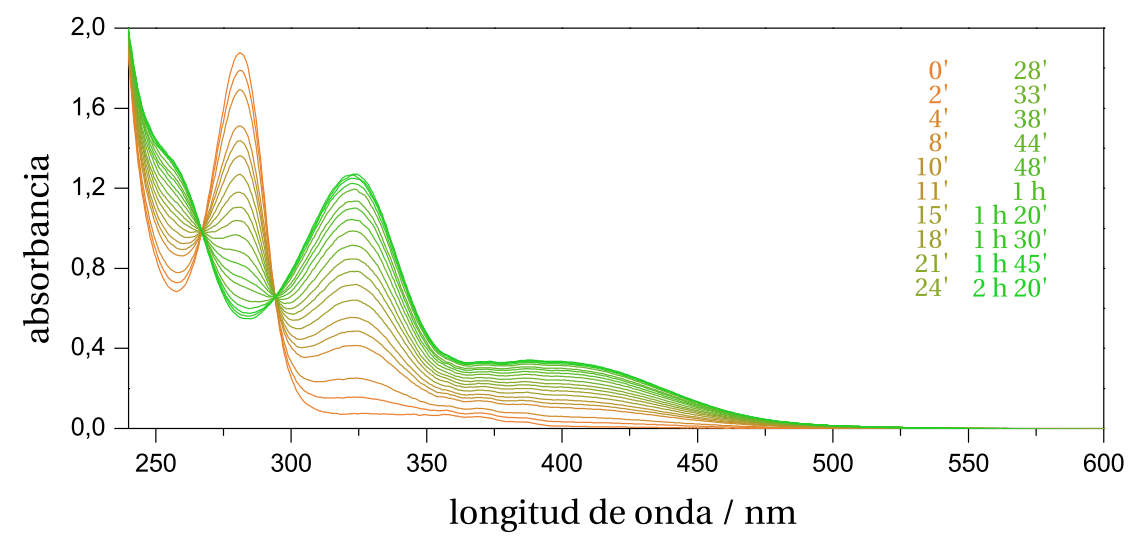

Figura 4.92: Variación con el tiempo del espectro de absorción del minoxidilo durante su nitrosación. $[\mathrm{MIN}]_{\circ}=5,81 \cdot 10^{-5} \mathrm{M}$, [NIT] $=1,83 \cdot 10^{-3} \mathrm{M}, \mathrm{pH}=4,0, T=20,0^{\circ} \mathrm{C}$.

Se observa que, sobre la banda de absorción característica del sistema nitroso/nitrito del primer espectrograma (en torno a $\lambda=350 \mathrm{~nm}$ ) van apareciendo dos bandas de absorción asociadas al producto de nitrosación nitrosominoxidilo, al mismo tiempo que disminuye la intensidad de la banda centrada en $\lambda=282$ $\mathrm{nm}$. Las dos nuevas bandas tienen sus máximos de absorción en $\lambda=321$ y 400 $\mathrm{nm}$. La figura 4.93 muestra los resultados obtenidos para medir sus coeficientes de absorción molar, trabajando siempre con exceso de nitrito. Se encontró así que:

$$
\begin{aligned}
& \varepsilon_{\mathrm{NMIN}, 321 \mathrm{~nm}}=14.070 \pm 80 \mathrm{M}^{-1} \mathrm{~cm}^{-1} \\
& \varepsilon_{\mathrm{NMIN}, 400 \mathrm{~nm}}=4.180 \pm 30 \mathrm{M}^{-1} \mathrm{~cm}^{-1}
\end{aligned}
$$

Los resultados obtenidos aconsejaron seguir la reacción de nitrosación del 


\begin{tabular}{cccccc}
\hline$[\mathrm{NMIN}] / \mathrm{M}$ & $A_{321}$ & $A_{400}$ & {$[\mathrm{NMIN}] / \mathrm{M}$} & $A_{321}$ & $A_{400}$ \\
\hline $1,62 \cdot 10^{-5}$ & 0,2058 & 0,0648 & $9,70 \cdot 10^{-5}$ & 1,3524 & 0,4030 \\
$3,23 \cdot 10^{-5}$ & 0,4294 & 0,1277 & $1,13 \cdot 10^{-4}$ & 1,5475 & 0,4602 \\
$4,85 \cdot 10^{-5}$ & 0,6587 & 0,1976 & $1,29 \cdot 10^{-4}$ & 1,7983 & 0,5355 \\
$8,09 \cdot 10^{-5}$ & 1,1150 & 0,3319 & $1,46 \cdot 10^{-4}$ & 2,0324 & 0,6074 \\
\hline
\end{tabular}

$$
\begin{aligned}
& y=-(0,02 \pm 0,007)+(14.070 \pm 80) x \\
& y=-(0,005 \pm 0,003)+(4.180 \pm 30) x
\end{aligned}
$$

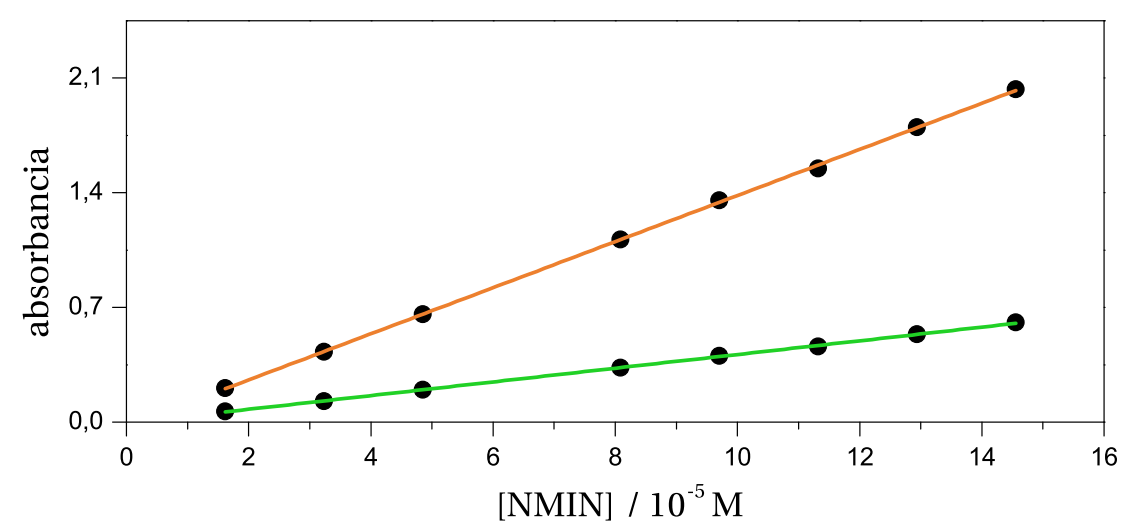

Tabla 4.49 y Figura 4.93: Cumplimiento de la ley de Lambert-Beer por el nitrosominoxidilo. $\lambda=321 \mathrm{~nm}$ (naranja), $\lambda=400 \mathrm{~nm}$ (verde), $\mathrm{pH}=4,0, T=20,0^{\circ} \mathrm{C}$.

minoxidilo en $\lambda=321 \mathrm{~nm}$, debido a la gran intensidad de esta banda y a la ausencia de otros picos que pudieran interferir.

\subsection{3. Órdenes parciales de reacción}

Para encontrar los órdenes parciales de reacción se ha utilizado los métodos de velocidades iniciales y aislamiento, trabajando con exceso de nitrito. De este 


\section{4 | Nitrosación del minoxidilo}

modo, la ecuación de velocidad

$$
v=k_{\mathrm{obs}}[\mathrm{MIN}]^{m}[\mathrm{NIT}]^{n}
$$

puede escribirse así:

$$
v=p[\mathrm{MIN}]^{m}
$$

siendo $p$ la pseudoconstante:

$$
p=k_{\mathrm{obs}}[\mathrm{NIT}]^{n}
$$

La forma logarítmica de la ecuación 4.140:

$$
\ln v_{\circ}=\ln p+m \ln [\mathrm{MIN}]_{\circ}
$$

se ha representado en la figura 4.94 que revela un orden parcial unitario respecto a la concentración de minoxidilo.

Trabajando con diferentes concentraciones en exceso de minoxidilo, se ha manejado la forma logarítmica de la ecuación 4.142:

$$
\ln p=\ln k_{\mathrm{obs}}+n \ln [\mathrm{NIT}]
$$

La figura 4.95 muestra que también es unitario el orden respecto a la concentración de nitrito.

\subsubsection{Determinación de las constantes de velocidad}

Para conocer la constante de velocidad de la reacción de nitrosación del minoxidilo se ha manejado el método de integración, con la misma concentración $a$ de ambos reactivos, de modo que:

$$
v=-\frac{d(a-x)}{d t}=k(a-x)^{2}
$$

La forma integrada de esa ecuación de velocidad es:

$$
\frac{1}{a-x}-\frac{1}{a}=k t
$$




\begin{tabular}{cccc}
\hline$[\mathrm{MIN}]_{\circ} / \mathrm{M}$ & $v_{\circ} / \mathrm{M} \mathrm{s}^{-1}$ & {$[\mathrm{MIN}]_{\circ} / \mathrm{M}$} & $v_{\circ} / \mathrm{M} \mathrm{s}^{-1}$ \\
\hline $2,99 \cdot 10^{-5}$ & 0,02339 & $8,99 \cdot 10^{-5}$ & 0,07189 \\
$4,49 \cdot 10^{-5}$ & 0,03760 & $1,044 \cdot 10^{-4}$ & 0,08209 \\
$5,99 \cdot 10^{-5}$ & 0,04980 & $1,198 \cdot 10^{-4}$ & 0,09430 \\
$7,49 \cdot 10^{-5}$ & 0,06149 & & \\
\hline
\end{tabular}

$$
y=(6,8 \pm 0,2)+(0,98 \pm 0,03) x
$$

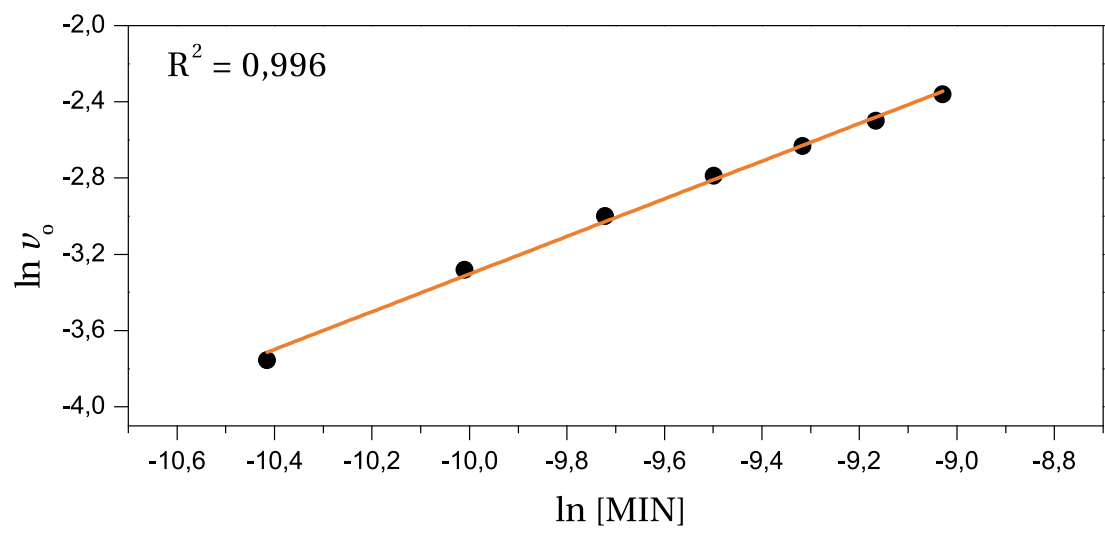

Tabla 4.50 y Figura 4.94: Influencia de la concentración de minoxidilo en la velocidad inicial de reacción. $[\mathrm{NIT}]=0,02 \mathrm{M}, \mathrm{pH}=4,00, I=0,2 \mathrm{M}, T=20,0^{\circ} \mathrm{C}$. 
266 | Nitrosación del minoxidilo

\begin{tabular}{cccc}
\hline$[\mathrm{NIT}] / \mathrm{M}$ & $p / \mathrm{s}^{-1}$ & {$[\mathrm{NIT}] / \mathrm{M}$} & $p / \mathrm{s}^{-1}$ \\
\hline $2,35 \cdot 10^{-2}$ & $3,58 \cdot 10^{-3}$ & $6,37 \cdot 10^{-2}$ & $1,001 \cdot 10^{-2}$ \\
$3,41 \cdot 10^{-2}$ & $5,35 \cdot 10^{-3}$ & $6,57 \cdot 10^{-2}$ & $1,001 \cdot 10^{-2}$ \\
$4,54 \cdot 10^{-2}$ & $6,72 \cdot 10^{-3}$ & $6,71 \cdot 10^{-2}$ & $1,001 \cdot 10^{-2}$ \\
$5,48 \cdot 10^{-2}$ & $8,34 \cdot 10^{-3}$ & & \\
\hline
\end{tabular}

$$
y=(1,9 \pm 0,1)+(1,00 \pm 0,02) x
$$

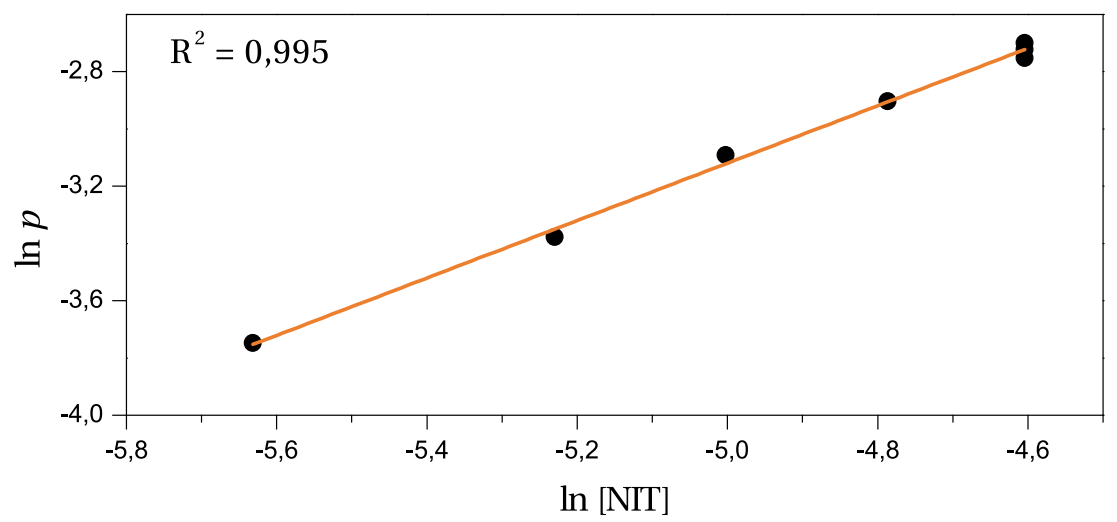

Tabla 4.51 y Figura 4.95: Influencia de la concentración de nitrito en el parámetro $p$. $\mathrm{pH}=4,00, I=0,2 \mathrm{M}, T=20,0^{\circ} \mathrm{C}$. 


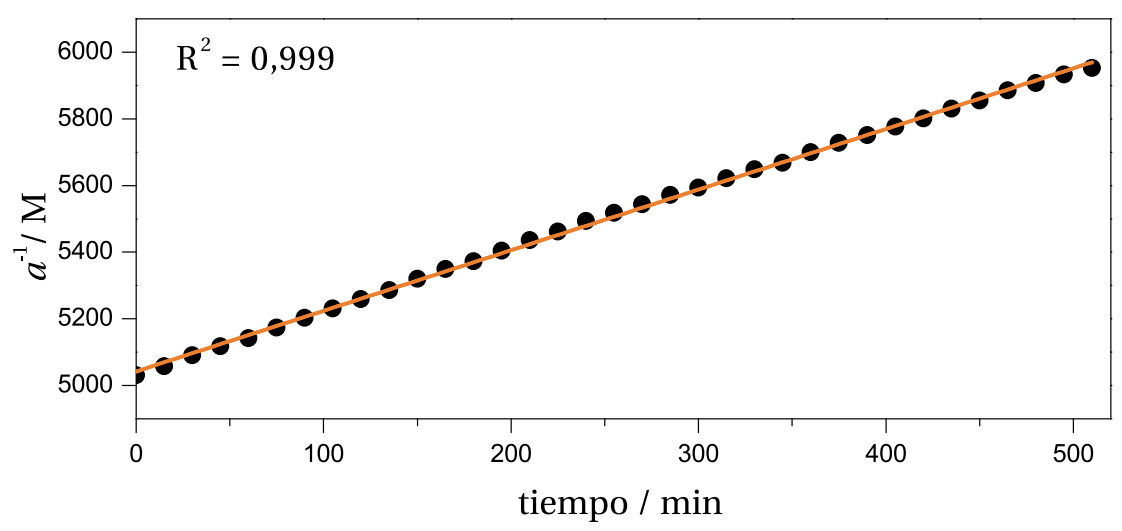

Tabla 4.52 y Figura 4.96: Ajuste de los datos experimentales a la forma integrada de la ecuación de velocidad de segundo orden. $[\mathrm{MIN}]_{\circ}=[\mathrm{NIT}]_{\circ}=a_{\circ}=2,00 \cdot 10^{-4} \mathrm{M}, \mathrm{pH}=4,00$, $I=0,2 \mathrm{M}, T=20,0^{\circ} \mathrm{C}$.

La figura 4.96 muestra el excelente ajuste de los resultados a la ecuación de velocidad de orden dos. La pendiente de la recta corresponde directamente a la constante de velocidad. El valor inverso de la ordenada en el origen $a^{-1}$ es, en efecto, la concentración inicial de reactivos, lo que supone una sanción favorable del método de trabajo utilizado.

\subsubsection{Influencia de acidez del medio}

Del mecanismo de reacción propuesto (esquema 4.8) se deduce con facilidad la ecuación 4.149. Con objeto de verificar la validez de este mecanismo, se programó una serie de experimentos cinéticos a diferentes pHs. La figura 4.97 muestra los resultados obtenidos.

$$
k_{\mathrm{obs}}=\frac{k_{a} K_{2}\left[\mathrm{H}^{+}\right]^{2}}{\left(\left[\mathrm{H}^{+}\right]+K_{1}\right)\left(1+\frac{k_{-a}}{K_{b} k_{c}}\left[\mathrm{H}^{+}\right]\right)}
$$




\section{8 | Nitrosación del minoxidilo}

$$
\begin{aligned}
& \mathrm{HNO}_{2} \stackrel{K_{1}}{\rightleftharpoons} \mathrm{NO}_{2}^{-}+\mathrm{H}^{+} \\
& \mathrm{HNO}_{2}+\mathrm{H}^{+} \stackrel{K_{2}}{\rightleftharpoons} \mathrm{H}_{2} \mathrm{NO}_{2}^{+} / \mathrm{NO}^{+}+\mathrm{H}_{2} \mathrm{O}
\end{aligned}
$$<smiles>Nc1cc(P)nc(N)[n+]1[O-]</smiles><smiles>Nc1c[n+]([O-])c([N+](=O)[O-])[c+]([O-])c(P)n1</smiles><smiles>NC1=[N+]([O-])C(=[NH2+])N=C(Pc2ccccc2)C1N=O</smiles>

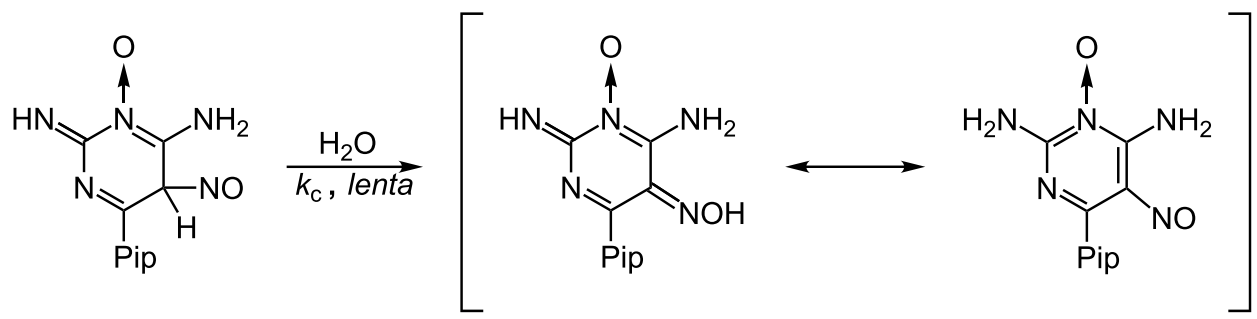

Esquema 4.8: Mecanismo propuesto para la nitrosación del minoxidilo.

De la misma forma que se procedió con los demás sustratos nitrosables, el ajuste de la ecuación 4.149 se ha hecho manejándola en la forma:

$$
k_{\mathrm{obs}}=\frac{\alpha\left[\mathrm{H}^{+}\right]^{2}}{\left(\left[\mathrm{H}^{+}\right]+K_{1}\right)\left(1+\beta\left[\mathrm{H}^{+}\right]\right)}
$$

obteniendo, para los parámetros ajustables $\alpha$ y $\beta$ los valores:

$$
\alpha=4.500 \pm 300 \mathrm{M}^{-2} \mathrm{~s}^{-1}
$$




\begin{tabular}{cccc}
\hline $\mathrm{pH}$ & $k_{\mathrm{obs}} / \mathrm{M}^{-1} \mathrm{~s}^{-1}$ & $\mathrm{pH}$ & $k_{\mathrm{obs}} / \mathrm{M}^{-1} \mathrm{~s}^{-1}$ \\
\hline 2,32 & 2,0563 & 3,63 & 0,2676 \\
2,48 & 1,8607 & 3,68 & 0,2276 \\
2,57 & 1,7210 & 3,68 & 0,1754 \\
2,71 & 1,4922 & 3,72 & 0,1877 \\
2,86 & 1,2240 & 3,75 & 0,1451 \\
2,99 & 1,0243 & 3,78 & 0,1933 \\
3,19 & 0,6168 & 3,83 & 0,1066 \\
3,27 & 0,5342 & 4,05 & 0,1137 \\
3,27 & 0,5390 & 4,61 & 0,0208 \\
3,39 & 0,4002 & 4,62 & 0,0168 \\
3,47 & 0,3256 & & \\
\hline
\end{tabular}

$$
y=\frac{(4.500 \pm 300)\left(10^{-x}\right)^{2}}{\left(10^{-x}+6,65 \cdot 10^{-4}\right)\left(1+(1.700 \pm 100) 10^{-x}\right)}
$$

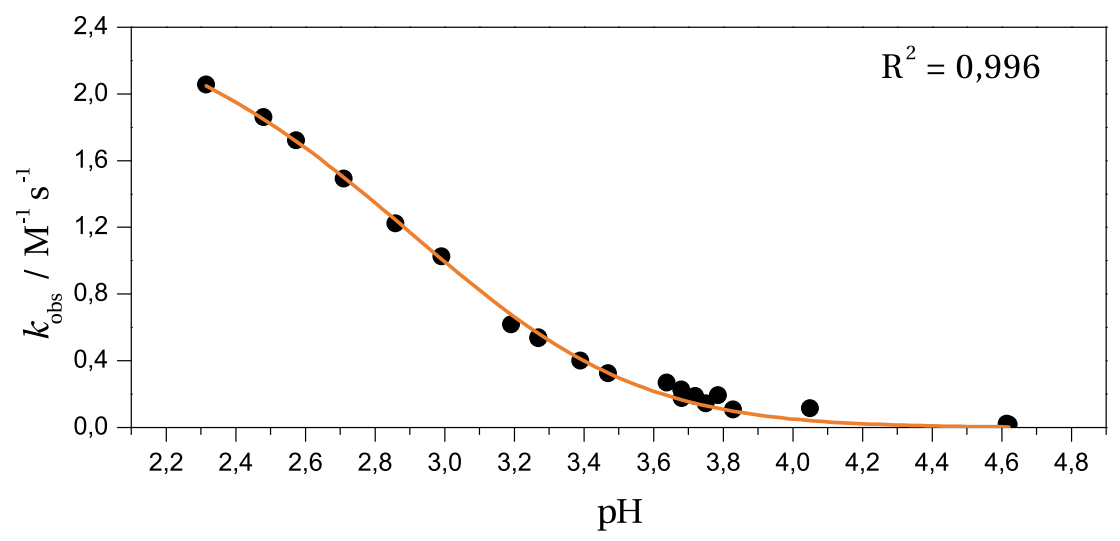

Tabla 4.53 y Figura 4.97: Influencia de la acidez del medio en la constante de velocidad observada. $[\mathrm{MIN}]_{\circ}=[\mathrm{NIT}]_{\circ}=2,00 \cdot 10^{-4} \mathrm{M}, I=0,2 \mathrm{M}, T=20,0^{\circ} \mathrm{C}$. 


\section{0 | Nitrosación del minoxidilo}

$$
\beta=1.700 \pm 100 \mathrm{M}^{-1}
$$

Con el valor del parámetro $\alpha$ se ha calculado el de $k_{a}$, constante de velocidad de la reacción de nitrosación del minoxidilo (esquema 4.8). Como $K_{2}=3 \cdot 10^{-7} \mathrm{M}^{-1}$ se obtiene que: ${ }^{81}$

$$
k_{a}=(1,5 \pm 0,1) \cdot 10^{10} \mathrm{M}^{-1} \mathrm{~s}^{-1}
$$

El orden de magnitud de la constante de velocidad sugiere que la reacción de nitrosación del minoxidilo se encuentra controlada por difusión.

\subsubsection{Influencia de la fuerza iónica}

Como con los demás sustratos de nitrosación investigados en este trabajo, se realizaron experimentos cinéticos con distintos valores de la fuerza iónica $I$, regulada con $\mathrm{NaClO}_{4}$ (que no da lugar a la formación de compuestos de nitrosilo). La figura 4.98 muestra que, también como en los casos anteriores, la fuerza iónica no ejerce influencia sobre la constante de velocidad $k_{\mathrm{obs}}$, coherentemente con el mecanismo propuesto.

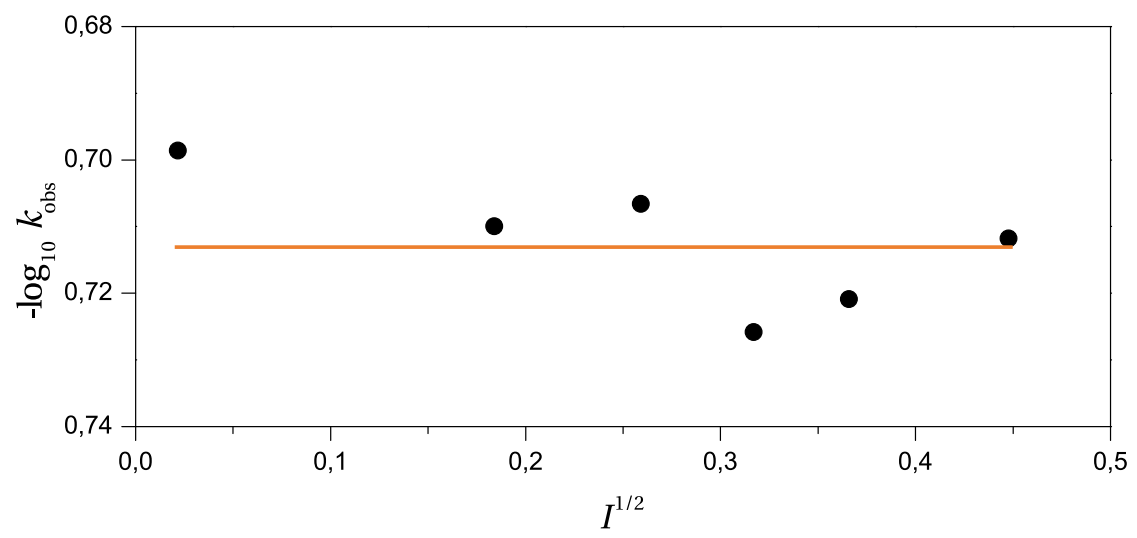

Figura 4.98: Influencia de la fuerza iónica en la constante de velocidad. $[\mathrm{MIN}]_{\circ}=[\mathrm{NIT}]_{\circ}$ $=2,00 \cdot 10^{-4} \mathrm{M}, \mathrm{pH}=4,00, T=20,0^{\circ} \mathrm{C}$. 


\subsubsection{Efecto isotópico cinético}

Realizando la misma reacción en dos medios diferentes, uno con agua y otro con agua pesada, se ha determinado el efecto isotópico cinético que aparece en la reacción de nitrosación del minoxidilo. A pH $=2,0,\left(k_{a} / K_{b} k_{c}\right)\left[\mathrm{H}^{+}\right] \gg 1$ y $\left[\mathrm{H}^{+}\right] \gg K_{1}$, la ecuación 4.149 se simplifica, obteniéndose el siguiente cociente entre las constantes en los dos medios:

$$
\frac{k_{\text {obs }}^{\mathrm{H}_{2} \mathrm{O}}}{k_{\text {obs }}^{\mathrm{D}_{2} \mathrm{O}}}=\frac{K_{2}^{\mathrm{H}_{2} \mathrm{O}}}{K_{2}^{\mathrm{D}_{2} \mathrm{O}}} \frac{k_{\mathrm{c}}^{\mathrm{H}_{2} \mathrm{O}}}{k_{\mathrm{c}}^{\mathrm{D}_{2} \mathrm{O}}}
$$

El estudio cinético de las reacciones de nitrosación en agua y agua deuterada condujo a los valores: $k_{\text {obs }}^{\mathrm{H}_{2} \mathrm{O}}=2,29 \mathrm{M}^{-1} \mathrm{~s}^{-1}$ y $k_{\text {obs }}^{\mathrm{D}_{2} \mathrm{O}}=0,73 \mathrm{M}^{-1} \mathrm{~s}^{-1}$. Como el coeficiente $K_{2}^{\mathrm{D}_{2} \mathrm{O}} / K_{2}^{\mathrm{H}_{2} \mathrm{O}}=2,7$, resulta que: ${ }^{257}$

$$
\frac{k_{\mathrm{c}}^{\mathrm{H}_{2} \mathrm{O}}}{k_{\mathrm{c}}^{\mathrm{D}_{2} \mathrm{O}}}=8,41
$$

El efecto isotópico así encontrado es coherente con la desprotonación del intermedio de Wheland en la etapa determinante de velocidad (esquema 4.8).

\subsubsection{Influencia de la temperatura}

Como con los demás sustratos nitrosables, se estudió la influencia de la temperatura sobre la constante $\mathrm{k}_{c}$ de la reacción de nitrosación de minoxidil. La tabla 4.54 recoge los resultados obtenidos al trabajar en el intervalo $T=20-40{ }^{\circ} \mathrm{C}$.

\begin{tabular}{cccc}
\hline$T /{ }^{\circ} \mathrm{C}$ & $k_{\text {obs }} / \mathrm{M}^{-1} \mathrm{~s}^{-1}$ & $T /{ }^{\circ} \mathrm{C}$ & $k_{\text {obs }} / \mathrm{M}^{-1} \mathrm{~s}^{-1}$ \\
\hline 20,0 & 0,1905 & 35,0 & 0,2850 \\
25,0 & 0,2246 & 40,0 & 0,3298 \\
30,0 & 0,2638 & & \\
\hline
\end{tabular}

Tabla 4.54: Influencia de la temperatura en la constante de velocidad. $[\mathrm{MIN}]_{\circ}=[\mathrm{NIT}]_{\circ}=$ $2,00 \cdot 10^{-4} \mathrm{M}, \mathrm{pH}=4,00, I=0,2 \mathrm{M}$. 


$$
y=(6,8 \pm 0,5)+(20 \pm 1) \cdot 10^{3} x
$$

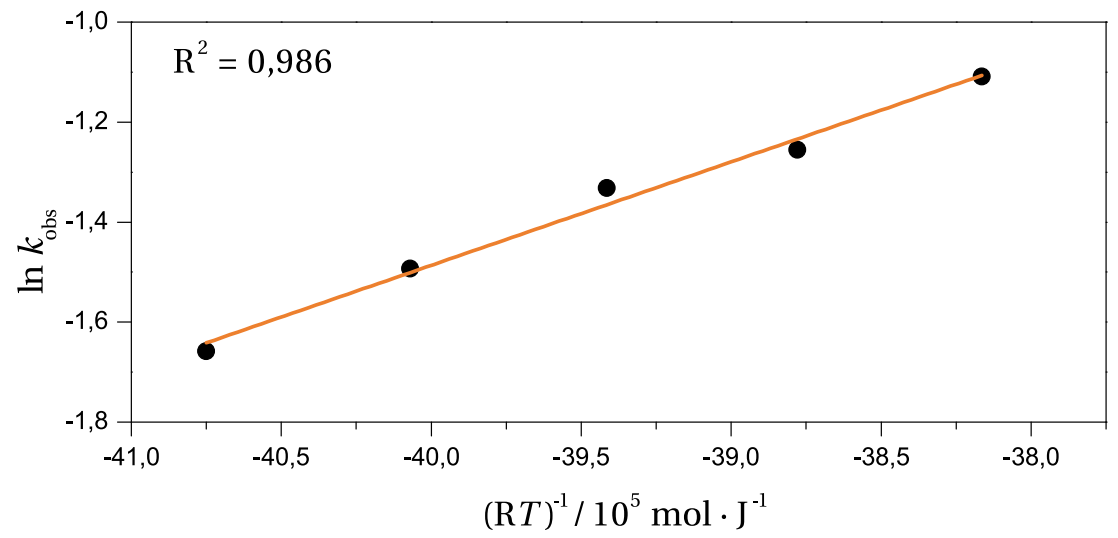

Figura 4.99: Cumplimiento de la ecuación de Arrhenius por los resultados de la tabla 4.54 .

$$
y=(0,068 \pm 0,004)+(18 \pm 1) \cdot 10^{3} x
$$

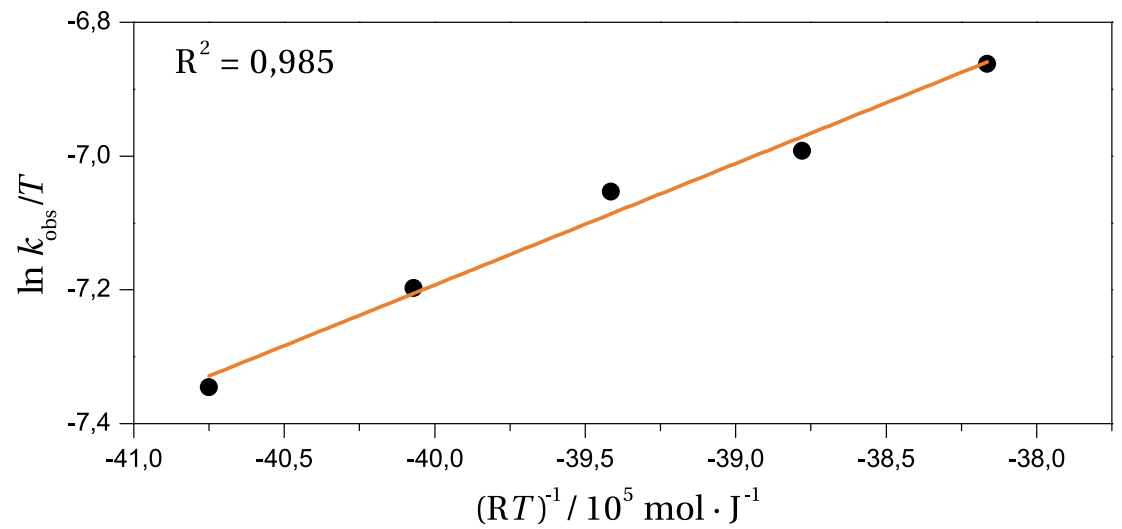

Figura 4.100: Cumplimiento de la ecuación de Eyring por los resultados de la tabla 4.54. 
Mediante las ecuaciones de Arrhenius y Eyring-Wynne-Jones (figuras 4.99 y 4.100) se obtuvieron los valores de los parámetros de activación:

\begin{tabular}{ccc}
\hline$E_{a} / \mathrm{kJ} \mathrm{mol}^{-1}$ & $\Delta H^{\ddagger} / \mathrm{kJ} \mathrm{mol}^{-1}$ & $\Delta S^{\ddagger} / \mathrm{J} \mathrm{K}^{-1} \mathrm{~mol}^{-1}$ \\
\hline $20 \pm 1$ & $18 \pm 1$ & $-163 \pm 20$ \\
\hline
\end{tabular}

Tabla 4.55: Parámetros de activación de la reacción de nitrosación del minoxidilo a partir de los datos de la tabla 4.54 .

\subsubsection{Determinación del producto de reacción}

En principio, el minoxidilo tiene cinco centros nitrosables en su estructura: el oxígeno del óxido de amina, el carbono 5 del anillo pirimidínico, los dos grupos amino primarios y uno terciario. Para averiguar cuál es el principal producto de reacción, se sintetizó el minoxidilo nitrosado (véase página 128), comprobando que es el mismo que se obtiene en los experimentos cinéticos y se ha caracterizado mediante diferentes técnicas, como se describe a continuación.

En primer lugar se obtuvo el espectro de masas del producto obtenido en un experimento cinético (figura 4.101). Junto al pico del minoxidilo $(210,0)$ se observa otro asignable al minoxidilo nitrosado $(210,0+39)$, lo que permite descartar una doble nitrosación del sustrato. Sin embargo, este resultado no aclara en qué sitio tiene lugar la nitrosación.

Los espectros de RMN de protón y carbono (páginas 276 y siguientes) han facilitado esa información. En el espectro de protón del minoxidilo (figura 4.103) se puede ver cómo aparecen dos bandas con varios picos casi solapadas en 1,46 y 1,54 ppm, correspondientes a los protones en meta y para del anillo de piperidina unido al anillo aromático. Sobre 3,34 aparecen los protones en orto del mismo anillo, desplazados por la influencia del nitrógeno adyacente a su carbono. Más desapantallado aparece un pico en 6,79 ppm, correspondiente al protón del carbono 5 aromático. En el espectrograma de ${ }^{1} \mathrm{H}$ RMN del nitrosominoxidilo se observa que ese pico desaparece (por eso el software del espectrómetro amplía la escala hasta el primer pico), lo que confirma que el protón correspondiente ha sido sustituido por el grupo nitroso. 


\section{4 | Nitrosación del minoxidilo}

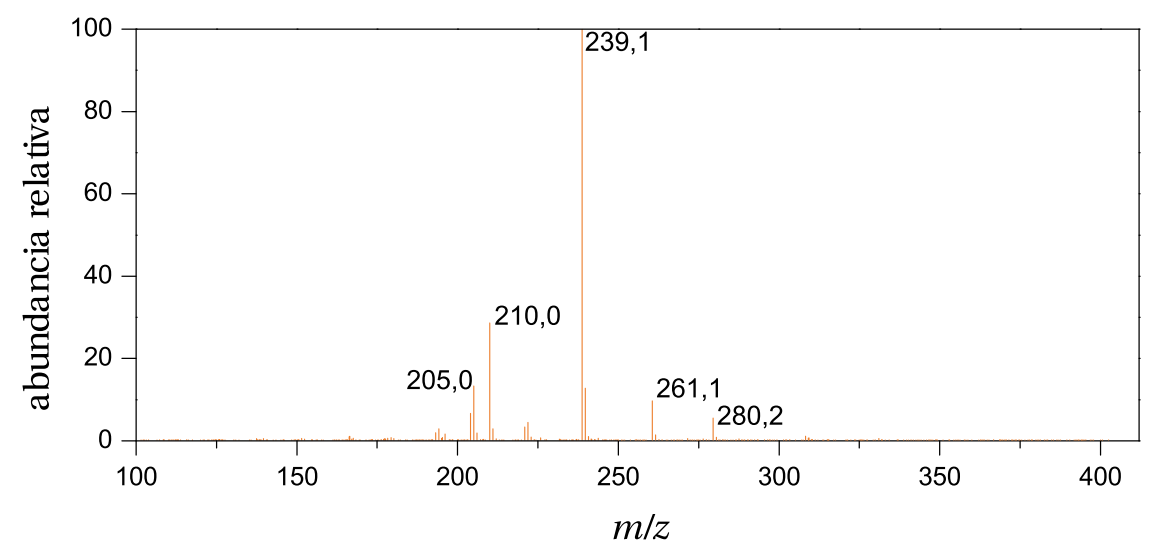

Figura 4.101: Espectro de masas por impacto electrónico positivo del nitrosominoxidilo.

Los espectros de resonancia magnética de carbono realizados a ambos compuestos también apuntan a que la nitrosación se produce en el carbono aromático. En el espectro realizado al minoxidilo se observan los picos correspondientes a los carbonos apantallados del anillo de piperidina (24,1 y 24,6 ppm) y los carbonos adyacentes al nitrógeno del mismo anillo (44,9 ppm). Los carbonos unidos a aminas del anillo de pirimidina aparecen desapantallados en 153,9, 152,9 y 151,7 ppm, mientras que el carbono 5 libre aparece más apantallado en $73,2 \mathrm{ppm}$. En el espectro de nitrosominoxidilo, se observa cómo este pico se ha desplazado hasta $139 \mathrm{ppm}$, lo que sugiere que ese carbono ha reaccionado con un grupo que le ha substraído densidad electrónica y lo ha desapantallado.

La prueba definitiva de el minoxidilo sufre C-nitrosación se ha obtenido por difracción de rayos X (figura 4.102). Los cristales de nitrosominoxidilo conseguidos por cristalización en metanol se han estudiado mediante esta técnica y se ha obtenido la celda unidad que se muestra en la figura 4.107. El nitrosominoxidilo se agrupa en celdas de cuatro moléculas de nitrosominoxidilo y cuatro moléculas de agua unidas por puentes de hidrógeno entre las moléculas de agua y las aminas y el óxido del nitrosominoxidilo. Los datos fundamentales del cristal y del refinado de la estructura se muestran en la tabla 4.56. Este difractograma confirma la estructura de la molécula nitrosada en el carbono aromático 5 del 


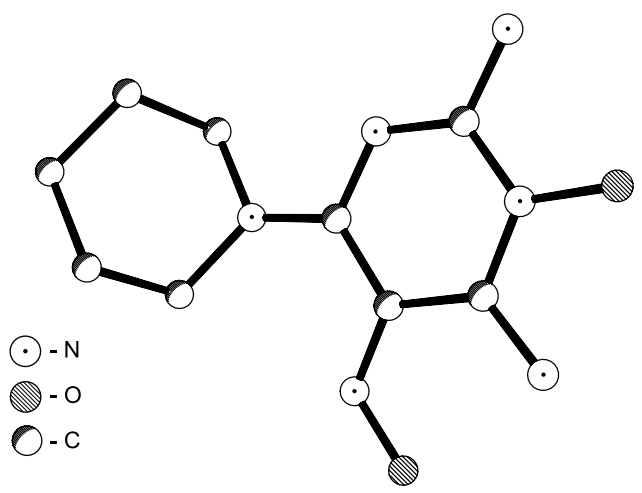

Figura 4.102: Detalle de una de las moléculas de nitrosominoxidilo en la celda unidad.

\begin{tabular}{ll}
\hline \multicolumn{1}{c}{ Propiedad } & \multicolumn{1}{c}{ Valor } \\
\hline Fórmula empírica & $4\left(\mathrm{C}_{9} \mathrm{H}_{1} 4 \mathrm{~N}_{6} \mathrm{O}_{2}\right) \mathrm{X}_{4} \mathrm{H}_{2} \mathrm{O}$ \\
Masa total de la celda & $1007,10 \mathrm{~g} / \mathrm{mol}$ \\
Temperatura & $293,2 \mathrm{~K}$ \\
Longitud de onda & $1,54178 \AA$ \\
Sistema cristalino, grupo espacial & Triclínico, P-1 \\
Dimensiones de la celda unidad & $\mathrm{a}=10,2884(3) \AA$ \\
& $\alpha=110,437(2)^{\circ}$ \\
& $\mathrm{b}=13,6490(3) \AA$ \\
& $\beta=95,594(2)^{\circ}$ \\
& $\mathrm{c}=18,6062(5) \AA$ \\
Coeficiente de absorción & $\gamma=91,674(2)^{\circ}$ \\
Tamaño del cristal & $0,886 \mathrm{~mm}^{-1}$ \\
Reflexiones medidas / singulares & $9.880 / 4.834$ \\
\hline
\end{tabular}

Tabla 4.56: Propiedades de la celda y del difractograma. 
276 | Nitrosación del minoxidilo

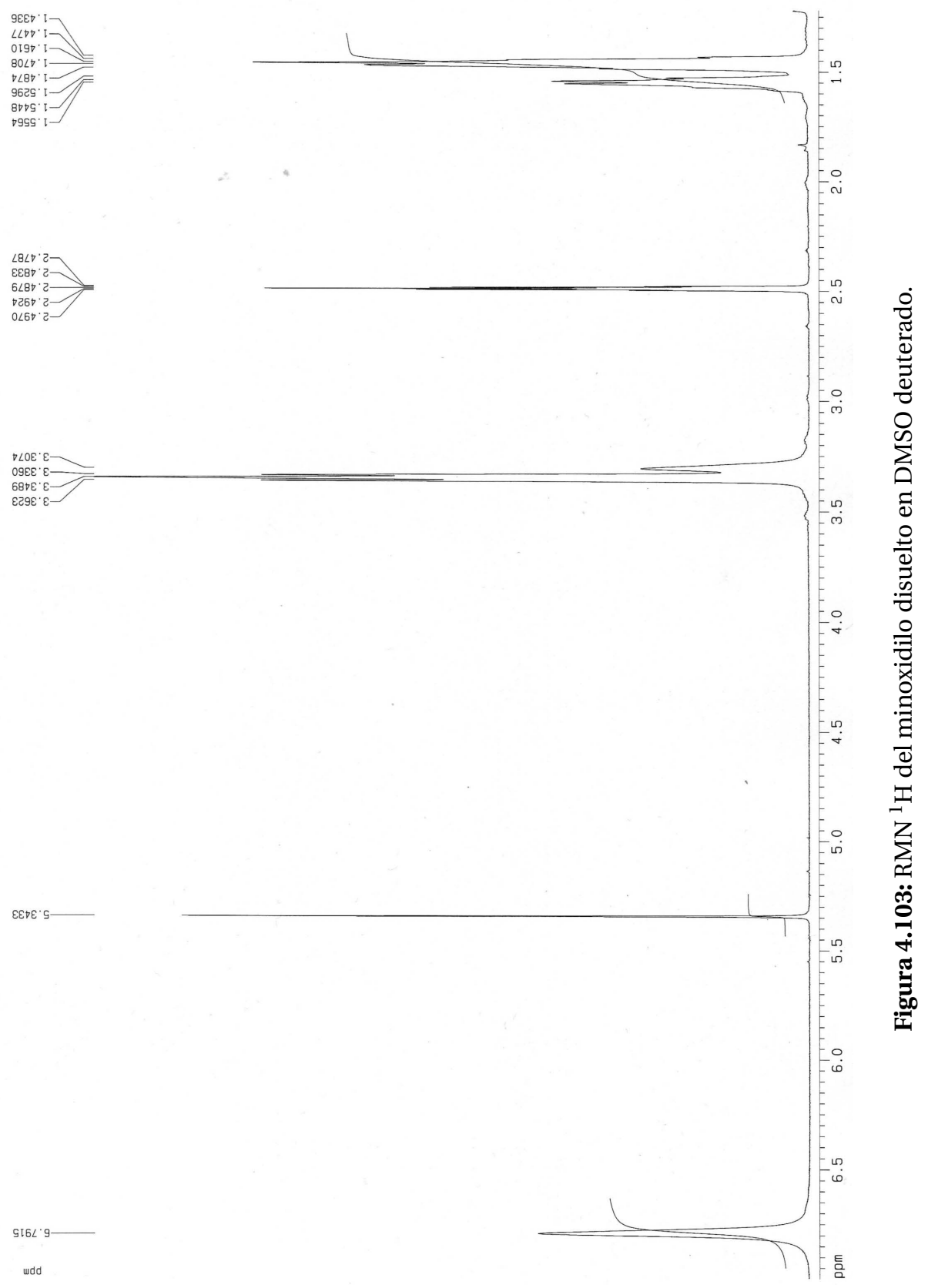


Resultados experimentales | 277

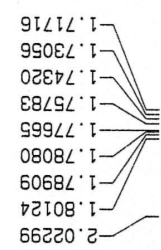

$\angle \nabla$ เ6己 $\varepsilon>$

ट๑९6ट $\varepsilon$

$\rightarrow 966 c^{\prime} \varepsilon$

$\neg \angle \varepsilon O \varepsilon^{\circ} \varepsilon$

$89 \angle 0 \varepsilon^{\circ} \varepsilon-$

$89+I I^{\circ} \mapsto$

IELCT' $\nabla$

SEIt०十
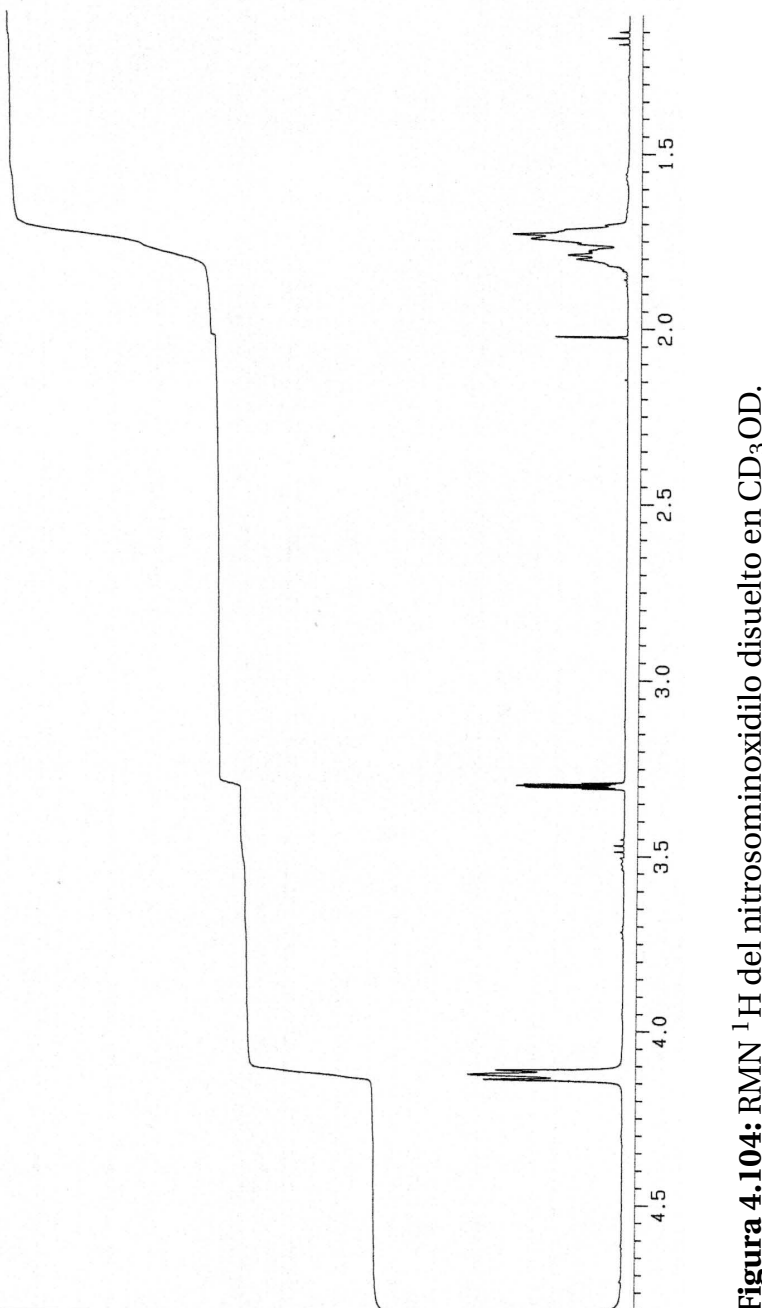

โอง $\angle \nabla \cdot S$

wdd

0 
278 | Nitrosación del minoxidilo

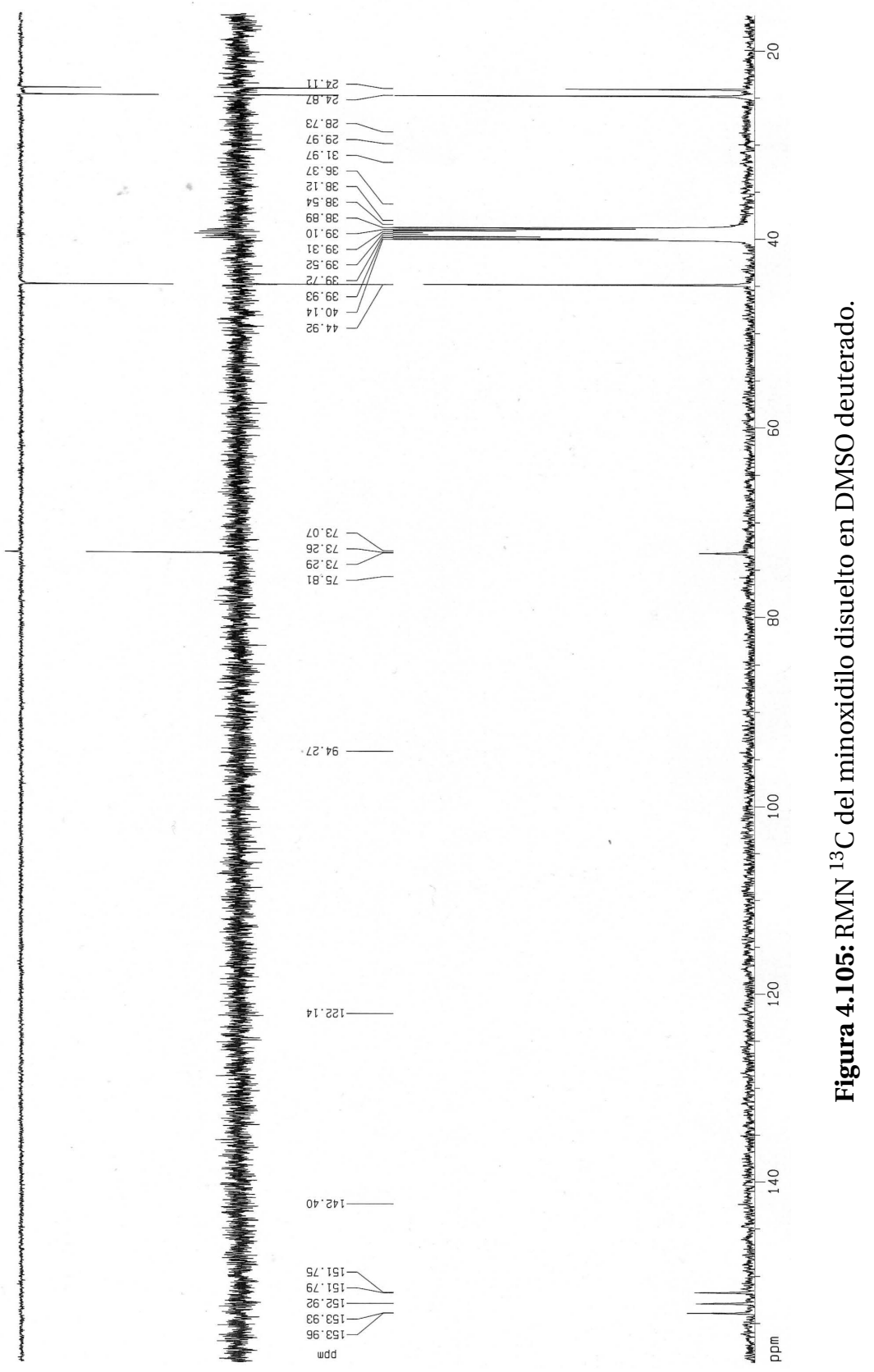


Resultados experimentales | 279

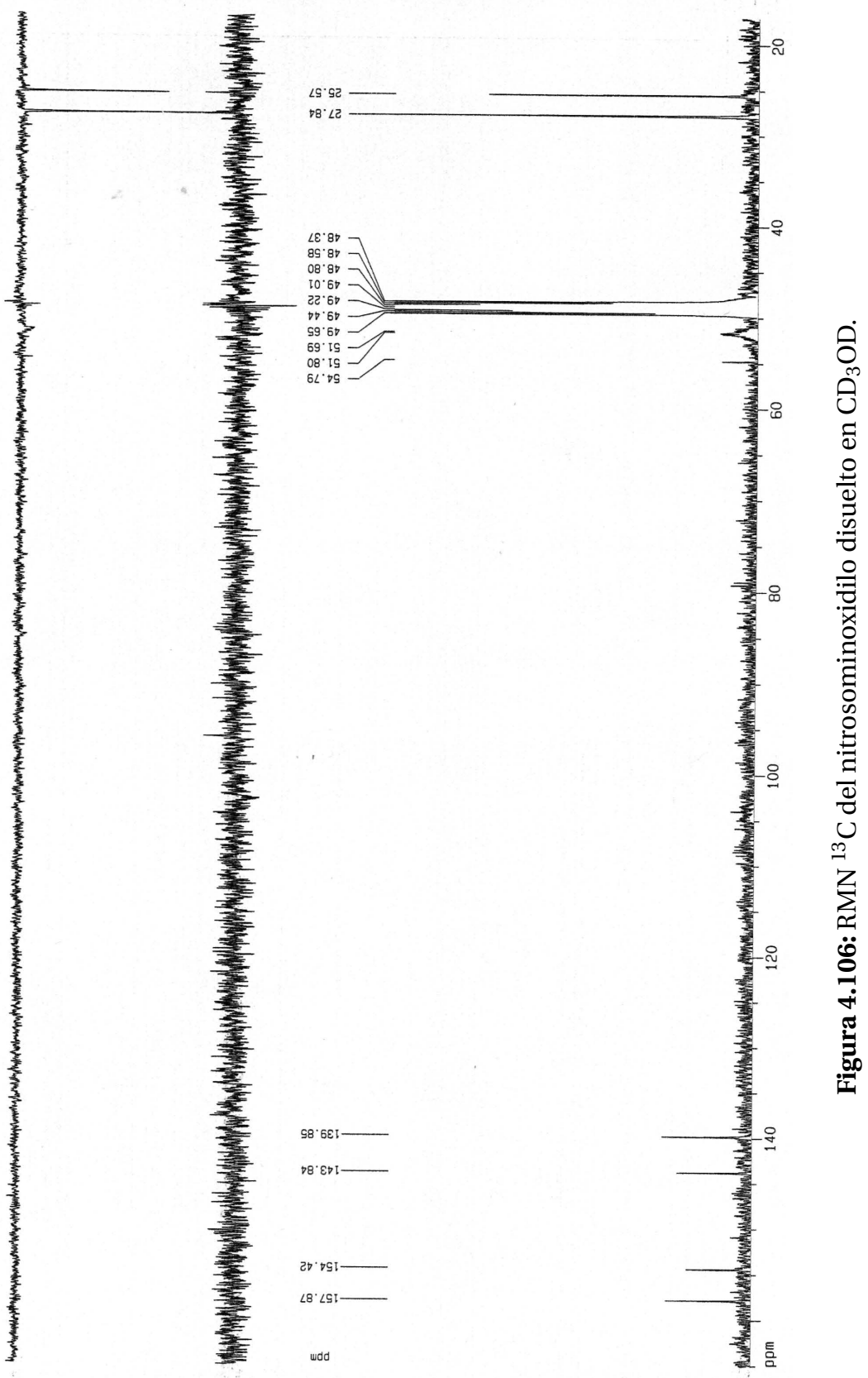



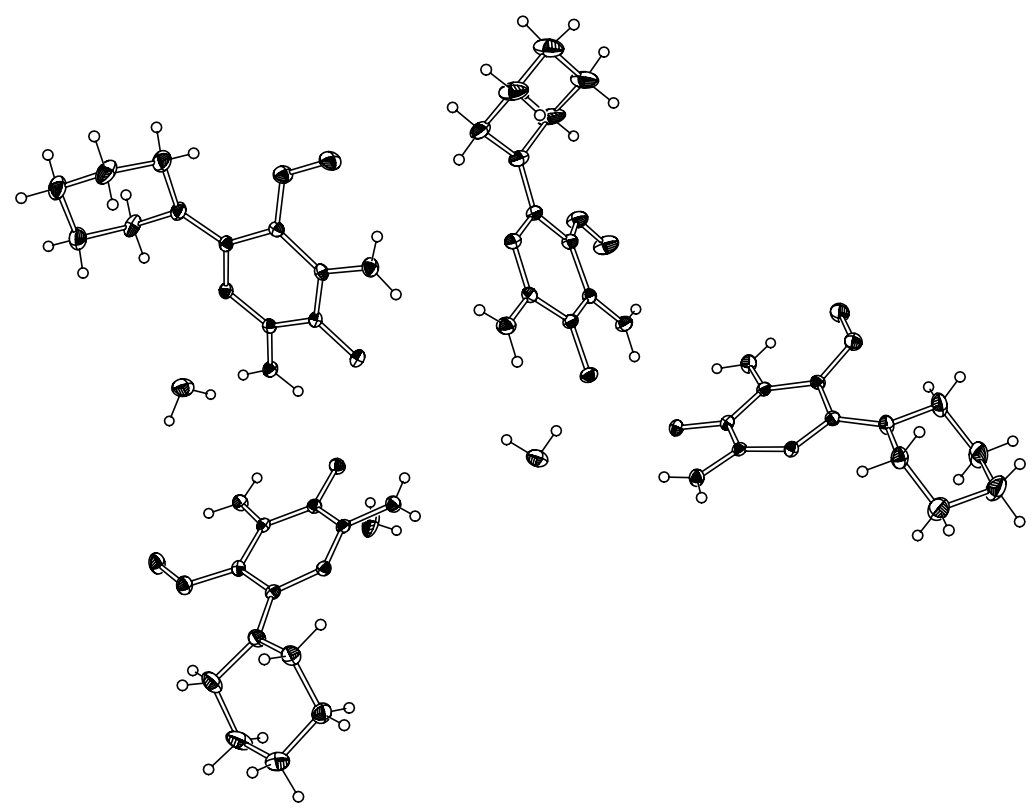

Figura 4.107: Geometría de la celda unidad de un cristal de nitrosominoxidilo.

anillo de pirimidina. Los cristales obtenidos de nitrosominoxidilo fundían a $T=180^{\circ} \mathrm{C}$.

\subsubsection{Actividad biológica del nitrosominoxidilo}

\section{Test de Ames}

La mutagenia del nitrosominoxidilo se ha determinado mediante el test de Ames. Los resultados obtenidos (tabla 4.57, figuras 4.108 y 4.109) demuestran que el nitrosominoxidilo no es un compuesto mutágeno en las dosis y cepas empleadas. Tanto en la cepa TA98, como en la TA100, con y sin activación con el sistema S9, no se produce para ninguna dosis un número de revertientes significativo con respecto a las placas a las que no se les añadía ningún compuesto (control negativo). Para descartar por completo la mutagenia del minoxidilo 


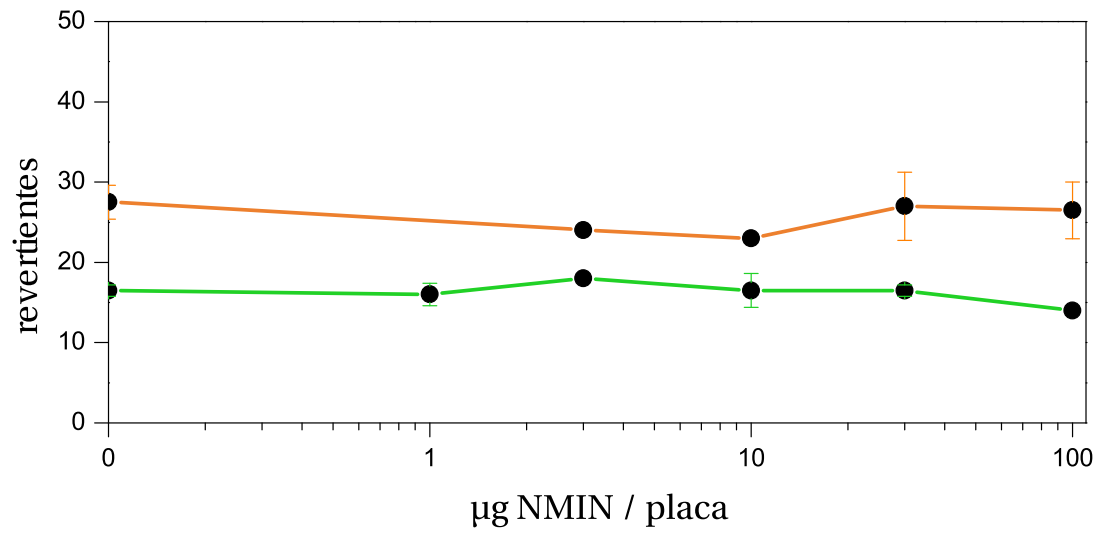

Figura 4.108: Resultados del Test de Ames con la cepa TA98 aplicado al nitrosominoxidilo. Los resultados sin extracto S9 se muestran de color naranja y los resultados con extracto S9, de color verde.

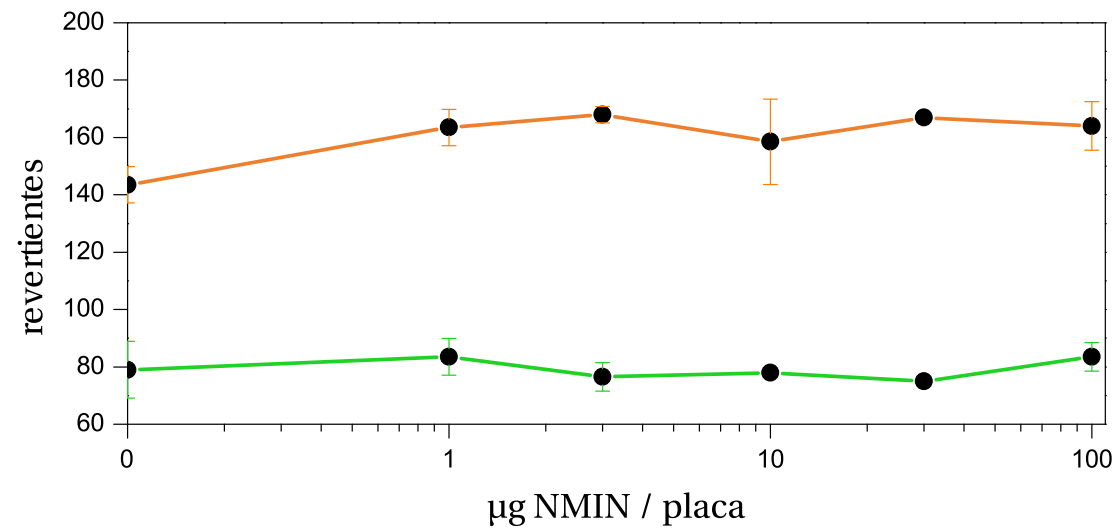

Figura 4.109: Resultados del Test de Ames con la cepa TA100 aplicado al nitrosominoxidilo. Los resultados sin extracto S9 se muestran de color naranja y los resultados con extracto S9, de color verde. 


\section{2 | Nitrosación del minoxidilo}

sería necesario repetir las experiencias con otras cepas de Salmonella typhimurium, como TA97 o TA102, y comprobar que tampoco las produce mutaciones.

\begin{tabular}{ccccc}
\hline$\mu \mathrm{g}$ NMIN / placa & TA98 & TA98 + S9 & TA100 & TA100 + S9 \\
\hline control negativo & $28 \pm 2$ & $16,5 \pm 0,7$ & $144 \pm 6$ & $80 \pm 10$ \\
1 & & $16 \pm 1$ & $164 \pm 6$ & $84 \pm 6$ \\
3 & 24 & 18 & $168 \pm 3$ & $76 \pm 5$ \\
10 & 23 & $16 \pm 2$ & $160 \pm 10$ & 78 \\
30 & $27 \pm 4$ & $16,5 \pm 0,7$ & 167 & 75 \\
100 & $26 \pm 3$ & $14 \pm 0$ & $164 \pm 8$ & $84 \pm 5$ \\
control positivo & 365 & 426 & $1.050 \pm 50$ & $730 \pm 10$ \\
\hline
\end{tabular}

Tabla 4.57: Resultados del test de Ames aplicado al nitrosominoxidilo. Controles positivos: TA98: $10 \mu \mathrm{g}$ NPD, TA98 + S9: $2 \mu \mathrm{g}$ 2AA, TA100: 0,3 $\mu \mathrm{g}$ 4NQO y TA100 + S9 $2 \mu \mathrm{g}$ 2AA

\section{Test del MTT}

Se ha estudiado la citotoxicidad del nitrosominoxidilo mediante el ensayo de proliferación celular MTT. Se han expuesto células V-79 durante 24 horas a cinco concentraciones diferentes del compuesto sintetizado y se ha medido la supervivencia de las células comparando la cantidad de MTT que reducen las células expuestas al compuesto con la cantidad reducida por células cultivadas en las mismas condiciones sin exposición a nitrosominoxidilo. Para todas las concentraciones, la supervivencia de las células ha sido aproximadamente del $100 \%$, por lo que se ha concluido que el nitrosominoxidilo, hasta una concentración de $1 \cdot 10^{-3} \mathrm{M}$, no es un compuesto citotóxico. 


\begin{tabular}{ccc}
\hline & {$[$ NMIN] $/ \mu \mathrm{M}$} & Supervivencia \\
\hline $\mathrm{a}$ & 0,1 & $(99 \pm 15) \%$ \\
$\mathrm{~b}$ & 1 & $(97 \pm 7) \%$ \\
$\mathrm{c}$ & 10 & $(98 \pm 5) \%$ \\
$\mathrm{~d}$ & 100 & $(99 \pm 5) \%$ \\
$\mathrm{e}$ & 1.000 & $(97 \pm 6) \%$ \\
\hline
\end{tabular}

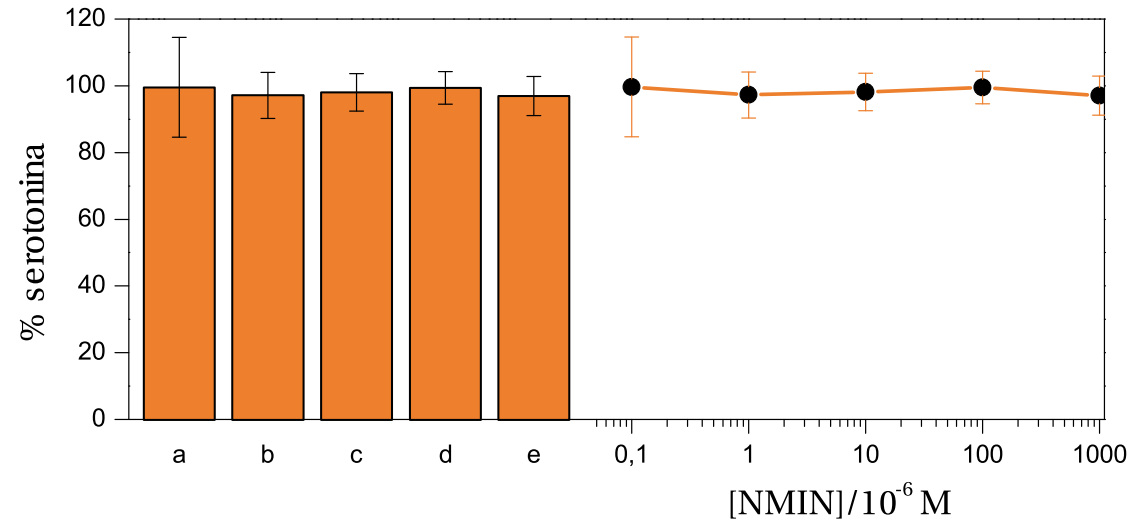

Tabla 4.58 y Figura 4.110: Supervivencia celular de V-79 en función de la concentración de nitrosominoxidilo. 


\section{4 | Determinación de nitrito con minoxidilo}

\subsection{Determinación de nitrito con minoxidilo}

Como se ha descrito en páginas anteriores de esta Memoria, los nitritos son compuestos ubicuos en el medio ambiente, lo que supone un peligro potencial, debido a su capacidad para formar complejos con la hemoglobina y para reaccionar con sustratos nitrosables presentes en los alimentos y formar nitrosocompuestos, muchos de los cuales son mutágenos y cancerígenos. Por ello, numerosos organismos internacionales recomiendan controlar la concentración de nitrito en los alimentos y en el agua (véase página 45).

Existen numerosos métodos para la detección y determinación de nitrito (véase página 51). Sin embargo, con frecuencia hay necesidad (sobre todo en el medio rural) de disponer de métodos sencillos y baratos que permitan la determinación de nitritos en aguas de pozos, manantiales, etc. Por ello, en este trabajo se propone un nuevo método colorimétrico que utiliza como reactivo la molécula de minoxidilo, que se puede adquirir a bajo precio en cualquier farmacia. La rapidez de la reacción minoxidilo-nitrito y el elevado coeficiente de absorción molar del nitrosominoxidilo simplifican notablemente las condiciones de experimentación.

El método que se propone también puede ser base de una práctica de laboratorio en currículos de medio ambiente o de grado en Química. ${ }^{266}$

\subsubsection{Descripción del método}

El método consiste en la preparación de un medio de reacción básico formado por minoxidilo como reactivo principal, ácido clorhídrico y cloruro sódico como catalizador que favorece la formación de cloruro de nitrosilo (página 62) y reduce el tiempo de reacción. Para ello se preparan disoluciones estándar de $\mathrm{HCl}\left(3,4 \cdot 10^{-2} \mathrm{M}\right), \mathrm{NaCl}(4,1 \mathrm{M})$ y minoxidilo $\left(3,9 \cdot 10^{-3} \mathrm{M}\right)$. Esta última disolución puede prepararse por pesada directa de minoxidilo o por dilución de un preparado farmacéutico de uso habitual contra la caída del cabello, que generalmente se comercializa en forma de disolución al 2 ó $5 \%$ de minoxidilo en una mezcla de agua, etanol y propilenglicol $(20 \%, 68-65 \%, 10 \%$, respectivamente).

Con esas disoluciones estándar se prepara el reactivo base con $10 \mathrm{ml}$ de mino- 
xidilo, $1 \mathrm{ml}$ de $\mathrm{NaCl}$ y $1 \mathrm{ml}$ de $\mathrm{HCl}$. El exceso de minoxidilo hace innecesario el empleo de tampón.

A continuación, el reactivo básico se mezcla con $10 \mathrm{ml}$ de la muestra a analizar y se mide la absorbancia en $\lambda=325 \mathrm{~nm}$, donde la banda del nitrosominoxidilo es muy intensa (figura 4.92, página 262). Cuando el perfil cinético alcanza la meseta, se mide la absorbancia y se calcula la concentración de nitrito.

\subsubsection{Curva de calibrado}

Para obtener la curva de calibrado se preparan seis disoluciones de $\mathrm{NaNO}_{2}$ de concentraciones entre $5,0 \cdot 10^{-5}$ y $3,00 \cdot 10^{-4} \mathrm{M}$, a partir de una disolución madre $1,0 \cdot 10^{-3} \mathrm{M}$. Con el método descrito en la sección anterior, se mezclan 10 $\mathrm{ml}$ de cada disolución con $12 \mathrm{ml}$ del reactivo base y se miden las absorbancias en $\lambda=325 \mathrm{~nm}$ (figura 4.111). Se comprobó que el pH de las disoluciones así preparadas se encontraba en el margen $\mathrm{pH}=4,01-4,03$.

Se medía la absorbancia una vez alcanzada la meseta y, con las concentraciones iniciales de nitrito, se dibujó la curva de calibrado. La ordenada en el origen

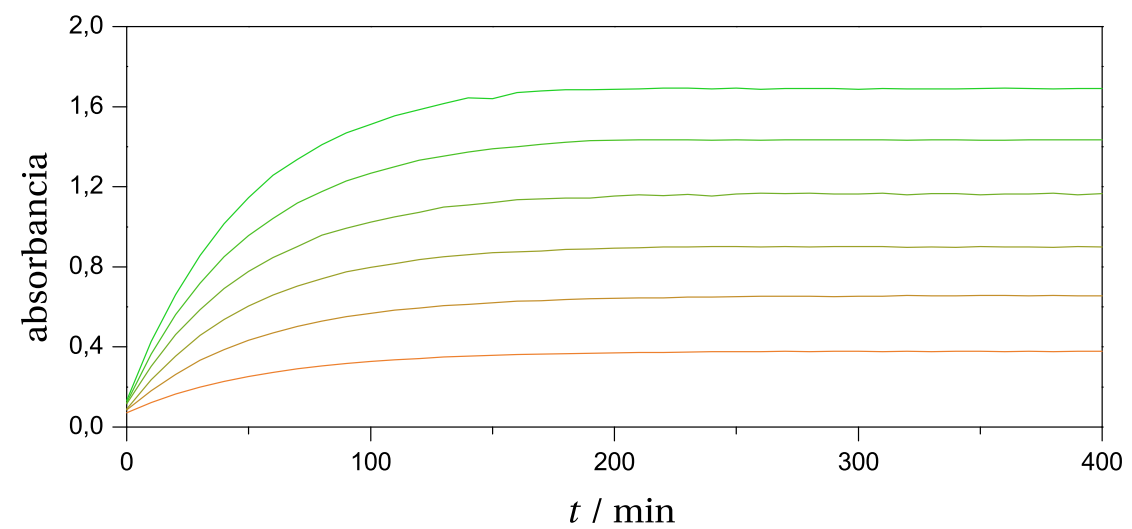

Figura 4.111: Perfiles cinéticos de las reacciones preparadas para el cálculo de la curva de calibrado. $\lambda=325 \mathrm{~nm}$, $[\mathrm{MIN}]=1,74 \cdot 10^{-3} \mathrm{M},\left[\mathrm{NaNO}_{2}\right]=2,37 \cdot 10^{-5}-1,42-4 \mathrm{M},[\mathrm{NaCl}]=$ $0,18 \mathrm{M}, \mathrm{pH}=4,01-4,03, T=25,0^{\circ} \mathrm{C}$. 


\section{6 | Determinación de nitrito con minoxidilo}

\begin{tabular}{cccc}
\hline$\left[\mathrm{NaNO}_{2}\right] / \mathrm{M}$ & $A_{325}$ & {$\left[\mathrm{NaNO}_{2}\right] / \mathrm{M}$} & $A_{325}$ \\
\hline $2,37 \cdot 10^{-5}$ & 0,3760 & $9,48 \cdot 10^{-5}$ & 1,1654 \\
$4,74 \cdot 10^{-5}$ & 0,6550 & $1,18 \cdot 10^{-4}$ & 1,4337 \\
$7,11 \cdot 10^{-5}$ & 0,9001 & $1,42 \cdot 10^{-4}$ & 1,6890 \\
\hline
\end{tabular}

$$
y=(0,119 \pm 0,007)+(11.040 \pm 70) x
$$

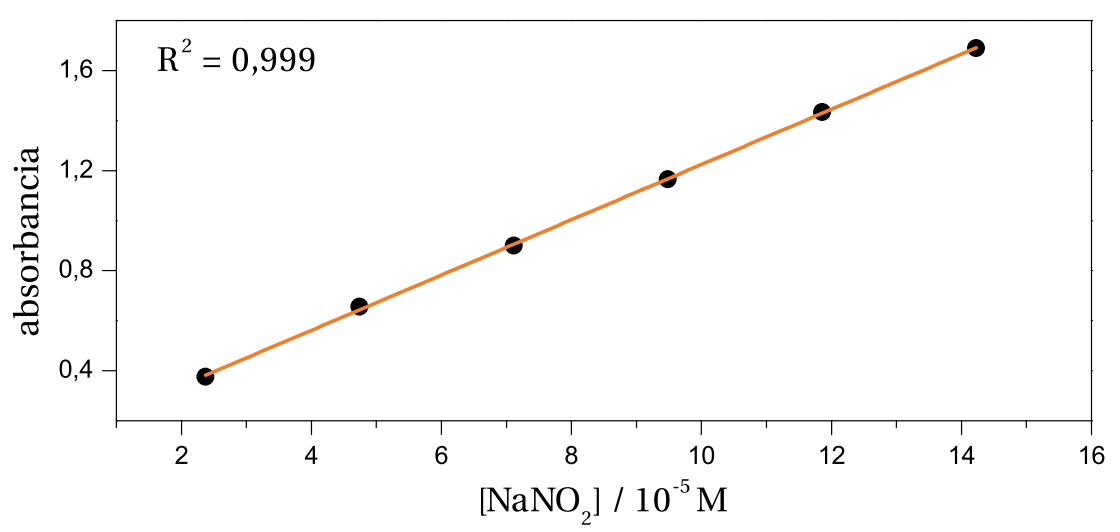

Tabla 4.59 y Figura 4.112: Curva de calibrado del nitrosominoxidilo. $\lambda=325 \mathrm{~nm}$, [MIN] $=1,74 \cdot 10^{-3} \mathrm{M},[\mathrm{NaCl}]=0,18 \mathrm{M}, \mathrm{pH}=4,01-4,03, T=25,0^{\circ} \mathrm{C}$.

no es cero porque, aunque muy poco, el minoxidil absorbe ligeramente en la longitud de onda de trabajo $\left(\varepsilon=29,0 \pm 0,5 \mathrm{M}^{-1} \mathrm{~cm}^{-1}\right)$.

\subsubsection{Catálisis por el ion cloruro}

Para estudiar el efecto de la catálisis en la reacción de nitrosación del minoxidilo se repitió el experimento con la concentración $1,42 \cdot 10^{-4} \mathrm{M}$ y se sustituyó en el reactivo base $1 \mathrm{ml}$ de disolución estándar de $\mathrm{NaCl}$ por $1 \mathrm{ml}$ de agua (figura 4.113).

La presencia de cloruro en el medio de reacción no afectó a la respuesta del 


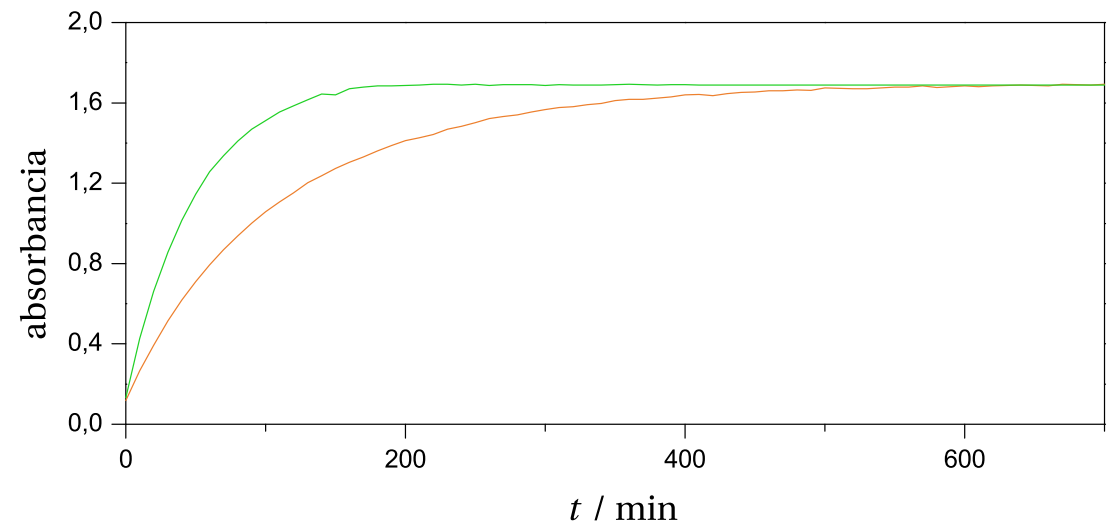

Figura 4.113: Efecto catalítico de los iones $\mathrm{Cl}^{-}$en el tiempo de reacción. La cinética sin $\mathrm{NaCl}$ se muestra de color naranja y la cinética con $\mathrm{NaCl}(0,18 \mathrm{M})$ se muestra de color verde. $\lambda=325 \mathrm{~nm},[\mathrm{MIN}]=1,74 \cdot 10^{-3} \mathrm{M},\left[\mathrm{NaNO}_{2}\right]=1,42 \cdot 10^{-4}, \mathrm{pH}=4,01, T=25,0{ }^{\circ} \mathrm{C}$.

método y la reacción fue tres veces más rápida.

\subsubsection{Efecto de iones metálicos}

Se estudió el efecto de la presencia de iones metálicos en el medio debido a la posibilidad de que el minoxidilo o el nitrosominoxidilo formen complejos de coordinación con ellos.

Se prepararon disoluciones estándar de $\mathrm{Al}$ (III), $\mathrm{Ca}$ (II), $\mathrm{Cr}$ (III), $\mathrm{Cu}$ (II), $\mathrm{Fe}$ (II), $\mathrm{Fe}$ (III), Ni (II) y Zn (II) con concentración $2,2 \cdot 10^{-2} \mathrm{M}$. Para cada metal $1 \mathrm{ml}$ de la disolución se han mezclado con $12 \mathrm{ml}$ del reactivo base y $9 \mathrm{ml}$ de la disolución estándar de nitrito $3,00 \cdot 10^{-4} \mathrm{M}$.

La mayor parte los iones no forman complejos de coordinación con el minoxidilo o el nitrosominoxidilo. Sólo el cobre (II) y el hierro (III) mostraron interferencias en la banda de absorción. El hierro (III) interfería con concentraciones superiores a $1 \cdot 10^{-5} \mathrm{M}$ y el cobre (II) con concentraciones superiores a $5 \cdot 10^{-4} \mathrm{M}$. 


\section{8 | Determinación de nitrito con minoxidilo}

\subsubsection{Precisión del método}

Se repitió doce veces la reacción entre $12 \mathrm{ml}$ del reactivo base y $10 \mathrm{ml}$ de la disolución estándar de nitrito $\left(3 \cdot 10^{-4} \mathrm{M}\right)$ para verificar la reproducibilidad del método. La tabla 4.60 muestra los resultados obtenidos.

\begin{tabular}{ccc}
\hline \multicolumn{3}{c}{ Absorbancias medidas } \\
\hline 1,072 & 1,058 & 1,049 \\
1,030 & 1,068 & 1,058 \\
1,063 & 1,027 & 1,036 \\
1,055 & 1,053 & 1,046 \\
\hline
\end{tabular}

Tabla 4.60: Absorbancias medidas en diferentes experimentos para determinar la precisión del método.

La desviación estándar y la desviación estándar relativa han sido de $\pm 2 \cdot 10^{-6}$ M y 1,6\%, respectivamente.

\subsubsection{Límites de detección y cuantificación}

Conociendo la desviación estándar del método $(\sigma=0,0143)$ es posible determinar su límite de detección, que es la minima cantidad o concentración que se puede detectar para un nivel de confianza dado. Para un nivel de confianza de detección de un 98,3\% la expresión utilizada es: ${ }^{263}$

$$
L D=\frac{3 \sigma}{m}
$$

donde $m$ es la pendiente de la curva de calibrado.

Así, para el método el límite de detección es de $3,88 \cdot 10^{-6} \mathrm{M}$.

El límite de cuantificación es la cantidad más pequeña a la que se pueden hacer medidas cuantitativas. Su cálculo se hace mediante la siguiente fórmula:

$$
L C=\frac{10 \sigma}{m}
$$


El límite de cuantificación del método es de $1,29 \cdot 10^{-5} \mathrm{M}$. Este límite lo hace adecuado para el análisis de muestras fisiológicas, alimentarias y medioambientales. $^{264}$

\subsubsection{Aplicación del método}

Se ha utilizado el método propuesto para determinar nitrito en una muestra de agua procedente de un pozo de Cardeñosa, provincia de Ávila. La muestra fue recogida, filtrada y guardada en una botella de poliestileno. Se mezclaron 10 $\mathrm{ml}$ de la muestra con $12 \mathrm{ml}$ de la mezcla base. Se determinó una concentración de nitrito de 2,51 $\left.\pm 0,02 \mathrm{ppm}\left((3,63 \pm 0,03) \cdot 10^{-5} \mathrm{M}\right)\right)$. En comparación con el resultado obtenido por el método oficial de medida, 2,48 $\pm 0,06 \mathrm{ppm}$, el método mostró un excelente comportamiento. 



\section{Capítulo 5}

\section{Discusión de los resultados}

\subsection{C-Nitrosación de compuestos aromáticos}

Como se ha indicado en páginas anteriores de esta Memoria, los mecanismos de C-nitrosación aromáticos han sido menos investigados que los de nitración aromática. La causa es que, para que aquellos puedan transcurrir a velocidad adecuada, es necesaria la presencia en el sustrato nitrosable de grupos dadores de carga electrónica. Los agentes nitrosantes ion nitrosonio, nitrosacidio y sales de nitrosonio son electrófilos mucho más débiles que el ion nitronio. Se estima que ion nitrosonio es $10^{14}$ veces menos reactivo que el ion nitronio. ${ }^{129}$

En su Tesis Doctoral, González Mancebo investigó los mecanismo de Cnitrosación de una amplia serie de compuestos fenólicos (figura 5.1). ${ }^{250}$ Como estos sustratos son estructuralmente similares a los del presente trabajo, es de esperar que las reacciones de nitrosación de todos ellos estén relacionados isocinéticamente. Esto quiere decir que si comparten el mismo mecanismo, las entalpías y entropías de activación de los procesos de nitrosación de los sustratos deben satisfacer la relación:

$$
\Delta H^{\ddagger}+\beta \Delta S^{\ddagger}=\text { cte }
$$

donde $\beta$ es un parámetro independiente de la temperatura. ${ }^{265}$

En la figura 5.2 se han representado las entropías de activación de las reacciones 
<smiles>Oc1ccccc1</smiles>

ph<smiles>Cc1ccccc1O</smiles>

oc<smiles>Cc1cccc(O)c1</smiles>

mc<smiles>Cc1ccc(O)cc1</smiles>

pc<smiles>Oc1ccccc1Cl</smiles>

ocp<smiles>Oc1ccccc1Br</smiles>

obp<smiles>Cc1cccc(C)c1O</smiles>

d26p<smiles>Cc1cc(C)cc(O)c1</smiles>

d35p<smiles>Cc1cccc(O)c1C</smiles>

d23p<smiles>CC(C)(C)c1cc(O)cc(C(C)(C)C)c1</smiles>

dt35p<smiles>Cc1cc(C)c(O)c(C)c1</smiles>

t246p

Figura 5.1: Compuestos estudiados por González Mancebo et al. ${ }^{250}$ Sus abreviaturas son ph, fenol; oc, $o$-cresol; mc, $m$-cresol; pc, $p$-cresol; ocp, $o$-clorofenol; obp, $o$ bromofenol; d26p, 2,6-dimetilfenol; d35p, 3,5-dimetilfenol; d23p, 2,3-dimetilfenol; dt35p, 3,5-di-tert-butilfenol y t246, 2,4,6-trimetilfenol.

de nitrosación de los diferentes sustratos frente a las entalpías de activación. Se puede observar que existe una correlación lineal entre todos los puntos, lo que aporta un nuevo argumento para admitir que todos los sustratos se nitrosan siguiendo el mismo mecanismo.

Otra prueba de que los compuestos comparten el mismo mecanismo la constituye el criterio de los soviéticos Viktor Palm y Regina Vizgert quienes, a través de una formulación matemática del efecto isocinético, demostraron que existe una relación lineal entre dos series de valores logarítmicos de la constante de velocidad observada a dos temperaturas diferentes: ${ }^{267}$

$$
\ln k_{T 2}=a+b \ln k_{T 1}
$$

La figura 5.3 muestra el buen ajuste de los resultados experimentales a la correlación de Palm-Vizgert, representando el logaritmo natural de las constantes de velocidad a $25,0^{\circ} \mathrm{C}$ frente al logaritmo de las constantes medidas a $30,0^{\circ} \mathrm{C}$. 
Discusión de los resultados | 293

\begin{tabular}{|c|c|c|c|c|c|}
\hline Sustrato & $\begin{array}{c}\Delta S^{\ddagger} \\
/ \mathrm{J} \mathrm{K}^{-1} \mathrm{~mol}^{-1}\end{array}$ & $\begin{array}{c}\Delta H^{\ddagger} \\
/ \mathrm{kJ} \mathrm{mol}^{-1}\end{array}$ & Sustrato & $\begin{array}{c}\Delta S^{\ddagger} \\
/ \mathrm{J} \mathrm{K}^{-1} \mathrm{~mol}^{-1}\end{array}$ & $\begin{array}{c}\Delta H^{\ddagger} \\
/ \mathrm{kJ} \mathrm{mol}^{-1}\end{array}$ \\
\hline DOP & -20 & 76 & $\mathrm{~d} 23 \mathrm{p}$ & -109 & 46 \\
\hline TYR & -54 & 70 & $\mathrm{mc}$ & -130 & 46 \\
\hline obp & -92 & 59 & oc & -115 & 45 \\
\hline ocp & -101 & 56 & $\mathrm{~d} 26 \mathrm{p}$ & -107 & 44 \\
\hline $\operatorname{SER}\left(k_{\mathrm{obs}, 2}\right)$ & -92 & 53 & d35p & -132 & 42 \\
\hline ph & -112 & 51 & MIN & -163 & 20 \\
\hline
\end{tabular}

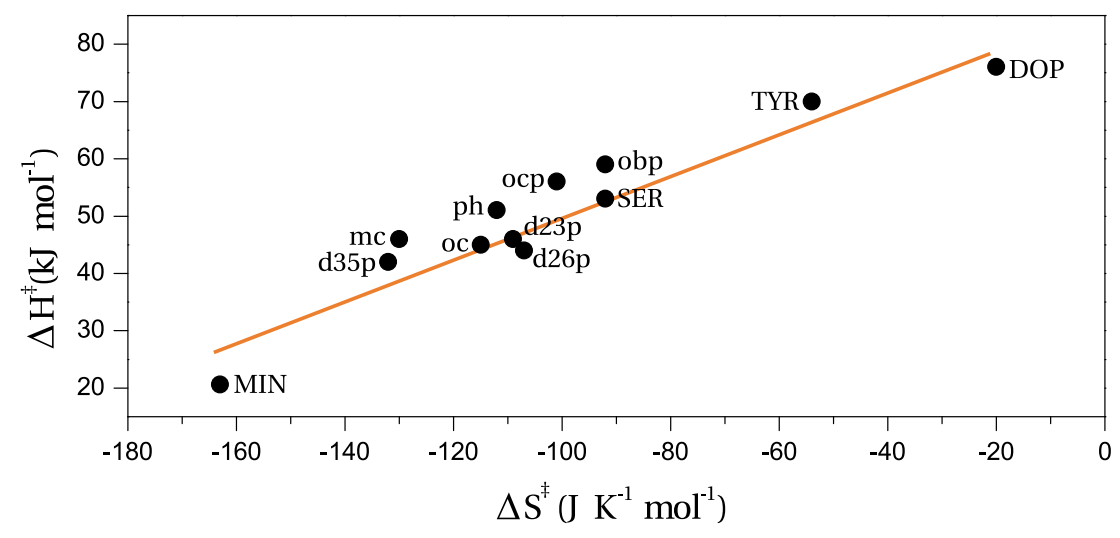

Tabla 5.1 y Figura 5.2: Relación isocinética entre los compuestos estudiados. 
294 | C-Nitrosación de compuestos aromáticos

\begin{tabular}{cccccc}
\hline Sustrato & $\begin{array}{c}k_{25} \\
/ \mathrm{M}^{-1} \mathrm{~s}^{-1}\end{array}$ & $\begin{array}{c}k_{30} \\
/ \mathrm{M}^{-1} \mathrm{~s}^{-1}\end{array}$ & Sustrato & $\begin{array}{c}k_{25} \\
/ \mathrm{M}^{-1} \mathrm{~s}^{-1}\end{array}$ & $\begin{array}{c}k_{30} \\
/ \mathrm{M}^{-1} \mathrm{~s}^{-1}\end{array}$ \\
\hline TYR & 0,0048 & 0,0072 & obp & 0,088 & 0,116 \\
DOP & 0,0252 & 0,0405 & oc & 0,116 & 0,162 \\
SER $\left(k_{\text {obs,2 }}\right)$ & 0,057 & 0,078 & $\mathrm{~d} 23 \mathrm{f}$ & 0,167 & 0,228 \\
pc & 0,070 & 0,101 & $\mathrm{~d} 35 \mathrm{f}$ & 0,166 & 0,234 \\
ocp & 0,078 & 0,109 & $\mathrm{MIN}$ & 0,224 & 0,264 \\
\hline
\end{tabular}

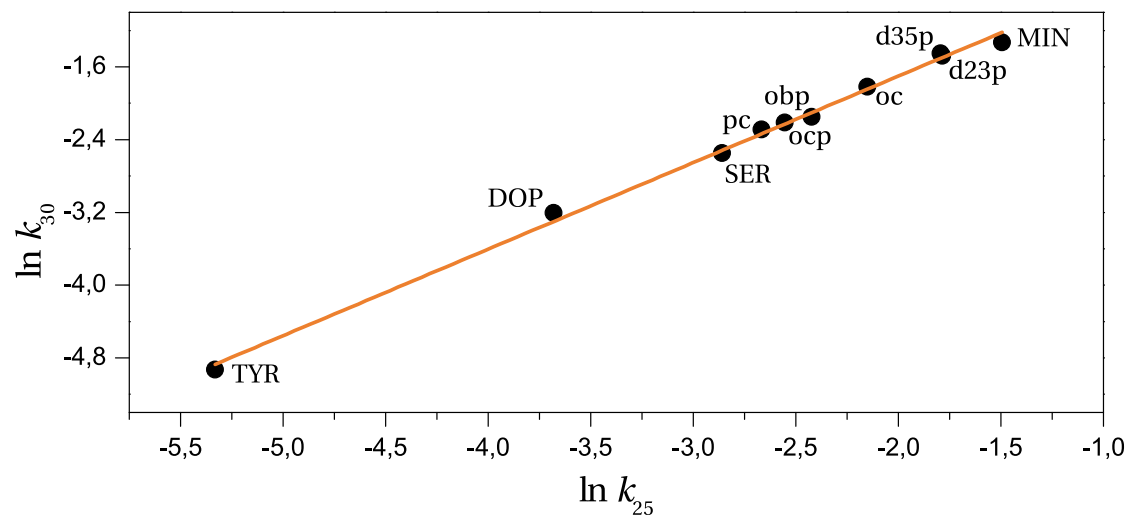

Tabla 5.2 y Figura 5.3: Representación de Palm-Vizgert. $T_{2} / T_{1}=0,983$. 
Se puede admitir pues, que todos los sustratos reaccionan a través de un mecanismo común. La tabla 5.3 muestra los valores experimentales de las constantes de velocidad y equilibrio del mecanismo de C-nitrosación de todos los sustratos. La constante $k_{a}$, recogida en la segunda columna, es la constante de velocidad de la adición del grupo nitroso al anillo aromático. Para todos los compuestos su valor es superior a $10^{8} \mathrm{M}^{-1} \mathrm{~s}^{-1}$, lo que significa que esta primera etapa se encuentra controlada por difusión. También reúne los valores del efecto isotópico cinético observado en cada sustrato. Se puede ver que todos los compuestos, al compartir el mismo mecanismo, muestran un incremento similar en la velocidad de nitrosación al sustituir el hidrógeno de su estructura por deuterio. Este efecto se muestra más pronunciado en la molécula de minoxidilo.

A partir de los datos de la tabla 5.3 se han calculado en cada caso los valores de $k_{\text {obs }}$ que se toman como índice de reactividad:

$$
k_{\mathrm{obs}}=k_{a} K_{3} K_{2} K_{1}
$$

La tabla 5.4 recoge los índices de reactividad de los sustratos investigados en esta tesis y por González Mancebo en una secuencia que va desde el compuesto más reactivo, minoxidilo, hasta los compuestos que no reaccionan con el ácido nitroso.

El orden de esta secuencia es razonable en términos de la activación de la posición nitrosable (sección 2.3.1), salvo en casos puntuales en los que el impedimento estérico interfiere reduciendo la reactividad de algún sustrato.

En los compuestos aquí estudiados el índice de reactividad varía varios órdenes de magnitud. El minoxidilo es el compuesto más reactivo, con su posición nitrosable libre situada en orto y para con respecto a tres aminas activantes. Además los nitrógenos heteroaromáticos se encuentran en posición meta, que es donde menos desactivan. La influencia del óxido de amina es pequeña en comparación con las aminas activantes.

La dopamina es el siguiente compuesto más reactivo con dos alcoholes activantes, uno de ellos en posición para.

La tiramina tiene una reactividad similar a la del $p$-cresol, puesto que ambos 


\begin{tabular}{|c|c|c|c|c|}
\hline Sustrato & $\begin{array}{c}k_{a} K_{2} \\
/ 10^{2} \mathrm{M}^{-2} \mathrm{~s}^{-1}\end{array}$ & $\begin{array}{c}k_{a} \\
/ 10^{9} \mathrm{M}^{-1} \mathrm{~s}^{-1}\end{array}$ & $\begin{array}{l}k_{-a} / K_{b} k_{c} \\
/ 10^{4} \mathrm{M}^{-1}\end{array}$ & $k_{\mathrm{c}}^{\mathrm{H}_{2} \mathrm{O}} / k_{\mathrm{c}}^{\mathrm{D}_{2} \mathrm{O}}$ \\
\hline $\mathrm{ph}$ & $6,6 \pm 0,5$ & $2,2 \pm 0,2$ & $6,3 \pm 0,5$ & 3,5 \\
\hline $\mathrm{mc}$ & $8,1 \pm 0,8$ & $2,7 \pm 0,3$ & $1,3 \pm 0,1$ & 4,4 \\
\hline oc & $7,1 \pm 1,0$ & $2,4 \pm 0,3$ & $0,97 \pm 0,15$ & 3,2 \\
\hline $\mathrm{pc}$ & $0,83 \pm 0,12$ & $0,28 \pm 0,04$ & $1,9 \pm 0,3$ & 3,0 \\
\hline d23p & $10,7 \pm 1,5$ & $3,6 \pm 0,2$ & $1,1 \pm 0,2$ & 3,0 \\
\hline d35p & $21,3 \pm 1,6$ & $7,1 \pm 0,5$ & $19,0 \pm 1,5$ & 4,3 \\
\hline d26p & $6,9 \pm 0,5$ & $2,3 \pm 0,2$ & $0,13 \pm 0,02$ & 3,0 \\
\hline $\mathrm{t} 246 \mathrm{p}$ & \multicolumn{4}{|c|}{ sin reacción con el nitrito } \\
\hline dt35p & \multicolumn{4}{|c|}{ sin reacción con el nitrito } \\
\hline оср & $1,0 \pm 0,1$ & $0,33 \pm 0,03$ & $2,0 \pm 0,2$ & 2,2 \\
\hline obp & $0,80 \pm 0,19$ & $0,27 \pm 0,06$ & $1,6 \pm 0,4$ & 1,9 \\
\hline ETH & \multicolumn{4}{|c|}{ sin reacción con el nitrito } \\
\hline TYR & $0,47 \pm 0,09$ & $0,16 \pm 0,03$ & $0,78 \pm 0,07$ & 2,9 \\
\hline DOP & $11 \pm 1$ & $3,66 \pm 0,03$ & $0,24 \pm 0,04$ & 3,4 \\
\hline $\operatorname{SER}\left(k_{\mathrm{obs}, 2}\right)$ & $13 \pm 2$ & $4,3 \pm 0,3$ & $1,8 \pm 0,3$ & 2,4 \\
\hline MIN & $45 \pm 3$ & $15 \pm 1$ & $0,17 \pm 0,01$ & 8,4 \\
\hline
\end{tabular}

Tabla 5.3: Constantes asociadas a las C-nitrosaciones aromáticas de diferentes sustratos. 


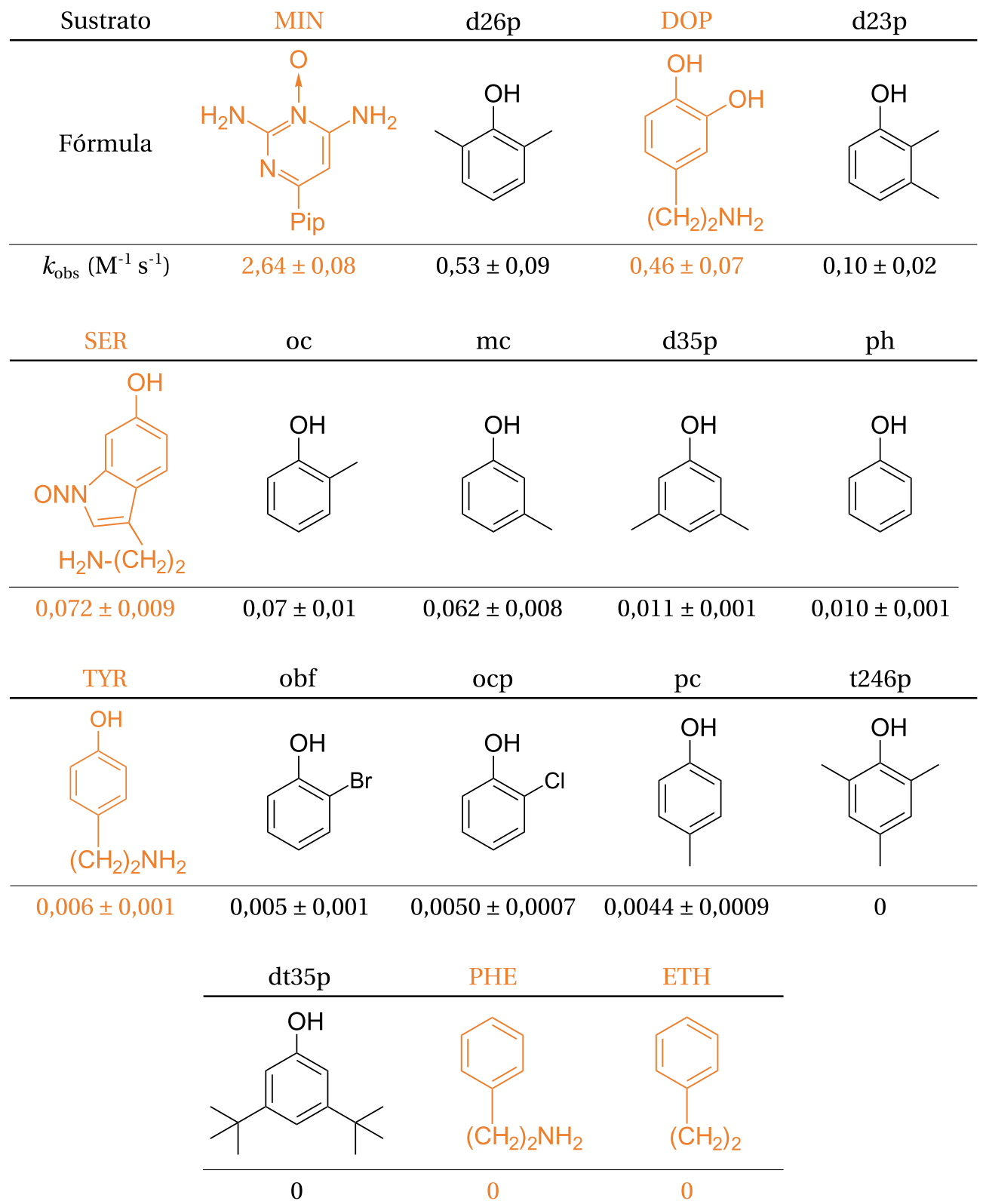

Tabla 5.4: Índices de reactividad de los sustratos aromáticos C-nitrosados en el presente trabajo y en el de González Mancebo ${ }^{250}$. 


\section{8 | Reacciones de N-nitrosación}

son fenoles cuya posición para se encuentra alquilada.

Los compuestos sin el grupo - $\mathrm{OH}$ en su estructura carecen de la activación necesaria para que reaccionen con el ion nitrosonio. Por eso ni la fenetilamina ni el etilbenceno experimentan C-nitrosación en las condiciones descritas.

El impedimento estérico no es un factor tan determinante en las moléculas estudiadas como en los sustratos investigados por González Mancebo, donde se reducía significativamente la velocidad en algunos compuestos. Dada su estructura el $m$-cresol tiene una reactividad 6 veces superior al 3,5-dimetilfenol. Tan sólo el minoxidilo tiene una posición significativamente impedida, con una amina y una piperidina en las posiciones adyacentes al centro de nitrosación. Sin embargo, como muestra la nitrosación del floroglucinol, dado que la etapa determinante es la ruptura del complejo de Wheland, la estabilización de este complejo por los grupos dadores de electrones influye mucho más en la velocidad de reacción que el impedimento estérico que puedan sufrir los compuestos. $^{264}$

\subsection{Reacciones de N-nitrosación}

En este trabajo se han estudiado dos tipos diferentes de N-nitrosación. Por un lado, la nitrosación de una amina primaria alifática, que se encuentra en todas las estructuras con las que se ha trabajado, salvo en el etilbenceno y el minoxidilo y, por otro lado, la nitrosación en el nitrógeno heteroatómico del anillo aromático de la serotonina.

Para investigar la nitrosación de la amina primaria se ha medido la velocidad de nitrosación de la fenetilamina. Esta molécula es representativa puesto que, tras el experimento con el etilbenceno, se ha demostrado que su anillo aromático no está lo suficientemente activado para sufrir C-nitrosación y, por lo tanto todo el nitrito reacciona exclusivamente con la amina de sus estructura.

Se ha comprobado que la nitrosación de la fenetilamina tiene las mismas características que las nitrosaciones de aminas primarias, donde el agente nitrosante es el $\mathrm{N}_{2} \mathrm{O}_{3}$ y la reacción se encuentra controlada por difusión. No obstante, la reacción requiere que la amina no esté protonada para poder transcurrir, lo que 
hace que, en el medio ácido en el que el trióxido de dinitrógeno se forma, la proporción de amina desprotonada sea muy baja y pese a estar controlada por difusión, la reacción sea significativamente lenta.

La serotonina no presenta este inconveniente porque el nitrógeno que se nitrosa es muy difícil de protonar al estar integrado en una estructura aromática. Sin embargo, pese a la rapidez de la reacción, la constante de velocidad del encuentro entre la serotonina y el trióxido de dinitrógeno no es lo suficientemente alta como para que la reacción se considere controlada por difusión. No obstante, tanto el efecto isotópico de 1,42, cercano al 1,25 provocado por la diferencia de viscosidad del agua pesada en las reacciones controladas por difusión, como la entalpía (tan sólo $6 \mathrm{~kJ} / \mathrm{mol}$ superior al límite de las reacciones controladas por difusión) sugieren que el mecanismo de reacción se encuentra cercano a control por difusión.

Challis y Lawson demostraron que los indoles con $\mathrm{pK}_{\mathrm{a}}$ superior a $-3,5$ siguen un mecanismo controlado por difusión. ${ }^{254} \mathrm{El} \mathrm{pK}_{\mathrm{a}}$ de la serotonina, -3,6, explica la cercanía al mecanismo al de una reacción controlada por difusión.

\subsection{Competencia entre $\mathrm{N}$-nitrosación y C-nitrosación}

Desde el punto de vista biológico, las nitrosaciones de aminas primarias son menos peligrosas que las de compuestos aromáticos ya que, generalmente, la molécula nitrosada se descompone rápidamente antes de actuar sobre la célula, dada la inestabilidad de la sal de diazonio, mientras que, por el contrario, la C-nitrosación forma compuestos estables que directa o indirectamente pueden alquilar el material genético (sección 2.3.2). Por eso es importante dilucidar qué reacción predomina en las moléculas aquí estudiadas.

Para conocer el tipo de nitrosación dominante se han comparado las velocidades de C-nitrosación de cada sustrato (tiramina, dopamina y serotonina) con la velocidad de $\mathrm{N}$-nitrosación representada por la fenetilamina. La diferencia de velocidad entre ambas nitrosaciones depende exclusivamente del $\mathrm{pH}$ y de la concentración de nitrito. La dependencia del nitrito se debe a que las $\mathrm{N}$ nitrosaciones son de orden dos respecto a ese reactivo y las C-nitrosaciones son 


\section{0 | Competencia entre N-nitrosación y C-nitrosación}

de orden uno. En consecuencia, cuanto menor sea la concentración de nitrito mayor será el predominio de la C-nitrosación. Este resultado se ve confirmado por los espectros de masas de los productos de nitrosación de las moléculas complejas.

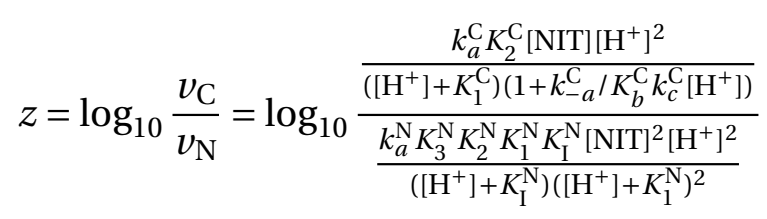

La ecuación 5.4 muestra la forma en que se han comparado ambas velocidades. Como la velocidad de nitrosación del anillo aromático es varios órdenes de magnitud superior a la de la amina, por simplicidad se ha escogido el término $z$ que corresponde al logaritmo decimal del cociente entre ambas velocidades. Esta ecuación se ha representado en un mapa de contornos para los tres sustratos en las figuras 5.5 y 5.4, de tal forma que se pueda ver la zona a partir de la cual la velocidad de C-nitrosación comienza a ser significativa respecto a la de N-nitrosación (diez veces superior). Para la tiramina (figura 5.5), que sufre la nitrosación aromática más lenta, ha sido necesario utilizar para la concentración del nitrito una escala más pequeña.

En estas gráficas se puede ver que las zonas donde la N-nitrosación es importante corresponde a $\mathrm{pHs}$ superiores a 4,0 y a concentraciones altas de nitrito $\left(2 \cdot 10^{-3} \mathrm{M}\right.$ para la tiramina y $6 \cdot 10^{-2} \mathrm{M}$ para la dopamina y la serotonina). Estas condiciones se encuentra muy alejadas de las que se pueden encontrar en el lumen del estómago, donde la baja concentración de nitrito y la alta acidez favorecen la C-nitrosación frente a la N-nitrosación, lo que es importante ante la amplia presencia de la tiramina en la alimentación. 
Discusión de los resultados | 301
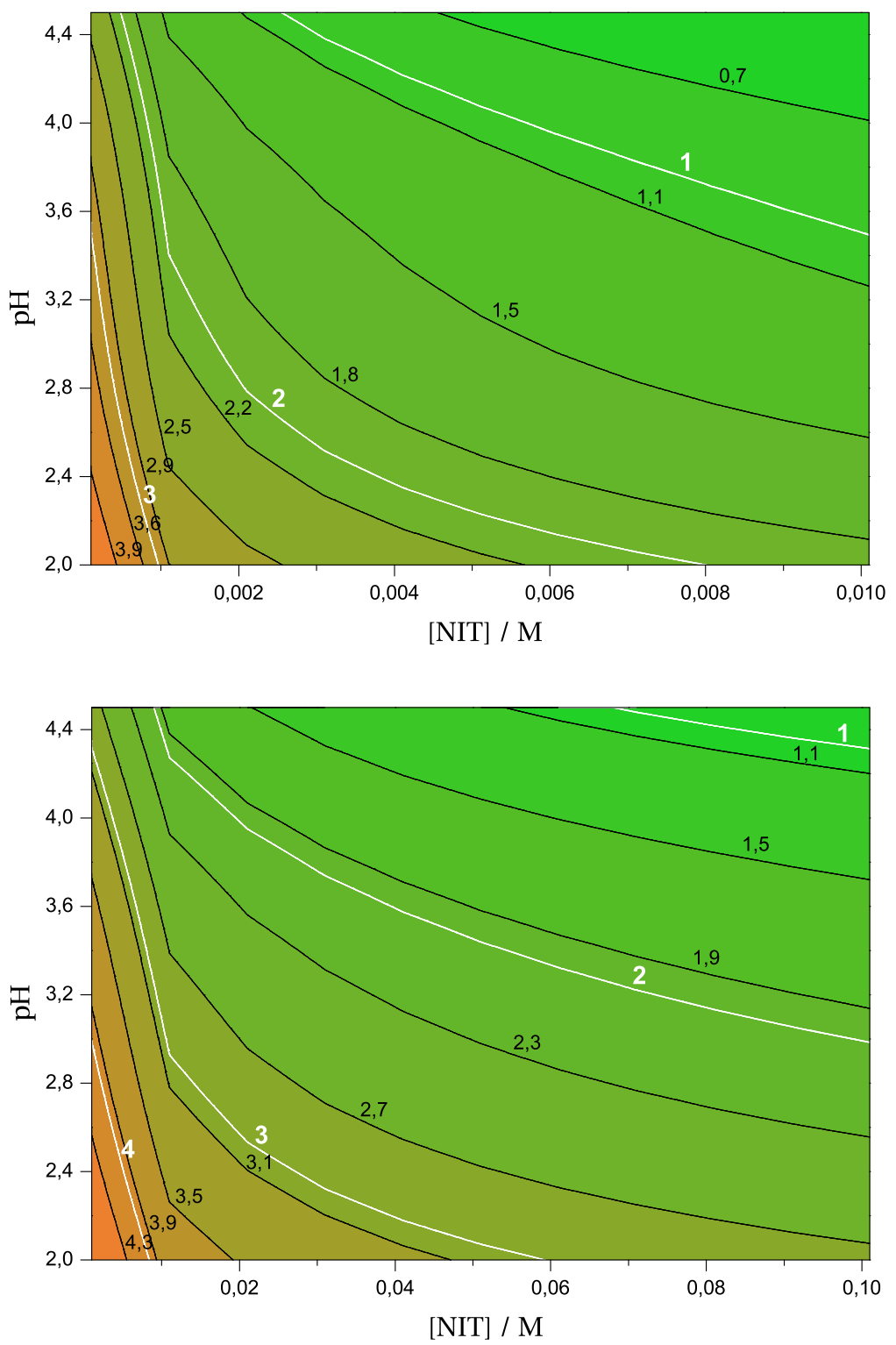

Figura 5.4: Influencia del pH y la concentración de nitrito en la relación $z$ en la nitrosación de la tiramina (gráfica superior) y la dopamina. 


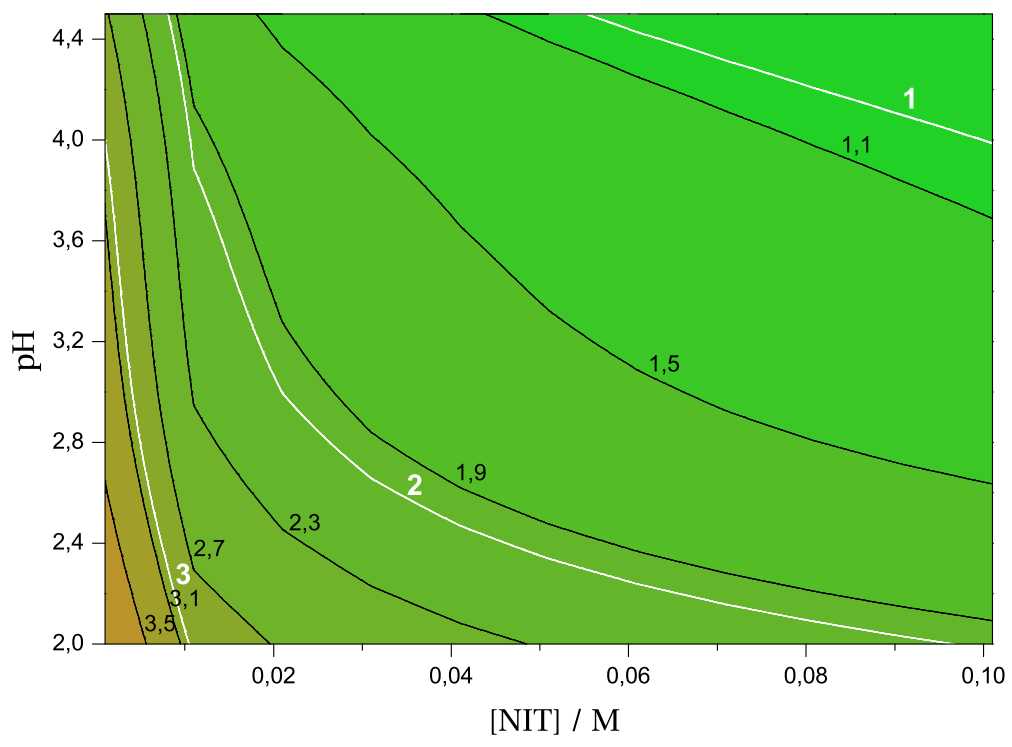

Figura 5.5: Influencia del pH y la concentración de nitrito en la relación $z$ en la nitrosación de la serotonina.

\subsection{Actividad biológica de los compuestos estudiados}

La aplicación del test de Ames y el test de aberraciones cromosómicas a los productos de nitrosación del presente trabajo ha demostrado que son compuestos poco (en el caso de la tiramina) o nada mutágenos y genotóxicos. Esto entra en contradicción con los estudios previos encontrados en la bibliografía (sección 2.5). No obstante, a diferencia de nuestro trabajo, que se realizó con los nitrosocompuestos sintetizados, los estudios de la bibliografía se llevaron a cabo poniendo en el medio de cultivo una disolución formada por el compuesto a estudiar, un ácido y un gran exceso de nitrito sódico, lo que induce la aparición de sales de diazonio aromáticas estables por la diazotación de los C-nitrosocompuestos formados (sección 2.3.2, página 77). ${ }^{191,196,211,214}$ Por ello, los trabajos de la bibliografía reflejan más la actividad biológica de estas sales 
de diazonio que la de los compuestos nitrosados, pese a que las condiciones de exceso de nitrito son difíciles de darse en medios in vivo.

Mediante el test del MTT se ha comprobado que los nitrosocompuestos obtenidos son citotóxicos en una intensidad según la secuencia:

$$
\text { NSER }>\text { NDOP }>\text { NTYR }>>\text { NMIN }
$$

Esta serie concuerda con la reactividad de los sustratos, salvo por el caso del nitrosominoxidilo. El nitrosominoxidilo no ha provocado una muerte significativa de las células V-79 en ninguna de las concentraciones a las que se han expuesto en este trabajo. Es posible que la ausencia de citotoxicidad de esta molécula se deba a su tamaño y a la alta polaridad del enlace dativo de su estructura, que dificultan que la molécula traspase la membrana celular. 



\section{Capítulo 6}

\section{Conclusiones}

El estudio cinético de las reacciones de nitrosación de etilbenceno, fenetilamina, tiramina, dopamina, serotonina y minoxidilo por espectrometría UVvisible ha conducido a las siguientes conclusiones:

1. El etilbenceno no se nitrosa en una escala significativa de tiempo, incluso en las condiciones más favorables para las reacciones de nitrosación.

2. En los márgenes de tiempo en que se ha trabajado, la fenetilamina sólo sufre $\mathrm{N}$-nitrosación en su grupo $-\mathrm{NH}_{2}$. La ecuación de velocidad experimental de la reacción de nitrosación es:

$$
v=\frac{\alpha[\mathrm{PHE}][\mathrm{NIT}]^{2}\left[\mathrm{H}^{+}\right]}{\left(\left[\mathrm{H}^{+}\right]+\beta\right)^{2}}
$$

3. El mecanismo de reacción propuesto para la nitrosación de fenetilamina incluye como etapa limitante de velocidad el ataque de trióxido de dinitrógeno sobre la amina desprotonada. Ese mecanismo conduce a la siguiente ecuación de velocidad:

$$
v=k_{a} K_{3} K_{2} K_{1} K_{\mathrm{I}} \frac{[\mathrm{PHE}][\mathrm{NIT}]^{2}\left[\mathrm{H}^{+}\right]^{2}}{\left(\left[\mathrm{H}^{+}\right]+K_{1}\right)^{2}}
$$

que se ajusta muy bien a los resultados experimentales. 
4. El cálculo por vía cinética del valor del $\mathrm{pK}_{\mathrm{a}}$ del ácido nitroso, efectuado sobre la base del mecanismo propuesto, concuerda bien con el bibliográfico, lo que apoya ese mecanismo.

5. El valor de la constante de velocidad de la etapa cinética determinante de la alquilación de fenetilamina por trióxido de dinitrógeno, $k_{a}=$ $(1,72 \pm 0,08) \cdot 10^{8} \mathrm{M}^{-1} \mathrm{~s}^{-1}$, y la entalpía de activación de esa reacción, $\Delta \mathrm{H} \approx$ $7 \mathrm{~kJ} \mathrm{~mol}^{-1}$, indican que se trata de un mecanismo controlado por difusión.

6. La molécula de serotonina experimenta dos nitrosaciones consecutivas en su anillo indólico: la primera tiene lugar en el nitrógeno heteroatómico, siendo la segunda una reacción de C-nitrosación. Aquélla obedece a la ecuación de velocidad:

$$
v=\frac{\alpha[\mathrm{SER}][\mathrm{NIT}]^{2}\left[\mathrm{H}^{+}\right]}{\left(\left[\mathrm{H}^{+}\right]+\beta\right)^{2}}
$$

El mecanismo propuesto conduce a una ecuación de velocidad análoga a la encontrada en el caso de la fenetilamina salvo que, debido a la estructura aromática en que se encuentra integrado el átomo de nitrógeno, éste no se puede protonar en las condiciones débilmente ácidas del medio de reacción:

$$
v=k_{a} K_{3} K_{2} K_{1} K_{\mathrm{I}} \frac{[\mathrm{SER}][\mathrm{NIT}]^{2}\left[\mathrm{H}^{+}\right]^{2}}{\left(\left[\mathrm{H}^{+}\right]+K_{\mathrm{I}}\right)\left(\left[\mathrm{H}^{+}\right]+K_{1}\right)^{2}}
$$

El de los resultados experimentales ajuste a esta ecuación ha conducido a un $\mathrm{pK}_{\mathrm{a}}=3,3 \pm 0,2$ para el sistema nitrito/ácido nitroso muy similar al bibliográfico lo que, también aquí, constituye un apoyo al mecanismo propuesto.

7. La segunda reacción de nitrosación de la serotonina, al igual que la nitrosación de tiramina, dopamina y minoxidilo, es una sustitución electrofílica aromática de un hidrógeno por el grupo nitroso. La ecuación de velocidad experimental es:

$$
v=\frac{\alpha[\text { sustrato }][\mathrm{NIT}]\left[\mathrm{H}^{+}\right]^{2}}{\left(\left[\mathrm{H}^{+}\right]+K_{1}\right)\left(1+\beta\left[\mathrm{H}^{+}\right]\right)}
$$


8. El mecanismo de nitrosación para los cuatro sustratos indicados en 7 . implica, como etapa determinante de velocidad, la ruptura del complejo de Wheland formado en el ataque de los iones nitrosonio/nitrosacidio al anillo aromático. El mecanismo propuesto conduce a la ecuación de velocidad:

$$
v=\frac{k_{a} K_{2}[\text { sustrato }][\mathrm{NIT}]\left[\mathrm{H}^{+}\right]^{2}}{\left(\left[\mathrm{H}^{+}\right]+K_{1}\right)\left(1+\frac{k_{-a}}{K_{b} k_{c}}\left[\mathrm{H}^{+}\right]\right)}
$$

9. En las reacciones de nitrosación en las que la etapa determinante es la ruptura del complejo sigma se ha observado un claro efecto cinético isotópico $k_{\mathrm{c}}^{\mathrm{H}_{2} \mathrm{O}} / k_{\mathrm{c}}^{\mathrm{D}_{2} \mathrm{O}}$ reflejo de transferencia protónica en esa etapa.

10. El excelente ajuste de los resultados a las relaciones isocinéticas $\Delta H^{\ddagger} / \Delta S^{\ddagger}$ $\mathrm{y} \ln k_{T 1} / \ln k_{T 2}$ tanto por parte de las reacciones ahora investigadas como por otras reacciones de C-nitrosación previamente estudiadas es indicativo (aunque no demostrativo) de un mecanismo común. La reactividad de estos compuestos está controlada por la activación del carbono nitrosable por su entorno electrónico.

11. En la tiramina, dopamina y serotonina las reacciones de C-nitrosación predominan sobre las de N-nitrosación.

12. El amplio uso comercial del minoxidilo y el elevado valor del coeficiente de absorción molar del nitrosominoxidilo acreditan a aquél como buen reactivo para el análisis de nitritos, con un excelente límite de detección $\left(3,88 \cdot 10^{-6} \mathrm{M}\right)$. Por la misma razón, como resultado colateral de esta investigación de Doctorado, se ha implementado una práctica de laboratorio para alumnos de química general y medioambiental.

13. En contraste con algunos resultados bibliográficos, los encontrados en este trabajo sugieren una baja mutagenia y genotoxicidad (test de Ames) de los nitrosocompuestos investigados. En cambio, su citotoxicidad (test del MTT) es consistente con la reactividad de los sustratos de los que proceden. El minoxidilo, probablemente debido a su tamaño y polaridad, no es citotóxico. 



\section{Bibliografía}

[1] Obra completa

San Juan de la Cruz

Alianza Editorial

Edición de E. Pacho, 2010, Madrid (España)

[2] ¡Oh, Dios, ceguera en la que estoy perdido...!

Felipe Doyagüez Chico

Kadmos

$1^{\text {a }}$ edición, 2002, Salamanca (España)

[3] Enciclopedia de la Ciencia

A. Craig, C. Rosney

Susaeta

1990, Madrid (España)

[4] Mémoire sur l'alcool amylique

A. J. Balard

Comptes rendus de l'Académie des sciences

19, 1844, 634-641

[5] Asparagin und Asparaginsäure

R. Piria

Justus Liebigs Annalen der Chemie

68, 1848, 343-350

[6] Recherches sur la constitution chimique de l'asparagine et de l'acide aspartique

R. Piria

Annales de Chimie et de Physique

22, 1848, 160-167

[7] Beiträge zur Kenntniss der flüchtigen organischen Basen

A. W. Hofmann

Justus Liebigs Annalen der Chemie

75, 1850, 356-368 


\section{0 | Bibliografía}

[8] Dyes and dyeing

H. A. Webb

Journal of Chemical Education

$19,1942,460-470$

[9] The history of chemistry

J. Hudson

Chapman \& Hall

$1^{\text {a }}$ edición, 1992, Nueva York (EE.UU.)

[10] Vorläufige notiz über die Einwirkung von salpetriger Säure auf Amidinitro- und Aminitrophenylsäure

P. Griess

Justus Liebigs Annalen der Chemie

106, 1858, 123-125

[11] Vorläufige Notiz über Diazobenzoësäure

P. Griess

Justus Liebigs Annalen der Chemie

120, 1861, 125-128

[12] Peter Griess - Discoverer of diazocompounds

Sister V. Heines

Journal of Chemical Education

35, 1958, 187-191

[13] Über die Einwirkung von salpetrigsaurem Kali auf salzsaures Diäthylamin

A. Geuther

Justus Liebigs Annalen der Chemie

128, 1863, 151-156

[14] Untersuchungen über die Constitution der Nitrolsäuren

V. Meyer, J. Locher

Chemische Berichte

7, 1874, 670-675

[15] Über die Pseudonitrole, die Isomeren der Nitrolsäuren

V. Meyer, J. Locher

Justus Liebigs Annalen der Chemie

180, 1876, 133-155

[16] Über die Einwirkung der salpetrigen Säure auf Dimethylanilin und über Nitrosophenol

A. Bäyer, H. Caro

Chemische Berichte

7, 1874, 963-968

[17] The first 85 Years of C-nitroso compounds: A survey of the salient features

B. G. Gowenlock, G. B. Richter-Addo

Journal of Chemical Education

85, 2008, 1243-1245 
[18] Nitrosation, diazotisation, and deamination

J. H. Ridd

Quarterly Reviews, Chemical Society

15, 1961, 418-441

[19] Zur Kenntniss der Nitrosamine

O. Fischer, E. Hepp

Chemische Berichte

19, 1886, 2991-2995

[20] Products of the action of nitrous acid on tetramethylenylmethylamine

N. J. Demjanov, M. Lushnikov

Zhurnal Russkago Fiziko-Khimicheskago Obshchestva

$35,1903,26-42$

[21] Structure and mechanism in organic chemistry

C. K. Ingold

Cornell University Press

$1^{\text {a }}$ edición, 1953, Ithaca, Nueva York (EE.UU.)

[22] Some toxic properties of dimethylnitrosamine

P. N. Magee, J. M. Barnes

British Journal of Industrial Medicine

11, 1954, 167-174

[23] The action of retrorsine on rat's liver

J. Davidson

The Journal of Pathology and Bacteriology

40, 1935, 285-295

[24] Senecio alkaloids: Primary liver tumours in rats as a result of treatment with (1) a mixture of alkaloids from S. Jacobaea Lin.; (2) Retrorsine; (3) Isatidine.

R. Schoental, M. A. Head, P. R. Peacock

British Journal of Cancer

8, 1954, 458-465

[25] The production of malignant primary hepatic tumours in the rat by feeding dimethylnitrosamine

P. N. Magee, J. M. Barnes

British Journal of Cancer

10, 1956, 114-122

[26] An outbreak of toxic liver injury in ruminants

N. Koppang

Nordisk Veterinaer Medicin

$16,1964,305-322$ 


\section{2 | Bibliografía}

[27] Isolation and identification of a hepatotoxic factor in herring meal produced from sodium nitrite preserved herring

F. Ender, G. Favre, A. Helgebostad, N. Koppang, R. Madsen, L. Ceh

Naturwissenschaften

51, 1964, 637-638

[28] Dimethylnitrosamine; its hepatotoxic effect in sheep and its occurrence in toxic batches of herring meal

J. Sakshaug, E. Sögnen, M. A. Hansen, N. Koppang

Nature

206, 1965, 1261-1262

[29] http://www .webofknowledge.com

ISI Web of Knowledge

[30] N-nitroso compounds in the diet

W. Lijinsky

Mutation Research

443, 1999, 129-138

[31] Description of the thermal energy analyzer (TEA) for trace determination of volatile and nonvolatile $\mathrm{N}$-nitroso compounds

D. H. Fine, F. Rufeh, D. Lieb, D. P. Rounbehler

Analytical Chemistry

$47,1975,1188-1191$

[32] Tumour-promoting agents in unburned cigarette tobacco

F. G. Bock, R. J. Shamberger, H. K. Myers

Nature

208, 1965, 584-585

[33] Directiva 93/11/CEE de la Comisión de 15 de marzo de 1993 relativa a la cesión de $N$ nitrosaminas y de sustancias $N$-nitrosables por las tetinas y chupetes de elastómeros o caucho

Diario Oficial de las Comunidades Europeas

$37,1993,1-2$

[34] N-Nitrosodiethanolamine in cosmetics, lotions and shampoos

T. Y. Fan, E. U. Golf, L. Song, D. H. Fine, G. P. Arsenault, K. Bieman

Food and Cosmetics Toxicology

$15,1977,423-430$

[35] Analysis of nitrosamines in cosmetics

K. Ikeda, K. G. Migliorese

Journal of the Society of Cosmetic Chemists

$41,1990,283-333$ 
[36] Contamination of beer with trace quantities of $\mathrm{N}$-nitrosodimethylamine B. Spiegelhalder, G. Eisenbrand, R. Preussmann

Food and Cosmetics Toxicology

17, 1979, 29-31

[37] Nitrate reduction and $N$-nitrosation in brewing

N. A. Smith

Journal of the Institute of Brewing

100, 1994, 347-355

[38] Formation of N-nitrosopyrrolidine in a dog's stomach

T. S. Mysliwy, E. L. Wick, M. C. Archer, R. C. Shank, P. M. Newberne

British Journal of Cancer

30, 1974, 279-283

[39] Formation of nitrosamines in food and in the digestive system

J. S. Wishnok

Journal of Chemical Education

54, 1977, 440-442

[40] Ascorbate-nitrite reaction: Possible means of blocking the formation of carcinogenic Nnitroso compounds

S. S. Mirvish, L. Wallcave, M. Eagen, P. Shubik

Science

$177,1972,65-68$

[41] Ascorbic acid blocking of aminopyrine nitrosation in NZO/BI mice

M. Greenblatt

Journal of the National Cancer Institute

50, 1972, 1055-1056

[42] Use of ascorbic acid to inhibit nitrosation: kinetic and mass transfer considerations for an in vitro system

W. R. Licht, S. R. Tannenbaum, W. M. Deen

Carcinogenesis

9, 1988, 365-372

[43] Chemical structure and carcinogenicity of aliphatic hydrazo, azo, and azoxy compounds and of triazenes, potential in vivo alkylating agents

R. Preussmann, H. Druckrey, S. Ivankovic, A. v. Hodenberg

Annals of the New York Academy of Sciences

163, 1969, 697-716

[44] Epidemiology of gastric cancer

D. Palli

Annali dell'Istituto Superiore di Sanita

32, 1996, 85-99 


\section{4 | Bibliografía}

[45] Catalysis and inhibition of $N$-nitrosation reactions

M. C. Archer

En IARC Scientific Publication

World Health Organization Press

57, 1984, 263-274

[46] Simultaneous C-and N-nitrosation of Synephrine. A kinetic Study

M. P. Fernández Liencres, F. Carazo, M. C. Cabeza, B. Quintero, J. Thomas, J. M. Álvarez Journal of the Chemical Society, Perkin Transactions II

1993, 2265-2273

[47] Cerebrospinal fluid nitrite/nitrate levels in neurologic diseases

S. Milstien, N. Sakai, B. J. Brew, C. Krieger, J. H. Vickers, K. Saito, M. P. Heyes

Journal of Neurochemistry

$63,1994,1178-1180$

[48] Breve historia de la química

I. Asimov

Alianza Editorial

$1^{\text {a }}$ edición, 1999, Madrid (España)

[49] Vitriol in the history of chemistry

V. Karpenko, J. A. Norris

Chemicke Listy

96, 2002, 997-1005

[50] Chemistry of the elements

N. Greenwood, A. Earnshaw

Butterworth Heinemann

$2^{\text {a }}$ edición, 1997, Oxford (Reino Unido)

[51] Kinetics of nitrous acid. III. Kinetics of nitrous acid decomposition

E. Abel, H. Schmid

Zeitschrift für Physikalische Chemie

136, 1928, 419-430

[52] The equilibrium between nitric acid, nitrous acid and nitric oxide

G. N. Lewis, A. Edgar

Journal of the American Chemical Society

33, 1911, 292-299

[53] The kinetics of oxidation by nitrous and nitric acid. Part III. Oxidation of oxalic acid by nitrous acid

P. A. Vamplew, K. Singer

Journal of the Chemical Society

1956, $1143-1146$ 
[54] Nitric acid, nitrous acid and nitrogen oxides

M. Thiemann, E. Scheibler, K. W. Wiegand

En Ullmann's Encyclopedia of Industrial Chemistry

Ed: B. Elvers; Wiley-VCH

$6^{\text {a }}$ edición, 2002, Weinheim (Alemania)

[55] Protolysis of nitrous acid in aqueous sodium nitrate and sodium nitrite solutions at different temperatures

J. Tummavuori, P. Lumme

Acta Chemica Scadinavica

22, 1968, 2003-2011

[56] Nitrates and nitrites

W. Laue, M. Thiemann, E. Scheibler, K. W. Wiegand

En Ullmann's Encyclopedia of Industrial Chemistry

Ed: B. Elvers; Wiley-VCH

$6^{\text {a }}$ edición, 2002, Weinheim (Alemania)

[57] Methemoglobinemia resulting from absorption of nitrates

J. C. Harris, B. H. Rumack, R. G. Peterson, B. M. McGuire

Journal of the American Medical Association

242, 1979, 2869-2871

[58] Brock biology of microorganisms

M. T. Madigan, J. M. Martinko, D. A. Stahl, D. P. Clark

Benjamin Cummings

13a edición, 2012, San Francisco, California (EE.UU.)

[59] Evaluation of bacterial nitrate reduction in the human oral cavity

J. J. Doel, N. Benjamin, M. P. Hector, M. Rogers, R. P. Allaker

European Journal of Oral Sciences

113, 2005, 14-19

[60] Microbes involved in dissimilatory nitrate reduction in the human large intestine

N. J. Parham, G. R. Gibson

FEMS Microbiology Ecology

31, 2000, 21-28

[61] Química agrícola. Volumen 3, alimentos

E. Primo Yúfera

Alhambra

$1^{\text {a }}$ edición, 1979, Madrid (España)

[62] Lawrie's Meat Science

R. A. Lawrie

Woodhead Publishing

6ª edición, 1998, Cambridge (Reino Unido) 


\section{6 | Bibliografía}

[63] Nitrite, nitrite alternatives, and the control of Clostridium Botulinum in cured meats

M. D. Pierson, L. A. Smoot, M. C. Robach

C R C Critical Reviews in Food Science and Nutrition

$17, \mathbf{1 9 8 3}, 141-187$

[64] Directiva 98/83/CE del consejo de 3 de noviembre de 1998 relativa a la calidad de las aguas destinadas al consumo humano

Diario Oficial de las Comunidades Europeas

$330,1998,32-54$

[65] Real Decreto 140/2003, de 7 de febrero, por el que se establecen los criterios sanitarios de la calidad del agua de consumo humano

Boletín Oficial del Estado

45, 2003, 7228-7245

[66] Directiva 95/2/CE del parlamento europeo y del consejo de 20 de febrero de 1995 relativa a aditivos alimentarios distintos de los colorantes y edulcorantes

Diario Oficial de la Unión Europea

61, 1995, 1-53

[67] Normas de identidad y pureza para aditivos alimentarios y evaluación de su toxicidad. Octavo informe Organización Mundial de la Salud 309, 1966, 1-30

[68] The nitrate-nitrite-nitric oxide pathway in physiology and therapeutics

J. O. Lundberg, E. Weitzberg, M. T. Gladwin

Nature Reviews

7, 2008, 156-167

[69] Efectos del óxido nítrico sobre la función cardíaca

J. Tamargo, R. Caballero, R. Gómez, L. Núñez, M. Vaquero, E. Delpón

Revista Española de Cardiología

6, 2006, 3A-20A

[70] Nitric oxide as a unique signaling molecule in the vascular system: a historical overview L. J. Ignarro

Journal of Physiologic Pharmacology

53, 2002, 503-514

[71] Cellular targets and mechanisms of nitros(yl)ation: an insight into their nature and kinetics in vivo

N. S. Bryan, T. Rassaf, R. E. Maloney, C. M. Rodriguez, F. Saijo, J. R. Rodriguez, M. Feelisch Proceedings of the National Academy of Sciences of the United States of America

101, 2004, 4308-4313

[72] The determination of nitrite: A critical review

J. B. Fox, F. B. Suhre

C R C Critical Reviews in Analytical Chemistry

$15,1985,283-313$ 
[73] Bemerkungen zu der Abhandlung der HH. Weselsky und Benedikt „Ueber einige Azoverbindungen"

P. Griess

Chemische Berichte

$12, \mathbf{1 8 7 9}, 426-428$

[74] L'acide azoteux dans la salive et dans l'aire exhalé

M. L. Ilosvay

Bulletin de l'Association belge des chimistes

3, 1889, 388-391

[75] The 125th anniversary of the Griess reagent

V. M. Ivanov

Journal of Analytical Chemistry

59, 2004, 1002-1005

[76] Detection and quantitative determination of nitrites and nitrates

D. Acel

Biochemische Zeitschrift

107, 1916, 1-12

[77] Análisis inorgánico cualitativo sistemático

F. Bucarons, F. Capitán García, L. F. Capitán Vallvey

Reverté

$1^{a}$ edición, 1986, Barcelona (España)

[78] Chemical redox agents for organometallic chemistry

N.G. Connelly, W. E. Geiger

Chemical Reviews

96, 1996, 877-910

[79] Redox equilibria of the nitrosonium cation and of its nonbonded complexes

K. Y. Lee, D. J. Kuchynka, J. K. Kochi

Inorganic Chemistry

29, 1990, 4196-4204

[80] Synthesis and reactivity of the tetrakis(acetonitrile)nitrosyirhodium dication

N. G. Connelly, P. T. Draggett, M. Green, T. A. Kuc

Journal of the Chemical Society, Dalton Transactions

1977, 70-73

[81] Nitrous acid equilibria in perchloric acid

T. A. Turney, G. A. Wright

Journal of the Chemical Society

1958, 2415-2418

[82] Nitrosation Reactions and Chemistry of the Nitric Oxide

D. H. L. Williams

Elselvier

2a edición, 2004, Ámsterdam (Países Bajos) 


\section{8 | Bibliografía}

[83] The spectra and equilibria of nitrosonium ion, nitroacidium ion, and nitrous acid in solutions of sulphuric, hydrochloric, and phosporic acids

N. S. Bayliss, D. W. Watts

Australian Journal of Chemistry

9, 1956, 319-332

[84] Mechanism of the azide-nitrite reaction. Part III. Reaction in [ $\left.^{[8} \mathrm{O}\right]$ water

C. A. Bunton, G. Stedman

Journal of the Chemical Society

1959, 3466-3479

[85] ${ }^{15}$ N NMR spectroscopic investigation of nitrous and nitric acids in sulfuric acid solutions of varying acidities

G. K. S. Prakash, L. Heiliger, G. A. Olahn

Inorganic Chemistry

29, 1990, 4965-4968

[86] Protonation of nitrous acid and formation of the nitrosating agent $\mathrm{NO}^{+}$: an ab initio Study M. Nguyen, A. F. Hegart

Journal of the Chemical Society, Perkin Transactions II

1984, 2037-2041

[87] Nitrosation, diazotisation, and deamination. Part IX. The influence of neutral salts on the kinetics of diazotisation

B. C. Challis, A. R. Butler

Journal of the Chemical Society

1962, 5197-5203

[88] Cytological methods for detecting chemical mutagens

B. C. Challis, A. R. Butler

En The Chemistry of the Amino Group

Ed: A. Hollaender; Wiley-Interscience

4, 1968, 1-29

[89] Studies in $N$-nitrosation reactions

S. S. Mirvish

En IARC Scientific Publication

World Health Organization Press

104, 1972, 279-295

[90] Micellar catalysis of the nitrous acid deamination reaction

R. A. Moss, C. S. Talkowski

Tetrahedron Letters

12, 1971, 703-706 
[91] Kinetik und Mechanismus der Diazotierung, 16. Mitt.: Kinetik der Reaktionen des Nitrosoacidiumions und des Distickstofftrioxyds mit diazotierbaren Aminen

H. Schmid, C. Essler

Monatshefte für Chemie

91, 1960, 484-499

[92] Kinetic studies on the formation of N-nitroso compounds. IV. Formation of mononitrosopiperazine and general discussion of $N$-nitrosation mechanisms in aqueous perchloric solution J. Casado, A. Castro, M. López-Quintela Monatshefte für Chemie 112, 1981, 1221-1238

[93] Hydroliysis equilibrium of dinitrogen trioxide in dilute acid solution G. Y. Markovits, S. E. Schwartz, L. Newman Inorganic Chemistry 20, 1981, 445-450

[94] The nitrous acid-dinitrogen trioxide equilibrium in aqueous perchloric acid T. A. Turney Journal of the Chemical Society 1960, 4263-4265

[95] Reaction mechanisms of inorganic nitrogen compounds G. Stedman Advances in Inorganic Chemistry and Radiochemistry 22, 1979, 113-170

[96] Kinetic studies on the formation of $\mathrm{N}$-nitroso compounds VI. The reactivity of $\mathrm{N}_{2} \mathrm{O}_{3}$ as a nitrosating agent

J. Casado, A. Castro, J. R. Leis, M. A. López Quintela, M. Mosquera Monatshefte für Chemie 114, 1983, 639-646

[97] Visible spectrum of dinitrogen trioxide in aqueous solution

A. M. M. Doherty, N. Haine, E. Jones, G. Stedman Journal of the Chemical Society, Perkin Transactions II 1996, 2055-2058

[98] The microwave spectrum of dinitrogen trioxide

R. L. Kuczkowski

Journal of the American Chemical Society 87, 1965, 5259-5260

[99] Nitrosation, diazotisation, and deamination. Part I. Principles, background, and method for the kinetic study of diazotisation E. D. Hughes, K. Ingold, J. H. Ridd Journal of the Chemical Society 1958, 58-65 


\section{0 | Bibliografía}

[100] Die Chemie des Nitrosyl-Ions. XI. Über die blaue oder rote Schwefelsäure und verwandte Verbindungen

F. Seel, H. Sauer

Zeitschrift für Anorganische und Allgemeine Chemie

292, 1957, 1-19

[101] The Preparation of N-Nitrosoamides Under Basic Conditions

J. M. Simpson, D. C. Kapp, T. M. Chapman

Synthesis

1979, 100-102

[102] The chemical properties of nitrosyl perchlorate: The neutralization equivalent

M. M. Markowitz, J. E. Ricci, R. J. Goldman, P. F. Winternitz

Journal of the American Chemical Society

79, 1957, 3659-3661

[103] Nitrosation of amines in nonaqueous solvents. 1. Evidence of a stepwise mechanism

L. García Río, J. R. Leis, E. Iglesias

Journal of Organic Chemistry

62, 1997, 4701-4711

[104] Nitrosation of amines in nonaqueous solvents. 2. Solvent-induced mechanistic changes

L. García Río, J. R. Leis, E. Iglesias

Journal of Organic Chemistry

$62,1997,4712-4720$

[105] Formation of nitrosamines in alkaline conditions: A kinetic study of the nitrosation of linear and cyclic secondary amines by alkyl nitrites

E. Calle, J. Casado, J. L. Cinos, F. J. Mateos, M. Tostado

Journal of the Chemical Society, Perkin Transactions II

1992, 987-991

[106] Structure-reactivity correlations in nitrosation reactions of secondary amines by alkyl nitrites in basic media

J. Casado, A. Castro. M. A. López-Quintela, F. M. Lorenzo-Barral

Bulletin de la Societe Chimique de France

1987, 401-404

[107] Kinetics of the aminolysis and hydrolysis of alkyl nitrites: Evidence for an orbital-controlled mechanism

M. P. García-Santos, E. Calle, S. González-Mancebo, J. Casado

Monatshefte für Chemie

127, 1996, 997-1003

[108] Studies in the hydrolysis and alcoholysis of some organic nitrites

A. D. Allen

Journal of the Chemical Society

1954, 1968-1974 
[109] Mechanisms of hydrolysis and nitrosation reactions of alkyl nitrites in various media E. Iglesias, J. Casado International Reviews in Physical Chemistry 21, 2002, 37-74

[110] T. Lauder Brunton and amyl nitrite: a Victorian vasodilator

W. B. Fye Circulation 74, 1986, 222-229

[111] The mysterious adventures of Sherlock Holmes

A. C. Doyle Puffin Classics $1^{a}$ edición, 1995, Londres (Reino Unido)

[112] Nitric oxide-Some old and new perspectives E. W. Ainscough, A. M. Brodie Journal of Chemical Education 72, 1995, 686-692

[113] Físicoquímica

G. W. Castellan Pearson Educación $2^{\text {a }}$ edición, 1987, Madrid (España)

[114] Über Nitrosoverbindungen, VI. zur photochemischen Nitrosierung aliphatischer und cycloaliphatischer Kohlenwasserstoffe mit Stickstoffmonoxyd und Chlor H. Metzger, E. Müller Chemische Berichte 90, 1957, 1179-1185

[115] Rapid formation of $\mathrm{N}$-nitrosamines from nitric oxide in the presence of silver (I) salts B. C. Challis, J. R. Outram Journal of the Chemical Society, Chemical Communications 1978, 707-708

[116] Nitric oxide: Chemical puzzles posed by a biological messenger S. Pfeiffer, B. Mayer, B. Hemmens Angewandte Chemie International Edition 38, 1999, 1714-1731

[117] Coordination chemistry of nitric oxide R. Eisenberg, C. D. Meyer Accounts of Chemical Research $8,1975,26-34$ 


\section{2 | Bibliografía}

[118] The nitroprusside ion as a nitrosating reagent. Kinetic studies on the nitrosation of morpholine

J. Casado, M. A. López Quintela, M. Mosquera, M. F. Rodríguez Prieto, J. Vázquez Tato Berichte der Bunsengesellschaft für physikalische Chemie

87, 1983, 1208-1211

[119] Nitrosation, diazotisation, and deamination. Part VI. Comparative discussion of mechanisms of $N$ - and $O$-nitrosation with special reference to diazotisation

E. D. Hughes, C. K. Ingold, J. H. Ridd

Journal of the Chemical Society

1958, 88-98

[120] Mechanism of the azide-nitrite reaction. Part IV

G. Stedman

Journal of the Chemical Society

1960, 1702-1709

[121] Kinetic studies on the formation of $N$-nitroso compounds IX. Nitrosyl acetate as a nitrosating agent

J. Casado, A. Castro, M. Mosquera, M. F. Rodríguez Prieto, J. Vázquez Tato

Monatshefte für Chemie

115, 1984, 669-682

[122] N-Nitrosation by nitrite ion in neutral and basic medium

L. K. Keeper, P. P. Roller

Science

181, 1973, 1245-1247

[123] Kinetic studies on the formation of $N$-nitroso compounds

J. Casado, A. Castro, M. A. López Quintela, M. F. Rodríguez Prieto

Zeitschrift für Physikalische Chemie

118, 1979, 43-57

[124] Spot Tests in Organic Analysis

F. Fagl

Elsevier

$5^{\text {a }}$ edición, 1956, Londres (Reino Unido)

[125] Catalytic Effect of p-Nitrosophenol

E. A. Walker, B. Pignatelli, M. Castegnaro

Journal of Agricultural and Food Chemistry

27, 1979, 393-396

[126] A new nitrite ionic liquid (IL-ONO) as a nitrosonium source for the efficient diazotization of aniline derivatives and in-situ synthesis of azo dyes

H. Valizadeh, A. Shomali

Dyes and Pigments

92, 2012, 1138-1143 
[127] Organic Chemistry

L. G. Wade

Prentice Hall

7a edición, 2010, Upper Saddle River, Nueva Jersey (EE.UU.)

[128] Advanced Organic Chemistry

F. A. Carey, R. J. Sundberg

Springer

$5^{\mathrm{a}}$ edición, 2007, Nueva York (EE.UU.)

[129] Electrophilic ipso-substitutions. Part 3. Reactions of 3-substituted indoles,4-substituted

$\mathrm{N}, \mathrm{N}$-dimethylanilines, and 1- and 3-substituted indolizines with nitrous acid

M. Colonna, L. Greci, M. Poloni

Journal of the Chemical Society, Perkin Transactions II

1984, 165-169

[130] The direct introduction of the diazonium group into aromatic nuclei. VI: Reaction mechanisms

M. Tedder, G. Theaker

Tetrahedron

$5,1959,288-292$

[131] Principios de química orgánica

T. A. Geissman

Reverté

$1^{\text {a }}$ edición, 1973, Barcelona (España)

[132] Amino acid nitrosation products as alkylating agents

M. P. García Santos, E. Calle, J. Casado

Journal of the American Chemical Society

123, 2001, 7506-7510

[133] Diazo chemistry I. Aromatic and heteroaromatic compounds

H. Zollinger

VCH Verlagsgesellschaft

$1^{\text {a }}$ edición, 1994, Weinheim (Alemania)

[134] The reaction of tertiary amines with nitrous acid

G. E. Hein

Journal of Chemical Education

40, 1963, 181-184

[135] Nitrosative cleavage of tertiary amines

P. A. S. Smith, R. N. Loeppky

Journal of the American Chemical Society

89, 1967, 1147-1157 


\section{4 | Bibliografía}

[136] Formation of N-nitrosodimethylamine from naturally occurring quaternary ammonium compounds and tertiary amines

W. Fiddler, J. W. Pensabene, R. C. Doerr, A. E. Wassermang

Nature

236, 1972, 307

[137] Natural bond orbital population analysis of p-substituted O-nitrosyl carboxylate compounds

L. Xiao-Hong, C. Qing-Dong, Z. Xian-Zhou

Structural Chemistry

20, 2009, 1043-1048

[138] Effects of vitamins $C$ and $E$ on $N$-nitroso compound formation, carcinogenesis, and cancer S. S. Mirvish

Cancer

$58,1986,1842-1850$

[139] Chemistry of sorbates. A basic perspective

B. R. Thakur, K. Singh, S. S. Arya

Food Reviews International

10, 1994, 71-91

[140] Formation of ethylnitrolic acid by the reaction of sorbic acid with sodium nitrite

M. Namiki, T. Kada

Agricultural and Biological Chemistry

$39,1975,1335-1336$

[141] A new N-nitropyrrole. 1,4-dinitro-2-methylpyrrole, formed by the reaction of sorbic acid with sodium nitrite

Y. Kito, M. Namiki, K. Tsuji

Tetrahedron

34, 1978, 505-508

[142] Formation of mutagens by sorbic acid-nitrite reaction: effects of reaction conditions on biological activities

M. Namiki, S. Udaka, T. Osawa, K. Tsuji, T. Kada

Mutation Research

73, 1980, 21-28

[143] Chemical aspects of mutagen formation by sorbic acid-sodium nitrite reaction

M. Namiki, T. Osawa, H. Ishibashi, K. Namiki K. Tsuji

Journal of Agricultural and Food Chemistry

29, 1981, 407-411

[144] Review: putative mutagens and carcinogens in foods

P. E. Hartman

Enviromental Mutagenesis

$5, \mathbf{1 9 8 3}, 217-222$ 
[145] Mutagen formation in the reaction of nitrite with the food components analogous to sorbic acid

T. Osawa, M. Namiki

Agricultural and Biological Chemistry

$46, \mathbf{1 9 8 2}, 2299-2304$

[146] Identification of a nonenylnitrolic acid in corn treated with nitrous acid

T. J. Hansen, S. R. Tannenbaum, M. C. Archer

Journal of Agricultural and Food Chemistry

29, 1981, 1008-1011

[147] Reactivity of amino acids in nitrosation reactions and its relation to the alkylating potencial of their products

M. P. García Santos, S. González Mancebo, J. Hernández Benito, E. Calle, J. Casado

Journal of the American Chemical Society

124, 2002, 2177-2182

[148] Reactivity of lactones and GBH formation

M. T. Pérez Prior, J. A. Manso, M. P. García Santos, E. Calle, J. Casado

Journal of Organic Chemistry

70, 2005, 420-426

[149] A kinetic approach to the alkylating potential of carcinogenic lactones

J. A. Manso, M. T. Pérez Prior, M. P. García Santos, E. Calle, J. Casado

Chemical Research in Toxicology

18, 2005, 1161-1166

[150] The unusual ability of $\alpha$-angelicalactone to form adducts: a kinetic approach

E. Fernández Rodríguez, J. A. Manso, M. T. Pérez Prior, M. P. García Santos, E. Calle, J. Casado International Journal of Chemical Kinetics

39, 2007, 591-595

[151] Alkylating potential of potassium sorbate

M. T. Pérez Prior, J. A. Manso, M. P. García Santos, E. Calle, J. Casado

Journal of Agricultural and Food Chemistry

53, 2005, 10244-10247

[152] Sorbic acid as an alkylating agent

M. T. Pérez Prior, J. A. Manso, M. P. García Santos, E. Calle, J. Casado

Journal of Solution Chemistry

37, 2008, 459-466

[153] Potential of the NBP Method for the Study of Alkylation Mechanisms: NBP as a DNA-Model R. Gómez Bombarelli, M. González Pérez, E. Calle, J. Casado Chemical Research in Toxicology

25, 2012, 1176-1191 


\section{6 | Bibliografía}

[154] Sorbate-Nitrite Interactions: Acetonitrile Oxide as an Alkylating Agent

M. T. Pérez Prior, R. Gómez Bombarelli, M. González Pérez, J. A. Manso, E. Calle, J. Casado Chemical Research in Toxicology

22, 2009, 1320-1324

[155] Inhibitory effects of phenolics, teas and saliva on the formation of mutagenic nitrosation products of salted fish

H. F. Stich, P. K. L. Chan, M. P. Rosin

International Journal of Cancer

$30,1982,719-724$

[156] Formation of peroxynitrite from the oxidation of hydrogen peroxide by nitrosonium ion: A pulse radiolysis study

S. Goldstein, G. Czapski

Inorganic Chemistry

35, 1996, 7735-7740

[157] The chemistry of peroxonitrites. Part II. Copper(II)-catalysed reaction between hydroxylamine and peroxonitrite in alkali

M. N. Hughes, H. G. Nicklin

Journal of the Chemical Society A

1970, 925-928

[158] The role of the reactions of NO with superoxide and oxygen in biological systems: A kinetic approach

G. Czapski, S. Goldstein

Free Radical Biology and Medicine

19, 1995, 785-794

[159] Technical guidance document on minimising and determining nitrosamines in cosmetics

Colipa - The European Cosmetics Association

Colipa Guidelines

Enero, 2009, Bruselas (Bélgica)

[160] Structural effects on the $\mathrm{N}$-nitrosation of amino acids

R. Gil, J. Casado, C. Izquierdo

International Journal of Chemical Kinetics

29, 1997, 495-504

[161] Isomérisation de l'oxyde de méthylène cyclohexane en hexahydrobenzaldéhyde et désamination de l'aminoalcool correspondant en cycloheptanone

M. Tiffeneau, P. Weill, B. Tchoubar

Comptes rendus de l'Académie des sciences

205, 1937, 54-56 
[162] The Demjanov and Tiffeneau-Demjanov one-carbon ring enlargements of 2-aminomethyl7-oxabicyclo[2.2.1]heptane derivatives. The stereo- and regioselective additions of 8oxabicyclo[3.2.1]oct-6-en-2-one to soft electrophiles

D. Fattori, S. Henry, P. Vogel

Tetrahedron

49, 1993, 1649-1664

[163] Nitrosation, thiols, and hemoglobin: Energetics and kinetics

W. H. Koppenol

Inorganic Chemistry

51, 2012, 5637-5641

[164] Kinetics and mechanism of thionitrite formation. Mercapto-carboxylic acid: a new range of efficient nitrous acid scavengers

L. R. Dix, D. L. H. Williams

Journal of the Chemical Society, Perkin Transactions 2

1984, 109-112

[165] S-N dissociation energies of S-nitrosothiols: On the origins of nitrosothiol decomposition rates

M. D. Bartberger, J. D. Mannion, S. C. Powell, J. S. Stamler, K. N. Houk, E. J. Toone Journal of the American Chemical Society

123, 2001, 8868-8869

[166] Physical Chemistry

R. G. Mortimer

Elsevier

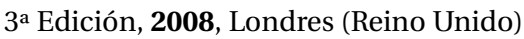

[167] Elementary steps in enzyme reactions (as studied by relaxation spectrometry)

M. Eigen, G. G. Hammes

En Advances in Enzymology and Related Areas of Molecular Biology

Ed: F. F. Nord; Willey

25, 2006, 1-38

[168] Principles of chemical kinetics

J. E. House

Elsevier

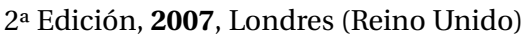

[169] Chemical reactivity and the concept of charge- and frontier-controlled reactions

G. Klopman

Journal of the American Chemical Society

90, 1968, 223-234

[170] The kinetics and mechanism of the aminolysis of phenethyl nitrite

S. Oae, N. Asai, K. Fujimori

Journal of the Chemical Society, Perkin Transactions II

1978, $1124-1130$ 


\section{8 | Bibliografía}

[171] DNA adducts of nitrosamines

D. E. Shuker, H. Bartsch

En IARC Scientific Publication

World Health Organization Press

125, 1994, 73-89

[172] Carcinogenic N-nitrosamines in the diet: occurrence, formation, mechanisms and carcinogenic potential

A. R. Tricker, R. Preussmann

Mutation Research

259, 1991, 277-289

[173] Review of human carcinogens. IARC monographs on the evaluation of carcinogenic risks to humans

International Agency for Research on Cancer

World Health Organization Press

100, 2012, Ginebra (Suiza)

[174] Biochemistry, biology, and carcinogenicity of tobacco-specific $\mathrm{N}$-nitrosamines

S. S. Hecht

Chemical Research in Toxicology

11, 1998, 559-603

[175] Nitrosamine and related food intake and gastric and oesophageal cancer risk: A systematic review of the epidemiological evidence

P. Jakszyn, C. A. González

World Journal of Gastroenterology

12, 2006, 4296-4303

[176] Dietary nitrates, nitrites, and N-nitroso compounds and cancer risk: a review of the epidemiologic evidence

M. Eichholzer, F. Gutzwiller

Nutrition Reviews

56, 1998, 95-105

[177] A review: dietary and endogenously formed N-nitroso compounds and risk of childhood brain tumors

M. Dietrich, G. Block, J. M. Pogoda, P. Buffer, S. Hecht, S. Preston-Martin

Cancer Causes and Control

16 , 2005, 619-635

[178] An overview of chemical processes that damage cellular DNA: Spontaneous hydrolysis, alkylation, and reactions with radicals

K. S. Gates

Chemical Research in Toxicology

22, 2009, 1747-1760 
[179] Instability and decay of the primary structure of DNA

T. Lindahl

Nature

362, 1993, 709-715

[180] Alkylation damage in DNA and RNA-repair mechanisms and medical significance

F. Drabløs, E. Feyzi, P. A. Aas, C. B. Vaagbø, B. Kavli, M. S. Bratlie, J. Peña-Diaz, M. Otterlei, G.

Slupphaug, H. E. Krokan

DNA Repair

3, 2004, 1389-1407

[181] Alkylation and subsequent repair of DNA after exposure to diethylnitrosamine and related compounds

A. E. Pegg

En Reviews in Biochemical Toxicology

Ed: E. Hogdson, J. R. Bend, R. M. Philpot; Elsevier

$5,1983,83-133$

[182] Ethylene: The organic chemical industry's most important building block

W. C. Fernelius, H. Wittcoff, R. E. Varnerin

Journal of Chemical Education

$56,1979,385-387$

[183] Ethylbenzene

V. A. Welch, K. J. Fallon

En Ullmann's Encyclopedia of Industrial Chemistry

Ed: B. Elvers; Wiley-VCH

$6^{\text {a }}$ edición, 2002, Weinheim (Alemania)

[184] A review of the genotoxicity of ethylbenzene

L. Henderson, D. Brusick, F. Ratpan, G. Veenstra

Mutation Research

635, 2007, 81-89

[185] Phenethylamine in neuropsychiatric disorders

M. E. Wolf, A. D. Mosnaim

General Pharmacology

$14,1983,385-390$

[186] Isolation of ethylbenzene from Oklahoma petroleum

J. D. White, F. W. Rose, Jr.

Bureau of Standards Journal of Research

10, 1933, 639-645

[187] Oxidation of $\beta$-phenylethylamine by both types of monoamine oxidase: Examination of enzymes in brain and liver mitochondria of eight species

O. Suzuki, Y. Katsumata, M. Oya

Journal of Neurochemistry

$36,1981,1298-1301$ 


\section{0 | Bibliografía}

[188] Beta-phenylethylamine: a specific substrate for type B monoamine oxidase of brain H. Y. Yang, N. H. Neff

The Journal of Pharmacology and Experimental Therapeutics

187, 1973, 365-371

[189] $\beta$-Phenylethylamine and noradrenergic function in depression

M. Nakagawara

Progress in Neuro-Psychopharmacology \& Biological Psychiatry

$16,1992,45-53$

[190] Anomalous pKa values of some substituted phenylethlamines

M. M. Tuckerman, J. R. Mayer, F. C. Nachod

Journal of the American Chemical Society

81, 1959, 92-94

[191] Genotoxicity of nitrosated red wine and of the nitratable phenolic compouds present in wine: Tyramine, quercetin and malvidine-3-glucoside

A. Laires, J. Gaspar, H. Borba, M. Proença, M. Monteiro, J. Rueff

Food and Chemical Toxicology

31, 1993, 989-994.

[192] Análisis de tiramina en la dieta popular costarricense

R. Masis Moya

Universidad de Costa Rica

1981, San José (Costa Rica)

[193] Kinetic study on p-tyramine metabolism in humans using stable isotope-labeled tracers M. Shimamura, H. Kodaka, T. Hayashi, H. Naruse Neurochemical Research

$18,1993,727-730$

[194] Relation of nitrite concentration to mutagen formation in soy sauce

A. Nagahara, K. Ohshita, S. Nasuno

Food and Chemical Toxicology

24, 1986, 13-15

[195] Formation of an activated N-nitrosocompound in nitrite-treated fava beans (Vicia fava)

B. G. Piacek-Llanes, S. R. Tannenbaum

Carcinogenesis

3, 1982, 1379-1384

[196] Tyramine is a major mutagen precursor in soy sauce, bein convertible to a mutagen by nitrite M. Ochiai, K. Wakabayashi, M. Nagao, T. Sugimura

Japanese Journal of Cancer Research (Gann)

$75,1984,1-3$ 
[197] Induction of oral cavity cancer by 3-diazotyramine, a nitrosated product of tyramine present in foods

Y. Fujita, K. Wakabayashi, S. Takayama, M. Nagao, T. Sugimura

Carcinogenesis

$8,1987,527-529$

[198] Analysis and significance of tyramine in foods

N. P. Sen

Journal of Food Science

$34, \mathbf{1 9 6 9}, 22-26$

[199] 42 salt forms of tyramine: structural comparison and the occurrence of hydrate formation

N. E. Briggs, A. R. Kennedy, C. A. Morrison

Acta Crystallographica Section B

64, 2012, 453-464

[200] Catechol compounds in rat tissues and in brains of different animals

K. A. Montagu

Nature

$180,1957,244-245$

[201] 3,4-Dihydroxyphenylalanine and 5-hydroxytryptophan as reserpine antagonists

A. Carlsson, M. Lindqvist, T. Magnusson

Nature

180, 1957, 1200

[202] The biochemical basis of neuropharmacology

J. R. Cooper, F. E. Bloom, R. H. Roth

Oxford University Press

$8^{\text {a }}$ edición, 2003, Oxford (Reino Unido)

[203] Classical neurotransmitters an their significance within the nervous system

A. Veca, J. H. Dreisbach

Journal of Chemical Education

65, 1988, 108-111

[204] CRC handbook of chemistry and physics

D. R. Lide (ed.)

CRC Press

90, 2010, Boca Ratón, Florida (EE.UU.)

[205] Quantum-dot/dopamine bioconjugates function as redox coupled assemblies for in vitro and intracellular $\mathrm{pH}$ sensing

I. L. Medintz, M. H. Stewart, S. A. Trammell, K. Susumu, J. B. Delehanty, B. C. Mei, J. S. Melinger, J. B. Blanco-Canosa, P. E. Dawson, H. Mattoussi

Nature Materials

9, 2010, 676-684 


\section{2 | Bibliografía}

[206] Autoxidation of dopamine: A comparison of luminescent and spectrophotometric detection in basic solutions

A. Klegeris, L. G. Korkina, S. A. Greenfield

Free Radical Biology \& Medicine

$18,1995,215-222$

[207] The role of superoxide anion in the autoxidation of eminephrine and a simple assay for superoxide dismutase

H. P. Misra, I. Fridovich

The Journal of Biological Chemistry

247, 1972, 3170-3175

[208] Kinetic and structural analysis of the early oxidation products of dopamine

M. Bisaglia, S. Mammi, L. Bubacco

The Journal of Biological Chemistry

282, 2007, 15597-15605

[209] The chemistry of adrenochrome and related compounds

R. A. Heacock

Chemical Reviews

59, 1959, 181-237

[210] Effect of pH on the oxidation pathway of dopamine catalyzed by tyrosinase

M. García-Moreno, J. N. Rodríguez-López, F. Martínez-Ortiz, J. Tudela, R. Varón, F. GarcíaCánovas

Archives of Biochemistry and Biophysics

288, 1991, 427-434

[211] Mutagenic activity of dopamine after nitrosation

S. Changhao, C. Bingqing, W. Suyan, L. Zicheng

Mutation Research

347, 1995, 17-19

[212] The discovery of serotonin and its role in neuroscience

P. M. Whitaker-Azmitia

Neuropsychopharmacology

21, 1999, 2S-8S

[213] Conformational dependence of serotonin theoretical pKa prediction

J. Pratuangdejkul, W. Nosoongnoen, G. A. Guérin, S. Loric, M. Conti, J. M. Launay, P. Manivet Chemical Physics Letters

420, 2006, 538-544

[214] Mutagenic activities of tyrptophan metabolites before and after nitrite treatment T. Hashizume, H. Santo, H. Tsujisawa, K. Kosaka, T. Ozawa, M. Yamashita, N. Kinae Food and Chemical Toxicology

29, 1991, 839-844 
[215] Treatment of essential hypertension with a new vasodilator in combination with betaadrenergic blockade

E. Gilmore, J. Weil, C. Chidsey

The New England Journal of Medicine

282, 1970, 521-527

[216] The history of the development of minoxidil

G. R. Zins

Clinics in dermatology

6, 1988, 132-147

[217] Crystal structure of minoxidil at low temperature and polymorph prediction

A. P. Martín-Islán, D. Martín-Ramos, C. I. Saínz-Díaz

Journal of Pharmacological Sciences

97, 2008, 815-830

[218] Minoxidil: mechanisms of action on hair growth

A. G. Messenger, J. Rundegren

British Journal of Dermatology

150, 2004, 186-194

[219] From surgery to pharmacology to gene therapy. The past, present, and future of hair restoration

S. Jandali

Annals of Plastic Surgery

4, 2010, 437-442

[220] Spectrophotometric and electroanalytical study of minoxidil

J. Arcos, B. García, J. López Palacios, J. M. Kauffmann, G. J. Patriarche

Analytical Letters

24, 1991, 357-376

[221] Acid-base equilibria of minoxidil

B. García, J. Arcos, P. L. Domingo, and J. M. Leal

Analytical Letters

24, 1991, 391-411

[222] Solubility of minoxidil in methanol, ethanol, 1-propanol, 2-propanol, 1-butanol, and water from (278.15 to 333.15) $\mathrm{K}$

H. Yan, R. Li, Q. Li, J. Wang, J. Gong

Journal of Chemical \& engineering data

56, 2011, 2720-2722

[223] The initial rate method in chemical kinetics. Evaluation and experimental illustration.

J. Casado, M. A. López-Quintela, F. M. Lorenzo-Barral

Journal of Chemical Education

$63, \mathbf{1 9 8 6}, 450-452$ 


\section{4 | Bibliografía}

[224] Exploring chemistry with electronic structure methods

J. B. Foresman, Æ. Frisch

Gaussian, Inc.

2a Edición, 1996, Pittsburgh (EE.UU.)

[225] Química cuántica

I. N. Levine

Pearson educación

5 Edición, 2001, Madrid (España)

[226] Extending the reliability and applicability of B3LYP

I. Y. Zhang, J. Wu, X. Xu

Chemical Communications

46, 2010, 3057-3070

[227] Computational Chemistry

D. Young

Wiley-Interscience

1ªdición, 2001, Nueva York (EE.UU.)

[228] Theoretical study on mechanism and selectivity of electrophilic aromatic nitration

K. J. Szabó, A. Hörnfeldt, S. Gronowitz

Journal of the American Chemical Society

$114,1992,6827-6834$

[229] New aspects of electrophylic aromatic substitution mechanism: Computational model of nitration reaction

A. V. Sokolov

International Journal of Quantum Chemistry

100, 2004, 1-12

[230] Scaling factors and uncertainties for ab initio anharmonic vibrational frequencies

R. D. Johnson III, K. K. Irikuta, R. N. Kacker, R. Kessel

Journal of Chemical Theory and Computation

6, 2010, 2822-2828

[231] Identification of rodent carcinogens and noncarcinogens using genetic toxicity tests: Premises, promises, and performance

E. Zeiger

Regulatory Toxicology and Pharmacology

28, 1998, 85-95

[232] Frameshift mutagenesis in Salmonella

B. N. Ames, H. J. Whitfield, Jr.

Cold Spring Harbor Symposia on Quantitative Biology

31, 1966, 221-225 
[233] Specialmicrobiological systems: 2. Observations on chemical mutagenesis in microorganisms W. Szybalski

Annals of the New York Academy of Sciences

76, 1958, 475-489

[234] Chromosomal alterations affecting regulation of histidine biosyntetic enzymes in Salmonella B. N. Ames, F. Jacob, P. E. Hartman Journal of Molecular Biology 7, 1963, 23-28

[235] Carcinogens are mutagens: A simple test system combining liver homogenates for activation and bacteria for detection

B. N. Ames, W. E. Durston, E. Yamasaki, F. D. Lee Proceedings of the National Academy of Sciences 70, 1973, 2281-2285

[236] Revised methods for the Salmonella mutagenicity test D. M. Maron, B. N. Ames Mutation Research 113, 1983, 173-215

[237] The Ames Salmonella/microsome mutagenicity assay K. Mortelmans, E. Zeiger Mutation Research $455,2000,29-60$

[238] Detection of carcinogens as mutagens in the Salmonella/microsome test: assay of 300 chemicals B. N. Ames, J. McCann Proceedings of the National Academy of Sciences 73, 1976, 950-954

[239] Salmonella mutagenicity test: III. Results from the testing of 255 chemicals E. Zeiger, B. Anderson, S. Haworth, T. Lawlor, K. Mortelmans, W. Speck Environmental Mutagenesis 9, Suppl. 9, 1987, 1-110

[240] Cytological methods for detecting chemical mutagens H. J. Evans En Chemical Mutagens, Principles and Methods for their Detection Ed: A. Hollaender; Plenum Press 4, 1976, 1-29 


\section{6 | Bibliografía}

[241] Chromosomal aberration tests on 29 chemicals combined with $\$ 9$ mix in vitro A. Matsuoka, M. Hayashi, M. Ishidate Jr. Mutation Research $66,1979,277-290$

[242] Chromosome aberrations in vitro related to cytotoxicity of nonmutagenic chemicals and metabolic poisons

C. A. Hilliard, M. J. Armstrong, C. I. Bradt, R. B. Hill, S. K. Greenwood, S. M. Galloway Environmental and Molecular Mutagenesis

31, 1998, 316-326

[243] Genetic toxicology of some known or suspected human carcinogens

M. D. Waters, N. E. Garrett, C. M. Covone-de-Serres, B. E. Howard, H. F. Stack

En Chemical Mutagens, Principles and Methods for their Detection

Ed: F. J. Serres; Plenum Press

8, 1983, 261-341

[244] Observations on the chromosomes of Chinese hamster cells in tissue culture

D. K. Ford, G. Yerganian

Journal of the National Cancer Institute

$21,1958,393-425$

[245] X-Ray damage and recovery in mammalian cells in culture

M. M. Elkind, H. Sutton

Nature

184, 1959, 1293-1295

[246] Rapid colorimetric assay for cellular growth and survival: Application to proliferation and cytotoxicity assays

T. Mosmann

Journal of Immunological Methods

65, 1983, 55-63

[247] Mitochondrial and non mitochondrial reduction of MTT: Interaction of MTT with TMRE, JC-1, and NAO mitochondrial fluorescent probes

T. Bernas, J. Dobrucki

Cytometry

47, 2002, 236-242

[248] Rapid colorimetric assay for cell growth and survival. Modifications to the tetrazolium dye procedure giving improved sensitivity and reliability

F. Denizot, R. Lang

Journal of Immunological Methods

89, 1986, 271-277

[249] Determinación estructural de compuestos orgánicos

E. Pretsch, P. Bühlmann, C. Affolter, A. Herrera, R. Martinez

Masson

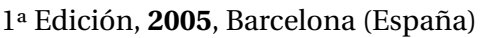


[250] Nitrosation of phenolic compounds: Inhibition and enhancement

S. González Mancebo, M. P. García Santos, J. Hernández Benito, E. Calle, J. Casado Journal of Agricultural and Food Chemistry

47, 1999, 2235-2240

[251] Taurine-nitrite interaction as a precursor of alkylation mechanisms

J. Arenas-Valgañón, R. Gómez-Bombarelli, M. González-Pérez, M. González-Jiménez, E.

Calle, J. Casado

Food Chemistry

134, 2012, 986-991

[252] Dissociation constants and thermodynamic properties of amino acids used in $\mathrm{CO}_{2}$ Absorption from (293 to 353) $\mathrm{K}$

E. S. Hamborg, J. P. M. Niederer, G. F. Versteeg

Journal of Chemical and Engineering Data

52, 2007, 2491-2502

[253] The mechanism of nitrosodecarboxylation of 3,5-dibromo-4-hydroxybenzoic acid and nitrosodeprotonation of 2,6-dibromophenol

K. M. Ibne-Rasa

Journal of the American Chemical Society

84, 1962, 4962-4969

[254] The chemistry of nitroso-compounds. Part II. The nitrosation of phenol and anisole

B. C. Challis, A. J. Lawson

Journal of the Chemical Society B

1971, 770-775

[255] Nitrosation of phenolic compounds: effects of alkyl substituents and solvent

S. González Mancebo, J. Lacadena, Y. García Alonso, J. Hernández Benito, E. Calle, J. Casado Monatshefte für Chemie

133, 2002, 157-166

[256] Nitrosation kinetics of phenolic components of foods and beverages

M. P. Fernández Liencres, E. Calle, S. González Mancebo, J. Casado, B. Quintero

International Journal of Chemical Kinetics

29, 1997, 119-125

[257] Kinetics of acid and nucleophile catalysis of the diazotization of 1-naphthylamine

J. Casado, A. Castro, E. Iglesias, M. E. Peña, J. Vázquez Tato

Canadian Journal of Chemistry

64, 1986, 133-137

[258] Comprehensive chemical kinetics. Volume 40: Kinetics of multistep reactions

F. G. Helfferich

Elsevier

$2^{\text {a }}$ Edición, 2004, Londres (Reino Unido) 


\section{8 | Bibliografía}

[259] The protonation of indoles. Basicity studies. The dependence of acidity functions on indicator structure

R. L. Hinman, J. Lang

Journal of the American Chemical Society

86, 1964, 3796-3806

[260] Diffusion control and pre-association in nitrosation, nitration and halogenation

J. H. Ridd

Advances in Physical Organic Chemistry

$16,1978,1-49$

[261] A formula for correlating $p K_{a}$ values determined in $\mathrm{D}_{2} \mathrm{O}$ and $\mathrm{H}_{2} \mathrm{O}$

A. Krężel, W. Bal

Journal of Inorganic Biochemistry

98, 2004, 161-166

[262] Nouveau traîte de chimie minerale

R. Vaillard

Masson

$1^{\text {a }}$ Edición, 1956, París (Francia)

[263] Estadística sencilla para estudiantes de ciencias

J. M. Fernández Solís, J. Pérez Iglesias, H. M. Seco Lago

Síntesis

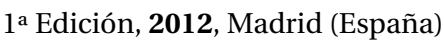

[264] Evaluation of phenolic assays for the detection of nitrite

J. Davis, K. J. McKeegan, M. F. Cardosi, D. H. Vaughan

Talanta

50, 1999, 103-112

[265] Glossary of terms used in physical organic chemistry (IUPAC Recommendations 1994)

P. Muller

Pure and Applied Chemistry

66, 1994, 1077-1184

[266] Detection of nitrite in water using minoxidil as a reagent

M. González-Jiménez, J. Arenas-Valgañón, I. F. Céspedes-Camacho, J. C. García-Prieto, E. Calle, J. Casado

Journal of Chemical Education

90, 2013,

[267] Correlation of rate constants in alkaline hydrolysis of aromatic sulfoacid esters, as dependent on structure of these compounds

V. A. Palm, R. V. Vizgert

Doklady Akademii Nauk SSSR

142, 1962, 1091-1097 


\section{Índice alfabético}

ácido ascórbico, 39, 52, 83

ácido nitroso, 41

actinomyces naeslundii, 46

Ames, Bruce, 131

analizador de energía térmica (TEA), 38

arilación de Meerwein, 79

autooxidación de la dopamina, 108, 201

Balard, Antoine-Jérôme, 65, 66

Barnes, John Morrison, 36, 37, 94

Brunton, Thomas Lauder, 66

carboxilatos de nitrosilo, 69

Carlsson, Arvid, 106

Challis, Brian, 59

Chidsey, Charles, 113

cinética química, 117

citocromo P450, 95, 134

clostridium botulinum, 38, 48

clostridium ramosum, 46

complejo de Wheland, 74, 112, 184

complejos del óxido nítrico, 69

constante de Markovits, 59

control orbitálico, 92

control por difusión, 90

correlación de Palm-Vizgert, 292

Demjanov, Nikolai Yakovlevich, 35, 37

dióxido de nitrógeno, 44, 68

dopamina, 100, 105, 107, 200

ecuación de Arrhenius, 119, 172 ecuación de Brønsted-Debye-Hückel, 120

ecuación de Eyring-Wynne-Jones, 120, 172

ecuación de velocidad, 118

efecto isocinético, 292

efecto isotópico cinético, 121, 188

Elkind, Mortimer, 139

Erspamer, Vittorio, 109

escherichia coli, 131

ésteres de nitrito, 33, 65, 81, 93

etilbenceno, 97, 99, 147

Faraday, Michael, 73

fenetilamina, 98, 100, 101, 153

Fischer, Otto, 35

Ford, Denys, 139

Furchgott, Robert, 48

Geber, falso, 41

González Mancebo, Samuel, 291

Griess, Johann Peter, 34, 37, 51

helicobacter pylori, 94

Hepp, Eduard, 35

hierba de Santiago, 36

Hofmann, August Wilhem von, 34, 37

Holmes, Sherlock, 67

Ignarro, Louis, 48

Ilosvay, Lajos, 51, 70

ion nitrosacidio, 56, 291

ion nitrosonio, 55, 74, 83, 291 


\section{0 | Índice alfabético}

Kekule, August von, 73

L-DOPA, 106

lactonas, formación de, 89

Lewis, Gilbert, 41

ley de Lambert-Beer, 154

límite de cuantificación, 288

límite de detección, 288

líquido iónico, 72

Magee, Peter Noel, 36, 37, 94

metamioglobina, 47

método de aislamiento de Ostwald, 118

método de flujo detenido, 122

método de Liebermann, 71

Meyer, Viktor, 35, 37

minoxidilo, 113, 115, 257, 284

mioglobina, 46, 50

Mirvish, Sidney, 39, 59

monoamina oxidasa, 100, 105, 106

Montagu, Kathleen, 105

Mosmann, Tim, 141

Murad, Ferid, 48

nitritos, 44, 45, 48, 70, 284

nitrosaminas, 33, 71, 78, 94

NO sintasa, 48

orden de reacción, 118

óxido nítrico, 39, 41, 48, 67

oximioglobina, 47

púrpura de anilina, 34

Palm, Viktor, 292

Parkinson, enfermedad de, 106

Perkin, William Henry, 34, 37

peróxido de hidrógeno, 85

Piria, Raffaele, 33, 37

reacción de copulación, 80

reacción de Gatterman, 79

reacción de Gomberg-Bachmann, 79

reacción de Piria, 33 reacción de Sandmeyer, 79

reacción de Schiemann, 79

reacciones consecutivas, 226

reactivo de Griess-Ilosvay, 51

reordenamiento de Demjanov, 36, 89

reordenamiento de Fischer-Hepp, 35, 82, 89

reordenamiento de Tiffeneau-Demjanov, 89

S9, extracto, 134

sales de diazonio, 34, 77, 78, 80, 95

sales de nitrosilo, 55, 62, 291

sales de Roussin, 69

Salmonella typhimurium, 131

serotonina, 109, 111, 223

sustitución electrófila aromática, 74

test de aberraciones cromosómicas, 137

test de Ames, 131

test del MTT, 141

tiramina, 100, 102, 103, 176

trióxido de dinitrógeno, 59, 68, 78

tripsinización, 140

V-79, células, 139, 142

veillonella atypica, 46

velocidad de reacción, 117

Vizgert, Regina, 292

Szybalski, Wacław, 131

Yerganian, George, 139 